\title{
Data Recovery Excavations at the J. B. White Site (41MM341), Milam County, Texas
}

\author{
E. Frances Gadus
}

Ross C. Fields

Karl W. Kibler

Cross Timbers Geoarcheological Services

Follow this and additional works at: https://scholarworks.sfasu.edu/ita

Part of the American Material Culture Commons, Archaeological Anthropology Commons, Environmental Studies Commons, Other American Studies Commons, Other Arts and Humanities Commons, Other History of Art, Architecture, and Archaeology Commons, and the United States History Commons

Tell us how this article helped you.

This Article is brought to you for free and open access by the Center for Regional Heritage Research at SFA ScholarWorks. It has been accepted for inclusion in Index of Texas Archaeology: Open Access Gray Literature from the Lone Star State by an authorized editor of SFA ScholarWorks. For more information, please contact cdsscholarworks@sfasu.edu. 


\section{Data Recovery Excavations at the J. B. White Site (41MM341), Milam County, Texas}

\section{Licensing Statement}

This is a work for hire produced for the Texas Department of Transportation (TxDOT), which owns all rights, title, and interest in and to all data and other information developed for this project under its contract with the report producer. The report may be cited and brief passages from this publication may be reproduced without permission provided that credit is given to TxDOT and the firm that produced it. Permission to reprint an entire chapter, section, figures or tables must be obtained in advance from the Supervisor of the Archeological Studies Branch, Environmental Affairs Division, Texas Department of Transportation, 125 East 11th Street, Austin, Texas, 78701. 


\title{
DATA RECOVERY EXCAVATIONS AT THE J. B. WHITE SITE (41MM341), MILAM COUNTY, TEXAS
}

\author{
by \\ E. Frances Gadus \\ Ross C. Fields \\ and \\ Karl W. Kibler \\ with contributions by \\ Karen M. Gardner \\ Robert H. Tykot \\ Raymond Mauldin \\ Brian S. Shaffer \\ M. E. Malainey \\ Leslie L. Bush \\ and \\ Barbara M. Winsborough \\ Principal Investigator: Ross C. Fields \\ REPORTS OF INVESTIGATIONS, NUMBER 145 \\ Prewitt and Associates, Inc. \\ Cultural Resources Services \\ Austin, Texas
}

ARCHEOLOGICAL STUDIES PROGRAM, REPORT NO. 87

Texas Department of Transportation

Environmental Affairs Division

Austin, Texas

CSJ No. 0185-04-033

January 2006

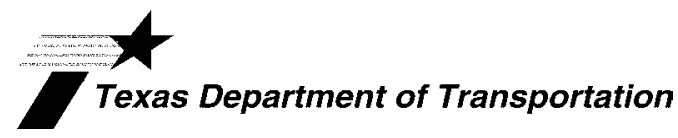

TEXAS ANTIQUITIES PERMIT NO. 2878 
DATA RECOVERY EXCAVATIONS AT THE J. B. WHITE SITE (41MM341), MILAM COUNTY, TEXAS

\section{Copyright (C 2006}

Texas Department of Transportation (TxDOT) and Prewitt and Associates, Inc. (PAI)

TxDOT and PAI jointly own all rights, title, and interest in and to all data and other information developed for this project under Contract 572XXSA005, Work Authorizations 57206SA005, 57210SA005, and 57215SA005. Brief passages

from this publication may be reproduced without permission provided that credit is given to TxDOT and PAI. Permission to reprint an entire chapter, section, figures or tables must be obtained in advance from the Supervisor of the Archeological Studies

Program, Environmental Affairs Division, Texas Department of Transportation, 125 East 11th Street, Austin, Texas, 78701.

jointly published by the

Texas Department of Transportation

Environmental Affairs Division

Archeological Studies Program

G. Lain Ellis, Ph.D., Supervisor

Archeological Studies Program, Report No. 87

$\mathrm{Al} \mathrm{McGraw,} \mathrm{Series} \mathrm{Editor}$

and

Prewitt and Associates, Inc.

Cultural Resources Services

Austin, Texas

Reports of Investigations, Number 145

Printed by Morgan Printing in Austin, Texas

ISBN 1-930788-57-6 


\section{TABLE OF CONTENTS}

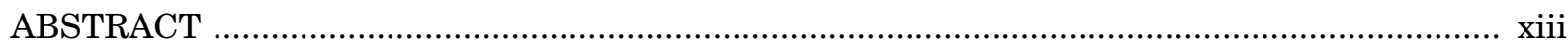

ACKNOWLEDGMENTS ................................................................................................ xiv

CHAPTER 1: INTRODUCTION, ENVIRONMENTAL SETTING, AND

ARCHEOLOGICAL BACKGROUND .......................................................... 1

Environmental Setting …...................................................................................... 3

Archeological Background ......................................................................................... 5

Late Archaic Period ....................................................................................... 5

Late Prehistoric Period .............................................................................. 9

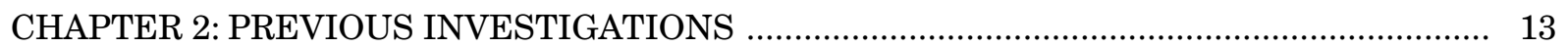

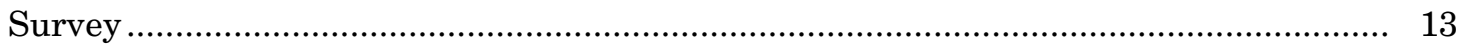

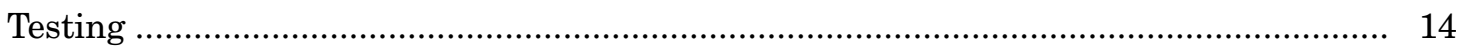

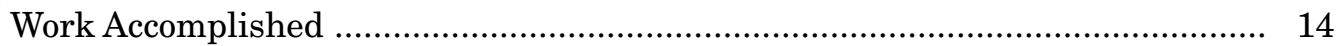

Stratigraphy, Features, and Radiocarbon Dates ........................................... 14

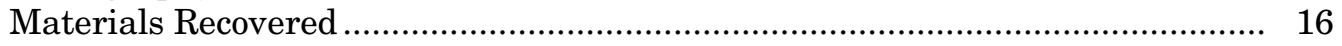

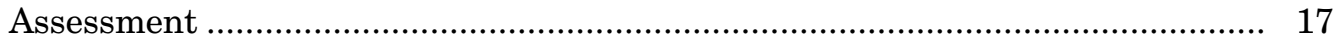

CHAPTER 3: SYNOPSIS OF THE DATA RECOVERY PLAN, OVERVIEW OF THE WORK ACCOMPLISHED, AND THE RESEARCH DESIGN ........................ 19

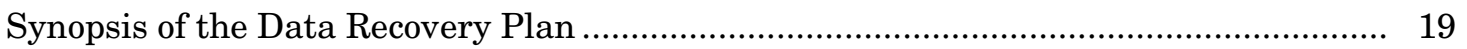

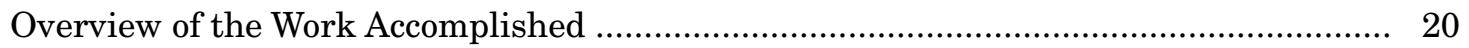

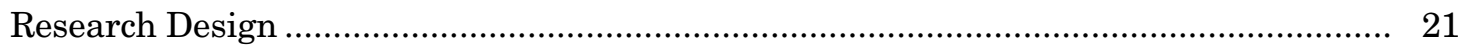

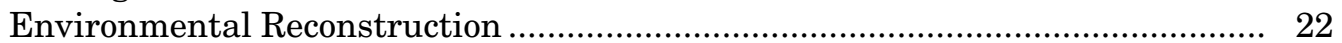

Subsistence Strategies ................................................................. 23

Assemblage Organization ............................................................................ 24

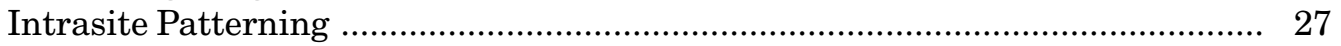

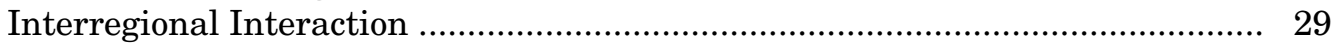

CHAPTER 4: WORK ACCOMPLISHED AND METHODS OF INVESTIGATION .................... 33

Work Accomplished and Field Methods ......................................................................... 33

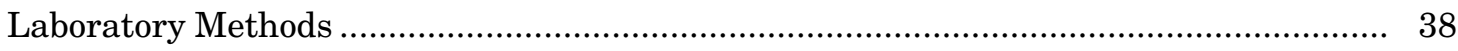

Special Sample Collection, Processing, and Selection for Analysis ............................... 40

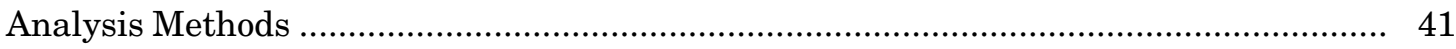

Chipped Stone Artifacts ....................................................................... 41

Lithic Reduction Debris Piles ................................................................. 41

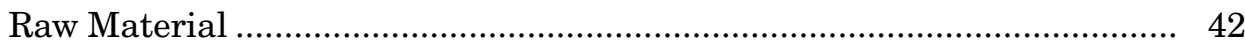

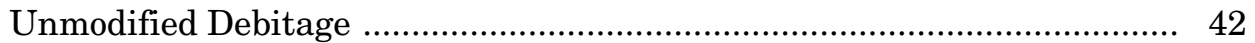

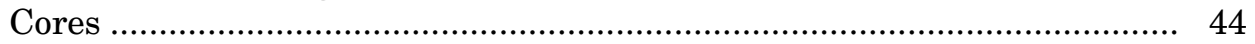

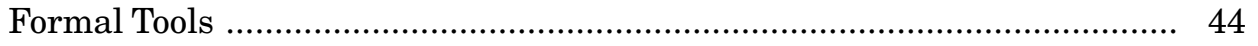




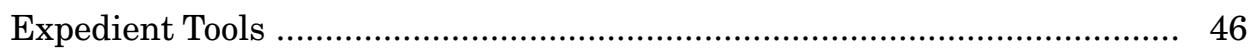

Ground and Battered Stone Artifacts ........................................................ 47

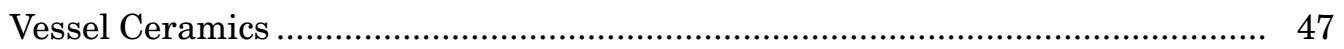

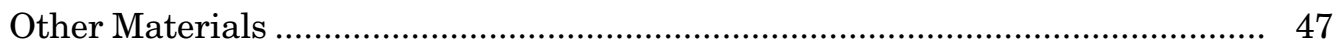

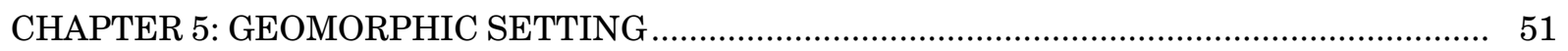

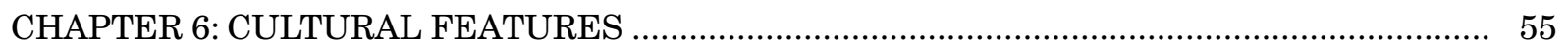

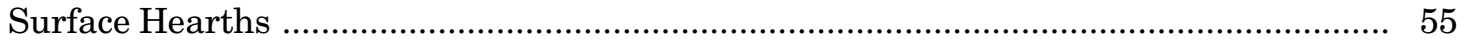

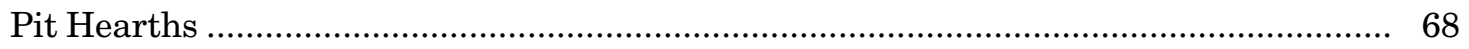

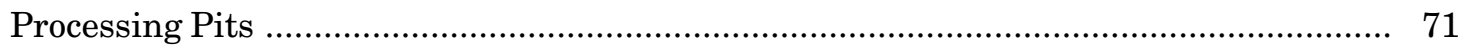

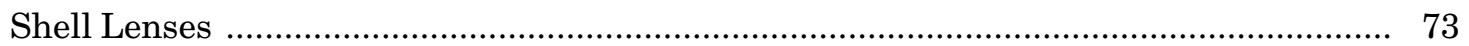

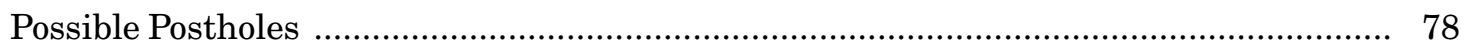

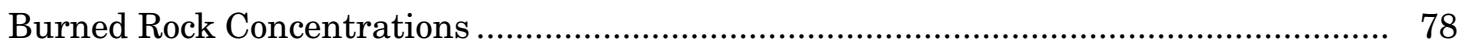

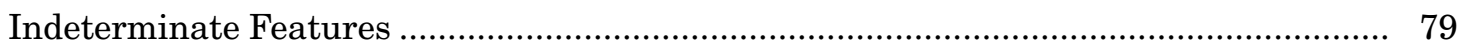

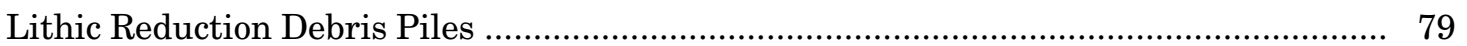

Minimum Number of Cobbles ......................................................................... 80

Extent of the Debris Piles .......................................................................... 82

Distribution of Refitted Cobbles and Easily Recognizable Materials ................. 83

Cobble Characteristics .............................................................................. 88

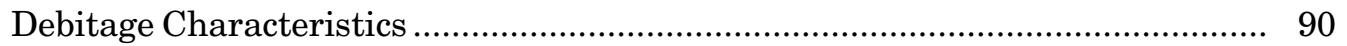

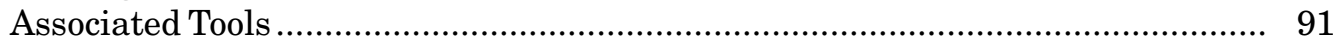

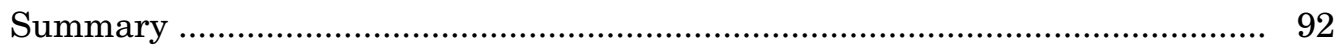

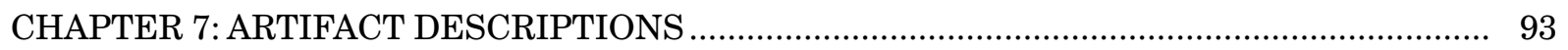

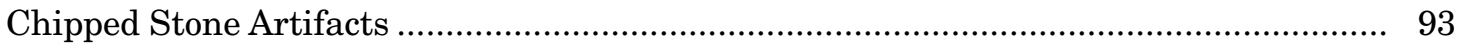

Unmodified Debitage .................................................................................. 93

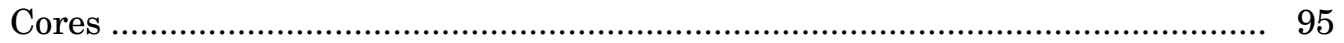

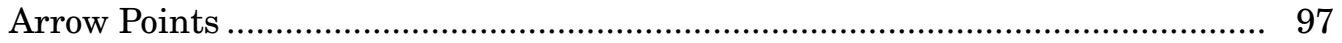

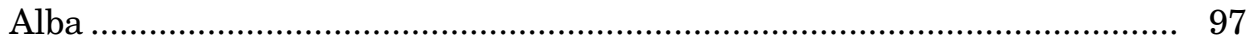

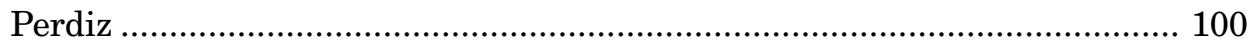

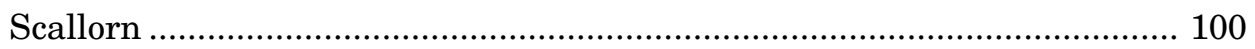

Untyped Arrow Points and Point Fragments ........................................... 103

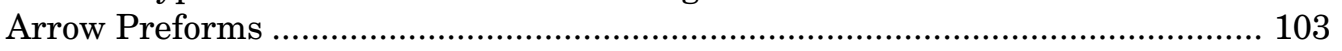

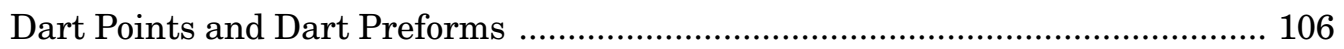

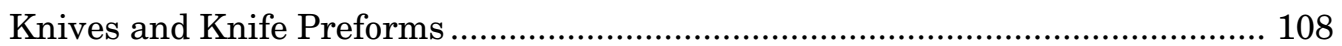

Perforators, Awls, and Gravers ............................................................ 112

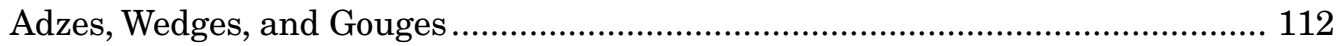

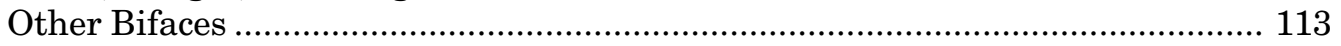

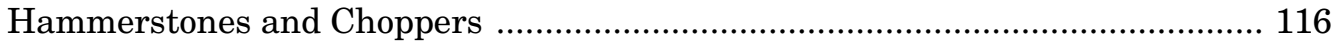

Expedient Chipped Stone Tools …..................................................................... 117

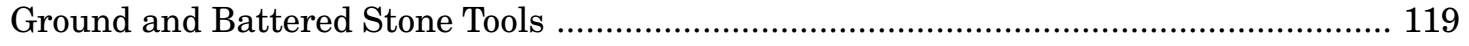

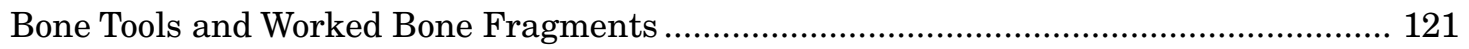

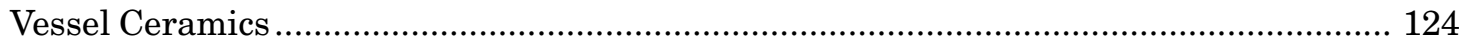




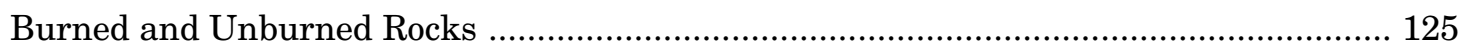

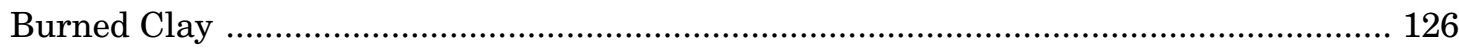

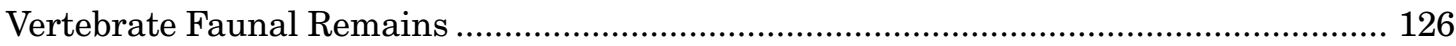

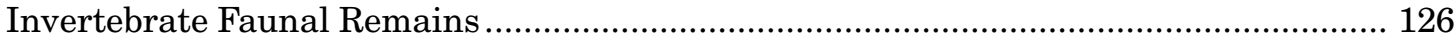

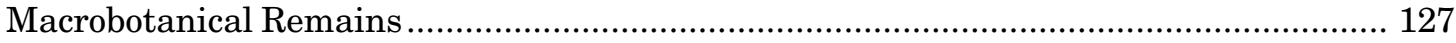

CHAPTER 8: DEFINITION OF ANALYSIS UNITS, SITE CHRONOLOGY, AND INTRASITE DISTRIBUTIONAL STUDIES ............................................... 129

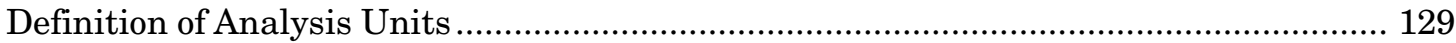

Lithic Reduction Debris Piles ....................................................................... 129

Distributions of Mussel Shells, Debitage, Burned Rocks, and Features .............. 130

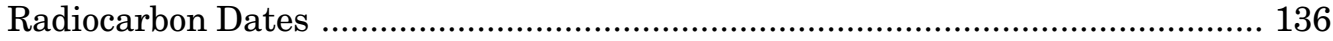

Analysis Units in the East and South Blocks ................................................... 136

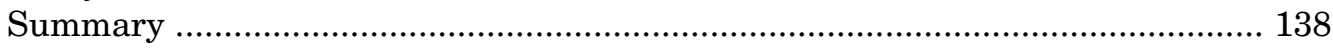

Analysis Unit Characterizations and Comparisons ...................................................... 138

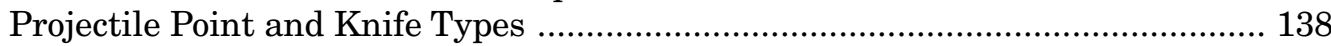

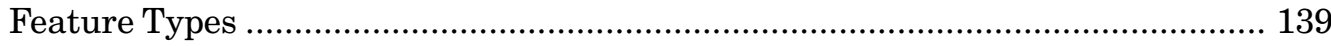

Lithic Reduction Strategies ............................................................................. 142

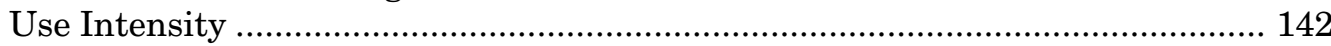

Tool Assemblages and Ranges of Activities ................................................... 145

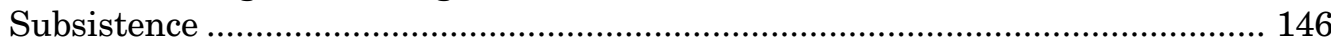

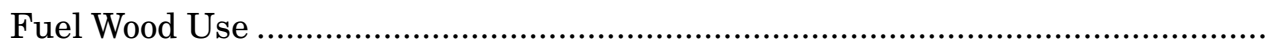
$15 \mathrm{~s} 1$

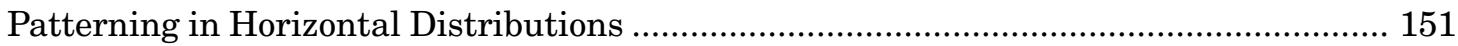

Material Distribution Patterns in the Main Block ............................................... 157

Tool Distribution Patterns within the Main Block ............................................ 160

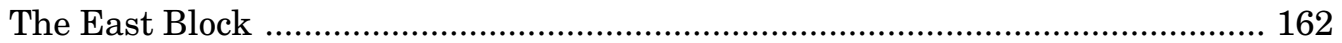

The South Block …............................................................................................... 163

CHAPTER 9: SUMMARY OF INTERPRETATIONS AND PROJECT ASSESSMENT ............... 165

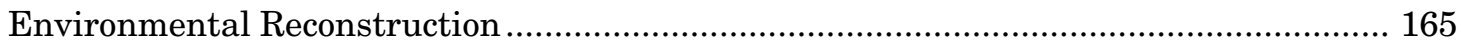

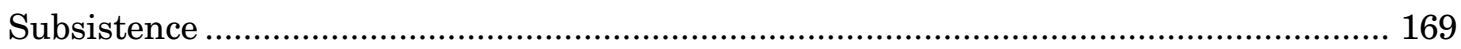

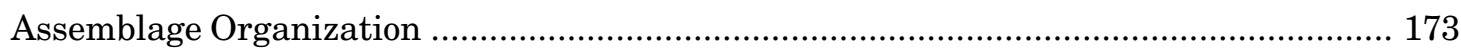

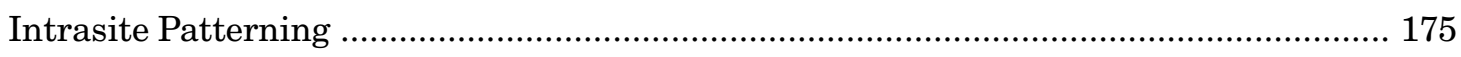

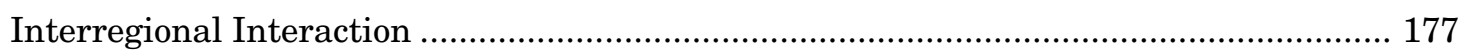

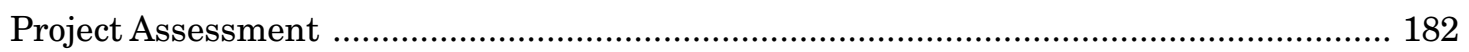

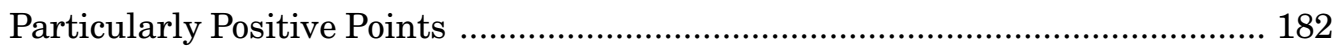

Particularly Negative Points .................................................................... 182

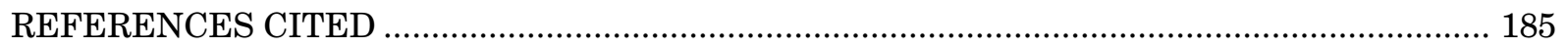

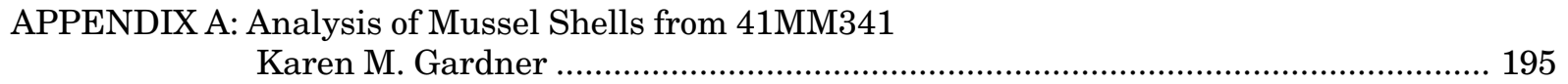


APPENDIX B: Analysis of Gastropod Shells from 41MM341

Karen M. Gardner

APPENDIX C: Stable Carbon and Oxygen Isotope Analysis of Mussel Shells from 41MM341

E. Frances Gadus and Robert Tykot, Ph.D

APPENDIX D: Stable Carbon and Oxygen Isotopic Variability in

Snail Shells from 41MM340 and 41MM341

Raymond Mauldin, Ph.D.

APPENDIX E: Analysis of the Vertebrate Remains from 41MM341

Brian S. Shaffer, Ph.D.

APPENDIX F: Analysis of the Fatty Acid Compositions of Archeological

Residues from 41MM341

M. E. Malainey, Ph.D

APPENDIX G: Analysis of Macrobotanical Remains from 41MM341

Leslie L. Bush, Ph.D. 273

APPENDIX H: Diatom Paleoecology of Burned Clay Samples from 41MM341

Barbara M. Winsborough, Ph.D. 299

APPENDIX I: Metric Data for Stone Tools 317

APPENDIX J: Radiocarbon Dates 331 


\section{LIST OF FIGURES}

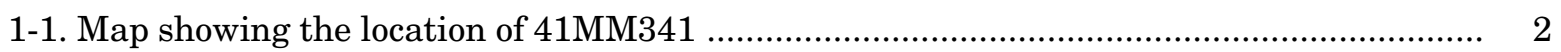

1-2. View to the southeast of 41MM341 at center of photograph ........................................... 3

1-3. Map of the location of 41MM341 in the Little River basin ............................................. 4

1-4. Distribution of modern plant communities in central and eastern Texas ......................... 6

1-5. Selected archeological project areas in the vicinity of 41MM341 .................................... 7

2-1. Plan of 41MM341 showing the 2000 test excavations and 1998 trenches ........................ 15

4-1. Plan of 41MM341 showing 2002 data recovery excavations ........................................... 34

4-2. View of initial Excavation Units 8 and 9 being opened on the east wall of Trench 3 ........ 35

4-3. View of a TxDOT Gradall stripping the area where the East and South Blocks

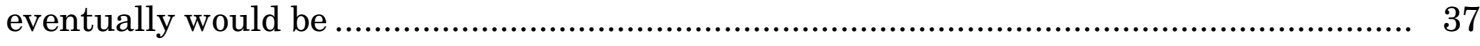

4-4. View of excavators exposing mussel shell lenses in the Main Block ................................ 38

4-5. View grid north to the partially completed Main Block with the South Block

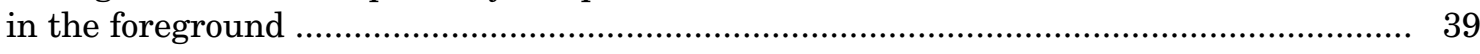

$5-1$. Topographic map of the 41MM341 project area …........................................................ 52

5-2. Schematic cross section of the Little River valley near 41MM341 .................................. 53

6-1. Plan of the excavations showing the locations of the cultural features ............................ 56

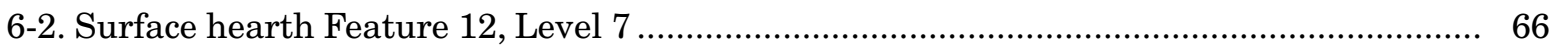

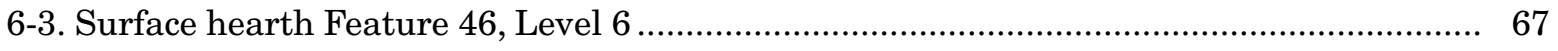

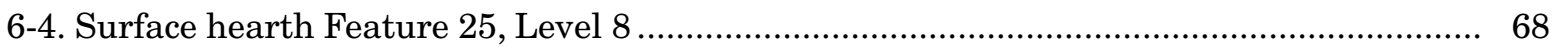

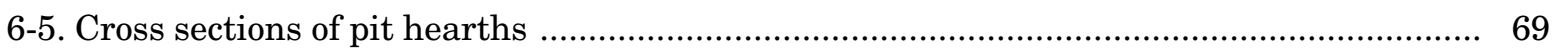

6-6. Pit hearth Feature 15 in plan view with its adjacent burned rock concentration,

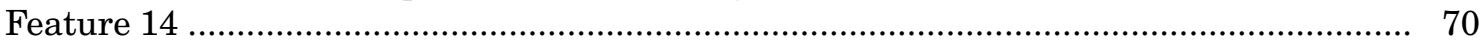

6-7. View to the south across the South Block excavated to the bottom of Level 8 .................. 72

6-8. Shell lenses in the Main Block ................................................................................... 74

6-9. Isopleth maps of mussel shell weight and Rabdotus count in Levels 6-9

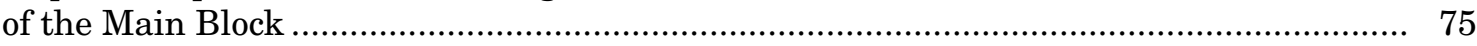

6-10. Possible posthole Feature 31 after cross sectioning .................................................... 79

6-11. Extent of the lithic reduction debris piles in the Main Block ......................................... 81

6-12. Reconstructed Cobble 4 from lithic reduction debris Pile 1 ............................................ 83

6-13. Reconstructed Cobble 7 from lithic reduction debris Pile 1 .......................................... 84

6-14. Refits between excavation units in the lithic reduction debris piles ................................ 86

6-15. Horizontal distributions of easily recognizable debitage within the Main Block .............. 87

6-16. Reconstructed Cobble 10 from Pile 4 showing bidirectional flake removals ...................... 89

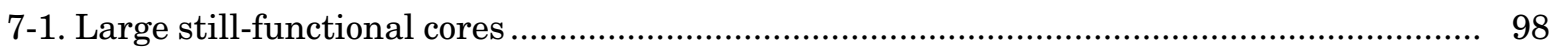

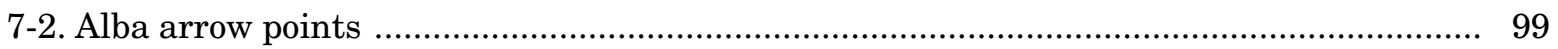




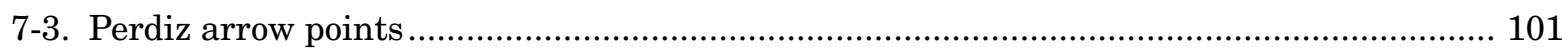

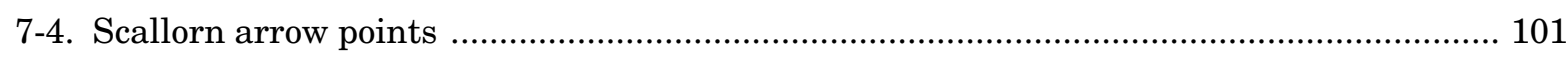

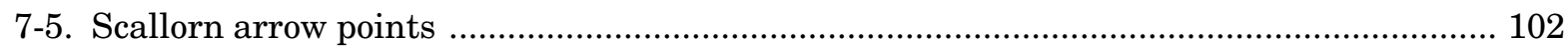

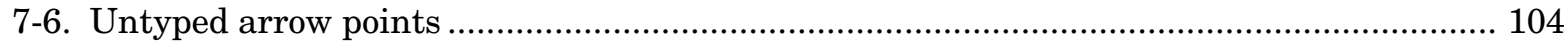

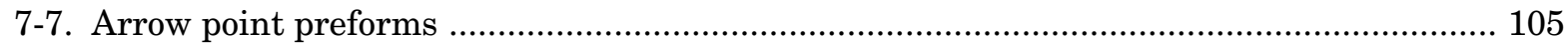

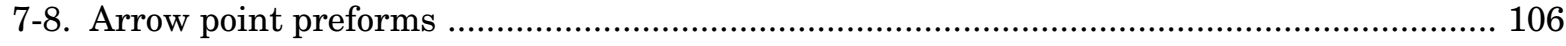

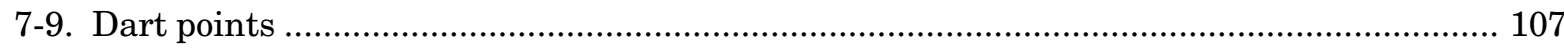

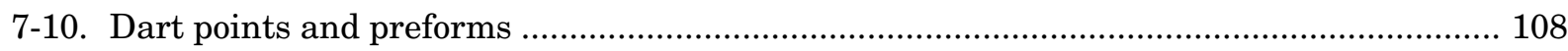

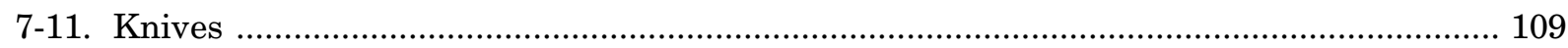

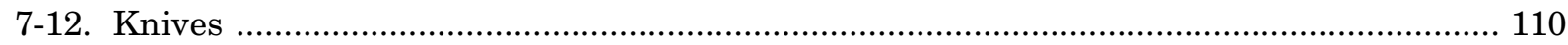

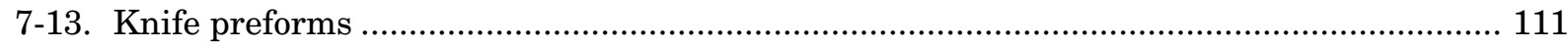

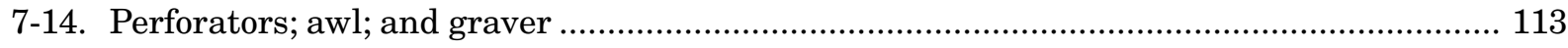

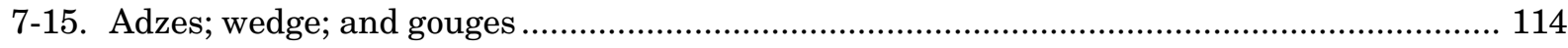

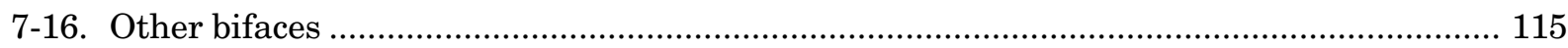

7-17. Chipped stone hammerstone; hammerstone/chopper; and chopper ................................. 116

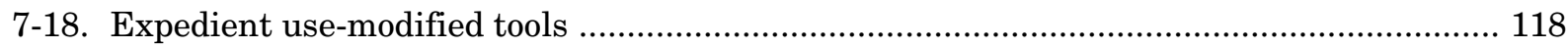

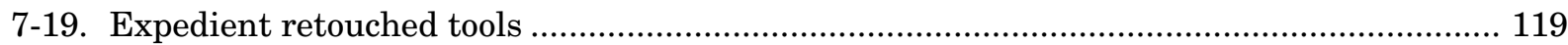

7-20. Expedient scrapers with two-sided use modification ..................................................... 120

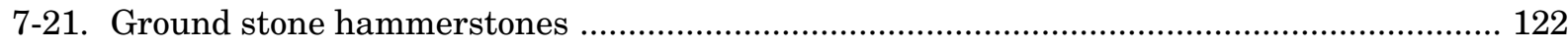

7-22. Ground stone hematitic sandstone abraders .................................................................. 123

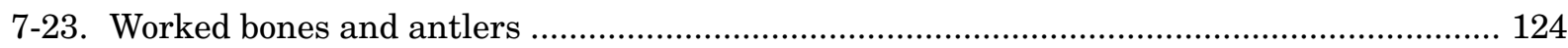

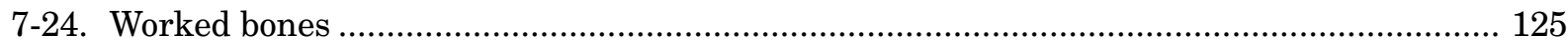

8-1. Plan of the Main Block showing excavation unit numbers and south-north lines used in graphing mussel shell, debitage, and burned rock weights or counts ................... 131

8-2. Mussel shell weights by excavation unit and level in the Main Block .............................. 132

8-3. Debitage frequencies by excavation unit and level in the Main Block .............................. 133

8-4. Burned rock weights by excavation unit and level in the Main Block .............................. 134

8-5. Cross sections through the Main Block showing shell features, surface hearths, pit hearths, and burned rock concentrations

8-6. Graphs of one-sigma ranges of radiocarbon dates from the Main Block grouped by analysis unit

8-7. Material distributions and hearth locations for Level 6 of the Main Block ....................... 153

8-8. Material distributions and hearth locations for Level 7 of the Main Block ...................... 154

8-9. Material distributions and hearth locations for Level 8 of the Main Block ....................... 155

8-10. Material distributions and hearth locations for Level 9 of the Main Block ........................ 156

8-11. Distributions of tools relative to the main parts of the debris scatters in Levels 6 and 8 of the Main Block 
9-1. Graph of $\delta^{18} \mathrm{O}$ values for sequentially sampled mussel shells from $41 \mathrm{MM} 341$ grouped by analysis unit, modern mussel shells from Belton Lake, and mussel shells from 41MM340

9-2. Graph of percentages of land gastropods by associated habitats by level in the column sample from $41 \mathrm{MM} 341$

C-1. Graph of $\delta^{18} \mathrm{O}$ values for sequentially sampled mussel shells from 41MM341

grouped by analysis unit and modern samples

D-1. Box plot of ${ }^{18} \mathrm{O}$ isotopic values of snail shell carbonates by approximate age for 41MM340 and 41MM341

D-2. Box plot of ${ }^{13} \mathrm{C}$ isotopic values of snail shell carbonates by approximate age for $41 \mathrm{MM} 340$ and $41 \mathrm{MM} 341$ 234 


\section{LIST OF TABLES}

4-1. Artifact frequencies in the initial excavation units

4-2. Chert color ranges based on cobbles from lithic reduction debris piles

4-3. Collections and references used in typological identification of projectile points and knives

4-4. Total area and sample area of features selected for shell analysis

6-1. Summary of the cultural features

6-2. Materials recovered from the cultural features

6-3. Formal chipped stone tools by shell lens feature.... 77

6-4. Charred wood recovered from flotation samples from shell lens features 77

6-5. Contents of the lithic reduction debris piles.

6-6. Summary of data on the horizontal and vertical extent of the lithic reduction debris piles

6-7. Chert color and material affiliation for the lithic reduction debris piles

6-8. Break types associated with selected formal chipped tools from the lithic reduction debris piles and off-pile contexts

7-1. Debitage completeness, cortex percentage, and size by lithic reduction debris pile

7-2. Flake type by lithic reduction debris pile

7-3. Colors and Fort Hood chert type affiliations of the cores and core fragments

7-4. Expedient tool use patterns by level

7-5. Flake type of expedient tools by level

8-1. Typed projectile points by analysis unit 139

8-2. Knife morphology by analysis unit 140

8-3. Feature types by analysis unit 140

8-4. Frequency of mussel species by analysis unit 141

8-5. Shell size distributions for Amblema plicata and Quadrula houstonensis by analysis unit

8-6. Flake type in the unmodified debitage by analysis unit 143

8-7. Summary of materials recovered by analysis unit 143

8-8. Formal chipped stone tools by analysis unit. 146

8-9. Ground and battered stone tools by analysis unit. 147

8-10. Expedient tool use by analysis unit 147

8-11. Vertebrate faunal taxa by analysis unit ......................................................................... 148

8-12. Frequency of animal bones by faunal group and analysis unit ...................................... 149

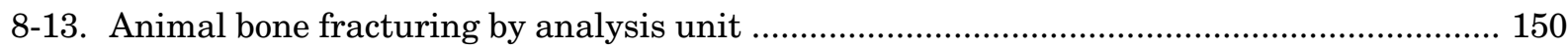

8-14. Possible plant food remains in the analyzed macrobotanical samples by analysis unit 150 
8-15. Tree species represented by wood charcoal by analysis unit 152

8-16. Relationships between contour intervals used to show abundance of material classes in the Main Block distributional analysis and summary statistics for those classes

8-17. Distributions of various tool classes relative to the main parts of the debris scatters in the Main Block 162

9-1. Land gastropod frequency in the column sample from 41MM341 by habitat association 168

9-2. Identifiable vertebrate faunal remains from 41MM341, 41WM130, and 41MM340 ......... 173

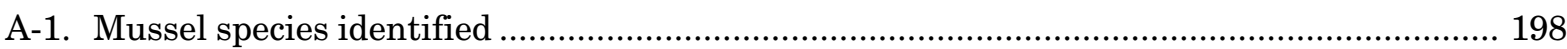

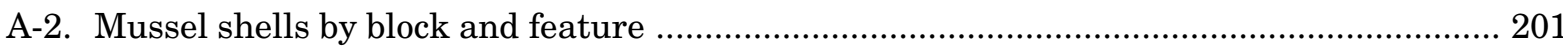

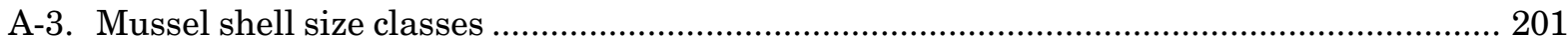

A-4. Mussel shell size classes by feature and block .................................................................. 203

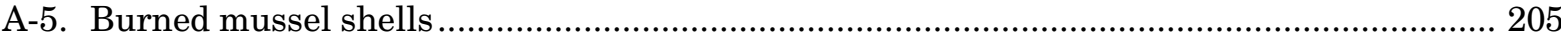

B-1. Gastropod species and number of species from all analyzed proveniences ....................... 210

B-2. Gastropods from column samples by level ........................................................................ 213

B-3. Gastropods from selected shell features in the Main Block by level ................................... 214

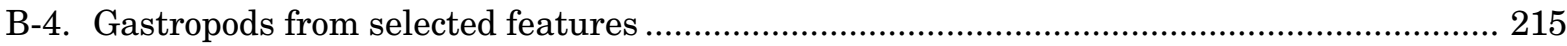

B-5. Rabdotus dealbatus dealbatus and Rabdotus sp. from Feature 17 by size class ............... 216

C-1. Results of stable carbon and oxygen isotope analysis of mussel shells ............................. 222

D-1. Carbon and oxygen isotopic values on snail shell carbonates, Little River ...................... 231

D-2. Summary statistics for carbon and oxygen readings in Table 1 .................................... 232

E-1. Number of identified specimens (NISP) and minimum number of individuals (MNI) by faunal taxon and common name .................................................... 240

E-2. Faunal taxa from nonfeature contexts and Features $6-17$............................................. 243

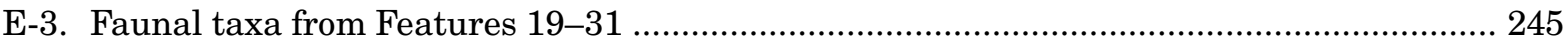

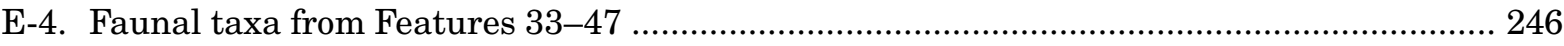

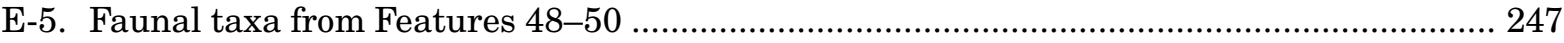

E-6. Portions of faunal taxa by site, nonfeature, and feature assemblages .............................. 248

E-7. Faunal taphonomy and total number of identified specimens (NISP) by provenience 250

E-8. Number of identified specimens (NISP) for deer, deer-sized artidactyl, and cervid elements

E-9. Comparison of vertebrate faunal remains (NISP) from 41MM341 and 41MM340

F-1. Summary of average fatty acid compositions (\%) of modern food groups generated by hierarchical cluster analysis 265

F-2. Criteria for the identification of archeological residues .................................................. 266

F-3. List of samples analyzed for organic residues 267 
F-4. Fatty acid composition and identification of residues from 41MM341

G-1. Uncarbonized macrobotanical remains from flotation samples (heavy and light fractions)

G-2. Carbonzied macrobotanical remains from flotation samples (heavy and light fractions) 281

G-3. Carbonized macrobotanical remains from 1/4-inch-screen samples .................................. 284

G-4. Wood charcoal from flotation samples (heavy and light fractions) .................................. 286

G-5. Wood charcoal from 1/4-inch-screen samples ............................................................... 289

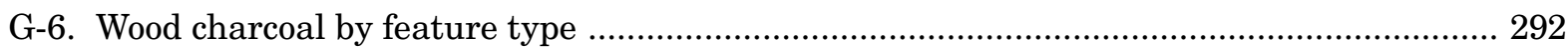

G-7. Nutrient composition of some domesticated bulbs, roots, and tubers ............................... 294

H-1. Diatom abundance in burned clay samples from 41MM341 ........................................... 303

H-2. Diatom abundance in modern samples collected in the vicinity of 41MM341 and in fired clay nodules previously analyzed from nearby 41MM340 305

H-3. Published autoecological characteristics of ancient diatoms preserved in burned clay nodules from 41MM340 and 41MM341 and modern diatoms collected from nearby Little River 307

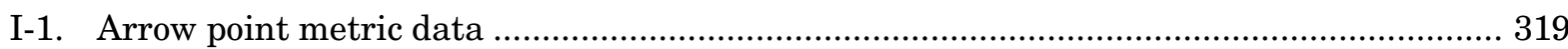

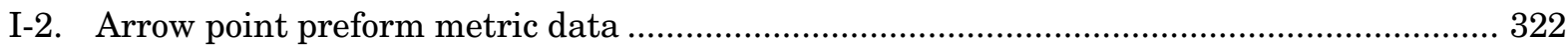

I-3. Dart point and dart point preform metric data ............................................................... 324

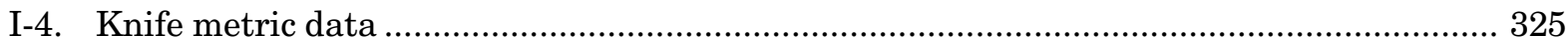

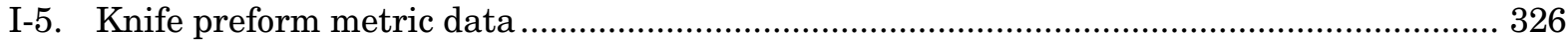

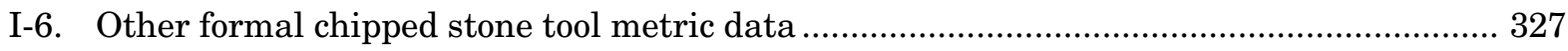

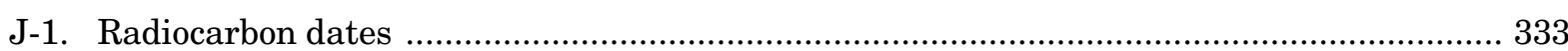




\begin{abstract}
In summer and fall 2002, personnel with Prewitt and Associates, Inc., undertook data recovery excavations at prehistoric site 41MM341 for the Texas Department of Transportation, Environmental Affairs Division, to address the requirements of Section 106 of the National Historic Preservation Act and the Texas Antiquities Code. Site 41MM341 is in central Milam County, Texas, just southeast of the town of Cameron, on a low rise in the modern floodplain of the Little River. The excavations were necessitated by the planned replacement of the State Highway 36 bridge spanning the Little River floodplain, which will directly affect the archeological deposits at 41MM341. The site, which was tested in 2001 and determined eligible for listing in the National Register of Historic Places and designation as a State Archeological Landmark, is well preserved and contains stratified, multicomponent prehistoric materials encased in late Holocene alluvium. The data recovery excavations focused on broad exposure of the remains of a series of Late Prehistoric occupations dating from A.D. 800 or 900 to 1300, with more-limited sampling of a component dating to the A.D. 600700 s. The excavations consisted of 4 backhoe trenches, 11 initial 1x1-m units, and 3 hand-excavated blocks covering $208 \mathrm{~m}^{2}$. The excavations identified a variety of cultural features and recovered the following: 303 shaped chipped stone tools; 494 expedient stone tools; 168 cores; 39,872 pieces of unmodified debitage; 30 stone tools modified by grinding or battering; 30 bone tools or modified bones; 4 ceramic sherds; 6,540 pieces of vertebrate faunal remains; more than $58.2 \mathrm{~kg}$ of invertebrate faunal remains; $1.6 \mathrm{~kg}$ of macrobotanical remains; $163.0 \mathrm{~kg}$ of burned and unburned rocks; and $30.0 \mathrm{~kg}$ of burned clay. The records generated by the excavations and later analyses and the artifacts and other materials retained for curation are housed at the Center for Archaeological Research, The University of Texas at San Antonio.

Analysis of the data recovered indicates that 41MM341 was a campsite occupied perhaps mostly during the summer months by hunter-gatherers who took mussels and fish from the river and hunted a variety of game, especially deer, on the Little River floodplain and the surrounding uplands. They may have used botanical resources less, although they did consume hardwood nuts and wild onion and false garlic bulbs. One important activity performed at the site was manufacture of stone tools-mostly arrow points, knives, and expedient flake tools-using chert collected from gravel bars in the river. Many of these tools were used in the wide variety of procurement, processing, and manufacturing activities that typified daily life at 41MM341, but some appear to have been made because they would be needed later in the year after people left the site. One anticipated need was for trade with the Caddo Indians of east Texas. The people who lived at 41MM341 and other sites in the Little River valley interacted regularly with the Caddo, perhaps in trade relationships that helped cement cooperative alliances aimed at regulating competition among groups. Site 41MM341 contributes important information on this topic, which remains an interesting research issue for Native American groups who used the Blackland Prairie between central and east Texas during the Late Prehistoric period.
\end{abstract}




\section{ACKNOWLEDGMENTS}

The successful undertaking of archeological investigations requires mustering a range of expertise, and the investigations at 41MM341 are no different. Thanks for and recognition of the efforts of everyone involved with this project are heartily extended here.

This project was initiated and carried out by the Environmental Affairs Division of the Texas Department of Transportation (TxDOT), and many of the archeologists of this agency lent their expertise and efforts to its completion. Ms. Cynthia Tennis and Dr. James T. Abbott oversaw field investigations and initial analysis, provided timely archeological advice, and also cleared the many administrative hurdles that tend to crop up with a project of long duration. Because he took part in the initial discovery of the site, Dr. Abbott's involvement with geomorphological investigations of the Little River floodplain provided invaluable continuity to this project. Dr. Mary Jo Galindo graciously assumed oversight of the project during the final analysis and report production stage. Also, Dr. Lain Ellis's and Dr. Owen Lindauer's interest in the project and receptivity to different research perspectives fostered a scholarly approach to this project.

Special thanks go to Mr. Allen Bettis, archeologist for TxDOT, for his enthusiastic help in devising a lithic analysis plan for the project. Using his skill and knowledge as an expert flint knapper in the perusal of the lithic tool collection and the debitage from several of the lithic reduction debris piles, he provided an understanding of the kinds of manufacturing techniques that generated these archeological remains. He also conducted a cobble-reduction experiment that helped confirm the type of debitage associated with this manufacture technique.

TxDOT personnel in the Bryan District were also extremely important to completion of the field investigations. Mr. Michael A. Carpenter, environmental coordinator, was instrumental in obtaining right of entry to the site. Mr. John W. Parsons of the Cameron office and his crews assisted with a variety of logistical details. These included access to the Cameron yards to fill our water truck, setting up an electric fence to keep the cattle at bay, providing equipment and operators to strip the site, pumping out the excavations after a work-stopping flood, and finally filling the excavations. Without their assistance and goodwill toward the archeological crew, fieldwork could not have efficiently moved forward.

All of the day-to-day backhoe work such as moving backdirt, digging trenches, and constructing and maintaining the waterscreen sump was undertaken by Mr. Jim Carter, owner of the JHC Ranch in Cameron. Mr. Carter's keen interest in prehistory and his willingness to oblige our every call, even when he probably should have been taking care of ranch business, will not be quickly forgotten.

Dr. Steve A. Tomka and Mr. Richard B. Mahoney of the Center for Archaeological Research (CAR) at The University of Texas at San Antonio went first into the Little River valley, testing 41MM341 and 41MM340 and conducting data recovery excavations at 41MM340. They provided assistance to the planning and execution of this project by sharing their knowledge of working in the area and were forthcoming about the particulars of the test excavations at 41MM341. Transfer of testing documentation was sped by the diligent efforts of Ms. Marybeth Tomka, laboratory director for CAR. Also, Dr. Raymond Mauldin produced an oxygen isotope analysis of Rabdotus shells from $41 \mathrm{MM} 341$ in conjunction with his research on shells from 41MM340.

Many in the archeological community were interested in how this project unfolded, and several provided their impressions on the site's place within Texas prehistory. Dr. Dee Ann Story, Dr. Harry J. Shafer, and Mr. Elton R. Prewitt reviewed the lithic artifact assemblage and made suggestions about typology and interpreting artifact relationships. In this respect, Mr. Prewitt's 
expertise with central Texas Late Prehistoric materials and Dr. Story's and Dr. Shafer's experience with the Davis site were invaluable in highlighting possible interregional connections.

Dr. Lee C. Nordt of Baylor University's Department of Geology, who had undertaken the geomorphological analysis of the Little River floodplain in the area of 41MM340 and 41MM341, provided invaluable assistance toward understanding the floodplain dynamics that shaped 41MM341. Mr. Robert G. Howells, malacologist for Texas Parks and Wildlife, kindly provided recent samples of the threeridge mussel (Amblema plicata) from his collections to be used as baseline data for mussel shell oxygen isotope analysis. Special analysts who contributed to this project are Dr. Leslie Bush, archeobotanist; Ms. Karen M. Gardner, malacologist; Dr. Mary Malainey, lipid residue analyst; Dr. Brian S. Shaffer, zooarcheologist; Dr. Robert Tykot, isotope analyst, and his assistant, Ms. Jennifer A. Kelly; and Dr. Barbara Winsborough, diatomist.

The project staff at Prewitt and Associates worked diligently toward this project's successful completion. Mr. Ross C. Fields was the principal investigator for the project; his involvement in all aspects of this project proved, as always, invaluable in guiding it to a successful conclusion. Mr. Karl W. Kibler, project geoarcheologist, undertook the task of interpreting the site's geomorphic history and relating it to Dr. Nordt's interpretations. Mr. Doug Boyd joined Mr. Kibler in providing insights helpful for interpreting the archeology of the site, particularly in relation to the topic of interregional interaction. Ms. Jennifer K. McWilliams, project archeologist, ran the daily field operations at the site with aplomb. Ms. McWilliams also handled the tedious task of coordinating record keeping between the field and lab, she served as site photographer, and she took part in the initial analysis and interim report preparation. E. Frances Gadus, archeological project manager, coordinated and contributed to all aspects of the project, including research design, prefield logistics, field operations, analysis design and execution, and report preparation.

As always, the field crew shouldered the heavy-lifting aspects of the project while still carefully attending to the science. The crew included Mr. John W. Arnn, Mr. Steven Baird, Mr. Cory Broehm, Mr. Tim Gibbs, Mr. Weldon Hammond, Ms. Virginia Hatfield, Mr. Mark Holderby, Ms. Carrie Kelly, Mr. Patrick McLoughlin, Mr. Daniel Teague, Mr. Rob Thrift, Mr. Waldo Troell, and Mr. Mike Wilder. Special mention goes to Mr. Arnn for taking on the onerous task of setting up and keeping the waterscreen station functional, as well as taking the lead in dealing with the water truck. He was helped in these tasks mainly by Mr. Thrift, Mr. Baird, and Mr. Teague. These four also kept the fieldwork on schedule by pushing to excavate the most levels in a single day (John Arnn and Rob Thrift) and by waterscreening the most proveniences in one day (Steven Baird and Daniel Teague).

Thanks also go to the laboratory and report production staff at Prewitt and Associates. Ms. Gadus, with assistance from Ms. Gemma Mehalchick and Mr. Gregory Labudde, completed the chipped stone analysis. Mr. Christopher W. Ringstaff made the initial typological identifications of the arrow and dart points. Ms. Gadus also described the ground stone tools, bone tools, and few ceramic vessel sherds. Ms. Gadus, Ms. McWilliams, and Mr. Thrift quantified and described all other materials recovered. All recovery brought back to Austin was organized, processed, and curated by Mr. Jonathan Grant under the direction of Ms. Karen M. Gardner. Ms. Gardner was also responsible for the curation of all records as well as for data entry and manipulation. The excellent graphic presentation in this report is because of Ms. Sandra L. Hannum and Mr. Brian J. Wootan. Mr. Jack Rehm photographed the artifacts. Mr. Fields, Ms. Audra L. Pineda, and Ms. Jane Sevier edited the report, and Ms. Pineda and Ms. Sevier produced it.

E. Frances Gadus

Archeological Project Manager

January 2005 



\section{INTRODUCTION, ENVIRONMENTAL SETTING, AND ARCHEOLOGICAL BACKGROUND}

This report is for data recovery excavations performed by Prewitt and Associates, Inc., at the J. B. White site, 41MM341. The work was done for the Texas Department of Transportation (TxDOT), Environmental Affairs Division, under Contract No. 572XXSA005, Work Authorizations 57206SA005, 57210SA005, and 57215SA005, to address the requirements of Section 106 of the National Historic Preservation Act of the Texas Antiquities Code. The data recovery excavations were necessitated by the planned replacement of the State Highway 36 bridge spanning the Little River floodplain, which will directly impact the archeological deposits at 41MM341. This site was determined eligible for listing in the National Register of Historic Places under Criterion D and for designation as a State Archeological Landmark as a result of test excavations done in 2000 (Mahoney and Tomka 2001). Work began in May 2002 with preparation of an initial research design and completion of an application for an antiquities permit. Following review of the research design by TxDOT, the Texas Historical Commission, and Native Americans, fieldwork began in July 2002 and was completed in November 2002. Laboratory processing, data analysis, and report preparation began upon completion of fieldwork and culminated in submittal of the draft of this report in January 2005.

Site 41MM341 is in central Milam County, Texas, just southeast of the town of Cameron (Figure 1-1). The site occupies a low rise in the modern floodplain of the Little River, ca. $400 \mathrm{~m}$ northwest of the current channel and ca. $750 \mathrm{~m}$ southeast of the base of the valley wall (Figure 1-2). As described in this report, 41MM341 is a well-preserved, stratified, multicomponent prehistoric site encased in late Holocene alluvium.
The data recovery excavations focused on broad exposure of the remains of a series of Late Prehistoric occupations dating from to A.D. 800 or 900 to 1300 , with more-limited sampling of a component dating to the A.D. 600-700s. The excavations consisted of the following: 4 backhoe trenches; 11 initial 1x1-m units; a $642-\mathrm{m}^{2}$ area in which the upper, largely sterile deposits were stripped mechanically for potential placement of blocks; and 3 hand-excavated blocks covering $208 \mathrm{~m}^{2}$; the total volume of sediments excavated manually was $95 \mathrm{~m}^{3}$. The excavations identified a variety of cultural features and recovered the following: 303 shaped chipped stone tools; 494 expedient stone tools; 158 cores; 39,872 pieces of unmodified debitage; 30 stone tools modified by grinding or battering; 30 bone tools or modified bones; 4 ceramic sherds; 6,540 pieces of vertebrate faunal remains; over $58.2 \mathrm{~kg}$ of invertebrate faunal remains; $1.6 \mathrm{~kg}$ of macrobotanical remains; $163.0 \mathrm{~kg}$ of burned and unburned rocks; and $30.0 \mathrm{~kg}$ of burned clay.

The recovered data contribute to numerous research questions that are important for the region, including some relating to reconstructing paleoenvironments; understanding subsistence practices; examining assemblage organization and what it says about tool manufacture and production strategies, tool function, and group organization; and looking at site function through intrasite patterning of features, artifacts, and ecofacts. Probably most significant, though, is what the site conveys about interregional interaction among Native American groups who lived in central and east Texas during the early and middle parts of the Late Prehistoric period.

This report consists of 9 chapters and 10 appendixes. The remainder of this chapter 


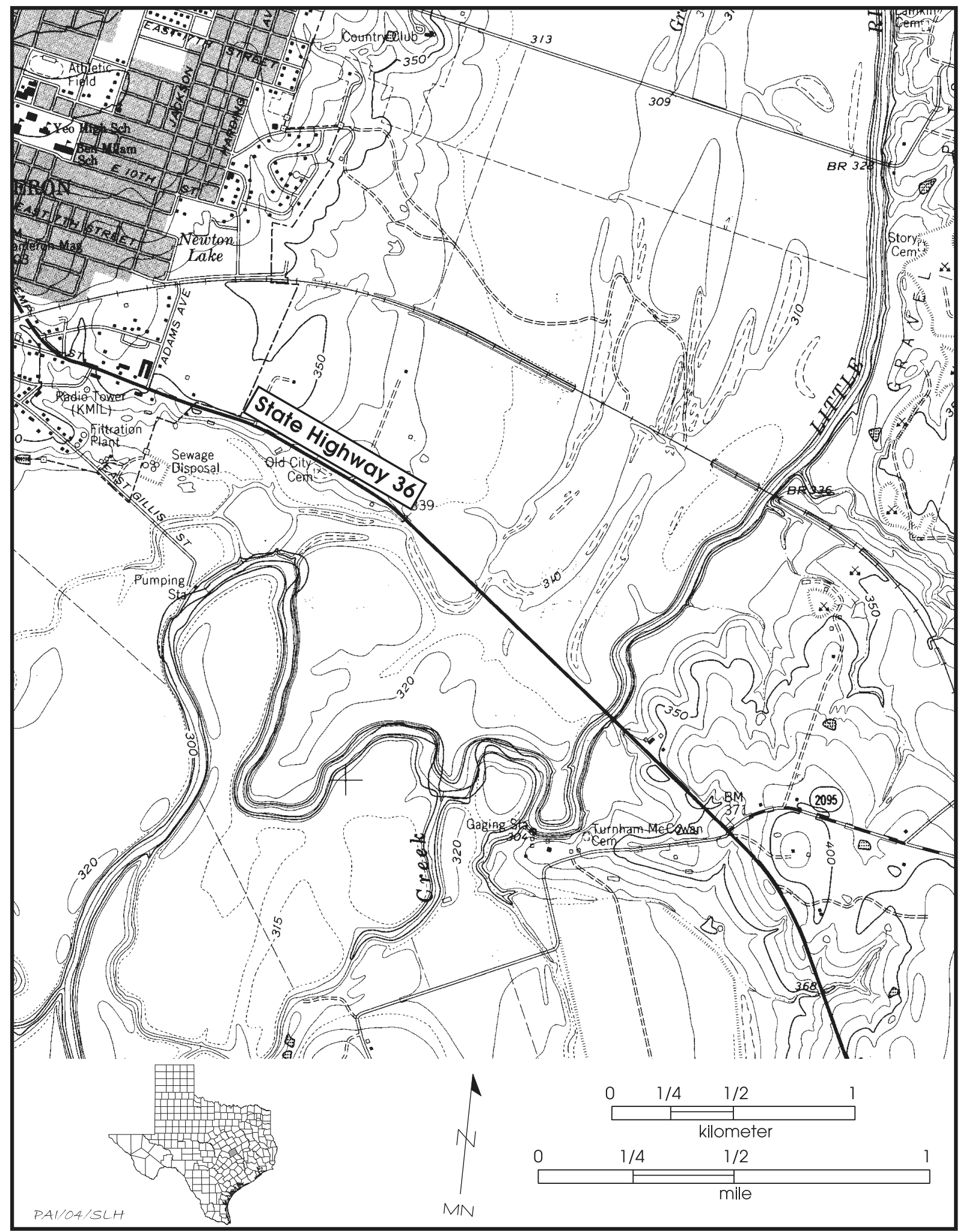

Figure 1-1. Map showing the location of 41MM341 (select copies of the report contain a pocket with Figure 1-1 showing the site location). 


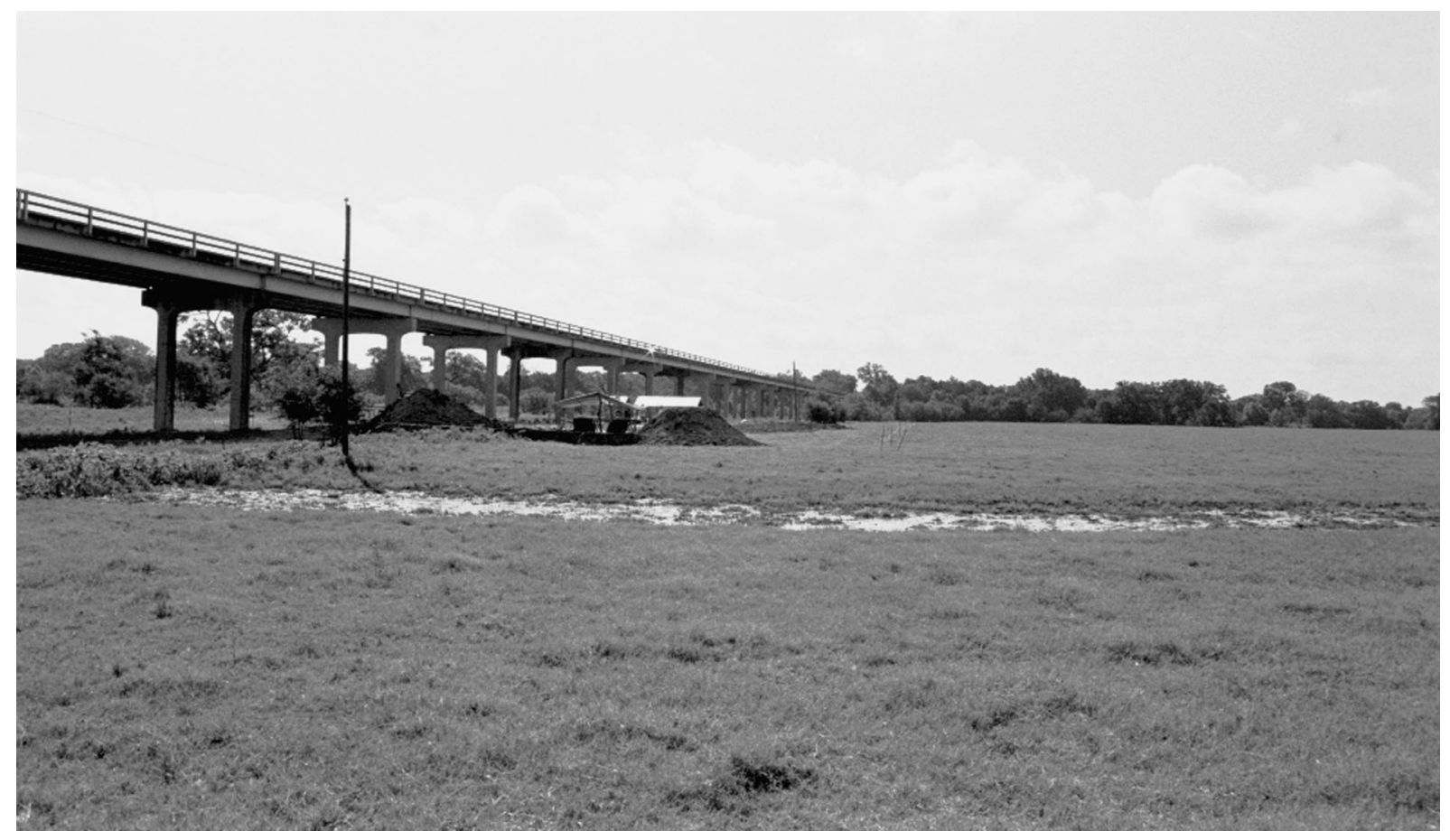

Figure 1-2. View to the southeast with project area at center of photograph. The State Highway 36 bridge is beyond, with the Little River in the far tree line and the shallow slough northwest of the site in the background.

describes the environmental setting of the project area and provides archeological background information. Chapter 2 describes the work done at 41MM341 and what was known about the site before the data recovery excavations. Chapter 3 presents overviews of the work plan that guided data recovery and the work accomplished, followed by the research design. Chapter 4 describes the work done in data recovery and the methods used. Chapter 5 discusses the geomorphology of 41MM341 and the surrounding Little River floodplain. Chapters 6 and 7 describe and discuss the cultural features and artifacts and other cultural materials found in the excavations. Chapter 8 defines analysis units and presents analyses of the vertical and horizontal distributions of the archeological remains. The final chapter uses the archeological data to address the questions asked in the research design. The report concludes with a list of references cited and appendixes reporting on various special studies, providing measurements and provenience information for the materials recovered, and listing radiocarbon dates.

\section{ENVIRONMENTAL SETTING}

This section describes the modern environ- mental setting of the project area. Site 41MM341 is located in the lower Little River basin in central Milam County (Figure 1-3). The Little River forms where the Leon and Lampasas Rivers join in east-central Bell County, roughly $54 \mathrm{~km}$ (following the river valley) west-northwest of the site. Above their confluence, the Leon and Lampasas Rivers drain territory underlain by Cretaceous deposits of central Texas, with the Leon River heading about $225 \mathrm{~km}$ northwest of the confluence in northern Eastland County and the Lampasas River heading about $135 \mathrm{~km}$ to the west-northwest in eastern Mills County. Roughly $45 \mathrm{~km}$ downstream from the confluence and just $11 \mathrm{~km}$ upstream from 41MM341, the Little River is joined by its major tributary, the San Gabriel River. The eastward-flowing San Gabriel also drains Cretaceous limestones before entering the Blackland Prairie, starting its journey in central Burnet County $120 \mathrm{~km}$ west of 41MM341. The Little River flows another $29 \mathrm{~km}$ east of the current project area before emptying into the Brazos River at the Milam-Robertson County boundary not far west of Hearne, Texas.

Using historical data from 1917 to 1955 , Mahoney et al. (2003:6-9) show that streamflow in the Little River tends to be highest in April 


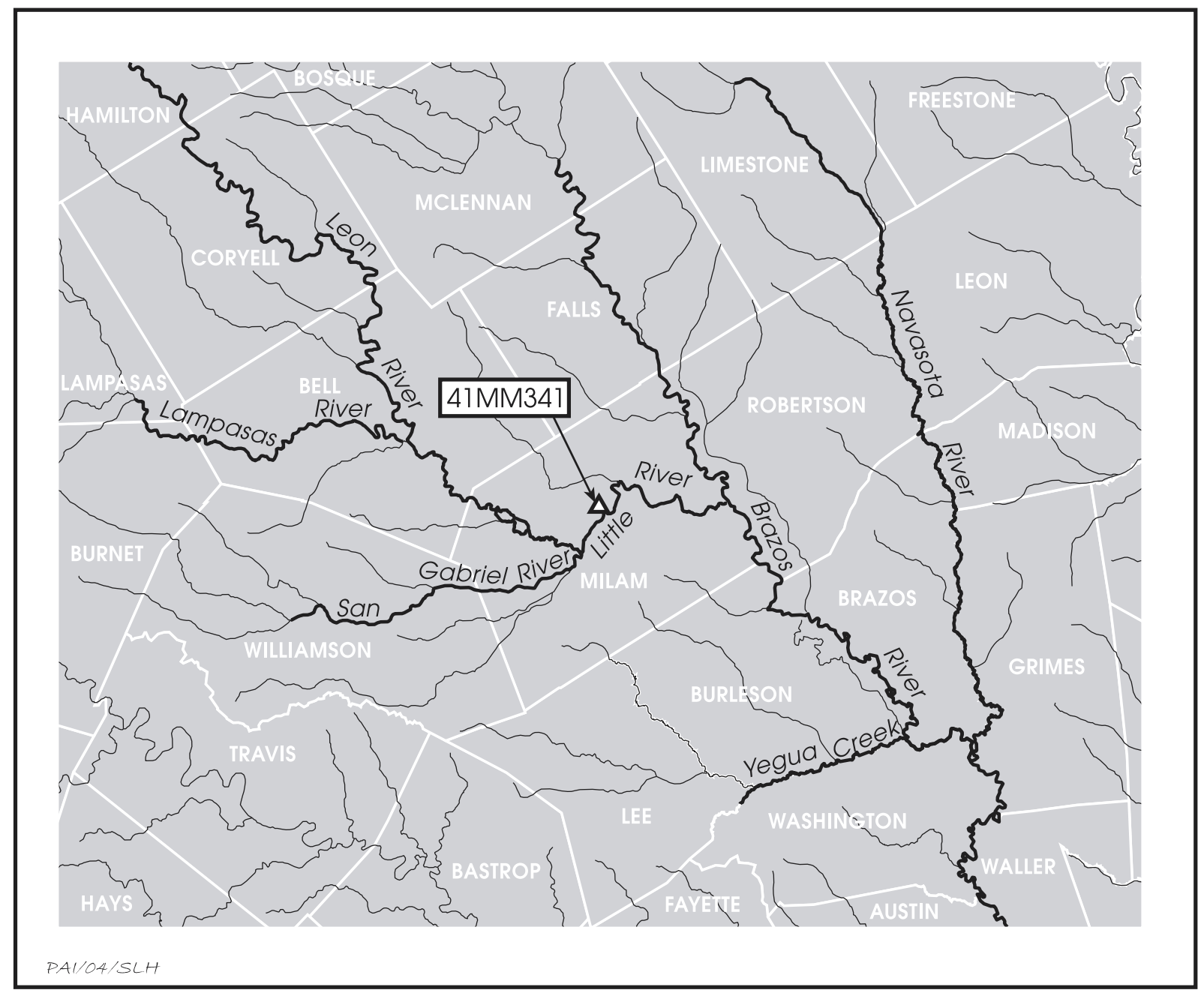

Figure 1-3. Map of the location of 41MM341 in the Little River basin.

and especially May; moderate in January through March, June, and September; and lowest in July and August. Their analysis suggests a rate of 1.13 floods per year before dams were built on the Leon, Lampasas, and San Gabriel Rivers. Flood events were most common by far in April and May (one event every 3.5-3.9 years), with much smaller peaks in January, June, and December (one event every 7.8-9.8 years). Flooding occurred more rarely in February, July, and September-November; March and August were the only months with no flood events.

Stream flow in the Little River is, of course, a function largely of rainfall, which averages about 34 inches per year in this area (Mahoney et al. 2003:6). May is the wettest month, averaging just over 5 inches, and July and August are the driest months, averaging 1.9 and
1.7 inches. September and October have moderately high rainfall totals of 3.5 and 3.7 inches, and precipitation tapers off through the remainder of the fall and winter months before starting to increase again in April.

The Milam County area has hot summers and cool winters, with a 248-day growing season running from early March to midNovember (Mahoney et al. 2003:6). Mean minimum and maximum temperatures are highest $\left(71-74^{\circ} \mathrm{F}\right.$ and $92-96^{\circ} \mathrm{F}$, respectively) in June through August. The months of December, January, and February have the lowest mean minimum $\left(39-44^{\circ} \mathrm{F}\right)$ and maximum $\left(62-67^{\circ} \mathrm{F}\right)$ temperatures.

The immediate project area is underlain by Holocene alluvium filling the Little River valley, and the soils developed in this calcareous alluvium are mapped as the Tinn series 
(Mahoney et al. 2003:11). The valley is quite wide at this location, as it is for its full length, with widths of $2-4 \mathrm{~km}$ being typical. The modern floodplain surface near 41MM341 stands at elevations of 310-320 ft above mean sea level. The modern river channel, which hugs the valley wall $400 \mathrm{~m}$ south of the site, is entrenched 6-7 $\mathrm{m}$ below this surface. In many places along its course, the Holocene valley is bordered by higher surfaces composed of gravelly Pleistocene terraces (Nordt et al. 2003:75). Such landforms are mapped on both sides of the river near the current project area, with both terraces being quite wide (averaging $2.5-3.5 \mathrm{~km}$ ) and reaching elevations of 390-410 ft above mean sea level. Beyond these Pleistocene terraces, deposits of the Eocene Midway Group (to the north) and Wilcox Group (to the south) are mapped, with the river following the strike separating the two (Nordt et al. 2003:75). These Tertiary deposits are mostly sandstones and mudstones. For most of its length, however, the Little River and its tributaries drain landscapes underlain by Cretaceous-age limestones and calcareous marls and muds.

The project area lies in the Western Gulf Coastal Plain physiographic province at the boundary of the Blackland Prairie to the west and the Oak Woodlands to the east (Figure 1-4). In terms of vegetation, the Oak Woodlands region is characterized by overcup oak, post oak, and black hickory deciduous forests (greater than 60 percent canopy cover), and bluejack oak, pine, post oak, and blackjack oak deciduous woodlands (26-60 percent canopy cover) (Diamond et al. 1987). The Blackland Prairie region contains tall grasslands (dominants greater than $1 \mathrm{~m}$ tall), primarily little bluestem and Indiangrass, with riparian deciduous forests of sugarberry and elm.

The Milam County area is within the Texan biotic province as defined by Blair (1950:100 102 ), who indicates that a minimum of 49 mammalian species have been documented in this province. Among the common ones are opossum, eastern mole, eastern fox squirrel, pocket gopher, fulvous harvest mouse, white-footed mouse, pocket mouse, deer mouse, hispid cotton rat, eastern cottontail rabbit, swamp rabbit, and jackrabbit. Also present are eastern box turtle, ornate box turtle, 16 species of lizards, 39 species of snakes, 5 species of amphibians, and 18 species of frogs and toads.

\section{ARCHEOLOGICAL BACKGROUND}

Before the excavations at 41MM340 and $41 \mathrm{MM} 341$ as a result of the replacement of the State Highway 36 bridge across the Little River floodplain, only a modest amount of professional archeological work had been done in Milam County, with most of the previous work involving survey and excavation at the Spanish Mission San Francisco Xavier near the confluence of Brushy Creek and the San Gabriel River (Gilmore 1969) and survey and limited testing and data recovery at the Sandow Mine in upland settings at the south edge of the county and in Lee County beyond (e.g., Betancourt 1977; Carlson et al. 1983; Ippolito and Childs 1978; James 1986; James and Moore 1987; Keller and LaVardera 1989; Ricklis 2001; Rogers 1997, 1999; Rogers and Cruse 1998; Rogers and Kotter 1995; Rushmore et al. 1980; Weed 1977; Weed and Ippolito 1977; Weed and Whittaker 1980). Because limited work had been done, the prehistory of this stretch of the Little River basin remained poorly known. As detailed later in this report, the excavations at 41MM341 have changed this for the early and middle parts of the Late Prehistoric period, and 41MM340 has contributed important information about use of the region during the middle part of the Late Archaic period (Mahoney et al. 2003).

To help set the stage for understanding the record at 41MM341, this section provides an overview of the Late Archaic and Late Prehistoric archeology of the project area and adjacent regions. Because 41MM341 is at the boundary between the Blackland Prairie and the Oak Woodlands, this overview draws on previous work in a variety of ecological settings, extending eastward and northeastward to follow the southern Oak Woodlands through the Brazos River basin and westward to the Edwards Plateau and Lampasas Cut Plain. This discussion treats the Late Archaic period first, then the Late Prehistoric period.

\section{Late Archaic Period}

All parts of the southern Oak Woodlands that have been studied archeologically contain sites dating to the latter part of the Archaic pe$\operatorname{riod}$ (i.e., 4,000-1,200 B.P.), and the Late Archaic represents the earliest time for which much is known about Native American lifeways in this 


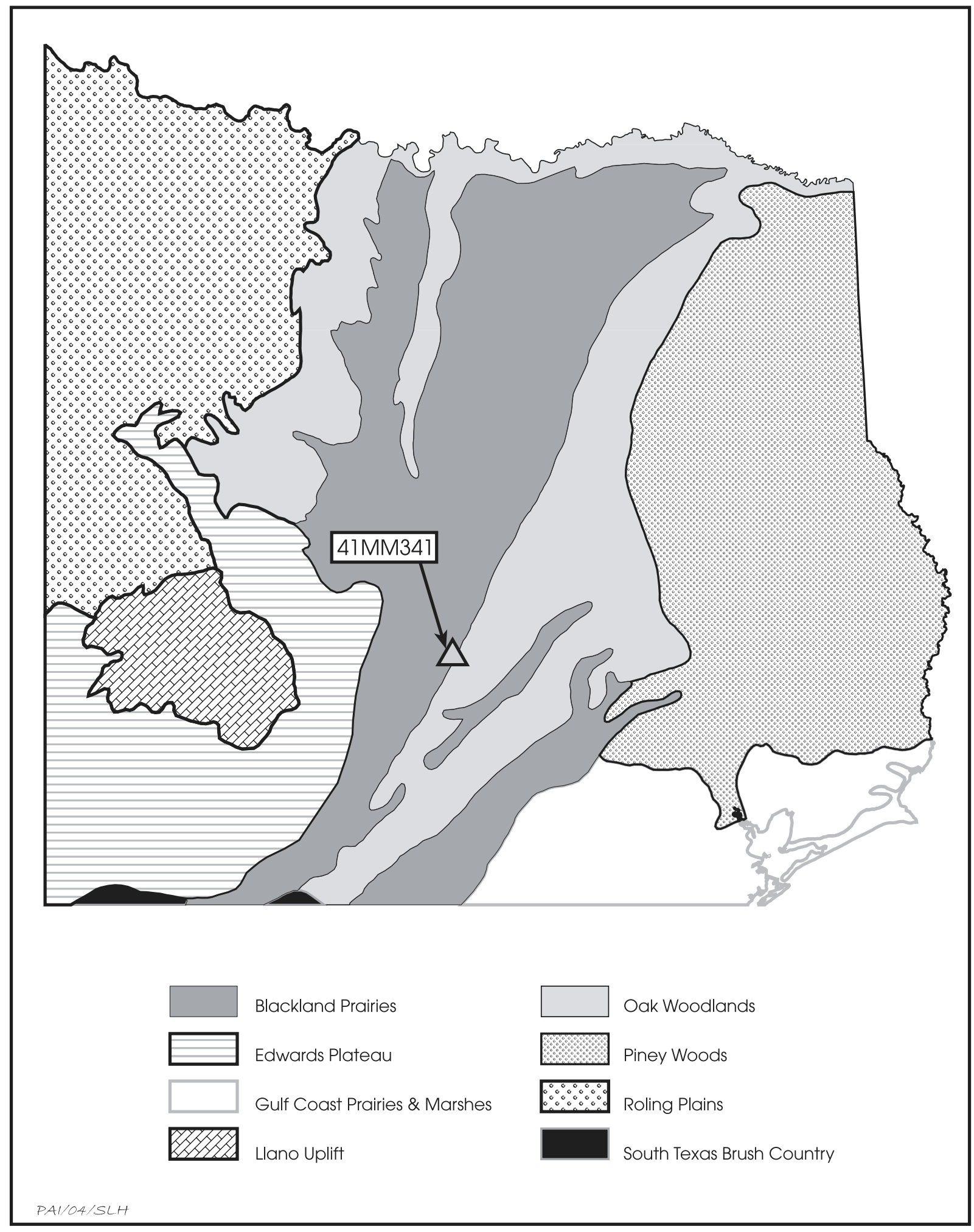

Figure 1-4. Distribution of modern plant communities in central and eastern Texas (after Diamond et al. 1987). 
part of Texas. One of the more-complete pictures of the archeology of the Late Archaic for this region comes from Lake Limestone and the Jewett Mine in Freestone, Leon, and Limestone Counties (Figure 1-5). Extensive work there indicates that this part of the Navasota River valley and the area eastward to and across the Trinity River divide were occupied with increased intensity during the Late Archaic period, although there is no evidence for any degree of sedentism (Fields 1995:307-309). Faunal and macrobotanical remains were not pre- served in the Late Archaic components there, except for the ubiquitous hickory nutshells, and thus data on subsistence are limited. Nonetheless, it is surmised that these hunter-gatherers subsisted on a variety of wild plant foods and game, especially deer. Of the 20 excavated components assigned to this period, 15 are interpreted as residential bases and 5 as procurement or processing locations. Five of the residentialbase components are situated along the Navasota River, and the others are in the uplands to the east. The analysis units interpreted

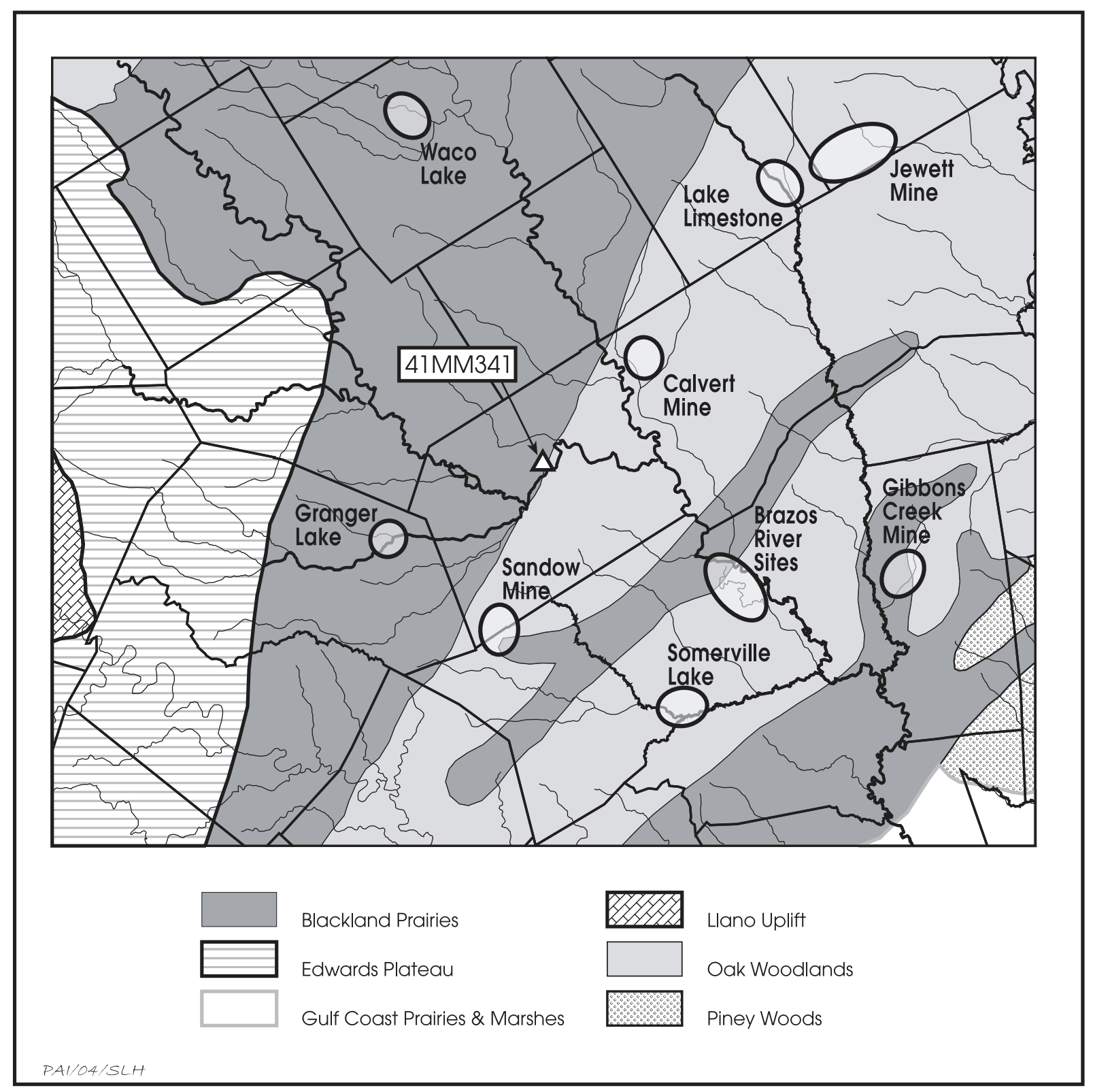

Figure 1-5. Selected archeological project areas in the vicinity of 41MM341. 
as procurement-processing locations appear to have focused primarily on plant processing and then on hunting-related activities. Four of these are along streams in the uplands, and the fifth is along a Navasota River tributary to the west. The data from these 20 components are consistent with the idea that Late Archaic groups were chiefly foragers because procurementprocessing locations suggesting logistical use are not frequent. Settlement systems appear to have been highly scheduled, probably by season, with residential sites in riverine settings differing from those in the uplands. The high frequency of Late Archaic components and overall greater intensity of use compared to earlier time periods suggest increased population densities, decreased territories, or both. The occurrence of a Late Archaic cemetery at the Cottonwood Springs site along Lambs Creek on the east side of the Navasota River valley also points to this shift (Fields and Klement 1995).

The constellation of projectile point styles (e.g., Dawson, Gary, Godley, Kent, Neches River oletha, and Yarbrough) from Lake Limestone and Jewett Mine indicates ties mostly to the north and east rather than to the south and west. Further, the area also has yielded information suggesting that ceramics may have been introduced into the material culture of local groups during the latest part of the Late Archaic, as they were across most of Texas to the east (where this interval usually is called the Early Ceramic period and sometimes the Woodland period).

At Lake Limestone and the Jewett Mine, a few shell-tempered sherds, a few sherds with a fine kaolin paste but no obvious temper, and larger numbers of sandy paste ceramics and grog- or bone-tempered ceramics were found in contexts that appeared to predate arrow points (i.e., the latter part of the Late Archaic). Although some of these could be genuinely early, especially the sandy paste wares that are so reminiscent of the early ceramics that predominate in east Texas south of the Sabine River, it is possible that the other sherds intruded from later deposits (Fields 1995:308). In either case, sherds were sufficiently infrequent to suggest that, although ceramic containers may have been a notable addition to the material culture, they were not abundant.

The Late Archaic archeology of other parts of southern east-central Texas has not been deciphered to the same extent as that at Lake Limestone and the Jewett Mine, but it is clear that similar, though not identical, cultural developments occurred within hunter-gatherer groups across the region. The single excavated site at the Calvert Mine in Robertson County, 41RT267, apparently contains a Late Archaic component, but small sample sizes and the lack of features hamper interpretation (Robinson and Turpin 1993). At the Gibbons Creek Mine in Grimes County at the east edge of the Oak Woodlands, most of the excavated sites have Late Archaic components, and Rogers (1995:167) suggests that this reflects "a less mobile population relying more heavily on the area's plant resources, particularly hickory nuts." Rock hearths are common at these sites, but other kinds of features are not. Not surprisingly, the most common dart point types-Gary, Kent, and Palmillas-show strong connections to the eastern part of the state rather than to central Texas (Rogers 1995:167). As at Lake Limestone and the Jewett Mine to the north, ceramics may have been added to the material culture during the latest Archaic. These early ceramics were sandy paste wares comparable to early ceramics elsewhere in southeastern Texas (Rogers 1995:167).

To the west, three sites along the west side of the Brazos River-Winnie's Mound, 41BU16, and 41BU51-have significant Late Archaic components (Bowman 1985; Fields et al. 2004; Roemer and Carlson 1987). All three contained cemeteries probably at least partly Late Archaic in age; these could point to increased population densities and definition of territories. The projectile point styles recovered-Bulverde, Darl, Dawson, Edgewood, Ensor, Fairland, Frio, Gary, Kent, Lange, Marcos, Pedernales, and Yarbrough-are a mix of types characteristic of central and eastern Texas.

Moving back toward Milam County, two of the excavated sites at the Sandow Mine in Lee County-the Chesser site and the Walleye Creek site-have strong Late Archaic components. At these sites, many burned rock features were found in association with dart point types such as Bulverde, Pedernales, Lange, Marshall, Marcos, Ensor, Darl, and Fairland (Rogers 1999:96; Rogers and Kotter 1995:134). Although these types show distinct ties to central Texas in general, Rogers (1999:96-97) argues that the last three represent more-local types especially common to the eastern margin of the Edwards 
Plateau. A single sandy paste sherd was recovered from the Chesser site, but it is unclear if it relates to terminal Archaic or Late Prehistoric use of the site. In either case, ceramics were a less-prominent part of the material culture here than they were farther to the east and north. The limited faunal and macrobotanical remains recovered suggest reliance on Carya nuts and deer (Rogers 1999:28, 31-32; Rogers and Kotter 1995:42-45, C-1-10).

Nearby at Somerville Lake on Yegua Creek, the single site excavated, Erwin's Bridge, contained a strong Late Archaic component, although it was difficult to isolate it from the Late Prehistoric component (Peterson 1965). Most of the kinds of projectile points recoveredBulverde, Castroville, Darl-like, Elam, Fairland, Palmillas, and Pedernales-resemble those from the Sandow Mine and indicate ties to central Texas to the west. Erwin's Bridge yielded a small collection of ceramics, primarily sandy paste, but it is impossible to tell if these relate to the Late Archaic or Late Prehistoric occupations.

Just a few hundred meters from 41MM341, site 41MM340 excavated in 2001-2002 contains a Late Archaic component dating mostly to about 1400 to 400 B.C. (Mahoney et al. 2003). This site contained numerous hearth features represented by both burned rock clusters and charcoal and burned clay concentrations. Subsistence data indicate that the huntergatherers who occupied the Little River valley at this time consumed the meat of a variety of fauna, including mussels, deer, bison, turtles, beavers, rabbits, raccoons, opossum, skunks, turkeys, ducks, and fish. Botanical remains were not as abundant, although nutshell fragments indicate that hickory and pecan nuts were part of the diet. Most of the dart points belong to types that firmly tie the region to central Texas to the west at this time, including Darl, Ensor, Godley, Marcos, Marshall, and especially Pedernales. Some more-eastern types, such as Gary, Kent, and Yarbrough, are represented, however.

The archeology of the central Texas region west of Milam County has been well synthesized in recent years (e.g., Collins 1995; Johnson and Goode 1994). Populations apparently continued to increase from earlier times (Prewitt 1985:217), and within stratified sites such as Youngsport near Stillhouse Hollow Lake in Bell County (Shafer 1963), Britton at Waco Lake in McLennan County (Story and Shafer
1965), Steele at Whitney Lake in Hill County (Stephenson 1970), and Loeve-Fox at Granger Lake in Williamson County (Prewitt 1982) the Late Archaic components contain the densest concentrations of cultural materials. The establishment of large cemeteries along drainages suggests strong territorial ties by certain groups (Story 1985:40).

Middle Archaic subsistence technology, including the use of rock and earth ovens, continued into the Late Archaic period in central Texas. Collins (1995:384) states that, at the beginning of the Late Archaic, the use of rock ovens and the resultant formation of burned rock middens reached its zenith and that the use of rock and earth ovens declined during the latter half of the Late Archaic. However, there is mounting evidence that midden formation culminated later (Black et al. 1997:270-284; Brownlow 2003: Kleinbach et al. 1995:795). A picture of prevalent burned rock midden development in the eastern part of the central Texas region after 2000 B.P. is gradually becoming clear. The use of rock and earth ovens for processing and cooking plant foods was part of a generalized foraging strategy. However, at times during the Late Archaic, this generalized foraging strategy appears to have been marked by shifts to a specialized economy focused on bison hunting (Kibler and Scott 2000:125-137). Castroville, Montell, and Marcos dart points are elements of tool kits often associated with bison hunting (Collins 1968).

The Archaic period represents a hunting and gathering way of life that was successful and that remained virtually unchanged in central Texas for more than 7,500 years. This notion is based in part on fairly consistent artifact and tool assemblages through time and localities and resource patches that were used continually for several millennia, as witnessed by the formation of burned rock middens. This pattern of generalized foraging, though marked by brief shifts to a heavy reliance on bison, continued almost unchanged into the succeeding Late Prehistoric period.

\section{Late Prehistoric Period}

Good data on how Native Americans used the southern Oak Woodlands of east-central Texas during the Late Prehistoric period come from Lake Limestone and nearby Jewett Mine 
in Freestone, Leon, and Limestone Counties. Work there identified 12 components dating predominately to the Late Prehistoric period, although not all are well dated (Fields 1995:313317; Gadus et al. 2002). Six are interpreted as residential bases, and the other 6 are procurement-processing locations. These sites suggest that, during the early part of the period, residential activities were more restricted to lowland sites than was the case in earlier time periods and the uplands were used mostly for hunting-related procurement and processing tasks. This pattern indicates that logistical strategies became more important, but there is no evidence that groups also became sedentary within the upper Navasota River basin itself. Only one site, McGuire's Garden, contained the kinds of features and other remains that suggest permanent (or nearly so) occupation, with this unusually sedentary use dating to a short interval around A.D. 1300. During the late part of the period, the area apparently saw a return to forager-oriented hunter-gatherer strategies entailing more equable use of upland and lowland settings. Faunal remains indicate that deer, turtles, and rabbits were hunted commonly, and other small mammals, bison, fish, birds, lizards, and snakes were taken as well. Hickory nutshells are by far the most common plant remains. The only evidence for the use of tropical cultigens came from the McGuire's Garden site. Scallorn and Steiner are the most common early arrow point styles, and use of dart points appears to have persisted through the early part of the period (Fields 1995:314). Perdiz is the dominant later arrow point style. Ceramics occur widely but infrequently, being common at only a handful of sites that date mostly to the middle and late parts of the period. Nonetheless, they all relate strongly to Caddoan wares from east of the Trinity River, with the moredistinctive sherds showing typological affinities to early types such as Holly Fine Engraved and Weches Fingernail Impressed and later types such as Maydelle Incised, Killough Pinched, Poyner Engraved, and Patton Engraved. Because Caddoan ceramics are present in these components but evidence for permanent occupations (i.e., structures) is scarce, Fields et al. (1991) suggest that Caddo Indians used most of these sites as base camps to support forays by hunting parties or other procurement and processing task groups, or perhaps that Caddo groups in transit between the eastern and central parts of the state used them. It is equally plausible, however, that local hunter-gatherer groups created them and that the ceramics resulted from trade with their Caddo neighbors.

At the Calvert Mine in the uplands between the Brazos and Navasota Rivers, the primary component at the single excavated site, 41RT267, appears to date to the early Late Prehistoric period (Robinson and Turpin 1993:2369). It contained Scallorn, Alba, and Granbury points, as well as a single potsherd and several burned rock features, and was interpreted as having been used mostly as a hunting camp with occasional use as a domestic campsite (Robinson and Turpin 1993:71-72). Jumping southeast to the far edge of the Oak Woodlands, Late Prehistoric remains are well represented at the Gibbons Creek Mine in Grimes County, with substantial occupations at 41GM281 and 41GM282 and more-limited occupations at several other sites (Rogers 1993:77, 102, 174, 214; 1994:154; 1995:138-143, 164-165). The predominate early and late arrow point styles are Scallorn and Perdiz, respectively. The ceramics from most of the excavated sites (Rogers 1993:102, 160-173, 210-212; 1994; 1995:108$123,168-171)$ are the sandy paste ware that occurs throughout southeast Texas, first in Late Archaic (or Woodland or Early Ceramic) contexts and then in some Late Prehistoric contexts (e.g., on the upper coast). Two sites (41GM281 and 41GM282) also have sizable samples of pottery tempered with grog or bone. Some of these probably are related to the Late Prehistoric San Jacinto ware that occurs on the upper coast to the east and southeast, and small numbers of sherds bear designs similar to those seen on Caddoan pottery to the northeast. Subsistence data from the Gibbons Creek Mine are sparse, but hardwood nutshells occur in most sites and liliaceous bulb fragments were recovered from a single site (Rogers 1993:74, 124, 214; 1994:120, $149 ; 1995: 56,153)$. The evidence indicates that, for the most part, the Gibbons Creek Mine sites represent short-term residential occupations by hunter-gatherers.

Westward along the Brazos River in Burleson County, early Late Prehistoric components represented by small numbers of Scallorn points were documented at Winnie's Mound and 41BU51, with the former site also yielding a few sandy paste sherds (Bowman 1985:43, 50, 
61-63; Fields et al. 2004). Alba, Perdiz, and Scallorn points were found at 41BU16 nearby, along with both sandy paste and bone- or grogtempered ceramics (Roemer and Carlson 1987:80-93). Perhaps most important, all three sites contained cemeteries that probably date partly to the early Late Prehistoric period (and partly to the Late Archaic period). These cemeteries could indicate continued high population densities from the Late Archaic period, as well as increased definition of territories. There is no evidence, however, that this was associated with sedentism or other changes from a huntergatherer lifestyle.

Northwestward back toward 41MM341, all three excavated sites at the Sandow Mine have Late Prehistoric components, but they appear to represent ephemeral use by hunter-gatherer groups. Materials diagnostic of this period include small numbers of Scallorn, Perdiz, Alba, and Cuney points; ceramics are scarce to absent (Ricklis 2001:150; Rogers 1999:96; Rogers and Kotter 1995:136). At Somerville Lake not far to the southeast in Burleson, Lee, and Washington Counties, arrow points typed as Alba, Cliffton, Granbury, Perdiz, Scallorn, and Young were recovered along with a handful of undecorated potsherds from the Erwin's Bridge site (Peterson 1965:22-27, 36-43), and small numbers of Alba, Scallorn, Perdiz, and Bonham points and sandy paste sherds were found at other sites investigated by Thoms and Ahr (1996). These sites probably represent shortterm hunter-gatherer campsites.

As described above, the Oak Woodlands to the northeast, east, and south of the 41MM341 area was not a cohesive cultural area during the Late Prehistoric period. Groups in different areas followed developmental trajectories that apparently varied somewhat (though the mobile hunting and gathering lifestyle generally prevailed), with those in the more northeasterly parts clearly being influenced by what was going on in the Caddoan area to the east and influences from coastal groups being especially strong on the southeastern edge. As discussed later in this report, these connections with Caddoan farmers are particularly relevant to interpreting 41MM341. Heading west from Milam County, you encounter a different situation because you bump up against one of the better-defined, better-synthesized archeological areas in Texas-the central Texas archeologi- cal region. In fact, Milam County is on the margin of this region as defined by most researchers, and, as the discussion of the Late Archaic period above indicates, the prehistory of this part of the Little River valley certainly is tied in with that of areas to the west.

In central Texas, the Late Prehistoric period generally is associated with the Austin and Toyah phases (Jelks 1962; Prewitt 1981:82-84), though Story (1990:364) argues for a horizon characterized by Alba points and early Caddoanlike pottery intermediate between the Austin and Toyah phases for the middle Brazos River basin. Noting that the sites that have yielded evidence of this intermediate horizon are difficult to interpret because "these sites have not been analyzed in detail (i.e., Chupik and Asa Warner) or the middle temporal phase remains have not been recognized as distinct," she goes on to suggest that these remains could represent "(1) groups from the east who occupied the area year around and/or seasonally, or (2) local groups who were interacting with Caddoans through trade, marriage, and visitations" (Story 1990:364). As discussed elsewhere in this report, $41 \mathrm{MM} 341$ contributes significant information about this subject.

Scallorn and Edwards points are characteristic of the Austin phase, and the introduction of these point styles into central Texas often was marked by violence and conflict, as many excavated burials contain these point tips in contexts indicating they were the cause of death (Prewitt 1981:83). Population densities appear to have dropped considerably from their Late Archaic peak during this period (Prewitt 1985:217). The generalized hunter-gatherer subsistence strategy that characterized the preceding Late Archaic period persisted through the first half of the Late Prehistoric period, and, at least in some areas, rock and earth oven use and consequent burned rock midden development continued as well (Black et al. 1997; Kleinbach et al. 1995:795).

Slightly more-xeric climatic conditions returned to the region during the latter half of the Late Prehistoric period, and bison returned in large numbers (Huebner 1991; Toomey et al. 1993). Utilizing this vast resource, Toyah peoples were equipped with Perdiz point-tipped arrows, end scrapers, four-beveled-edge knives, and plain bone-tempered ceramics. The technology and subsistence strategies of the Toyah phase 
represent a completely different tradition than the preceding Austin phase. Collins (1995:388) states that the formation of burned rock middens ceased, as bison hunting and group mobility obtained a level of importance not witnessed since Folsom times. Although the importance of bison hunting and high group mobility hardly can be disputed, a recent examination of Toyah-age radiocarbon assays and assemblages by Black et al. (1997) suggests that their association with burned rock middens represents more than a "thin veneer" capping Archaic-age features. Black et al. (1997) claim that burned rock midden formation, Although not as prevalent as in earlier periods, played a role in the adaptive strategies of Toyah peoples.

Although the paragraphs above convey a generalized picture of the Late Prehistoric culture history of central Texas, they gloss over details that are important for providing a context for interpreting 41MM341, particularly since some of the sites that have yielded important information about the late prehistory of central Texas are located on the Blackland Prairie not far west of the current project area. Among these are Hoxie Bridge and Loeve-Fox at Granger Lake and Rowe Valley not far west of Granger Lake, all in Williamson County (Bond 1978; Johnson 2000; Prewitt 1982). The information from these sites, coupled with that from $41 \mathrm{MM} 341$ presented in this report, shows that the simple Austin-Toyah sequence of central Texas is not an adequate chronological framework for the lower Little River basin and surrounding Blackland Prairie. The late prehistory of this area was more complicated than that. This topic, and what 41MM341 tells us about the relationships between Native Americans who occupied this region, central Texas to the west, and the Caddoan area to the east during the early to middle Late Prehistoric period, are taken up in the last chapter in this report. 


\section{PREVIOUS INVESTIGATIONS}

Site 41MM341 was investigated at the survey level in 1998, with testing to assess its eligibility for listing in the National Register of Historic Places and designation as a State Archeological Landmark following in 2000. These two episodes of work are described here.

\section{SURVEY}

Site 41MM341 was discovered in 1998 by TxDOT archeologists during systematic trenching of the Little River floodplain within the State Highway 36 corridor (Ahr and Abbott 1999). Eight trenches, six of which contained cultural materials, were excavated in the immediate vicinity of the site, which was estimated to cover an area of $80 \times 40 \mathrm{~m}$. The following is a description of the site taken from the site form completed by Steven Ahr of TxDOT:

Archeological materials at this site were initially identified in BHT 4, ranging from $120 \mathrm{~cm}$ to nearly $2 \mathrm{~m}$ below surface. BHT 4 yielded a thin and diffuse scatter of burned rock, mussel shell, and charcoal-stained sediment between 160 and $190 \mathrm{~cm}$. Mussel shell was also observed in the west and east walls at $180 \mathrm{~cm}$. Additional trenches (BHTs $15,17,23$, and 24) yielded several artifacts, including sizeable quantities of debitage, cores, modified flakes, and burned rock from 40-190 cm. BHT 15 yielded an abundance of burned clay, burned rock, flakes, bone, and charcoal beginning at $40 \mathrm{~cm}$. Mussel and charcoal were diffuse. The majority of materials was distributed between 45 and

\section{2}

$100 \mathrm{~cm}$, although dispersed mussel shells were located between 110 and $115 \mathrm{~cm}$. A 0.5-cm-wide dark stained area was exposed in the floor at $60 \mathrm{~cm}$. Charcoal samples were collected from the floor at about $73 \mathrm{~cm}$. Within the north wall of the trench at 50-60 cm below surface, two distinct hearth-shaped, dark stained features were observed in profile. Numerous clay lumps, a few burned rocks, and abundant associated charcoal bits were present within the feature profile. Materials in BHT 17 were concentrated between 40 and $90 \mathrm{~cm}$, and sparse materials at around $150 \mathrm{~cm}$. BHT 17 also yielded numerous flakes, mussel shells, charcoal, bone, snails, and a few scattered burned rock from 40$70 \mathrm{cmbs}$. At $90 \mathrm{~cm}$, a sandstone feature was encountered in the southeast corner of the trench. BHT 24 contained debitage, cores, a utilized flake, burned rock, and mussel fragments from $50 \mathrm{~cm}$ to $85 \mathrm{~cm}$. A 15-cm-wide heat-treated chert feature was encountered at $85 \mathrm{~cm}$. Bone, mussel were also present.

TxDOT obtained two calibrated radiocarbon dates: 155 B.C.-A.D. 60 on charcoal in matrix from 180-185 cm in Trench 4 at the south end of the site; and A.D. 890-1040 on charcoal from $40-45 \mathrm{~cm}$ in Trench 17 at the north end of the site. Because the site contained wellpreserved, buried archeological remains, it was considered potentially eligible for listing in the National Register of Historic Places and designation as a State Archeological Landmark. Test excavations for a fuller assessment were recommended. 


\section{TESTING}

\section{Work Accomplished}

Testing at 41MM341 was done by personnel with the Center for Archaeological Research (CAR), The University of Texas at San Antonio, in 2000. The work involved reopening Trenches 15 and 24 dug when the site was first recorded, excavating two $2 \times 2-m$ blocks off of those trenches, and excavating 121 auger tests to determine site extent (Figure 2-1). The two trenches, both in the northern part of the site, had encountered features, and the testing excavation blocks were placed to further explore those features (Mahoney and Tomka 2001:22).

Block 1 was placed at the southwest end of Trench 24, and Block 2 was on the east wall of Trench 15. Excavation was carried out within the blocks in $1 \times 1-m$ provenience units using $10-\mathrm{cm}$ levels. Excavation extended to $160 \mathrm{~cm}$ below the surface, with the upper $40 \mathrm{~cm}$ removed by backhoe from three 1x1-m units in each block. As a result, a total of $10.4 \mathrm{~m}^{3}$ was hand excavated. Three occupation zones and a total of five features were identified within the blocks.

The horizontal extent of the site was estimated using auger tests spaced at 5-m intervals across an area of $2,625 \mathrm{~m}^{2}$ along the proposed and existing State Highway 36 right of way. Positive tests, which produced mussel shells, burned rocks, burned clay, or chipped stone artifacts, indicated a site area (within the existing and proposed right of way) of ca. $875 \mathrm{~m}^{2}$ (see Figure 2-1; as shown later in this report, this was an underestimate because the cultural deposits proved to have a patchy distribution). The eastern and northern site boundaries were not well defined, however; auger testing stopped before going under the bridge to the east and downslope toward a slough to the north. Block 1 and Trench 24 were on the eastern edge of the auger testing and indicated that the site likely extends under the bridge, although the site may be disturbed in this area because of bridge construction. Downslope to the north, observations made during excavation of the sedimentation pond used during testing indicated that the site probably ends shortly beyond the positive auger tests in that direction.

\section{Stratigraphy, Features, and Radiocarbon Dates}

A series of depositional units, several capped by paleosols, were recognized in Trenches 15 and 24 as part of a study of the geoarcheology of the Little River floodplain (Nordt 2001:13-20). Archeological materials were found in the upper two units, which apparently were deposited as flood basin veneers associated with nearby sloughs. A paleosol was documented at ca. $70 \mathrm{~cm}$ below the surface and marked the termination of Unit 2, the deeper of the two veneers. This paleosol appeared to have accumulated slowly, as stratification within it was not prominent. The paleosol was typified by a clayey A-BW horizon sequence and was very dark gray to dark gray with a dark gray to grayish brown subsoil. Unit 3-clay loam that was dark gray, brown, and pale brown in color-buried the Unit 2 paleosol. A thin zone displaying pedogenesis was noted in Unit 3 at ca. $40 \mathrm{~cm}$ below the surface suggesting a brief period of slowed deposition. The units, composed of dark soils similar in texture, were not readily traceable through the excavation blocks, thereby necessitating excavation by arbitrary $10-\mathrm{cm}$ levels. Artifacts recovered from these levels, the features identified, and associated radiocarbon assays were used to define the cultural stratigraphy at the site. This cultural stratigraphy appeared to be generally associated with the identified paleosols.

The investigators identified three cultural zones within the two excavation blocks (Mahoney and Tomka 2001:49). Zone 1 extended from the surface to $50-70 \mathrm{~cm}$ below the surface and was encompassed within the upper part of depositional Unit 3. The zone included Feature 1 , a possible refuse pit that produced a radiocarbon assay with a one-sigma date range of A.D. 1407-1440, and a small frequency peak of chipped stone artifacts at $30-40 \mathrm{~cm}$ below the surface in Block 1. In addition, 11 ceramic sherds came from ca. $30 \mathrm{~cm}$ below the surface in Block 1. These discoveries caused the investigators to suggest that this zone could contain a component associated with the Toyah phase of the Late Prehistoric period.

The top of cultural Zone 2 was at ca. $60-80$ $\mathrm{cm}$ below the surface in Block 1 and $50-70 \mathrm{~cm}$ below the surface in Block 2. This zone was marked by a chipped stone artifact frequency peak in Level 7 of Block 1 that corresponded to 


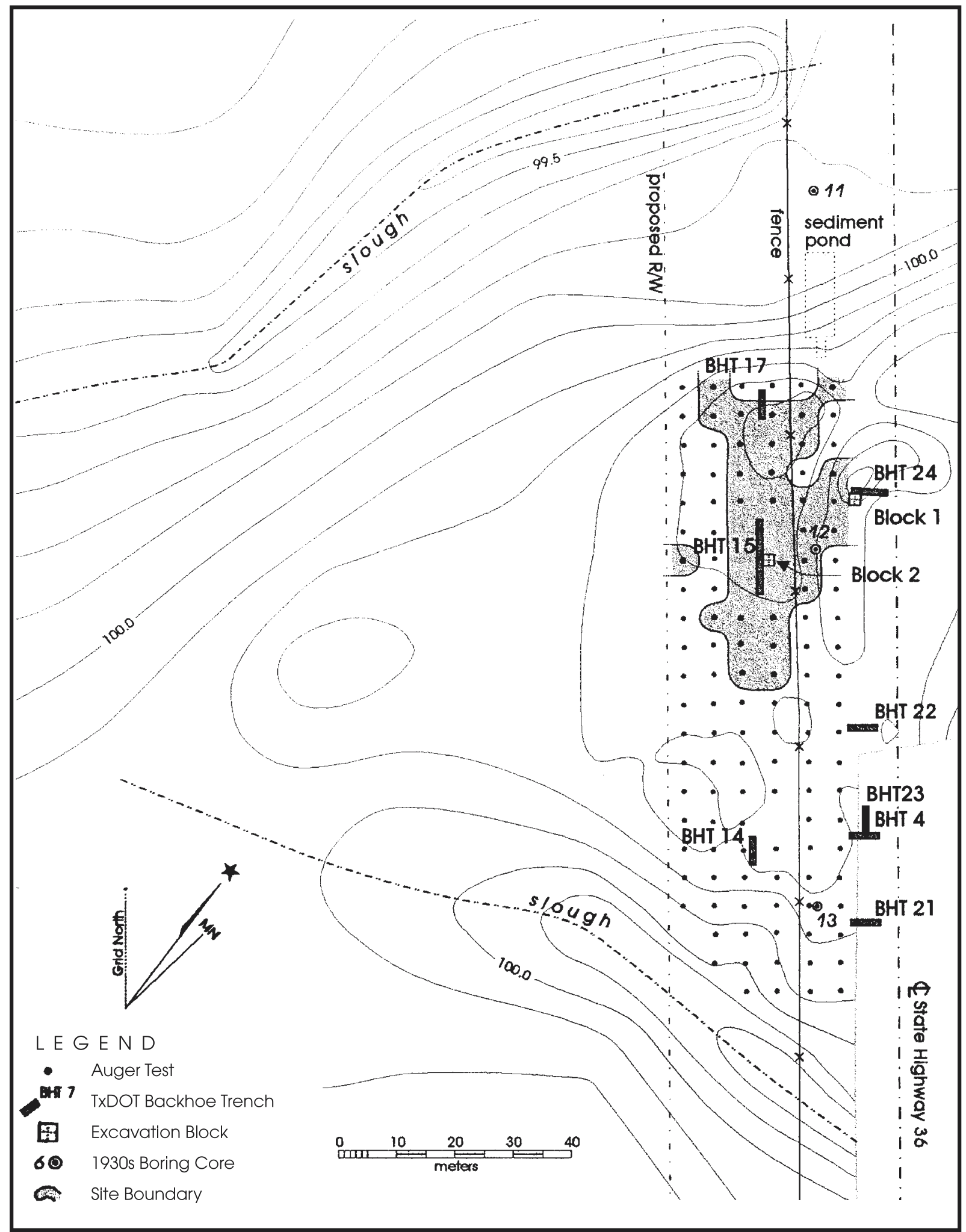

Figure 2-1. Plan of 41MM341 showing the 2000 test excavations and 1998 trenches (from Mahoney and Tomka 2001). 
Feature 3 (a shell lens) and Feature 5 (a pit hearth) identified in that block. At the same level in Block 2, Feature 4 (a processing pit) was discovered, and Feature 2 (another processing pit) cut through the zone. Zone 2 and its features appeared to correspond to the paleosol at the top of depositional Unit 2. Radiocarbon assays on charcoal samples from the bottoms of Features 3 and 4 dated the zone and the paleosol to A.D. 685-780 and 1020-1160 based on calibrated one-sigma ranges (Mahoney and Tomka 2001:50). Based on these dates, the investigators concluded that the zone represents an early Late Prehistoric component associated with the central Texas Austin phase.

Cultural Zone 3 also was within depositional Unit 2 and was recognized mainly as a chipped stone artifact frequency peak in Levels 9-11 (90-110 cm below the surface) in both blocks, although recovery from this zone was most pronounced in Block 2 (Mahoney and Tomka 2001:49, 55). Cultural materials continued within the Unit 2 subsoil, tapering off to a depth of $160 \mathrm{~cm}$. Component definition for Zone 3 was questionable, as no radiocarbon assays were obtained and the single diagnostic artifact, a Friday knife, has a long temporal span. The zone's stratigraphic placement below Zone 2 suggested that it could represent a Late Archaic component similar in age to that investigated previously at $41 \mathrm{MM} 340$ nearby.

\section{Materials Recovered}

Cultural materials recovered from the testing blocks consisted of 776 chipped stone items, 1 ground stone tool, 11 ceramic sherds, 3,487 fire-cracked rocks $(11,200 \mathrm{~g}), 153 \mathrm{~g}$ of animal bones, 4,497 $\mathrm{g}$ of mussel shells and shell fragments, and 1,238 $\mathrm{g}$ of snail shells (Mahoney and Tomka 2001:54). Macrobotanical remains were limited in the general matrix, and the one flotation sample processed from Feature 3 produced "only six very small $(<2 \mathrm{~mm})$ thin nutshell fragments" (Mahoney and Tomka 2001:57).

Included in the chipped stone count were one Scallorn point, one Friday knife, one unidentified biface, two cobble tools, and one expedient side scraper. Also, one Hare biface was recovered from $20 \mathrm{~cm}$ below the surface in $\mathrm{Au}$ ger Test 57 (Mahoney and Tomka 2001:51). The Scallorn point was recovered from Level 7 within Block 2. The Scallorn point and the nearby ra- diocarbon date (A.D. 1020-1160 from Feature 4) supported the association of Zone 2 within the early part of the Late Prehistoric period. The Friday knife was recovered from Level 9 in Block 2 , placing it at the transition between Zones 2 and 3. This tool is associated with the Late Archaic and Late Prehistoric periods (Turner and Hester 1993), although Prewitt (1981:83) places the Friday biface as a representative artifact of the early Late Prehistoric Austin phase. He also places the Hare biface in the transitional Late Archaic period and suggests that it may extend into the Austin phase (Prewitt 1981:76, 82 ). Though apparently out of place at $20 \mathrm{~cm}$ below the surface for the stratigraphy reported above, the Hare biface and the Friday biface added some doubt as to the interpretation of Zone 3 as a Late Archaic component. Rather, the recovery of the Friday and Hare bifaces suggested that a transitional Late Archaic-early Late Prehistoric component could be present.

Analysis of the lithic debitage from testing showed a trend for corticate flakes to increase, relative to decorticate flakes, with depth (Mahoney and Tomka 2001:56), suggesting that the debitage could reveal changes in stone tool manufacturing patterns through time. In addition, the ceramic sherds from the site were considered to have the potential to provide baseline data on group interactions as evidenced through ceramic vessel trade or technological exchanges. Some of the sherds in the small sample of ceramics from Zone 1 were found to exhibit characteristics similar to those of east Texas Caddoan ceramics (Perttula 2001:124-125).

The differences between the testing blocks in chipped stone and bulk material recovery (such as fire-cracked rocks) suggested that identifiable activity areas could be present. This possibility appeared to be best presented for the early Late Prehistoric materials of Zone 2. Block 1 (Levels 7 and 8) showed a peak in chipped stone artifact recovery, and Block 2 (Levels 6 and 7) had a peak in fire-cracked rocks. The peaks in both blocks corresponded to the top of the paleosol for depositional Unit 2. This difference was interpreted as possibly representing different activities, such as a general discard area in Block 1 and a cooking area in Block 2 (Mahoney and Tomka 2001:56).

The recovery of faunal and macrobotanical remains, except for mussel and snail shells, was limited. Only seven faunal taxa were identified, 
including deer, opossum, three kinds of turtles, and two rabbits. Unidentified bones, probably from large animals such as deer, were found to be highly fragmented but little weathered, suggesting they were rapidly buried after deposition and that fragmentation likely occurred before burial. The overall good condition of the fragmentary bones led the faunal analyst to conclude that preservation was not a major factor in the low bone recovery (Meissner 2001:90).

Mussel shells were well represented at 41MM341. In a sample of 40 shells selected for analysis, four species of the family Unionidae were identified. The species composition of the sample was similar to that of nearby 41MM340 and, when compared to modern samples from the Brazos River, appeared to suggest a shift to an arid environment. The analyst cautioned, however, that species within an archeological sample may have been selected by the site inhabitants, a practice that would make questionable the use of an archeological sample for environmental reconstruction without natural offsite samples for comparison (Howells 2001:97). The use of the shell sample for seasonality determinations also was problematic. Though the shells were in generally good condition, Howells (2001:97) found that the shell margins were worn. The shell margin is essential in determining the final stage of growth or rest in marking the season of harvest.

Land snails provided some environmental data. The land snail sample was taken from Block 1, Level 6, 1/4-inch-screen and flotation recovery. Eleven species from eight families were identified; most of these species prefer a moist woodland setting (Fullington 2001:109).
An attempt was made to recover additional environmental data in the form of pollen, phytoliths, and diatoms. Jones (2001:104) found that pollen and phytoliths were present in the samples taken from Feature 3 (shell lens) of Block 1, but both pollen and phytoliths were extensively degraded. Based on those initial results, Jones concluded that additional analysis of pollen and phytoliths would not be fruitful. Diatom analysis did not appear any more promising. Of the two samples submitted for analysis, neither produced diatoms (Winsborough 2001:115-116). One sample was from the matrix of Feature 3 (shell lens) in Block 1 , and the second sample was from burned clay from the base of Feature 5 in the same block. Diatoms were found in varying numbers in burned clay samples from nearby 41MM340, however, and thus it was considered possible that burned clay samples from 41MM341 could yield the silica shells of these photosynthetic algae.

\section{Assessment}

In sum, testing results indicated that the site consists of three components, which the investigators related to the Late Prehistoric Toyah and Austin phases of central Texas and the Late Archaic period (or maybe transitional Late Archaic-Austin phase) (Mahoney and Tomka 2001:60). The first two of these were judged to have the capacity to produce important information for understanding Texas prehistory. As such, the site was recommended as being eligible for listing in the National Register of Historic Places and designation as a State Archeological Landmark and as warranting data recovery excavations. 



\section{SYNOPSIS OF THE DATA RECOVERY PLAN, OVERVIEW OF THE WORK ACCOMPLISHED, AND THE RESEARCH DESIGN}

The bulk of this chapter is devoted to the research design that guided the data recovery excavations and subsequent analyses. An initial version of the research design was prepared before fieldwork began. After completion of fieldwork, it was revised to account for what was found at $41 \mathrm{MM} 341$, and it is that revised version that is included here. A synopsis of the data recovery plan that accompanied the original version of the research design, and an overview of the work that was actually done, are presented first, though, to provide a bridge between what we thought we knew about the importance of the site at the end of testing and what, with the benefit of more-extensive excavations, the importance of the site turned out to be. A morecomplete account of the work accomplished and the methods used appears in Chapter 4.

\section{SYNOPSIS OF THE DATA RECOVERY PLAN}

Anticipating that the data recovery excavations would encounter the remains of stratigraphically discrete occupations, the scope of work issued by TxDOT specified block excavations totaling $100 \mathrm{~m}^{3}$. This target figure was arbitrary but was considered large enough to provide an opportunity to look at broad horizontal exposures of the archeological deposits. The amount of the site that would be sampled by the excavations was unknown because the site extends an unknown distance beyond the proposed right of way. Effectively, then, the approach was to acquire a sample using judgmentally placed excavations focused on the areas shown by the test excavations to have useful information.

The data recovery plan prepared in response to the scope of work called for excavation of the blocks in traditional 1x1-m units and 10-cm levels under the assumption that such controls would be sufficient for segregating the remains into useful spatial analytical units. It was proposed that the blocks be placed central to the site as defined by the auger tests dug in 2000, connecting Blocks 1 and 2 (see Figure 2-1). Trenches 15 and 24 were to be reopened and extended to the north and west, and a new trench was proposed east of Trench 15 and south of Trench 24. These three trenches were to provide a stratigraphic guide for the excavations. Also, Trench 17 was to be reopened and extended south toward Trench 15. This fourth trench, along with reopened Trench 15, was intended to provide a stratigraphic profile across the site that would be useful for site-specific geomorphic investigations. This fourth trench also was considered potentially important as an excavation guide if the block was expanded northward.

As discussed in Chapter 2, the test excavations revealed that the site contained three stratified components, with the early Late Prehistoric component (which the investigators associated with the Austin phase), at a depth of ca. 50-90 cm in both testing blocks, being the one with the clearest capacity to contribute important information. The later Late Prehistoric component (associated with the Toyah phase) at $0-40 \mathrm{~cm}$ in Block 1 was considered potentially important, but the testing data suggested that this component had a more-patchy distribution than the earlier component. Depending on how extensive the later component turned out to be, it was recognized that it might or might not be worth pursuing in the data recovery excavations. The Late Archaic (or transitional Late Archaicearly Late Prehistoric) component was well 
represented in Block 2 at $80-120 \mathrm{~cm}$ but was difficult to interpret because of the lack of features, radiocarbon dates, and definitive diagnostic artifacts. In planning data recovery, it was thought that this component might not be worth pursuing if it did, in fact, date to the Late Archaic period, since recently excavated 41MM340 nearby contained a component of apparently comparable age. This temporal assessment was considered tenuous, however, and thus some additional investigation of these lower deposits was judged to be warranted.

To determine how much effort should be devoted to the later Late Prehistoric and Late Archaic (or transitional Late Archaic-early Late Prehistoric) components, it was proposed that the block excavations begin with the placement of eleven 1x1-m units off of Trenches 15, 17, and 24 and the new east-west trench. These initial units were to be dug in 10-cm levels from the surface to a depth of $130 \mathrm{~cm}$ to encompass all three site components. The assessment of whether the later Late Prehistoric component warranted further work was to hinge on whether the cultural materials were sufficiently abundant and extensive to allow an interpretable sample to be recovered. For the other component, the assessment was to hinge on whether its interpretation based on testing - that is, a Late Archaic component with limited datable materials and few if any features-held up. If so, further work would not be warranted. On the other hand, if these first units revealed that this early component was something else (e.g., a transitional Late Archaic-early Late Prehistoric component, or even a Late Prehistoric component predating the one identified at ca. $50-90 \mathrm{~cm}$ ), then additional attention might be needed.

It was recognized that, with this approach, flexibility had to be maintained to configure the block as the archeological remains dictated. At one extreme, in the unlikely event that all three components were capable of contributing important information, the block would cover an area of only ca. $77 \mathrm{~m}^{2}$ (holding the amount to be excavated at $100 \mathrm{~m}^{3}$ and assuming a consistent depth of $130 \mathrm{~cm}$ ). Alternatively, if only the early Late Prehistoric component identified in testing needed further work, the block would cover as much as $182 \mathrm{~m}^{2}\left(100-\mathrm{m}^{3}\right.$ total excavation volume, assuming a consistent component thickness of $50 \mathrm{~cm}$, and subtracting the upper and lower parts of the first 11 exploratory units). It was presumed that a block this large would encompass the area between Trenches 15 and 24 and probably extend northward where auger tests suggested that early Late Prehistoric materials were present in the vicinity of Trench 17.

\section{OVERVIEW OF THE WORK ACCOMPLISHED}

The data recovery plan described above was implemented, resulting in the excavation of 4 backhoe trenches, 11 initial 1x1-m units, and 3 hand-excavated blocks covering $208 \mathrm{~m}^{2}$. The total volume of sediments excavated manually was $95 \mathrm{~m}^{3}$. The initial $1 \mathrm{x} 1-\mathrm{m}$ units confirmed the presence of the stratified components identified by the test investigations and provided additional information concerning the distribution of these components across the site. The artifact recovery from the initial units indicated that the later Late Prehistoric component was ephemeral and localized to the area immediately surrounding testing Block 1. Because this component appeared to be insubstantial, it was concluded that it was not worth pursuing during data recovery excavations.

A component thought to be Late Archaic in age was encountered at ca. 90 to $130 \mathrm{~cm}$ below the surface in most of the initial units. It was marked by artifact frequency peaks in two of the units and an associated pit hearth and mussel shell lens. A single dart point resembling the Pedernales type found a little higher $(80-90 \mathrm{~cm}$ below the surface) suggested that this component was similar in age to the Late Archaic component recently excavated at nearby 41MM340. As such, further exploration of this component was not considered warranted. Hence, the early Late Prehistoric component became the focus of the data recovery excavations.

In the area targeted for excavation, the upper $40-50 \mathrm{~cm}$ of essentially sterile deposits were removed by machine, and manual excavations were done in three blocks covering 170,28 , and $12 \mathrm{~m}^{2}$ (the $170-\mathrm{m}^{2}$ figure for the Main Block includes two of the initial $1 \times 1-m$ units). Each block was excavated in four to five 10-cm levels. As described later in this report, the distributions of the many features and artifacts found and the 34 radiocarbon dates indicate that three components are represented in these targeted deposits. The two predominate ones date to the 
early and middle parts of the Late Prehistoric period (A.D. 800 or $900-1100$ and 1100-1300). The third, which was sampled less extensively than the others, appears to date to the A.D. 600 $700 \mathrm{~s}$. This component was found at the bottom of two of the blocks and represents the upper part of the deposits that were thought to be Late Archaic in age based on the 2000 testing and the initial data recovery units. Late Archaic materials may indeed be present at greater depths, but the radiocarbon dates and diagnostic artifacts show that at least the upper part of this component is transitional Late Archaic-early Late Prehistoric.

\section{RESEARCH DESIGN}

Two fundamental research questions were proposed to guide the investigations at 41MM341: How did the site occupants make a living, and how did their physical environment as well as cultural developments in neighboring regions affect this? The research issues relevant to answering these questions were identified in the preliminary research design developed before fieldwork under five headings: environmental reconstruction; subsistence strategies; assemblage organization; interregional interaction and mobility; and settlement patterns, site structure, and chronology. All these issues were couched in terms of evolutionary and ecological theory, out of which the foragercollector model was drawn (Binford 1980, 1982; Hayden 1986) as a unifying theme. After consideration of the kinds of data recovered from 41MM341, however, it was recognized that the forager-collector model, although powerful in identifying group organization and its close relationship to the physical environment, is limited in its ability to address the social milieu of the people who utilized 41MM341.

Shortly after Binford began to develop the forager-collector model, new ethnographic studies, some concerning the same "forager" societies (Gwi San) Binford used to formulate the model, demonstrated that interactions between hunter-gatherer societies and complex societies had more to do with why groups retained or changed their particular organization than any direct response to natural environments (Headland and Reid 1989; Lee 1992; Pedersen and Waehle 1988; Wilmsen 1989). These revisionist ethnographic studies call to question the valid- ity of the results of many archeological studies based solely on the Binford model. A number of archeologists responded to the Binford model and its base in evolutionary and ecological theory by examining how hunter-gatherer organization responds to interactions on many levels (e.g., group to environment, individual to group, group to group, group to society, and society to society) (Bender 1985; Cobb and Nassaney 1995; Marquardt 1985; Moore 1983; Peregrine 1995; Root 1983; Sassaman 1995). Sassaman (1995:178) challenges archeologists to begin to incorporate the results of these archeological and ethnographic studies into future work by at least recognizing the importance of interaction for both modern societies and their prehistoric predecessors. Such recognition applied to Binford's model would allow investigation of issues such as whether foragers and collectors existed side by side in the same environment, how forager groups would be affected by interaction with nearby groups using collector strategies and vice versa, and why group organization might change when ecological factors appear constant.

While not abandoning Binford's model as an interpretive tool, it is clear that more can be drawn from archeological data if perspectives are open to the possibility of addressing social, political, or economic issues based on how group organization responded to interactions. Consequently, a wider definition of hunter-gatherer group organization is proposed as the unifying theme of this study.

A way to explore the impact of interaction on organization at many levels is to combine aspects of the Binford model with a model developed by Woodburn $(1982,1988)$. Woodburn's model is based on his ethnographic research concerning hunter-gatherers in central and south Africa. The model defines immediatereturn and delayed-return organizational systems. In immediate-return systems, people are organized around present needs and, not unlike Binford's foragers, obtaining foods as needed using portable, easily manufactured tools. Their frequent movement possibly keyed to resource availability also enabled them to avoid accumulation of assets or debts that could create dependencies. Delayed-return system organization is based on past, present, and future needs with personal or corporate rights over assets and a yield on labor input over time. Assets can 
include facilities of production, stored foods and materials, and managed wild products. Binford's logistically oriented collectors could be considered a delayed-return system since their gearing-up activities for an anticipated resource extraction event would imply an expected yield on labor input over time. However, neither foragers nor collectors are locked into either immediate-return or delayed-return systems. One can construct scenarios in which foragers (people utilizing scattered resources) exercise rights to territory or particular resources within a territory. Simple sharing and gift giving, though creating limited dependencies, could provide access to the assets of others in times of need. Collectors may avoid creating or altering dependencies by adopting a forager lifestyle at certain times of the year. The point here is that the social environment affects adaptive responses as much as the natural environment does.

It is clear from the amounts and kinds of materials recovered from 41MM341 and their distributions that many of the research issues initially proposed can be addressed. The research issues are discussed here in regard to the data generated from the excavations. Specific questions are proposed, and the appropriate ways that the data may be used to answer the research questions are presented.

\section{Environmental Reconstruction}

Environmental reconstruction is important for interpreting the behaviors of the huntergatherers who once occupied 41MM341, providing baseline data to determine how the site occupants may have been affected by regional conditions and how local conditions may have ameliorated such effects. Site-specific information can help refine the model of regional climatic fluctuations developed using pollen data gathered from Boriack, Weakly, and Patschke Bogs (Bousman 1998; Camper 1991). Those pollen data suggest that, during the time that 41MM341 was occupied (ca. A.D. 600-1300), woodlands may have been expanding at the expense of grasslands, which appear to have dominated for much of the middle Holocene.

Research questions applicable to environmental reconstruction include:

1. How was the environment at the time
41MM341 was occupied similar to or different from modern conditions on regional and local scales?

2. How was the environment at the time 41MM341 was occupied similar to or different from earlier environmental conditions on regional and local scales?

3. How did change in environmental conditions, whether local or regional, affect the organizational or subsistence orientation of the occupants of 41MM341?

Two lines of investigation will be directed at regional environmental reconstruction; these are diatoms preserved in burned clay drawn from radiocarbon-dated features and oxygen isotope analysis on mussel and Rabdotus shells. The diatom analysis will provide data on species composition and hence wet vs. dry climatic regimes because diatoms were brought to the site by flooding and, as such, may be representative of regional conditions (Winsborough 1995). Similarly, oxygen isotope values from mussel and Rabdotus shells can be related to rainfall and thus wet vs. dry climates (Rye and Sommer 1980). The results of both of these investigations will address the first two questions listed above.

Relevant materials recovered for examining local environmental conditions are macro- and microgastropod samples from flotation columns and feature samples. Gastropods are limited in movement and have specific habitat preferences; as such, they can provide a clear indication of local conditions (Claassen 1998:122-125). Macro- and microgastropods from one $0.5 \times 0.5$ $\mathrm{m}$ column located between the Main Block and the South Block will be used to address local environmental conditions based on species identification and abundance. This column was outside the main site activity areas and thus should be representative of natural snail regimes. The column was sampled in 5-cm vertical increments throughout $1.5 \mathrm{~m}$ of site sediments, starting at the modern surface (i.e., above the cultural zone) and extending through and below the cultural deposits targeted during the excavations. The results of these investigations will provide data to address the first two research questions above.

Macrobotanical recovery from both water 
screening and feature flotation was good, with the bulk of these remains being wood charcoal. The tree species represented can provide information on local climatic conditions through reconstruction of the local woody plant community (knowing, of course, that the sample is biased by cultural selection) (Diamond et al. 1987; Gould 1962; Johnson 1931). Similarly, the wellpreserved vertebrate faunal remains and abundant invertebrate remains will provide information on animals available for exploitation and, hence, habitats in the vicinity of the site (once again, acknowledging the effects of cultural selection and the possibility of mediumand long-distance transportation of partly processed kills). The results of these investigations will also provide data to address the first two research questions.

Addressing the third question (i.e., how environmental conditions may have affected the organizational or subsistence orientation of the site occupants) will entail reconstruction of those orientations as outlined below. With that reconstruction in hand, comparisons will be made on both diachronic and synchronic bases. Diachronic comparisons will be made using data gathered from nearby site 41MM340, which encompasses 1,000 years of occupation during the Late Archaic period (Mahoney et al. 2003). Site 41MM341 itself will provide information on a 700-year span of occupations postdating those at 41MM340. The location of 41MM341 on the Blackland Prairie-Oak Woodlands boundary indicates that comparisons with wellstudied contemporaneous sites located to the west (i.e., the central Texas archeological region) and the east (i.e., the Caddoan area) could yield information on the third question. Sites to be used in such a comparative study should be selected based on their age and the abundance and quality of paleoenvironmental information they yielded.

\section{Subsistence Strategies}

Environmental conditions certainly affected how prehistoric hunter-gatherers organized themselves in relation to the landscape of the Little River basin to utilize the resources available. Application here of the forager-collector model developed by Binford (1980, 1982) and Hayden (1986) provides a means of elucidating the relationships of these hunter-gatherers to their environment. A foraging strategy incorporates a high degree of residential mobility because segments of the resource base are scattered, do not occur in large quantities, or are not dependable. Collectors organize logistically and move less residentially because they can take advantage of resources that occur reliably at specific times in large quantities. Of course, the prehistoric occupants of 41MM341 probably did not operate exclusively in one or the other of these modes, but may have changed or combined strategies as their social situation warranted. Evidence of the subsistence strategies employed by the occupants of 41MM341 is present primarily in the kinds of faunal and floral remains recovered from the site and in the ways these resources were processed, as suggested by data related to feature types.

Questions concerning subsistence strategies include:

1. What kinds of faunal and floral resources were utilized at 41MM341, and how were these resources distributed (location, quantity, and dependability) across the landscape?

2. How were resources used? That is, were they processed for storage, consumed on the spot, or intensively exploited?

3. Do the kinds of resources utilized provide any indication of subsistence stress? And if so, how might the occupants of 41MM341 have responded to that stress?

4. Did resource use change over time, and if so did that change follow regional or local patterns of resource use?

The many animal bones recovered from 41MM341, as well as the many invertebrate shells in the numerous shell lenses, will provide reliable information on the kinds and relative frequencies of animals procured. Simple percentage comparisons of general categories, family, genus, and species will be used to address questions concerning subsistence stress and change in resource utilization. Also, bone breakage patterns and evidence of burning will be investigated as a means of addressing use patterns through processing or intensive exploitation. 
The relative importance of mussels and snails (Rabdotus) to the subsistence base will also be explored. Mussel shells were recovered from feature contexts that represent discrete depositional episodes. Species abundance and age classes based on size within these contexts can be compared within and between analysis units to address questions concerning intensity of exploitation and, by extrapolation, the contribution of these animals to subsistence. Also, season of death will be addressed through oxygen isotope analysis on mussel shells, hence contributing to an assessment of the season(s) of occupation. Snail shells, specifically Rabdotus, were a major component of many of the mussel shell features, with Feature 17 composed almost completely of Rabdotus. Rabdotus age classes based on shell size will be determined using samples drawn from feature contexts and will be used to address whether the Rabdotus concentrations were natural or resulted from subsistence activities. The use of age classes to address this question is based on the idea that high frequencies of snails in the oldest (largest) age class may represent resource selection.

The floral materials recovered are mostly wood charcoal, but charred onionlike materials, fleshy fruits, nuts, and grass seeds also are present from both feature flotation samples and general 1/4-inch-screen recovery. These floral materials, identified to the lowest possible taxonomic level, will be compared using frequencies or percentages based on weight or count. Comparison by analysis unit will provide information on change or stability in the subsistence assemblage over time. Comparison of species by feature type will also be undertaken to address questions concerning food processing.

Another source of information on how resources were processed will entail identifying fatty acids preserved on burned rocks and burned clay from features. Three distinct kinds of heat-related features were present at 41MM341 based on their form and content. It is assumed that these features were related to cooking, with one-a large pit with extremely heat-fragmented rocks-probably used for food processing. Burned rock and burned clay samples were recovered from these features as one means of identifying what foods may have been associated with them and whether there are differences by feature type. The technique for identifying fatty acids on burned rocks and burned clay as established by Mary E. Malainey (1997), and Malainey et al. (1999) will be employed for this purpose.

\section{Assemblage Organization}

Assemblage organization concerns how the kinds of tools recovered reflects the ranges of activities performed at the site, including tool production itself. Tools are well represented at 41MM341. Formal tools, with a recovery rate of $3.8 / \mathrm{m}^{3}$, consist of those shaped for specific tasks and include chipped stone tools $(\mathrm{n}=303)$, ground or battered stone tools $(\mathrm{n}=30)$, and bone tools $(\mathrm{n}=30)$. Expedient tools, with a recovery rate of $5.2 / \mathrm{m}^{3}$, consist of edge-modified flakes $(\mathrm{n}=494)$. Such an assemblage can provide evidence of how activities were structured, which relates to how groups were organized. For example, the relative importance of formal tools vs. expedient tools should differ for groups organized for immediate return as opposed to those organized for delayed return. Formal tools that are shaped to perform efficiently for specific tasks should be well represented in a tool kit devised for future use, whereas less-structured, on-the-spot procurement tasks should favor the flexibility of expedient tools made or utilized with little regard to form.

Tool production strategies can also provide evidence of group organization. Foragers or groups organized for immediate return should replace tools as needed basis, resulting in a high ratio of use breaks to manufacture breaks. Collectors or future-return groups should gear up as they systematically refurbish and manufacture tools for well-defined procurement events. As a result, future-oriented groups produce tool blanks, preforms, and tools with manufacture breaks.

Tool production strategies and their relationships to group organization should also be reflected in the byproducts of tool manufacture (i.e., debitage and cores). For example, a debitage assemblage from a forager campsite or a camp used by a group organized around immediate return should look different from that of a special-purpose procurement-processing location or a supporting field camp of a group in a future-return system. The difference should be demonstrable in terms of the attributes of the flakes and perhaps the abundance of debitage 
relative to tools. An as-needed campsite should have a broader range of flake types than a collector location or field camp. Such future-return sites may have either a higher or lower ratio of tools to debitage, depending on the extent of tool manufacture or refurbishment at the collector site and whether the tools were removed from the site after use.

Questions concerning assemblage organization are:

1. What were the functions of the various classes of formal tools and expedient tools recovered from the site?

2. Is there evidence of particular tool kits associated with particular extraction needs?

3. What kind of chipped stone tool manufacturing took place at the site, and what were the tool production strategies?

4. What do the kinds of tools used indicate about how the groups utilizing 41MM341 were organized? Do the tool kits suggest immediatereturn or delayed-return systems or aspects of both?

5. What kinds of activities do the tool assemblages suggest, and how do those activities define the site's role within an overall subsistence and settlement system?

Answering these questions will necessitate the functional classification and comparison of formal and expedient tools, as well as investigating the remnants of lithic tool manufacture (i.e., debitage and cores). The functional classification of all formal tools will be made based on overall morphology and the placement of use wear (distinguished under low-power magnification of $10 \mathrm{x}$ to $30 \mathrm{x}$ ) on tool surfaces. General morphological descriptions of the tools using a measure of completeness and overall size will be included in this study to provide a baseline of comparison that will ground the functional classifications and use-wear locational data. Tool functional classifications will be based on descriptions drawn from previous central Texas and east-central Texas archeological studies (e.g., Fields et al. 1991:63-77; Gadus et al. 2002:125-128; Johnson 1995:247-272; Mehalchick et al. 1999:28-32). Use-wear place- ment on tools as a factor for determining function has also been used extensively in these previous studies. As an example, a stone cobble may have a flat, polished, and striated surface indicating that it was used in grinding while at the same time having pitting on a rounded end indicating use as a hammerstone. Kinds of ground stone tools will include anvils, grinding slabs, hammerstones, and abraders. Kinds of chipped stone tools will include projectile points, projectile point preforms, knives, knife preforms, scrapers, adzes, drills, wedges, and choppers. Bone and antler tools, though few in number, will include pressure flakers, awl fragments, and pin fragments. While the precise functions of some of these tool types may be debatable, the consistencies of their morphologies imply some degree of functional consistency, thus making characterization of ranges of activities to address the first and last research questions listed above possible.

Another direction of the formal chipped stone tool analysis, specifically projectile points, knives, and their preforms, will focus on the causes of tool fracture. Three causes can be identified: use, manufacture, and postdepositional (Tomka et al. 1999:34). Experimentation has provided the link between the diagnostic morphologies of fractures and break cause for bifacially worked tools (e.g., Johnson 1979, 1981; Odell and Cowan 1986). These morphologies will be compared to the attributes seen on the archeological specimens to determine cause. Comparisons of the frequencies of manufacture and use breaks may provide a measure of whether projectiles were manufactured for immediate use at 41MM341 or were manufactured or refurbished for future use. Manufacture focused on immediate use would replace tools as needed and should produce comparable frequencies of use-broken and manufacture-broken tools. Conversely, manufacture for future needs, such as gearing up for a future hunt or manufacture for trade, should result in the production of many more tools than immediately needed, with many breaking and being discarded at the blank or preform stage. Thus, manufacturing breaks should exceed use breaks, since successfully finished tools were taken from the site to be used elsewhere. As such, the study of fracture type on projectile points, knives, and their preforms can be used to address the fourth research question. 
Expedient tools, which are defined as usemodified or minimally retouched flakes or chunks, will be separated from the debitage sample and sorted by wear pattern or retouch pattern. Wear pattern will be determined under low-power magnification and may consist of sawing/slicing, scraping, or engraving (Johnson 1994:160-167; 1995:147-151). Size of the flake/chunk and number of use-modified edges will also be recorded. These characteristics will provide a measure of function for the expedient tools and intensity of use, which can be compared to formal tools to address the first, fourth, and fifth research questions. The original flake type (see definition of flake type below) of these expedient tools will also be recorded to determine where in the production sequence these flake/chunks came from and whether production of flakes specifically for expedient use took place. These attentions to production will provide data that can be used to answer the third research question.

Comparisons between formal tools and expedient tools will be made using simple frequencies and ratios of tool types to characterize the importance of associated activities. For example, a high ratio of projectile points and preforms to other formal tools could suggest that hunting and related activities were important, and a low ratio of ground stones to other formal tools could suggest that processing of seeds and nuts was less important. These comparisons will address the last three research questions.

Chipped stone tool production strategies will be explored using the numerous cores and core fragments recovered and selected debitage samples. Debitage was abundant, with most coming from the Main Block excavation. A sample of debitage for analysis will be drawn from the Main Block recovery. This sample will be taken from individual debitage concentrations within the analysis units defined for the Main Block. Ten debitage concentrations apparently representing discrete or semidiscrete lithic reduction episodes have been defined. A debitage sample will be drawn from each concentration to define the kind of production represented.

The kind of production represented by each debitage concentration can best be determined based on the characteristics of the flakes and chunks of which it is composed. Debitage characteristics include flake type and debitage size. Flake type represents a series of flake attributes (including overall shape, number of dorsal scars, and number of platform facets) that have been demonstrated to define flakes produced through specific reduction sequences. These types may include: biface-reduction flakes, bifacialthinning flakes, biface-resharpening flakes, notching flakes, platform or core preparation flakes, uniface-manufacturing or resharpening flakes, and macroflakes (Tomka et al. 1999:3638). Those flakes that cannot be assigned to a type will be placed in general descriptive categories (e.g., chips, chunks).

Cores and core fragments often occur with the lithic concentrations. Some initial refitting of flakes to cores drawn from the same lithic concentrations demonstrates that they are associated and stresses the importance of cores in determining the nature of production that resulted in the concentrations. Most of these cores appear to have originated as cobbles recovered from the local Little River gravels. Recording the nature of the core (e.g., cobble, tabular, indeterminate) will help quantify this. In addition, several attributes related to core reduction strategies will be recorded. These will include directionality of the flakes removed (e.g., single, bi-directional, multidirectional) and the presence or absence of evidence of core platform preparation (e.g., grinding and preparation scars vs. crushing). These attributes will provide a measure of how patterned core reduction strategies were. It is expected that flake production aimed at expedient tools will be less patterned than flake production linked to formal tool production. Explication of these patterns will thus address the third and fourth research questions.

The debitage and cores generated from the production of as-needed expedient tools should be composed of flake types different from those generated by the production of formal tools. Formal tool production should generate a broader range of flake types, and the production of flakes for expedient use may only include biface-reduction flakes and platform- or corepreparation flakes. Finally, information concerning the lithic concentrations and the production they represent will be combined with the data on the formal chipped stone tools and preforms to provide a complete picture of the kinds of chipped stone tool production and refurbishment that took place at the site. Comparisons of lithic concentrations and their related tools within and between analysis units will allow discus- 
sion of changes in production through time, which will be a basis for defining tool kits. As such, this part of the analysis will be key to addressing the second, third, and fourth research questions listed above.

\section{Intrasite Patterning}

One way to understand the subsistence and settlement systems of the occupants of $41 \mathrm{MM} 341$ is to use intrasite patterning to define site type (i.e., site function). Under the forager-collector model, functional site types are residential bases, extraction locales, field camps, stations, and caches (Binford 1980; Hayden 1986). The first two types occur with forager systems, and all five are part of the collector system. These particular site types may not be strictly related to the immediate- vs. futurereturn model. Yet, there are exceptions, such as the residential base and extraction locale of the Hadza hunter-gathers of east Africa, whom Woodburn (1968:105-107) considers to practice an immediate-return strategy. His work does interject a caution in strict definition of site type, however, as he indicates that camp size and movement from camp to camp can be highly flexible depending on resource motivation as well as a variety of other reasons (e.g., illness, kin associations, and conflicts). Woodburn's (1988:32) delayed-return strategy considers past, present, and future needs, as it accounts for traditional rights to assets and products of labor. Such assets could be expressed as site features and concentrations of materials related to facilities of production as well as food and material storage. Rights to assets might also be expressed by a multiplicity of sites (e.g., field camps and stations) at resource loci.

Relating ethnology to the archeological record, both Binford and Hayden use differences in stone tool assemblages. Hayden (1986:84-86) argues that, other things being equal (i.e., ethnicity), stone tool assemblages should exhibit activity-specific characteristics. The kinds of activities or numbers of activities should differentiate between site type, regardless of whether groups were operating as collectors or foragers. Given the vagaries of ethnographic and archeological definitions of site type, however, using multiple lines of interrelated evidence (i.e., features, tool assemblages, and the associations between them) to address this issue should be more reliable than using stone tool assemblages alone, and this is the approach that will be used to interpret 41MM341.

The tool assemblage, features, and other materials from 41MM341 provide important information on intrasite patterning that will be used to define the site's function within an overall subsistence-settlement system. Within the 40-50-cm-thick targeted deposit are shell lenses, burned clay-ash hearths, burned clay scatters, pit hearths, burned rock concentrations, burned rock scatters, and lithic artifact concentrations. Patterning of these materials in the Main Block suggests they represent activity areas (e.g., eating/cooking and craft areas) with nearby discard piles, both likely reflecting the remains of mundane activities. In addition, the activity areas in the Main Block are spatially separated (ca. 6 to $10 \mathrm{~m}$ ) from what appears to be a special-purpose processing area located in the South Block. Dominating the South Block was one type of feature consisting of several large intersecting pits with burned rocks, burned rock shatter, charred wood, and burned clay in the fill. Limited recovery of other kinds of materials and tools surrounding these features suggests that the tasks associated with them were sufficiently bothersome or noxious to cause them to be performed away from the main living area. Further examination of these patterns will generate both specific and general research questions.

Questions related to intrasite patterning at 41MM341 are:

1. What activities do specific feature types represent, and how are they distributed among the analysis units?

2. What kinds of activities occurred at the site based on tool function or evidence of tool manufacture?

3. What activities can be linked through features, other materials, and artifact types to particular areas of the site, and how are these activity areas structured?

4. How do activities defined for particular analysis units indicate consistency or change in the site's function within an overall subsistencesettlement system?

Intrasite pattern determinations will be 
based on feature functions and the distributions of features, tool functions and tool distributions, and the associations between features, tools, and other materials (e.g., faunal remains, burned rocks, burned clay, debitage). Determining contemporaneity will be important to this study, since the more discrete the component is, the more precise the definition of activities and site function can be. Three analysis units are defined for the site based on the stratification of the mussel shell lenses, debitage concentrations, and hearth features and the numerous radiocarbon assays from those features. Each analysis unit represents at least 200 years of occupation, but it is possible that more-discrete entities can be defined within some analysis units, such that composite patterns of activities can be discerned. Comparing those composite patterns between the three analysis units will allow us to address changes in site function over time.

Feature function determinations will be based on their structure and content. For instance, three kinds of features display evidence of heat: surface hearths, pit hearths, and processing pits. Definition is based on size (length, width, and depth) as well as content (e.g., burned rocks, burned clay) and quantity of content. Finer definitions based on content may be made by looking at macrobotanical and faunal remains and fatty acids from burned rocks and burned clay samples. The results of this feature study will relate specifically to the first research question listed above.

Ethnographic studies of hunter-gatherers (e.g., Bartram et al. 1991:136-139; Yellen 1977) have shown that the simple presence or absence of certain feature types is not always indicative of different functional camp types. Other factors such as the proportion of primary to secondary refuse in conjunction with feature and tool associations hold more promise for site type definition. Ethnographic study has shown that a greater proportion of primary refuse to secondary refuse occurs at short-term camps. Longterm or base camp refuse patterning is reversed, with proportionally larger secondary deposits (Bartram et al. 1991). Using refuse patterning to determine site type means that refuse type must be discerned in the archeological record, and here association plays a significant role. Primary discard loci often occur near consumption areas such as hearths or structural features that afford shade or protection from the wind (these structural features may simply be trees and bushes), while secondary refuse deposits occur away from such features (Bartram et al. 1991:135-138). The distance of secondary refuse from the area of consumption may vary depending on the method of removal. For instance, swept refuse may not move far whereas dumping and tossing may move items a long way.

Determining refuse patterns at $41 \mathrm{MM} 341$ will require extensive examination of distributional patterning and the associations of the materials recovered. Isoplethic representations of the distributions of mussel shells, Rabdotus shells, bones, burned rocks, and burned clay will be completed by level. These isopleth maps will then be matched to patterns recognized in the field (e.g., maps of mussel shell and debitage concentrations) and most importantly the placement of hearths. Initial pattern recognition within Level 6 suggests that mussel shell and debitage concentrations occur together around a burned clay hearth. Comparisons of other material distributions may or may not show this pattern. The Level 6 pattern may be critical to discerning earlier patterns, as the remains in this uppermost level are least disturbed by subsequent occupations and overprinting.

The analysis of refuse patterning will also entail comparison of characteristic artifacts within material types. For instance, the distribution of burned rock shatter (small chunks and chips of stone with evidence of cracking, crazing, or spalling) will be compared with that of the burned rocks. The idea behind such a comparison is that small shatter likely stayed in its primary location of deposition whereas larger burned rock pieces, more onerous under foot, may have been moved. Bone breakage patterns may be another indication of primary refuse. For example, spiral- fractured bones-that is, bones intentionally broken for marrow extractionfound near hearths likely are in primary context near the cooking or processing feature. If, however, they are scattered across the excavation block or concentrated away from the hearth area, they probably are in secondary context. Thus, looking at the patterns of refuse will be critical to answering the third research question.

The patterning of tools will also be important in determining activity areas. As discussed in the section concerning assemblage organization above, tool function will be established 
based on overall tool morphology, the placement of use wear, and break type. The distributions of different functional classes or combinations of classes will be examined in relation to specific feature types. This study will address the kinds of tools, formal or expedient, recovered in proximity to the hearth features, and the function of those tools will shed light on the activities that were performed within the hearth areas. Similarly, the kinds of formal tools and preforms in or near the lithic concentrations will indicate what was being manufactured or refurbished. Clues such as break type (i.e., broken in manufacture) and material type may be useful in linking specific tools to particular debitage concentrations representing discrete episodes of reduction. These kinds of tool characteristics and their associations will be useful in answering the second and third research questions listed above.

The techniques discussed so far have focused on defining patterns within analysis units. But also of interest is whether these patterns remain consistent through time. Initial attempts at pattern definition suggest that there is little difference between the analysis units as expressed in the Main Block by feature type and material distributions. However, as noted above, simple presence or absence of certain feature types is not always indicative of different functional camp types. In this respect, measures of diversity based on formal and expedient tool recovery will be used to discern whether analysis units represent similar or functionally different site types. A more-diverse tool assemblage is expected to be associated with base camps where numerous kinds of activities were performed (see Yellen 1977:108-109). The measures of diversity that will be used include richness and evenness, where richness addresses the number of tool classes per analysis unit and evenness addresses tool frequencies within classes and provides an indication of the degree to which all classes are equally represented. Comparisons using these measures will address the fourth research question listed above.

\section{Interregional Interaction}

This research issue is directed at explicating not only how the hunter-gatherers who utilized 41MM341 distributed themselves across the landscape, a topic also addressed in the pre- ceding section, but also the extent to which and how interactions with neighbors affected their distribution. This is important because factors related to interaction, such as opportunities (e.g., access to different sets of resources) and constraints (e.g., intergroup hostilities leading to loss of territory), can affect adaptive responses. Interest in this issue is piqued for 41MM341 because of the site's location at the Blackland Prairie-Oak Woodlands boundary between the central Texas archeological region to the west and the Caddoan area of east Texas. Archeological evidence suggests that central Texas groups retained a hunter-gatherer lifestyle and bandlevel social organization throughout prehistory. But by A.D. 800 east Texas Caddo groups were on their way toward developing complex social and political systems based on social ranking and status with ties to similar kinds of societies located in the lower Mississippi valley (Perttula 1992:13). As such, the Blackland Prairie-Oak Woodlands boundary may have social, economic, and political implications.

One way to get at interaction preserved in the archeological record is to trace the movement of goods between groups. Projectile points and ceramic vessel sherds associated with the central Texas region and the east Texas Caddo coexist in sites within the middle Brazos River basin, which crosscuts the Blackland PrairieOak Woodlands boundary. Some studies suggest that exchange of central Texas lithic materials occurred prehistorically and that this exchange continued over a considerable length of time (Fields et al. 1991:282). Dee Ann Story (1990:364) has attempted to explain the apparent social interactions marked by these artifacts for the Late Prehistoric period of the middle Brazos basin by acknowledging a much more complex cultural milieu than that of the oftenproposed Austin-Toyah phase dichotomy for central Texas. Story sees evidence for an intermediate horizon between the Austin and Toyah phases that is characterized by Alba arrow points and early Caddoan pottery. Noting that the sites that have yielded evidence of this intermediate horizon are difficult to interpret because "these sites have not been analyzed in detail (i.e., Chupik and Asa Warner) or the middle temporal phase remains have not been recognized as distinct," she goes on to suggest that these remains could represent "(1) groups from the east who occupied the area year round 
or seasonally, or (2) local groups who were interacting with Caddoans through trade, marriage, and visitations" (Story 1990:364). Taking the next step in this argument, Harry Shafer (2004) has proposed that many early to middle Late Prehistoric sites in the middle Brazos basin, such as Chupik and Asa Warner, were "prairie Caddo" settlements and seasonal sites occupied by people who served as the sustaining population for the ceremonial center at the George C. Davis site in Cherokee County. While a single site could never resolve this issue, 41MM341 can contribute relevant information because it was occupied at the same time as the George C. Davis site, and it has the same kinds of chipped stone tools that are associated with similar-aged sites to the east and west.

The question is how participation in the interactions described above would be represented in a site such as 41MM341. The prevalence of lithic debitage concentrations and formal chipped stone tools at $41 \mathrm{MM} 341$ provides the best entry point to answering that question. These materials suggest that the site occupants had access to abundant chert in the Little River gravel deposits that were similar in quality to central Texas materials that are often found traded east to the Caddo. In addition, the arrow points and knives recovered from 41MM341 indicate skilled craftsmanship. Consequently, the site occupants could have entered into interactions based on trade of good-quality lithic tools manufactured from these resources. Evidence of gearing up, if it is proven to exist at the site, may have been in part oriented to future trade. What the site occupants would have gotten in return is less clear, especially since ceramic vessel sherds are not significant at the site. Yet, simply demonstrating that the activities at 41MM341 were linked to wider interactions will affect how those interactions are eventually understood. Certainly, Shafer's proposal of a Caddo identity within the middle Brazos River basin suggests a degree of complexity that goes beyond down-the-line transmission of information and innovation spurred by straightforward reciprocity as might be expected in mobile hunting-gathering societies (Wiessner 1982). And the presence of Alba points and Gahagan knives fashioned from central Texas chert in the Caddo burial mound at the George C. Davis site (Shafer 1973) indicates that social elites were exercising some degree of control within the system.
But solidification of elite control may have been continually thwarted by scattered producers who found ways to maintain access to all stages of production and who could have used the items produced themselves (Nassaney 1996). Thus, the continued reproduction of a stylistically simple tool kit (composed of arrow points and knives) may provide some explanation as to why the Caddoan presence or influence at sites such as 41MM341 may be marked by only a few ceramic vessel sherds (Perttula et al. 2003:63).

Research questions directed at interregional interactions are:

1. What was the source of the lithic materials utilized at 41MM341?

2. Are all stages of lithic tool production represented at the site, thereby indicating that all stages of reduction took place there?

3. What kinds of tools were manufactured or refurbished at the site, and were the tools manufactured at the site used there?

4. Were lithic tools leaving 41MM341 and, if so, what kinds of tools were leaving (e.g., preforms, finished projectile points, and knives), and what does this indicate about the site occupants' desires to satisfy present vs. future needs?

5. Is style in projectile point and knife forms any indicator that the groups who occupied the site were involved in interaction?

The above discussion suggests that lithic tool production and use at 41MM341 has promise for addressing the topic of interregional interaction. One place to start is through the identification of the sources of the lithic raw material utilized at the site. Initial investigation suggests that the lithic debitage and tools recovered are composed of materials from lithic cobbles local to 41MM341 (i.e., gravels from the Little River and its terraces). However, debitage with a wide variety of colors and inclusions was observed within the lithic concentrations. Some of these colors and inclusions are reminiscent of the kinds and qualities of materials identified for the Fort Hood area of central Texas proper (Douglas K. Boyd, personal communication 2004). While it is likely that central Texas chert would be in the bed load of the Little River 
(since it originates on the Edwards Plateau), a recent Little River cobble sample gathered near 41MM341 appears to be less diverse in color and inclusions than might be expected given the archeological evidence (Tomka et al. 2003:149). Consequently, efforts at distinguishing lithic resource utilization at $41 \mathrm{MM} 341$ will be pursued.

To address the nature of the lithic materials, both cobble and tool characteristics will be investigated. First, cobble size and origin will be addressed by identifying the kind of cortex present on flakes within the debitage concentrations (i.e., does the cortex display the polish and battering associated with a stream-rolled cobble?). Cobble color and inclusions have already been identified for the debitage within the lithic concentrations and compared to material samples from Fort Hood (Trierweiler 1994) and from local gravels (Tomka et al. 2003). The next step will be to examine chert color and inclusions in the formal lithic tools relative to those identified in the debitage and in off-site resource samples. These observations will be made in conjunction with the general debitage and lithic tool analysis described above and will address the first research question listed above.

The technological, functional, and stylistic aspects of the formal chipped stone tools, especially the projectile points and knives, will also provide information through which issues of interaction can be explored. Technological and functional aspects of formal tools will be addressed as the methods of use and production are explored through the assemblage investigations described above. Important here will be information such as preform manufacture, break type, rejuvenation, and use wear, which will allow different tools to be followed through their use lives, a process that can point to the kinds of tools, if any, that were leaving the site. If complete formal tools were carried away from the site, it is likely that their removal can be attributed to future-oriented activities or gearing up. Ascribing future-oriented activities to a particular need will be difficult, as various possibilities such as trade or actual use for resource procurement or processing may have similar signatures in the archeological record. In addition, simple anticipation of moving away from an abundant lithic resource area, such as the Little River, could have affected formal tool production (see Parry and Kelly 1987:300-301). Still, looking at the complete context of tool production may provide clues as to what future needs were being addressed. For instance, does activity area structure suggest a forager or a collector organization that would complement future-oriented tool production? Similarly, the relationship between the resource processing that took place at 41MM341 and the formal tools produced there will be an important point of comparison, as will the relationship of expedient to formal tools in task completion. These kinds of relationships will be important in addressing the second, third, and fourth research questions listed above.

In terms of investigating the relationships between social connections and style in the chipped stone tools, such studies usually benefit from the use of large samples that help even out variation injected into the lithic form by reuse and refurbishment (Rick 1996:245-248). However, style comparisons specifically addressing reuse and refurbishment have also raised important questions concerning how projectile point style might be influenced by curation (Rondeau 1996). Taking a slightly different and more-directed approach, this study proposes to apply the arrow point and knife trajectory of use defined during the assemblage investigations to questions of interregional connections and style. In this study, arrow point and knife styles will be defined based on "new" forms (i.e., tools that are complete and unused or slightly used, nearly complete but unused, or broken late in the manufacturing process). Defining a "new" form for selected types should allow style attribute measurements (i.e., base, stem, and blade) to address tool form before that form was reshaped by reuse (though it may seem intuitive that resharpening would follow the original shape, this may not be the case with small projectile point forms such as Alba). As such, this study is directed at defining a shared technological form that may have been maintained as a marker of participation in shared social relations (Braun $1986: 123)$. It is recognized that few "new" forms remain in the archeological record unless they were compromised and abandoned very late in the manufacturing process, or unless they were cached. The fact that chipped stone tool manufacture was an obviously important activity at 41MM341 makes it a good candidate for having "new" tools. As stated above, the presence of the Alba arrow point and Gahagan knife form in 
central Texas sites suggests an eastward link to the socially ranked Caddoan society of east Texas. If "new" tools defined at 41MM341 dis- play similar attributes to tools made of central Texas materials in east Texas, then eastwardoriented interaction would be supported. 


\section{WORK ACCOMPLISHED AND METHODS OF INVESTIGATION}

\section{WORK ACCOMPLISHED AND FIELD METHODS}

Data recovery excavations began the week of July 22, 2002, and ended on November 22, 2002. During this period, fieldwork was performed over 13 weeks, with the site being shut down for several weeks in October and November because of flooding. Excavations consisted of the following: 4 backhoe trenches; 11 initial 1x1-m units; a $642-\mathrm{m}^{2}$ area in which the upper, largely sterile deposits were stripped mechanically for potential placement of blocks; and 3 hand-excavated blocks covering $208 \mathrm{~m}^{2}$. The initial units were dug to depths of $130-140 \mathrm{~cm}$ below the modern surface. Block excavations extended $30-60 \mathrm{~cm}$ below the stripped surface, or 70-100 $\mathrm{cm}$ below the ground surface. The total volume of sediments excavated manually was $95 \mathrm{~m}^{3}$. This is 5 percent less than the $100-\mathrm{m}^{3}$ goal specified in the data recovery plan. It was determined that this shortfall would not affect our ability to interpret the archeology of the site for two reasons: (1) the block excavations were extensive and had exposed many features, providing ample opportunities to examine feature and artifact distributions and identify spatial patterning; and (2) artifact densities turned out to be much higher (ca. five times) than suggested by the 2000 testing, and thus the $95 \mathrm{~m}^{3}$ excavated yielded a much larger collection of artifacts than anticipated. This conclusion was presented to the Texas Department of Transportation (TxDOT) and the Texas Historical Commission, and permission to end the excavations short of the original goal was granted.

Work began with re-locating testing Blocks 1 and 2 and re-locating, reopening, and extending previously excavated Trenches 15,17 , and
24 (these are labeled Trenches 3,4 , and 1, respectively in Figure 4-1). A fourth trench (Trench 2 ) was excavated $8 \mathrm{~m}$ south of Trench 1 (all directions given here are based on grid north oriented to the existing State Highway 36 bridge, which actually is oriented northwest). The trenches were 13-18 m long with an average depth of $170 \mathrm{~cm}$ below the surface. The trenches facilitated placement of the 11 initial $1 \times 1-m$ units. The trenches also confirmed the locations of the testing blocks, provided an opportunity to examine the geomorphology of the site, and revealed previously undiscovered lenses of mussel shells and burned clay.

The initial 1x1-m units, labeled Excavation Units 1-11, were placed on Trenches 1-4. Unit spacing along the trenches was approximately 3-4 m, with some adjustments to intersect cultural materials observed in the trench walls (Figure 4-2). These initial units were excavated in 10-cm levels to a depth of $130 \mathrm{~cm}$ below the surface, with all sediments removed waterscreened through 1/4-inch-mesh hardware cloth. The unit levels refer to depths below datum such that Levels 2-4 correspond to the ground surface, reflecting a $20-\mathrm{cm}$ rise in elevation from Excavation Units 1 to 11 . The initial units confirmed the presence of the stratified components identified by the test investigations and provided more information concerning the distribution of these components across the site. The artifact recovery from the initial units, including debitage, cores, formal chipped stone tools, expedient chipped stone tools, ground stone tools, and a ceramic sherd, indicated that the later Late Prehistoric component identified in the upper $40 \mathrm{~cm}$ of the site during testing is ephemeral, with only Excavation Units 4 and 11 yielding eight or more artifacts (Table 4-1). 
Data Recovery Excavations at the J. B. White Site

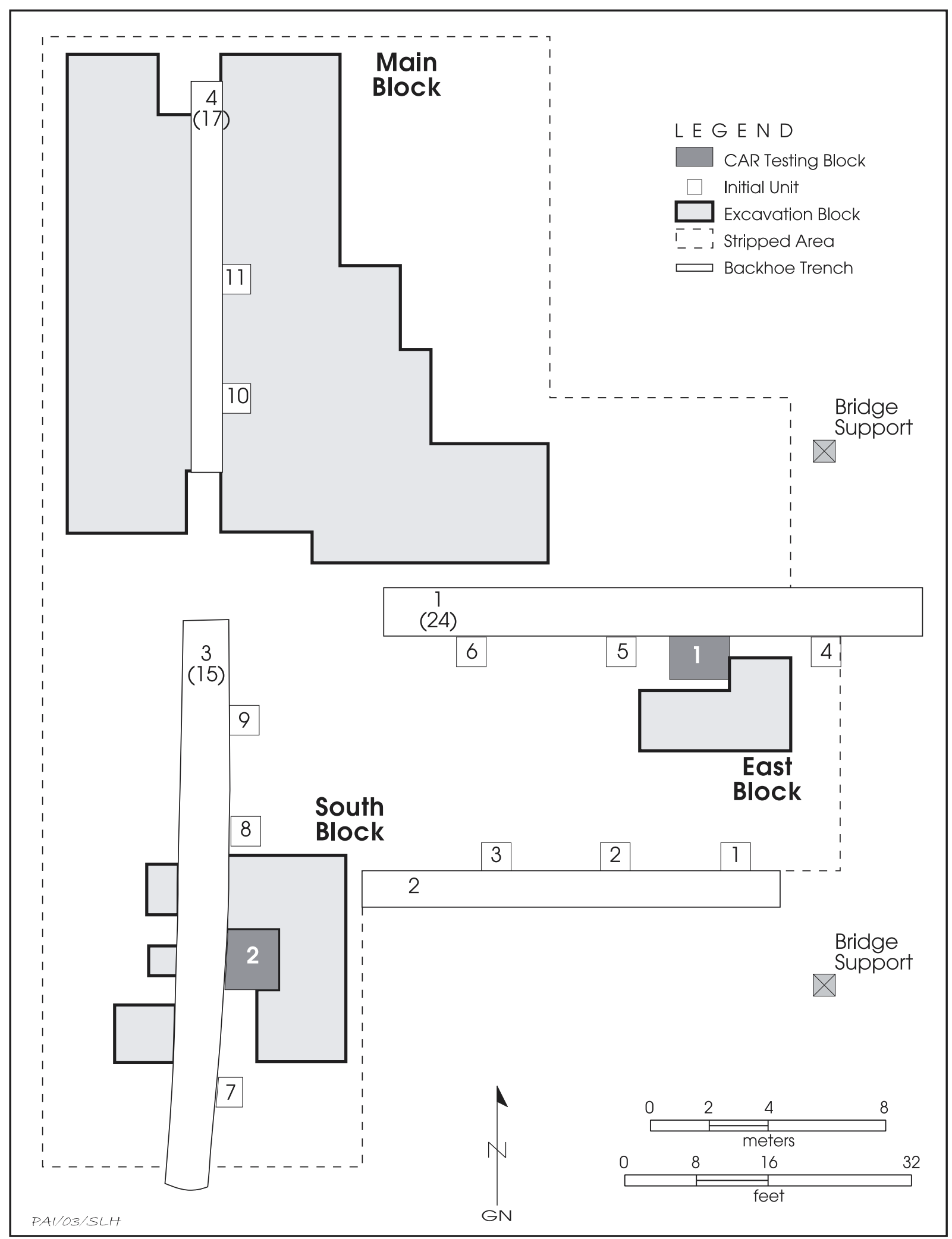

Figure 4-1. Plan of 41MM341 showing 2002 data recovery excavations. 


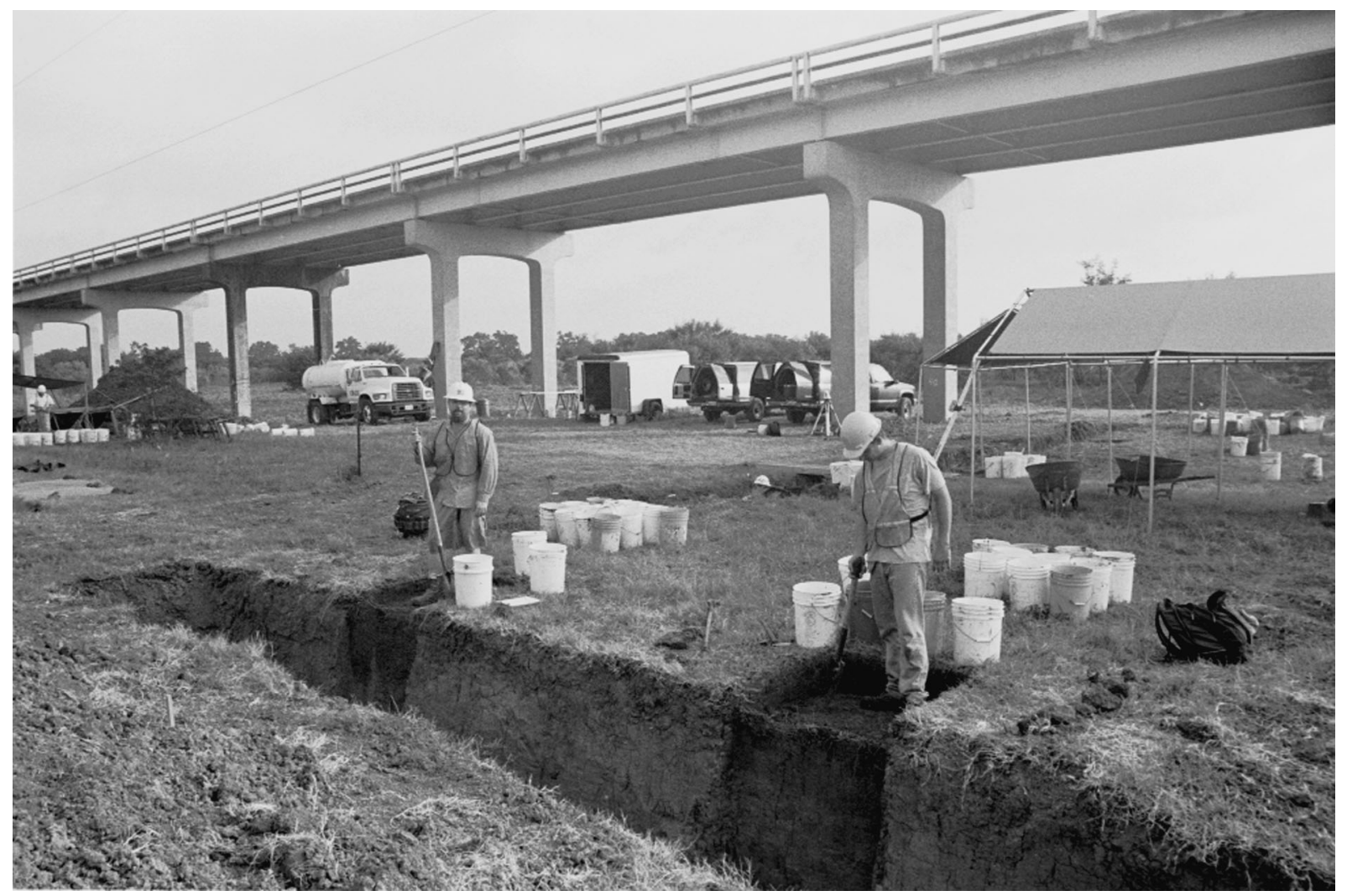

Figure 4-2. View of initial Excavation Units 8 and 9 being opened on the east wall of Trench 3.

Table 4-1. Artifact frequencies in the initial excavation units

\begin{tabular}{c|r|r|r|r|r|r|r|r|r|r|r}
\hline & \multicolumn{10}{c|}{ Excavation Unit } \\
\cline { 2 - 11 } Level & 1 & 2 & 3 & 4 & 5 & 6 & 7 & 8 & 9 & 10 & 11 \\
\hline 1 & - & - & - & - & - & - & - & - & - & - & - \\
2 & - & - & - & - & - & - & - & 1 & 0 & 0 & 3 \\
3 & - & - & - & - & - & - & 0 & 3 & 0 & 0 & 0 \\
4 & 0 & 2 & 2 & 1 & 1 & 0 & 0 & 0 & 0 & 0 & 0 \\
5 & 1 & 0 & 0 & 1 & 2 & 0 & 2 & 0 & 0 & 0 & 15 \\
6 & 0 & 0 & 0 & 0 & 2 & 0 & 0 & 0 & 0 & 26 & 157 \\
7 & 1 & 1 & 0 & 6 & 0 & 0 & 2 & 0 & 0 & 52 & 28 \\
8 & 1 & 0 & 0 & 4 & 2 & 0 & 3 & 1 & 3 & 108 & 6 \\
9 & 2 & 0 & 0 & 8 & 1 & 0 & 1 & 1 & 63 & 51 & 45 \\
10 & 7 & 1 & 0 & 47 & 11 & 0 & 18 & 2 & 33 & 62 & 118 \\
11 & 16 & 2 & 0 & 21 & 20 & 1 & 58 & 0 & 5 & 195 & 19 \\
12 & 55 & 24 & 0 & 29 & 0 & 10 & 178 & 4 & 13 & 33 & 4 \\
13 & 8 & 4 & 18 & 45 & 0 & 22 & 19 & 2 & 3 & 8 & 1 \\
14 & 0 & 0 & 0 & 7 & 2 & 2 & 2 & 0 & 2 & 1 & 0 \\
15 & 0 & 0 & 16 & 4 & 0 & 0 & 6 & 4 & - & - & - \\
16 & 1 & 0 & 14 & 3 & 0 & 1 & - & - & - & - & - \\
\hline Total & 92 & 34 & 50 & 176 & 41 & 36 & 289 & 18 & 122 & 536 & 396 \\
\hline
\end{tabular}


The recovery of two Perdiz points at $30-50 \mathrm{~cm}$ in Excavation Unit 4 and a single small ceramic sherd at $0-10 \mathrm{~cm}$ in Excavation Unit 5 provided some support for associating the sparse upper materials with the latest component, but because this component appeared so insubstantial it was concluded that it was not worth pursuing during data recovery excavations.

A component thought to be Late Archaic in age was encountered in the lower levels (ca. 90$130 \mathrm{~cm}$ below the surface) in most of the initial units. It was marked most strongly by artifact frequency peaks in Excavation Units 7, 10, and 11 (see Table 4-1), as well as by an associated pit hearth and mussel shell lenses. What was thought to be a Pedernales dart point (later considered to be an untyped dart) was recovered in Level 10 (80-90 cm) of Excavation Unit 10. The recovery of this point suggested this was not a transitional Late Archaic-early Late Prehistoric component, but instead a component similar in age to the Late Archaic component at 41MM340. Because data recovery excavations had been undertaken there, further exploration of this component at $41 \mathrm{MM} 341$ was not considered warranted.

The initial units suggested that there was enough separation between the lowest component and the early Late Prehistoric component above to allow the latter to be removed as a largely discrete unit. As block excavations proceeded, however, it became evident that, in some areas of the site, isolation of the early Late Prehistoric materials is not as clear cut. Investigation of superimposed shell features in the southeastern part of the main excavation block necessitated the excavation of $43 \mathrm{~m}^{2}$ of deeper deposits in Level 10 (90-100 cm below the surface). The recovery and analysis of additional diagnostic artifacts and radiocarbon assays from these deeper deposits eventually showed that the deposits are, in fact, transitional Late Archaic-early Late Prehistoric rather than contemporaneous with the Late Archaic occupation at $41 \mathrm{MM} 340$. Overall, $10.3 \mathrm{~m}^{3}$ were excavated from this oldest site component. A complete discussion of component definition is presented in Chapter 8.

Based on information recovered during testing, early Late Prehistoric materials were expected to occur mostly in Levels 6-9. Artifact frequencies within the initial units were gener- ally low at these depths, with very few artifacts recovered from Excavation Units 1-3 and 6-8 (see Table 4-1). However, Excavation Units 10 and 11 located on Trench 4 contained abundant artifacts at these depths. These frequency peaks corresponded with a burned clay lens that ran the length of the trench, and shell lenses not visible in the trench walls were exposed in both units at similar depths. Given the low frequency of materials in the initial units between testing Blocks 1 and 2, opening an excavation that connected these blocks, as originally proposed, was not considered worthwhile. Instead, the decision was made to begin an excavation block where artifact frequencies were highest (i.e., around Excavation Units 10 and 11 on the east side of Trench 4).

To expedite excavation of the targeted early Late Prehistoric component and allow expansion of the block as recovery indicated, the upper $40-50 \mathrm{~cm}$ of virtually sterile site sediments were mechanically removed from the central part of the site using both a backhoe and Gradall (Figure 4-3). The area stripped encompassed all four backhoe trenches, the 11 initial units, and the testing blocks, covering ca. $642 \mathrm{~m}^{2}$ (see Figure 4-1).

Once excavation of the block east of Trench 4 began, mussel and Rabdotus shell lenses were encountered within patchy midden-like deposits that also contained burned clay, burned rocks, lithic tools, debitage, animal bones, and charcoal (Figure 4-4). The block was excavated in arbitrary $10-\mathrm{cm}$ levels in contiguous $1 \mathrm{x} 1-\mathrm{m}$ units numbered consecutively as they were opened. Multiple units were excavated simultaneously, providing large horizontal exposures of the shell lenses and adjacent features and enabling investigators to begin to identify spatial relationships between features. This process was complemented by charting artifact frequencies by unit and 10-cm level. Both kinds of information were used to determine whether the excavators were within the cultural zone, thus guiding the direction of block expansion. Because of the many features and high artifact frequencies encountered, this main block grew to $170 \mathrm{~m}^{2}$ and encompassed both sides of Trench 4 (see Figure 4-1).

After the Main Block around Trench 4 was well under way, two smaller blocks were opened around the testing blocks to further determine the nature of the occupations in those areas (Fig- 


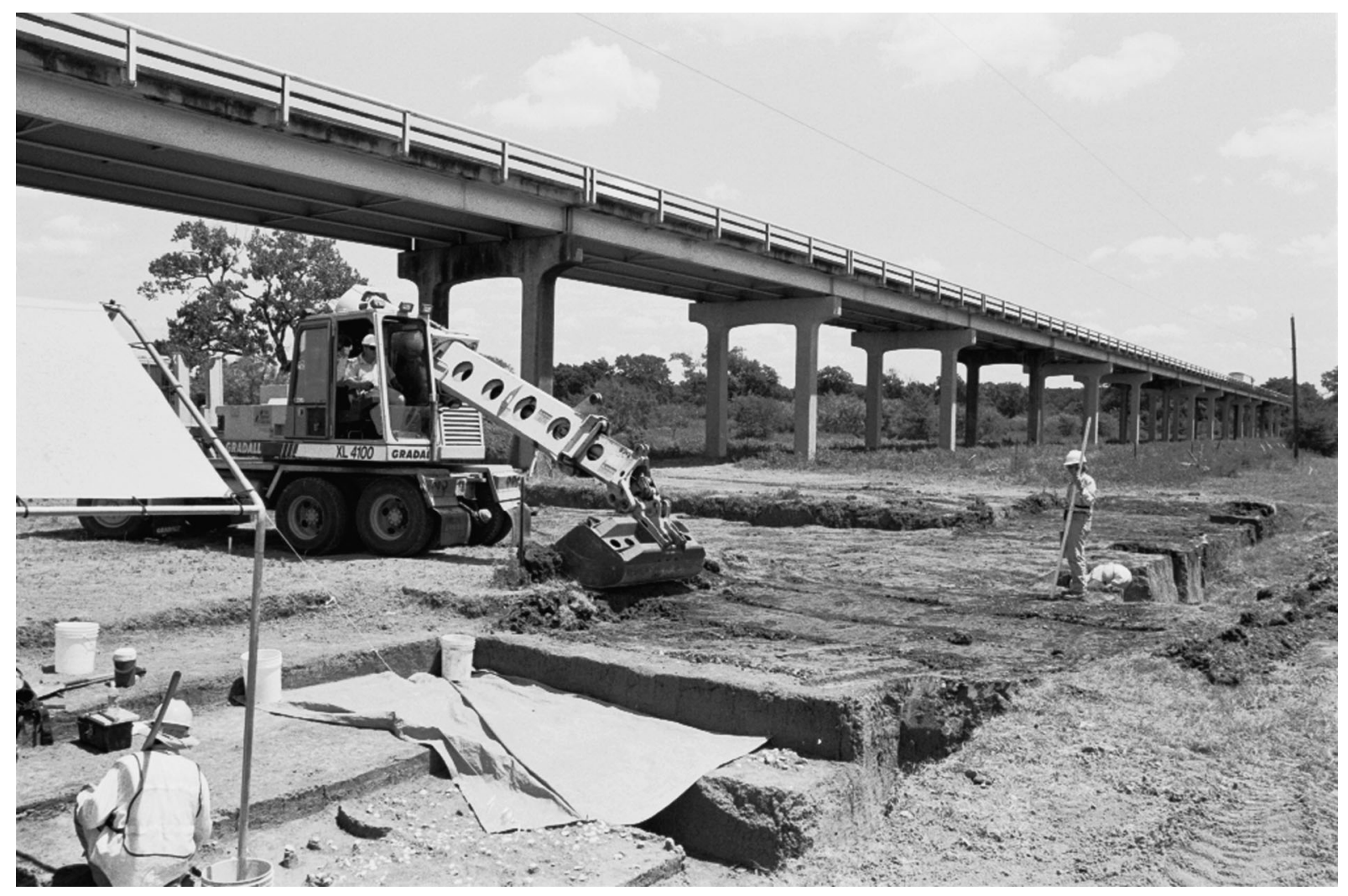

Figure 4-3. View of a TxDOT Gradall stripping the area where the East and South Blocks eventually would be opened as excavations in the Main Block begin.

ure 4-5). The East Block consisted of $12 \mathrm{~m}^{2}$, in addition to Excavation Units 4 and 5, adjacent to testing Block 1. The South Block consisted of $28 \mathrm{~m}^{2}$ opened around testing Block 2 along with Excavation Units 7 and 8 (see Figure 4-1). The East Block produced similar kinds of materials as seen in the Main Block, though in lower frequencies. However, the South Block was unique in that it revealed a complex of features of a type not seen in the other blocks, - that is, overlapping pit features filled with burned rocks and burned clay. A total of $7 \mathrm{~m}^{2}$ of the South Block placed west of testing Block 2 produced little. Though this part of the South Block was discontinued because of flooding at the end of the field season, it did show that the burned features did not extend to the west beyond Trench 3.

Forty-five cultural features, including the shell lenses, burned rock concentrations, pit hearths, surface hearths represented by ash or burned clay concentrations, and possible postholes were identified within the initial units and excavation blocks. These were given a num- ber designation starting from the last feature (Feature 5) identified during testing. All features were cleaned, mapped, and photographed in plan view. This was the main method of recordation used for shell lenses and burned rock concentrations, as they were generally only a few shells or one to two rocks thick. All other features were cross sectioned and appropriately recorded. Part of each nonshell feature was taken as a flotation sample, and the remainder was water screened. For shell lenses, the shells were removed with the matrix that surrounded them and water screened by the unit and level provenience in which they occurred. The densest part of each lens was bagged as a flotation sample. Other samples collected from features included burned rocks for lipid analysis, burned clay for diatom analysis, and charcoal for radiocarbon dating.

Standard excavation record forms were used for block, unit, and feature notes and were completed by the individual crew members involved in their excavation. These forms include information on beginning and ending depths, a 


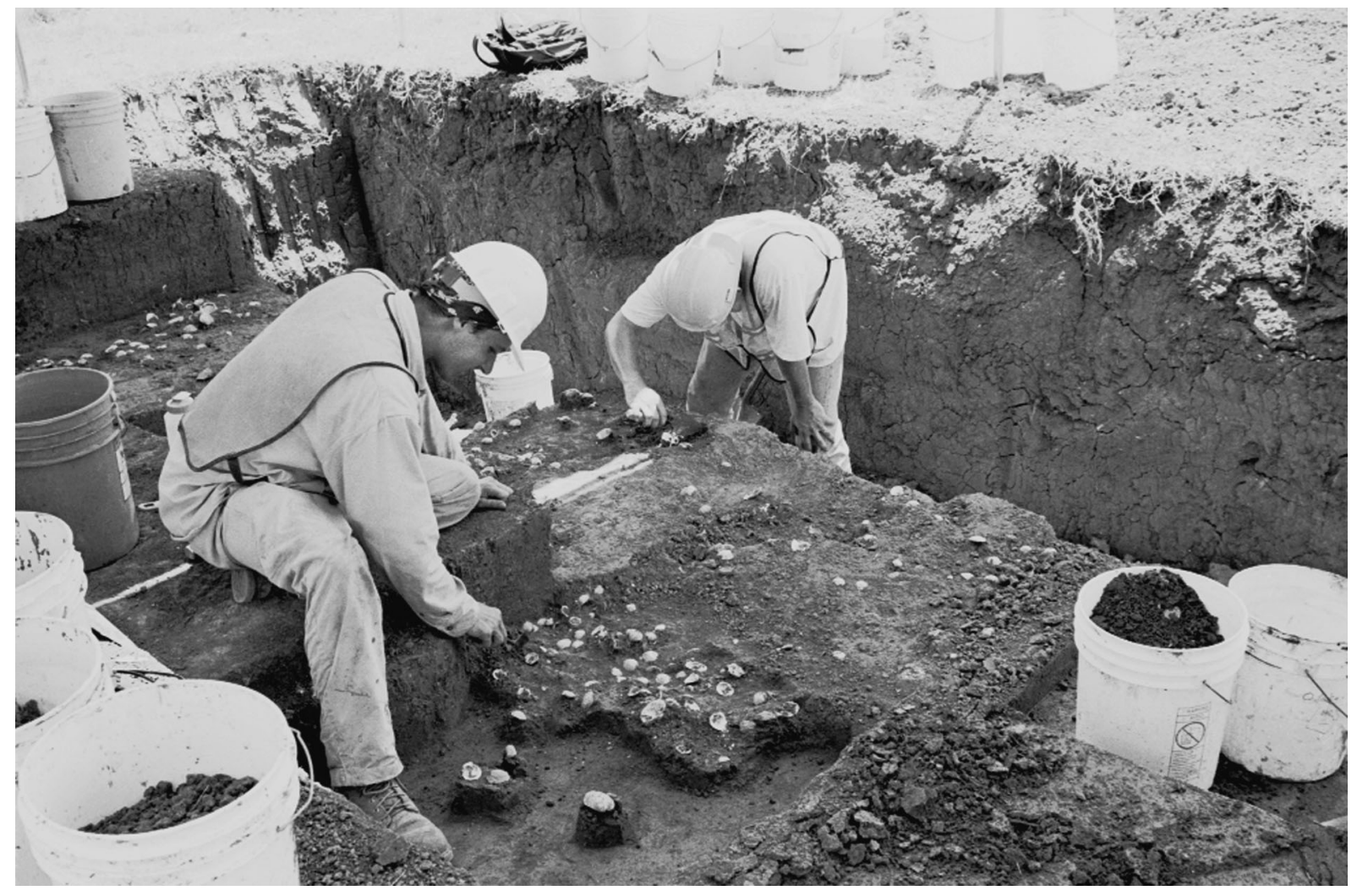

Figure 4-4. View of excavators exposing mussel shell lenses in the Main Block on the east side of Trench 4.

description of matrix or feature fill, a description of associations and significant disturbances, and plan and cross-section maps. Other documentation consisted of stratigraphic profiles of selected trench walls, a photographic record of all features and excavations including blackand-white prints and color slides with accompanying logs, and the project archeologist's daily journal of site activities. The project archeologist also kept a working site map of the extent of all features within the excavation blocks and added to the map as sections of shell lens and nonshell features were exposed. Finally, throughout the excavation, the project archeologist assigned and kept a log of lot numbers for each unique provenience such as features, unit levels, samples, and point-plotted artifacts. These numbers facilitated infield tracking of materials at the water-screen station and effected a swift transition of materials from the field to the lab.

Water screening was used to process the excavated sediments through $1 / 4$-inch hardware mesh. The method employed was similar to that used during the excavation of $41 \mathrm{MM} 340$
(Mahoney et al. 2003:36). A sump was dug just off the north end of the site in the same area as the one used during testing. A screening station set up next to the sump used water that was trucked in until the sump retained enough water to be recycled (see Figure 4-5). Sediments excavated from the blocks were presoaked in buckets containing a solution of sodium bicarbonate and water before screening. This aided dissolution of the clayey sediments and greatly sped up the screening process. A sorting station was established close to the screening station; here, screened materials were dried and selected classes of materials recovered were counted or weighed. Some material classes such as unmodified animal bones, charcoal, burned clay, and Rabdotus snails were indicated as present or absent. The materials recovered were recorded on a water screen log by lot and provenience.

\section{LABORATORY METHODS}

At the end of each week, the materials and special samples recovered during the excavations at 41MM341 were returned to the labora- 


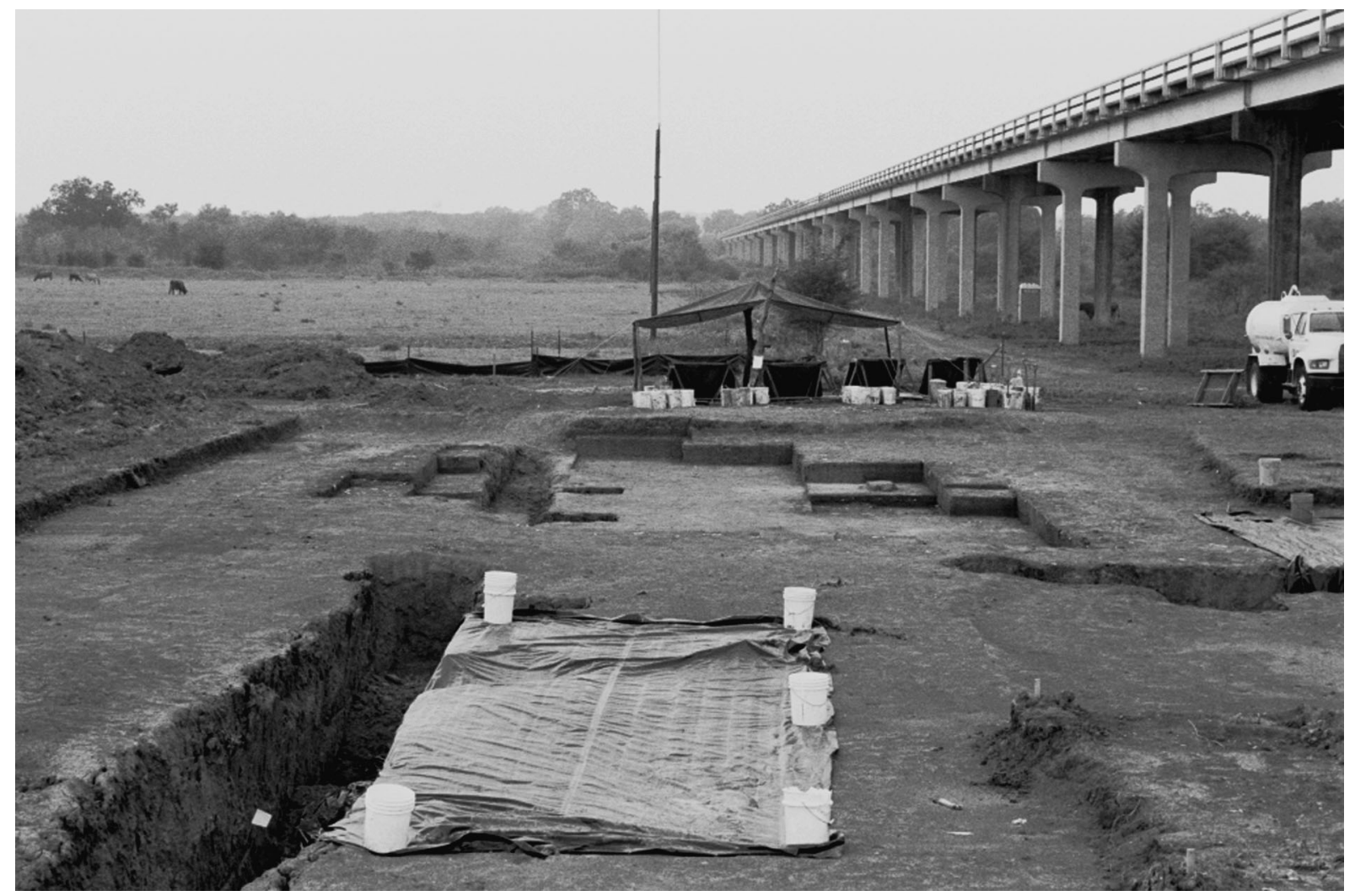

Figure 4-5. View grid north to the partially completed Main Block with the South Block in the foreground under the tarp. The water-screen station is beyond the Main Block.

tory at Prewitt and Associates in Austin for processing. Artifacts were washed, and the sorting of artifacts and counts done in the field were rechecked. Classes of materials that were not sorted in the field were sorted and then counted or weighed by provenience. Artifacts considered tools were labeled with the site number, their lot number, and a lot-specific specimen number so that they could be tracked throughout the analysis process. In addition, a $20-25$ percent sample of debitage from each provenience where it occurred was labeled with site and lot number. All artifacts and item classes were recorded in a specimen inventory catalog by lot number, thereby linking them to provenience. Both the field lot log and the specimen inventory catalog are paper records through which provenience information could be double-checked. After the excavations were complete, a provenience database was established, which could be linked by lot number to all databases generated by subsequent analyses.

A total of 121 flotation samples were collected from soil matrix columns $(n=65)$ and fea- ture contexts $(\mathrm{n}=56)$; all but 7 samples from feature contexts were processed. Samples not floated were screened through 1/4-inch-mesh hardware cloth. Eight processed feature samples were combined with others from the same features, as a review of feature documentation showed there was no reason for the excavators to have made provenience distinctions within the features.

Processing of flotation samples was completed using a Flote-Tech Flotation System. All samples were presoaked in a solution of sodium bicarbonate and water to release materials from the clayey sediments. A flotation log was kept that detailed the volume per provenience processed, the kinds of materials coming out of the sample as observed by the technician, and any additional comments concerning individual samples. Two recovery fractions were obtained from each sample; they consisted of a fine fraction composed of materials that floated and were caught in a $0.32-\mathrm{mm}$ screen and a coarse fraction that did not float and was recovered from a $1.0-\mathrm{mm}$ screen. After drying, the fine fractions 
of 50 samples were set aside to be sent to the archeobotanist for analysis. Materials such as lithic debitage, animal bones, macrobotanical materials, and snails were separated from the coarse fractions and sent to the appropriate analyst or incorporated into artifact categories.

All artifacts and ecofacts recovered and databases, inventories, $\operatorname{logs}$, field notes and journals, site maps and drawings, analysis notes, and photographs generated by this project are curated at the Center for Archaeological Research, The University of Texas at San Antonio. These materials were prepared according to that facility's curatorial standards.

\section{SPECIAL SAMPLE COLLECTION, PROCESSING, AND SELECTION FOR ANALYSIS}

Special samples taken from features and the general site matrix included burned rocks and burned clay for lipid analysis, charcoal for radiocarbon dating, burned clay for diatom studies, mussel and snail shells for isotopic analysis, and macro- and microgastropods for environmental reconstruction.

Burned rock samples $(n=30)$ were identified in situ from pit hearth and burned rock concentrations. An average of three rocks were taken from each selected feature; an "X" was scratched on the upper surface of the rock to mark its orientation within the feature, and the rocks were bagged for shipment to the lipid analyst without any additional preparation. Two burned clay samples for lipid analysis were also extracted in situ from hearth features that had no associated rocks. These burned clay samples were made up of large chunks, giving them a good possibility of retaining lipids. Dr. Mary Malainey of Brandon University, Manitoba, Canada, carried out this analysis. Her results are presented in Appendix F.

Burned clay samples were taken from water-screen recovery from selected surface hearth features for diatom analysis. Surface hearths are thin patches of burned clay, ash, and charcoal. They appear to be the result of fires constructed directly on the surface with little or no preparation of the underlying sediments; the burned clay, therefore, could have preserved diatoms that were within the flood-deposited sediments. Seven burned clay samples were selected from hearths that had been radiocarbon dated; the samples are associated with each of the analysis units defined for the site. These samples were sent to Barbara Winsborough of Winsborough Consulting, Leander, Texas, for analysis; her results are presented in Appen$\operatorname{dix} \mathrm{H}$.

Charcoal, consisting of mainly wood, was abundant within the Main and South Blocks, and many samples $(\mathrm{n}=113)$ were identified in situ. Nineteen charcoal samples collected in situ were radiocarbon dated. In addition, 15 samples pulled from water-screen recovery or from flotation recovery were dated. Charcoal samples taken in situ were placed in foil and then bagged with provenience information. Once in the lab, these samples were air-dried; dirt was removed from the sample, and it was weighed and packaged in a plastic bag for storage. In February 2003 , shortly after initial review of the recovered materials was complete, 12 charcoal samples were selected from mussel shell features and sent to Beta Analytic, Inc., of Miami, Florida, for processing under TxDOT's radiocarbon dating contract. Later, in August 2003, another round of samples mostly from surface hearths, pit hearths, and processing pits was selected for dating. This second round of samples was sent to the new dating contractor, the Center for Applied Isotope Studies at the University of Georgia.

Mussel shells and snail shells were selected for oxygen isotope analysis, which can be useful in environmental reconstruction and determinations of season of death. The mussel shells were chosen from 12 proveniences within the shell features along with 1 provenience among the scattered shells of Level 10 in the East Block. One to 3 shells of Amblema plicata with posterior margins mostly intact were selected from each provenience for a total of 33 shells. In addition, 3 Amblema plicata shells collected by Texas Parks and Wildlife Department personnel from Belton Lake in the Brazos River basin in 1996 and 2000 were submitted for analysis as a control sample. These modern samples were identified and generously provided for analysis by Mr. Robert G. Howells. Oxygen isotope analysis of the mussel shells was done by Dr. Robert Tykot of the University of South Florida (see Appendix C).

Eighteen Rabdotus shells recovered from Features 17, 20, and 21a were submitted to the Center for Archaeological Research, The 
University of Texas at San Antonio, for isotopic analysis and potential examination of paleoenvironmental variation through time. The samples from 41MM341 were analyzed in conjunction with 38 Rabdotus samples from 10 proveniences at nearby $41 \mathrm{MM} 340$. The results of those analyses are summarized in Appendix D.

Additional evidence of environmental stability or change was sought through analysis of macro- and microgastropod samples. Gastropods were recovered from three $50 \times 50-\mathrm{cm}$ columns that produced a total of 56 samples of the site sediments. Column samples were taken in 5 -cm vertical increments. One column was placed near testing Block 1 off of Excavation Unit 4; another was between the Main Block and the South Block off of Excavation Unit 9. Each of these columns was $1.05 \mathrm{~m}$ deep and extended from Levels 4 through 14 (i.e., through the entire cultural zone). A third column was taken from the Main Block in Excavation Unit 171. This column was $0.7 \mathrm{~m}$ deep and extended through the cultural zone from Levels 6 through 12. Gastropod shells were recovered from all 56 of the column samples using the flotation process described above. After processing, the Excavation Unit 9 column was selected for analysis because it produced good microgastropod recovery. Further, its location between the Main and South Blocks in an area where cultural materials were sparse (through Level 8) suggested that the gastropod samples might be less affected by cultural activities and more representative of surrounding environmental conditions. Gastropods from 11 samples from this column (every other 5-cm level, i.e., one sample for each level used in the block excavations) were analyzed. Seven additional samples of macro- and microgastropods from the flotation recovery of mussel shell features were also analyzed and compared to the column recovery. This analysis was carried out by Karen M. Gardner of Prewitt and Associates (see Appendix B).

\section{ANALYSIS METHODS}

This section describes how the artifacts and other materials recovered were analyzed for descriptive and interpretive purposes. All cultural materials recovered were quantified and described to some extent because the assemblage as a whole is useful for interpretation as representative of chiefly early to middle Late
Prehistoric period occupations, with a minor admixture of terminal Late Archaic materials. Most of the materials could be segregated into analytical units that are temporally more discrete, and the methods by which this was done and interpretations about how the site was used through time are presented in Chapter 8.

\section{Chipped Stone Artifacts}

\section{Lithic Reduction Debris Piles}

Ten lithic reduction debris piles were defined in Levels 6 through 9 of the Main Block. These concentrations are composed of debitage, cores and core fragments, and tools and tool fragments; they were generally restricted to single levels, although some crosscut levels. These concentrations became the focus of lithic debitage, core, and tool analyses in an attempt to explicate the tool production strategies practiced at the site (see Chapter 6 for a discussion of the characteristics of these concentrations). Because of their discrete nature, the concentrations also provided important information used to address site structure and definition of analysis units.

Analysis of the debris piles began by sorting like debitage within groups for nearby unit levels containing high debitage frequencies. The purpose of this was to identify groups of debitage representing debris from single episodes of core or biface reduction. Color, texture, and inclusions of the lithic materials were the variables used to make the sorts. Each group of like debris identified per concentration was given a cobble number. These "cobbles" may be considered similar to the Minimum Analytic Nodules (MANs) used by Larson and Kornfeld (1997:1-17) to address site structure and technological issues. These cobble identifications were strengthened by refitting pieces. Though extensive refitting of flakes to flakes, flakes to cores, and core fragments to core fragments was not done, some obvious refits in these categories were identified, and enough refits were found to confirm the presence of distinct reduction episodes.

A material sample of each cobble was bagged for ease of comparison. These samples were continually referred to as the debitage from each level within a concentration was analyzed. In this way, cobbles were tracked through the units of a concentration and, in a few cases, beyond the edges of the concentrations. Notes on each 
concentration recorded the number of flakes, chunks, and cores or core fragments associated with each cobble per unit and level. The number and provenience of refits within the concentration and a description of each cobble identified were also recorded. As the lithic tool analysis progressed, identified cobbles were compared to the tools from each concentration or from nearby proveniences. In several instances, cobble materials and refits to tools broken in manufacture were identified.

\section{Raw Material}

Except for a few items of quartzite and novaculite, all of the chipped stone artifacts recovered are of chert. As discussed in Chapter 3 , research issues relating to the use of local chert gravels vs. nonlocal lithic resources are relevant for interpreting 41MM341. The identification of chert type and cortex type was used to address these issues.

Two lines of evidence were used to identify chert type, both of which were initially based on materials within the lithic reduction debris piles. First, chert color ranges were established based on the colors exhibited by the lithic concentration cobbles identified. Chert color was recorded for each cobble using a Munsell soil color chart. These colors were grouped into 11 color ranges (Table 4-2). These color ranges could then be used to compare the concentration cobbles to the 14 chert material types identified by CAR within a sample of Little River gravels collected from the modern channel near 41MM340 and 41MM341 (Tomka et al. 2003:149-153). This comparison provides an indication of whether the kinds of materials coming out of the modern channel are similar to the materials coming from 41MM341 and whether the four material types identified as nonlocal at $41 \mathrm{MM} 340$ are present at 41MM341.

Second, the chert taxonomy developed at Fort Hood (Trierweiler 1994:Appendix C) and a small comparative collection of some of the ubiquitous types there were used to assess whether these particular chert types are at 41MM341. The comparative collection includes examples of Type 4, Seven-Mile Mountain Novaculite; Type 8, Fort Hood Yellow; Type 14, Fort Hood Gray; and Type 15, Fort Hood Gray-BrownGreen. The chert taxonomy for Fort Hood is rel- evant because that area is drained by tributaries of the Little River.

Chert colors and types were used in conjunction with cortex type to identify local vs. nonlocal materials within the 41MM341 collection. For instance, if cobble cortex is common on debitage and cores of a particular chert, then it is likely that that material is from the local gravels. Cortex type was identified for the unmodified debitage and cores and core fragments as: cobble cortex, weathered rind, or indeterminate. Items with cobble cortex have remnants of a battered or polished surface produced by tumbling in the river (i.e., transported some distance), while items with traces of a chemically weathered rind having a matte or dull finish are presumed to have come from bedded sources rather than gravel bars.

\section{Unmodified Debitage}

A total of 39,872 pieces of unmodified debitage was recovered. Given this large recovery, an analysis sample was drawn from the lithic reduction debris piles. This sample consists of all the debitage associated with 6 of the 10 piles. The decision to focus on these particular piles, rather than drawing samples from all piles, was based on the fact that these were relatively discrete and generally restricted to individual levels. Further, they represent Levels 6 though 9 of the Main Block. Since a concentration was not defined in the small section of the Main Block excavated to Level 10, the debitage from that level in the East Block was added, even though it does not constitute a concentration. In all, 11,525 pieces of debitage form the analysis sample, which consists of 1,701 pieces of debitage from lithic reduction debris Pile 1 and 1,297 pieces from Pile 3 of Level 6; 2,932 pieces from Pile 9 in Level 7; 1,854 pieces from Pile 6 and 1,502 pieces from Pile 7 in Level 8; 1,285 pieces from Pile 8 in Level 9; and 954 pieces from Level 10 in the East Block.

The purpose of the debitage analysis is to define the kinds of lithic production that occurred at the site and to determine if production changed through time. As such, this analysis is based on flake types presenting a series of interrelated characteristics (i.e., shape, number of dorsal scars, and number of platform facets) shown to be related to particular reduction sequences. Flake types used include biface 
Table 4-2. Chert color ranges based on cobbles from lithic reduction debris piles

\begin{tabular}{|c|c|}
\hline Color Range & Munsell Colors \\
\hline Dark gray & $\begin{array}{c}\text { Gley } 14 / \mathrm{N} \\
2.5 \mathrm{Y} 3 / 1 \\
2.5 \mathrm{Y} 4 / 1 \\
7.5 \mathrm{YR} 3 / 1 \\
7.5 \mathrm{YR} 4 / 1 \\
\text { 10YR } 3 / 1 \\
\text { 10YR } 3 / 2 \\
\text { 10YR } 4 / 1\end{array}$ \\
\hline Gray to light gray & $\begin{array}{c}2.5 Y \text { Y } 5 / 1 \\
2.5 Y \text { Y } 6 / 1 \\
2.5 \mathrm{YR} 5 / 1 \\
2.5 \mathrm{YR} 6 / 1 \\
2.5 \mathrm{YR} 7 / 1 \\
7.5 \mathrm{YR} 5 / 1 \\
7.5 \mathrm{YR} 6 / 1 \\
7.5 \mathrm{YR} 7 / 1 \\
\text { 10YR } 5 / 1 \\
\text { 10YR } 6 / 1 \\
\text { 10YR } 7 / 1 \\
\end{array}$ \\
\hline Pinkish gray & $\begin{array}{c}\text { 5YR 6/2 } \\
7.5 \text { YR 6/2 } \\
7.5 \text { YR 7/3 } \\
7.5 \text { YR 8/3 }\end{array}$ \\
\hline $\begin{array}{l}\text { Grayish brown to } \\
\text { brownish gray }\end{array}$ & $\begin{array}{c}2.5 \mathrm{Y} 4 / 2 \\
2.5 \mathrm{Y} 5 / 2 \\
2.5 \mathrm{Y} 6 / 2 \\
2.5 \mathrm{YR} 5 / 2 \\
2.5 \mathrm{Y} 6 / 2 \\
2.5 \mathrm{Y} 6 / 3 \\
10 \mathrm{YR} 5 / 2 \\
10 \mathrm{YR} 6 / 2 \\
\end{array}$ \\
\hline Brown & $\begin{array}{l}7.5 \text { YR } 4 / 2 \\
7.5 \text { YR } 4 / 3 \\
7.5 Y R ~ 4 / 4 \\
7.5 Y R ~ 5 / 2 \\
7.5 Y R ~ 5 / 3 \\
7.5 Y R ~ 5 / 4 \\
7.5 Y R ~ 6 / 4 \\
\text { 10YR 4/2 } \\
\text { 10YR 4/3 } \\
\text { 10YR 5/3 }\end{array}$ \\
\hline $\begin{array}{l}\text { Dark yellowish brown } \\
\text { to brownish yellow }\end{array}$ & $\begin{array}{l}\text { 10YR 4/4 } \\
\text { 10YR 4/6 } \\
\text { 10YR 5/4 } \\
\text { 10YR 5/6 } \\
\text { 10YR 6/6 }\end{array}$ \\
\hline Pale brown & $\begin{array}{c}\text { 2.5YR 6/3 } \\
\text { 10YR 4/4 } \\
\text { 10YR 4/6 } \\
\text { 10YR 5/4 } \\
\text { 10YR 5/6 } \\
\text { 10YR 6/6 }\end{array}$ \\
\hline Yellow & $2.5 \mathrm{Y} 6 / 4$ \\
\hline
\end{tabular}


Table 4-2, continued

\begin{tabular}{l|c}
\hline Color Range & Munsell Colors \\
\hline & $2.5 Y 7 / 3$ \\
& $2.5 Y 7 / 3$ \\
& $2.5 Y 7 / 4$ \\
& 10 YR 7/6 \\
& 10 YR $8 / 4$ \\
\hline Light blue gray & Gley $17 / \mathrm{N}$ \\
\hline Greenish gray & $10 Y 5 / 1$ \\
\hline Red & $5 Y R 5 / 6$ \\
\hline
\end{tabular}

reduction, thinning, and resharpening flakes; notching flakes; core preparation/reduction flakes; blade blanks; uniface manufacture/repair flakes; and flakes of indeterminate type. Tomka et al. (1999:36-38) provide detailed descriptions of these flake types. In addition, debitage representing these flake types, produced by Steve Tomka during the replication of particular reduction scenarios, was used for comparison. The analyst also consulted with Allen Bettis, an experienced lithic technologist and archeologist with TxDOT. Mr. Bettis reduced several fist-sized stream-rolled cobbles using hard and soft hammers with particular intent such as biface manufacture or core reduction. Reduction debris for each experimental cobble was collected and notes were made on the percussor used and the finished product. A sample of the debris for each experimental reduction was later analyzed using the same technique as used for the prehistoric materials to better understand the results of the prehistoric lithic debris analysis.

Additional categories used to describe the unmodified debitage are flake completeness, size, cortex percentage, and cortex type. Flake completeness was recorded as complete, proximal fragment (with platform), chip, and chunk. Generally, flake type was recorded for only complete and proximal flakes. Size is an overall measure that was recorded in 0.5 -inch increments so that graduated sieves could be used to speed this determination. The size groups are converted to millimeters in the analysis. Cortex was recorded as $0,1-50,51-99$, and 100 percent. Cortex type, as described above, is intended to provide information on the origin of the material.

In addition to flake type and other debitage characteristics, lot number, lithic concentration number, and if defined, cobble number, were recorded for each piece of unmodified debitage in the analysis sample. In this way, the debitage can be used to characterize each concentration within the sample and comparisons between concentrations can be made.

\section{Cores}

All cores and core fragments recovered from the site were analyzed, focusing once again on defining lithic reduction scenarios. For instance, patterned flake removals may indicate blade blank or biface production for eventual formal tool production, while unpatterned removals may signal the production of flakes for use as expedient tools. Attributes that can be used to address these questions include discard stage, directionality of flake scars, and number of flake removals. Discard stage addresses the point at which the core entered the archeological record. Choices are: a tested cobble with cortex mostly intact and not more than two or three flakes removed, an operational core such that additional flake removal is possible, an exhausted core, and a core fragment. Direction of flake removal scars was recorded as unidirectional, bidirectional, multidirectional, and indeterminate, as might be the case for small core fragments. The count of flake removals did not include small scars resulting from platform preparation or crushing resulting from flake removal.

Maximum dimension also was recorded using a ring scale graduated in $0.5-\mathrm{cm}$ increments. Cortex type was recorded using the same criteria as was used for the unmodified debitage. Material color and chert type were recorded as described above.

\section{Formal Tools}

Most of the formal chipped stone tools recovered are bifacially worked. These include 
projectile points (i.e., arrow points and dart points) and their preforms, knives and knife preforms, adzes, gouges, wedges, perforators, gravers, choppers, hammerstones, hammerstones/choppers, early-stage bifaces, and indeterminate bifaces. Variables used for all tools are completeness, shape, break type, and edge wear or intentional modification. Maximum length, width, and thickness measurements were also taken for all tools with those dimensions intact. Projectile point measurements also include stem length, blade length, neck width, and base width. Base width was also recorded for knives and all preforms. Finally, the projectile points and knives were related to established diagnostic types.

There is no evidence in this collection to suggest that heat treatment of lithic materials was practiced to improve chipping quality. Tools that show obvious heat alteration, that is discoloration, potlidding, and cracking, constitute only 12 percent $(n=37)$ of the formal lithic tool recovery. This low percentage-along with the observation that most alteration is either partial or so extensive that the tool was fracturedindicate that what heating did take place was postdepositional. Thus, heating was not recorded as a variable but was noted when it occured.

\section{TOOL COMPLETENESS AND SHAPE}

The completeness variable provides a measure of the fragmentation within various tool types. For projectile points and knives, it also describes the break location, which can provide additional evidence for determining manufacture vs. use breaks. Completeness categories are: complete or nearly complete, proximal fragment, stem, medial fragment, distal fragment, distal tip, longitudinal fragment, barb, and indeterminate fragment.

Tool shape is important information in determining associations with diagnostic tool types. Two shape attributes were recorded for projectile points, knives, and their preforms. These attributes are stem edge/base shape and blade edge shape; they were recorded only if the stem or blade is intact or nearly intact. Blade edge shapes are straight, convex, recurved, and concave. Stem edge/base shapes are contracting/contracting, contracting/concave, straight/contracting, straight/ convex, straight/concave, straight/straight, flaring/ straight, flaring/convex, and flaring/concave.

\section{FRACTURE TYPE}

Eight types of fractures, including excavation damage, postdepositional heat damage, and an indeterminate break, were identified within the tool collection from 41MM341. Types that can be associated with manufacturing or tool resharpening include lateral snap, reverse fracture, and perverse fracture. Those fractures characteristic of tool use include impact and stem fractures. The causes of fractures, however, are not always clear. For example, a lateral snap can also be associated with use. The location of the fracture on the tool and the telling signs of other edge damage, or lack thereof, distinguish when the fracture occurred. For knives, which are likely to have been used in a prying fashion leading to a snap break, lateral snap fractures near the proximal or distal ends are considered the result of use unless there is evidence of edge damage near the break. For all preforms, a lateral snap is considered manufacture related. Fracture morphology and other break characteristics that distinguish these fracture types are described below.

A lateral snap bisects the tool at an obtuse angle with the long axis of the tool producing a gentle curving fracture face. This fracture can occur when the force of a thinning blow produces end shock by exceeding the elasticity of the material (Johnson 1979:25). It is considered an indirect fracture, as it can be removed from the point of impact. Experimentation, however, has shown it may also result from a direct side blow (Johnson 1981:25). A perverse fracture is considered a direct fracture that begins at the point of impact and spirals or twists through the tool corresponding to the direction of force (Crabtree 1972:82). This type of break often occurs when attempting to thin a tool or tool preform by removing a mass. A reverse fracture is a direct fracture that occurs during manufacture or resharpening; it removes the bifacial edge opposite the point of impact (Johnson 1979:25).

Impact fractures are defined by a number of end damage characteristics (confirmed by experimentation). This damage includes lateral snap fracture, snap and step fracture, step and hinge fracture, feather and hinge fracture, crushing, and burination, all located at or near the distal tip of a point or knife (see Odell and Cowan 1986:195-212). At the other end of the tool, stem fractures consist of lateral snap or 
shearing. The lateral snap occurs at the stemto-body transition as the tool is broken in its haft. Shearing fractures occur when a tool is twisted in the haft; such a fracture can remove part or all of the stem. Often, a corner or a lateral edge of the stem will break off.

\section{EDGE WEAR AND}

INTENTIONAL MODIFICATION

Edge wear implies damage to a tool edge through use. Such damage can include polish, step fracturing, crushing, microflaking, or a combination of these attributes. Wear and wear patterns on tools provide one line of evidence of tool function that can be used to reconstruct site activities. For instance, extensive polish on the distal tip of a knife and along its lateral cutting edges suggest it was used in piercing and cutting soft material such as hides or vegetal materials. Polish on the proximal end of an adze or gouge may indicate hafting, whereas step fracturing along the working edge suggests use on hard materials such as bow wood.

Some signs of tool function include modification that was intentionally done to refurbish a worn tool edge or as part of the process of putting the first sharp edge on the tool. Signs of this modification are edge grinding and retouch flaking. Edge grinding is usually found on preforms, as it strengthens the edge for thinningflake removal and may signal the tool's transition to the final stage of manufacture. At the other end of the tool's functional life, retouch flaking reflects resharpening, especially on projectile points and knives. Thus, recognition of intentional modification provides evidence for when in its life a tool entered the archeological record.

\section{PROJECTILE POINT AND KNIFE TYPES}

Projectile points recovered from the site include the arrow point types Alba, Perdiz, and Scallorn and the dart point types Darl, Pedernales, and Williams (Table 4-3). The knife and knife fragments recovered from 41MM341 have similarities to the types Friday and Gahagan. Type definitions were drawn from standard sources such as Suhm and Jelks (1962) and selected excavated site collections. The morphological characteristics considered in assigning type include stem and base shape and, where possible, blade shape. In addition, general workmanship and the effects of breakage and reworking were taken into account. Points and knives that do not fit established types and those that are too fragmentary for classification are considered untyped specimens.

\section{Expedient Tools}

A large number of expedient tools, consisting of flakes, chips, and chunks with evidence of use-related damage or minimally retouched along one or more edges, were identified in the debitage recovered. All of these expedient tools were subjected to the same baseline analysis as the unmodified debitage by recording size, flake type, completeness, and cortex percentage for each specimen. These attributes allow comparison to the unmodified debitage to discern whether flake production for expedient use was a goal, and to what extent expedient tools did the job of formal tools.

It is sometimes difficult to distinguish usemodified tools from those minimally retouched to enhance use. This distinction was made based on the idea that larger, deeper, and more-regular flaking denotes intentional retouching and that specific retouch patterns reflect particular usages (Johnson 1997:116-119). A use/retouch pattern was recorded for each tool edge, and the number of utilized edges was recorded for each tool. Patterns were distinguished using lowpower 10x magnification. The presence of polish or other distinguishing characteristics was noted where they occurred in association with the modified edges.

The seven use/retouch patterns defined for this analysis are based on Johnson's (1994:160 $167 ; 1995: 147-151 ; 1997: 114-118)$ work. These patterns are use-modified sawing/cutting, usemodified scraping, retouched scraping, retouched denticulate, retouched spokeshave, retouched graver, and indeterminate use. Wide, short flake-removal scars with hinge or snap terminations define the use-modified sawing/ cutting pattern. These scars are often spaced irregularly along an edge and can occur on both faces of the flake. Johnson's (1997:116) experimentation shows that this use pattern occurs from unavoidable twisting or wiggling of the flake in a deep sawing groove. The use-modified scraping pattern generally occurs along the edge 
Table 4-3. Collections and references used in typological identification of projectile points and knives

\begin{tabular}{l|l|l}
\hline & $\begin{array}{l}\text { Comparative Site } \\
\text { Collection }\end{array}$ & Reference \\
\hline Alba & $\begin{array}{l}\text { George C. Davis } \\
\text { Hoxie Bridge }\end{array}$ & $\begin{array}{l}\text { Shafer 1973 } \\
\text { Bond 1978 }\end{array}$ \\
\hline Darl & $\begin{array}{l}\text { Hoxie Bridge } \\
\text { Loeve-Fox }\end{array}$ & $\begin{array}{l}\text { Bond 1978 } \\
\text { Prewitt 1982 }\end{array}$ \\
\hline Friday knife & Loeve-Fox & Prewitt 1982 \\
& Kyle & Jelks 1962 \\
\hline Gahagan knife & George C. Davis & Shafer 1973 \\
& Hoxie Bridge & Bond 1978 \\
\hline Pedernales & 41MM340 & Mahoney et al. 2003 \\
\hline Perdiz & Kyle & Jelks 1962 \\
& McGuire's Garden & Gadus et al. 2002 \\
\hline Scallorn & Kyle & Jelks 1962 \\
& Hoxie Bridge & Bond 1978 \\
& Pecan Springs & Sorrow 1966 \\
\hline Williams & Youngsport & Shafer 1963 \\
\hline
\end{tabular}

scrape or shave a resilient material. Finally, a retouched graver is a pressure-flaked projection with a tip that shows evidence of polish or a snap fracture. This damage suggests that the projection was used to score or groove a resilient material.

\section{Ground and Battered Stone Artifacts}

Limestone grinding slabs and quartzite hammerstones, abraders of sandy limestone or hematitic sandstone, and a pitted sandy limestone slab make up this category. The abraders are slabs that are tabular and exhibit grinding on at least one surface. The maximum length, width, thickness, and weight were measured for these artifacts, and

of one face of a flake so utilized. The pattern that results can have both hinged and feathered flake terminations, and, though often consistent along an edge, flake scars are generally irregular in size and shape.

Scraping of soft material produces a lowangle edge that is rounded and shows polish. Scraping a hard material such as horn or wood produces high-angle edge nibbling (Johnson 1997:114). Johnson (1997:115-116) also points out that scraping of a hard material such as bone or dry wood can produce a jagged or saw-toothed edge. This suggests that an intentionally retouched flake with a scalloped edge, considered here a retouched denticulate, may have been used in scraping a hard material.

One obvious indication of intentional modification is retouch flaking that establishes an acute edge angle for scraping. Johnson (1994:161) points out, however, that retouched specimens used for scraping often have additional stepped microflaking or crushing along the retouched edge. Consequently, tools having edges with an acute angle with large, regular flaking and those with a moderate angle with crushing and step-fracturing on top of regular flaking are considered retouched scrapers for this analysis. In addition, a flake with a retouched notch into an edge is considered a retouched spokeshave. Again, hinge-terminated microflakes and crushing along the interior edge of the notch suggest that the notch was used to evidence of polish or striations on the working surface(s) was noted. For quartzite hammerstones, weight and a maximum dimension using a graduated ring scale were recorded. Placement of battering on the hammerstones was described, and the presence or absence of stream-rolled cobble cortex was noted. The pitted stone is unmodified except for a single pecked pit. It was measured and weighed, and the dimensions of the pit were recorded.

\section{Vessel Ceramics}

Data recovery excavations produced only four small ceramic vessel sherds. The sherds were sized using a ring scale graduated in halfcentimeter increments, and their thickness was measured. Paste and grog characteristics were determined, and interior and exterior surface treatments were described. One sherd is a rim fragment on which rim orientation and lip characteristics were noted.

\section{Other Materials}

Other materials recovered from 41MM341 consist of modified bones and bone tools, unmodified vertebrate faunal remains, invertebrate faunal remains, macrobotanical remains, burned and unburned rocks, and burned clay. These materials were generally counted or weighed by provenience. 
A small number $(\mathrm{n}=30)$ of modified bones and bone tools were recovered from the Main Block and the initial units. These tool fragments were described as to the element from which they were fashioned and the nature of their modification.

All unmodified vertebrate faunal remains were counted and weighed. Faunal recovery from all unit levels above Level 12 and all features (minus two mixed proveniences) was sent to zooarcheologist Brian S. Shaffer, Ph.D., of the Dallas Museum of Natural History for analysis. The analyzed sample constitutes 96 percent of the animal bones recovered. The results of the analysis are presented in Appendix E.

Invertebrate faunal remains-freshwater mussel shells and land gastropod shells-were abundant at the site. Mussel shells from most proveniences were both counted and weighed. Because only counts were tabulated at the beginning of the excavations, however, weights are not available for Excavation Units 1-47, constituting 23 percent of the proveniences that produced shells. For the distributional analyses presented later in this report, the missing shell weights are estimated based on the data from the proveniences where both counts and weights were recorded. Counts for mussel shells include only whole shells and umbo fragments. Snail shells were only counted, and those counts include whole shells and identifiable fragments. Given the large quantities of mussel and snail shells recovered, samples were selected for analysis to address questions concerning environmental change and resource exploitation by identifying species and the age/size composition of the samples.

Shell samples were analyzed from 7 of the 11 identified mussel shell features (Features $9,10,16,20,21 \mathrm{a}, 21 \mathrm{~b}$, and 24), Rabdotus snail shell Feature 17, and Level 10 of the East Block. The mussel shells from the East Block were analyzed, though they were scattered and not considered a feature in the field, to provide a sample that can be compared with the mussel shells from the Main Block as well as to provide a larger sample from Level 10, which was marked by small discontinuous areas of shells (Feature 24) in the Main Block. Otherwise, the features or parts of features selected for sampling are those where shells were densest and best preserved within each level.
Sampling of a shell-bearing site is an issue that has been debated (see Claassen 1998:99104). The results of this debate suggest that the methods used depend on the nature of the deposit and the proposed questions. Attention has been given to "time averaging" in recognition that a sample could represent several episodes of deposition that took place over an unknown period of time. Given that the shell feature samples from 41MM341 would be compared on the basis of analysis units representing a couple hundred years of occupation each, questions of time averaging were not considered critical to this analysis. Otherwise, the questions posed in this analysis depend on the recovery of samples with sufficient quantities of whole shells that could be identified to species and sized to determine shell age at death. Consequently, an effort was made to select large enough samples from each feature to provide comparable samples of whole shells. Since the shell features were horizontally extensive but vertically limited to less than $10 \mathrm{~cm}$, and often no more than two or three shells, in thickness, the samples selected had to be horizontally extensive. They consist of 40 67 percent of the feature areas as defined in the field (Table 4-4). As such, each feature sample consists of two to five generally contiguous unit/ level proveniences for a total of 33 samples. These samples were selected after the full extent of the feature and the state of preservation of the shell within the feature was known. In the case of Features 10,20, and 24, the samples include shells recovered from the same levels but not recognized as parts of the features in the field.

Table 4-4. Total area and sample area of features selected for shell analysis

\begin{tabular}{c|c|c|c}
\hline Feature & Level & $\begin{array}{c}\text { Total Area } \\
\left(\mathrm{m}^{2}\right)\end{array}$ & $\begin{array}{c}\text { Sample Area } \\
\left(\mathrm{m}^{2}\right)\end{array}$ \\
\hline 9 & $8-9$ & 6.0 & 4.0 \\
10 & 6 & 4.5 & 2.5 \\
16 & $8-9$ & 5.0 & 2.5 \\
17 & 8 & 3.5 & 1.5 \\
20 & $9-10$ & 5.0 & 2.4 \\
$21 \mathrm{a}$ & $6-7$ & 6.0 & 3.0 \\
$21 \mathrm{~b}$ & 7 & 7.0 & 2.8 \\
24 & 10 & 1.5 & 1.0 \\
East Block & 10 & 12.0 & 12.0 \\
\hline
\end{tabular}


Most of the shell samples were recovered by water screening sample matrix. Hand collection of samples initially was attempted but was abandoned as the excavators broke many shells trying to remove them individually from the hard soil. In addition, at least one sample per feature was processed by flotation (two flotation samples were analyzed from Feature 17), and the shells from a total of nine samples were included in the analysis. The flotation samples provide data on small snails often lost in the 1/4-inch screening process. Recovery from flotation samples is especially critical to questions concerning the utilization of Rabdotus, since flotation is the best way to recover all size classes of this snail. Analysis of the invertebrate remains was done by Karen M. Gardner of Prewitt and Associates, and the results are presented in Appendixes A and B.

Macrobotanical remains recovered include charcoal, nutshells, and other charred plant materials, including seeds and bulbs. Materials recovered from the 1/4-inch screens were weighed by provenience. Though most of this recovery was wood charcoal, when burned nutshells, burned bulbs, or seeds were observed, they were separated and counted. A total of 21 unit/level proveniences that yielded either bulb or nut remains were selected for analysis. They consist of 15 proveniences from Levels 7 through 9 of the Main Block and 6 proveniences from Level 8 in the South Block. The South Block samples generally surrounded the processing pit features identified there. The Main Block samples were recovered from above and below mussel shell Features 21a and $21 \mathrm{~b}$ as well as at the north end of the Main Block adjacent to surface and pit hearth Features 12, 39, 40, 41, and 44. The bulk of the macrobotanical materials analyzed, however, are from flotation samples from 50 feature proveniences.

Depending on feature size, a quarter to a half of most nonshell features (i.e., surface hearths, pit hearths, burned rock concentrations, processing pits, possible postholes, and indeterminate features) was collected as flotation samples and processed. However, Feature 50, consisting of a series of interconnected processing pits in the South Block, deviated from this collection norm. This feature's large size and multiple use episodes made it difficult to identify individual pits until the feature was almost completely excavated. As a result, a series of 11- to 25-liter flotation samples were taken from near the bottom of each of the five identified pits with at least one sample coming from each pit. Also, samples were taken from the upper parts of Pit 4 of Feature 50 and nearby Feature $49 \mathrm{~b}$. These two samples consisted of $50 \times 50 \times 10-$ $\mathrm{cm}$ sections from Level 8 taken before individual pit outlines could be distinguished. In all, the macrobotanical remains from 36 out of the 42 flotation samples collected from the nonshell features were analyzed (13 analyzed samples came from 9 processing pits). Samples not analyzed had scant flotation recovery. In addition, for all nonshell features, materials recovered from the parts of the features not processed by flotation were sent for analysis. These 1/4-inchscreen feature samples total 19.

Flotation samples from horizontally extensive features such as mussel and Rabdotus shell lenses were collected across the feature extent. These samples correspond to the densest areas of shell and were collected using unit and level designations within the features. This sampling technique resulted in two to three samples collected from each of the larger shell lenses (a flotation sample was not collected from Feature 10 as initially defined east of Trench 4). In all, 15 samples were collected from nine shell features, and the macrobotanical recovery from all of the samples was analyzed. Leslie Bush, Ph.D., of Austin, Texas, completed this analysis, and her results are presented in Appendix G.

A prodigious amount of burned and unburned rocks was recovered from both feature and nonfeature contexts. These rocks were counted and weighed by material type and include chert, quartzite, limestone, petrified wood, hematite/limonite, and conglomerate. All of these materials likely came from the Little River either as gravel bed deposits or as bedded materials exposed by the river. Most of these rocks, even the limestone, have the battered/smoothed exterior of a stream-rolled cobble. Identifying burning on different material types can be challenging. Four often-used criteria for identifying burning were employed. These are: evidence of surface cracking, crazing, or spalling; angular fracturing; oxidized reddish or blackish color change; and friable exterior surface. In addition, burned rock shatter, small chunks and chips of stone displaying evidence of cracking, crazing, or spalling, were counted and weighed as indeterminate material type. 
Burned clay was also extensive across the site and concentrated within features. Burned clay is yellowish brown to reddish gray with a hard, but friable, earthy texture. Few stick and grass impressions were noted in the burned clay, and their small number suggests that they are fortuitous and not indicative of clay used as daub. Burned clay from most proveniences was weighed. Because only counts were tabulated at the beginning of the excavations, however, weights are not available for Excavation Units $1-47$, constituting 10 percent of the proveniences that produced burned clay. For the distributional analyses, weights were estimated where needed using an average derived from count and weight data from 91 proveniences. 


\section{GEOMORPHIC SETTING}

Site 41MM341 is situated on the north side of the Little River valley below the surface of the floodplain, which stands ca. 6-7 $\mathrm{m}$ above the channel. Floodplain soils are mapped as calcareous clayey Mollisols of the Frio series and Vertisols of the Tinn series (Mahoney et al. 2003:11; Nordt et al. 2003:75). The floodplain surface in the vicinity of 41MM341 is marked by a number of sloughs. The sloughs transport floodwaters that spill out of the main channel during floods (Nordt et al. 2003:78). These sloughs cut across the inside of large meander loops located at valley constrictions formed, in the case of the project area, by Pleistocene terraces. The constrictions serve as funnels discharging large volumes of high-velocity floodwaters through the sloughs, which merge and diverge before re-entering the main channel, and into broader portions of the valley downstream. Site 41MM341 is situated inside a larger meander loop of the main channel, and more specifically on the outside of a meander loop of a slough, between the slough and the Little River channel (Figure 5-1).

Below the floodplain surface at and near the project area is ca. 6 to $12 \mathrm{~m}$ of late Holocene alluvium resting on a bedrock valley floor of Eocene Midway Group shales (Nordt et al. 2003:80-82) (Figure 5-2). Earlier investigations at 41MM340 and 41MM341 (Nordt 2001; Nordt et al. 2003) revealed that the late Holocene alluvium consists of three unconformably bound alluvial units. Deposition of the earliest of the three units, Unit 1, began before 4390 B.P. and continued until ca. 1270 B.P. (or probably a little earlier, based on radiocarbon dates obtained from the overlying deposits during the excavations reported here). At that time, deposition slowed significantly resulting in formation of a buried A-Bk soil profile in the upper overbank facies of Unit 1. As the channel migrated southward across the valley, high-magnitude floods topped the floodplain and cut the sloughs into the floodplain surface. Subsequently, the sloughs slowly filled with clayey sediments representing Unit 2. Unit 2 sediments also cap the pedogenically altered sediments of Unit 1 preserved between the sloughs, and they contain the cultural materials targeted during data recovery excavations at 41MM341.

The largest and most topographically visible slough in the project area can be traced from cutbank exposures on the river ca. $3 \mathrm{~km}$ upstream from the current bridge across the floodplain surface where it meanders between $41 \mathrm{MM} 340$ and 41MM341. It is possible that this slough represents a tributary channel that was later pirated by the modern meander loop, or even the Little River main channel which later avulsed to its modern position. Regardless, by about 1300 B.P. this slough and the smaller one south of it on the north edge of 41MM341 probably were abandoned and filling with Unit 2 sediments (Nordt et al. 2003:86). By 500 B.P., the Little River channel became entrenched at or near its current location (Nordt et al. 2003:84). This resulted in less-frequent flooding of the floodplain surface, decreased slough sedimentation, and confinement of deposition of Unit 3 to the margins of the river channel and as a thin mantle covering portions of the floodplain surface.

The soil-stratigraphy at 41MM341 was examined throughout the trench profiles. In his previous investigations, Nordt (2001) noted that each of the three Holocene-age alluvial units at the site displayed soils. During the current investigations, the soil imprint on the top of 


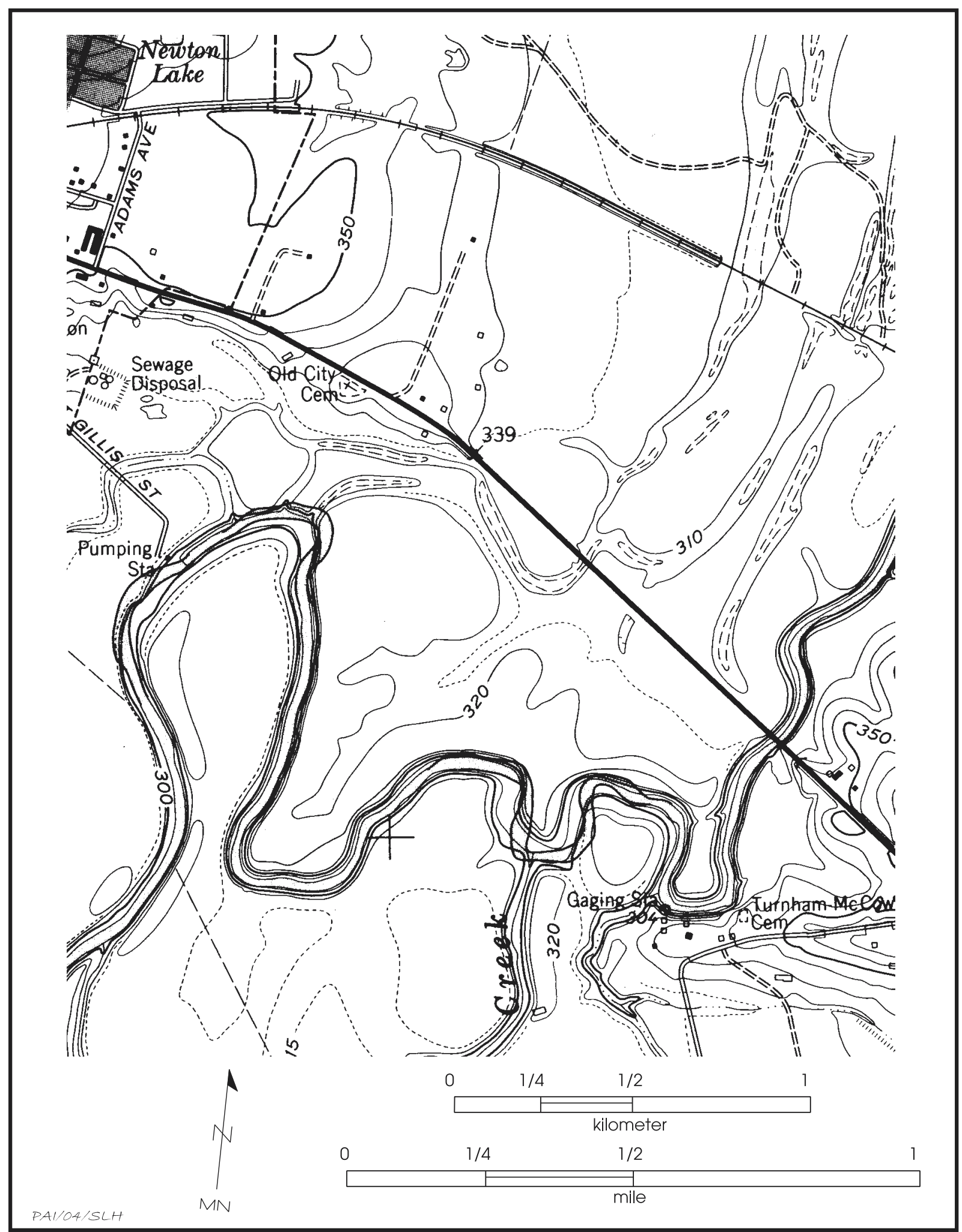

Figure 5-1. Topographic map of the $41 \mathrm{MM} 341$ project area (select copies of the report contain a pocket with Figure 5-1 showing the locations of 41MM341 and 41MM340). 


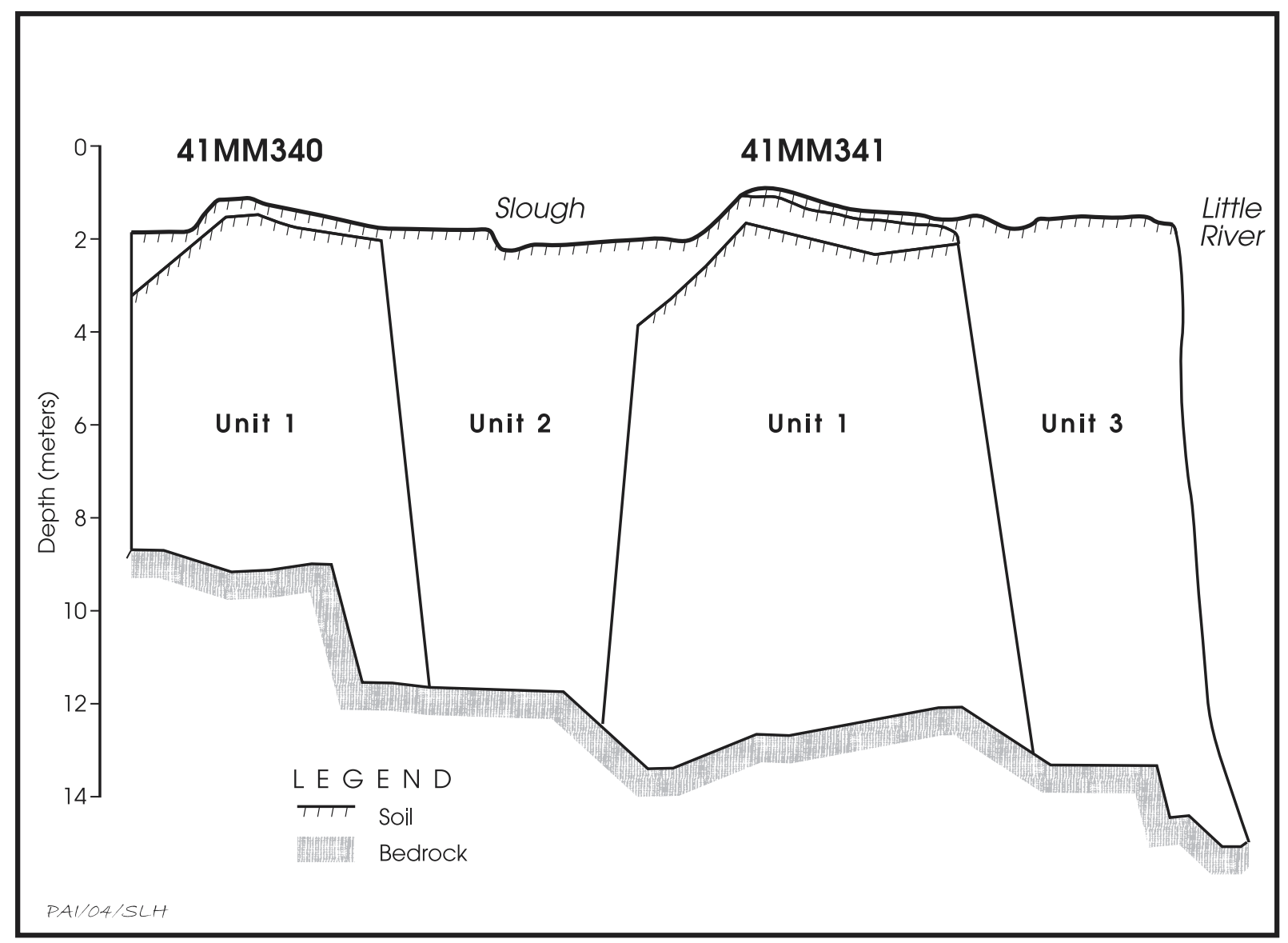

Figure 5-2. Schematic cross section of the Little River valley near 41MM341 (adapted from Figure 8-4 in Nordt et al. 2003).

Unit 1 was observed at the base of four of the backhoe trenches at ca. $140 \mathrm{~cm}$ below the surface. This soil appeared as a dark gray (10YR $4 / 1$ ) to very dark gray (10YR 3/1) clay with few carbonate filaments and moderate medium angular blocky structure. A soil capped by sediments that are slightly, or not at all, pedogenically modified also was observed in Unit 3 during the current investigations. This more-recent soil appeared as a gray (10YR 5/1) to dark gray (10YR 4/1) silty clay to clay with weak medium blocky angular structure.

Nordt (2001) also defined a soil imprint capping Unit 2, however, the current investigations found it difficult to delineate this soil, and in many cases it appears that this soil is indistinguishably welded to the overlying soil in Unit 3. Other than the sporadic presence of a discrete lens of cultural materials that may represent a quasi-stable floodplain surface, it is difficult to recognize any criteria to distinguish two soils. For example, Nordt's (2001) profile description of Backhoe Trench 15 (Backhoe Trench 3 in the current investigations) denotes the A horizon of Unit 3 at 24-53 cmand the A horizon capping Unit 2 at 53$79 \mathrm{~cm}$.

Aside from the presence of a lens of cultural materials, the current investigations did not observe a consistent horizon or stratigraphic boundary at or around $53 \mathrm{~cm}$ that would serve to delineate these two soils. Hence, for the area of 41MM341 investigated it is more appropriate to interpret the soils capping Units 2 and 3 as a single thick cumulic A horizon, with the overall Backhoe Trench 3 profile representing an AC-2Ab-2Bwkb-3Akb sequence. The AC horizon (ca. $0-40 \mathrm{~cm}$ ) is imprinted on Unit 3 and is a dark gray (10YR 4/1) to gray (10YR 5/1) silty clay. The $2 \mathrm{Ab}$ horizon (ca. $40-85 \mathrm{~cm}$ ), which contains the bulk of the cultural deposits targeted during the data recovery excavations, is imprinted on Unit 2 and is a dark gray (10YR 4/1) to very dark gray (10YR 3/1) silty clay to clay. 
The underlying 2Bwkb horizon (ca. 85-140 cm), containing the lowermost part of the targeted cultural zone, is a dark gray (10YR 4/1) clay. The $3 \mathrm{Akb}$ horizon (ca. $140+\mathrm{cm}$ ) is imprinted on Unit 1 and is a dark gray (10YR 4/1) to very dark gray (10YR 3/1) clay.

The geomorphic picture at $41 \mathrm{MM} 341$ is consistent with other regional data on cumulic A horizons forming on late Holocene alluvium around 1500-1000 B.P. and containing archeological remains associated with occupations during the late part of the Late Archaic period and the early to middle parts of the Late Prehistoric period (e.g., Mehalchick et al. 1999, 2000; Nordt 1995). The mechanisms that triggered this apparent regional phenomenon are not clearly understood, but climatic shifts cer- tainly may have been involved (see Bousman 1998).

Overall, it appears that the occupation of 41MM341 took place in the absence of long-term floodplain stability, as lenses of cultural materials are present throughout unmodified (pedogenically) portions of Unit 2 and the cumulic A horizon that is imprinted on Unit 2. In other words, there is little correlation between long-term floodplain stability and prehistoric use of the locality. Nordt et al. (2003:94) noted this based on their work at nearby site 41MM340 when they stated that "these dynamic episodes were of sufficiently short duration that they never prevented the reoccupation of the site for periods sufficiently long to be measured by radiocarbon assays." 


\section{CULTURAL FEATURES}

Fifty-five cultural features were identified at 41MM341, including a complex of 5 pits recorded under one feature number and the 5 features found during testing (Figure 6-1). Not included in this total are 3 postholes associated with a modern fence marking the edge of the existing right of way found in the main block. The 55 features are described below by feature type, which is defined based on morphology and content. These are surface hearths $(n=15)$ (Features 22 and 26 form one hearth), pit hearths $(\mathrm{n}=5)$, processing pits $(\mathrm{n}=10)$, shell lenses $(\mathrm{n}=12)$, burned rock concentrations $(\mathrm{n}=6)$, possible postholes $(\mathrm{n}=2)$, and type indeterminate $(\mathrm{n}=5)$. Table $6-1$ summarizes the characteristics of these features, while Table $6-2$ provides a summary of the materials recovered from them. The latter part of this chapter addresses 10 concentrations of lithic reduction debris that appear to represent discrete episodes (or sets of episodes) of stone tool production. These were not designated as features in the field, but they are described here because they are like features in that they represent spatially restricted loci of particular activities.

\section{SURFACE HEARTHS}

Surface hearths are the most common feature type identified (Features 1, 6, 8, 11, 12, 22/ $26,25,30,35,40,41,43,44,46$, and 47). The hearth locations are concentrations of burned clay and/or ash, and a few such as Features 12 and 35 display reddening of the sediments. All are generally oval or amorphous in plan view and flat bottomed in cross section (Figures 6-2 through 6-4). They vary in size, with long axes ranging from 25 to $180 \mathrm{~cm}$ and depths ranging from 2 to $15 \mathrm{~cm}$. Most of the hearths were in the Main Block on top of or adjacent to the shell lenses (see Figure 6-1). One hearth (Feature 1) was identified in testing Block 1, also near a shell lens. Another hearth (Feature 6) in the southernmost initial unit (Excavation Unit 7) appears isolated. Feature 6 was identified in Levels 10 and 11 and may be associated with the earliest occupation of the site.

Other burned materials, though often substantial in units adjacent to these hearths, were generally limited in direct association. This suggests that the hearths are disturbed to some degree, perhaps by flooding or reoccupation, with associated materials scattered around them. For example, Features $8,11,12$, and 46 produced few or no burned rocks (see Table 6-2), but the unit levels surrounding them produced 300 to $1,000 \mathrm{~g}$ or more of burned rocks. Burned rock shatter was also limited within the features, though small quantities often were recovered from the levels containing the hearths or from adjacent units. Feature 11 produced no shatter, but 358 pieces came from the level in which the feature was found. Charcoal recovery from these features is also minimal with a total of $1.9 \mathrm{~g}$ for all 15 hearths. Other artifacts directly associated with these hearths are also minimal. All of these hearths together produced only 239 pieces of debitage. Also, a burned arrow point stem fragment-possibly Alba-was recovered from Feature 47, an early-stage biface fragment came from Feature 44, an expedient tool from a usemodified scraper came from Feature 22/26, and a retouched scraper was recovered from Feature 35.

Analysis of the charred plant materials recovered from 1/4-inch screens and flotation samples from these hearths indicates that a 


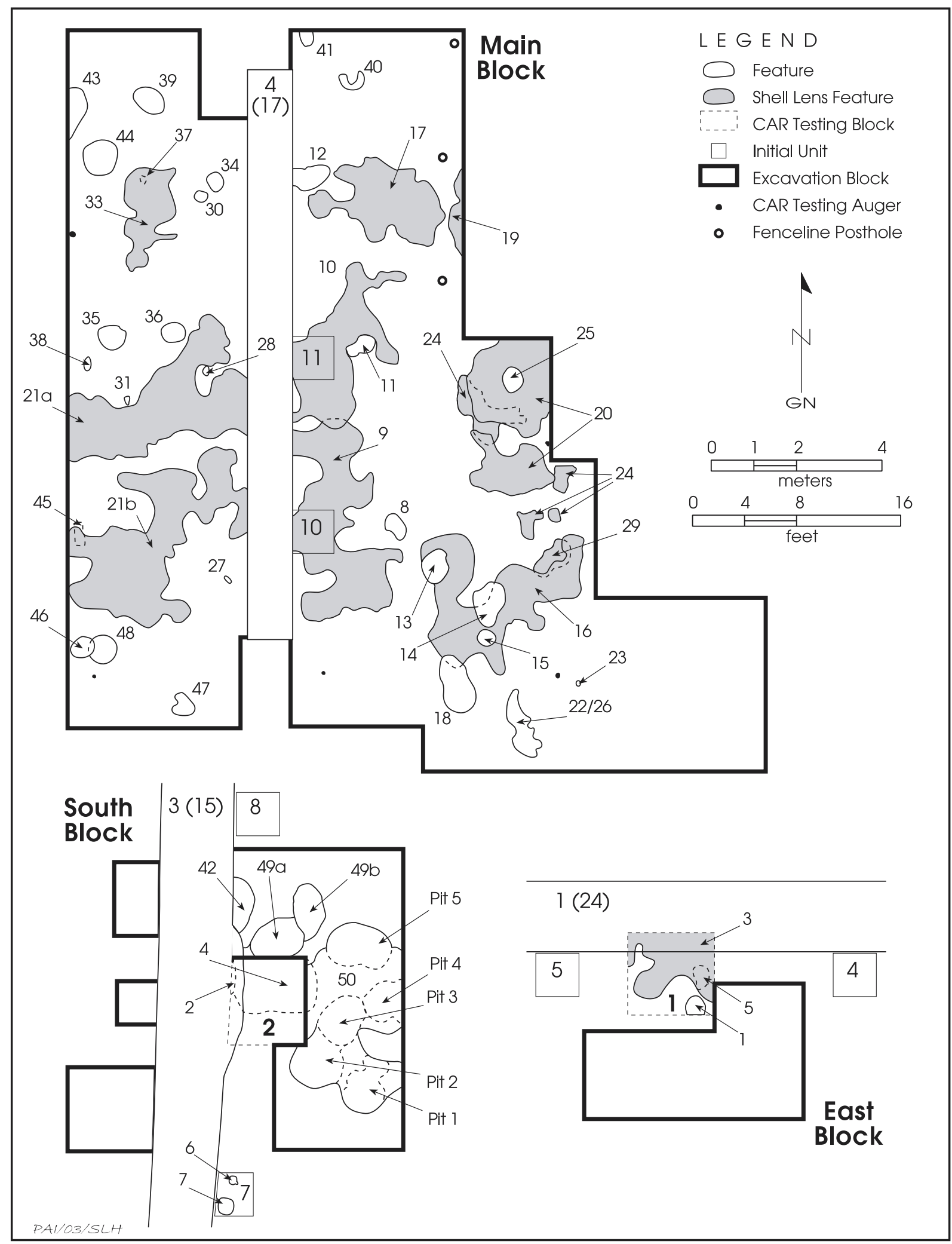

Figure 6-1. Plan of the excavations showing the locations of the cultural features. 


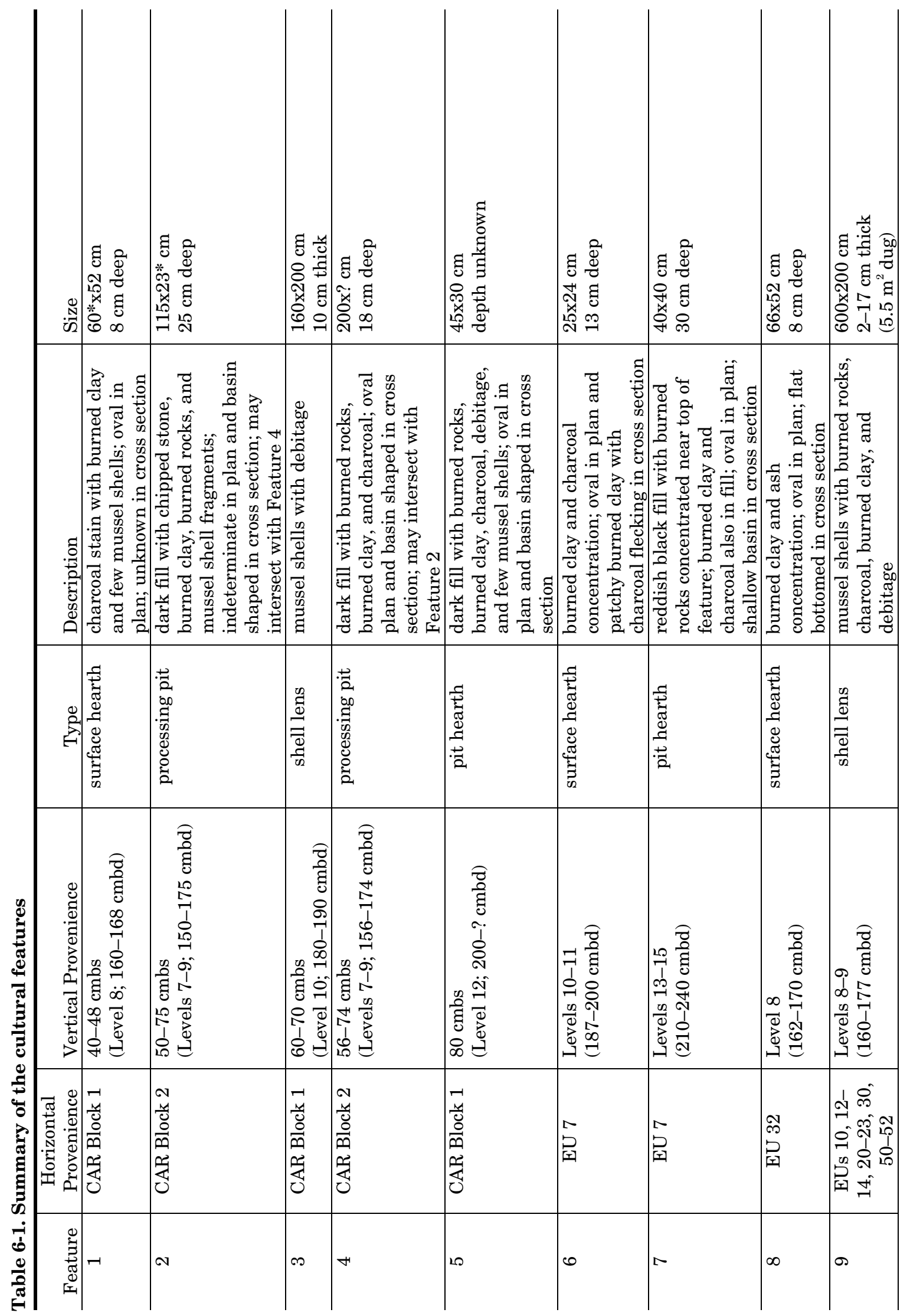




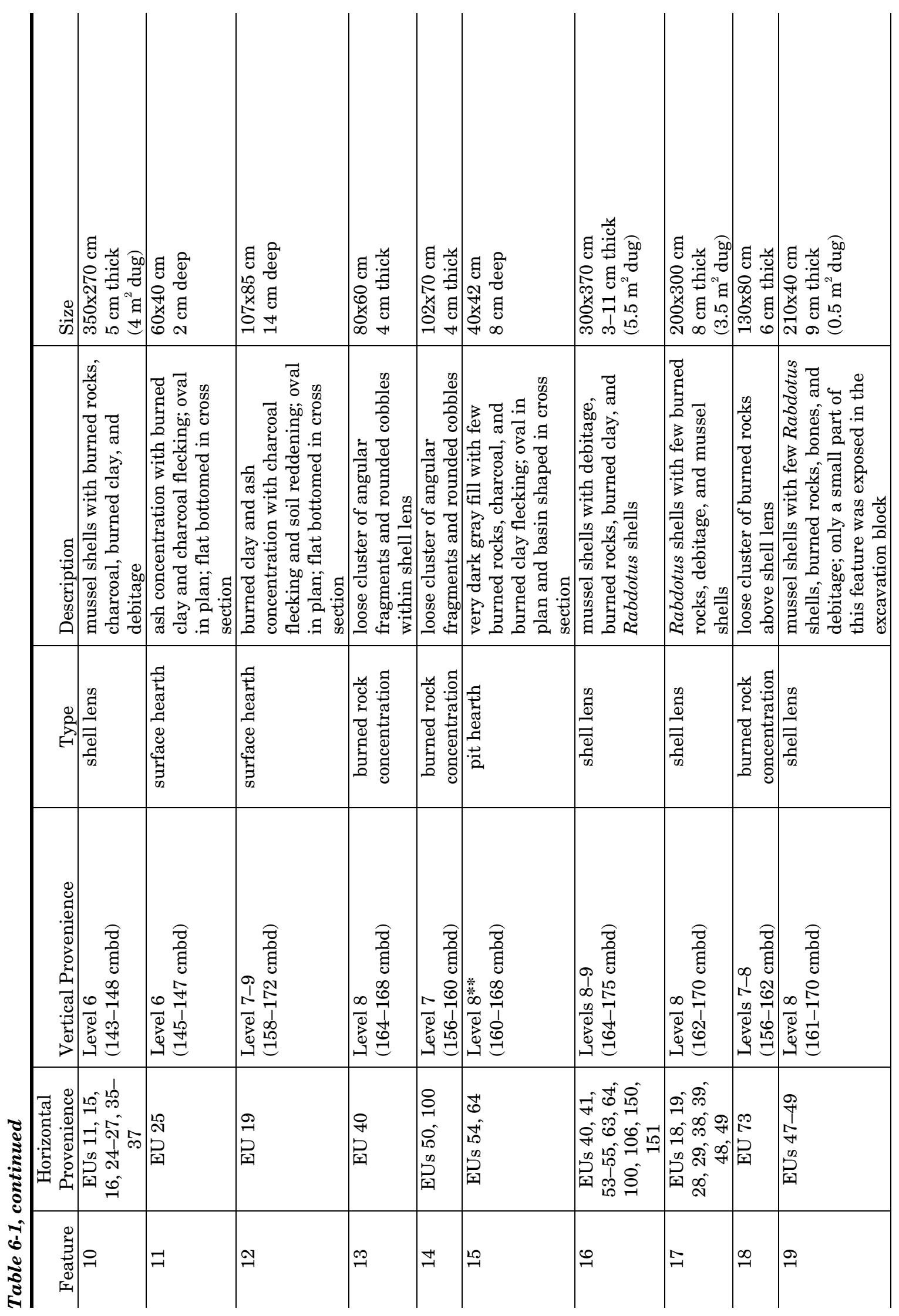




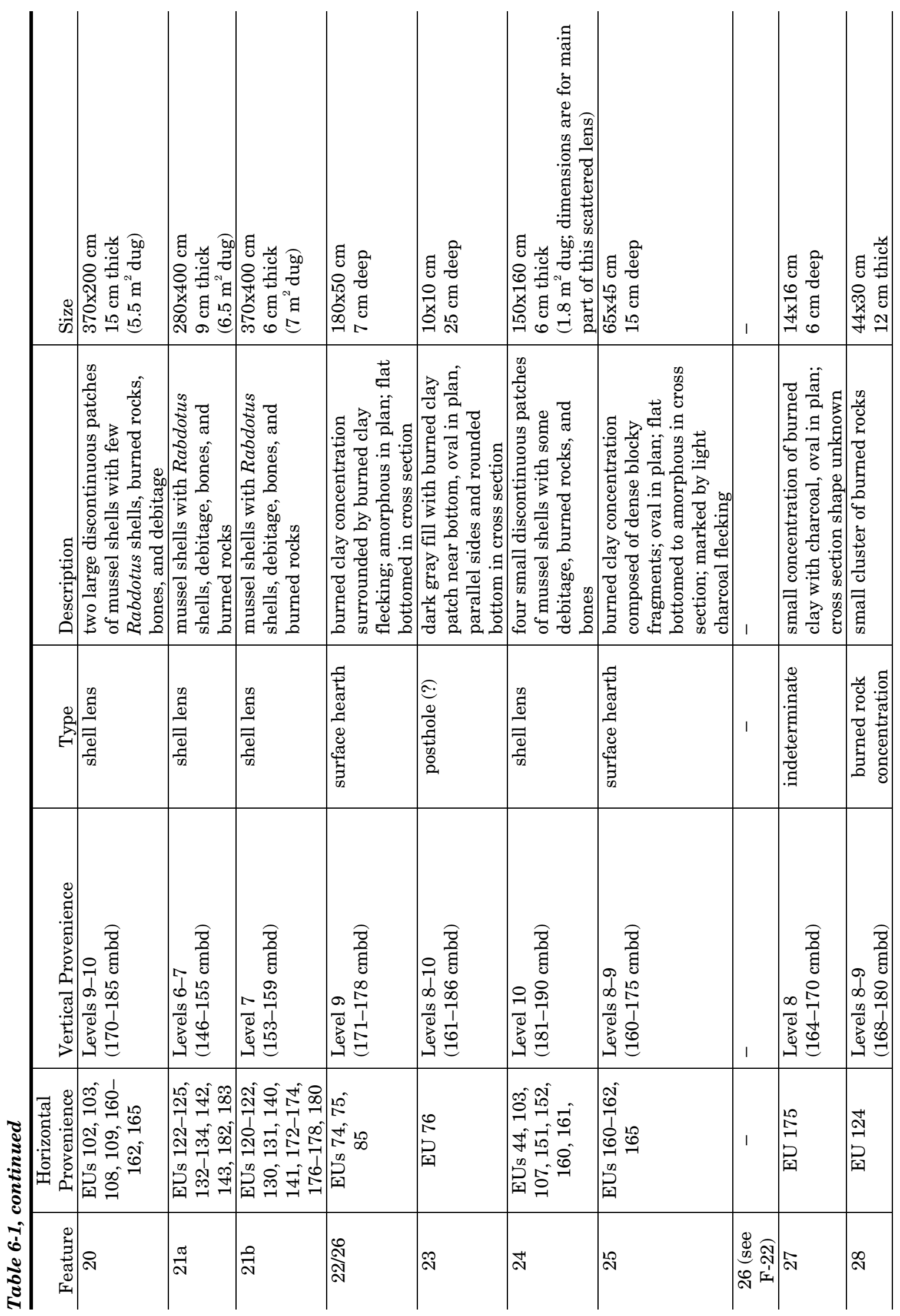




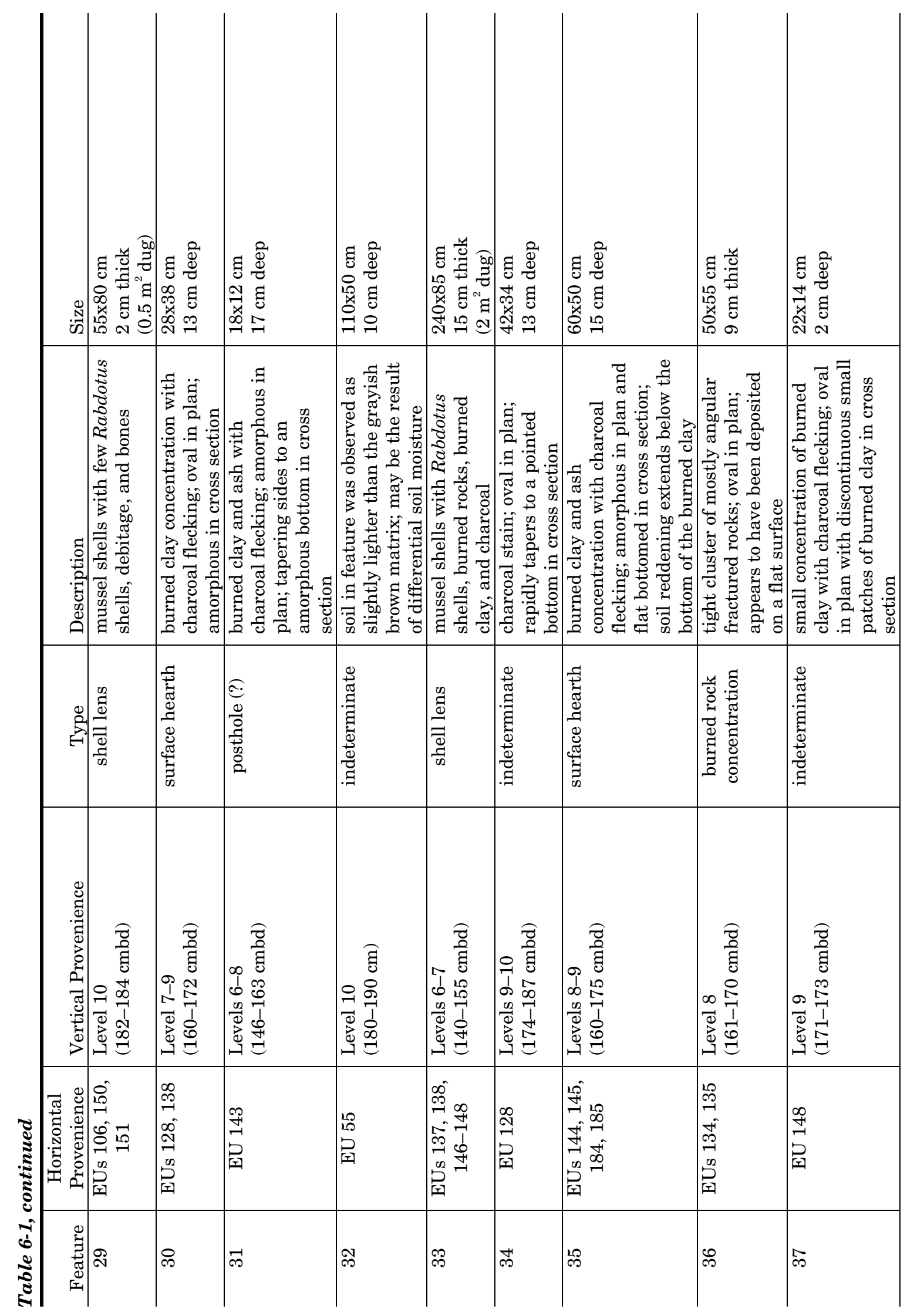




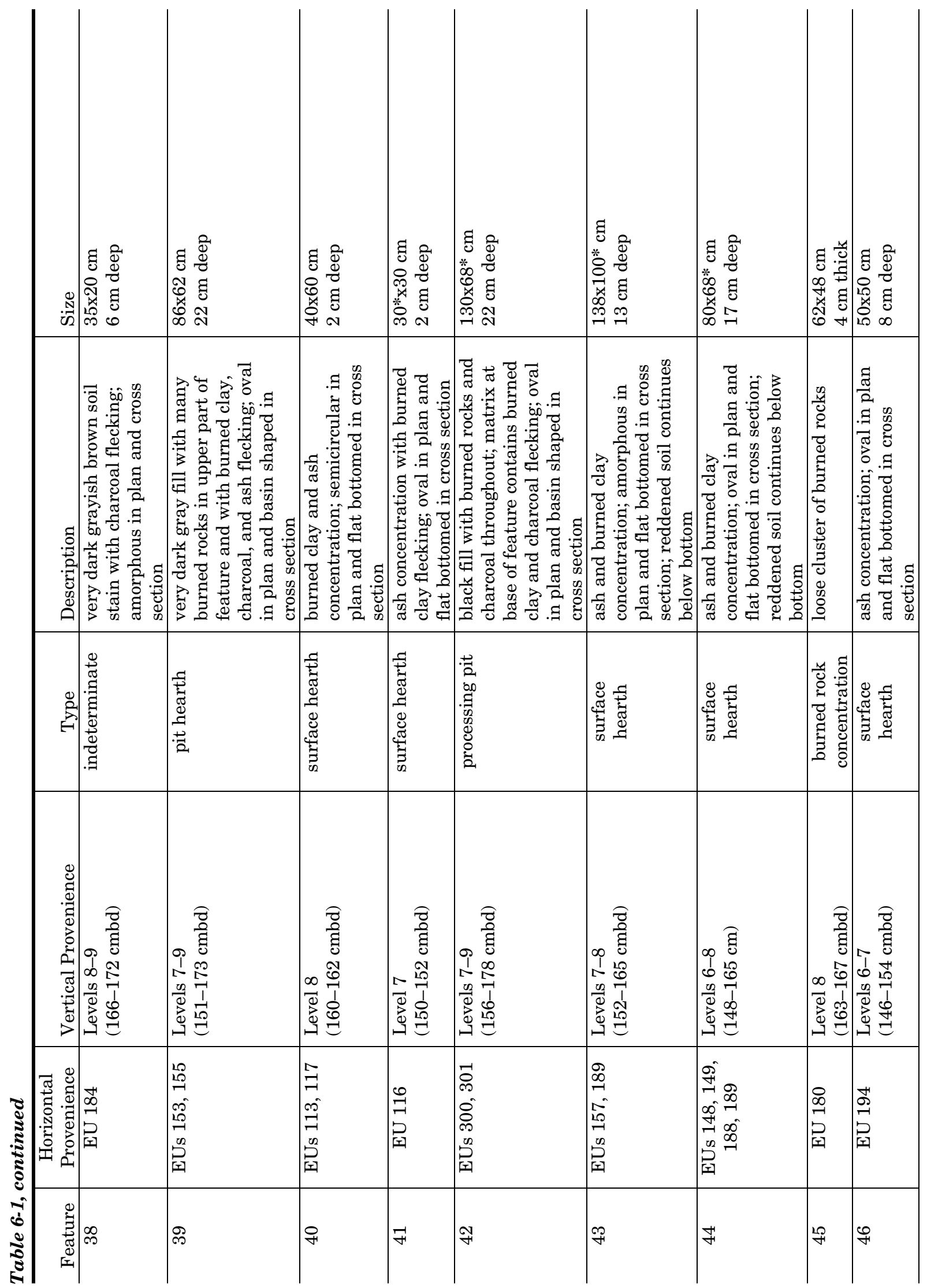




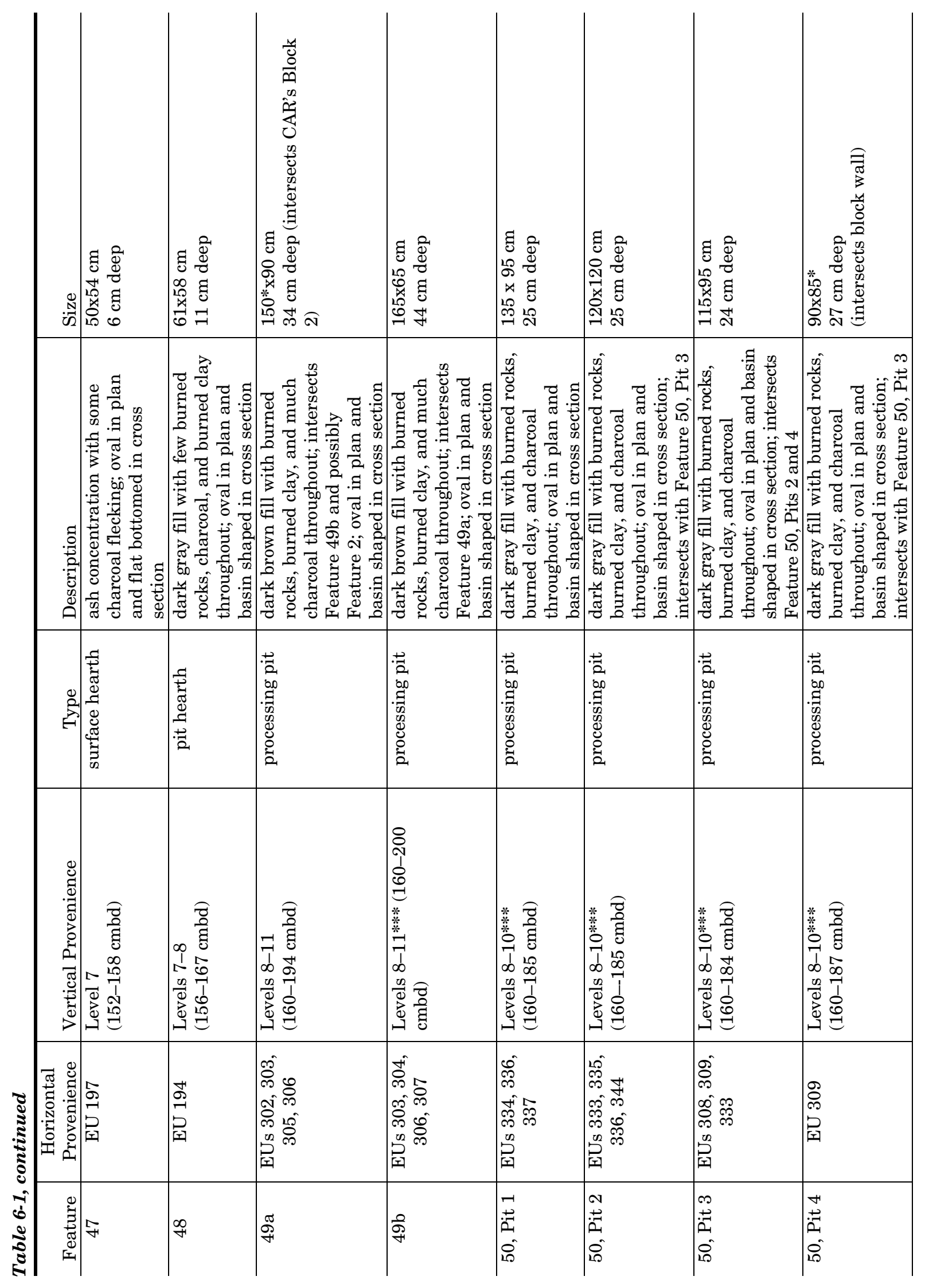




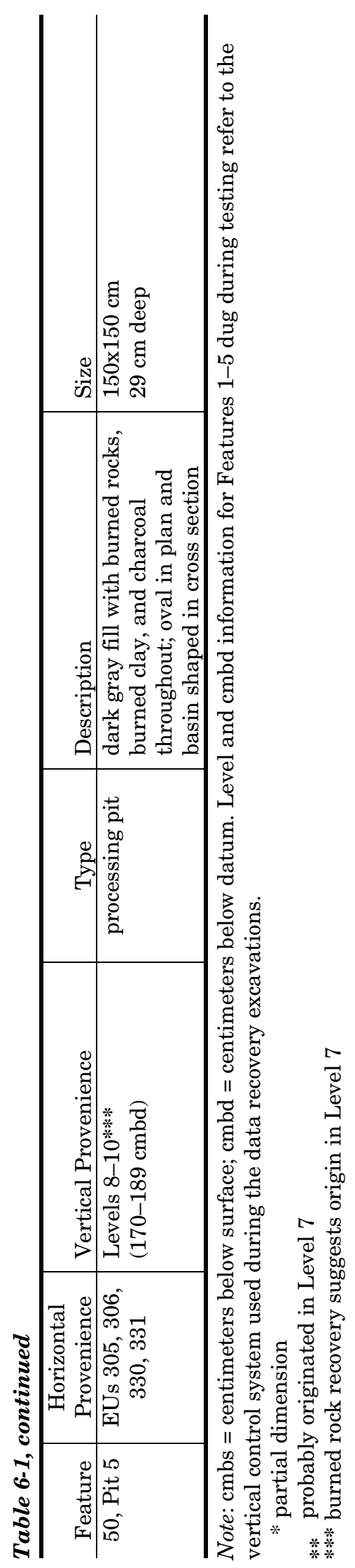




\section{Data Recovery Excavations at the J. B. White Site}

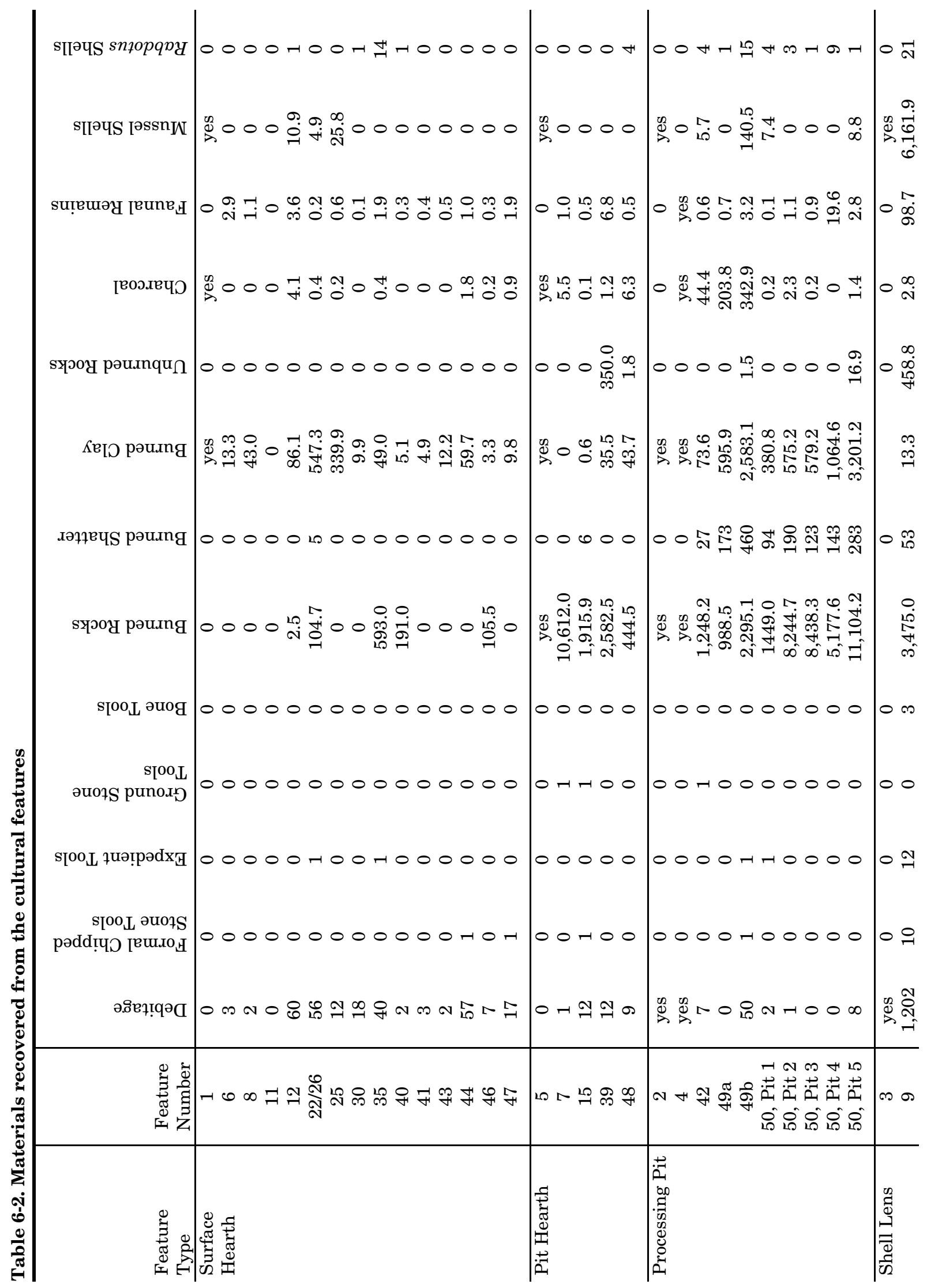




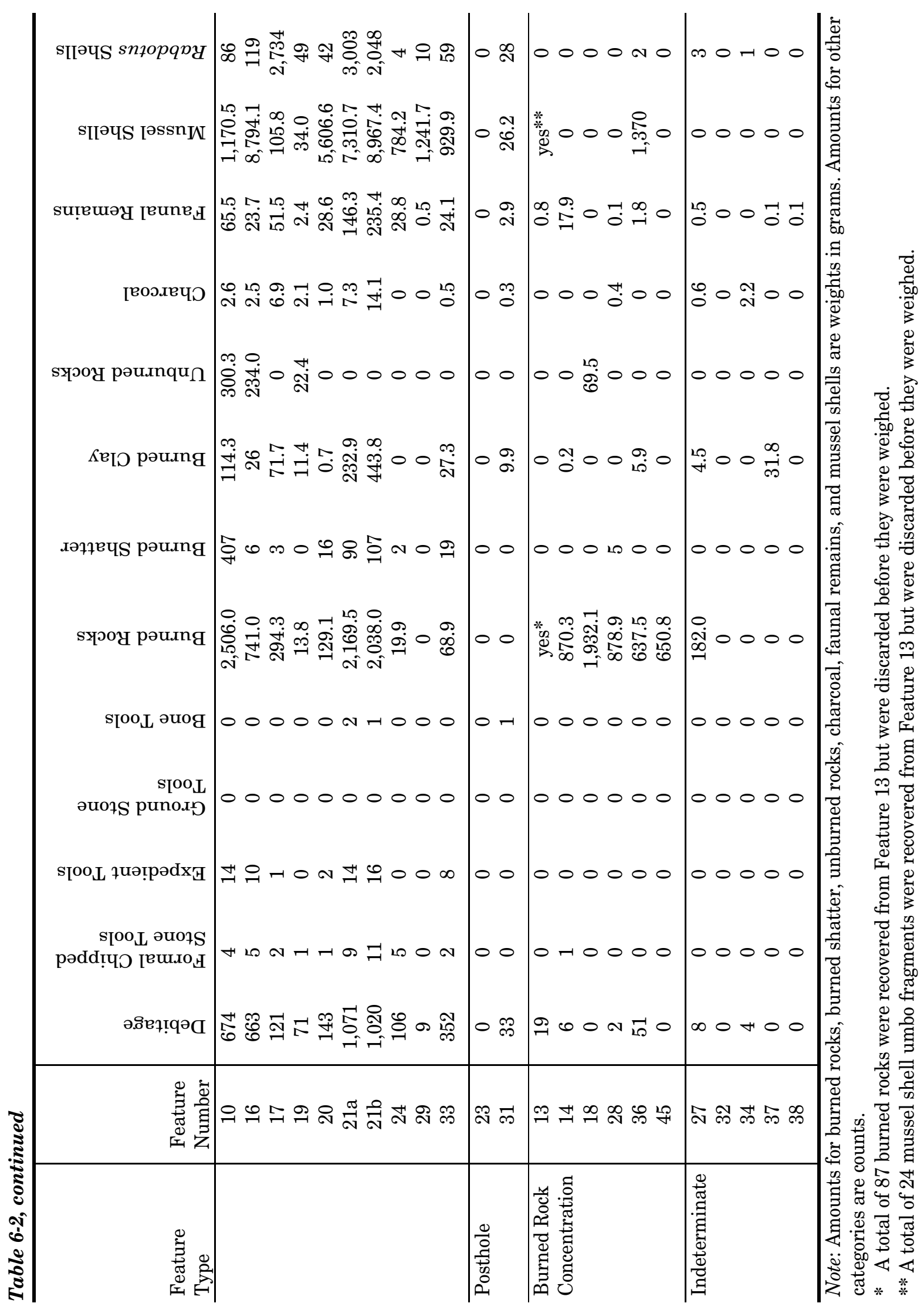


Data Recovery Excavations at the J. B. White Site

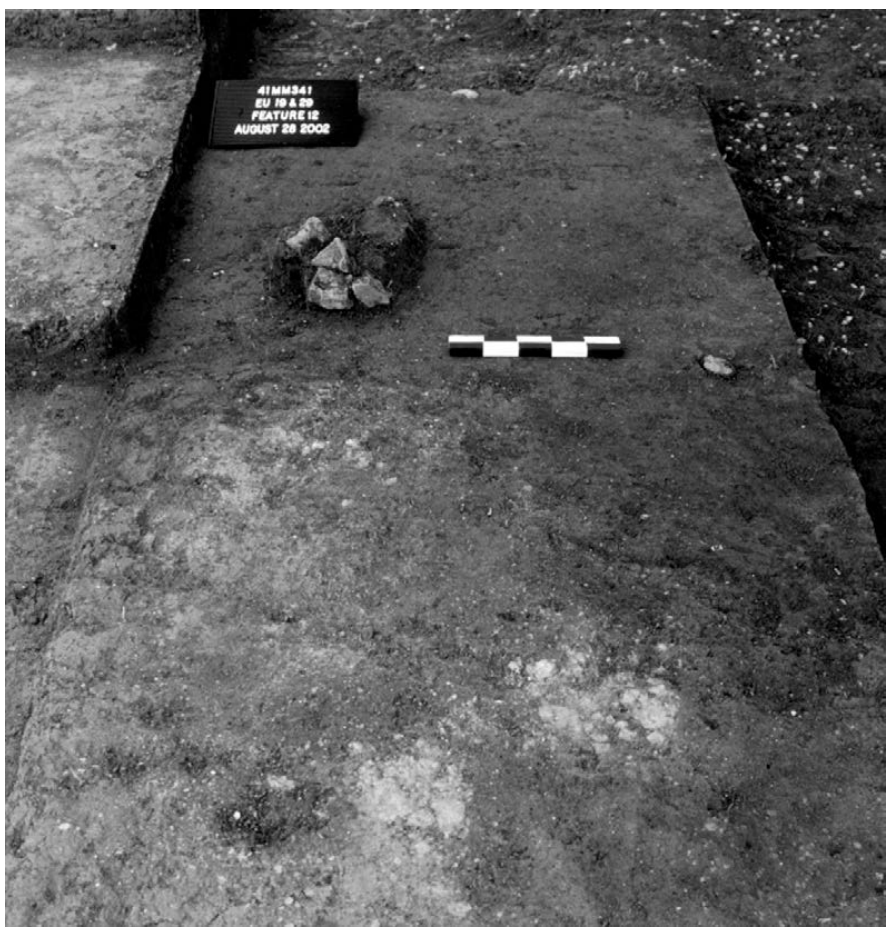

a

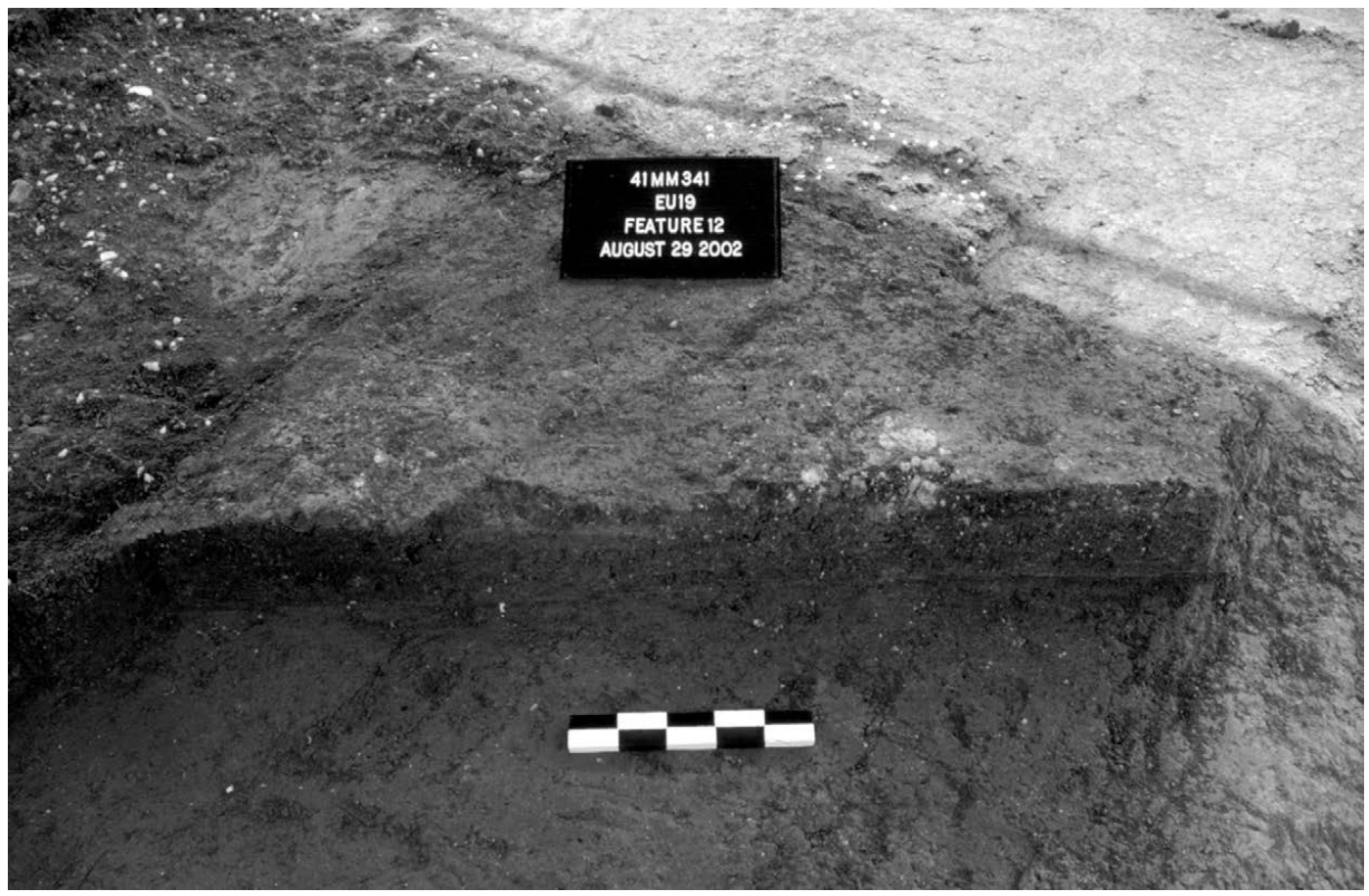

b

Figure 6-2. Surface hearth Feature 12, Level 7. (a) Plan view; and (b) cross section. 


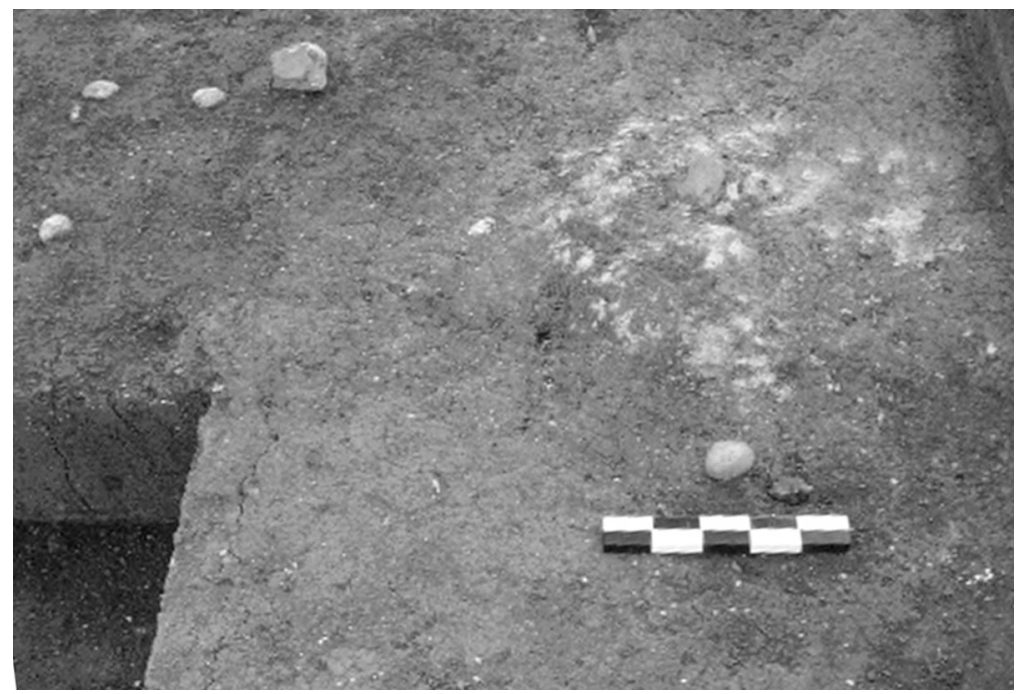

a

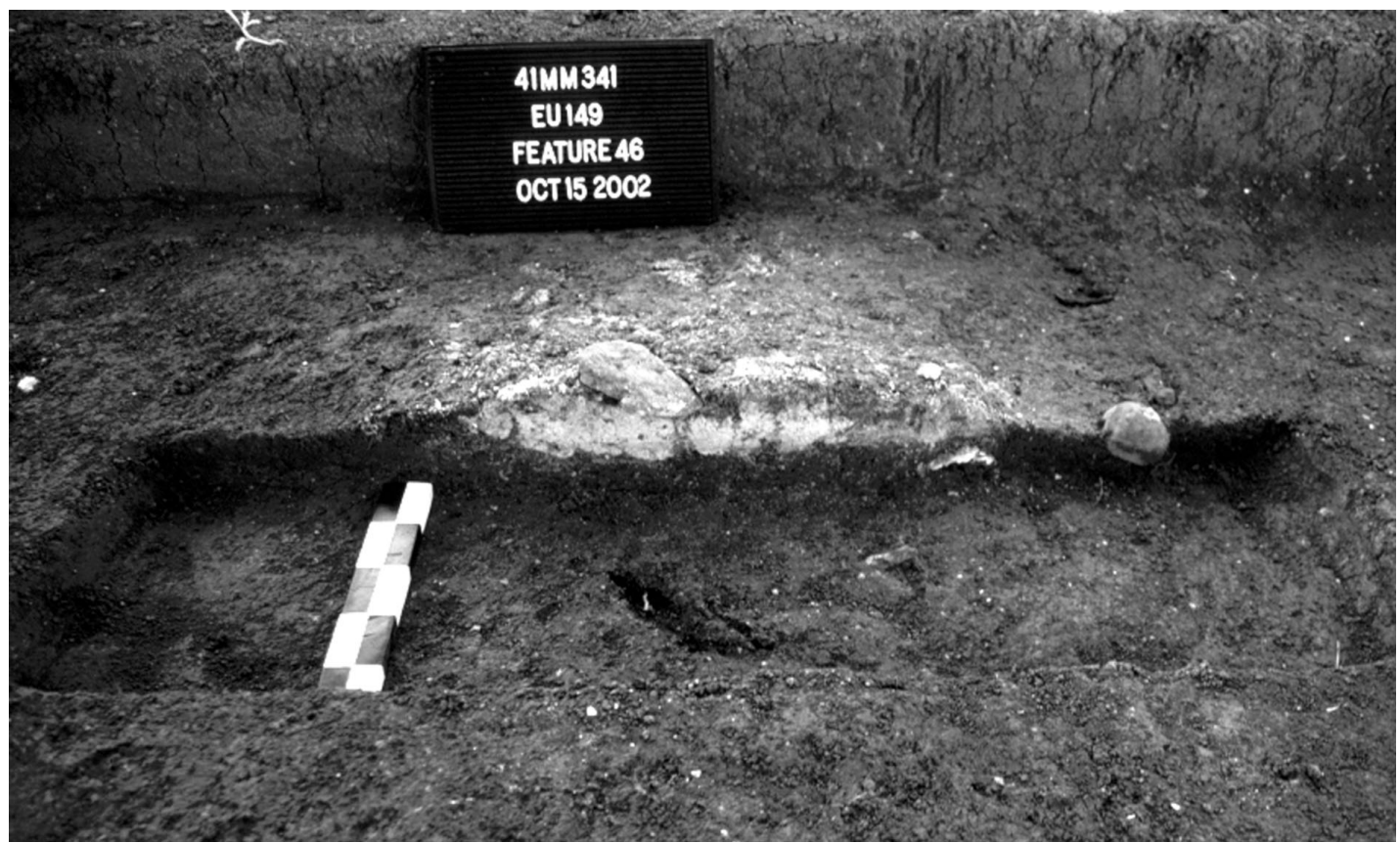

b

Figure 6-3. Surface hearth Feature 46, Level 6. (a) Plan view; and (b) cross section.

variety of woods were used as fuel. Woods identified are oak, white oak, red oak, box elder, box elder/maple, maple/holly, plum/cherry, hickory/ pecan, ash, persimmon, honey locust, hackberry, and hard elm (see Appendix G). Though flotation samples were processed from 12 hearths, only 5 samples produced other identifiable charred plant remains. Small amounts of hickory nutshells were recovered from Features $6(0.13 \mathrm{~g}), 25(0.01 \mathrm{~g}), 41(0.01 \mathrm{~g})$, and $46(0.02 \mathrm{~g})$. Feature 46 also produced $0.59 \mathrm{~g}$ of acorn meat and $0.06 \mathrm{~g}$ of acorn shells. Feature 44 differed in that it produced $0.01 \mathrm{~g}$ of probable Allium/ Nothoscordum bulb and $0.02 \mathrm{~g}$ of unidentifiable bulb remains. Feature 35 was the only hearth to produce marshelder $(<0.01 \mathrm{~g})$. 


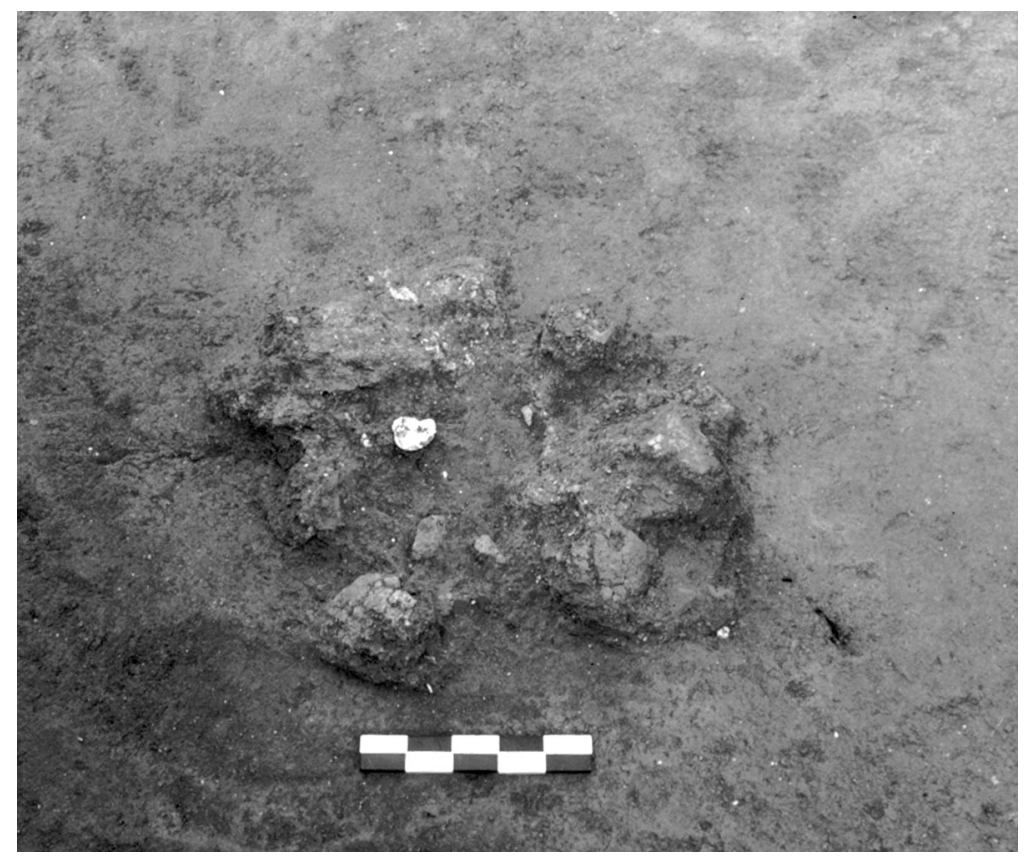

Figure 6-4. Surface hearth Feature 25, Level 8.

Animal bones recovered from these features total only $4.0 \mathrm{~g}$, of which 30 percent are burned. Taxa identified from this small sample are turtle (Testudinata), snake (Serpentes), rabbit (Sylvilagus), micro-mammal, and large mammal (see Appendix E). Fatty acid residue analysis was done on burned clay samples taken from Features 12 and 25 and rock samples from Features 35 and 46. Residues from organic materials with moderate-high fat content, possibly plants or medium-sized mammals, were found in the samples from Features 12 and 46, while the sample from Feature 25 falls on the borderline between materials with medium and moderate-high fat content. Feature 35 produced residue from organics with medium fat content, possibly plants. Though no direct correlations can be made at this time, the presence of charred acorn and hickory nuts within Feature 46 may account for the residue of materials with moderate-high fat content from that feature. The presence of plant or animal fat residues suggests that these features did have a cooking or processing function as opposed strictly to heating.

The features identified as surface hearths are likely the remains of small general-purpose hearths built directly on an occupational surface. Unlike pits, they have no fill but rather are marked by patches of ash, burned clay, and charcoal flecking. As such, they are shallow in vertical extent, though for some, evidence of burning can reach as much as $15 \mathrm{~cm}$ in depth. Maximum horizontal extent averages $70 \mathrm{~cm}$ and likely marks the actual locus of the fire. Burned rocks and burned clay flecking often occur in units adjacent to the hearths, suggesting that some hearth materials may have been moved from the hearths by cultural or natural agents. Though little in the way of artifacts was recovered from the hearths themselves, they are considered general-purpose heating or cooking features because of the multiplicity of artifacts and other materials recovered around them, suggesting that most of the different kinds of activities represented at the site occurred close to these features.

\section{PIT HEARTHS}

Pit hearths (Features 5, 7, 15, 39, and 48) often differ from surface hearths in that they are shallow basins containing burned rocks along with dark fill with burned clay, charcoal, and ash flecking. The long axes of these features range from 40 to $86 \mathrm{~cm}$, and basin depths range from 8 to $30 \mathrm{~cm}$. Their small size indicates limited cooking capacity, which would be expected for a feature used as part of routine camp activities (Black 2002:22-23).

Feature 7, discovered in Level 13 of Excavation Unit 7, produced the most burned rock at $10,612 \mathrm{~g}$, even though it was not the largest pit hearth (see Table 6-2). These rocks came mostly from the upper feature fill and probably reflect materials discarded back into the pit after the cooked foodstuffs were removed (Figure 6-5a). A similar configuration of rocks was found in Feature 39 in the northwest corner of the Main Block in Level 7. Feature 15 (Level 7) produced substantially fewer burned rocks than the aforementioned features, but a burned rock concentration (Feature 14) was adjacent to this pit (Figure 6-6). As with the surface hearths, the burned rocks in proximity to this pit hearth may have been associated with it originally, having been removed and scattered when the pit was 


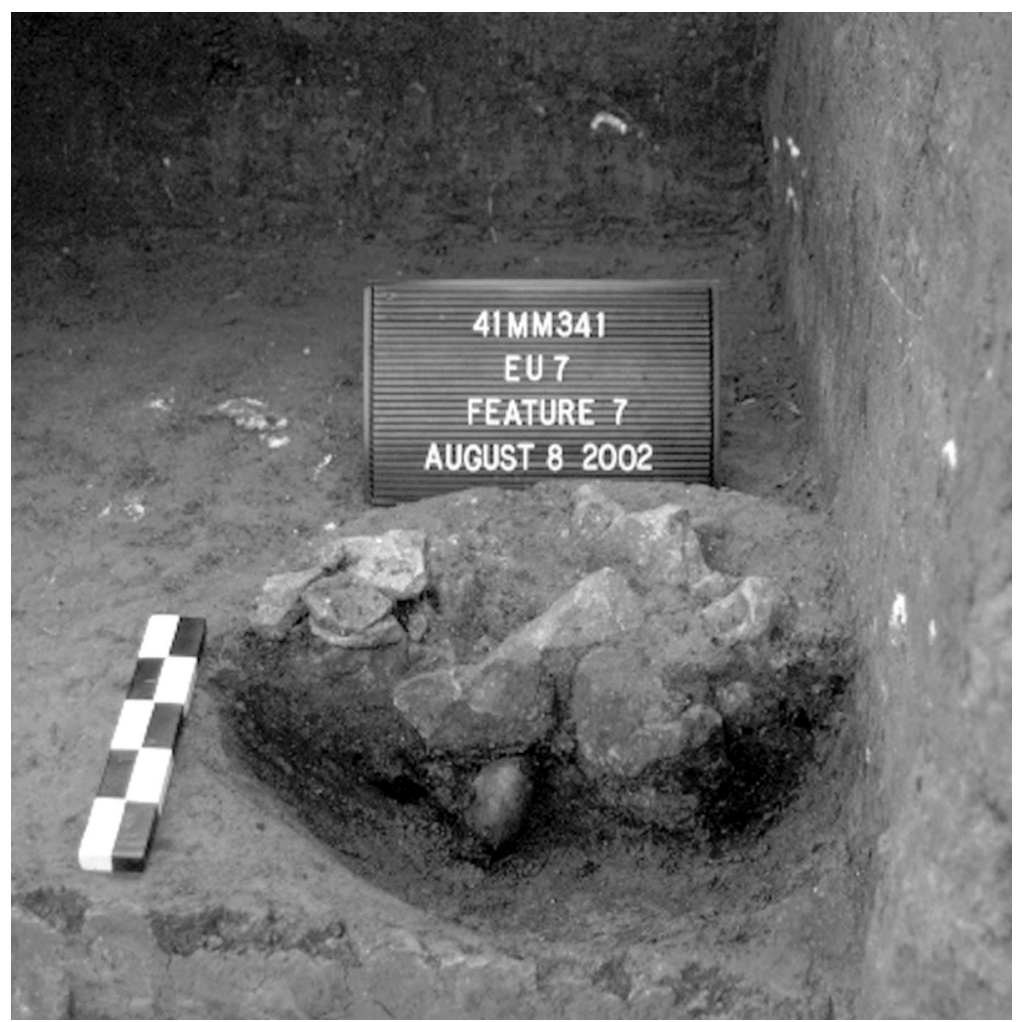

a

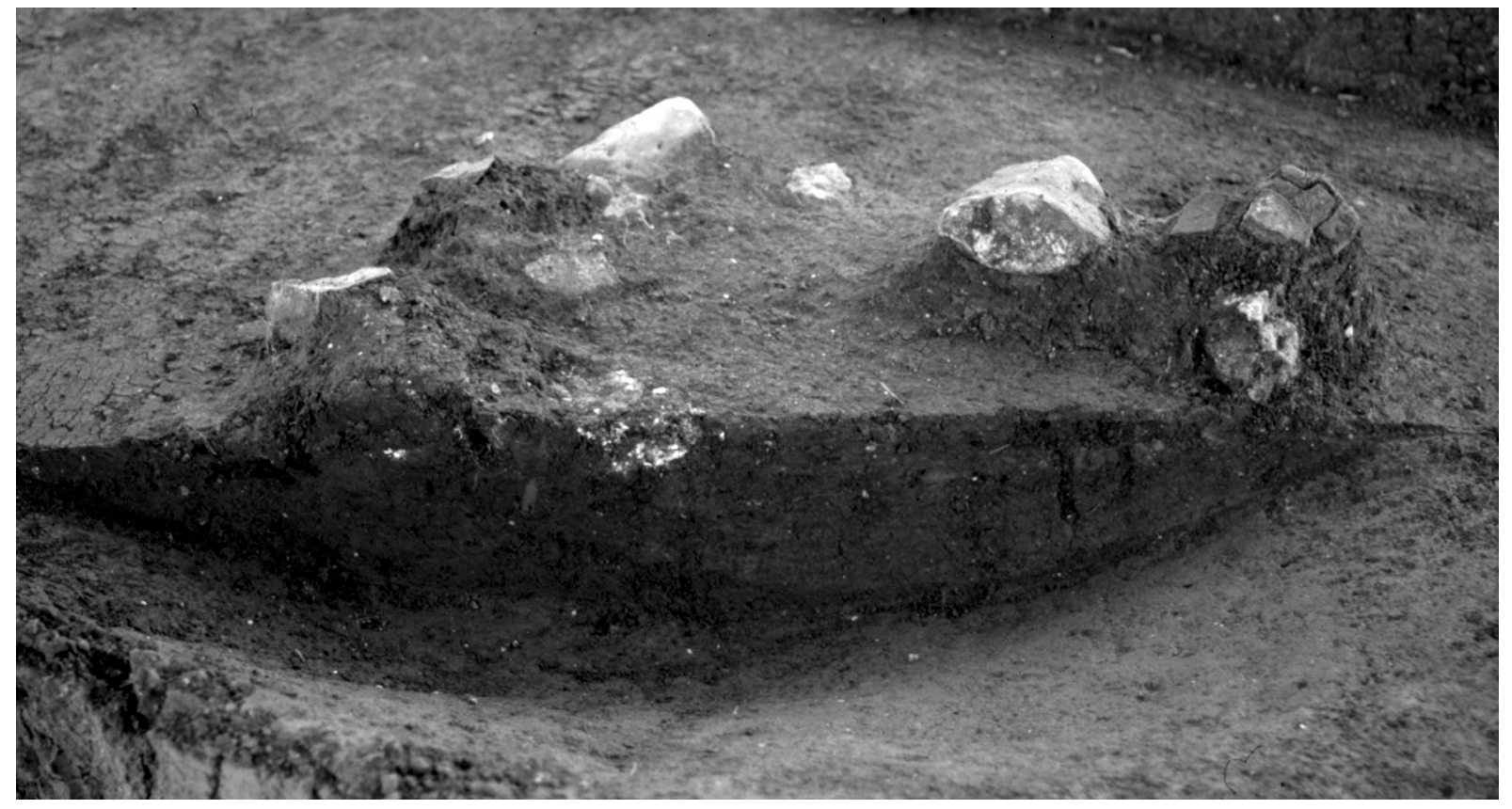

b

Figure 6-5. Cross sections of pit hearths. (a) Feature 7; and (b) Feature 39. 


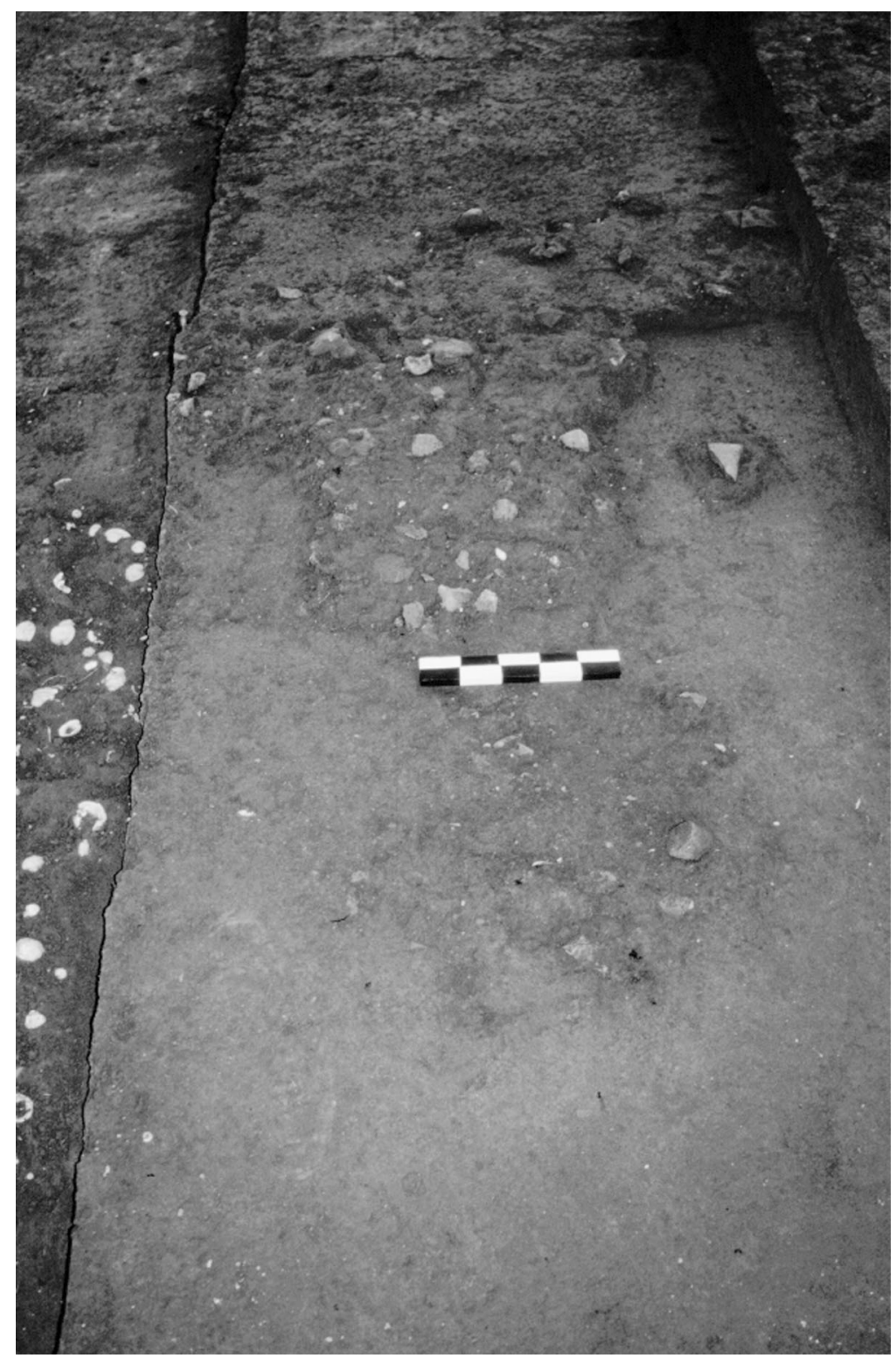

Figure 6-6. Pit hearth Feature 15 in plan view with its adjacent burned rock concentration, Feature 14. Both features overlie shell lens Feature 16.

opened. Testing records indicate that just four burned rocks came from Feature 5 in testing Block 2. An associated burned rock concentration or scatter was not discovered for Feature 48. However, given the proximity of the feature to the edge of the Main Block, such a scatter could have been located outside the block or may have been disturbed by overlying Feature 46 .

Charcoal and burned clay recovery from these features are minimal with totals of $13.1 \mathrm{~g}$ and $79.8 \mathrm{~g}$ for all five of the pit hearths (see Table $6-2$ ). Features 7 and 48 produced the most char- coal at 5.5 and $6.3 \mathrm{~g}$, respectively. Feature 39 was the only pit hearth with a substantial amount of unburned rock $(350 \mathrm{~g})$. Together, these hearths produced only 74 pieces of debitage. However, a small but interesting variety of tools was recovered from these features. Feature 7 produced the only pitted stone recovered from the site. A ground stone abrader was recovered from Feature 15 along with an indeterminate biface.

Analysis of the charred plant materials indicates that these features contained less of a variety of woods than the surface hearths. Four of the features contained white oak, and other woods identified include live oak, ash, persimmon, plum, cherry, buckthorn, and hard elm (see Appendix G). Other charred botanical materials include $0.07 \mathrm{~g}$ of hickory nutshells from Feature 7. Feature 48 produced floral remains that look similar to those obtained from the surface hearths and the processing pits discussed below. Materials from Feature 48 include acorn $(<0.01 \mathrm{~g})$, wild onion $(0.08 \mathrm{~g})$, Allium/ Nothoscordum $(0.21 \mathrm{~g})$, and plum $(0.47 \mathrm{~g})$.

Animal bones recovered from these features total $8.8 \mathrm{~g}$, of which 30 percent are burned. Taxa identified are limited to small rodent and micromammal (see Appendix E). Fatty acid residues were found on six rock samples taken from three pit hearths. The results suggest that a mixture of organic materials was processed in the hearths (see Appendix F). One sample from Feature 7 produced residue from materials with moderatehigh fat content such as certain plants or medium-sized mammals, and another sample from this feature produced residues suggesting a combination of materials with medium fat and low fat content. Residues from two of the three samples from Feature 39 are consistent with large herbivores, while the third produced resi- 
due suggesting medium-fat-content materials such as plants. A single sample from Feature 48 also produced residue from medium-fat-content materials.

Pit hearths may have functioned as small earth ovens with river gravels used for heat retention. As such, they appear to be smaller versions of the processing pits described below. This is supported by the similarity of form for both pit types (i.e., oval in plan and shallow basin shaped in cross section) and the fact that burned rocks are the main material recovered from the dark gray to black pit fill in both. Pit hearths range in area from 0.11 to $0.28 \mathrm{~m}^{2}$, with a mean of $0.21 \mathrm{~m}^{2}$ (standard deviation $=0.12$ ), while the processing pits range from 0.60 to $1.13 \mathrm{~m}^{2}$, with a mean of $0.99 \mathrm{~m}^{2}$ (standard deviation $\left.=0.34\right)$.

\section{PROCESSING PITS}

Processing pits have fill that is similar to that of pit hearths with burned clay, charcoal, and ash; however, these pits are larger (i.e., they have greater capacity) and contain numerous burned rocks and rock shatter suggesting they were loci of intensive heating. Repeated reuse of these pits could account for the highly fractured nature of the burned rocks associated with them as well as the abundance of rock shatter, burned clay, and charcoal in them. These pits are all located in the South Block and adjacent to testing Block 2. They are Features 2, 4, 42, 49a, 49b, 50 (Pits 1-5) (see Figure 6-1). Pit cross sections indicate that the features were wide but shallow basins (Figure 6-7). Pit sizes based on length range from 130 to $200 \mathrm{~cm}$, and minimum depths range from 18 to $44 \mathrm{~cm}$. Of the 10 pits identified, the 5 pits that constitute Feature 50 are interconnected, as are Features $49 \mathrm{a}$ and $49 \mathrm{~b}$ and Features 2 and 4 . Features 49 and 50 were first identified at the base of Level 7 as large, amorphous stains, and the individual pits were not defined until feature excavation was complete. The depths given for these pits are from the top of Level $8(160 \mathrm{cmbd})$, where they were initially recognized. However, given the amount of burned material in Level 7 of the South Block, it is likely that these features originated, like Feature 42, in the lower half of Level 7. Burned material from Level 7 includes 9,377 $\mathrm{g}$ of burned rocks, $1,764 \mathrm{~g}$ of burned clay, and $1,660 \mathrm{~g}$ of burned rock shatter.

Aside from the substantial quantities of burned rocks, burned shatter, and burned clay, a total of $591.1 \mathrm{~g}$ of charcoal was recovered from the features. Most of this came from Features $42,49 \mathrm{a}$, and $49 \mathrm{~b}$. Oak was the fuel of choice, though hackberry/elm, Acer/Ilex, hickory/pecan, other hardwoods, and softwoods are also present (see Appendix G). Bulb fragments were present in all the processing pit features, including the undifferentiated fill in the upper part of Feature 50. Total recovery includes wild onion $(0.59 \mathrm{~g})$, false garlic $(0.21 \mathrm{~g})$, Allium/ Nothoscordum (1.31 g), and unidentified bulb (2.06 g).

A total of $34.4 \mathrm{~g}$ of animal bones were recovered from the processing pits, with most (19.6 g) coming from Feature 50, Pit 4. Most of the bones are unburned. A range of taxa are represented. Included are small fish, pond turtle (Emydidae), cotton rat (Sigmodon), rabbit (Sylvilagus), rodent, micromammal, deer (Odocoileus), medium artiodactyl, and medium to large mammal (see Appendix E). Whether these represent what was processed in the pit features or what found its way into the feature fill as refuse is unclear. However, given that the faunal recovery from all these features is only 1 percent of the total recovery from the site, it is clear that if animal parts were cooked in these pits, they were removed and the bones discarded mostly elsewhere after the meat was eaten.

Fourteen rock samples from Features 42 and 50 (Pits 1-5) were analyzed for fatty acid residues (see Appendix F). Nine samples had positive results, though 6 samples (all from the pits of Feature 50) have relatively low concentrations of residues. Residues from Feature 42 are from medium-fat-content plants and high-fat-content meat such as large herbivores. Residues from Feature 50 are from medium-fat-content plants and both high-fat and lean meat. The multiple kinds of fatty acid residues on these rocks suggest that both animals and plants may have been cooked in these features.

Other refuse in and around these features is extremely limited, indicating that this part of the site likely served solely as a locus of processing, probably of foodstuffs. One untyped arrow point proximal fragment was recovered from Feature $49 \mathrm{~b}$. That fragment is finely worked with a serrated edge and a twist break. Also, a burned Scallorn arrow point was recovered from the north wall of Feature 50, Pit 5, in Level 8 (see Figure 7-4a). However, it is likely that the 

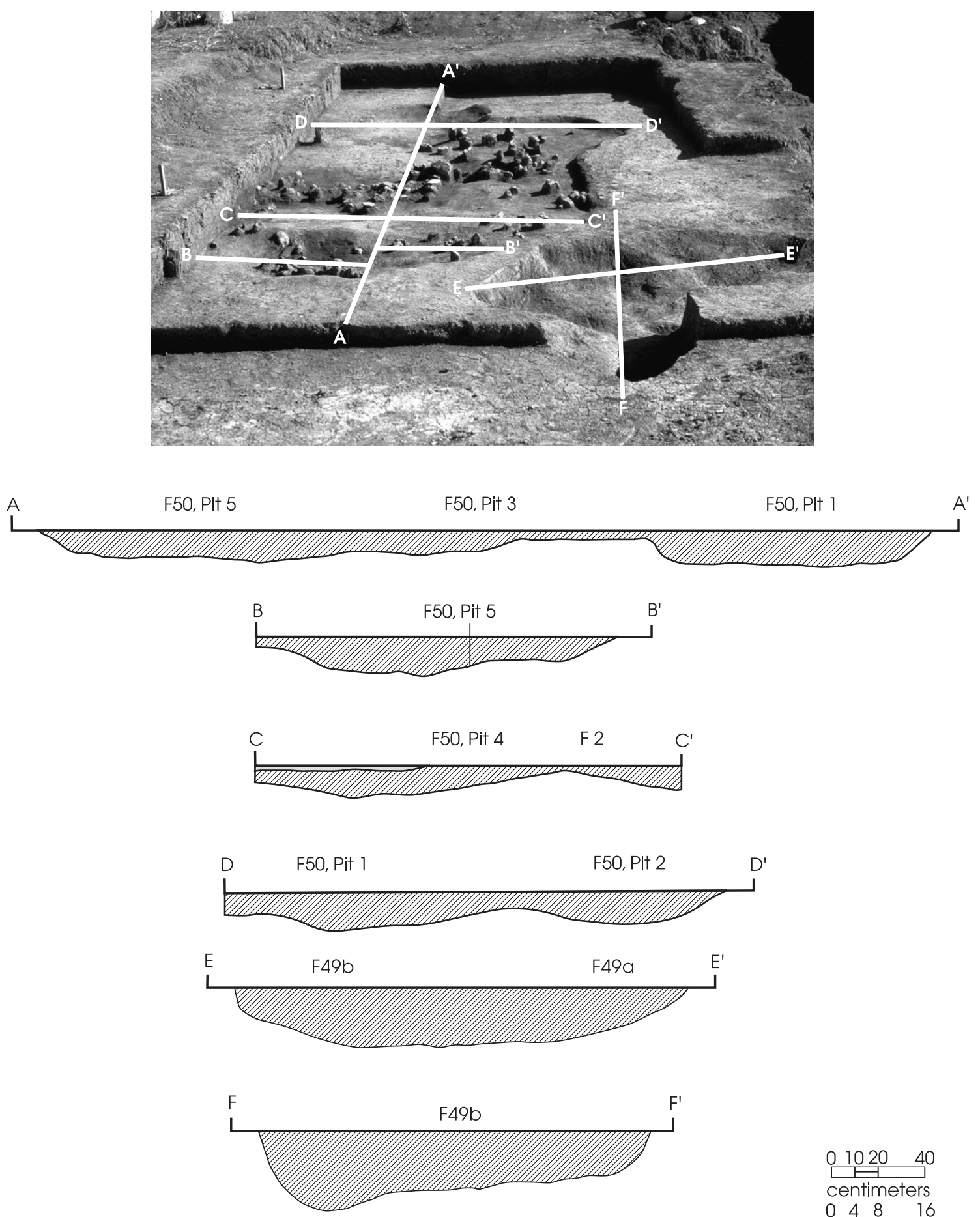

$$
\begin{aligned}
& 01020 \quad 40 \\
& \text { centimeters } \\
& 0 \quad 4 \quad 16 \\
& \text { inches }
\end{aligned}
$$

$P A I / 03 / B W$

Figure 6-7. View to the south across the South Block excavated to the bottom of Level 8. Features 49 and 50 have been cleaned out, with the burned rocks in Feature 50 left on pedestals. The cross sections show the shallow pit features defined within Features 49 and 50. 
point is associated with the matrix surrounding the feature rather than the feature itself. Last, Feature $49 \mathrm{~b}$ produced a use-modified/ scraping expedient tool, and Feature 50, Pit 1, produced an expedient retouched denticulate.

Like the pit hearths, processing pits may have functioned as earth ovens with the chert and sandy limestone river gravels functioning as a heat retention element. On average, the processing pits are almost five times larger than the pit hearths, which is indicative of their larger capacity. Fatty acid residues left on burned rocks within the pits suggest that both plants and animals were cooked, while the limited animal bone recovery from the pits and from the surrounding matrix suggests that what was cooked was removed and consumed elsewhere. Based on the facts that all of the processing pits are in the South Block and cultural materials other than those associated directly with these pits are sparse in this part of the site, it appears that these features represent a processing area that was set apart from the habitation and workshop areas exposed in the Main Block.

\section{SHELL LENSES}

Shell lenses were found in all levels within the Main Block (Features 9, 10, 16, 17, 19, 20, 21a, 21b, 24, 29, and 33) and within Level 10 of testing Block 1 (Feature 3) (see Table 6-1). These lenses consist mainly of freshwater mussel shells, although Rabdotus snail shells form significant parts of some lenses (Features 21a and 21b) and Feature 17 consists almost entirely of Rabdotus shells. Shell density within the lenses varies, with dense concentrations of shells giving way to moderately dense concentrations and dispersed scatters of shells (Figure 6-8a-b). Definition of the features in the field was keyed to the dense to moderately dense concentrations, and thus the plan of the shell features in Figure 6-1 gives only an approximation of the total extent of the lenses. Isopleth maps of mussel shell weight and Rabdotus count by level, with the features superimposed, give a clearer indication of the sizes of the lenses (Figure 6-9). Density is not always reflected in lens thickness. Some dense deposits are only one or two shells, or $2-3 \mathrm{~cm}$ thick, while others are made up of $10-15 \mathrm{~cm}$ of closely packed shells. It should also be noted that not all lenses were completely exposed within the excavation blocks and that some were cut by Backhoe Trench 4 . Those lenses that were totally exposed are Features 16,17 , and 33 .

Samples of the mussel shells from Features $9,10,16,20,21 \mathrm{a}, 21 \mathrm{~b}$, and 24 , as well as shells from the general recovery of Level 10 in the East Block, were subjected to species identification. The East Block sample is likely associated with Feature 3, the shell lens identified in the adjacent testing block. The analysis of these samples indicates that Amblema plicata (threeridge mussel) and Quadrula houstonensis (smooth pimpleback mussel) constitute the overwhelming majority of the shells in all of these features. Both species can be found in mud, sand, and gravel substrates of fast- to slow-moving rivers, conditions that likely occurred in the nearby Little River. There also is evidence that mussels were selectively harvested, as most whole shells from the common species range in size between 31 and $44 \mathrm{~mm}$. Since this pattern holds for all of the analyzed features, it suggests that there was a consistent harvesting technique and that the harvests did not deplete the resource. Complete results of the mussel shell analysis are presented in Appendix A.

A sample of Rabdotus snail shells was selected from the center (Level 8 of Excavation Units 38 and 39) of Feature 17 that includes both 1/4-inch-screen and fine-screen recovery. Whole shells from this sample were sized to determine if the snails represent a range of sizes that would be expected in a natural community of snails, or if the sample is skewed to larger individuals suggesting intentional collection by humans (Brown 2002:248-251). A total of 1,231 Rabdotus dealbatus dealbatus were measured in this sample, and 99 percent $(n=1,224)$ range in size between 16 and $30 \mathrm{~mm}$, with 66 percent ( $\mathrm{n}=814$ ) in the 21-25-mm range (see Appendix B). The almost complete lack of small snails (i.e., juvenile Rabdotus) strongly indicates that Feature 17 represents a Rabdotus harvest.

Additional evidence that Feature 17 represents a snail harvest comes from the fact that Rabdotus shells are not prevalent in the column samples collected adjacent to Excavation Unit 9 , which was between the block excavations where occupational debris was sparse and where the snails recovered should represent a relatively natural population for the site. Levels 6 9 in that column produced 1,744 snail shells, only 5 of which (0.3 percent) are Rabdotus. 


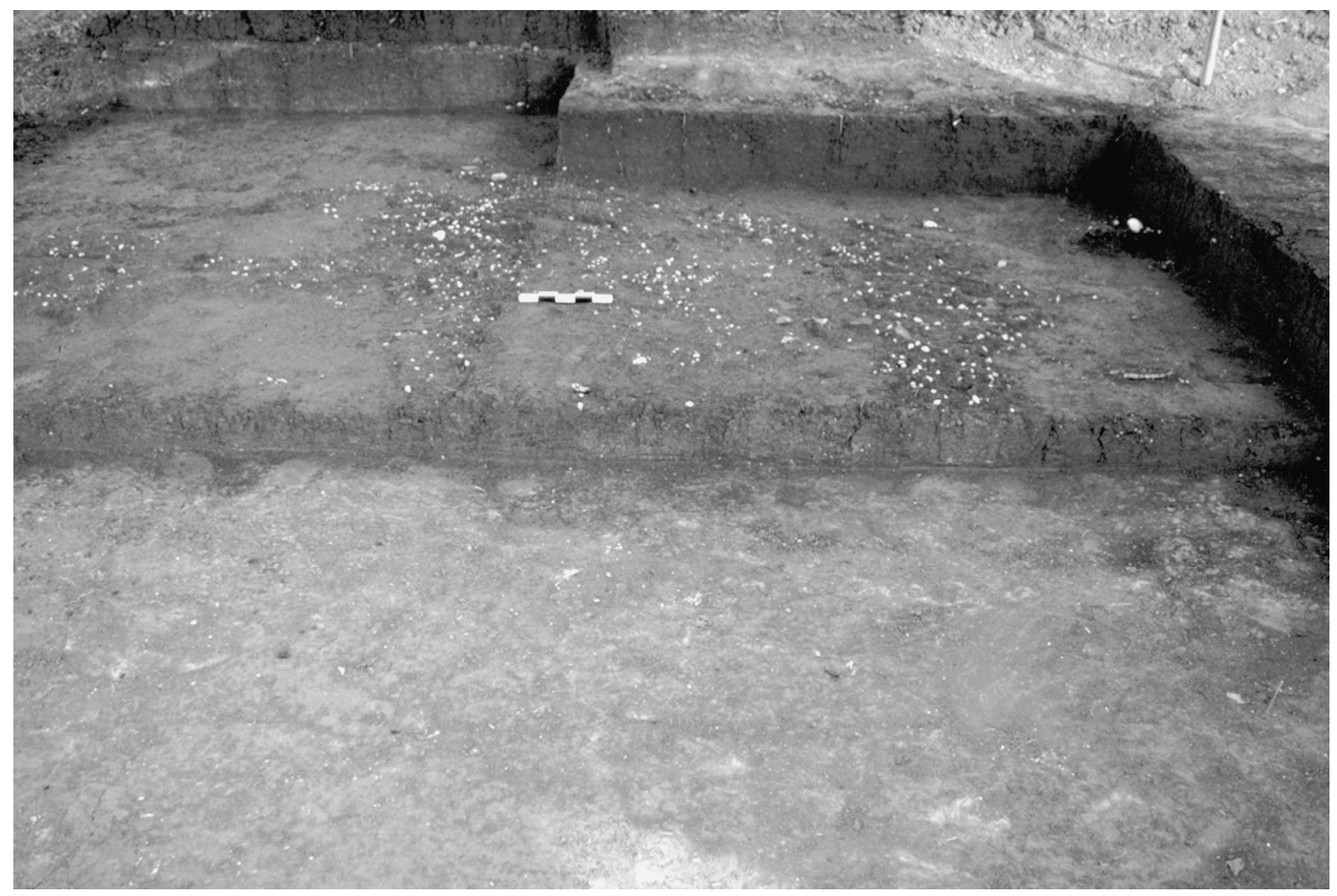

a

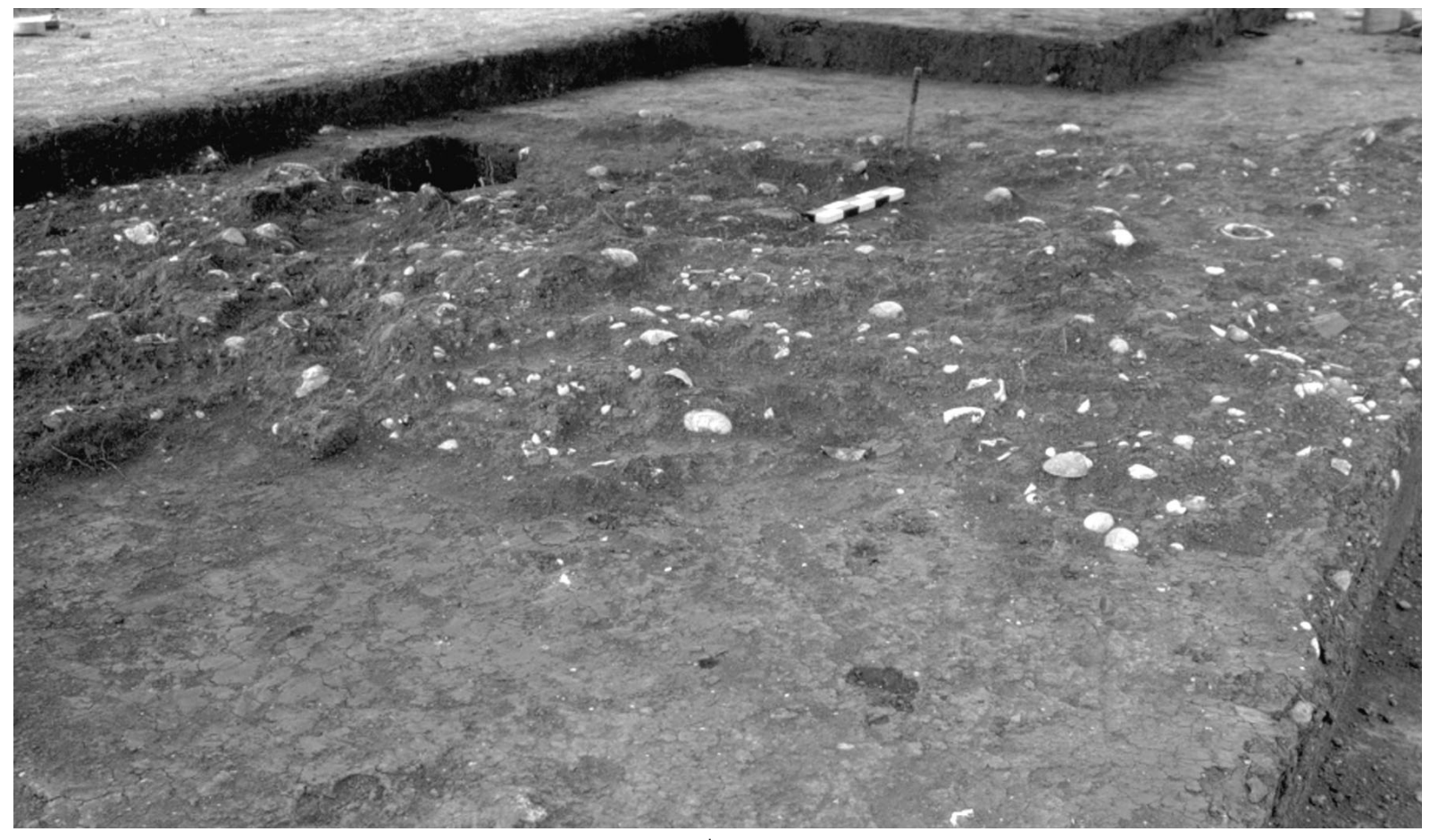

b

Figure 6-8. Shell lenses in the Main Block. (a) North view of Rabdotus shell lens Feature 17; (b) north view of mussel and Rabdotus shell lens Feature 21a showing variation in shell density within the lens. 


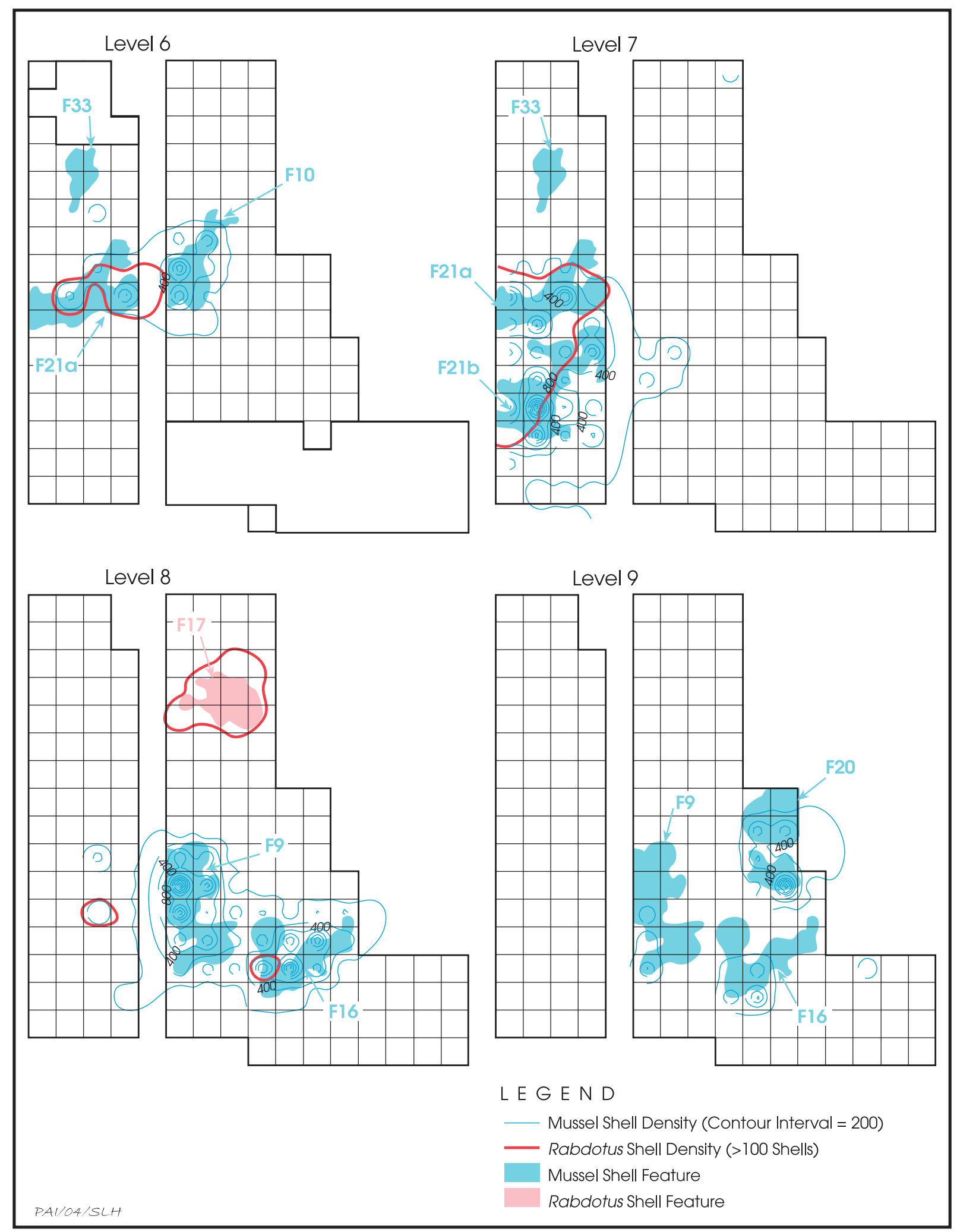

Figure 6-9. Isopleth maps of mussel shell weight and Rabdotus count in Levels 6-9 of the Main Block, with shell feature extent as defined in the field (excludes Feature 19, only a small part of which was exposed in Level 8, and Features 24 and 29, which were restricted to Level 10). 
Feature samples have Rabdotus percentages that far exceed this. In the samples from Feature 17, Rabdotus makes up 74 percent of all snails (less unidentified fragments). In a sample from Feature 21a, Rabdotus constitutes 62 percent of all snails recovered. The contrasts between the feature and column samples indicate that the site area in general was not good habitat for Rabdotus and that snails were harvested, presumably for food, and their shells discarded in the shell lenses.

There has long been discussion in the archeological literature as to whether snails, and in particular Rabdotus, were eaten by prehistoric Native Americans in Texas. As part of his analysis of the land snails recovered from the Smith Creek Bridge site, Kenneth Brown (2002:229-251) provides a comprehensive discussion of the arguments for and against such utilization of this snail. The kinds of snail data presented above for 41MM341 are touted by Brown (2002:251) as the best means to demonstrate that snails used as food can account for large quantities of Rabdotus shells in archeological features. He concedes that the question will not be totally resolved until better information about the lifeways of Rabdotus is known. Yet, to answer archeologists who wonder why native people would go to the trouble to collect these little snails, Brown (2002: 248-250) points out that Rabdotus can be considered a good protein source, they can be easily collected in mass at certain times of the year, and they can be easily parboiled to retrieve the meat.

Tools recovered from the shell features consist of 49 formal chipped stone tools, 77 expedient chipped stone tools, and 6 bone tools. The 6 bone tools consist of 1 possible bone pin manufacture waster and 2 indeterminate fragments from Feature 9, 2 ulna flaker fragments from Feature 21a, and 1 indeterminate fragment from Feature 21b. The formal chipped stone tools include almost the complete range of tool categories, representing 16 percent of all the formal chipped stone tools recovered. The numbers of formal tools per category are presented in Table 6-3. Features 3 and 29 have no associated formal chipped stone tools and do not appear in the table.

Diagnostic arrow points from the shell features include: an Alba point from Feature 10 (see Figure 7-2b), two Alba points from Feature 21a (see Figure 7-2f-g), a Scallorn point from Fea- ture 19 (see Figure 7-4b), a Scallorn point from Feature 21a (see Figure 7-3h), a Scallorn point from Feature 33 (see Figure 7-3b), and a Perdiz point from Feature 21a (see Figure 7-5f). In addition, Darl dart points were recovered from the bottom of Feature 9 (see Figure 7-10e) and Feature 24 (see Figure 7-10d).

Burned rocks were recovered from all but two of the shell lenses, though most of the rocks came from several of the larger features (Features 9, 10, 16, 21a, and 21b) (see Table 6-2). Some of these rocks (such as the $751 \mathrm{~g}$ recovered from Feature 16) probably are associated with burned rock Features 13 or 18 that are adjacent, or with Feature 14 positioned above the shell lens. In other shell lenses such as Feature 9 (2,144.3 $\mathrm{g}$ in Level 8 of Excavation Unit 10), Feature 21a (981.6 g in Level 7 of Excavation Unit 133), and Feature 21b (906.2 g in Level 7 of Excavation Unit 121), concentrations of burned rocks are present that were not noted as separate features. Burned clay recovery is also highest in the shell features that produced the most burned rocks. Burned materials concentrated in some of these features suggests that hearth remnants other than those identified in the field were present but masked by the general refuse deposits.

The 16 flotation samples taken from the shell features produced a variety of wood charcoal and other charred materials (see Appendix G). Oak is well represented in the shell lenses from Levels 6 through 8; oak is also present in the much smaller samples from the lenses in Levels 9 and 10 (Table 6-4). This suggests a consistent selection of oak wood through at least the latter part of the occupation of the site. The wood charcoal within these lenses likely reflects general fuel wood usage at the site, and the predominance of oak is not surprising.

Charred nut remains in the form of hickory and pecan shells were recovered from every shell lens except Features 16 and 29. A small amount of acorn meat was also recovered from Feature 21a, Level 6. Charred bulbs are more restricted; they came from Features 9, 21a, 21b, and 33. Most of these are unidentified bulbs, but wild onion, false garlic, and Allium/Nothoscordum are present in Features 21a and 21b. Other identifiable charred botanical materials from these features in quantities of $0.02 \mathrm{~g}$ or less include marshelder, plum, hawthorn, nightshade, and grass seeds and stems (Poaceae). 
Table 6-3. Formal chipped stone tools by shell lens feature

\begin{tabular}{l|c|c|c|c|c|c|c|c|c|c|c}
\hline \multirow{2}{*}{ Tool Category } & \multicolumn{10}{c|}{ Feature } & \multirow{2}{*}{ Total } \\
\cline { 2 - 11 } & 9 & 10 & 16 & 17 & 19 & 20 & $21 \mathrm{a}$ & $21 \mathrm{~b}$ & 24 & 33 & 10 \\
Arrow point & 2 & 1 & 1 & 0 & 1 & 0 & 3 & 1 & 0 & 1 & 10 \\
Arrow preform & 3 & 0 & 2 & 0 & 0 & 0 & 0 & 1 & 0 & 0 & 6 \\
Knife & 1 & 0 & 0 & 0 & 0 & 0 & 0 & 1 & 1 & 0 & 3 \\
Knife preform & 0 & 0 & 1 & 0 & 0 & 0 & 1 & 1 & 0 & 0 & 3 \\
Early-stage biface & 0 & 0 & 0 & 1 & 0 & 0 & 3 & 1 & 0 & 1 & 6 \\
Indeterminate biface & 2 & 2 & 1 & 0 & 0 & 0 & 0 & 1 & 0 & 0 & 6 \\
Adze & 1 & 1 & 0 & 0 & 0 & 0 & 1 & 1 & 0 & 0 & 4 \\
Awl & 0 & 0 & 0 & 0 & 0 & 0 & 0 & 1 & 0 & 0 & 1 \\
Gouge & 1 & 0 & 0 & 0 & 0 & 0 & 0 & 1 & 0 & 0 & 2 \\
Wedge & 0 & 0 & 0 & 0 & 0 & 0 & 0 & 2 & 0 & 0 & 2 \\
Hammerstone & 0 & 0 & 0 & 0 & 0 & 1 & 0 & 0 & 1 & 0 & 2 \\
Hammerstone/chopper & 0 & 0 & 0 & 1 & 0 & 0 & 0 & 0 & 1 & 0 & 2 \\
\hline Total & 0 & 0 & 0 & 0 & 0 & 0 & 0 & 0 & 2 & 0 & 2 \\
\hline
\end{tabular}

Table 6-4. Charred wood recovered from flotation samples from shell lens features

\begin{tabular}{l|c|c|c|c|c}
\hline & $\begin{array}{c}\text { Level 6 } \\
\text { Feature 21a, 33 }\end{array}$ & $\begin{array}{c}\text { Level 7 } \\
\text { Feature 21a, 21b }\end{array}$ & $\begin{array}{c}\text { Level 8 } \\
\text { Feature 9, 16, 17 }\end{array}$ & $\begin{array}{c}\text { Level 9 } \\
\text { Feature 20 }\end{array}$ & $\begin{array}{c}\text { Level 10 } \\
\text { Feature 24, 29 }\end{array}$ \\
\hline Live oak & 1 & 4 & 10 & 0 & 0 \\
White oak & 12 & 31 & 23 & 2 & 0 \\
Red oak & 0 & 4 & 0 & 0 & 0 \\
Oak & 0 & 0 & 4 & 0 & 2 \\
Box elder/maple & 6 & 5 & 8 & 0 & 0 \\
Ash & 5 & 4 & 13 & 0 & 0 \\
Pecan & 0 & 3 & 0 & 0 & 0 \\
Hackberry/elm & 7 & 0 & 3 & 0 & 0 \\
Sweetgum & 0 & 2 & 9 & 0 & 0 \\
Hickory & 0 & 1 & 0 & 0 & 0 \\
Hickory/pecan & 3 & 1 & 0 & 0 & 0 \\
Plum/cherry & 0 & 1 & 0 & 1 & 0 \\
Persimmon & 0 & 0 & 0 & 0 & 1 \\
Honeylocust & 0 & 0 & 0 & 0 & 3 \\
Cottonwood & 0 & 0 & 3 & 0 & 0 \\
Sycamore & 0 & 0 & 1 & 0 & 0 \\
Buckthorn & 0 & 0 & &
\end{tabular}


A total $705.5 \mathrm{~g}$ of animal bones were recovered from the shell features. This is 90 percent of the bone recovery from all features, but only 20 percent of the total faunal recovery from the site. Features 9, 10, 21a, and 21b produced nearly 80 percent of the bones from the shell features (see Table 6-2). Taxa certainly or probably representing deer (medium/large mammals, Artiodactyla, Cervidae, and Odocoileus sp.) are present in all shell features except Feature 29. These are most frequent in Features 9, 10, 21a, and 21b. Similarly, turtles are represented in all shell features except Feature 33 and are notable for their frequency in Features 9, 16, $21 \mathrm{a}$, and $21 \mathrm{~b}$. Several other taxa that are well represented within particular features are: snakes (Colubridae) in Feature 16, cotton rats (Sigmodon sp.) in Feature 10, rabbit (Sylvilagus sp.) in Feature 21b, opossum (Didelphis virginiana) in Feature 24, and raccoon (Procyon lotor) in Features 21a and 21b. Lastly, though limited at the site in general, no fish or birds were recovered from the shell features.

These lenses likely reflect deposition of shells at or near the locations where the mussels and gastropods were cooked and eaten, with the shells becoming part of the primary refuse deposits surrounding the surface hearths and pit hearths. The abundance of formal and expedient chipped stone tools, debitage, burned rocks, burned clay, animal bones, and charcoal within the shell lenses supports this interpretation. The shells, especially where densely concentrated, may have to some extent limited the horizontal and vertical movement of artifacts and other debris within the site matrix and thus helped preserve the structure of activities represented by the refuse scatters.

\section{POSSIBLE POSTHOLES}

The possible postholes identified are Features 23 and 31. They are located across the Main Block from each other and do not appear to have been associated (see Figure 6-1). There is no evidence that they mark structures, and as noted below at least one may not even be cultural. Both are less than $20 \mathrm{~cm}$ in diameter, and they are 17 and $25 \mathrm{~cm}$ deep. Cross sections show generally cylindrical outlines with tapered or flat bottoms and burned clay and ash within an otherwise dark fill (Figure 6-10). These features were identified only because of the ash or burned clay in their fill. There is some evidence that at least Feature 31 may have resulted from a root burning in place, although it is also possible that the root took advantage of the preexisting posthole. A flotation sample from Feature 31 produced burned wood, some of which can be interpreted as a burned root of a plum or cherry tree (see Appendix G). Otherwise, Feature 31 produced 33 pieces of debitage, 1 indeterminate bone tool fragment, $26.2 \mathrm{~g}$ of mussel shells, 28 Rabdotus shells, $2.9 \mathrm{~g}$ of animal bones, $0.3 \mathrm{~g}$ of charcoal, and $9.9 \mathrm{~g}$ of burned clay. Feature 23 had no recovery (see Table 6-2).

\section{BURNED ROCK CONCENTRATIONS}

Burned rock concentrations (Features 13, $14,18,28,36$, and 45) were found above, adjacent to, within, and below the shell lenses. They vary in length from $44 \mathrm{~cm}$ across to $130 \mathrm{~cm}$ and in area from 0.09 to $0.82 \mathrm{~m}^{2}$. The numbers of rocks in these features vary widely with a minimum of 6 cobbles and cobble fragments in Feature 36 to a maximum of 87 in Feature 13. The average number of rocks per feature is 32 . The average density of rocks within the concentrations is $50 / \mathrm{m}^{2}$, with Feature 28 covering the least area and being the most dense and Features 14 and 18 covering the largest areas and being least dense. The rocks within the concentrations are mainly limey sandstone both in terms of weight (73 percent) and number (66 percent). Other rock types identified are quartzite (26 percent by weight and 28 percent by number) and conglomerate ( 1 percent by weight and 6 percent by number). Minimal amounts of other materials such as debitage, burned clay, charcoal, snail shells, and animal bones were associated with these features (see Table 6-2). Feature 36 did produce a fair quantity of mussel shells, but this is likely due to the fact that it was near shell Feature 21a. Only one formal chipped stone tool, an early-stage biface, was recovered from within Feature 14.

Rock samples from Features 14, 18, and 36 were analyzed for fatty acid residues (see Appendix F). The samples are similar in that residues from plant fats or a mixture of plant and animal fats are present. Two rock samples from Feature 14 produced residues from medium-fatcontent materials, possibly plants, and borderline medium- to high-fat-content materials of 


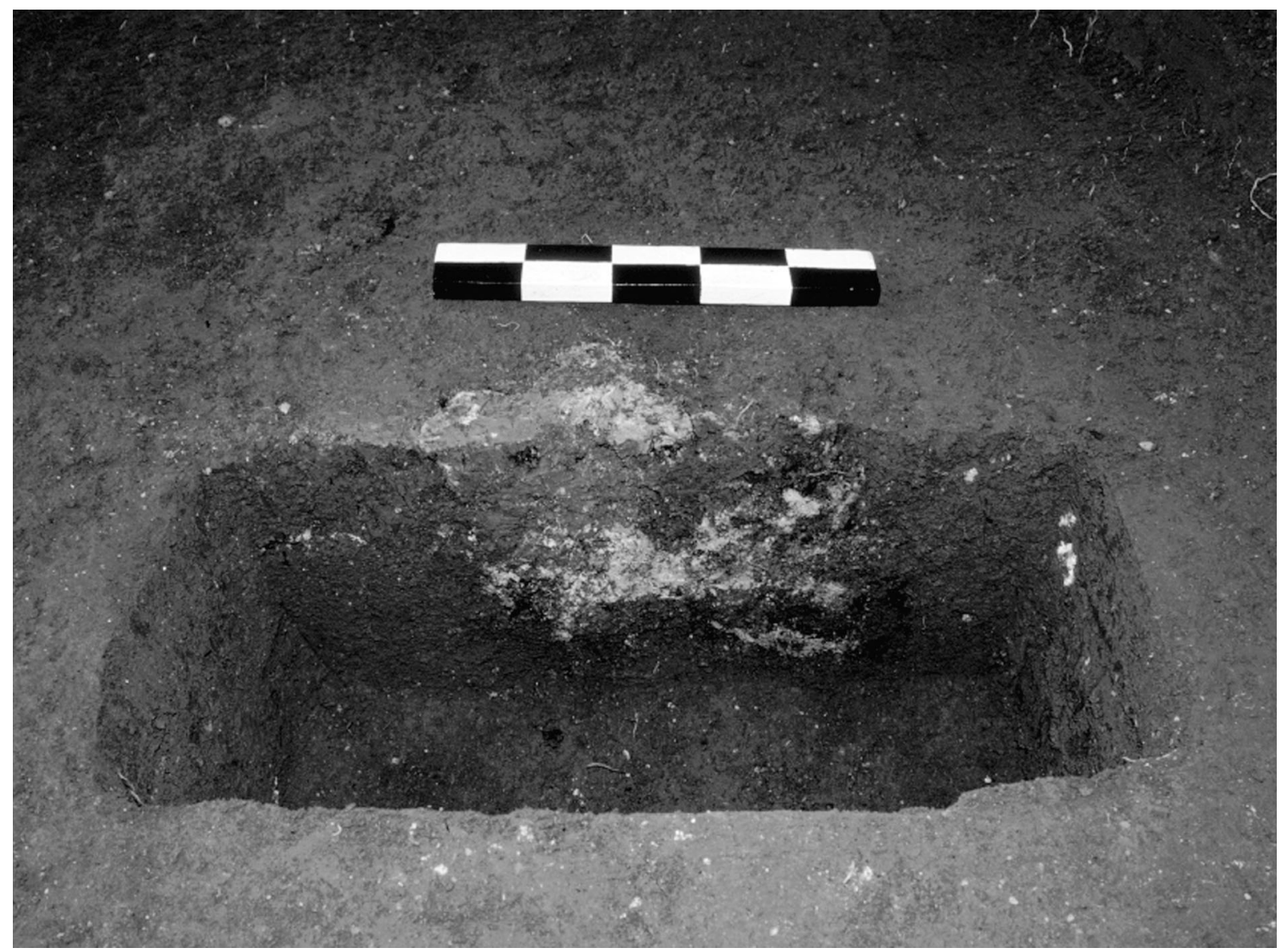

Figure 6-10. Possible posthole Feature 31 after cross sectioning.

mixed origin. All three samples from Feature 18 produced residues from materials with medium fat content, possibly plants. Two samples from Feature 36 produced residues from medium-fat-content materials and high-fat materials such as seeds or animals.

It is likely that the burned rock concentrations represent materials removed from their primary contexts within hearths by human activity. Three of the largest concentrations (Features 13, 14, and 18) surround Feature 15 (a pit hearth), and two surface hearths (Features 8 and 22/26) are also nearby. Scattered burned rocks were also recovered from the shell lenses and the cultural zone in general. Thus, the occurrence of burned rocks, whether in concentrations or not, is indicative of their original association with nearby loci of heating.

\section{INDETERMINATE FEATURES}

Several features do not fit any of the types described above, and these features are consid- ered indeterminate as to type. These features are either dark stains that are amorphous in plan and cross section (Features 34 and 38) or small (ca. $20 \mathrm{~cm}$ in diameter), shallow (ca. 2 to $6 \mathrm{~cm}$ deep) patches of burned clay (Features 27 and 37). Some of these features are likely root or rodent disturbances or possibly roots that burned in place as a result of surface fires. Indeterminate Feature 32 appeared as a light gray stain that may have resulted from differential drying within the site matrix. Recovery from these features was limited (see Table 6-2).

\section{LITHIC REDUCTION DEBRIS PILES}

Lithic reduction debris piles were not identified in the field or given feature designations, although field tracking of debitage frequencies by unit and level provided indications that such piles might be definable. For example, Excavation Unit 27 produced 706 flakes and chunks from Level 6, and the similarities in color and 
texture of the lithic materials suggested to the excavators that this debitage could represent a discrete depositional event representing a limited number of reduction episodes. This was supported by the dramatic drop of debitage frequency to a mere 55 pieces in Level 7 of the same unit.

Though no other single level matches the quantity of debitage recovered from Level 6 in Excavation Unit 27, several proveniences in different areas of the Main Block produced debitage numbers in the 300-500 range. During excavation, it was recognized that these units could be the loci of other reduction episodes. Surrounding these loci are levels with moderate to high debitage frequencies, and beyond them are levels with low frequencies. As described below, during analysis efforts were made to determine whether these concentrations do, in fact, represent discrete depositional events. This involved examining the lithics from in and around 10 apparent concentrations, with the examined proveniences making up 43 percent of the levels in the Main Block. The East and South Blocks were excluded from this study because no comparable concentrations were found in these much smaller excavations.

The analysis concluded that, to varying degrees, the 10 concentrations do represent fairly intact, fairly discrete events, with the results of these events restricted to 15 percent of the Main Block levels. None of these may be single knapping episodes. Rather, the abundance of material, presence of many cobbles, sizes of the piles, and variety of reduction strategies represented by each pile indicate that they are the result of multiple knapping episodes, albeit ones that happened over limited time spans (i.e., within single occupational episodes). Thus, like the shell features, these piles appear to be in primary contexts adjacent to the hearth features. Numbered in order of investigation, these are as follows: Piles 1 and 3 in Level 6; Piles 2, 4, 5, and 9 in Level 7; Piles 6, 7, and 10 in Level 8; and Pile 8 in Level 9 (Figure 6-11). Together, these 10 piles contain over 16,000 pieces of debitage, or 44 percent of the debitage from the Main Block (Table 6-5).

\section{Minimum Number of Cobbles}

To demonstrate that groups of adjacent levels with high to moderate frequencies are asso- ciated as lithic reduction debris piles, the debitage from these proveniences was sorted based on color, texture, and inclusions. This was done with the idea that the greater number of flakes and cores that could be associated based on matching materials (same color, texture, and inclusions), the more likely a concentration of lithic materials would represent a discrete depositional event. Between 13 and 33 percent of the debitage in each pile could be matched in this way (see Figure 6-5), with the average being 22 percent. Pile 3 in Level 6, Pile 5 in Level 7, and Pile 7 in Level 8 are at the low end of the range (13-16 percent), and Pile 9 in Level 7 defines the upper end. In effect, this sort identified a minimum number of cobbles (MNC) within each pile. This number ranges between 10 and 21, with the average being 14 (see Table 6-5). The fewest MNC are in Pile 2 in Level 7 and Pile 10 in Level 8, and the greatest MNC are in Piles 4 and 9 in Level 7.

An average of 78 percent of the debitage in each pile could not be matched with like materials. This almost certainly reflects the presence of additional, unrecognized cobbles, but it also is a function of the difficulty of matching both highly homogeneous and highly variable materials, as well as the presence of many small pieces of debitage. These characteristics also hampered refitting pieces of cobbles. Refitting is time-consuming because it requires the analyst to compare not only color, texture, and inclusions across multiple proveniences but also to remember and compare shapes of potentially refitting pieces. Still, refitting was attempted because refits would unmistakably confirm associations. An average of 24 person-hours was spent trying to identify refits for each pile. More time spent likely would have resulted in at least several more refits for each, but the analyst stopped once the debitage from all proveniences in the pile had been compared and all refits that could be readily identified had been sorted.

Refits range from 0 to 69 per pile (see Table 6-5). The average is 5.5 refits per pile when the extreme ends of the range are dropped. The largest number of refits is in Pile 1, which also produced 20 cores and core fragments, with refits occurring between cores and flakes and flakes and flakes. The high number of refits enabled reconstruction of several of the cobbles identified (Figures 6-12 and 6-13). These reconstructed 


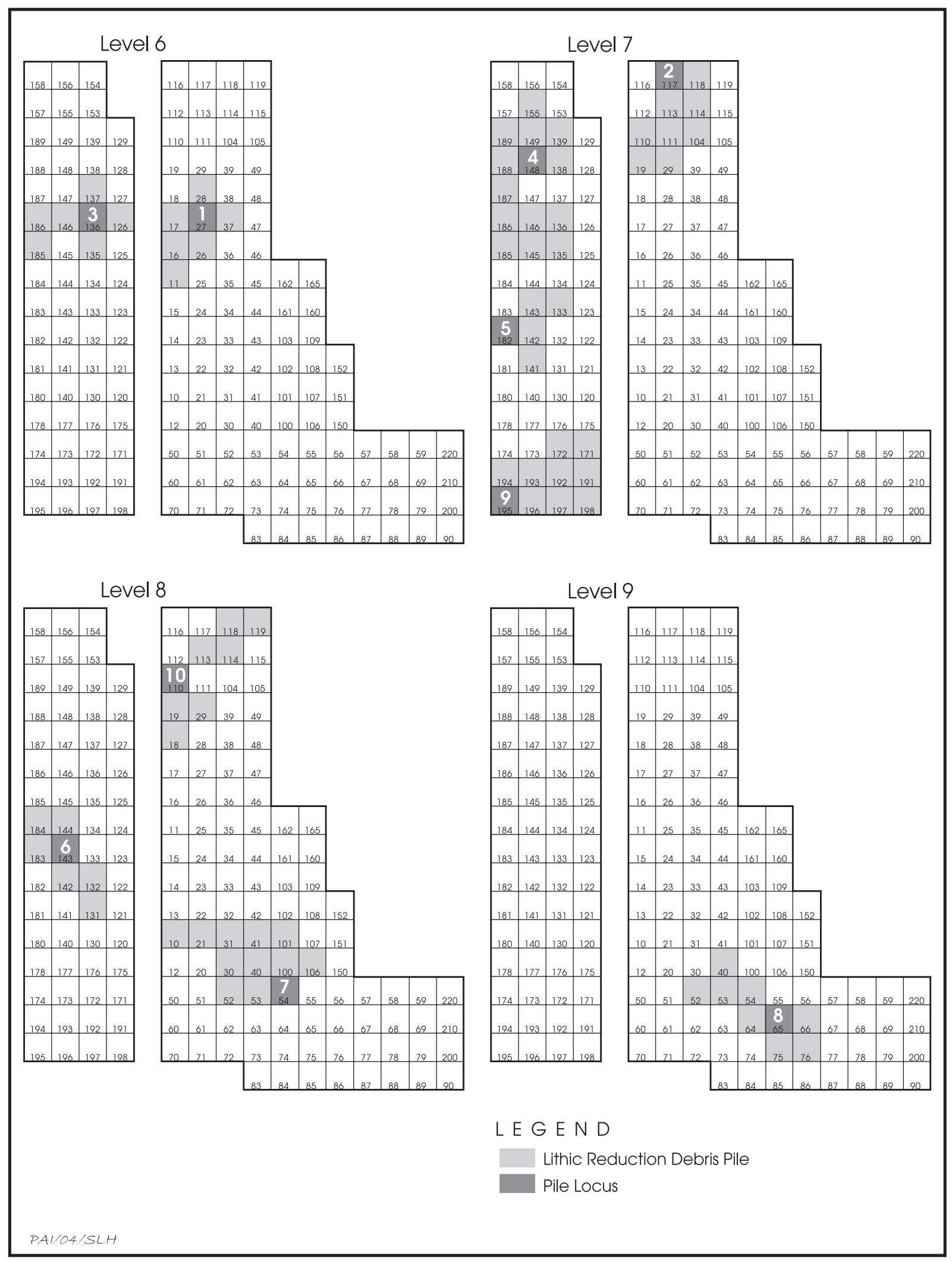

Figure 6-11. Extent of the lithic reduction debris piles in the Main Block. 
Table 6-5. Contents of the lithic reduction debris piles

\begin{tabular}{c|c|c|c|c|c|c|c|c}
\hline Pile & Level & $\begin{array}{c}\text { Debitage } \\
\text { Count }\end{array}$ & $\begin{array}{c}\text { Matching } \\
\text { Debitage (\%) }\end{array}$ & Refits & MNC & Cores & $\begin{array}{c}\text { Formal } \\
\text { Tools }\end{array}$ & $\begin{array}{c}\text { Expedient } \\
\text { Tools }\end{array}$ \\
\hline 1 & 6 & 1,708 & 26 & 69 & 12 & 20 & 6 & 30 \\
2 & 7 & 1,175 & 22 & 1 & 10 & 2 & 17 & 10 \\
3 & 6 & 1,276 & 13 & 3 & 15 & 6 & 13 & 18 \\
4 & 7 & 2,891 & 25 & 11 & 21 & 4 & 22 & 48 \\
5 & 7 & 1,028 & 15 & 7 & 14 & 7 & 7 & 26 \\
6 & 8 & 1,988 & 26 & 5 & 14 & 4 & 16 & 22 \\
7 & 8 & 1,389 & 16 & 9 & 11 & 5 & 5 & 17 \\
8 & 9 & 1,469 & 20 & 1 & 14 & 5 & 8 & 5 \\
9 & 7 & 2,854 & 33 & 7 & 18 & 3 & 23 & 5 \\
10 & 8 & 716 & 26 & 0 & 10 & 7 & 4 & 4 \\
\hline Total & & 16,494 & 24 & 113 & 139 & 63 & 121 & 185 \\
\hline
\end{tabular}

cobbles are clear evidence for the integrity of Pile 1.

\section{Extent of the Debris Piles}

Because of the high frequency of refits, Pile 1 became the standard of what a relatively intact lithic reduction pile might look like. As noted above, this pile stood out in the field because its locus, Level 6 of Excavation Unit 27, produced over 700 pieces of debitage. Six units surrounding this unit also produced high debitage frequencies; these units complete the pile's horizontal extent (see Figure 6-11). The full extent of Pile 1, minus that removed by Trench 4, was encompassed within the excavation block such that most of the pile was recovered. Examination of the debitage from 26 units in Level 6 (including the 7 units assigned to the pile) and 8 units in Level 7 indicates that this pile is vertically restricted to Level 6. Table 6-6 shows that 100 percent of its matching debitage is from that level. Since excavation started in Level 6 after machine removal of the overlying deposits, it cannot be stated with certainty that Pile 1 did not extend above Level 6. However, this seems unlikely, since only 15 pieces of debitage were recovered from Level 5 of initial Excavation Unit 11 nearby. Given its position in Level 6 and the limited materials above it, the reduction episodes represented by Pile 1 probably were among the last events to occur in this part of the site.

The overwhelming majority of the matching debitage in most of the other debris piles also is generally associated with single $10-\mathrm{cm}$ levels, and these are considered to be the levels at which the piles were deposited (these are the levels indicated on Table 6-5). Including Pile 1, eight of the debris piles have 90 percent or more of their matched debitage in one level (see Table 6-6). The other two-Piles 2 and 5-have 7576 percent in Level 7. Almost all of the rest of the matched debitage associated with Pile 2 was found in Level 6 above the main concentration. Pile 5 appears to have been distributed more widely, with two-thirds of the rest of the matched debitage in Level 8 below the main concentration and one-third in Level 6 above it. These distributions probably reflect crosscutting of the debris piles by the arbitrary 10 -cm levels used in excavation, although movement of artifacts by various ground-disturbing agents cannot be ruled out. Regardless, the restricted vertical distributions of the identified cobble materials (i.e., matching debitage) in most of the piles indicates discreteness and integrity.

Since the lithic reduction debris piles were not defined during excavation, their actual shapes and sizes are unknown. Based on unitby-unit analysis, however, their main parts appear to range in size from about 5 to $14 \mathrm{~m}^{2}$, with an average of $10 \mathrm{~m}^{2}$. These figures are underestimates of their true sizes, however, since they are based only on units with high debitage frequencies and high counts of matching materials. Proveniences were considered parts of the main debris piles if they contained more than 5-10 pieces of matching materials. Consequently, the horizontal extent figures above re- 

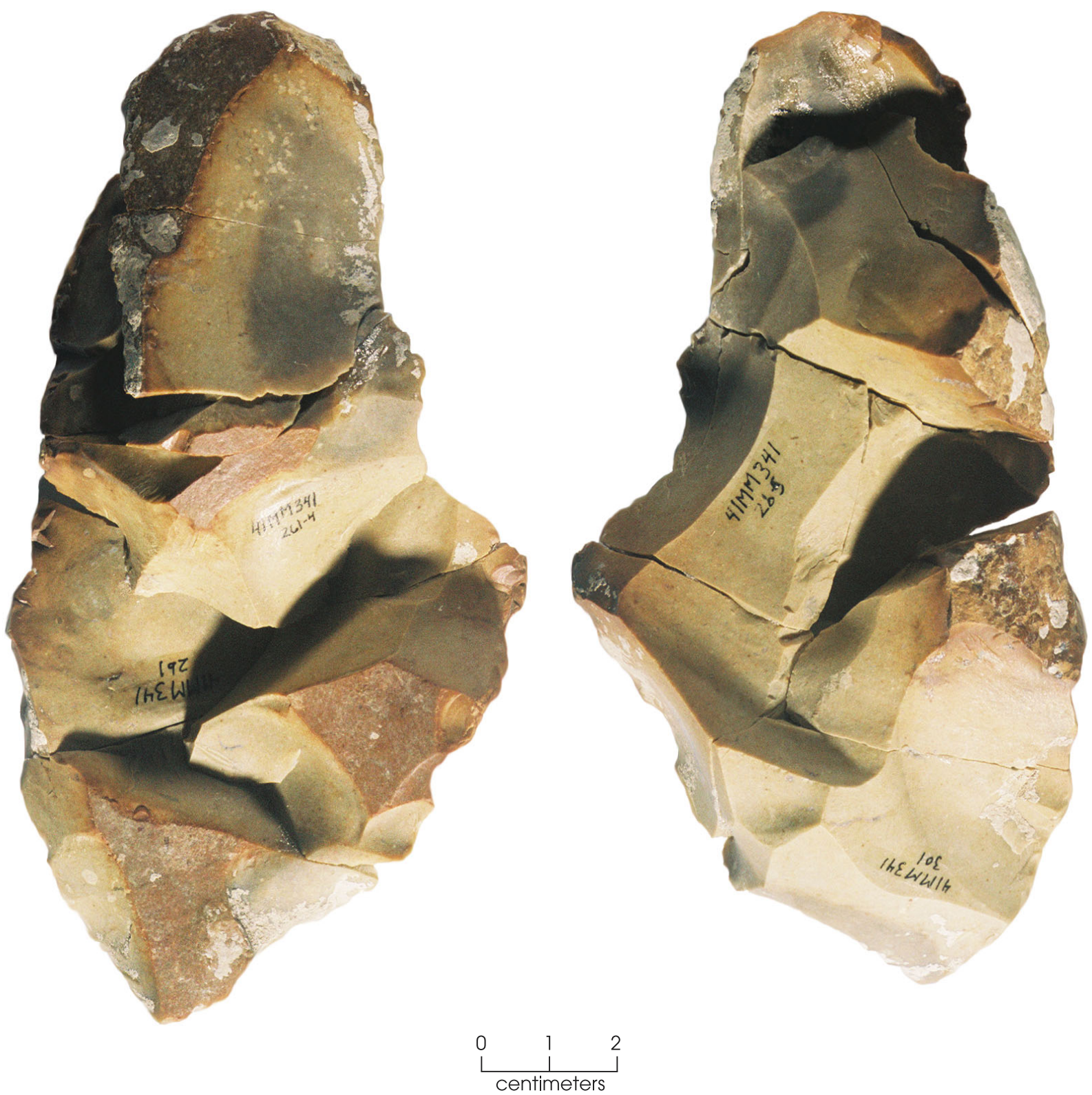

Figure 6-12. Reconstructed Cobble 4 from lithic reduction debris Pile 1.

fer only to the densest parts of the piles. Also, some piles were only partially explored as they abut edges of the excavation block. For instance, Pile 9, located in the southwest corner of the block, produced more matching materials than any other pile and still likely remains partially unexplored outside the block.

\section{Distribution of Refitted Cobbles and Easily Recognizable Materials}

The total number of refits for all piles, including the main levels and adjacent ones, is
116 (see Table 6-6). At the extremes, Pile 10 has no refits and Pile 1 has 69 . No refits were identified between piles. Rather, most of the refitting pieces are within single $10-\mathrm{cm}$ levels of individual units. An extreme case is Pile 1, where 64 of the 69 refits are from Level 6 of Excavation Unit 27. Only 15 refits are between units and, of these, only 3 extend beyond the delineated edges of Piles 1 and 9 (Figure 6-14). Further, only 3 refits were identified between levels within a pile (see Table 6-6). This preponderance of refitting within piles rather than between them, or even just beyond their 

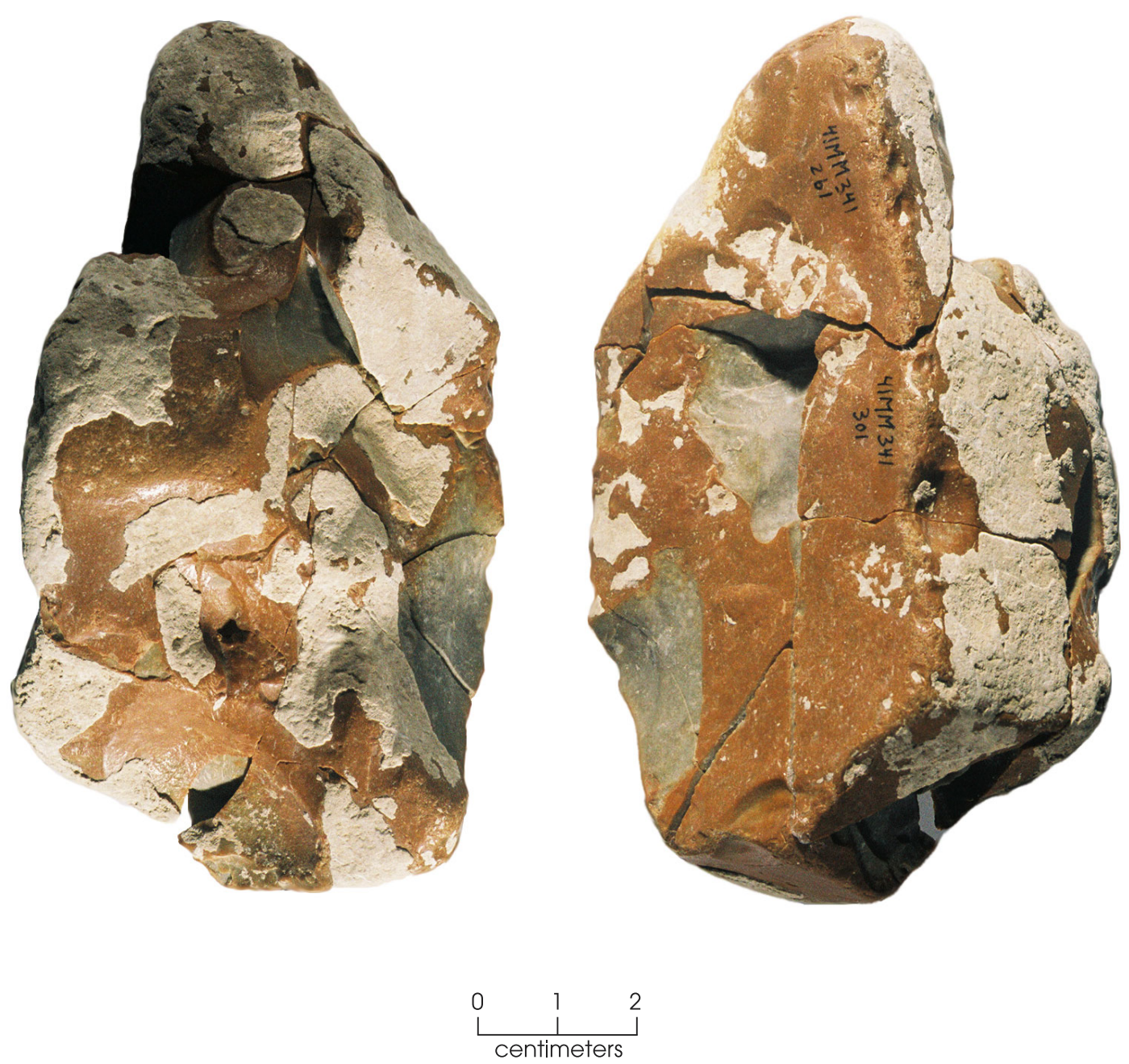

Figure 6-13. Reconstructed Cobble 7 from lithic reduction debris Pile 1.

main parts, strengthens the conclusion that the piles are generally discrete and little disturbed.

The reasons that so many fewer refits were identified in all the piles other than Pile 1 may be complex. It may relate to the type of reduction represented by a pile. For example, it stands to reason that it could be easier to refit pieces from simple core reduction vs. the myriad of small flakes generated by bifacial tool production. Also, the longer a pile was exposed to reoccupation of the site, the greater the chance for overprinting or dispersal (accidental or intentional) of larger pieces to other parts of the site not explored by the excavations or not included in this study. As discussed below, Pile 1 is unusual in that it appears to represent more core reduction than the other piles. And as noted above, Pile 1 was deposited late in the site's his- tory, reducing the chances for overprinting and disaggregation.

Remembering that this analysis uses color, texture, and inclusions as a basis for cobble identification and to establish MNC, certain easily recognizable materials in the collection can be used in addition to refits to explore the distributions of cobble materials relative to the lithic reduction piles in which they originated. Several materials stand out from the brown, gray, and yellow cherts of most of the recognized cobbles, and these unusual materials were recognized with confidence wherever they occurred during analysis. The distributions of seven such cobbles are shown in Figure 6-15.

These seven easily recognizable cobbles include 10 fragments of light bluish gray novaculite designated Cobble 2 of Pile 1 . This is the only novaculite identified and the only unique 
Table 6-6. Summary of data on the horizontal and vertical extent of the lithic reduction debris piles

\begin{tabular}{|c|c|c|c|c|c|c|}
\hline Pile & Level & $\begin{array}{c}\text { Levels } \\
\text { Analyzed }\end{array}$ & $\begin{array}{l}\text { Levels } \\
\text { in Pile }\end{array}$ & $\begin{array}{c}\text { Matching } \\
\text { Debitage (\#) }\end{array}$ & $\begin{array}{c}\text { Matching } \\
\text { Debitage }(\%)\end{array}$ & Refits \\
\hline \multirow[t]{2}{*}{1} & 6 & 26 & 7 & 444 & 100 & 69 \\
\hline & 7 & 8 & 0 & 0 & 0 & 0 \\
\hline \multirow[t]{3}{*}{2} & 6 & 13 & 5 & 77 & 23 & 1 \\
\hline & 7 & 19 & 8 & 253 & 76 & 1 \\
\hline & 8 & 9 & 0 & 1 & 1 & 0 \\
\hline \multirow[t]{2}{*}{3} & 6 & 8 & 7 & 167 & 91 & 3 \\
\hline & 7 & 11 & 0 & 16 & 9 & 1 \\
\hline \multirow[t]{3}{*}{4} & 6 & 8 & 0 & 20 & 3 & 0 \\
\hline & 7 & 18 & 14 & 734 & 96 & 11 \\
\hline & 8 & 9 & 0 & 9 & 1 & 0 \\
\hline \multirow[t]{3}{*}{5} & 6 & 6 & 1 & 16 & 8 & 0 \\
\hline & 7 & 13 & 5 & 150 & 75 & 7 \\
\hline & 8 & 9 & 1 & 33 & 16 & 1 \\
\hline \multirow[t]{3}{*}{6} & 7 & 6 & 0 & 0 & 0 & 0 \\
\hline & 8 & 17 & 8 & 510 & 100 & 5 \\
\hline & 9 & 6 & 0 & 0 & 0 & 0 \\
\hline \multirow[t]{3}{*}{7} & 7 & 7 & 0 & 1 & 1 & 0 \\
\hline & 8 & 14 & 12 & 227 & 93 & 9 \\
\hline & 9 & 7 & 1 & 17 & 7 & 0 \\
\hline \multirow[t]{3}{*}{8} & 8 & 10 & 3 & 25 & 8 & 0 \\
\hline & 9 & 9 & 9 & 300 & 90 & 1 \\
\hline & 10 & 6 & 0 & 6 & 2 & 0 \\
\hline \multirow[t]{3}{*}{9} & 6 & 6 & 0 & 9 & 1 & 0 \\
\hline & 7 & 11 & 10 & 938 & 97 & 7 \\
\hline & 8 & 6 & 0 & 16 & 2 & 0 \\
\hline \multirow[t]{3}{*}{10} & 7 & 6 & 0 & 0 & 0 & 0 \\
\hline & 8 & 16 & 8 & 185 & 92 & 0 \\
\hline & 9 & 10 & 1 & 17 & 8 & 0 \\
\hline Total & & 294 & 100 & 4,171 & & 116 \\
\hline
\end{tabular}

material to have refitting pieces. Two refits occurred within Excavation Unit 27 (the locus of Pile 1) and one between Excavation Units 14 and 37 (see Figure 6-14). All novaculite pieces are in Pile 1 and to the south of it. From Pile 2 came a translucent brown to light gray chert with a waxy texture totaling 62 pieces. Designated Cobble 8, this material is distributed across Pile 2, below the northern edge of Pile 1, and across Trench 4 on the eastern edge of Pile 4 (see Figure 6-15). Cobble 1 from Pile 3 con- sists of 20 pieces and 1 core of coarse gray chert with light gray banding. This cobble also crosses Trench 4, as pieces of this material were recovered from Pile 2 (see Figure 6-15). From Pile 4, Cobble 13 is a waxy light gray chert with yellow hair-like veins. A total of 14 flakes and 1 core were recovered, all tightly clustered in the southern lobe of the pile. Another apparently tightly clustered unique material is Cobble 5 from Pile 6 . This cobble is composed of waxy chert with fine pinkish gray bands. A total of 35 flakes were 


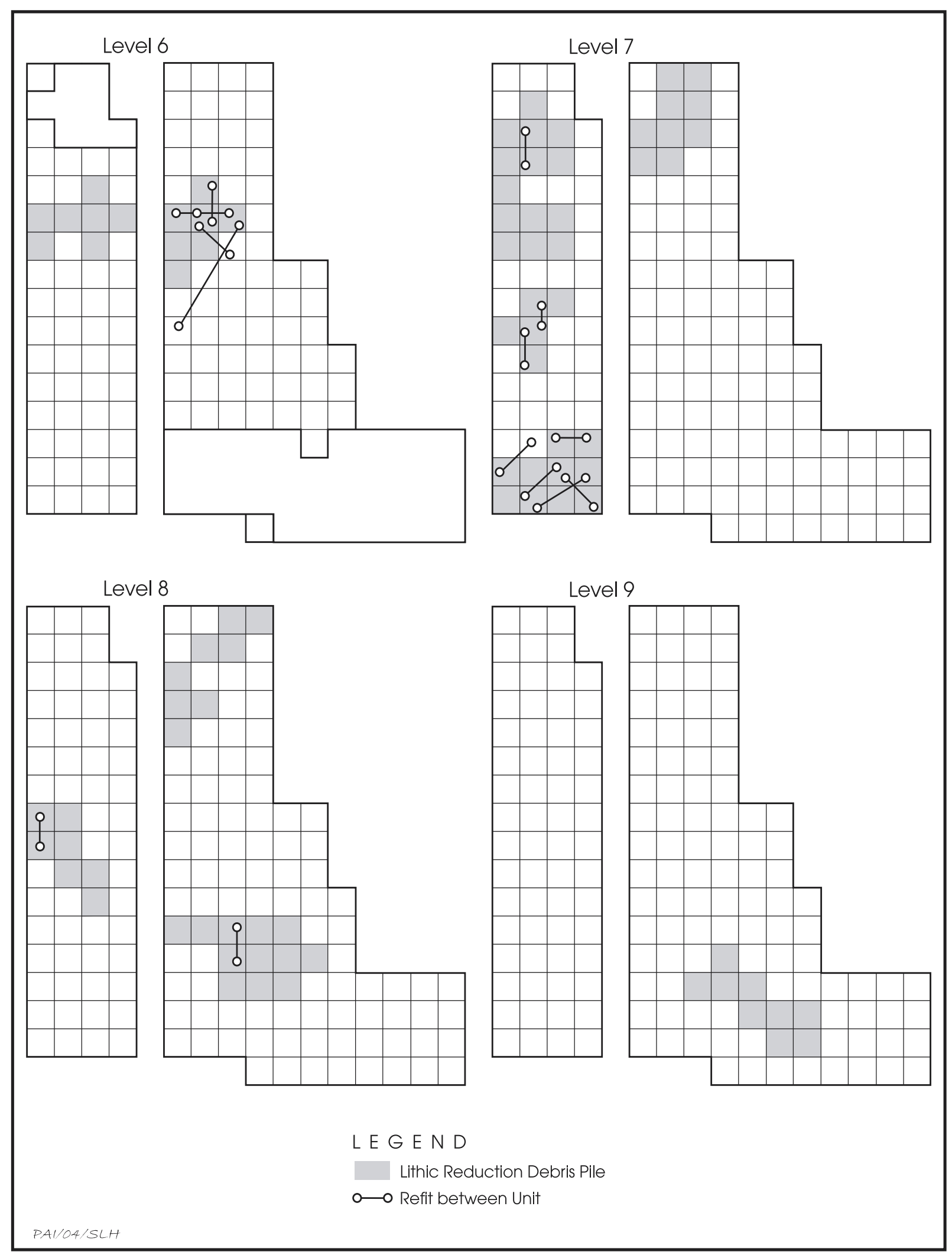

Figure 6-14. Refits between excavation units in the lithic reduction debris piles. 


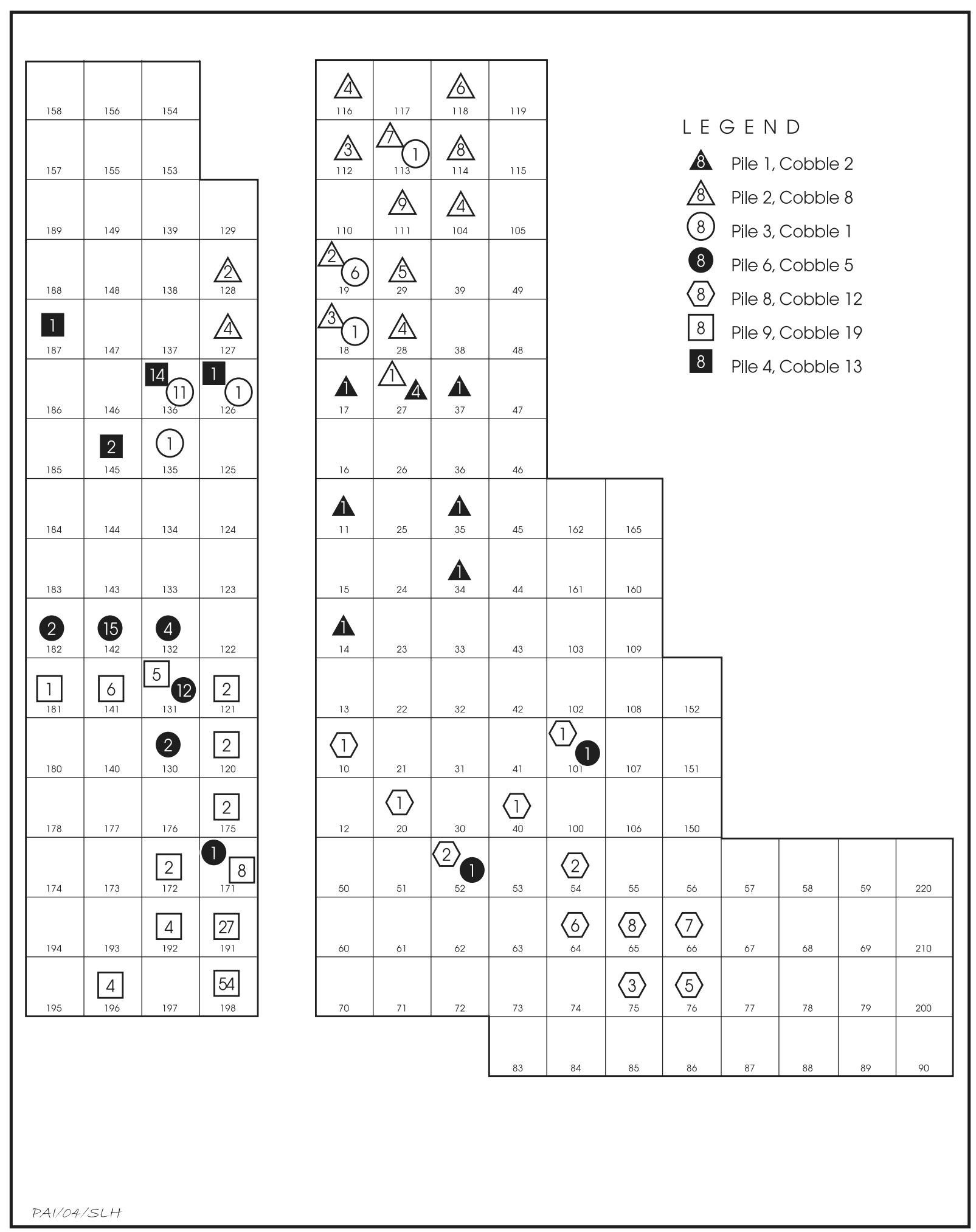

Figure 6-15. Horizontal distributions of easily recognizable debitage within the Main Block (the numbers within the symbols reflect the frequency of a particular material within the unit). 
recovered from the southern edge of Pile 6. One core came from Excavation Unit 171 at the north edge of Pile 9, and 2 flakes were found to the east of Trench 4 in Units 52 and 101 of Pile 7 (see Figure 6-15). Pile 9 also produced a unique oolitic chert with light gray and red oolites producing a speckled effect. This material (Cobble 19) consists of 95 flakes concentrated mostly in the southeast corner of Pile 9, but also scattered north along Trench 4 to the southern edge of Piles 5 and 6 . This material was not seen across Trench 4. Across the trench in the southeast section of the block, Pile 8 produced Cobble 12, a pinkish gray fine-grained quartzite. Most of this cobble occurs in the southeastern end of Pile 8, but it also is scattered to the northwest into Pile 7 (see Figure 6-15).

The distributions of unique materials described above indicate that, although a few cobble fragments extend beyond the main pile concentrations, as in Cobble 1 of Pile 3 and Cobble 5 of Pile 6 , most stay within $2-3 \mathrm{~m}$ of their pile of origin. This confirms what the refitting of cobble pieces suggests-that the integrity of the lithic piles is high.

\section{Cobble Characteristics}

The characteristics of these cobbles, including number, size, and material type, are important as they can be used to address questions concerning local access vs. trade for lithic resources, as well as what tools were manufactured at the site and what reduction strategies were employed in those manufacturing processes. Based on the analysis of the lithic reduction debris piles, there is a minimum of 139 distinct cobbles represented within the debitage associated with the piles (see Table 6-5). Given that 168 cores were recovered from the three excavation blocks and only 63 of these were from the reduction debris piles, it is obvious that many more cobbles were reduced onsite than identified in the piles.

Cores played a significant part in the identification and reconstruction of cobbles. The number of cores per identified cobble ranges from 1 to 5 with an average of 1.4. As would be expected, cores from the piles are mainly exhausted specimens ( $n=28,37$ percent) or fragmentary ( $\mathrm{n}=32,42$ percent). Many of these cores display bidirectional flake removals $(\mathrm{n}=34$, 45 percent) though multidirectional cores
( $\mathrm{n}=21,28$ percent) and unidirectional cores ( $\mathrm{n}=21,28$ percent) are well represented. Bidirectional flake removals are also present on reconstructed Cobble 10 from Pile 4 (Figure 6-16). However, Cobble 10 is reconstructed from 12 flakes that refit an exhausted multidirectional core. This reconstruction suggests that bidirectional flake removal was an initial part of the cobble reduction process.

The many multidirectional cores recovered, as well as some of the reconstructed cobbles, suggest that reduction was often unpatterned. Unpatterned reduction appears especially significant for Pile 1, which produced nine multidirectional cores. The intended result of this cobble core reduction (even of the unpatterned kind) could be the production of flakes for arrow point or expedient tool production. One clear example of the use of unpatterned reduction for tool production is Cobble 7, Pile 1. This cobble was almost completely reconstructed based on seven flakes and one multidirectional core (see Figure 6-13) but is missing one large, thin, interior flake. It is possible that the missing flake was used to fashion the broken Alba arrow point of the same material type that was also recovered from Pile 1 (see Figure 7-2b).

Cobble size was not addressed during analysis of the lithic reduction piles, other than through reconstruction of four mostly whole cobbles. These are Cobbles 4, 7, and 10 from Pile 1 and Cobble 10 from Pile 4. They have maximum dimensions ranging from 8.9 to $15.6 \mathrm{~cm}$. This places them at the high end of the size range for cores, which is $4.0-13.5 \mathrm{~cm}$ (mean = $6.6 \mathrm{~cm}$ ). Choppers and hammerstones/choppers, some of the largest chipped stone tools, are basically cobbles with one end bifacially worked; they are slightly smaller than the reconstructed cobbles at 6.5 to $10.7 \mathrm{~cm}$. Knives and knife preforms, another large chipped stone tool category, have a maximum dimension range of 5.6$10.7 \mathrm{~cm}$. Again, these tools are slightly smaller than the range of the reconstructed cobbles. This simple comparison, though based on a small sample size, suggests that the cobbles associated with the lithic reduction piles are large enough to accommodate the production of the large chipped stone tools recovered from the site.

The origins of the lithic reduction debris pile cobbles can be addressed by considering cobble cortex. Water-rolled chert cobbles have exteriors shaped by battering and then smoothing 

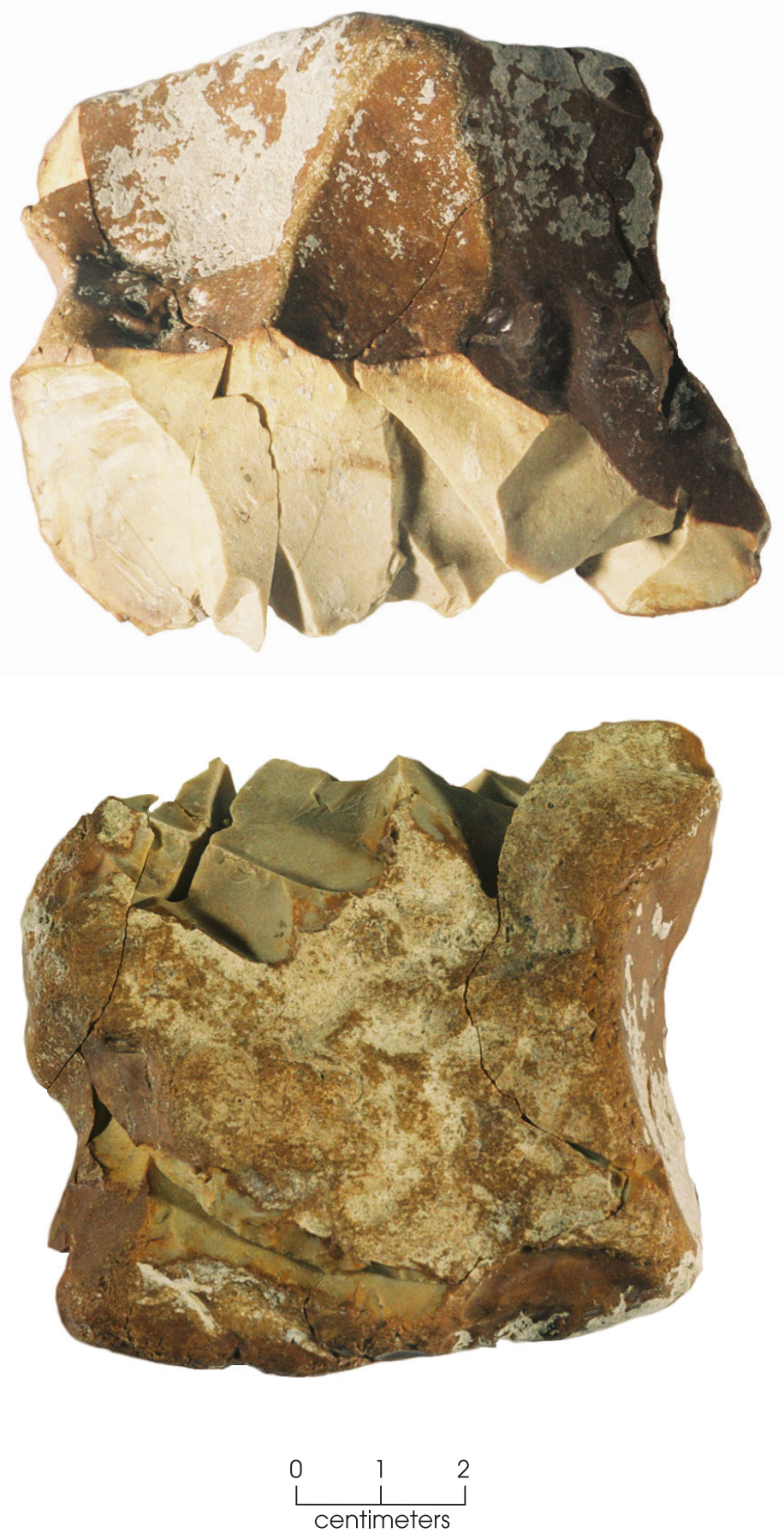

Figure 6-16. Reconstructed Cobble 10 from Pile 4 showing bidirectional flake removals.

from transport as bed load. Cortex on bedded chert may be smooth from chemical weathering but is chalky and distinctive from that of waterrolled cobbles. Ninety-six percent of the analyzed debitage with cortex from the lithic reduction debris piles appears to have come from water- rolled cobbles, while 3.6 percent is indeterminate and only 0.4 percent may be from bedded materials. This strongly suggests that almost all of the raw lithic materials were gathered from either Little River gravel bars or Pleistocene gravel deposits exposed by the river. Personnel with CAR collected chert nodules from the Little River during their excavations of nearby site 41MM340. Most cobbles in that collection range in size from 8 to $12 \mathrm{~cm}$ with a maximum of $16 \mathrm{~cm}$ (Tomka et al. 2003:149). This cobble size fits well with the reconstructed cobbles from 41MM341.

The materials in the CAR gravel collection are described as "a variety of yellows, tans, and light browns" (Tomka et al. 2003:149). The most common colors seen in the cobbles of the lithic reduction debris piles are brown, gray to light gray, grayish brown or brownish gray, and pale brown (Table 6-7). These distinctions suggest that a gray color, occurring in 52 percent of the cobble sample, is much more common than in the recent CAR Little River sample.

It apparently is not more common than in the debitage sample from 41MM340, however, because a gray color is prominent in more than half $(\mathrm{n}=9)$ of the 14 chert types identified by Tomka et al. (2003:151). These color differences could reflect some sampling bias or suggest that different gravel beds were exposed at the time the site was occupied.

The lithic reduction pile cobbles also were compared to samples of central Texas chert. The lithic material types used for comparison were defined from archeological investigations at Fort Hood in Bell and Coryell Counties (Trierweiler 1994:151-153). These types include Leona Park chert, Fort Hood Gray chert, Gray-Brown-Green chert, Fort Hood Yellow 
Table 6-7. Cobble color and material affiliation for the lithic reduction piles

\begin{tabular}{|c|c|c|c|c|c|c|c|c|}
\hline Color & $\begin{array}{c}\text { No Material } \\
\text { Affiliation }\end{array}$ & 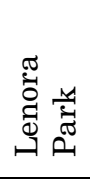 & 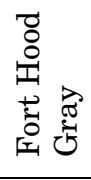 & 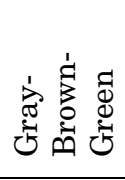 & 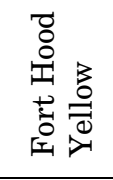 & 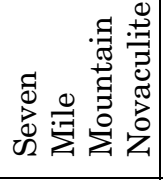 & $\begin{array}{c}\text { Total } \\
\text { Cobbles } \\
(\text { No. })\end{array}$ & $\begin{array}{c}\text { Total } \\
\text { Cobbles } \\
(\%)\end{array}$ \\
\hline Brown & 16 & 0 & 0 & 0 & 0 & 0 & 16 & 10.7 \\
\hline Dark gray & 5 & 0 & 4 & 0 & 0 & 0 & 9 & 6.0 \\
\hline $\begin{array}{l}\text { Dark yellowish } \\
\text { brown-yellowish } \\
\text { brown }\end{array}$ & 9 & 0 & 0 & 1 & 0 & 0 & 10 & 6.7 \\
\hline Gray-light gray & 26 & 1 & 0 & 5 & 0 & 0 & 32 & 21.5 \\
\hline $\begin{array}{l}\text { Grayish brown- } \\
\text { brownish gray }\end{array}$ & 17 & 0 & 0 & 13 & 0 & 0 & 30 & 20.0 \\
\hline Light blue gray & 1 & 0 & 0 & 0 & 0 & 0 & 1 & 0.7 \\
\hline Pale brown & 17 & 0 & 0 & 1 & 14 & 0 & 32 & 21.5 \\
\hline Pinkish gray & 6 & 0 & 0 & 0 & 0 & 0 & 6 & 4.0 \\
\hline Red & 1 & 0 & 0 & 0 & 0 & 0 & 1 & 0.7 \\
\hline Yellow & 3 & 0 & 0 & 0 & 1 & 0 & 4 & 2.7 \\
\hline Indeterminate & 7 & 0 & 0 & 0 & 0 & 1 & 8 & 5.4 \\
\hline Total & $108 / 72 \%$ & $1 / 1 \%$ & $4 / 3 \%$ & $20 / 14 \%$ & $15 / 9 \%$ & $1 / 1 \%$ & 149 & \\
\hline
\end{tabular}

chert, and Seven Mile Mountain Novaculite. Table 6-7 shows that the color categories grayish brown-brownish gray and pale brown are most often associated with Gray-Brown-Green and Fort Hood Yellow, respectively. There is variation in color within these chert types, and gradation between them has been noted (Ellis and Abbott 1994:277). This variation likely accounts for several different color categories being associated with the Gray-Brown-Green material type (see Table 6-7). Over one-quarter of the identified cobbles in the debris piles ( $\mathrm{n}=41,27.5$ percent) can be related to specific Fort Hood chert types. All 41 have water-rolled cortex indicating that they probably were brought to the vicinity of the site by the Little River. Although comparable materials with water-rolled cortex do occur in the Fort Hood area (along with bedded chert with chalky white to yellow cortex), there is no reason to think that cobbles were imported to 41MM341. The gravel bars of the Little River provided a highquality and local lithic resource for the occupants of 41MM341, and they used that resource intensively.

\section{Debitage Characteristics}

The characteristics of the debitage in the lithic debris piles provide important information on the kinds of reduction the piles repre- sent. The debitage from the main levels of six of the piles (Piles 1, 3, 6, 7, 8, and 9) was analyzed, and the results are presented in Chapter 7. Pertinent aspects of that analysis are summarized here.

The major result of the analysis is that few differences are apparent between the piles in terms of debitage characteristics, except for Pile 1. Most of the piles have about 50 percent chips, with flakes at 48 percent and chunks at 1 percent. Pile 1 diverges with 52 percent flakes. In terms of debitage size, all piles are composed of a significant amount (29-40 percent) of small debris $(<1.5 \mathrm{~cm})$, while Pile 1 produced the highest amount (9 percent) of large debris $(>3.8 \mathrm{~cm})$. Large debris makes up only $2-4$ percent of the other piles. Most of the piles are composed of decorticate debris (7074 percent). But once again, Pile 1 has the most debris (14 percent) that displays $>50$ percent cortex.

Comparison of the analyzed reduction piles based on flake type as an indication of reduction emphasis indicates that all but Pile 1 have similar percentages of biface-reduction and biface-thinning flakes (19-22 percent) vs. core preparation/reduction flakes (17-24 percent). Pile 1 stands out with only 11 percent biface-reduction and thinning flakes and 32 percent core preparation/reduction flakes. These flake type percentages-along with the 
many relatively large and corticate flakesindicate that Pile 1 likely was generated mainly through cobble core reduction and that all the other piles were generated by a more-even mix of core reduction and biface production. In addition, biface-resharpening flakes, which are evidence of tool refurbishing, occur in all piles, even Pile 1, at 4 to 7 percent.

\section{Associated Tools}

It is likely that many of the lithic tools found in association with the debris piles are the result of the lithic reduction that generated the piles. A total of 121 formal chipped stone tools were recovered from the 10 piles (see Table 6-5). These artifacts make up 39 percent of the total chipped stone tool recovery $(\mathrm{n}=314)$ from all excavation blocks and include specimens in 15 of the 16 tool categories. Not surprisingly, most of these are arrow points $(n=27)$, arrow point preforms $(\mathrm{n}=31)$, knives $(\mathrm{n}=14)$, and knife preforms $(n=17)$. Other formal tool categories represented are dart points $(\mathrm{n}=2)$, dart point preforms $(\mathrm{n}=1)$, early-stage bifaces $(\mathrm{n}=8)$, indeterminate bifaces $(\mathrm{n}=13)$, adzes $(n=2)$, gouges $(n=1)$, gravers $(n=2)$, perforators $(n=1)$, choppers $(n=1)$, and chipped stone hammerstones $(\mathrm{n}=1)$.

Expedient tools $(n=185)$ from the debris piles constitute 37 percent of the total expedient tool recovery. The numbers of expedient tools within the piles range from 4 in Pile 10 of Level 8 to 48 in Pile 4 of Level 7, with the mean being 19 tools (see Table 6-5). The highest concentra- tion consists of 17 tools recovered from Pile 1 in Level 6 of Excavation Unit 27. As described above, Pile 1 appears to have been produced mainly through cobble core reduction. Given the concentration of expedient tools there, it can be suggested that one purpose of that reduction was the production of flakes for expedient use. The mere presence of the tools in these contexts indicates that the need for them was immediate, with tool acquisition, use, and discard occurring at the same place.

It is reasonable to think that formal tools would not be deposited in the same debris pile as the residue from their manufacture unless they were made and used on the spot or if they broke during the manufacturing process. Tools that can be matched with identified cobbles are, thus, the best indicators of what was manufactured to produce any particular debris pile. A clear example of this cobble to tool association is a knife preform recovered in three pieces from Pile 9 (Excavation Unit 196, Level 7). This preform is of the same material as Cobble 14 from this pile. In addition, flakes from the same level that are associated with Cobble 14 refit to the preform (see Figure 7-13d). This tool-cobble match indicates beyond a doubt that bifacial reduction for the production of knives and knife preforms partly generated Pile 9 .

Another way to establish what was being manufactured is to compare the break types in the formal tools associated with the debris piles to those tools recovered off the piles. Table 6-8 shows that most arrow and knife preforms (67 percent) were broken with lateral snaps and that most of these broken tools (63 percent) are

Table 6-8. Break types associated with selected formal chipped tools from the lithic reduction debris piles and off-pile contexts

\begin{tabular}{|c|c|c|c|c|c|c|c|c|c|c|c|c|c|c|c|c|}
\hline & \multicolumn{2}{|c|}{ Damage } & \multicolumn{2}{|c|}{ Heat } & \multicolumn{2}{|c|}{ Impact } & \multicolumn{2}{|c|}{ Stem } & \multicolumn{2}{|c|}{$\begin{array}{c}\text { Lateral } \\
\text { Snap }\end{array}$} & \multicolumn{2}{|c|}{ Perverse } & \multicolumn{2}{|c|}{ Complete } & \multicolumn{2}{|c|}{ Totals } \\
\hline & On & Off & On & Off & On & Off & On & Off & On & Off & On & Off & On & Off & On & Off \\
\hline Arrow & 1 & 0 & 2 & 3 & 0 & 13 & 5 & 10 & 12 & 13 & 3 & 2 & 4 & 11 & 28 & 51 \\
\hline $\begin{array}{l}\text { Arrow } \\
\text { Preform }\end{array}$ & 2 & 0 & 0 & 0 & 0 & 1 & 0 & 0 & 21 & 16 & 4 & 9 & 4 & 3 & 31 & 29 \\
\hline Knife & 0 & 0 & 2 & 0 & 0 & 0 & 0 & 0 & 9 & 15 & 1 & 0 & 2 & 2 & 14 & 17 \\
\hline $\begin{array}{l}\text { Knife } \\
\text { Preform }\end{array}$ & 0 & 0 & 0 & 1 & 0 & 0 & 0 & 0 & 14 & 5 & 1 & 1 & 2 & 0 & 17 & 7 \\
\hline $\begin{array}{l}\text { Early } \\
\text { Biface }\end{array}$ & 0 & 0 & 0 & 0 & 0 & 0 & 0 & 0 & 4 & 12 & 1 & 2 & 3 & 6 & 9 & 19 \\
\hline $\begin{array}{l}\text { Indeter- } \\
\text { minate } \\
\text { Biface }\end{array}$ & 0 & 0 & 2 & 3 & 0 & 0 & 0 & 0 & 7 & 7 & 3 & 0 & 1 & 4 & 13 & 14 \\
\hline
\end{tabular}


in the debris piles. A lateral snap occurs when excessive force is applied to the side or end of a biface during manufacture or refurbishment (Johnson 1981:25). Perverse fractures also may be considered manufacturing breaks (Crabtree 1972:82). Perverse fractures on arrow preforms are common both in the debris piles and off them, as are lateral snap breaks for all tools; this suggests that some final stages of production or refurbishment are reflected in both contexts. Lateral snap breaks also may occur during use of knives, and the high frequency of off-pile breaks in this tool class ( 48 percent of all knives) may reflect common tool use away from the loci of tool production. The clearest evidence of use occurs in the arrow points. All arrows recovered with impact fractures and most of those with stem fractures ( 67 percent) were recovered from off-pile contexts. Impact fractures occur when a projectile strikes something hard, and stem fractures may occur when the arrow point is twisted in its haft.

\section{Summary}

Analysis of lithic concentrations in the Main Block, some of which were identified during fieldwork, confirms that they are lithic reduction debris piles and that they are fairly discrete and fairly intact. Groupings of like debitage and cores identify an average of 14 cobbles, minimally, for each pile. Debitage refits confirm cobble identifications, and few refits occur horizontally beyond the piles or vertically beyond the main concentrations.

Material colors of the identified cobbles, the stream-rolled cortex on those cobbles, and reconstructed cobble sizes indicate that most of the materials in the piles are from the local Little River gravels. Even lithic materials similar to several central Texas chert types recovered from the piles display stream-rolled cortex. Clearly, the people who occupied 41MM341 had ready access to high-quality chert.

Finally, analysis of the lithic reduction debris piles provides answers to research questions concerning assemblage organization or, more specifically, the kinds of tools that were produced at the site. Formal chipped stone tools associated with identified cobbles in the piles and information on break types point to the manufacture chiefly of arrow points and knives. Some maintenance and use of these tools, and probably all formal tools, also occurred in onpile and off-pile contexts.

Another major production strategy represented in the debris piles is core reduction. Core reduction/preparation flakes, exhausted cores, and core fragments make up significant parts of all analyzed piles. Many of the cores and some of the reconstructed cobbles suggest that core reduction was often unpatterned, especially for Pile 1. The intended products of the unpatterned core reduction could have been flakes for arrow point production or use as expedient tools. The former is demonstrated by reconstructed Cobble 7 and an Alba point of the same material in Pile 1 . The latter is demonstrated by the fact that a small number of expedient tools $(n=6)$ could be related directly to identified cobbles and the fact that numerous expedient tools were recovered from all piles. 


\section{ARTIFACT DESCRIPTIONS}

The materials recovered from 41MM341 provide information for addressing all of the research questions posed for the site. This chapter presents descriptions of these materials, which consist of chipped stone debitage, cores, chipped stone tools, ground and battered stone tools, bone tools and modified bones, vessel ceramics, burned and unburned rocks, and burned clay. Several categories of materials that are described and analyzed in appendixesvertebrate and invertebrate faunal remains and macrobotanical remains-are summarized as well. Metric data for the chipped stone and ground and battered stone tools can be found in Appendix I.

\section{CHIPPED STONE ARTIFACTS}

Chipped stone artifacts consist of unmodified debitage $(\mathrm{n}=39,872)$, cores $(\mathrm{n}=168)$, arrow points and their preforms $(\mathrm{n}=139)$, dart points and preforms $(\mathrm{n}=18)$, knives and their preforms $(n=55)$, perforators $(n=2)$, awls $(n=2)$, gravers $(n=4)$, adzes $(n=8)$, wedges $(n=2)$, gouges $(n=10)$, other bifaces and biface fragments $(n=60)$, hammerstones $(n=3)$, hammerstones/choppers $(\mathrm{n}=4)$, choppers $(\mathrm{n}=6)$, and expedient tools consisting of usemodified and minimally retouched debitage $(\mathrm{n}=494)$.

\section{Unmodified Debitage}

The unmodified lithic debitage consists of 37,338 pieces from the Main Block, 1,472 pieces from the East Block, 153 pieces from the South Block, and the remainder from the isolated initial units. A sample of 11,525 pieces, or 29 percent of the total, was analyzed, and the results are discussed here. This sample was drawn mostly from the Main Block and includes all the debitage associated with lithic reduction debris Piles $1,3,6,7,8$, and 9 . These piles were selected because the matching and refitting debitage within them demonstrates that they were contained in single levels, and thus they appear most discrete (see Chapter 6 for an explanation of how these piles were defined). Two such discrete piles were selected from each of the four principal levels in the Main Block (Levels 6-9). Also included in the analyzed sample is the debitage from Level 10 of the East Block. It was added to provide a larger sample from Level 10-that is, the deepest part of the excavation-than is available from the Main Block.

Table 7-1 shows the composition of the samples based on debitage completeness, cortex percentage, and size class. Most of the samples, particularly Piles $3,6,7,8$, and 9 , are remarkably consistent in terms of these attributes. They have nearly equal percentages of chips and flakes and negligible percentages of chunks, they are overwhelmingly decorticate (70-74 percent), and they are predominately small with 82-89 percent being less than $2.5 \mathrm{~cm}$. Pile 1 stands out from the other samples in all these respects. It has higher percentages of flakes and chunks, less decorticate debitage (65 percent) and about twice as much debitage with more than 50 percent cortex (14 percent) as the other piles, and less debitage smaller than $2.5 \mathrm{~cm}$ (74 percent).

Comparing size and debitage completeness, it is not surprising that chips are generally small with 92 percent at $2.5 \mathrm{~cm}$ or less. Flakes and chunks are larger, as 76 and 71 percent, respectively, are $2.5 \mathrm{~cm}$ or less. And 3 percent of the chunks are greater than $5 \mathrm{~cm}$ in maximum 
Data Recovery Excavations at the J. B. White Site

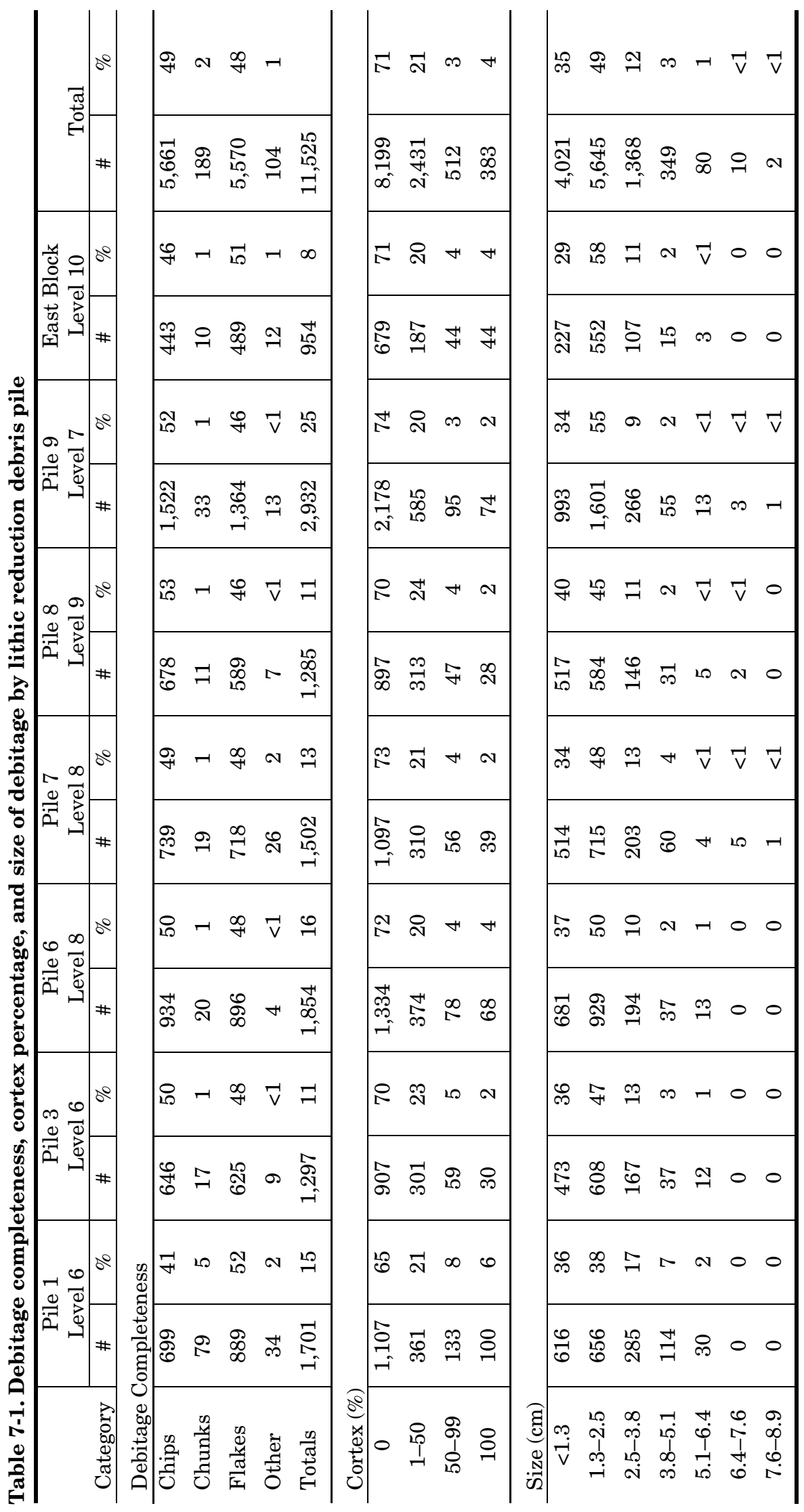


dimension, whereas only 1.5 percent of the flakes are this large. Decorticate debitage is also small with 91 percent being $2.5 \mathrm{~cm}$ or less in size. Small decorticate debitage makes up between 56 and 69 percent of the samples. Piles 6 and 9 have the highest frequencies of this debitage at 67 and 69 percent, respectively. Pile 1 has the lowest at 56 percent.

Flake type analysis indicates that each pile is made up of debitage resulting from a variety of tool production strategies. For example, bifacereduction and biface-thinning flakes constitute 19 percent of the overall sample, while core preparation/reduction is comparable at 22 percent (Table 7-2). Most samples are close to these overall percentages, varying between biface and core reduction by only 1-3 percent. Pile 1 is the exception; in this pile, core preparation/ reduction flakes outnumber biface-reduction and thinning flakes combined by two to one. This relative emphasis on core reduction for Pile 1 explains the higher percentages of large debitage and debitage with cortex noted above.

Biface-resharpening flakes are a small but consistent constituent of each pile at 4-7 percent. Present in even smaller numbers are blade blanks, uniface manufacture/repair flakes, and notching flakes. The low frequency of blade blanks may indicate that blades were not essential for these particular production strategies and that less well-patterned flakes sufficed. The occurrence of the few uniface manufacture/ repair flakes seems incongruous given that no formal unifacial tools were recovered from the site. It is possible that some of the unifacially retouched expedient tools can account for this flake type in the sample, or that formal unifacial tools were carried away from the area exposed by the excavation blocks. Still, the low numbers of uniface manufacture/repair flakes indicate that unifacial tools were not a major production goal. Notching flakes, on the other hand, seem under-represented given that tool production was oriented partly to projectile point production. The limited number of notching flakes may be due to their small size (all notching flakes are less than $1.5 \mathrm{~cm}$ in maximum dimension) and the difficulty in recognizing small, broken specimens.

In summary, the debitage characteristics and flake type breakdown indicate an overall similarity between the samples. Each pile appears to represent more than a single reduction strategy; these strategies include (in order of overall importance): core preparation/reduction, bifacial reduction, bifacial thinning, and bifacial resharpening likely associated with tool refurbishment. Present, but in very low frequencies, is debitage associated with blade production, uniface manufacture/repair, and notching. Blade and uniface production appear to have been genuinely unimportant. The low numbers of notching flakes, especially associated with arrow point production, may be due to size and survivability.

Given the similarities between the piles, only a few differences in reduction emphasis are apparent. For instance, Pile 1 appears to be strongly associated with core reduction based on its numerous large cortical flakes and its high frequencies of core preparation/reduction flakes. Though not particularly evident based on flake type, an emphasis on late-stage reduction or resharpening is indicated in Piles 6 and 9 where small decorticate debitage is numerous. Finally, the sample from Level 10 of the East Block, though dissimilar from the other samples in terms of context (i.e., it is not a recognized lithic reduction debris pile representing a limited number of knapping episodes), is similar to Piles $3,6,7,8$, and 9 in almost all respects. Of course, it is possible that it is similar to these piles contextually, but that this was not discernible because of the small size of the East Block.

\section{Cores}

A total of 122 cores and 46 core fragments were recovered. Exhausted specimens constitute over half the cores ( $\mathrm{n}=62 ; 51$ percent); the remainder are still-functional cores (cores from which flakes could still be struck) $(\mathrm{n}=48)$ or tested cobbles $(n=12)$. The number of flake removals on all cores and core fragments ranges from 1 to 12 with an average of 4 removals. Many of the cores and core fragments have bidirectional removals ( $\mathrm{n}=74 ; 44$ percent), and unidirectional ( $\mathrm{n}=48 ; 27$ percent $)$ and multidirectional ( $\mathrm{n}=45 ; 28$ percent) removals occur in equal proportions. The directionality of removals on only 1 core could not be determined.

Maximum dimensions range from 4 to $15 \mathrm{~cm}$ with an average of $6.6 \mathrm{~cm}$. The maximum dimensions of the 12 tested cobbles are at the high end, as they range from 6.5 to $11.0 \mathrm{~cm}$ and average $8.6 \mathrm{~cm}$. The tested cobbles provide an 
Data Recovery Excavations at the J. B. White Site

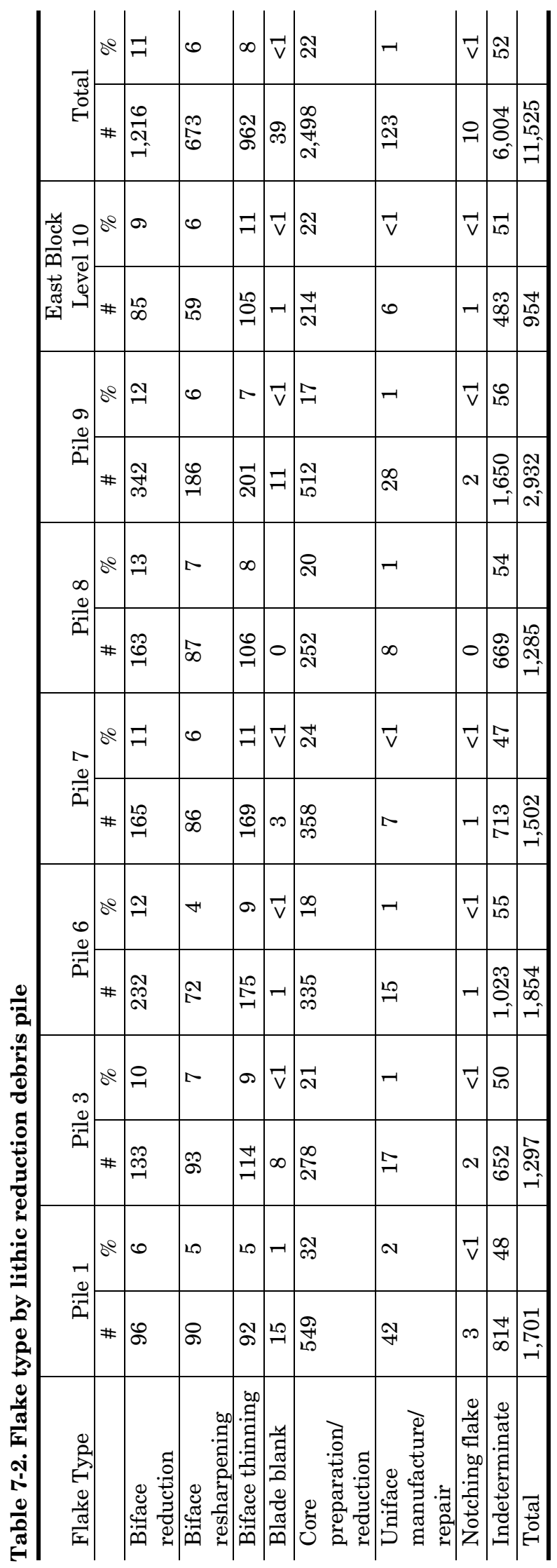


indication of the size of the cores available for tool production. However, several functional cores with 4-10 flake removals are even larger at $11.5,12.0,13.5$, and $15.0 \mathrm{~cm}$. These suggest that cobbles at least as large as $15.0 \mathrm{~cm}$ were available for tool production (Figure 7-1).

One of the research questions addressed by this study concerns the sources of the lithic materials utilized at the site. Given that 90 percent $(n=151)$ of the cores and core fragments display stream-rolled cortex, it is likely that they were gathered from nearby Little River gravel bars or from Pleistocene gravel deposits exposed by the river. Only 2 cores display a chemically weathered cortex suggestive of a bedded source. Neither of these can be related to a particular nonlocal chert source. One is a brown chert, and the other is of indeterminate color as it has been burned. Only 15 specimens display no cortex and could not be classified.

Most of the core and core fragments ( $\mathrm{n}=153 ; 91$ percent) show no evidence of heat alteration. For the few $(n=15)$ that do, it appears to be postdepositional. The original color and texture of only 4 of these heat-altered specimens are compromised to a degree that they could not be associated with any particular chert type.

Forty-three cores and core fragments, or 26 percent, could be related to specific cherts identified in the Fort Hood area of Bell and Coryell Counties (Trierweiler 1994:151-153). Most of these specimens are similar in color and texture to Fort Hood Yellow and Gray-BrownGreen, although three other types are represented as well (Table 7-3). Twenty of those that appear to represent Fort Hood cherts are from the lithic reduction debris piles, where they constitute 28 percent of the 71 specimens associated with the cobbles identified in these piles. As noted, the presence of these cherts at 41MM341 is not surprising given that tributaries of the Little River drain the Fort Hood area.

\section{Arrow Points}

\section{Alba}

Sixteen arrow points and point fragments are classified as the type Alba. Fourteen of the most complete specimens are pictured in Figure 7-2. These points are characterized by parallel to slightly expanding stems with flat, rounded, or concave bases. The blade margins are generally recurved, though a few have concave lateral edges. Fine pressure-flake scars are present on both faces of these points, though they often have stepped terminations that give the centers of the blades a jagged appearance. All points and fragments that retain a portion of the blade display short uneven serrations.

All of the Alba points are fashioned from chert. The most common color is gray to light gray occurring with six specimens. Other chert colors are grayish brown $(\mathrm{n}=3)$, brown $(\mathrm{n}=1)$, pale brown $(\mathrm{n}=2)$, yellow $(\mathrm{n}=2)$, and red $(n=1)$; color is indeterminate for two due to burning. Fort Hood chert types (Fort Hood Yellow and Gray-Brown-Green) are associated with eight (50 percent) of the specimens. Eight points (50 percent) are from the lithic reduction debris piles, and three could be associated with particular cobbles based on color, texture, and inclusions. These are Cobble 12 of Pile 1, Cobble 11 of Pile 6, and Cobble 17 of Pile 9.

These points consist of four complete or nearly complete specimens, seven proximal fragments, and five distal fragments. Break types are dominated by use fractures with five stem fractures and three impact fractures near the distal tips. Another five specimens have lateral snaps on the blades, and at least one of these clearly resulted from a resharpening error as evidenced by damage along the edge at the break.

Focusing on their recurved and serrated blades, the Alba points from 41MM341 appear to be a consistent group. However, there are differences in stem and shoulder characteristics. For instance, strong shoulders with outflaring barbs appear to dominate, but several points (one from Level 7 and two from Level 8) have expanding shoulders with large downwardoriented barbs (Figure 7-2k-m). No correlation can be made between stem edge/base form and shoulder characteristics, but it is interesting to note that stem edge/base forms generally differ by level. Level 8 has two points with expanding stems and flat bases (one point not pictured) and two with straight stems and rounded bases. Level 7 produced two points with expanding stems and rounded bases that are almost bulbous in form (Figure 7-2j-k) and a point with a straight stem and rounded base. Level 6 also produced a point with straight stem and a rounded base (Figure 7-2e) along with two points 

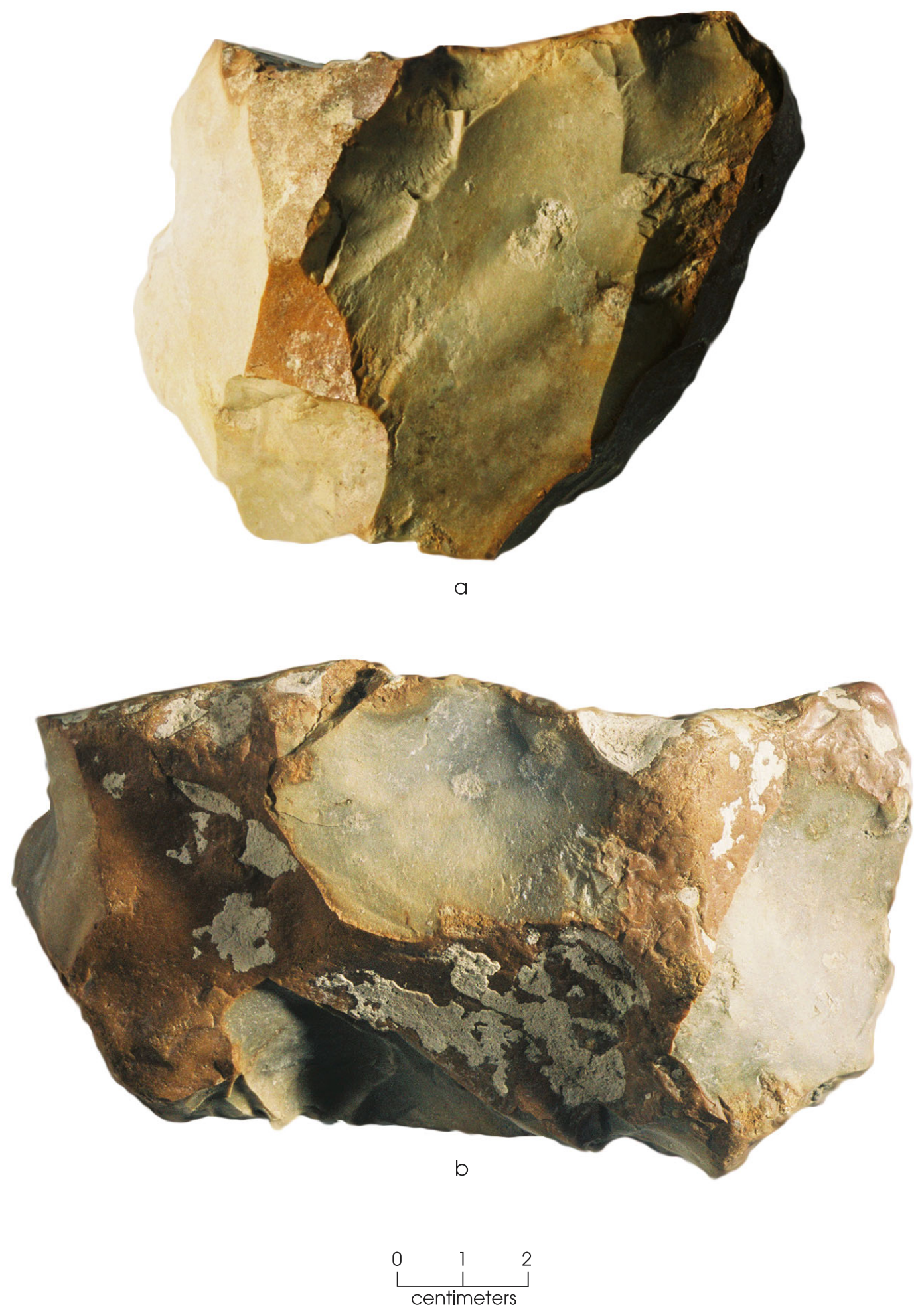

Figure 7-1. Large still-functional cores. (a) Multidirectional core measuring $11.5 \mathrm{~cm}$ from Excavation Unit 138, Level 7; (b) unidirectional core measuring $15.0 \mathrm{~cm}$ from Excavation Unit 319, Level 9. 
Table 7-3. Colors and Fort Hood chert type affiliations of the cores and core fragments

\begin{tabular}{l|c|c|c|c|c|c|c}
\hline Color & $\begin{array}{c}\text { Heiner } \\
\text { Lake Tan }\end{array}$ & $\begin{array}{c}\text { Fort Hood } \\
\text { Yellow }\end{array}$ & $\begin{array}{c}\text { Fort Hood } \\
\text { Gray }\end{array}$ & $\begin{array}{c}\text { Gray-Brown- } \\
\text { Green }\end{array}$ & $\begin{array}{c}\text { Lenora } \\
\text { Park }\end{array}$ & $\begin{array}{c}\text { No Type } \\
\text { Affiliation }\end{array}$ & Total \\
\hline Brown & 0 & 0 & 0 & 0 & 0 & 18 & 18 \\
\hline Dark gray & 0 & 0 & 1 & 0 & 0 & 6 & 7 \\
\hline $\begin{array}{l}\text { Dark yellowish } \\
\text { brown to } \\
\text { brownish yellow }\end{array}$ & 0 & 0 & 0 & 0 & 0 & 7 & 7 \\
\hline $\begin{array}{l}\text { Gray to light } \\
\text { gray }\end{array}$ & 0 & 0 & 0 & 8 & 1 & 27 & 36 \\
\hline $\begin{array}{l}\text { Grayish brown to } \\
\text { brownish gray }\end{array}$ & 0 & 0 & 0 & 10 & 0 & 23 & 33 \\
\hline Pale brown & 2 & 14 & 0 & 5 & 0 & 22 & 43 \\
\hline Pinkish gray & 0 & 0 & 0 & 0 & 0 & 7 & 7 \\
\hline Yellow & 0 & 2 & 0 & 0 & 0 & 4 & 6 \\
\hline Indeterminate & 0 & 0 & 0 & 0 & 0 & 11 & 11 \\
\hline Total & 2 & 16 & 1 & 23 & 1 & 125 & 168 \\
\hline
\end{tabular}

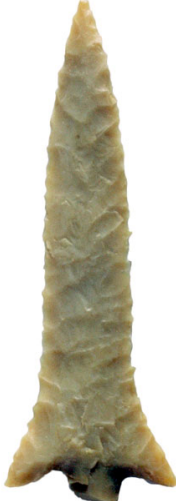

a

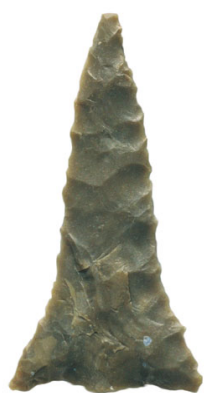

b

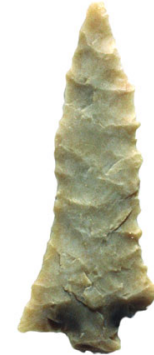

C

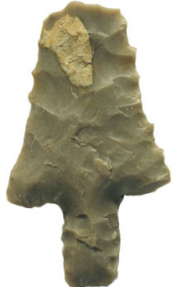

d

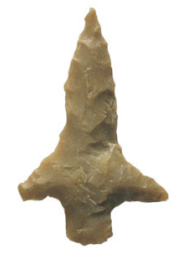

e

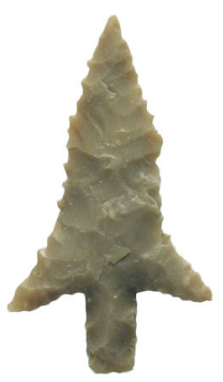

f

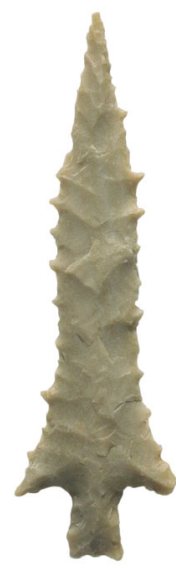

g

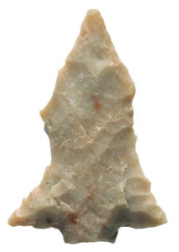

$\mathrm{h}$

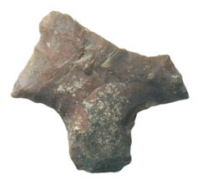

i

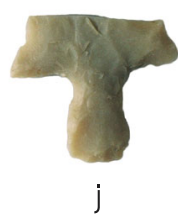

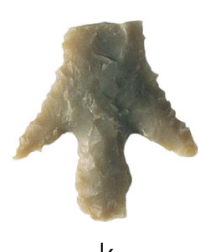

k

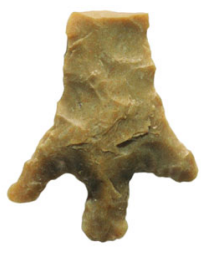

।

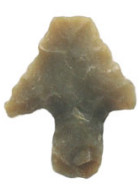

m

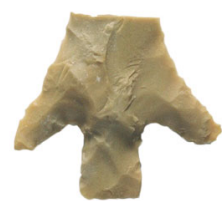

n

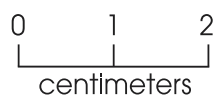

Figure 7-2. Alba arrow points. (a-f) Level 6; (g-k) Level 7; (l-n) Level 8. 
with straight stems and straight bases (Figure 7-2d, f). Another point from Level 7 (Figure 7$2 \mathrm{~g}$ ) with an expanding stem and concave base may be considered by some to be a Cuney arrow point (Suhm and Jelks 1962). However, the fine workmanship, outflaring barbs, long recurved blade, and base form are found in the collection of Alba points from a burial context at the George C. Davis site in Cherokee County (Shafer 1973:196-204). Variability within this small collection of Alba points suggests that stem edge/ base form may be the most sensitive of any arrow point characteristic to the preference of individual knappers. Since the stem is not seen in the finished product (i.e., the complete arrow), which may be otherwise socially or culturally controlled, stem edge/base form may be idiosyncratic to individual knappers.

That arrows with Alba points were significant cultural and social markers is demonstrated by their use as burial offerings at the George C. Davis site. The occurrence of Alba points in jumbled clusters and clusters of aligned points suggests they were deposited as containers of unhafted points and quivers of hafted points. Shafer (1973:194-195) illustrates 24 Alba points selected from the 150 recovered from Feature 134. The stem and base characteristics of all the Alba points from 41MM341 are present in this illustrated group of 24. Similar diversity in form is seen in Alba points from a possible quiver of 28 recovered from Feature 161, Cluster 1, at the George C. Davis site (Shafer 1973:199-202). Shafer defined five subgroups out of the 28 based on variations in form. These can be reinterpreted as four subgroups based solely on stem edge/base form. They are bulbar stems $(n=6)$, straight/straight $(n=7)$, straight/ rounded $(n=8)$, and straight/concave $(n=7)$. Such diversity in points from a single instance in time suggests a collection of points fashioned by various knappers-possibly from different groups. The presence of arrows from many knappers in a single quiver or container suggests trade in finished arrows or arrow points.

\section{Perdiz}

Eight arrow points and fragments are classed as Perdiz (Figure 7-3). These points are finely worked on both sides and have triangular blades that are serrated, often with irregular projections similar to those associated with the Steiner arrow point type. Stems are contracting or straight with rounded bases, while barbs are short to moderately long and generally sweep downward. Three specimens show evidence of postdepositional heating. All five broken specimens display lateral snaps suggesting they were broken during manufacture.

The materials of two specimens could be related to Cobbles 14 and 16 of Pile 9, suggesting that these points were made onsite. One of these (Figure 7-3e) is fashioned from a pale brown chert, and the other (Figure 7-3d) is a distinctive light gray chert with large white mottles. The other six specimens are gray $(\mathrm{n}=1)$, pale brown $(\mathrm{n}=2)$, or indeterminate due to heating $(\mathrm{n}=3)$. One of the gray specimens could be related to Fort Hood Gray-Brown-Green chert.

The Perdiz points from 41MM341 are reminiscent of the Perdiz points recovered from the McGuire's Garden site in Freestone County (Gadus et al. 2002:90-91). These Freestone County points are, again, well flaked on both sides with straight to contracting stems and rounded bases. The McGuire's Garden site produced radiocarbon assays indicating an occupation date of ca. A.D. 1290-1310, which would be contemporaneous with the late part of the occupation at 41MM341. Of the 95 Perdiz points recovered from McGuire's Garden, nearly a quarter ( $\mathrm{n}=23 ; 24$ percent) were considered to be fashioned from nonlocal central Texas chert.

\section{Scallorn}

Twenty-six points and point fragments are classed as Scallorn. Figures 7-4 and 7-5 illustrate all but 3 point fragments. These points are corner notched with expanding stems. Blades are triangular with straight edges, though a few are convex and recurved. Most of these blades are serrated, though serrations can be obliterated on retouched edges. Three specimens from Level 7 have deep, even serrations with 2 of these also displaying elongated blades (Figure $7-4 c-d$, and $h$ ). The unique blade style of the specimens shown in Figure 7-4c and d allows the former to be typed as Scallorn, even though it is missing most of its stem. The stem edge/ base configurations of the Scallorn points are strongly expanding stem edges with straight ( $\mathrm{n}$ $=11)$, concave $(n=7)$, or convex $(n=4)$ bases. 


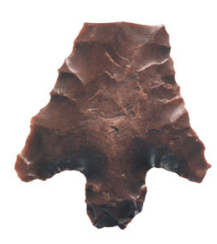

a

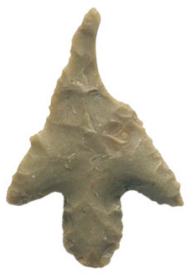

e
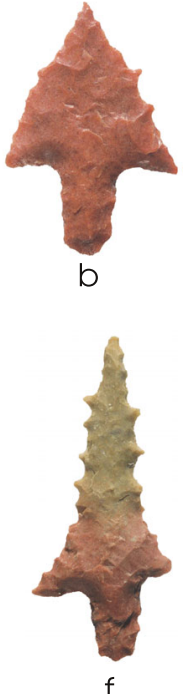

f

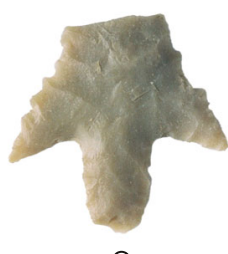

c

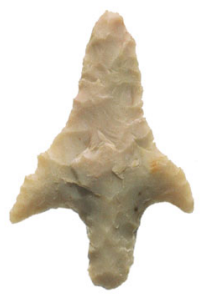

g
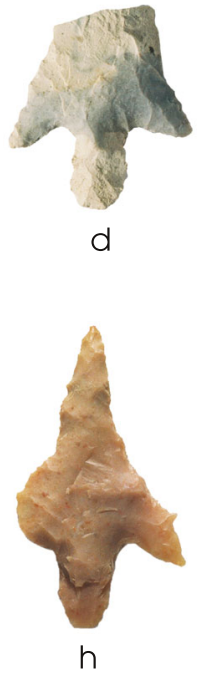

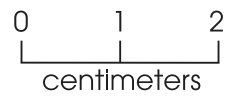

Figure 7-3. Perdiz arrow points. (a-b) Level 6; (c-g) Level 7; (h) Level 8.
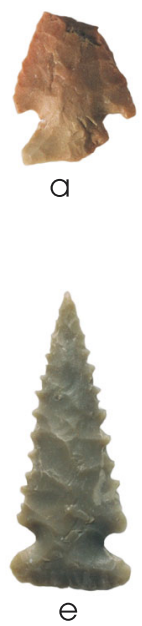

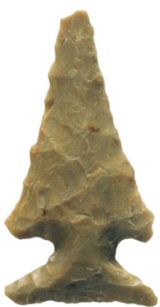

b

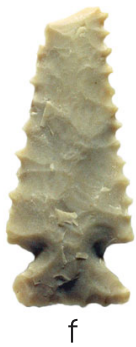

$f$

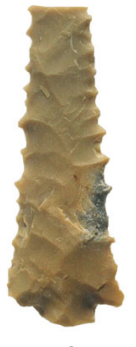

C

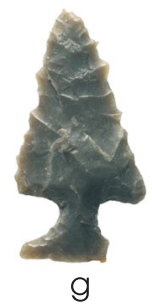

(1)
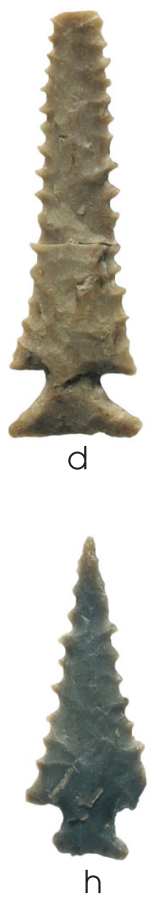

h

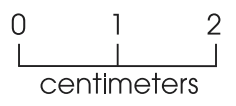

Figure 7-4. Scallorn arrow points. (a-b) Level 6; (c-h) Level 7. 


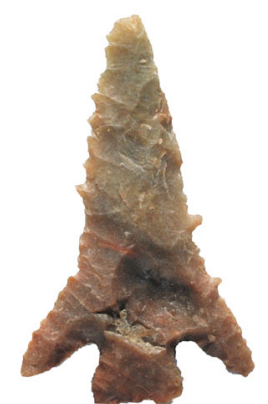

a
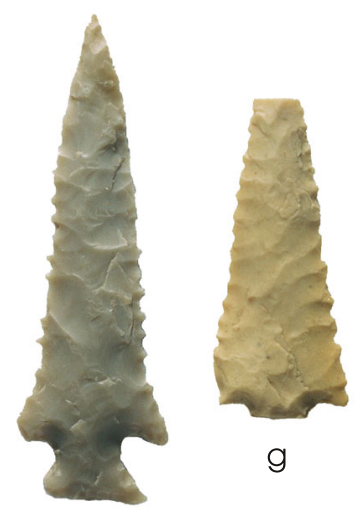

g

f
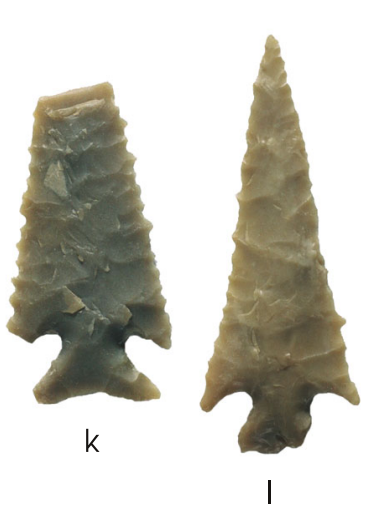

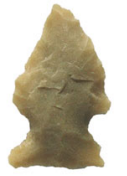

d
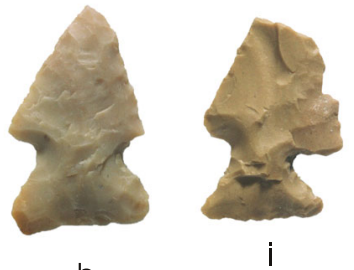

$\mathrm{h}$
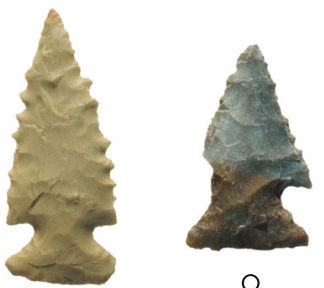

n
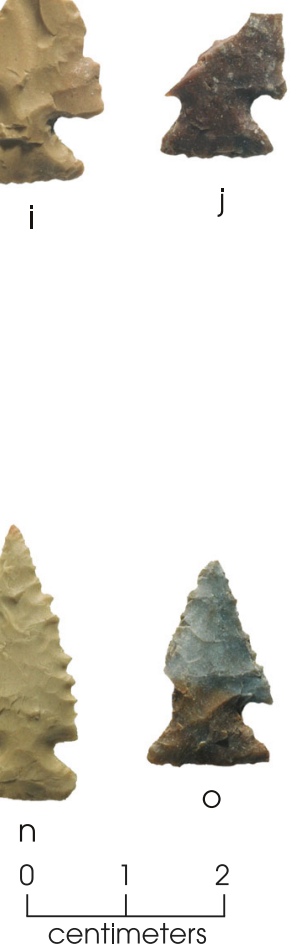

○

2

m

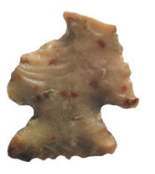

e

Figure 7-5. Scallorn arrow points. (a-h) Level 8; (i-j and m-o) Level 9; (k-l) Level 10.

The strongly expanding stems are almost as wide as the widest parts of the blades (i.e., at the shoulders), and in a few cases they are just as wide or slightly wider than the blades. Points with strongly expanding stems generally have short horizontal barbs, though 2 points from Level 8 and 2 from Level 10 have downwardpointing barbs (Figure 7-5a, f, and k-l). The stem and barb configuration appears to be a function of the angle at which the hafting notch was cut into the basal corner of the point. An angle of $15-30^{\circ}$ was measured for those points that have strongly expanding stems with short horizontal barbs.

Five of the Scallorn points (19 percent) are from lithic reduction debris piles, and three of these points could be associated with identified cobbles. Two complete points are associated with Cobble 9 of Pile 2 (Figure 7-4g) and Cobble 15 of Pile 4 (Figure 7-4e). The third is a proximal fragment associated with Cobble 14 of Pile 4. The material colors are mainly grayish brown 
$(\mathrm{n}=5)$, gray to light gray $(\mathrm{n}=5)$, and pale brown $(\mathrm{n}=6)$, with few dark gray $(\mathrm{n}=2)$, brown $(\mathrm{n}=1)$, and yellow $(n=2)$ specimens. Another five specimens are indeterminate due to heating. Eight specimens (31 percent) can be related to Fort Hood chert types: five Gray-Brown-Green, two Fort Hood Gray, and one Fort Hood Yellow.

Of the 26 Scallorn points, 57 percent appear to have been broken during use. Use fractures occur on 9 points with nine impact fractures to the distal ends and 6 points with stem fractures. Only 4 specimens display lateral snaps that suggest manufacture or resharpening errors. One other point was fractured by postdepositional heating.

The points with strongly expanding stems and short horizontal barbs are similar to the Scallorn variety Sattler described by Jelks (1962:27-31) for the Kyle site. Jelks notes that this variety is most common in south-central Texas and along the coast. At the Kyle site, the Scallorn form that dominates is the variety Coryell, which has a moderately expanding stem with downward-slanting barbs. It is similar to the few Scallorn points from 41MM341 with downward- projecting barbs. Both varieties of Scallorns were also recovered from the Hoxie Bridge site at Granger Lake in Williamson County (Bond 1978:144-146).

There are other notable differences in this collection. For instance, several Scallorn points in Level 7 have wide stems with thin necks, and they display deep, even serrations along the blade margins (this form includes the two points with deeply serrated blades mentioned above) (Figure 7-4b-d, and g-h). These points contrast with points from Levels 8 and 9 that have wide stems with thick necks and shallow serrations on the blades (Figure 7-5c-e, h-j, and $\mathrm{m}-\mathrm{o}$ ). The neck widths of these are measurably different. Mean neck width of the selected points in Levels 6 and 7 is $5.5 \mathrm{~mm}$, while in Level 8 and 9 it is $7.0 \mathrm{~mm}$. These differences suggest changes in the Scallorn form over time.

\section{Untyped Arrow Points and Point Fragments}

A total of 29 untyped arrow points and point fragments were recovered. Only 8 of these have significant portions of the point remaining, and these are pictured in Figure 7-6. The remainder are distal $(n=15)$, medial $(n=4)$, or proximal $(\mathrm{n}=2)$ fragments. Breaks are often lateral snaps $(n=12)$. Given the finished appearance of these fragments, it is likely that these snap breaks occurred during resharpening or in the final stages of manufacture. Five specimens have perverse fractures through the blades and are definite manufacturing failures. Use breaks on distal tips or stems were identified on 5 specimens. Three were fractured by heat, 1 was fractured during excavation, and 3 are considered unbroken.

Generally, the characteristics of blade shape, barb shape, and serrations suggest these untyped arrow points and fragments are related to the three main arrow types recovered from the site. For instance, the long, thin, serrated blade and expanding stem of one almostcomplete point are suggestive of a distal fragment reworked to appear Scallorn-like (Figure 7-6a). Other unique specimens in the collection consist of two lozenge-shaped points; one has a vestige of a stem while the other does not (Figure 7-6e-f). Both are fashioned from flakes with minimal bifacial working.

The material colors are pale brown $(\mathrm{n}=10)$, brown $(n=5)$, gray to light gray $(n=3)$, grayish brown $(n=2)$, and yellow $(n=1)$. Another 8 are of indeterminate color due to heating. Thirteen of the specimens ( 48 percent) are from the lithic reduction debris piles, and 7 could be related to particular cobbles. This high recovery rate from lithic reduction piles and association with pile cobbles suggest that these untyped points and fragments were less likely to move from the area of manufacture and probably were discarded there as part of a refurbishment task. This conclusion, along with the material colors and the characteristics of the points as discussed above, suggest that these untyped points are part of the manufacture and use debris generated at the site.

\section{Arrow Preforms}

Sixty bifaces and biface fragments are arrow point preforms. These preforms are identified by their unfinished edges that appear irregular with step-fractured flake removals, cortex, and edge grinding for platform preparation. Generally, preforms are elongated ovoids in shape. However, comparisons of measures of length, width, thickness, and form demonstrate that differences do exist within the collection. 

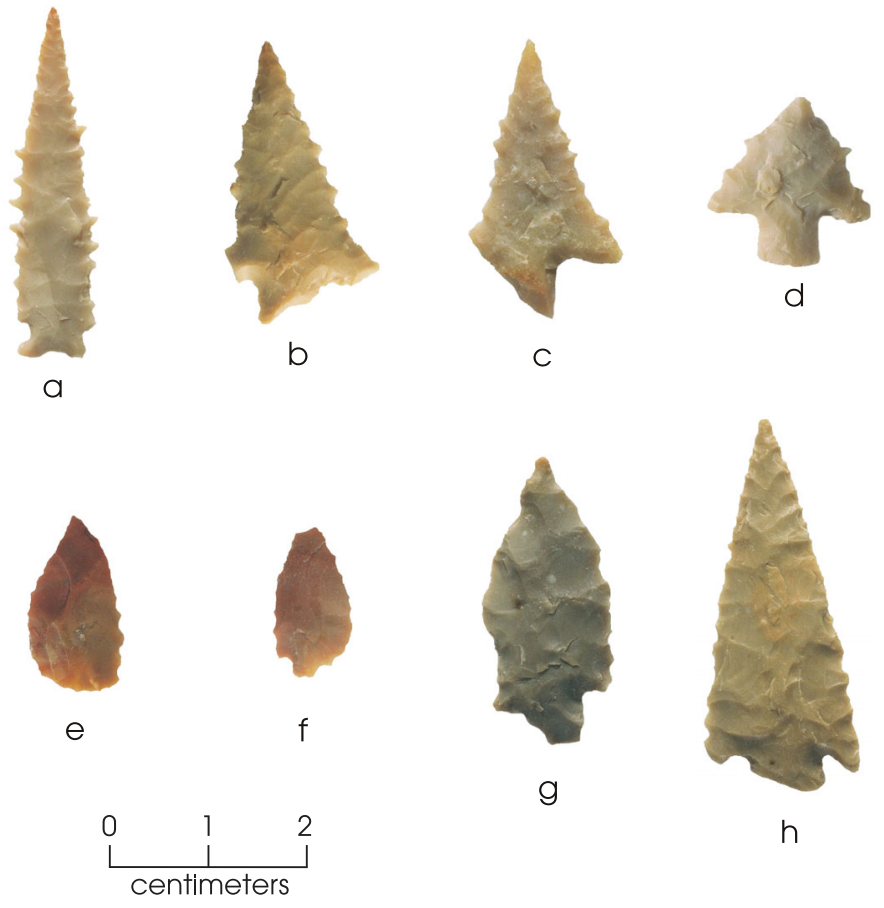

d
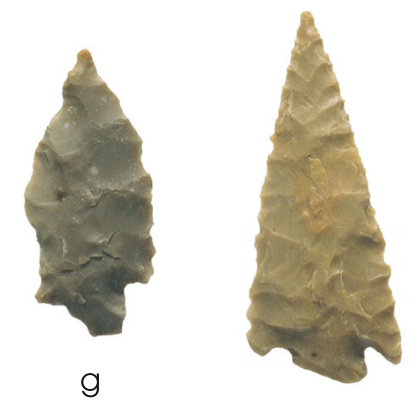

h

leaves out the uncharacteristic specimen with extremely expanding barbs [see Figure 7-4a]).

Two additional preform groups are present in the collection. The items in these groups are beginning to take on the shapes and sizes of finished points, and they may be functional points to some degree. However, because 10x magnification of their edges shows edge grinding for platform preparation, step fracturing, and generally sinuous unfinished edges, they are considered late-stage preforms. The third group consists of late-stage preforms possibly associated with Scallorn points; these have extremely narrow blades that expand rapidly as they near rounded bases (Figure 7-8a-d). Only five examples of this preform were recovered, and all came from Levels 7, 8, and 9 where Scallorn points are common. These preforms are also similar to the Granbury variety Bono points as illustrated in the Austin phase component at the Loeve-Fox site (Prewitt 1982:71-73). The fourth

Twenty-three specimens illustrated in Figures 7-7 and 7-8 are complete enough to be used to identify four different groups.

Groups 1 and 2 stand out as long narrow preforms $(\mathrm{n}=5)$ and shorter, wider preforms $(\mathrm{n}=8)$. The long and narrow preforms have straight to slightly contracting proximal portions and straight to rounded bases (Figure 7-7a-e). Only two specimens are complete, and their lengths are 55.4 and $58.8 \mathrm{~mm}$. Mean width is $18.8 \mathrm{~mm}$ (standard deviation [sd] = 1.4), and mean thickness is $4.5 \mathrm{~mm}(\mathrm{sd}=0.5)$. The short and wide preforms have straight to contracting proximal portions and rounded bases (Figure 7-7f-m). Mean dimensions on this form are as follows: length, $40.9 \mathrm{~mm}$ ( $\mathrm{sd}=7.8$ ); width, $23.6 \mathrm{~mm}$ ( $\mathrm{sd}=1.9$ ); and thickness $4.9 \mathrm{~mm}$ ( $\mathrm{sd}=1.1)$. This second group may be Alba or Perdiz preforms, as the width would allow for wide barbs. The narrower group likely consists of preforms for Scallorn points. Comparison of the mean widths of the three arrow point types demonstrates that Alba and Perdiz in this collection are of similar width and wider than the Scallorn points. The mean widths of the points are as follows: Alba, $18.7 \mathrm{~mm}(\mathrm{sd}=2.3$ ); Perdiz, $18.6 \mathrm{~mm}$ ( $\mathrm{sd}=2.3$ ); and Scallorn, $13.0 \mathrm{~mm}$ ( $\mathrm{sd}=1.7$ ) (the mean width for Scallorn group of preforms consists of five points that may be an intermediate step to finished Alba or Perdiz points (Figure 7-8e-j). Three of these specimens are similar to Cliffton arrow points, though one of these has the beginnings of a recurved blade (see Figure 7-8f-h). Another preform in this group (Figure 7-8i) is similar to Granbury variety Joshua points (Prewitt 1982:71-73). Four of these five preforms were recovered from Levels 6 and 7 where Alba and Perdiz points are common, and one came from Level 8.

In all, 53 ( 88 percent) of the arrow point preforms are broken fragments. Of the total preform recovery, 61 percent $(n=37)$ have lateral snaps and 22 percent $(n=13)$ have perverse fractures; these fracture types suggest that most preforms were broken during manufacture. Other break types consist of 1 specimen with an impact fracture and 2 with excavation damage.

Discard of these preforms appears to have been mainly in or near the lithic reduction debris piles where they were fashioned. Over half $(n=31 ; 51$ percent $)$ of all preforms are from the lithic debris piles. This is a higher percentage than for any of the three main arrow point types, thus suggesting that manufacture 


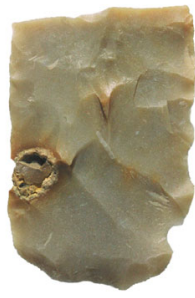

a

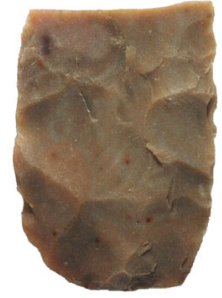

b

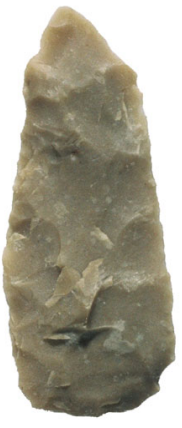

C

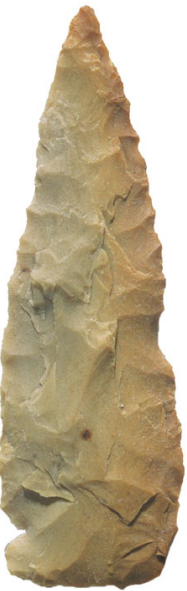

d

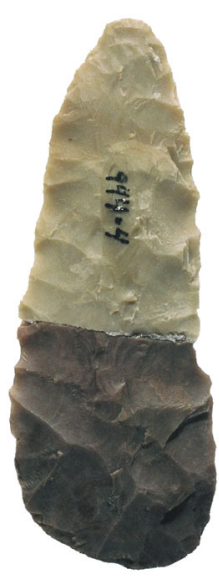

e
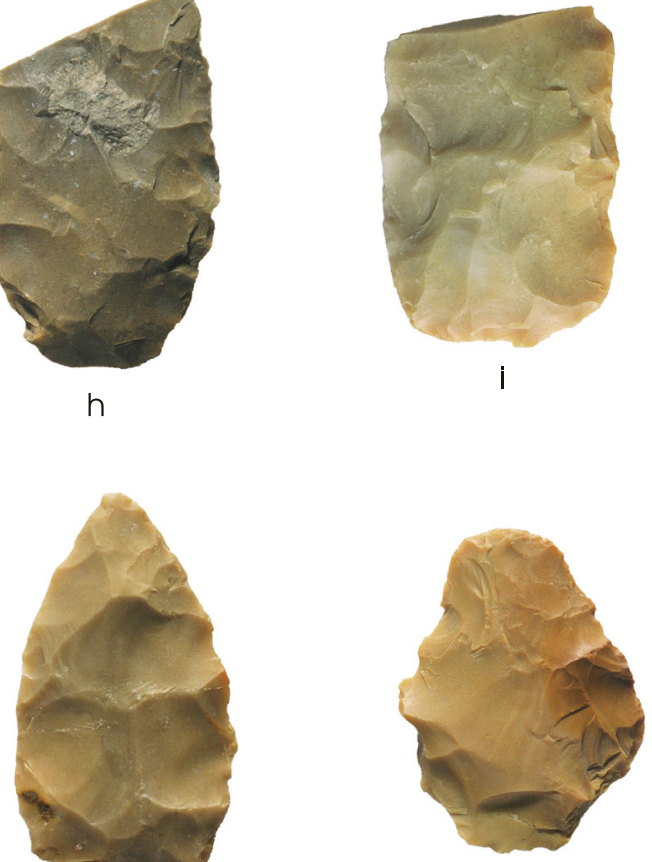

h

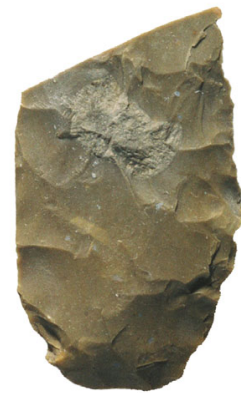

( $m$
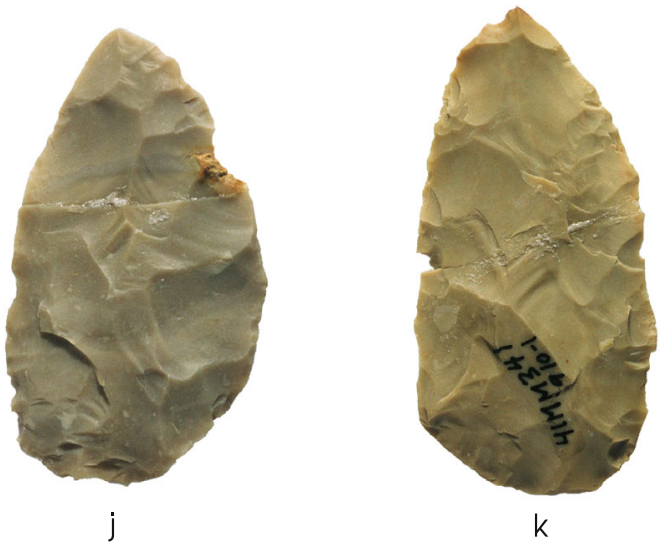

Figure 7-7. Arrow point preforms. (a-e) Group 1; (f-m) Group 2.

mishaps occurred more often at the preform stage. A substantial number of preforms ( $\mathrm{n}=19 ; 31$ percent) can be associated with pile cobbles. Again, this association is higher than for finished Alba, Perdiz, or Scallorn points, and it confirms that arrow points of all three types were manufactured at the site.

The two main material colors are grayish brown $(n=20)$ and pale brown $(n=13)$. Other material colors are gray to light gray $(\mathrm{n}=7)$, yellow $(\mathrm{n}=4)$, brown $(\mathrm{n}=3)$, dark gray $(\mathrm{n}=3)$, and red $(\mathrm{n}=1)$. Nine specimens (15 percent) are of indeterminate color due to heating. Fort Hood chert types could be associated with 27 percent of these preforms. These consist of nine specimens of Fort Hood GrayBrown-Green, four specimens of Fort Hood 


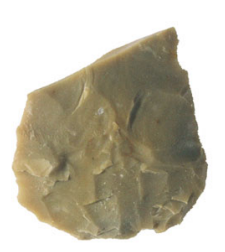

a

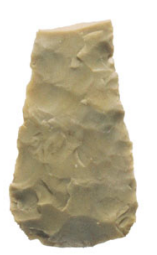

b

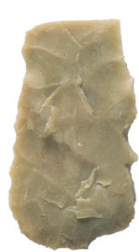

C

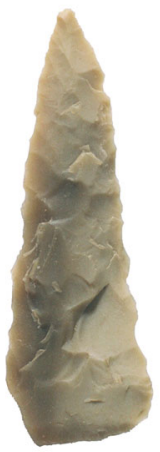

d

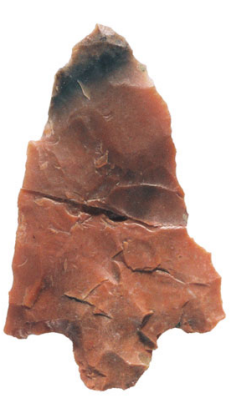

e

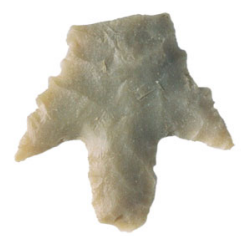

h

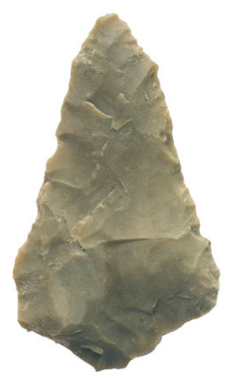

f

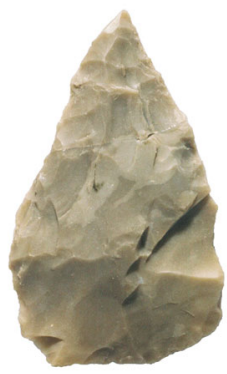

i

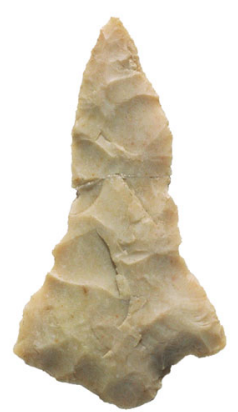

9

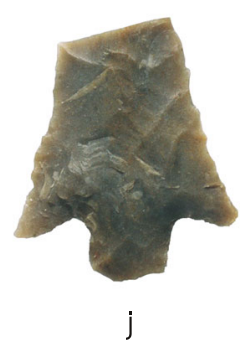

Figure 7-8. Arrow point preforms. (a-d) Group 3; (e-j) Group 4.

Yellow, and three specimens of Fort Hood Gray.

\section{Dart Points and Dart Preforms}

Thirteen dart points and dart point fragments and 5 dart point preforms were recovered. The dart points and fragments consist of 5 points that can be typed as Darl, 2 as Ensor, and 1 as Williams; 5 are untyped. Ensor and Williams points both have broad triangular blades; the Ensor displays shallow side notching, and the Williams point has deep notches forming well-developed barbs. The Ensor points consist of 1 mostly complete point missing one basal corner (Figure 7-9a) and an additional basal corner fragment. The Williams point (Figure 7-9b) is also missing a basal corner and a barb. These basal breaks appear to be shearing breaks that likely occurred by twisting in the haft.

The untyped dart points consist of two complete or nearly complete specimens, three medial fragments, and one distal fragment. One nearly complete specimen is a stemmed point with a narrow triangular blade that gives the 


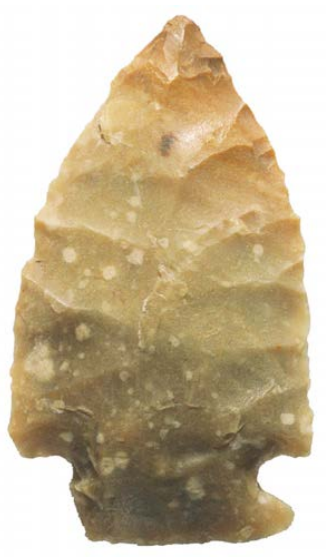

a

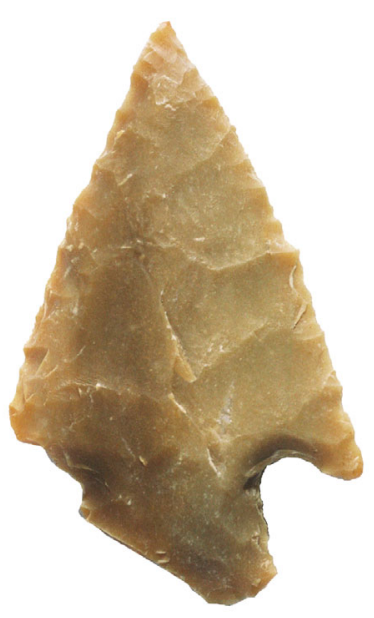

b

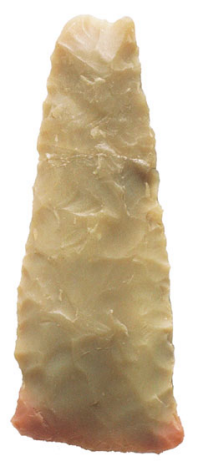

C

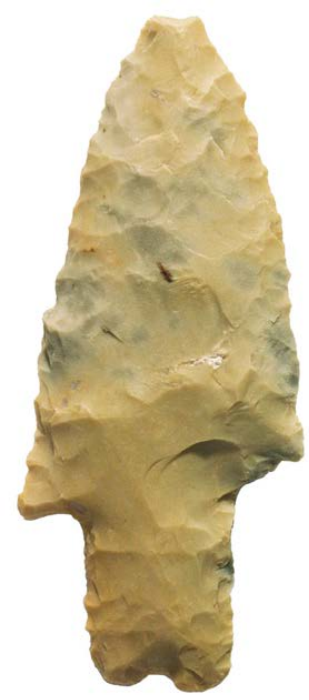

d

Figure 7-9. Dart points. (a) Ensor; (b) Williams; (c-d) untyped.

suggestion of a Darl point (Figure 7-9c). The other complete point is also stemmed with welldefined shoulders and a hint of bifurcation at the base (Figure 7-9d). These characteristics suggest that the point may be related to the Late Archaic Pedernales dart points found in profusion at 41MM340 nearby (Mahoney et al. 2003). However, Darl points and Darl-like points from both the Hoxie Bridge and Loeve-Fox sites show that Darl points can also have deeply concave bases that appear bifurcated (Bond 1972:Figure 38a; Prewitt 1982:76-77). Given these vagaries of classification, the point remains untyped.

Both nearly complete untyped specimens have impact fractures that removed their distal tips (see Figure 7-9c-d). The force of the impact also snapped the blade of one specimen; it was found in two pieces and reconstructed (see Figure 7-9c). An untyped medial specimen also displays an impact fracture that removed the distal portion of the point and a heat fracture that removed the base. The remaining two untyped dart fragments both display lateral snaps, suggesting that the breaks occurred in manufacture or, more likely, during resharpening.

The Darl points, all of which are pictured in Figure 7-10a-e, have straight or slightly convex blades with shallow, even serrations. Each blade shows evidence of beveling. Darl stems are often slightly flaring, though one specimen has a straight stem and another a slightly contracting stem. Edge grinding to facilitate hafting is evident on the stems of all five specimens. Base form is either straight or concave. Break types associated with the Darl points consist of two impact fractures, a lateral snap, and a heat fracture. The Darl points with impact fractures display stepped fracturing proceeding away from the breaks. The fractures took just the tip of one point and the whole distal third of the other (see Figure 7-10b, d).

The five dart point preforms and preform fragments have unfinished edges displaying grinding for platform preparation and step fracturing. Two of the most complete preforms have convex blade margins and concave or slightly convex bases. These characteristics and their general size suggest that they are most likely Darl preforms (Figure 7-10f-g). Most of the preforms display lateral snaps $(n=4)$, though one is heat fractured. One preform broken by a lateral snap was reconstructed (Figure 7-10f). It appears to have broken along an inclusion during final finishing. The frequency of lateral snaps on these performs indicates that most were broken during manufacture.

Material colors for all dart points and dart preforms are gray to light gray $(n=1)$, grayish brown $(\mathrm{n}=4)$, brown $(\mathrm{n}=3)$, pale brown $(\mathrm{n}=3)$, and yellow $(\mathrm{n}=2)$, with five specimens 


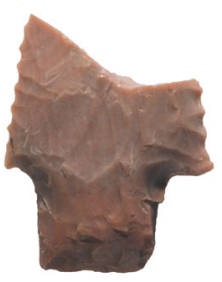

a

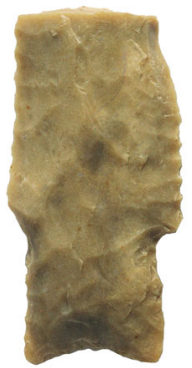

$\mathrm{b}$
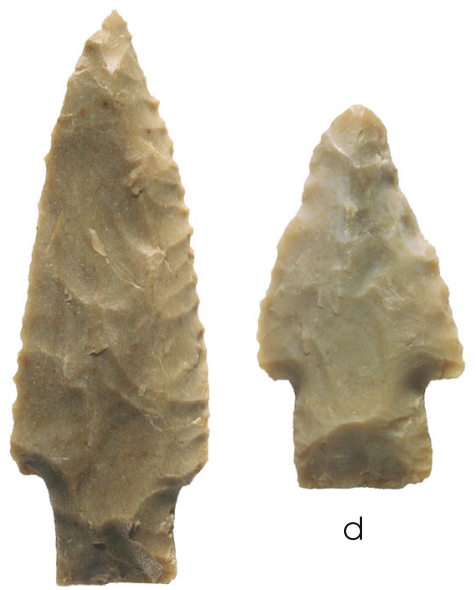

d

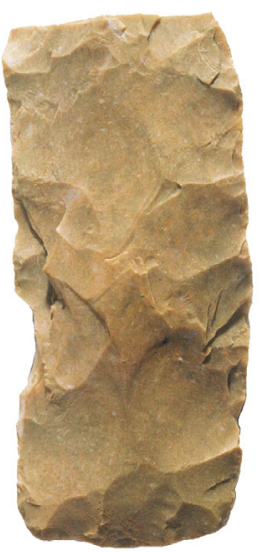

9

f

Figure 7-10. Dart points and preforms. (a-e) Darl points; (f-g) preforms.

indeterminate due to heating. Only one preform could be associated with a Fort Hood chert, GrayBrown-Green. One untyped dart and one heated preform are from Pile 6. No identified cobbles in the debris piles could be associated with any of the dart points or preforms.

\section{Knives and Knife Preforms}

Knives and knife fragments $(\mathrm{n}=31)$ and knife preforms $(n=24)$ are well represented (Figures 7-11 through 7-13). The complete knives and fragments indicate a finished bifacial form consisting of a thin, elongated, triangular blade with straight $(\mathrm{n}=4)$, recurved $(n=4)$, or convex $(n=2)$ edges. Blade edges are even and finely pressure flaked; in a few instances, they display shallow uniform serrations (Figure 7-12a). Near the base, blade edges may be straight, expanding, or slightly contracting. Base form is either concave $(n=7)$ or straight $(n=4)$, again with fine pressure flaking. These knives were not assigned to previously defined types because these types are not particularly useful in describing the collection as a whole. However, the base and blade forms show clear affinities to both Friday and Gahagan bifaces (Turner and Hester 1999:254-255). Similar forms, typed or not, occur at numerous central Texas sites including: Hoxie Bridge (Bond 1978:159-161); Kyle (Jelks 1962:41); LoeveFox (Prewitt 1982:79-81); sites in the Belton 


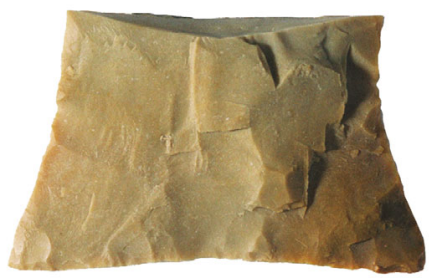

a

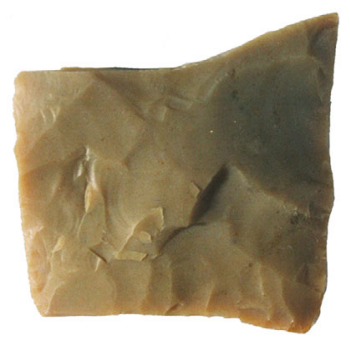

e

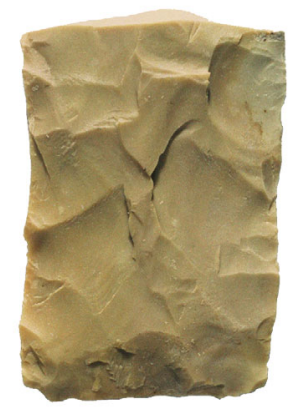

$\mathrm{b}$

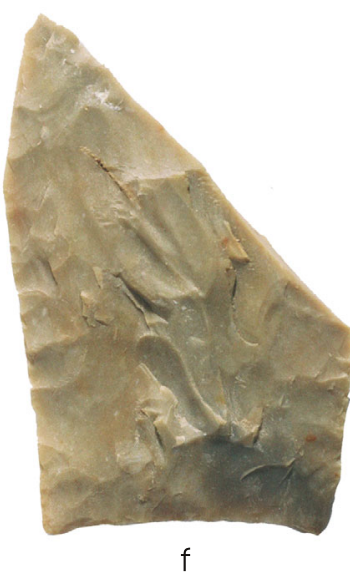

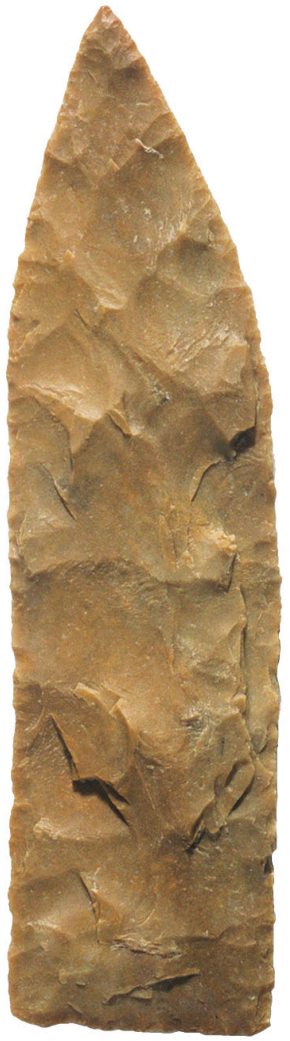

C

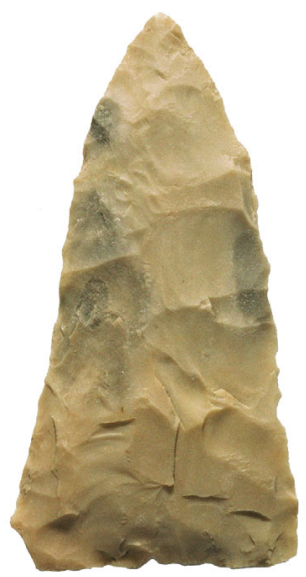

d

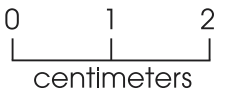

Figure 7-11. Knives. (a, c) Level 6; (b and d-f) Level 7.

Lake area (Shafer et al. 1964:Figure 11); and even as far afield as Pecan Springs in Ellis County (Sorrow 1966:Figure 17a-b) and the George C. Davis site of east Texas (Shafer 1973:Figure 19).

The designation "knife" was given instead of biface because polish and microflaking occur as edge wear on at least 10 specimens indicating use as cutting implements on resilient materials. Two specimens in particular display extensive edge polish (Figure 7-12f-g); the blades on both specimens are also extremely narrow, suggesting a history of use and refurbishment. It is likely that both were discarded whole because further refurbishment was not practical. Other evidence of refurbishment consists of edge grinding as platform preparation on 13 finished specimens. This edge grinding often occurs on knife fragments that have lateral snap breaks $(n=10)$, suggesting that they were broken and discarded during the refurbishment process. Lateral snaps $(\mathrm{n}=24)$ are the most common breaks on knife fragments. Other break types observed are one perverse fracture and two heat fractures; four are unbroken. Several basal fragments with lateral snaps, such as those pictured in Figure 7-11a, b, and e, suggest that the breaks may have been caused by overstressing while the knives were hafted. All of this morphological evidence indicates that the knives were used and refurbished at the site.

The 24 knife preforms and preform fragments represent various stages of production. However, all have the same elongated, triangular shape, and they often have straight or convex bases (see Figure 7-13). They are defined by their overall rough chipping when compared to finished specimens and their sinuous edges with step fracturing and edge grinding. Most are broken or display significant material flaws 


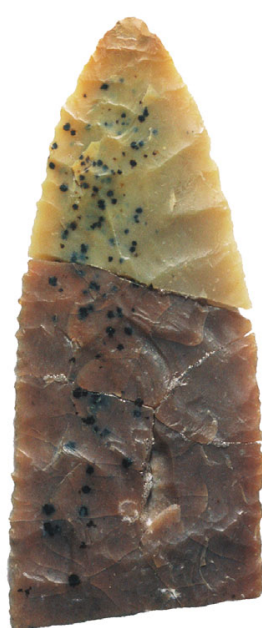

a

e

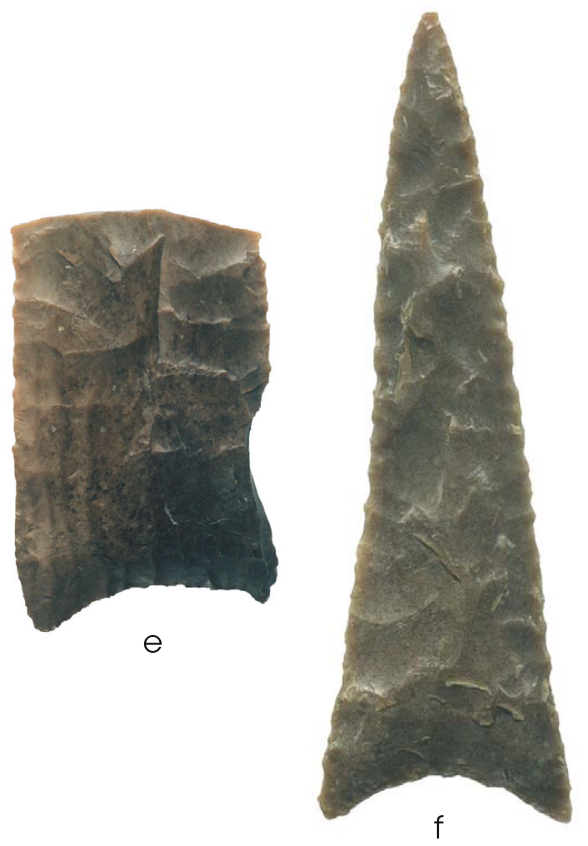

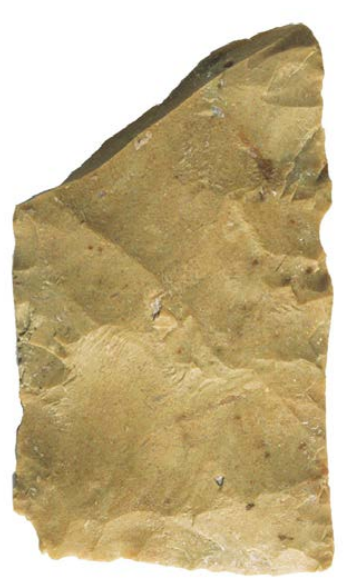

b

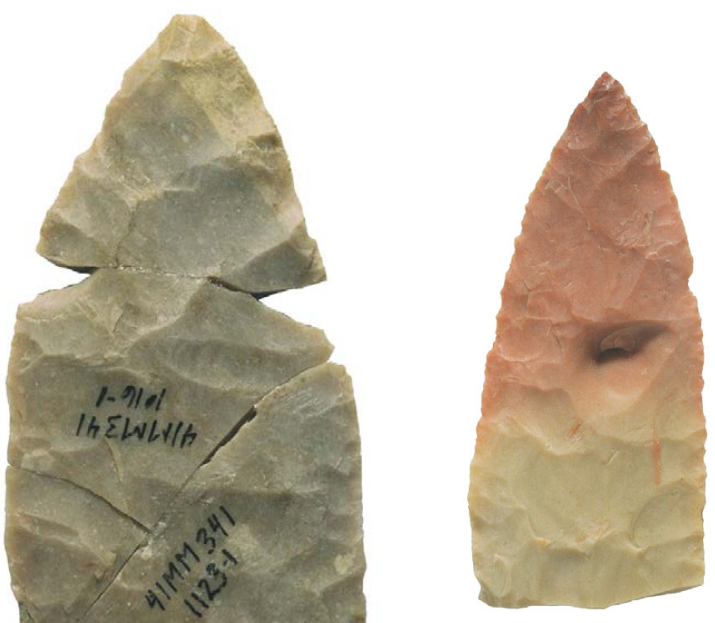

d
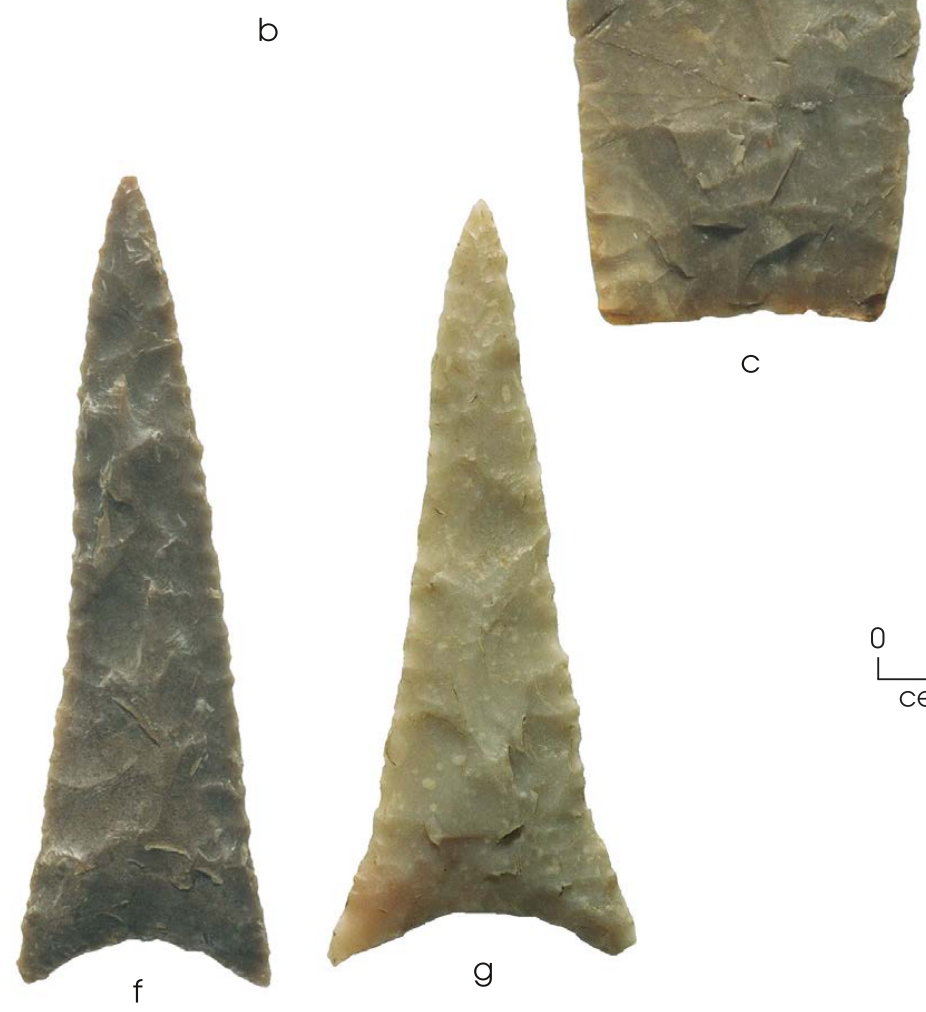

C

Figure 7-12. Knives. (a-e) Level 8; (f-g) Level 9.

that probably prompted their discard. One complete and one reconstructed specimen have large inclusions that obviously could not be successfully removed (Figure 7-13d, g). Breaks on the preforms consist of 19 lateral snaps, 2 perverse fractures, and 1 heat fracture; 2 are unbroken. That these breaks occurred during manufacture is best represented by 1 reconstructed preform (see Figure 7-13d). The preform was trisected by 2 lateral snaps, both of which were likely caused by efforts to remove a large basal inclusion. Debitage from the preform was recovered from the same lithic reduction debris pile (No. 9) as the fragments of the preform. Association between the debitage and the preform is confirmed by material color and texture and at least 1 refitted flake (the refitted flake is included on the reconstructed preform in Figure 7-13d.) Another example of a break during manufacture is a preform in the final stages of manufacture that snapped at the point of an attempted flake removal (Figure 


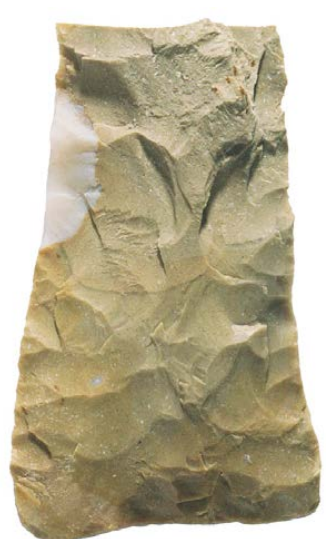

a

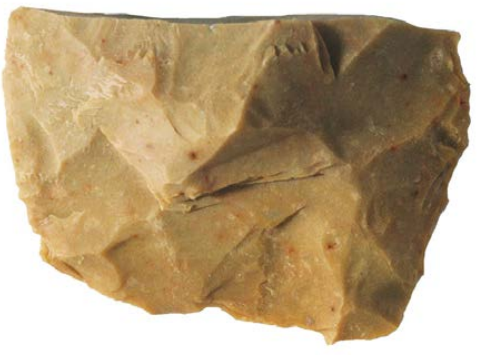

b

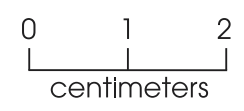

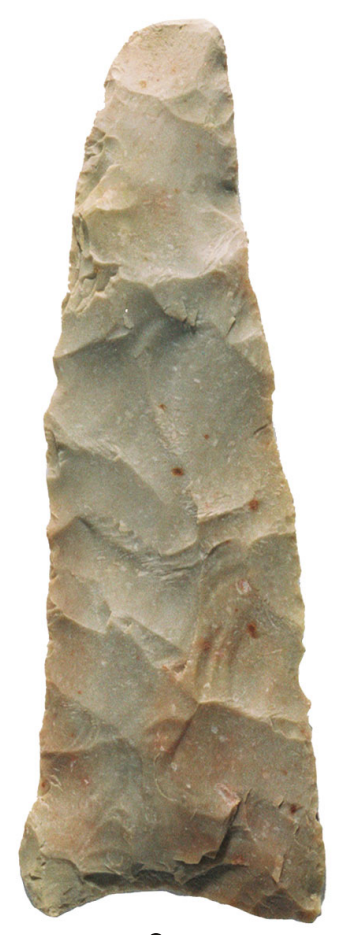

e

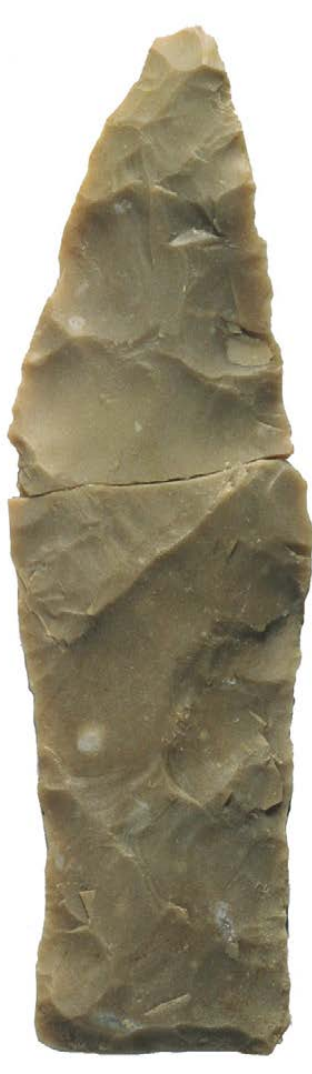

f
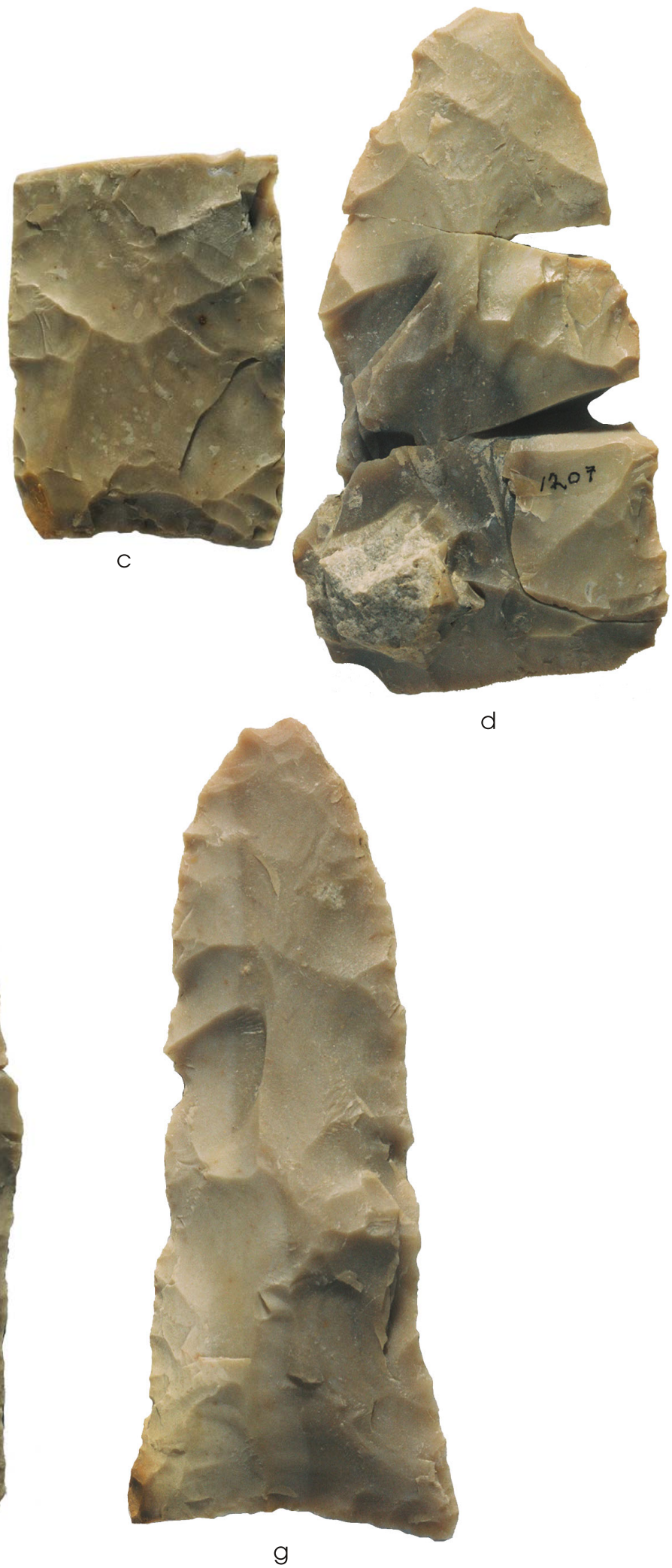

Figure 7-13. Knife preforms. (a) Level 6; (d, f-g) Level 7; (c, e) Level 8; (b) Level 9. 
7-13f). Edge damage on the distal part of the preform near the break marks the attempted removal.

Along with the break type information, the strong associations between knives and knife preforms and lithic reduction debris piles indicate that knife manufacture was performed onsite. In all, 24 percent of the knives $(n=5)$ and preforms $(\mathrm{n}=8)$ can be associated with cobbles identified within 8 of the 10 lithic debris piles. These cobble associations indicate that knife manufacture was done using locally available materials. The colors of the lithic materials for both knives and their preforms consist of dark gray $(\mathrm{n}=3)$, gray to light gray $(\mathrm{n}=12)$, grayish brown $(\mathrm{n}=14)$, brown $(\mathrm{n}=8)$, pale brown $(\mathrm{n}=9)$, yellowish brown $(\mathrm{n}=3)$, yellow $(\mathrm{n}=3)$, and indeterminate due to heating $(n=3)$. The materials of nine of the specimens could be related to Fort Hood chert types. These are Gray-Brown-Green $(n=7)$ and Gray $(\mathrm{n}=2)$.

\section{Perforators, Awls, and Gravers}

Two chipped stone perforators or drills were recovered. Both are bifacially chipped with expanding proximal ends. One is complete with its shaft and working bit intact, and the other is a proximal fragment with the shaft broken by a lateral snap (Figure 7-14a-b). The proximal end of the complete specimen displays edge grinding, suggesting that this tool was fashioned to be hafted. The width of the shaft of the complete specimen halfway from the haft to the bit is $5.8 \mathrm{~mm}$; on the broken specimen measured near the break, the shaft is $5.2 \mathrm{~mm}$ wide. Both are made from a gray to light gray chert. The complete specimen was recovered from lithic reduction debris Pile 5.

Two awls were recovered. Both are bifacially worked to sharply pointed ends. One is complete and triangular in shape with a rounded proximal end (Figure 7-14c). The other is a distal end broken by a lateral snap. Edge wear on these specimens consists of polish on the pointed ends and microflaking along the lateral edges, mainly near the points, suggesting use for puncturing and cutting. These specimens are of gray to light gray and brown chert. Neither tool is associated with a lithic reduction debris pile.

Four bifacially worked cobble fragments are identified as gravers. These have one or more flaked projections exhibiting polish and microflaking along their worked edges, suggesting that the projections were used to score resilient materials (Figure 7-14d). The material colors of these tools are gray to light gray $(\mathrm{n}=1)$, grayish brown $(\mathrm{n}=1)$, and brown $(\mathrm{n}=2)$. Two gravers were recovered from the areas of lithic reduction debris Piles 2 and 6.

\section{Adzes, Wedges, and Gouges}

Eight bifacially worked tools, six of which are complete, are identified as adzes. These tools are relatively thin and well shaped with biconvex working edges that are step fractured, suggesting they were used to cut resilient materials (Figure 7-15a-c). Both adze fragments consist of working edges or bits removed by reverse fractures. This fracture type implies tool refurbishment. At least one complete specimen displays edge grinding on the proximal end, likely indicating that the tool was hafted. The material colors of these tools are gray to light gray $(n=5)$, pale brown $(n=1)$, and indeterminate due to heating $(\mathrm{n}=2)$. Two adzes appear to be fashioned from Fort Hood Gray-Brown-Green chert. One fragment could be associated with Cobble 14 of lithic reduction debris Pile 4 , and a complete specimen is from Pile 9.

Two bifacial tools are identified as wedges. These are roughly flaked, thick, triangular tools (Figure 7-15d). Both have cortex on their proximal ends, and their distal working ends have been blunted by intense step fracturing. One specimen is gray to light gray, while the other is yellow and can be related to Fort Hood Yellow chert. Neither is associated with a lithic reduction debris pile.

Gouges are represented by 10 complete specimens. These tools are thick, bifacially worked ovoids with steep angles to the working edges (Figured 7-15e, f). They all show a combination of step fracturing and microflaking along the bit edges, which suggests they were used to cut resilient materials. The material colors are gray to light gray $(n=5)$, pinkish gray $(n=1)$, pale brown $(n=2)$, brown $(n=1)$, and indeterminate due to heating $(\mathrm{n}=1)$. Three of the gray to light gray specimens can be related to Fort Hood Gray-Brown-Green chert. One specimen is from the vicinity of lithic reduction debris Pile 3. 


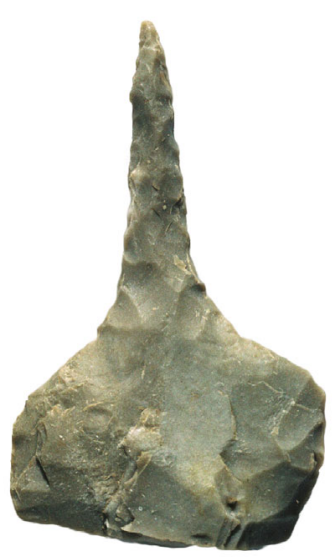

a

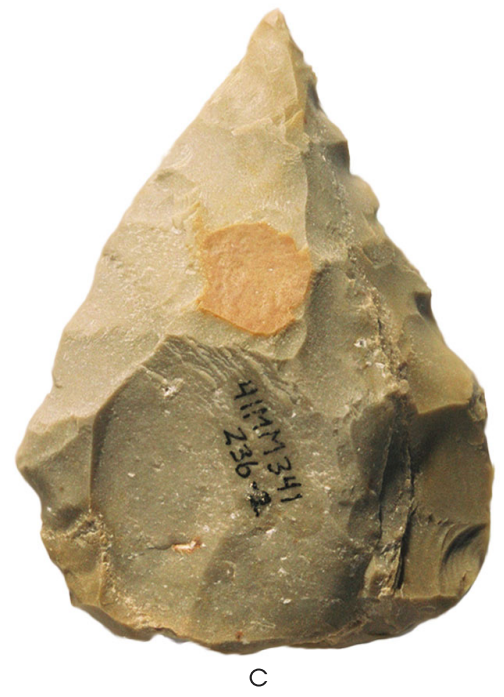

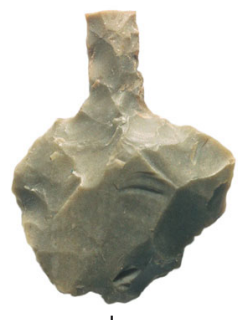

$\mathrm{b}$

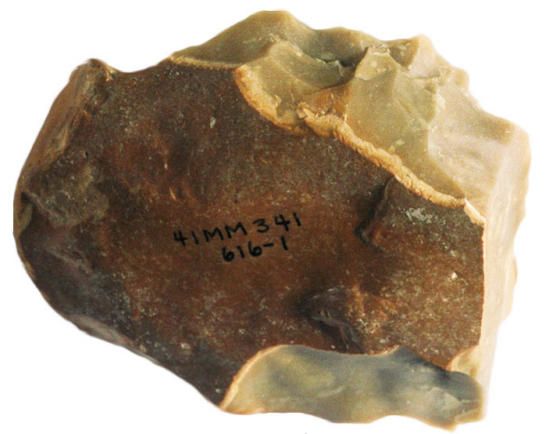

d

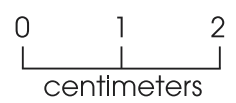

Figure 7-14. Perforators (a-b); awl (c); and graver (d).

\section{Other Bifaces}

Other bifaces consist of 31 early-stage bifaces and biface fragments and 29 indeterminate biface fragments. Early-stage bifaces exhibit rough percussion flaking, often retain some cobble cortex, and are thick and generally ovoid in shape (Figure 7-16 a-b). These bifaces appear to be large enough to allow for further reduction to the preform stages of the various projectile points and knives discussed above. Nine complete specimens range in length from 38.4 to $103.4 \mathrm{~mm}$ and in width from 25.9 to $69.0 \mathrm{~mm}$. Break types on the fragmentary specimens sug- gest discard during manufacture and consist of 17 lateral snaps, 3 perverse fractures, and 2 indeterminate fractures. Only 4 early-stage bifaces can be associated with three cobbles from three lithic reduction debris piles, though another 7 bifaces are from the areas of debris piles.

The 29 indeterminate bifaces and biface fragments include specimens that are percussion flaked and generally ovoid in shape, but they display no edge modification or morphology that would allow confident placement in another tool category. Based on the 5 complete specimens, these bifaces appear to have been discarded at an intermediate stage between an 

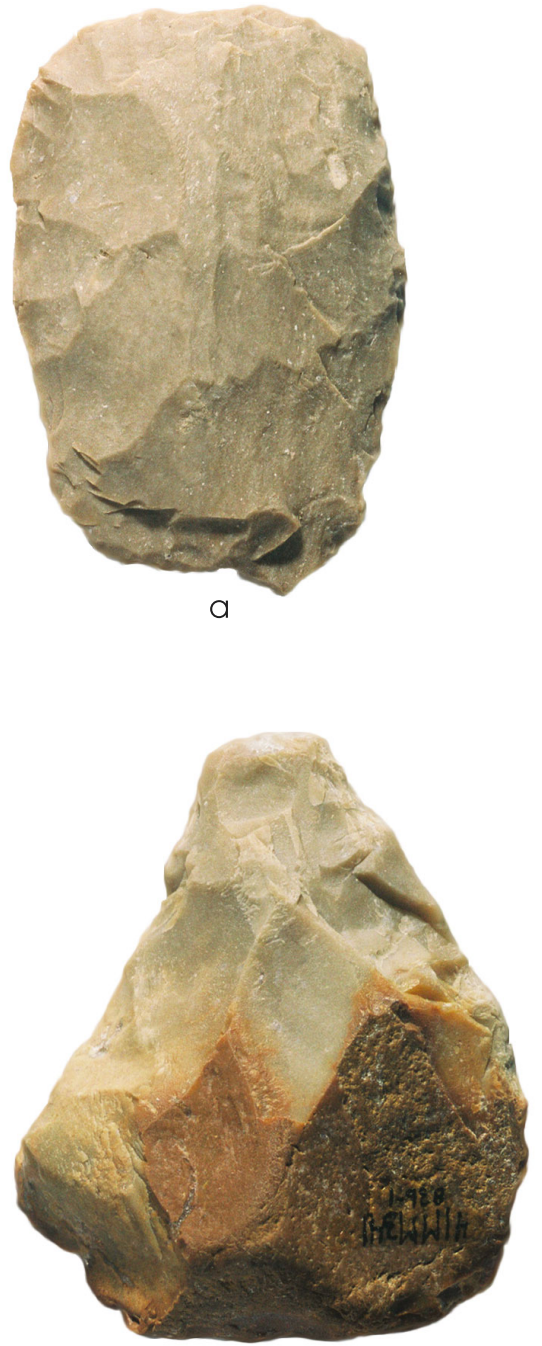

d

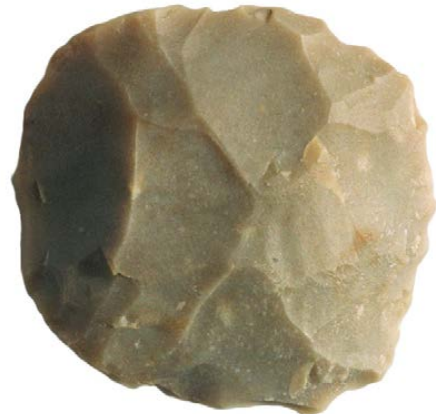

b

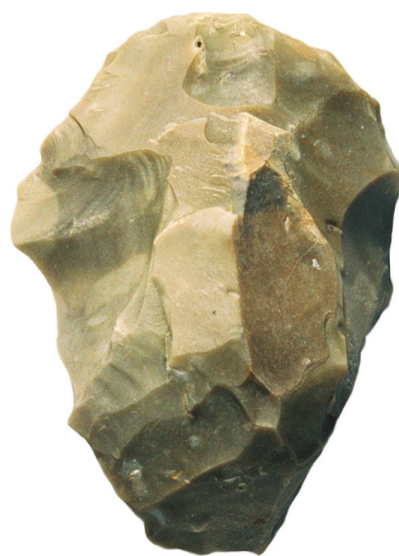

e
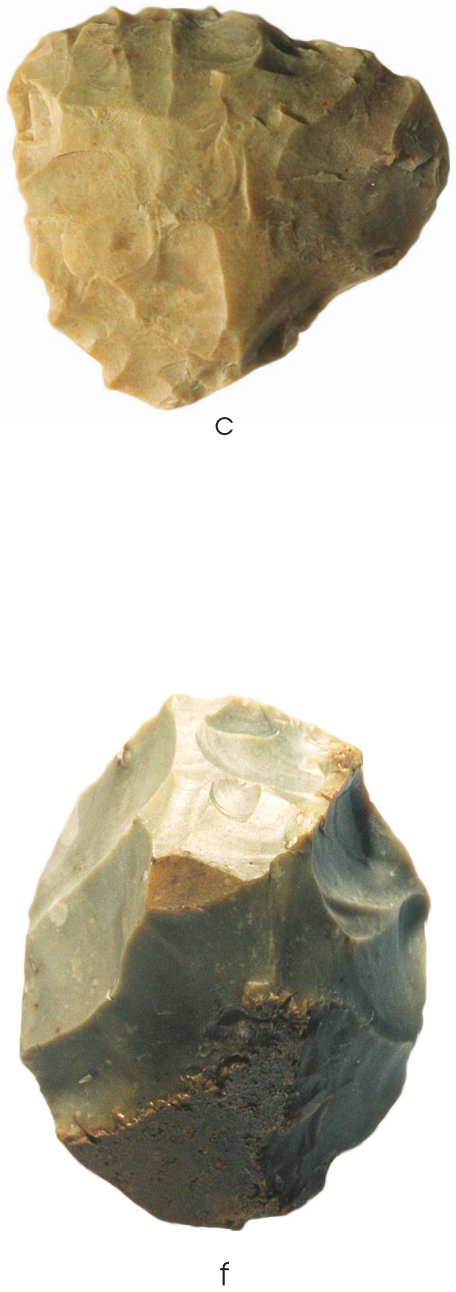

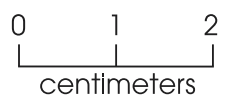

Figure 7-15. Adzes (a-c); wedge (d); and gouges (e-f)

early-stage biface and a projectile point preform, or before they could be fashioned into other chipped stone tools such as wedges, gouges, or adzes (Figure 7-16c-d). Break types associated with these biface fragments are 14 lateral snaps, 3 perverse fractures, 8 heat fractures, and 1 indeterminate fracture. These breaks suggest that many of these were discarded during manufacture. Five indeterminate bifaces can be associated with four cobbles from four lithic reduction debris piles, and another 8 bifaces are from the areas of debris piles.

Material colors of the early-stage and indeterminate bifaces are dark gray $(n=5)$, gray to light gray $(\mathrm{n}=18)$, grayish brown $(\mathrm{n}=7)$, pale brown $(\mathrm{n}=9)$, yellowish brown $(\mathrm{n}=3)$, yellow $(\mathrm{n}=3)$, and indeterminate color $(\mathrm{n}=15)$. Nine specimens (14 percent) can be related to Fort Hood cherts: Gray-Blue-Green $(\mathrm{n}=5)$, Gray $(\mathrm{n}=2)$, and Yellow $(\mathrm{n}=2)$. 

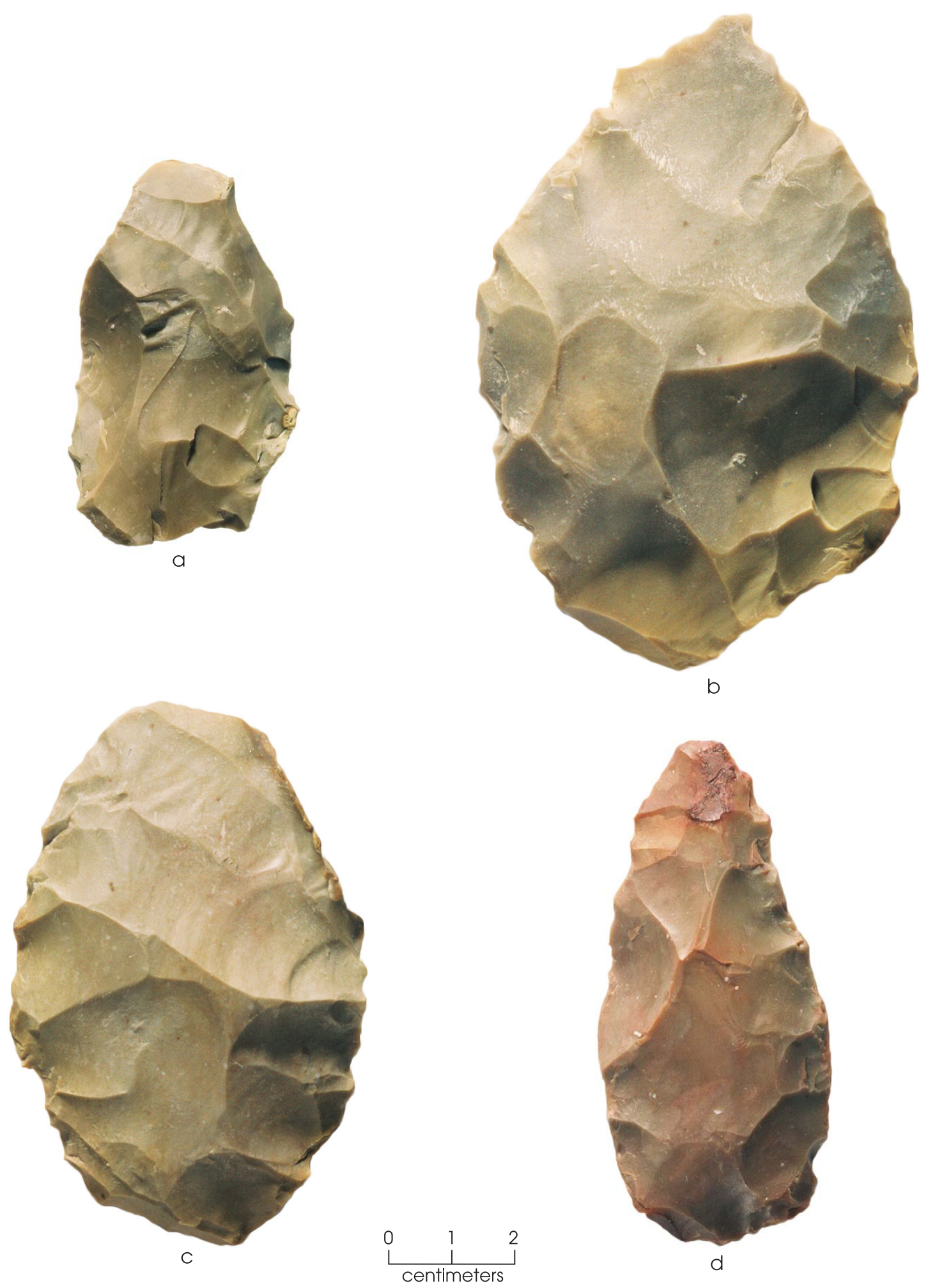

Figure 7-16. Other bifaces. (a-b) Early-stage bifaces; (c-d) indeterminate bifaces. 


\section{Hammerstones and Choppers}

Seven tools are classed as chipped stone hammerstones and hammerstones/choppers, and six are classed as choppers. These tools are chert cobbles that have been bifacially flaked to form at least one working edge (Figure 7-17). On the hammerstones and hammerstones/ choppers, flaking extends most or all the way around the tool margins, and battering and crushing are so extensive that in places the original flaked edges are no longer visible (Figure 7-17b). In several instances, heavy battering has produced completely rounded hammerstones (Figure 7-17a). Tools where battering is not so extensive (i.e., not on all margins) are classed as hammerstones/choppers. Similar heavily battered chipped cobbles identified as "crushers" were found at the Loeve-Fox site where they were associated with the Late Archaic Driftwood
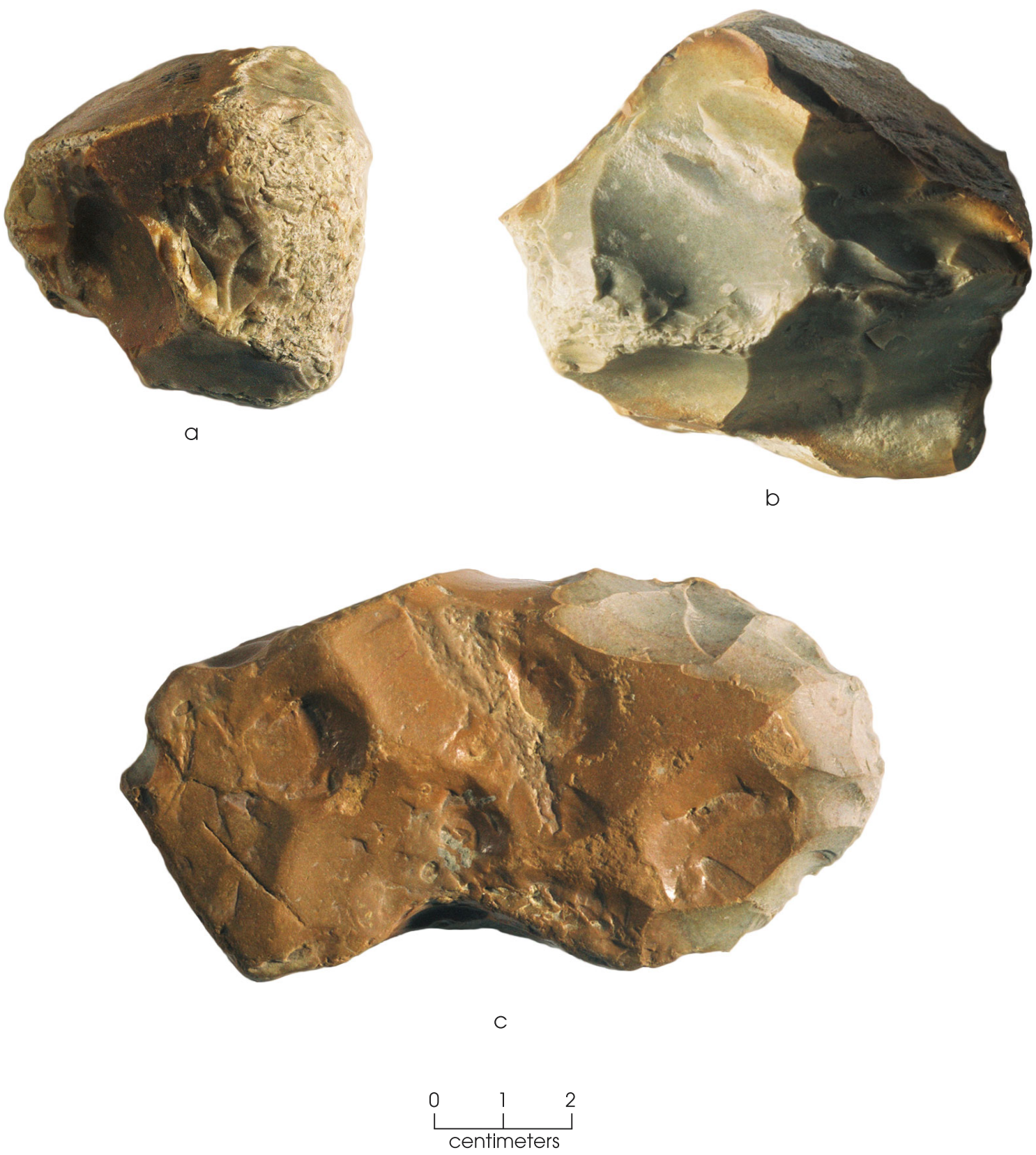

Figure 7-17. Chipped stone hammerstone (a); hammerstone/chopper (b); and chopper (c). 
and Twin Sisters phases (Prewitt 1982:119-120, 184, 190).

Choppers are flaked on one end only, and the other opposing ends retain the original cobble cortex (Figure 7-17c). Generally, they were fashioned from flat, angular cobbles rather than rounded ones. Unlike hammerstones, extensive battering is not present on choppers, though their working edges are step fractured and crushed as if they were used on resilient materials. A very similar specimen labeled a "core chopper" was found in a Driftwood phase context at Loeve-Fox (Prewitt 1982:119-121). Another similar implement was recovered from the Hoxie Bridge site. It was called a "chipped celt" and was considered a woodworking implement (Bond 1978:163).

Most of these tools are from the deeper parts of the excavations at 41MM341 (Levels 8-11). A hammerstone and a hammerstone/chopper were recovered from Feature 24, a mussel shell lens in Level 10. In addition, a hammerstone/ chopper and chopper were recovered from lithic reduction debris Pile 10 in Level 11, a hammerstone was recovered from the area of Pile 10 in Level 8, and a chopper was recovered from Pile 9 in Level 7.

\section{Expedient Chipped Stone Tools}

A total of 494 expedient tools were recovered. These consist of pieces of chipped stone debitage that display edge modification through use, as well as slight intentional modification in the form of retouching to improve the edge angle or form a projection. These tools complement the formal chipped stone tools and are important in interpreting the full range of activities that took place at the site. These tools represent on-the-spot tasks whose successful completion did not require the specificity of formal tools and that possibly enhanced task completion by their inherent flexibility. Analysis of these tools looked at both the patterns of modification observed and the overall characteristics of the debitage chosen for use. Identification of the patterns of modification is an attempt to assign tool function (see Chapter 4 for an explanation of how use/retouch patterns were defined), which can be used to help define site activities. Description of the characteristics of the debitage used as expedient tools provides an indication of whether production strategies were affected by the kinds of debitage selected for use.

Several of the expedient tools have more than one utilized edge; 55 multi-edge tools make up 11 percent of the collection. The occurrence of these tools raises the number of utilized edges to 549. Using this edge count, use-modified edges make up over half ( $\mathrm{n}=350 ; 64$ percent) of the tool edges. Thirty-five percent of edges $(n=191)$ show evidence of retouch; and few tools $(n=16)$ have both retouched and use-modified edges.

Most of both the use-modified and retouched expedient tool edges appear to have been used for scraping (Table 7-4). Use-modified sawing/ cutting edges and retouched gravers, the second most-prevalent modifications, account for only 4 and 8 percent of the edges, respectively, while all other modifications account for 5 percent. One percent of the edges display indeterminate modification. Examples of these expedient tool modifications are shown in Figures 7-18 and 7-19. An interesting variation occurs on 6 percent $(n=34)$ of the use-modified scraping edges. These have scraping modifications on both sides of an edge, but offset from one another (Figure 7-20). This two-sided modification suggests that the flake was turned over and the same edge used again for a similar scraping task. Another variation is polish or edge rounding observed on 9 percent $(n=36)$ of the use-modified scrapers. Polish and edge rounding suggest scraping of a soft material.

The debitage that was selected for expedient tool use consists mainly of flakes ( $\mathrm{n}=337$; 68 percent) or chips ( $\mathrm{n}=134 ; 27$ percent). The maximum dimension of this debitage is 2.5$5.1 \mathrm{~cm}(\mathrm{n}=323 ; 65$ percent $)$, with 3 percent $(\mathrm{n}=14)$ smaller than $1.3 \mathrm{~cm}$ and 1 percent $(\mathrm{n}=6)$ greater than $7.6 \mathrm{~cm}$. Only slightly more than half ( $\mathrm{n}=264$; 53 percent) display some amount of cortex, and only 2 percent $(n=9)$ are completely corticate. Sorting the expedient tools by flake type indicates that 35 percent are associated with core preparation/reduction and 32 percent resulted from biface reduction and biface thinning (Table 7-5). Comparison of flake type selection for expedient tools by level indicates some variation. For example, core preparation/reduction flakes are especially common in Level 6, while biface-reduction and bifacethinning flakes are relatively infrequent. Such a difference would be expected if core reduction 
Table 7-4. Expedient tool use patterns by level

\begin{tabular}{|c|c|c|c|c|c|c|c|c|c|c|c|c|}
\hline \multirow[b]{2}{*}{ Use Pattern } & \multicolumn{2}{|c|}{ Level 6} & \multicolumn{2}{|c|}{ Level 7} & \multicolumn{2}{|c|}{ Level 8} & \multicolumn{2}{|c|}{ Level 9} & \multicolumn{2}{|c|}{ Level 10+ } & \multicolumn{2}{|c|}{ Total } \\
\hline & $\#$ & $\%$ & $\#$ & $\%$ & $\#$ & $\%$ & $\#$ & $\%$ & $\#$ & $\%$ & $\#$ & $\%$ \\
\hline Retouched graver & 12 & 10 & 15 & 8 & 9 & 8 & 4 & 7 & 5 & 10 & 45 & 8 \\
\hline Retouched scraper & 27 & 22 & 50 & 25 & 28 & 25 & 9 & 15 & 14 & 27 & 128 & 24 \\
\hline Retouched spokeshave & 1 & $<1$ & 1 & $<1$ & 2 & 2 & 0 & 0 & 1 & & 5 & 1 \\
\hline Retouched denticulate & 2 & 1 & 4 & 2 & 1 & $<1$ & 2 & 3 & 0 & 0 & 9 & 1 \\
\hline $\begin{array}{l}\text { Use-modified } \\
\text { sawing/cutting }\end{array}$ & 6 & 5 & 6 & 3 & 5 & 4 & 2 & 3 & 0 & 0 & 19 & 4 \\
\hline Use-modified scraper & 73 & 59 & 121 & 61 & 65 & 58 & 42 & 71 & 29 & 57 & 330 & 61 \\
\hline Indeterminate & 2 & 1 & 2 & 1 & 2 & 2 & 0 & 0 & 2 & 4 & 8 & 1 \\
\hline Total & 123 & & 199 & & 112 & & 59 & & 50 & & 544 & \\
\hline
\end{tabular}

Note: Five flakes (edges) from feature proveniences are not included in this table.

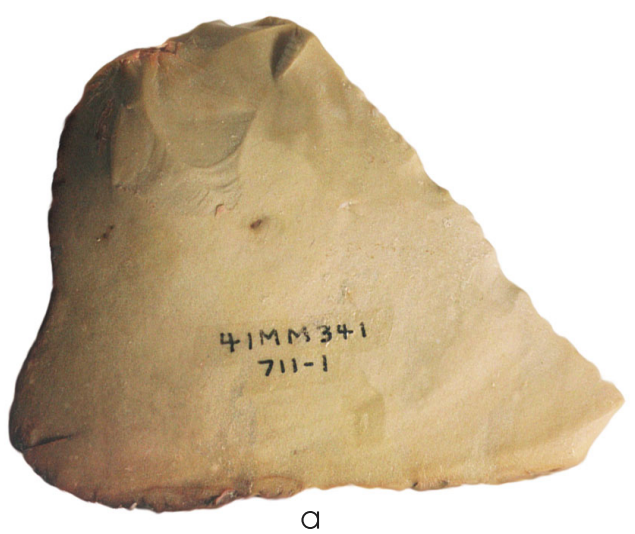

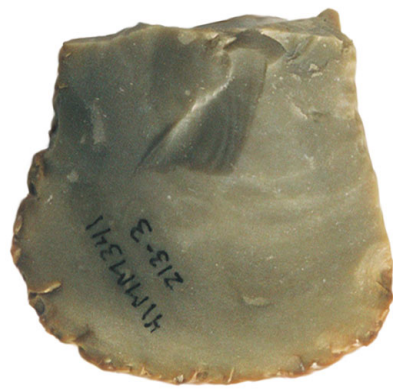

$\mathrm{b}$
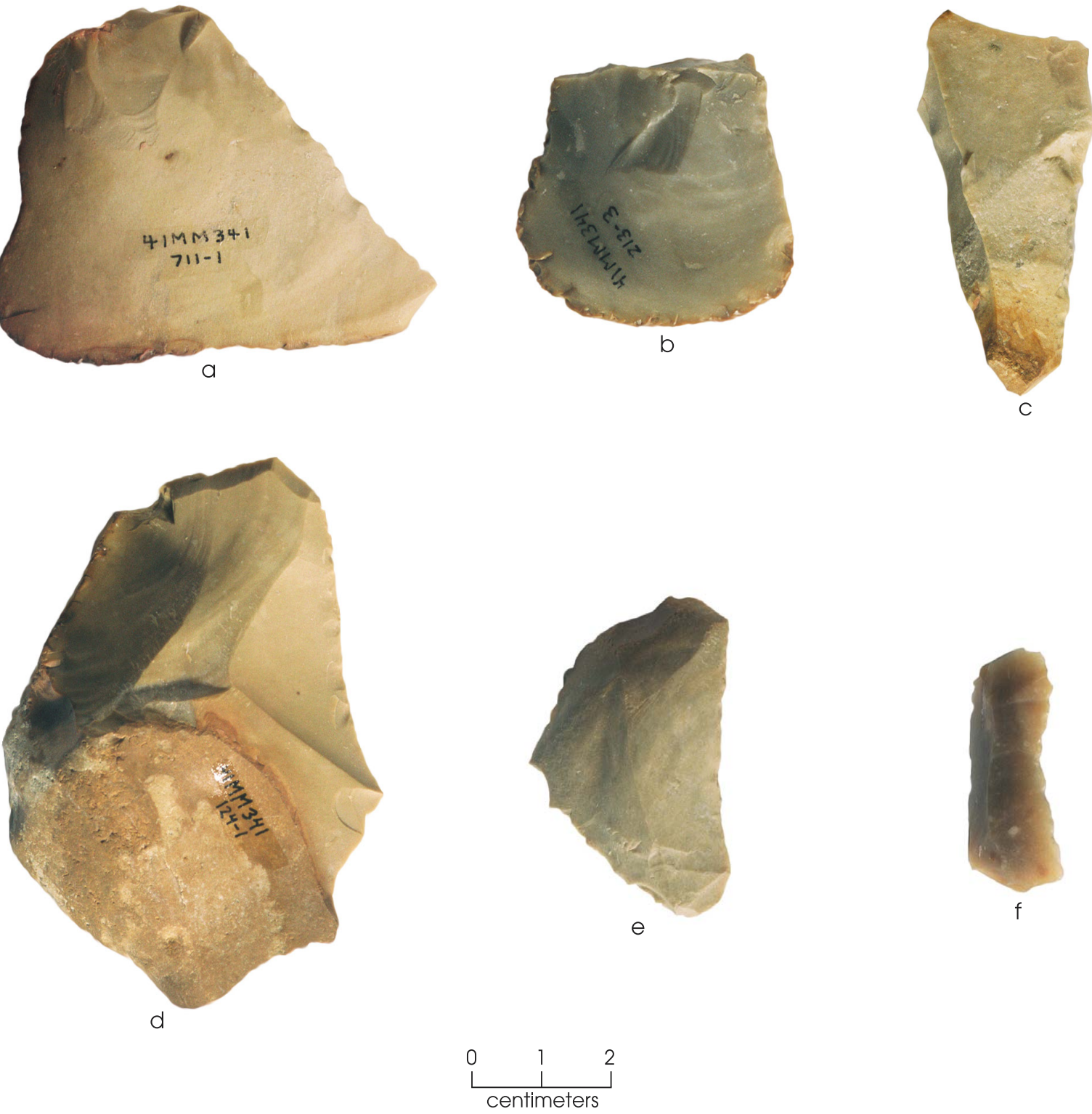

Figure 7-18. Expedient use-modified tools. (a-c) Scrapers; (d-f) sawing and cutting tools. 


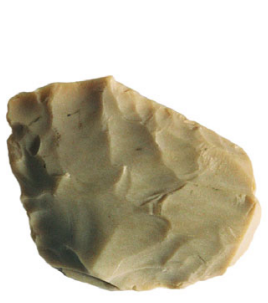

a

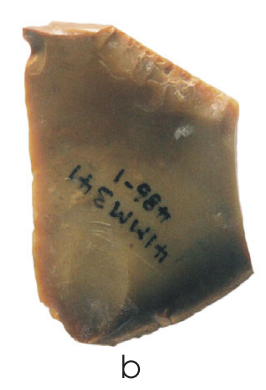

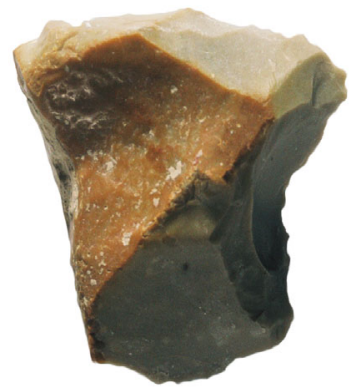

C

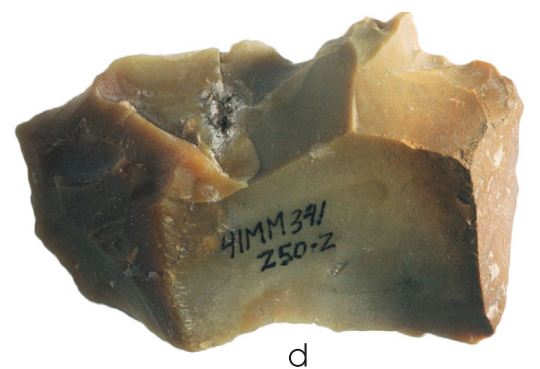

d
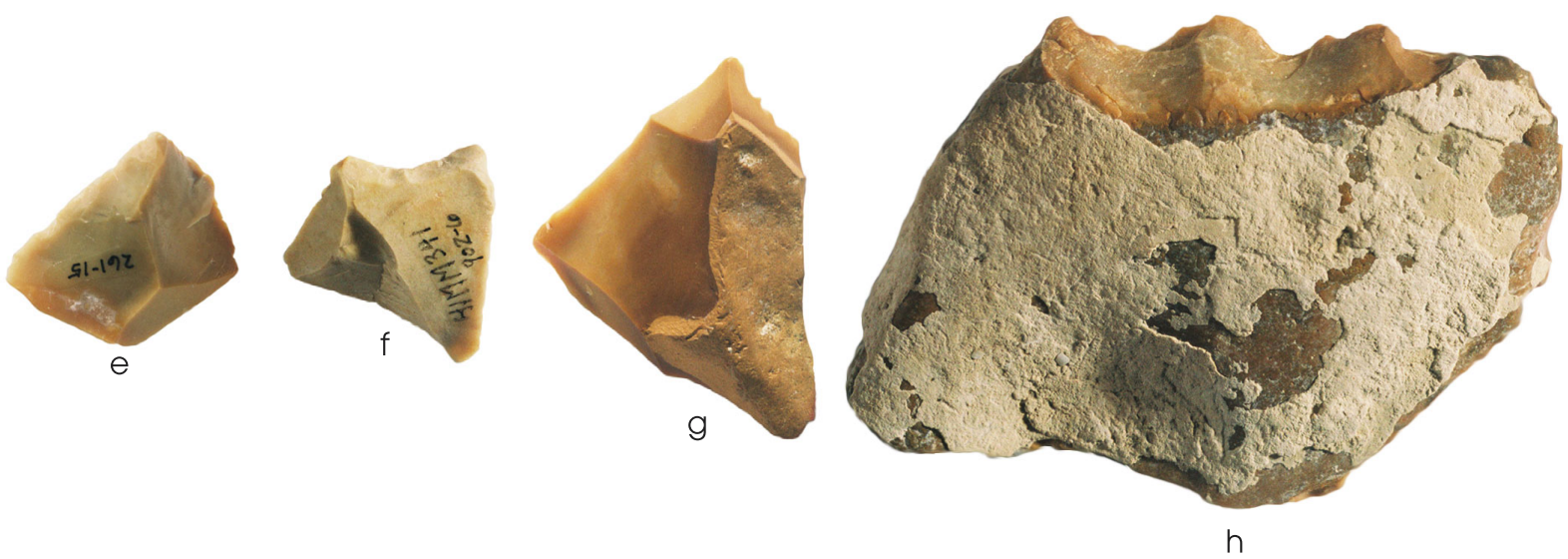

\begin{tabular}{lll}
0 & 1 & 2 \\
\multicolumn{2}{|l|}{} & 1 \\
\multicolumn{2}{|l}{ centimeters }
\end{tabular}

Figure 7-19. Expedient retouched tools. (a-c) Scrapers; (d-e) gravers; (f) spokeshave; (g-h) denticulates.

were specifically geared to producing flakes for expedient use late in the occupation of the site.

Comparing the expedient tool debitage characteristics to those of the unmodified debitage, it appears that larger $(>2.5 \mathrm{~cm})$, more-complete flakes were selected for use. Selection for larger flakes would explain the high cortex percentage within the expedient tools as opposed to the unmodified debitage (28 percent with cortex), as they can be struck early in the reduction sequence and are more likely to retain some cortex. Also, biface-reduction/thinning and core-preparation flakes are elevated for the expedient tools by 13-14 percent above their percentages in the unmodified debitage. Of particular interest are blade blanks, which constitute 5 percent of the expedient tools but less than 1 percent of the unmodified debitage. Blade-blank tools again point to selection for and possibly production of flakes that would provide maximum edge length for expedient use.
The expedient tools provide insights into the range of activities that occurred at the site. It is obvious that activities such as processing and manufacture that involved scraping were important and that these activities were successfully undertaken, though no formal scraping tools are in the site collection. That a variety of scraping tasks was performed is evidenced by the occurrence of both retouched and use-modified scraping tools. In addition, the evidence for specific modifications, such as two-sided scraping edges and evidence of polish on use-modified scrapers, suggests that the edges likely resulted from various tasks.

\section{GROUND AND BATTERED STONE TOOLS}

Included here are 21 hammerstones, 8 abraders, and 1 pitted stone. Also included in this category are 3 quartzite cobble manuports 

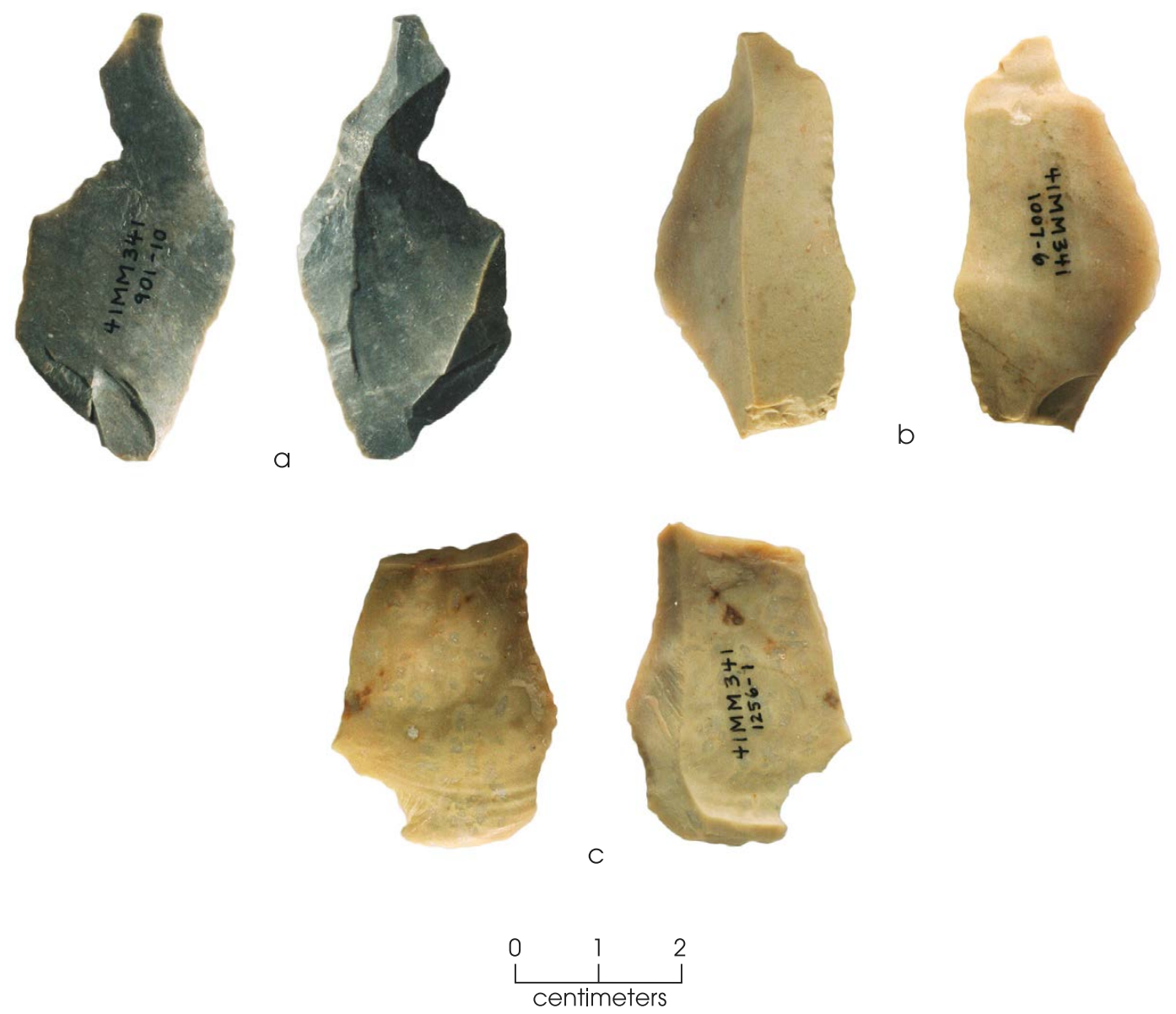

Figure 7-20. Expedient scrapers with two-sided use modification.

Table 7-5. Flake type of expedient tools by level

\begin{tabular}{l|c|c|c|c|c|c|c|c|c|c|c|c}
\hline \multirow{2}{*}{ Flake Type } & \multicolumn{2}{|c|}{ Level 6} & \multicolumn{2}{|c|}{ Level 7} & \multicolumn{2}{c|}{ Level 8} & \multicolumn{2}{c|}{ Level 9 } & \multicolumn{2}{c|}{ Level 10+ } & \multicolumn{2}{c}{ Total } \\
\cline { 2 - 12 } & $\#$ & $\%$ & $\#$ & $\%$ & $\#$ & $\%$ & $\#$ & $\%$ & $\#$ & $\%$ & $\#$ & $\%$ \\
\hline Biface reduction & 13 & 12 & 34 & 18 & 18 & 17 & 9 & 17 & 6 & 13 & 80 & 16 \\
Biface resharpening & 1 & 1 & 0 & 0 & 1 & 0 & 0 & 0 & 0 & 0 & 2 & $<1$ \\
Biface thinning & 7 & 6 & 39 & 21 & 17 & 16 & 8 & 15 & 6 & 13 & 77 & 16 \\
Blade blank & 6 & 6 & 10 & 5 & 2 & 2 & 4 & 7 & 2 & 4 & 24 & 5 \\
Core preparation/ & 52 & 49 & 60 & 33 & 32 & 31 & 15 & 29 & 15 & 33 & 174 & 35 \\
reduction & & & & & & & & & & & \\
Uniface manufacture/ & 0 & 0 & 0 & 0 & 1 & 1 & 1 & 2 & 0 & 0 & 2 & $<1$ \\
repair & & & & & & & & & & & \\
Notching flake & 0 & 0 & 0 & 0 & 0 & 0 & 0 & 0 & 0 & 0 & 0 & \\
Indeterminate & 27 & 25 & 40 & 22 & 32 & 31 & 15 & 29 & 16 & 36 & 130 & 26 \\
\hline Total & 106 & & 183 & & 103 & & 52 & & 45 & & 489 & \\
\hline
\end{tabular}

Note: Five flakes from feature proveniences are not included in this table 
that, although they do not show evidence of use, were recovered from a provenience that produced battered stones. The manuports weigh 525,650 , and $826 \mathrm{~g}$. Two come from a cluster of 4 stones that includes 2 quartzite hammerstones; this cluster was recovered from Excavation Unit 132, Levels 8 and 9. This cluster may be associated with lithic reduction debris Pile 6 in Level 8. The third manuport was recovered from Excavation Unit 111, the same unit that produced 2 quartzite hammerstones. These specimens came from Levels 6,7 , and 8 and may be associated with debris Pile 2 in Level 7 . Though it is not associated with a manuport, another cluster of 3 limestone hammerstones was noted in Excavation Unit 119, Level 7, on the edge of Pile 2.

Hammerstones are oval cobbles that display evidence of light to heavy battering on one or both ends. They include 14 quartzite cobbles, of which 8 are unbroken, and 7 unbroken limestone cobbles (Figure 7-21). Four of the fragmentary quartzite specimens show heat discoloration, as do 4 complete specimens. Two limestone hammerstones are also discolored by heat. Unbroken quartzite cobble hammerstones have a weight range of 198.4-452.3 g, and the limestone cobble hammerstones range in weight from 93.1 to $409.8 \mathrm{~g}$.

Abraders in this collection consist of four sandy limestone slabs and four generally thinner, hematitic sandstone slabs. Sandy limestone is coarse sand cemented with calcium carbonate, whereas the hematitic sandstone is cemented with hematite or another iron-rich mineral. The hematitic sandstone abraders display smoothing and polish on a single face (Figure 7-22). It is difficult to tell if individual specimens are complete or fragmentary, as evidence of wear does not generally extend over the edges of the specimens. Two specimens that appear to be complete have lengths of 76.3 and $168.5 \mathrm{~mm}$ and weights of 65.5 and $325.5 \mathrm{~g}$. None of the sandy limestone abraders may be complete, but they range in weight from 62.1 to $130.2 \mathrm{~g}$. Generally, one surface is well smoothed with smoothing extending over the edges. No striations are visible, and the material does not appear to maintain a polish. All four fragmentary specimens appear discolored by heat.

The single pitted stone is a thin sandy limestone slab that is $132.5 \mathrm{~mm}$ long and $17.4 \mathrm{~mm}$ thick. It weighs $291.0 \mathrm{~g}$. There is one small pit, $4.0 \mathrm{~mm}$ deep and $13.4 \mathrm{~mm}$ in diameter, on one face of the slab. Otherwise, no smoothing, polish, or striations other than scratches from excavation damage are visible on either face of this specimen. This specimen shows no evidence of being heated.

\section{BONE TOOLS AND WORKED BONE FRAGMENTS}

Thirty bone tools and worked bone fragments were recovered. Most appear to have been fashioned from artiodactyl bones or antlers, most likely white-tailed deer. Otherwise, a single worked bird long bone fragment was recovered. The artiodactyl specimens consist of 3 antler tip punches/flakers, 1 worked antler burr, 5 distal fragments of ulna tools, 4 distal awl fragments, 3 medial needle fragments and 1 proximal needle fragment, 5 worked metacarpal fragments, and 7 tool shaft fragments fashioned from long bones and likely parts of awls or needles. Generally, these fragments are small; their lengths range from 15.3 to $71.0 \mathrm{~mm}$.

The single worked bird bone fragment is $51.7 \mathrm{~mm}$ long with a cut and polished end 10.9 $\mathrm{mm}$ across (Figure 7-23a). This may be a tubular bead fragment. However, it is substantially larger than the four bird bone beads recovered from 41MM340; those were less than $26.0 \mathrm{~mm}$ in length (Meissner and Mahoney 2003:203).

One deer bone awl, at the upper limit of the overall length range, may be a complete specimen; it is a bone splinter shaped into a functional tool (Figure 7-23b). Another large distal awl fragment indicates that extensively shaped and polished deer metapodial awls were also used at 41MM341 (Figure 7-23c). Both types of awls are also known from the Kyle site (Jelks 1962:62-63).

Two of the antler tine tips and the antler burr are burned, and another tip is deteriorated. All display abrasions and polish from shaping (Figure 7-23d-f). The tips are rounded to blunt ends. The two burned and better-preserved specimens show use striations on their rounded ends. Worked antler tine tips have often been recovered from sites in east-central and central Texas (Gadus et al. 2002:128; Shafer et al. 1964). They have been interpreted as pressure-flaking tools or punches used in the production of 


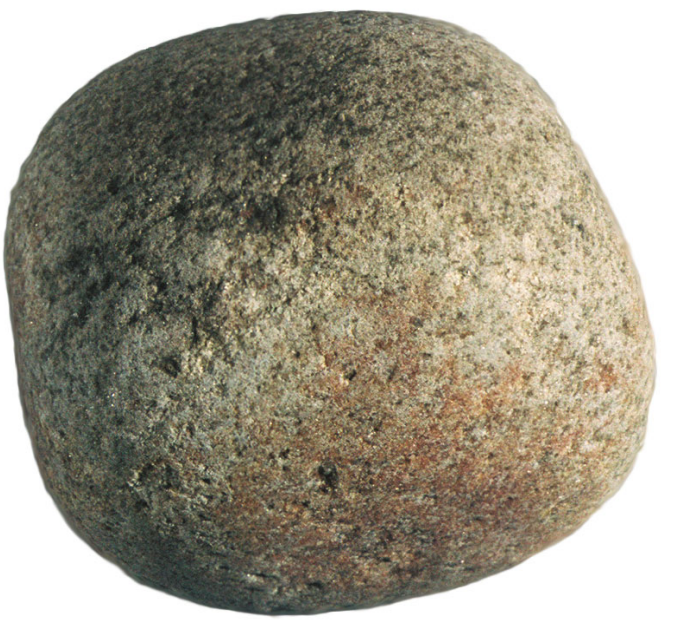

a

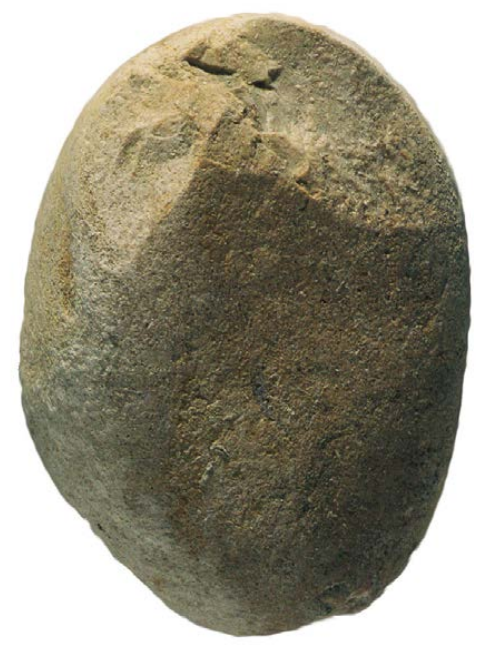

C

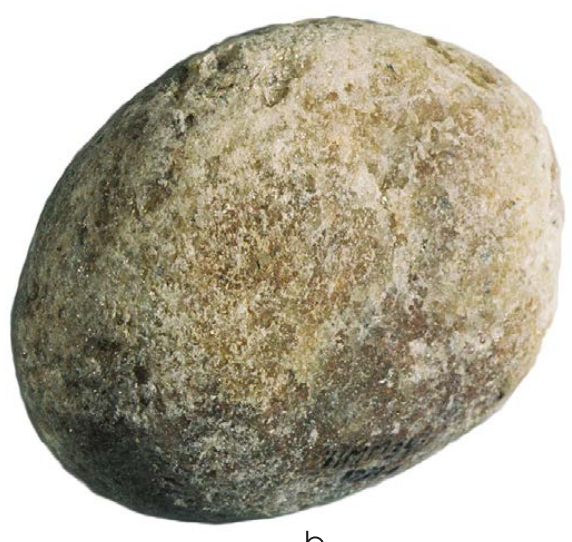

b

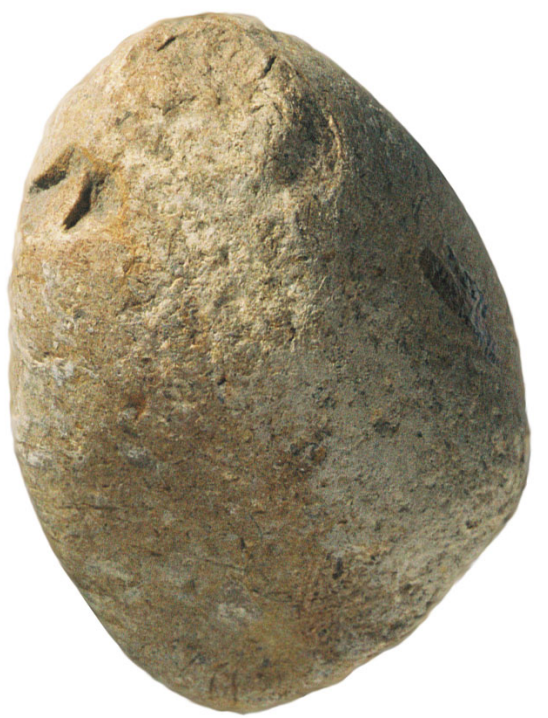

d

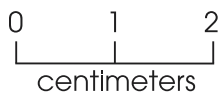

Figure 7-21. Ground stone hammerstones. (a-b) Quartzite hammerstones; (c-d) limestone hammerstones.

chipped stone tools. Also supposedly part of the chipped stone tool production tool kit are bone tools fashioned from deer ulnae (Jelks 1962:63; Prewitt 1982:164; Suhm 1955:48). Five distal fragments of ulna tools were recovered from 41MM341 (Figure 7-23g-i). All have characteristic blunt, rounded ends; one has striations on its tip similar to the striations on the tip of one of the recovered antler tips.

Six fragments representing three bone needles were recovered. A 15.3-mm-long, 4.8mm-wide, proximal end fragment and an 18.5- mm medial section of the same bone needle are from Excavation Unit 140, Level 7 (Figure 7-24a). The tool is considered a needle as it has a thin, highly polished shaft with a spiral groove cut $7.4 \mathrm{~mm}$ from its rounded proximal end. This groove likely functioned as a thread attachment in place of a needle eye. Two fragments of another needle are from Excavation Unit 160, Level 7. These two fragments do not refit, but their color and size suggest that they represent the same tool (Figure 7-24b). This second needle is thinner, ranging in width from 4.3 to $3.9 \mathrm{~mm}$. 

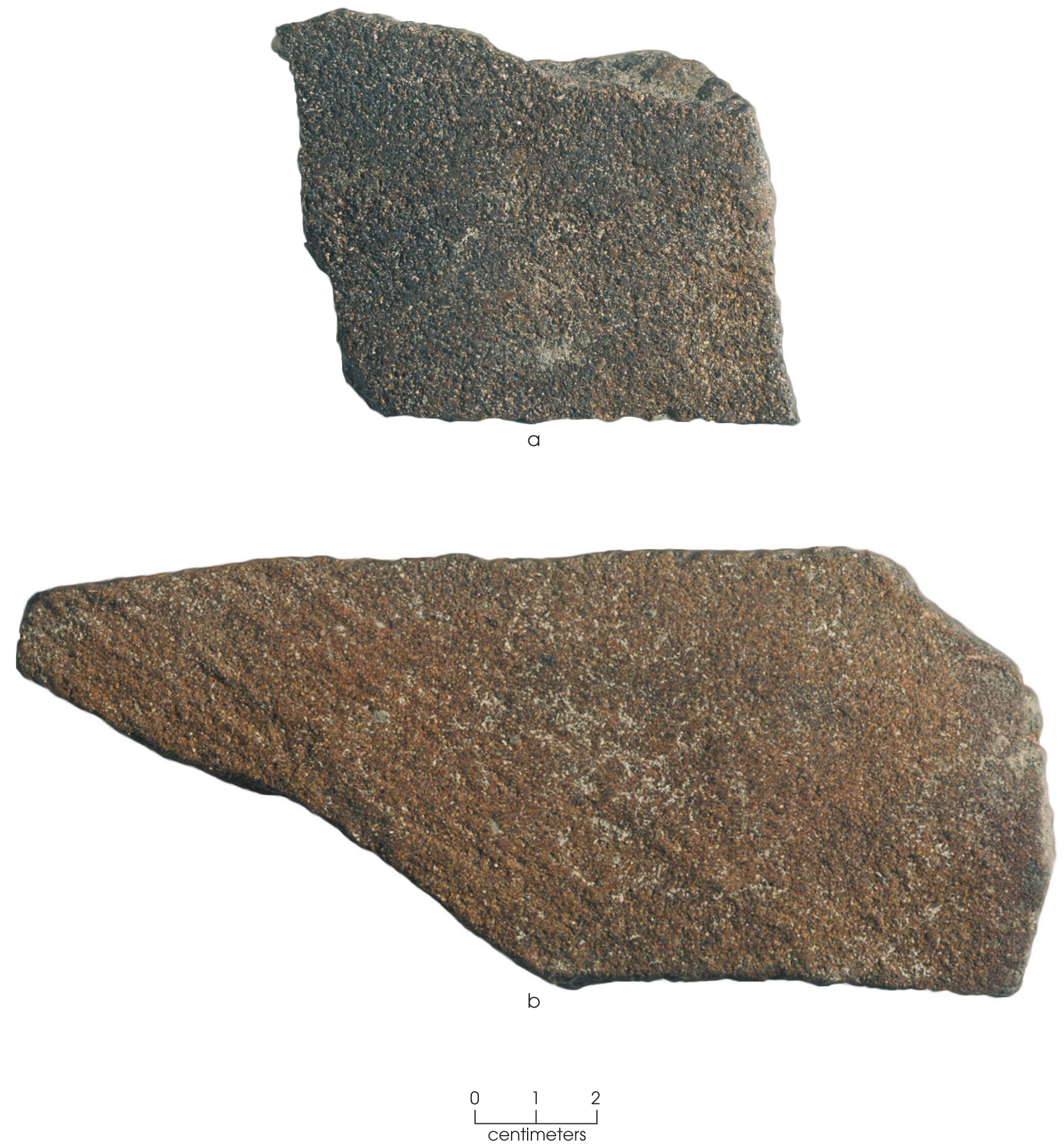

Figure 7-22. Ground stone hematitic sandstone abraders. 


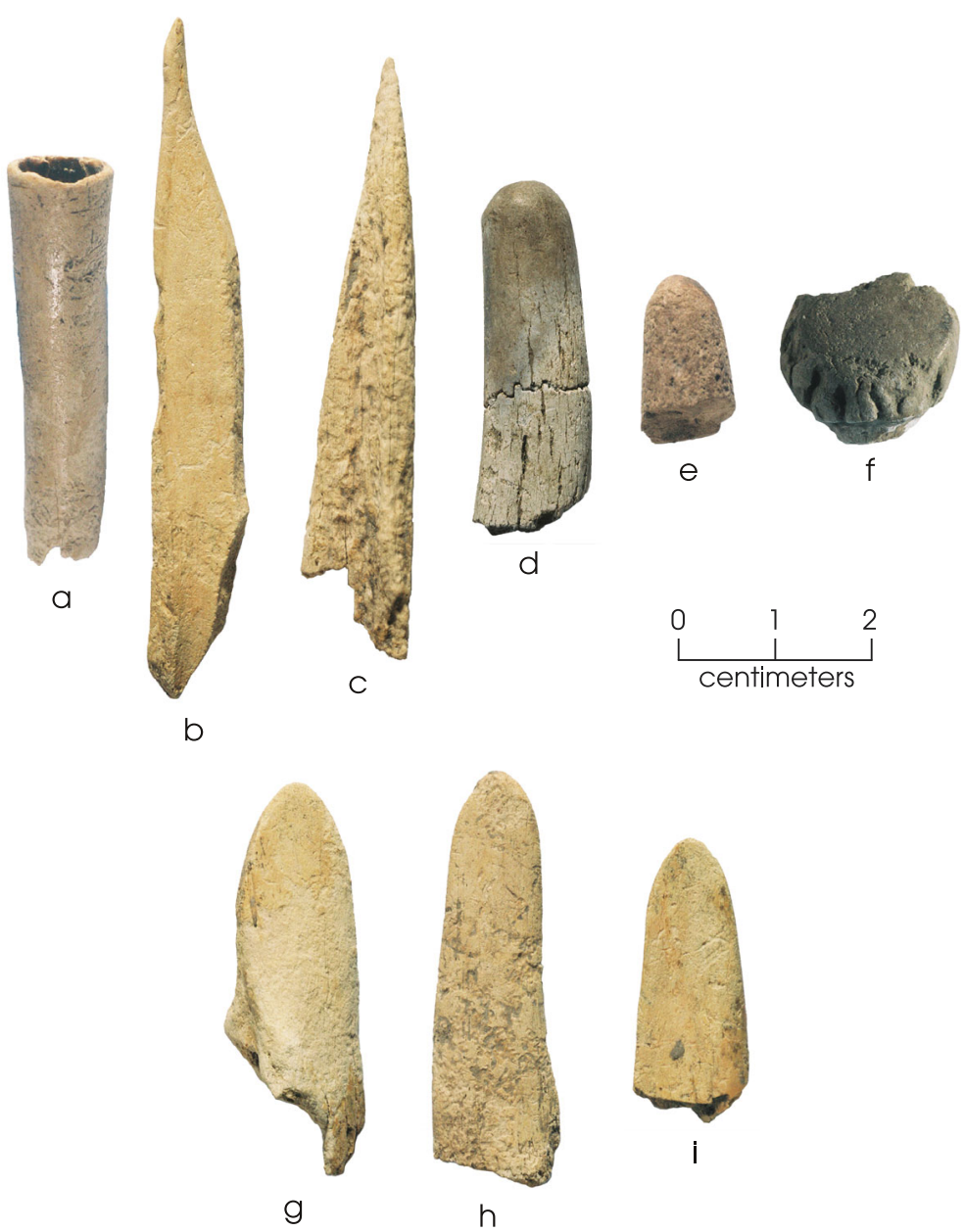

Figure 7-23. Worked bones and antlers. (a) Bird bone bead; (b) splinter awl; (c) deer metapodial awl; (d-e) worked antler tine tips; (f) antler burr; (g-i) deer ulna tool fragments.

Another medial shaft fragment $6.5 \mathrm{~mm}$ wide may be an additional needle fragment; its surface is deteriorated and does not retain polish (Figure 7-24c). The presence of these three thin shafts suggests that needle use was common. Bone needle fragments with and without eyes were recovered from the Austin phase deposits at the Kyle site (Jelks 1962:66).

Five worked bones are identified as cut and smoothed deer metapodial waster fragments (Figure 7-24d-g). Three specimens have grooveand-snap terminations, one has a cut termination, and the fifth is broken; two have portions of the articulating ends still intact. Three specimens with groove-and-snap terminations also were recovered from 41MM340. Meissner and Mahoney (2003:201-204) interpret these specimens as "tool platforms" after Harrell (1983:40
41). Sorrow (1966:47-49) called similar specimens from the Pecan Springs site "pin blanks." In effect, one end of the metapodial was held while the other was worked into the desired shape, and the part held was then cut away and discarded. This seems like an efficient method of partially shaping thin tools such as needles. Pulling the metatarsal fragment across an abrading stone by the "platform" to shape the tool would explain the striations and polish that appear on the discarded "platform."

This small assemblage, which includes splinter and metapodial awls, ulna tools, antler flakers/ punches, and bone needles, is similar to bone tool collections from central Texas sites with Austin phase components, such as the Kyle site (Jelks 1962) in Hill County, the Pecan Springs site (Sorrow 1966) in Ellis County, and the Belton Lake sites of Bell and Coryell Counties (Shafer et al. 1964). Given the presence of the possible bone tool wasters or platform ends, it is likely that manufacture of some bone toolspossibly needles-took place at the site using a manufacture method similar to that practiced during the Late Archaic period at nearby site 41MM340.

\section{VESSEL CERAMICS}

The data recovery excavations produced just four ceramic vessel sherds. The sherds came from three proveniences in the East Block (Level 8 of Excavation Unit 312 and Level 9 of Excavation Units 310 and 316), as well as Level 4 of initial Excavation Unit 5 near the East Block. The sherds are small, ranging from 0.5 to $3.0 \mathrm{~cm}$ in diameter and with a thickness range of 7.4$8.2 \mathrm{~mm}$ (thickness could be measured on only three sherds). Three are bone tempered with black cores, and one has no visible temper but does have an extremely sandy paste. The bonetempered sherds are undecorated vessel body 

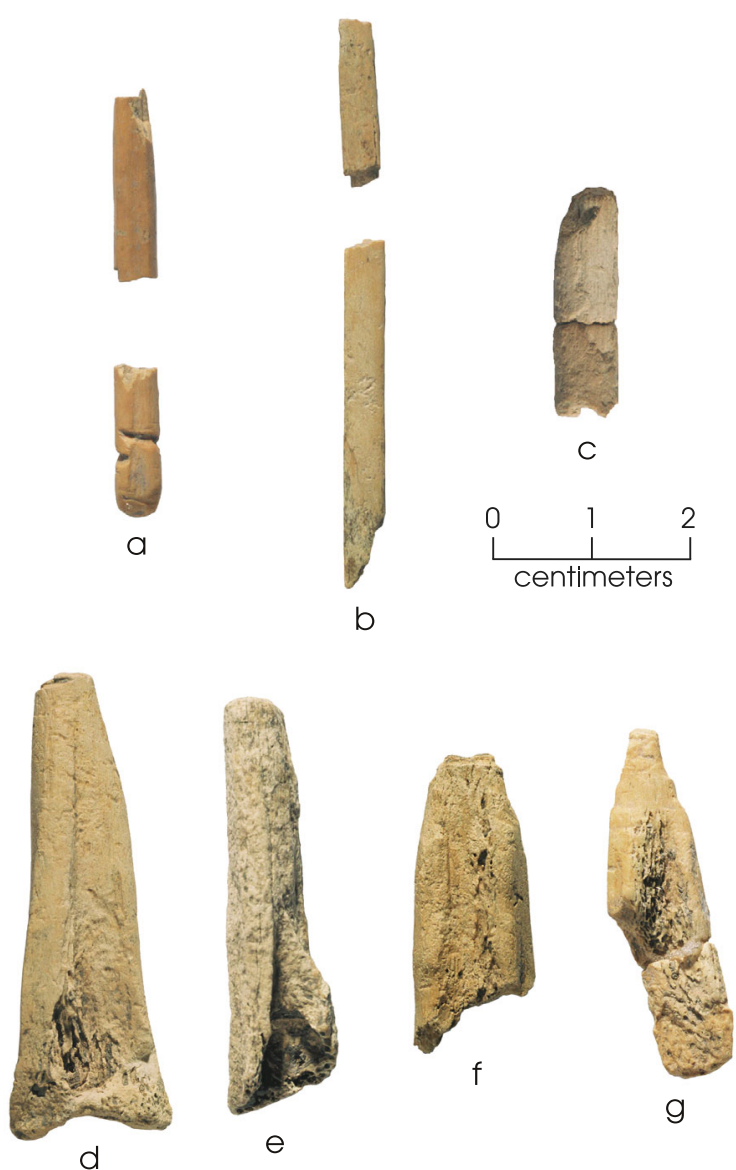

g

Figure 7-24. Worked bones. (a-c) Needle fragments; $(\mathrm{d}-\mathrm{g})$ deer metapodial waster fragments.

sherds. Most of their surfaces are eroded, though one still retains some evidence of exterior burnishing and another has a smoothed interior and exterior. The sandy paste sherd, from Excavation Unit 310, is part of an undecorated vessel rim; its interior and exterior are eroded, although some evidence of burnishing survives on the lip. The rim is everted with a flattened lip.

These 4 sherds were recovered from an area of the site that had produced 13 ceramic sherds during test excavations ( 5 of these sherds were less than $1 \mathrm{~cm}$ in length and width). Timothy K. Perttula (2001:124-125) analyzed the sherds recovered during testing and concluded that they represent two vessels. One vessel represented by 11 sherds was identified as an undecorated, bone-tempered, thick-walled jar, and the other vessel represented by 2 sherds was a bone/grog-tempered, carinated bowl decorated with a single broad horizontal incised line above the carination. Perttula rejects associating these vessels with bone-tempered Leon Plain ware of central Texas because of the thickness of the sherds and the absence of interior and exterior burnishing. Rather, he suggests a Caddoan connection based on the grog tempering and carinated bowl form.

Eleven of these 13 sherds came from from 0 to $30 \mathrm{~cm}$ below the surface in testing Block 1 , and the other 2 came from the backdirt of adjacent Backhoe Trench 24 (Mahoney and Tomka 2001:52). Based on depth, the sherd from Excavation Unit 5 probably goes with those found in testing and may relate to the sparse later Late Prehistoric component that was removed mechanically before data recovery excavations began. The deeper sherds from the East Block could be intrusive from the later deposits above, or they may actually be associated with the early to middle Late Prehistoric component targeted in the data recovery work. In either case, ceramics are so sparse that it is clear that ceramic vessels did not play any significant role in activities performed at the site.

\section{BURNED AND UNBURNED ROCKS}

A total of $156,177.0 \mathrm{~g}$ of burned and 6,777.5 $\mathrm{g}$ of unburned rocks were recovered. The burned rocks represent materials used for heat retention in cooking facilities (i.e., the surface and pit hearths and the processing pits). The unburned rocks may be rocks brought onto the site for that purpose but never used, or perhaps they were used minimally and thus do not display signs of burning. These are categorized as follows: burned limestone, 71,371.7 g; unburned limestone, 2,314.0 g; burned sandy limestone, $38,610.8 \mathrm{~g}$; unburned sandy limestone, $1,845.8 \mathrm{~g}$; burned conglomerate, $1,607.1 \mathrm{~g}$; burned quartzite, 29,450.5 g; unburned quartzite, 1,403.9 g; burned silicified wood, $668.7 \mathrm{~g}$; unburned silicified wood, $101.3 \mathrm{~g}$; burned limonite/hematite, 297.5 g; unburned limonite/hematite, 666.8 g; burned chert, 13,109.9 g; unburned chert, $445.7 \mathrm{~g}$; and burned indeterminate rock, $1,060.8 \mathrm{~g}$.

Many of the rocks still retain water-rounded exterior surfaces, suggesting they were gathered from gravel bars within the Little River or from gravels within the Pleistocene terraces that 
border this stretch of the Little River valley. The rocks range from heat shatter $0.2 \mathrm{~cm}$ in diameter to chunks of limestone $15 \mathrm{~cm}$ across. Heat shatter was classified as indeterminate as to rock type and simply weighed. All other rocks more than $1 \mathrm{~cm}$ in diameter were classified, counted, and weighed by provenience unit. Angular cracking, spalling, potlidding, and changes in coloration were the attributes used to identify burned rocks. These criteria were applied liberally such that the presence of only one attribute was needed to identify a rock as burned or having been exposed to heat.

\section{BURNED CLAY}

A total of $30,043.0 \mathrm{~g}$ of burned clay was recovered: $55.0 \mathrm{~g}$ from the initial units; $11,978.6 \mathrm{~g}$ from the Main Block; $28.3 \mathrm{~g}$ from the East Block; and $17,981.1 \mathrm{~g}$ from the South Block. This weight represents 90 percent of the proveniences that produced burned clay. In the other 10 percent (all in the initial units and the Main Block), burned clay was quantified only by counts (in the distributional analyses presented in Chapter 8 , these counts were used to estimate weights based on count and weight data from nearby units). Grass and twig impressions were noted on some fragments, but all of the burned clay appears to represent scattered debris from hearths or other burned features rather than wattle-impressed daub. The burned clay appears to represent sediment that was fired incidental to hearth use, rather than clay used to prepare hearths.

\section{VERTEBRATE FAUNAL REMAINS}

A total of 6,540 vertebrate faunal bone fragments $(3,426.4 \mathrm{~g})$ were recovered, reflecting animals procured for food, hides, and perhaps other purposes by the people who lived at the site. As discussed in Appendix E, this sample is composed predominately of terrestrial species, especially deer and deer-sized artiodactyl. Other well-represented taxa include turtles, cottontail rabbit, raccoon, and fish. The assemblage appears typical for hunter-gatherers exploiting the resources available on the floodplain of the Little River and in the river itself.

Most of the bones came from the Main Block ( $\mathrm{n}=5,753)$, constituting 88 percent of the col- lection. Bones from the initial 11 excavation units total 568 pieces (9 percent), while only 162 fragments ( 2 percent) were recovered in the East Block and 57 fragments (1 percent) came from the South Block.

\section{INVERTEBRATE FAUNAL REMAINS}

Substantial quantities of invertebrate faunal remains were recovered. As discussed in Appendixes A and B, these remains consist of the shells of 11 species of freshwater mussels and 12 species of land gastropods. A total of 10,362 mussel shell umbos were recovered from the entire site (weighing of complete shells and umbo fragments from 77 percent of the proveniences that yielded mussel shells provided a total weight of 58,249.5 g). Amblema plicata (threeridge mussel) and Quadrula houstonensis (smooth pimpleback mussel) dominate the recovery. Both of these occur in a variety of habitats and have been documented previously in the Brazos basin, and there is no doubt that the archeological specimens at 41MM341 represent mussels procured for food from the Little River nearby. Most of the mussel shells (8,712 umbos, or 84 percent) are from the Main Block. The initial 11 excavation units produced 968 umbos, the East Block produced 631, and the South Blocks produced 51. Within the Main Block, half of the umbos are from the shell lens features in Levels 8 and $9(\mathrm{n}=4,366)$. Thirty-seven percent $(\mathrm{n}=3,363)$ are from the shell features in Levels 6 and 7 . Eleven percent $(\mathrm{n}=934)$ are from features in Level 10, and the remaining 1 percent (49 umbos) are from other contexts. As discussed in Chapter 6, these shell lenses represent loci of discarded food debris as well as the remains of other activities.

Of the gastropods recovered from 1/4-inch screening and from features, Rabdotus predominates. A total of 11,459 shells were recovered (excluding those from the 50x50-cm sample columns) and were quantified to address the likelihood that this gastropod was utilized as food. Rabdotus and the other 11 species were recovered and quantified from samples selected from seven of the shell lens features and from a sample column taken from the south wall of initial Excavation Unit 9. The column provenience places it in an area with sparse cultural deposits between the Main Block and the South 
Block. As such, the contents of this column may have been less affected by cultural activities and more representative of local environmental conditions.

Concentrations of Rabdotus shells were observed only in the Main Block. These concentrations occurred within the mussel shell lens features, and in one instance a $2 \times 3-m$ concentration of mostly Rabdotus shells was designated a feature in its own right (Feature 17). As discussed in Chapter 6 and Appendix B, it is clear that Feature 17 represents procurement of snails for food, and it is likely that other concentrations do as well. A total of 11,000 (96 percent) of these gastropods came from the Main Block, while 208 (2 percent) came from the East Block. Only 86 shells (1 percent) were recovered from the initial 11 units, and 165 shells (1 percent) were counted in the South Block. By level in the Main Block, 58 percent $(\mathrm{n}=6,433)$ of the Rabdotus shells came from Levels 6 sand 7 , and 36 percent $(\mathrm{n}=4,016)$ came from Levels 8 and 9 . Level 10 produced only 5 percent $(\mathrm{n}=531)$.

\section{MACROBOTANICAL REMAINS}

Macrobotanical remains collected through the water-screening process and in situ from the excavation blocks and features consist predominately of wood charcoal (mostly oak wood), though the charred remains of nutshells, bulbs, a tuber, pit fragments from fruits, seeds, and grass stems were also recovered (see Appendix G). Charred macrobotanical remains total $1,614.4 \mathrm{~g}-798.6 \mathrm{~g}$ from $118 \mathrm{in}$ situ sam-ples and $815.8 \mathrm{~g}$ recovered from the screens. Most was recovered from the Main Block, totaling 1,076.8 $\mathrm{g}(67$ percent). The initial 11 units produced $335.9 \mathrm{~g}$ (21 percent). The South Block produced $195.8 \mathrm{~g}$ (12 percent), and the East Block produced only $5.9 \mathrm{~g}(<1$ percent). Within the excavation blocks, feature proveniences yielded most of the macrobotanical remains $(1,244.0 \mathrm{~g}$, or 77 percent). In terms of food resources used by the people who lived at 41MM341, hardwood nuts (hickory, pecan, and acorn) and bulbs (wild onion/garlic) are best represented. Neither is especially abundant, however. 



\section{DEFINITION OF ANALYSIS UNITS, SITE CHRONOLOGY, AND INTRASITE DISTRIBUTIONAL STUDIES}

As discussed below, 41MM341 was occupied intermittently for about 700 years, with the most-intensive use occurring over a 400 - or 500-year period from A.D. 800-900 to 1300 . This chapter starts with an examination of how best to segregate the archeological remains into more-discrete units of time for analysis. Then, the contents of these analytical units are compared to look at change, or the lack thereof, in use of the site through time. Finally, the horizontal distributions of the archeological materials are examined for insights into site structure and function.

\section{DEFINITION OF ANALYSIS UNITS}

Three analysis units are defined within the Main Block. Levels 6 and 7 are assigned to Analysis Unit 1, which appears to date to A.D. 1100-1300. Levels 8 and 9 are assigned to Analysis Unit 2, dating from A.D. 800 or 900 to 1100. And Level 10 is assigned to Analysis Unit 3 , which dates to the A.D. 600 s and maybe 700 s. As described below, this simple breakdown provides the best fit for the multiple lines of evidence presented by the site, but defining these analysis units presented challenges. These challenges are the result of the following. First, the cultural deposits occurred as patchy lenses of artifacts and ecofacts associated with intact features in slowly aggrading late Holocene alluvium. Among the features were concentrations of lithic artifacts clearly representing the debris from sets of discrete reduction episodes. As such, the site appears to have a high degree of horizontal integrity and offers the tantalizing possibility of examining short slices of time, at least in some of the remains. Second, the archeo- logical remains clearly are stratified, but the deposits are thin enough $(50 \mathrm{~cm})$ and distributed vertically in such a way (i.e., scattered patchily) that it is not always easy to discern what goes with what, especially given that the excavations were done in arbitrary $10-\mathrm{cm}$ levels. And third, the radiocarbon dates indicate an overall occupation span of ca. 700 years, with most of the remains apparently having been deposited over a 400- or 500-year span. As shown below, the dates do not present a simple picture of the chronology of the site, however.

The analysis units were defined based on the horizontal and vertical distributions of the following: the lithic reduction debris piles, mussel shells, debitage, burned rocks, features, and radiocarbon dates. As described in Chapter 6, analysis of the lithic reduction debris piles was undertaken to determine their integrity and provide a measure of artifact movement between levels.

The distributions of mussel shells, debitage, and burned rocks were examined using a crosssectional format that provides information on the geometry of the lenses of cultural materials and how they relate to each other across the main excavation block. This information then was compared to the features defined in the field. Lastly, the results of radiocarbon assays on charcoal from features were compared with the other distributional information to establish chronological parameters for the analysis units. The various lines of evidence are discussed below.

\section{Lithic Reduction Debris Piles}

As discussed in Chapter 6, the lithic reduction debris piles were not given feature 
designations during the excavations, although field tracking of debitage frequencies and observations of the materials recovered clearly indicated that concentrations of lithics were present and that they could represent discrete depositional events. Subsequent analysis has confirmed that this is the case. A total of 10 lithic concentrations representing such debris piles have been identified within Levels 6 through 9 in the Main Block. All but Pile 8, a small concentration in Level 9, were included in helping to identify analysis units.

Analysis of the lithic concentrations began by sorting like materials within unit levels containing the highest frequencies of flakes and chunks. The purpose was to relate groups of debitage to unique materials using color, texture, and inclusions. The number of distinct debitage groups in each concentration ranges from 10 to 21, averaging 14. Each group within each concentration appears to represent a distinct episode of cobble or biface reduction. Though extensive refitting of flakes and chunks within groups was not attempted, enough obvious refits were identified to bolster the idea of distinct reduction episodes. Nine of the concentrations contain refits, ranging from as few as 1 to as many as 69 . Debitage groups identified by material type and refits were then traced through levels adjacent to, above, and below the main concentrations.

Tracing of debitage groups into levels above and below the main concentrations showed that most have very restricted vertical distributions (see Table 6-6). Two concentrations are restricted to single levels, and six others are nearly so. Only two of the lithic reduction debris piles substantially crosscut levels: Concentration 2 is in Levels 6 and 7, and Concentration 5 is in Levels 7 and 8. Also, only 3 percent of the refits identified for all the debitage groups are between levels, while 97 percent are within single levels. These figures support the discrete nature of the concentrations and indicate that movement of artifacts up or down from these concentrations generally was limited. Based on this line of evidence alone, it would appear justifiable in most parts of the block to create an analysis unit for each level. As shown below, however, other evidence argues against this.

\section{Distributions of Mussel Shells, Debitage, Burned Rocks, and Features}

The occurrence of mussel shells, debitage, and burned rocks was graphed by unit and level using a series of south-north cross sections through the Main Block, labeled Lines 1-16 in Figure 8-1. The graphs display mussel shell and burned rock weights and debitage frequencies by unit and level (Figures 8-2 through 8-4). Weights or frequencies are shaded light gray if they are within one standard deviation above the mean unit level recovery for a particular material and dark gray if they are greater than one standard deviation above the mean. For mussel shell weight, the mean is $152 \mathrm{~g}$ and one standard deviation above the mean is $473 \mathrm{~g}$. For burned rock weight, the mean is $171 \mathrm{~g}$ and one standard deviation above the mean is $450 \mathrm{~g}$. The mean debitage frequency is 60 , and one standard deviation above the mean is 142 pieces.

The cross sections show the lenses of mussel shells, burned rocks, and debitage, some of which were noted in the field and designated as features. In some places, single lenses predominate. In others, multiple stacked lenses are evident. For example, a single main lens with high densities of mussel shells, debitage, and burned rocks is present almost exclusively in Level 7 in the southern part of Line 1. Moving northward, mussel shells and burned rocks become less frequent, but high debitage frequencies continue to mark the lens in Level 7 almost to the edge of the block. High debitage frequencies in Levels 6 and 8 in some units on the central and northern parts of Line 1 suggest that multiple superimposed lenses are present. This also could reflect thickening of a single main lens centered in Level 7 into the levels above and below, however. Superpositioning can be seen more clearly in the mussel shell distributions in Line 6, where one lens is evident in Level 6 mostly north of another lens in Levels 8 and 9. The upper lens can be traced as far west as Line 4 and maybe Line 2 and as far east perhaps as Line 9 . The lower lens appears not to extend westward, and it goes eastward maybe only a meter or so. Importantly, the cross sections emphasize the horizontal nature of the deposits by displaying no indication that the lenses slope (this is also the case when looking at cross sections oriented east-west). This line of evidence could be used 


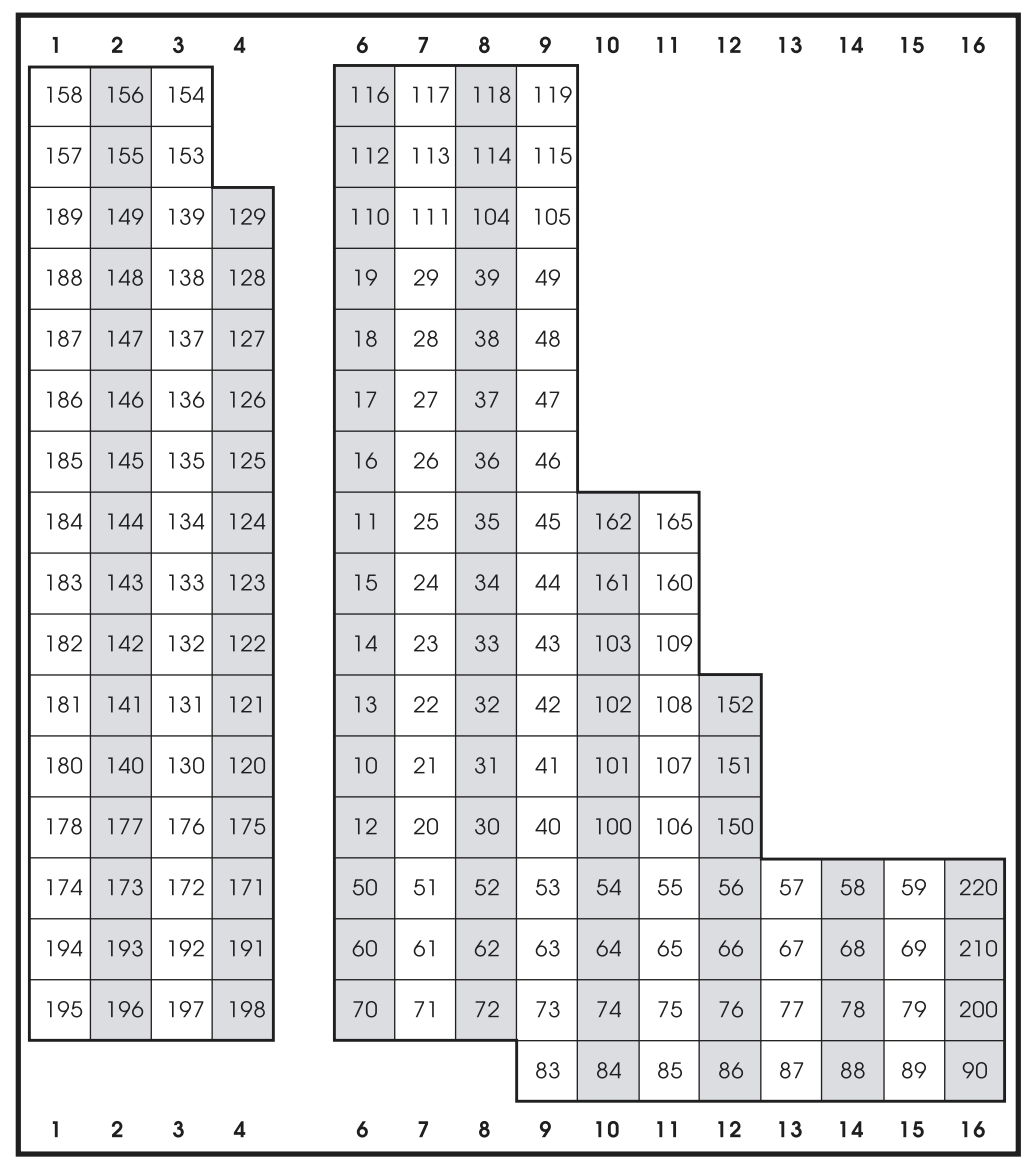

Figure 8-1. Plan of the Main Block showing excavation unit numbers and south-north lines used in graphing mussel shell, debitage, and burned rock weights or counts.

to support identification of analysis units that in some places consist of single levels and in other places multiple levels involving various combinations of Levels 6 and 7, Levels 6-8, Levels 7 and 8, Levels 8 and 9, and Levels 9 and 10 .

Adding the cultural features helps clarify the picture because it shows that features sometimes crosscut levels and peaks in the cultural materials, indicating that analysis units should consist of multiple rather than single levels (Figure 8-5; pit hearths, though included on the cross sections [shown as trapezoids], are not considered in this discussion because their levels of origin were difficult to discern and because their intrusive nature likely was associated with a high degree of disturbance). This is most obvious for several mussel shell features. For example, the vertical extent of mussel shell Feature 21a corresponds to mussel shell peaks highlighted in Levels 6 and 7 (see Figure 8-2,
Lines 1-4). Excavators recorded that Feature 21a began in the middle of Level 6 and ended in the middle of Level 7. This suggests that it would be prudent to combine the peaks associated with the feature in Levels 6 and 7. Similar combinations can be justified for Features 9 and 16 in Levels 8 and 9 (see Figure 8-2, Lines 6-8 and 911).

Additional support for combining levels as indicated above for at least some analytical purposes comes from what does not crosscut the levels. For instance, on the west side of the block, mussel shell Feature 21b, defined in Level 7, does not cross into Level 8, and Levels 8 and 9 produced few peaks in shell weight below Feature 21b. In the eastern part of the block, this pattern is reversed with Level 7 producing few peaks above the shell features in Levels 8 and 9. Thus, a break between Levels 7 and 8 is supported both by what was observed in the field (i.e., how features were defined) and by the plotted distributions of the cultural materials.

Also relevant are the levels of origin of the surface hearths (see Figure 8-5). Most of these hearths start either in mid-Level 6 to the top of Level 7 (Features 11, 41, 43, 44, 46, and 47) or at the top of Level 8 to the top of Level 9 (Features 8, 22/26, 25, 35, and 40), with just one (Feature 30) starting at the transition between Levels 7 and 8 . None of these cross substantially from Level 7 into Level 8 (oxidation from burning associated with the ash-covered tops of Features 43 and 44 in Levels 6 and 7 did penetrate into the top of Level 8 but was clearly below the features themselves). Only one hearth (Feature 12) has substantial components in both Levels 7 and 8, apparently having originated in the upper of these. Hence, the levels of origin of 92 percent of the hearths support the argument for combining Levels 6 and 7 into Analysis Unit 1 and Levels 8 and 9 into Analysis Unit 2. 


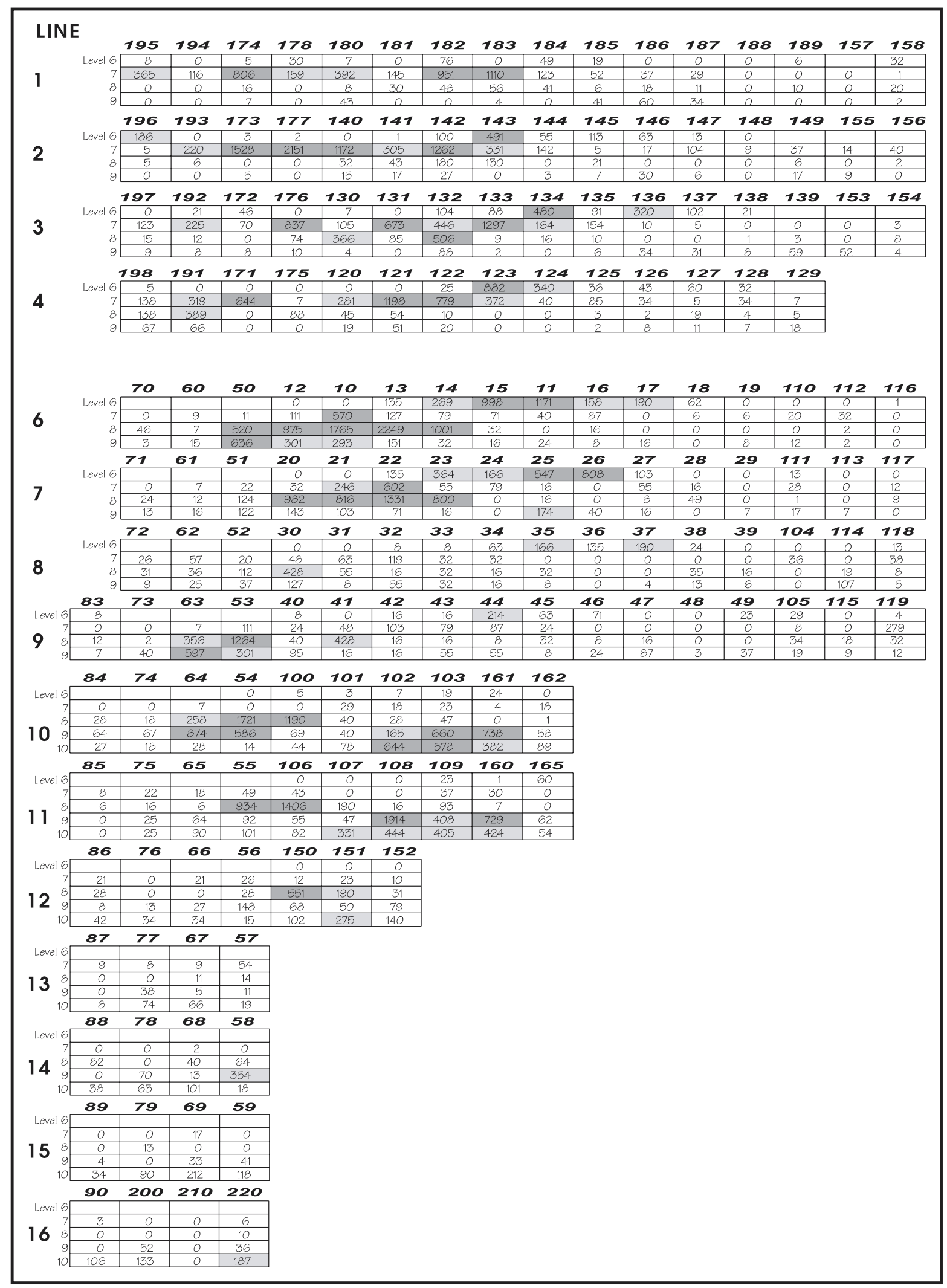

Figure 8-2. Mussel shell weights (g) by excavation unit and level in the Main Block. Shaded levels have aboveaverage quantities (light gray = less than one standard deviation above the mean; dark gray = more than one standard deviation above the mean). 


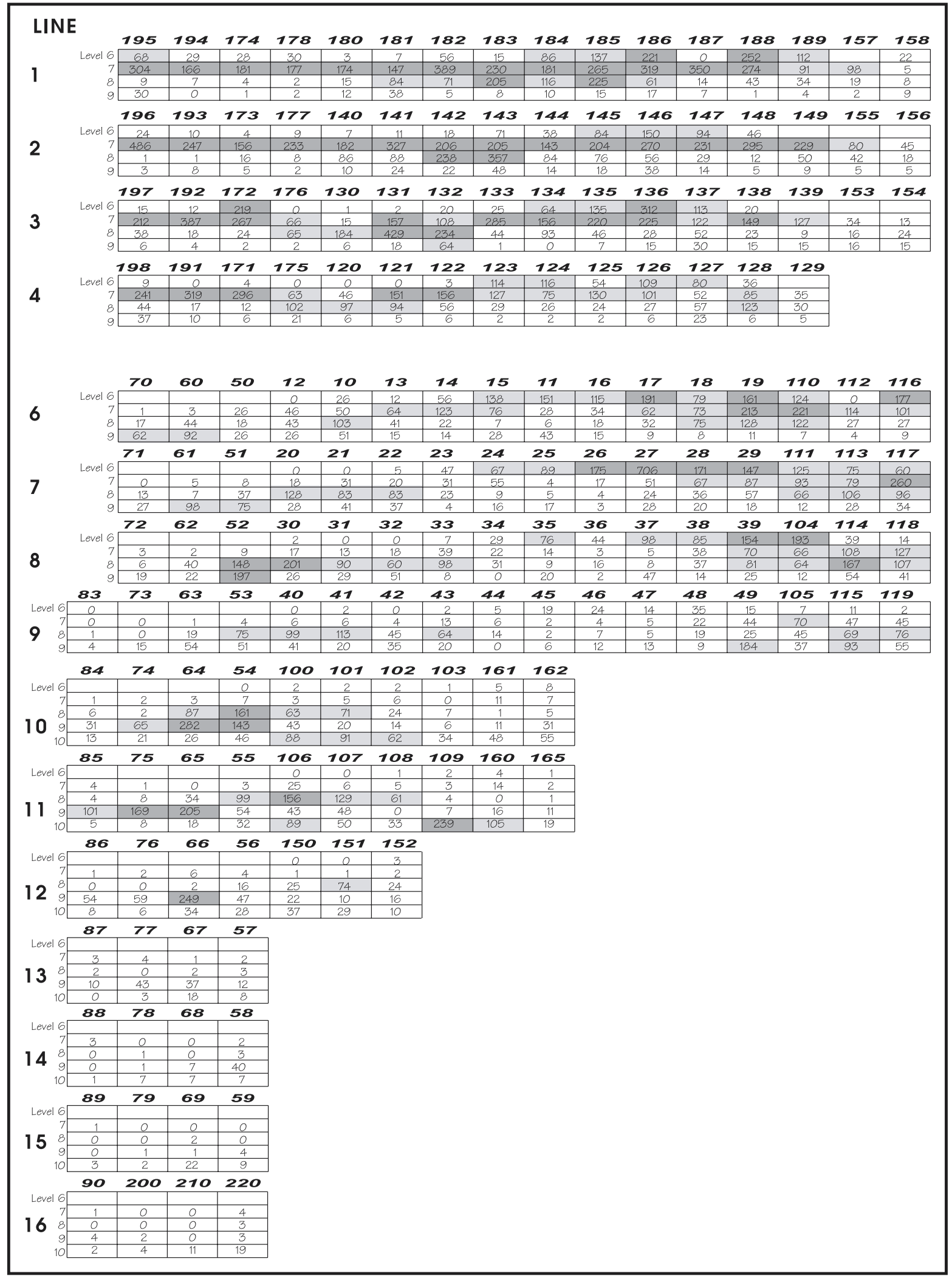

Figure 8-3. Debitage frequencies by excavation unit and level in the Main Block. Shaded levels have aboveaverage quantities (light gray = less than one standard deviation above the mean; dark gray = more than one standard deviation above the mean). 


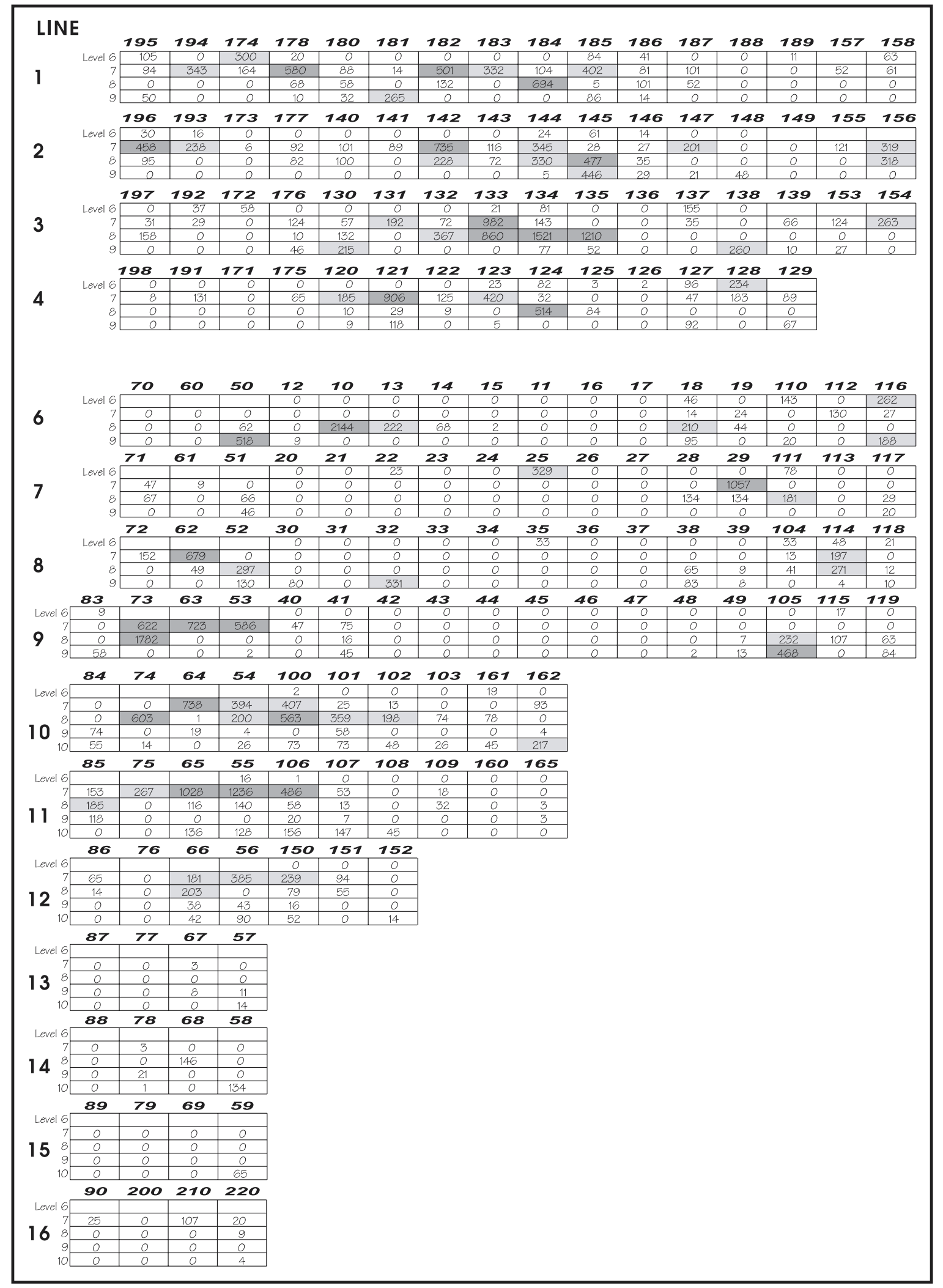

Figure 8-4. Burned rock weights (g) by excavation unit and level in the Main Block. Shaded levels have above-average quantities (light gray = less than one standard deviation above the mean; dark gray = more than one standard deviation above the mean). 


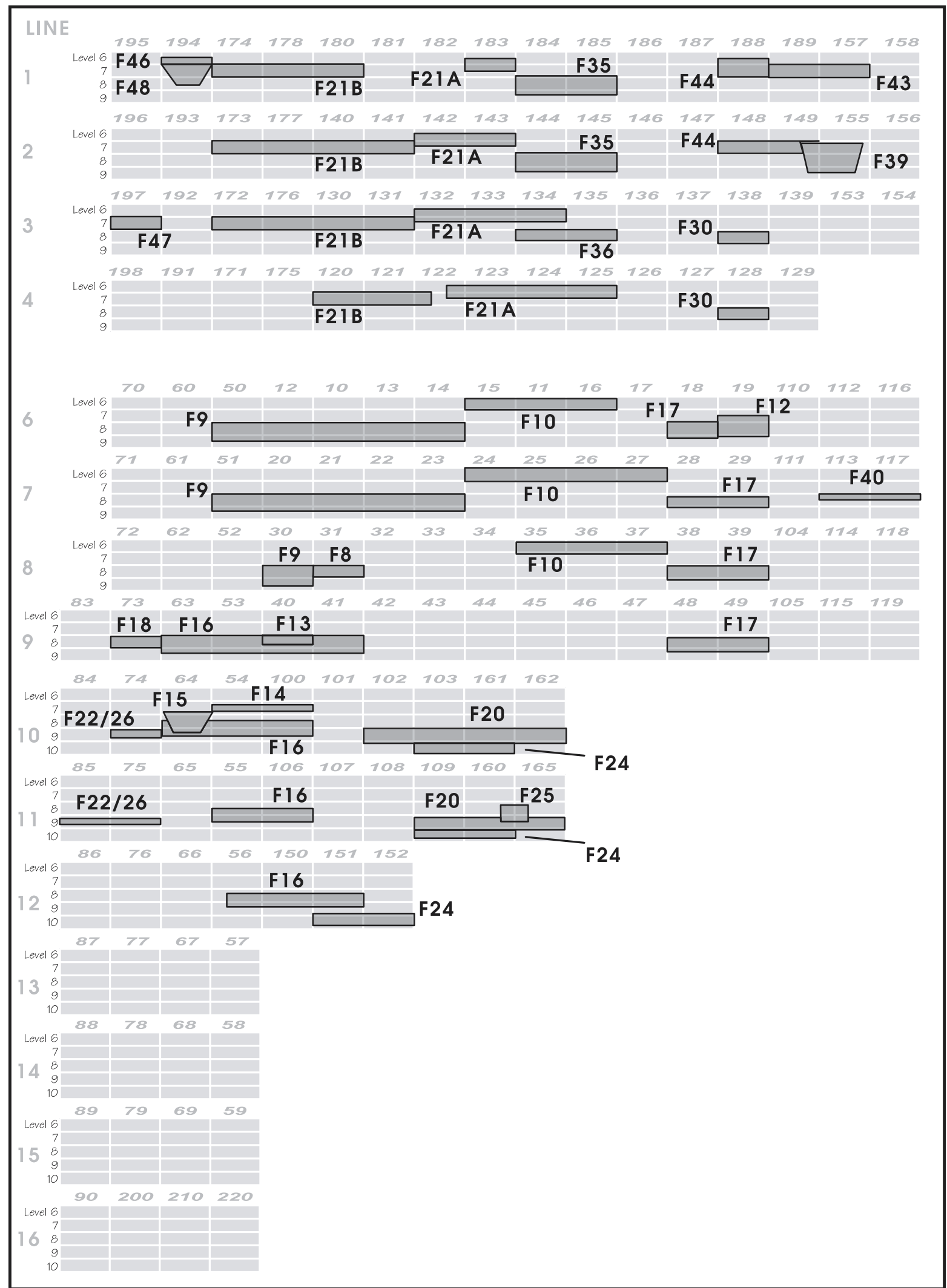

Figure 8-5. Cross sections through the Main Block showing shell features, surface hearths, pit hearths, and burned rock concentrations. 


\section{Radiocarbon Dates}

The one-sigma ranges of the radiocarbon dates from the Main Block indicate that Levels 6 through 10 represent a 700-year span from ca. A.D. 600 to 1300 , though most of the dates fall within a 400-year span from A.D. 900 to 1300 (Figure 8-6; see Appendix J for information on all the dates obtained). There is considerable overlap in the dates, and while there is a general trend for older dates to be deeper, this is not consistently the case. In short, they do not always help in separating features and levels into analysis units. Of course, this is not surprising given the span of time represented and the thickness of the deposit. The date ranges are presented in Figure 8-6 grouped according to the analysis units defined above and using a third unit that is defined chiefly based on dates. Dates from pit hearth Features 15, 39, and 48 are not considered as they crosscut levels and might have mixed dated materials.

Mussel shell Feature 24 and the base of shell Feature 20 in Level 10 represent the earliest occupation sampled by the Main Block. These dates, which range from A.D. 615 to 680 , are the main reason for splitting Level 10 off as Analysis Unit 3. These are at least 100 years older than the earliest date from Analysis Unit 2 above. The 12 dates from Analysis Unit 2 in Levels 8 and 9 (Features 9, 12, 16, 17, 22/26, 25, 35,36 , and 40) range from A.D. 780 to 1250 , with all but one being later than A.D. 895. These assays indicate a starting date for Analysis Unit 2 at least by A.D. 895, and maybe by A.D. 780 . The 11 dates from Analysis Unit 1 in Levels 6 and 7 (Features 10, 21a, 21b, 33, 44, 46, and 47) range from A.D. 1010 to 1380 , with 6 entirely postdating A.D. 1160 and 4 extending to A.D. 1280-1310. A start date for Analysis Unit 1 and terminal date for Analysis Unit 2 is hard to determine because many of the dates from Levels 8 and 9 overlap many of those from Levels 6 and 7. Based on the multiple intercepts of two of the dates from Feature 9 and two of those from Feature 21b, however, a date of A.D. 1100 is proposed.

Simply considering assays from the surface hearth features, which likely have the least chance of dated materials moving into them, provides a similar picture (see Figure 8-6). The dates from Feature 40 in Level 8 and Features $22 / 26$ and 25 in Level 9 are the oldest and over- lap within an overall range of A.D. 895 to 1040 . The earliest intercept for the date from Feature 12, also from Level 8, also is consistent with this range. These assays support combining Levels 8 and 9 into one analysis unit. Proceeding upward, two almost identical date ranges mark the interface between Levels 7 and 8. One (A.D. 1020-1160) comes from the bottom of hearth Feature 47 and thus the very bottom of Level 7, while the other (A.D. 1030-1170) comes from top of hearth Feature 35 and the top of Level 8. As above, it is suggested that the true age of the former is somewhere in the latter part of its range, while the true age for the Feature 35 sample is in the early half of its range. Hearth Feature 44, also in Level 7, produced a date range of A.D. 1160-1255, and Feature 46 in Level 6 produced the youngest date with intercepts at A.D. 1260-1310 and 1370-1380. The latter intercept seems much too recent given the other dates and the materials recovered from the site.

\section{Analysis Units in the East and South Blocks}

Radiocarbon dates can be used to relate the analysis units defined in the Main Block to the cultural deposits sampled in the East and South Blocks. Recovery from the East Block was limited in terms of artifacts and features. However, test excavations in this part of the site in 2000 produced a radiocarbon assay (A.D. 685-780) from a mussel shell feature in Level 10 that is slightly younger than Analysis Unit 3 in the Main Block. Because of these similarities in age and depth and to augment the Main Block sample, the materials from Levels 10 and 11 of the East Block (9 formal chipped stone tools, 27 expedient tools, 4 cores, 1,223 pieces of unmodified debitage, 1,858 $\mathrm{g}$ of burned rocks, 2,098 $\mathrm{g}$ of mussel shells, and $62 \mathrm{~g}$ of animal bones) are included in Analysis Unit 3. Cultural materials are scant from Levels 8 and 9 in the East Block ( 1 formal chipped stone tool, 7 expedient tools, 1 core, 249 pieces of unmodified debitage, 3 ceramic sherds, $192 \mathrm{~g}$ of burned rocks, $436 \mathrm{~g}$ of mussel shells, and $23 \mathrm{~g}$ of animal bones) and may be mixed with an ephemeral late component, based on the recovery of the few sherds and a date of A.D. 1407-1440 obtained from a comparable depth during the 2000 testing. Hence, materials from Levels 8 and 9 are not 


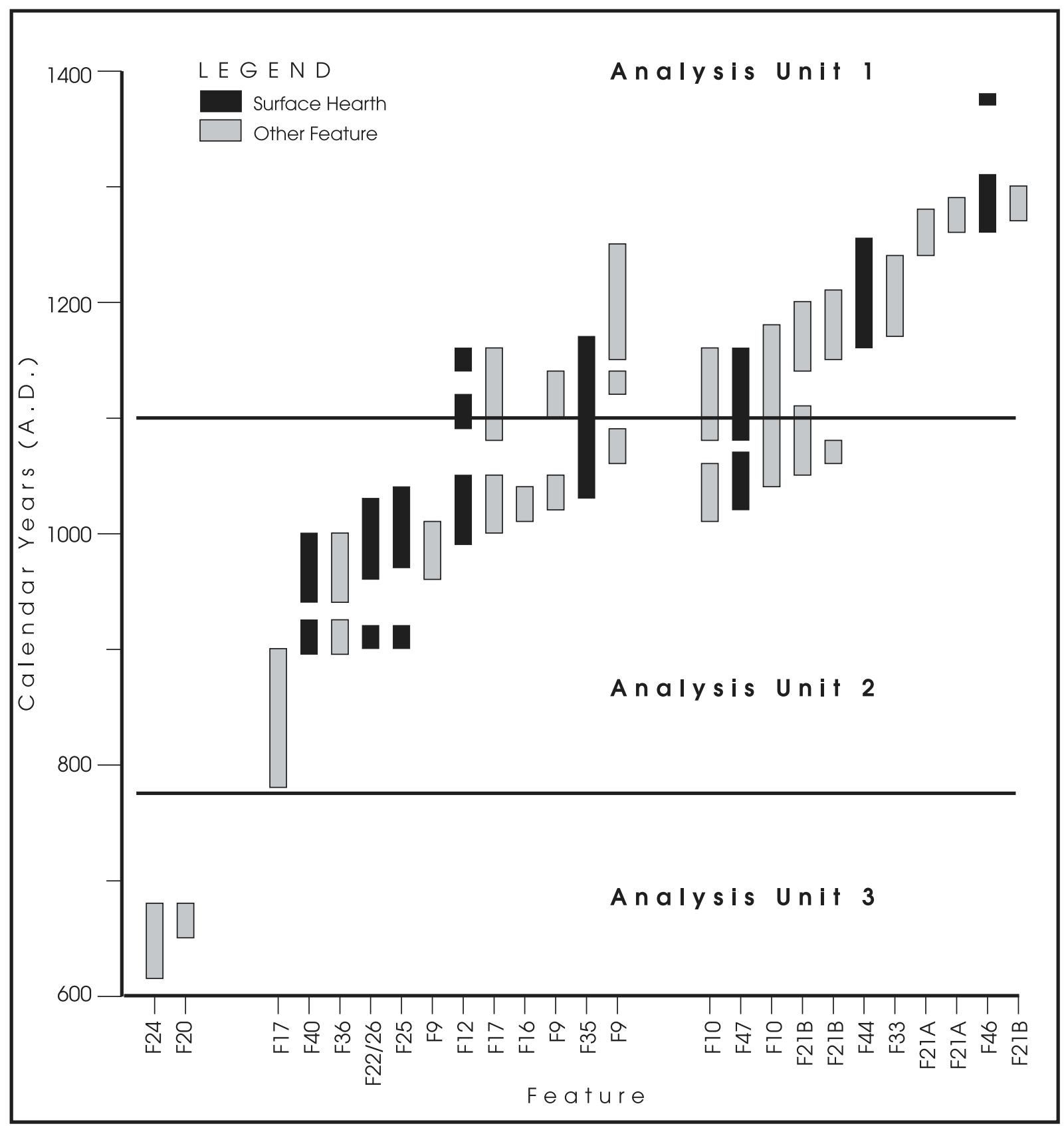

Figure 8-6. Graphs of one-sigma ranges of radiocarbon dates from the Main Block grouped by analysis unit (excludes dates from pit hearths).

included in any of the analysis units. Levels 6 and 7 were mechanically stripped from this block.

The artifacts from the South Block are not formally assigned to analysis units, even though the five radiocarbon dates indicate that the concentration of processing pits there go mostly or entirely with Analysis Unit 1 in the Main Block; three of these dates span the period from
A.D. 1160 to 1275 , one has a range of A.D. 1030 1190 , and the fourth has two intercepts after A.D. 1100 (A.D. $1110-1190$ and 1200-1210) along with an earlier intercept of A.D. 1040-1100 (see Appendix J). This concentration of pits was first identified in Level 7 and at the boundary between Levels 7 and 8 as an amorphous area of blackened sediment and fire-cracked rocks over much of the part of the block east of Trench 3. 
The pits became better defined in Levels 8 and 9 and extended into Levels 10 and 11. Because pit margins were sometimes indistinct, however, it is hard to be certain what was actually inside and outside the features. Further, because the South Block was about $10 \mathrm{~m}$ from the Main Block, it is hard to correlate levels between the blocks. And finally, other than burned rocks and charcoal, the South Block contained very sparse cultural materials, and thus adding them to the analysis units would not add much to the interpretations. For example, this block yielded only 3 formal chipped stone tools, 5 expedient tools, 175 pieces of unmodified debitage, 1 battered stone, $535 \mathrm{~g}$ of mussel shells, and $60 \mathrm{~g}$ of animal bones. The yields for burned rocks and charcoal were comparatively high at 87,069 g and $745 \mathrm{~g}$, respectively.

One small pit hearth (Feature 7) was identified adjacent to the South Block in Level 13 of Excavation Unit 7. It produced a onesigma date with intercepts of A.D. $640-710$ and 750-760, indicating that the deposits below the South Block probably go with Analysis Unit 3 in the Main Block. Because these deposits were uninvestigated only by one unit in this area, however, there is little reason to add these materials to this analytical unit.

\section{Summary}

Six sometimes overlapping lines of evidence were used to explore the best way to group proveniences in analyzing the data from 41MM341: the distributions of lithic concentrations representing lithic reduction episodes; the distributions of mussel shells; the distributions of debitage; the distributions of burned rocks; the distributions of cultural features; and the distributions of radiocarbon dates. Combined, these lines of evidence suggest that analysis and interpretation of the site can be approached on two levels. One uses the analytical units defined here to look at components broadly definedthat is the ca. 200-year-long spans of time that can be identified most consistently and most reliably across the Main Block and between it and the East and South Blocks. These analysis units are useful for characterizing the occupations in terms of the ranges of features and tool types used (and hence activities), the ranges of subsistence resources utilized and so on and for looking at how these did or did not change through time. The following section presents these characterizations and comparisons. On a finer level, interpretation of the spatial distributions of some of the remains can provide insights into site structure and function. This part of the analysis is presented in the last section of this chapter.

\section{ANALYSIS UNIT CHARACTERIZATIONS AND COMPARISONS}

\section{Projectile Point and Knife Types}

The typed projectile points associated with the analysis units suggest that arrow point styles changed through time, but there were no dramatic replacements of one type by another (Table 8-1). Scallorn points are notably frequent in all analysis units and appear to have been used throughout the occupation. Alba points are especially common in Analysis Unit 1, but they also make up almost 20 percent of the points from Analysis Unit 2. Perdiz points are relatively restricted to the latest deposits, while the Darl dart points are similarly restricted to the earliest deposits. The Ensor dart points are too few to mention, except to say that the single specimen in Analysis Unit 1 probably reflects recycling. The point assemblage from Analysis Unit 3 is consistent with the radiocarbon evidence associating it with the late end of the Late Archaic period, when it would have been possible for both arrow points and dart points to have been part of the hunting technology.

Darl and Ensor points both are common to the eastern margin of the Edwards Plateau and indicate ties or contacts between groups on the Blackland Prairie and those to the west (Rogers 1999:96-97). Scallorn points have been associated with the early part of the Late Prehistoric period and are considered diagnostic of the Austin phase of central Texas, although they are common outside central Texas as well (Prewitt 1981, 1995:129). The dating of Analysis Unit 2 (A.D. 800 or 900 to 1100) may indicate the span within the Late Prehistoric period when Scallorn points saw their most prevalent use. Alba and Perdiz points apparently supplemented the tool kit during the latter part of the occupation. As noted in Chapter 7, the Perdiz points from 41MM341 are not the classic central Texas va- 
Chapter 8: Analysis Units, Chronology, and Distributional Studies

Table 8-1. Typed projectile points by analysis unit

\begin{tabular}{l|c|c|c|c|c|c|c}
\hline \multirow{2}{*}{ Type } & \multicolumn{2}{|c|}{ Analysis Unit 1 } & \multicolumn{2}{c|}{ Analysis Unit 2 } & \multicolumn{2}{c|}{ Analysis Unit 3 } & Total \\
\cline { 2 - 8 } & $\#$ & $\%$ & $\#$ & $\%$ & $\#$ & $\%$ & \\
\hline Alba & 13 & 43 & 3 & 18 & 0 & 0 & 16 \\
Perdiz & 7 & 23 & 1 & 6 & 0 & 0 & 8 \\
Scallorn & 9 & 30 & 12 & 71 & 4 & 44 & 25 \\
Darl & 0 & 0 & 1 & 6 & 4 & 44 & 5 \\
Ensor & 1 & 3 & 0 & 0 & 1 & 11 & 2 \\
\hline Total & 30 & & 17 & & 9 & & 56 \\
\hline
\end{tabular}

riety often associated with Toyah components (Prewitt 1981:82-84). Rather, they are similar to a variety of the point that is well flaked and has shorter stems and barbs and that is often recovered from the eastern part of Texas (Gadus et al. 2002:90, 136). The presence of this eastern Perdiz form along with the Alba points, which are most-famously associated with the George C. Davis site in Cherokee County (Shafer 1973), suggests substantial interaction with east Texas groups.

Also relevant to this issue are the chipped stone knife styles at 41MM341. Several knife types have been defined by archeologists based on blade and base shape. The types found at 41MM341 include the Friday biface and the Gahagan biface (Jelks 1962:42; Shafer 1973:224-331). The Friday biface, associated with the central Texas Austin phase (Prewitt 1981), has convex to straight lateral edges with a generally straight base. The Gahagan biface has recurved lateral edges flaring near the concave base. Gahagan bifaces, almost always fashioned from central Texas chert, clearly are imported items when they appear in east Texas Caddo sites such as George C. Davis and in Louisiana where they were first defined at the Gahagan site (Webb and Dodd 1939).

At 41MM341, there are no strong patterns of association between analysis units and knife type, perhaps in part because the sample is so small. Of the 30 knives and knife fragments, lateral edge shape and base form could be discerned on only 11 specimens. Three specimens have the classic Gahagan form with flaring nearbase lateral edges with a concave base, and 4 specimens have the straight lateral edges with a straight base characteristic of the Friday biface. Both forms occur in Analysis Units 1 and 2, with Gahagan bifaces slightly more common in the earlier unit and Friday bifaces more common in the later unit (Table 8-2). With so few identified specimens, it is hard to attach much meaning to these distributional differences, however. What may be most important is that neither form was found in Analysis Unit 3, where knives in general were scarce.

\section{Feature Types}

Most of the cultural features can be assigned to analysis units based on their stratigraphic placement (i.e., the level in which they were identified), although for some (e.g., the pit hearths and possible postholes) this is complicated by uncertainties over where they actually originated. Table 8-3 shows that the analysis units generally have similar kinds of features. For instance, all analysis units produced surface hearths adjacent to or within shell lens features. Surface hearths are likely small general-purpose hearths built on occupation surfaces. Burned clay, ash, some soil reddening, and few burned rocks mark these features. Surface hearths associated with Analysis Unit 1 are Features 11, 12, 41, 43, 44, 46, and 47. Surface hearths in Analysis Unit 2 are Features 1, 8, $22 / 26,25,30,35$, and 40 . Feature 6 is the only surface hearth in Analysis Unit 3. The contention that these features functioned in a similar way is supported not only by their structure, but also to a limited degree by what may have been cooked in these hearths. Analysis of carbonized plant remains from Feature 6 of Analysis Unit 3, Feature 25 of Analysis Unit 2, and Features 41 and 46 of Analysis Unit 1 shows small amounts of hickory nutshells in each. In addition, the analysis of fatty acids on burned rocks and burned clay nodules from Features 12 and 46 of Analysis Unit 1 and Feature 25 of 
Table 8-2. Knife morphology by analysis unit

\begin{tabular}{l|c|c|c|c}
\hline Blade Edge and Base Shape & Analysis & Analysis & Analysis & Unit 1 \\
Unit 2 & Unit 3 & Total \\
\hline Contracting lower lateral edge, concave base & 2 & 1 & 0 & 3 \\
Flaring lower lateral edge, concave base & 1 & 2 & 0 & 3 \\
Straight lateral edge, concave base & 0 & 1 & 0 & 1 \\
Straight lateral edge, straight base & 3 & 1 & 0 & 4 \\
Indeterminate & 11 & 7 & 1 & 19 \\
\hline Total & 17 & 12 & 1 & 30 \\
\hline
\end{tabular}

Table 8-3. Feature types by analysis unit

\begin{tabular}{|c|c|c|c|c|c|c|c|}
\hline \multirow[b]{2}{*}{ Feature Type } & \multicolumn{2}{|c|}{ Analysis Unit 1} & \multicolumn{2}{|c|}{ Analysis Unit 2} & \multicolumn{2}{|c|}{ Analysis Unit 3} & \multirow[t]{2}{*}{ Total } \\
\hline & \# & $\%$ & \# & $\%$ & \# & $\%$ & \\
\hline Surface hearth & 7 & 25.9 & 7 & 33.3 & 1 & 14.3 & 15 \\
\hline Pit hearth & 3 & 11.1 & 0 & 0.0 & 2 & 28.6 & 5 \\
\hline Processing pit & 10 & 37.0 & 0 & 0.0 & 0 & 0.0 & 10 \\
\hline Shell lens & 4 & 14.8 & 5 & 23.8 & 3 & 42.9 & 12 \\
\hline Burned rock concentration & 2 & 7.4 & 4 & 19.0 & 0 & 0.0 & 6 \\
\hline Possible posthole & 1 & 3.7 & 1 & 4.8 & 0 & 0.0 & 2 \\
\hline Indeterminate & 0 & 0.0 & 4 & 19.0 & 1 & 14.3 & 5 \\
\hline Total & 27 & & 21 & & 7 & & 55 \\
\hline
\end{tabular}

Analysis Unit 2 indicates that organic materials with medium to moderate-high fat content were likely cooked in these hearths.

Shell lenses of freshwater mussels and land gastropods are part of the midden debris that surrounds the surface hearths. Lenses associated with Analysis Unit 1 are Features 10, 21a, $21 \mathrm{~b}$, and 33. Shell lenses in Analysis Unit 2 are Features 9, 16, 17, 19, and 20. Features 3, 24, and 29 are the shell lenses associated with Analysis Unit 3. Samples of the mussel shells from seven of these (Features 9, 10, 16, 20, 21a, $21 \mathrm{~b}$, and 24) were analyzed (see Appendix A). Because the shell lenses in Analysis Unit 3 were small, mussel shells collected from Level 10 of the East Block were added to the shell analysis. These shells are likely associated with Feature 3 originally identified in testing Block 1 . The mussel species Amblema plicata and Quadrula houstonensis dominate all of these lenses except for Feature 17, which is composed almost entirely of Rabdotus shells. These common mussel species make up 62 to 90 percent of the identifiable shells in the combined analyzed samples from each analysis unit (Table 8-4). The percentages are lowest for the earliest unit, but those lower percentages are offset by a higher percentage of unidentifiable fragments. The same is true, but to a lesser extent, in Analysis Unit 2. The Analysis Unit 1 samples consistently have low percentages of unidentified fragments. Given that fragmentation is negatively correlated with intensity of use (see Use Intensity below), it appears that it is not due to trampling. If that was the case, one would expect the greatest fragmentation in Analysis Unit 1, or maybe the immediately underlying deposits in Analysis Unit 2. Instead, fragmentation appears to be related to age, with the oldest remains simply being more poorly preserved. Factoring out the unidentified specimens, Amblema is the predominate mussel in Analysis Units 1 and 2 (55 and 62 percent, respectively), while Quadrula predominates in Analysis Unit 3 (61 percent). This difference could reflect changes through time in the local mussel population, but it could just as easily be a function of spatial differences between procurement areas. In any case, the difference probably is not significant given that these species have similar habitat preferences.

Table 8-5 shows some variation in the sizes of the mussels acquired between Analysis Units 
Table 8-4. Frequency of mussel species by analysis unit

\begin{tabular}{l|c|c|c|c|c|c|c|c|c}
\hline & \multicolumn{2}{|c|}{ Amblema } & \multicolumn{2}{c|}{ Quadrula* } & \multicolumn{2}{c|}{ Others } & \multicolumn{2}{c}{ Unidentified } & \multicolumn{2}{c}{ Total } \\
\cline { 2 - 10 } & $\#$ & $\%$ & $\#$ & $\%$ & $\#$ & $\%$ & $\#$ & $\%$ & \\
\hline Analysis Unit 1: & & & & & & & & & \\
Feature 10 & 47 & 38 & 63 & 50 & 8 & 6 & 7 & 6 & 125 \\
Feature 21a & 188 & 51 & 153 & 41 & 31 & 8 & 0 & 0 & 372 \\
Feature 21b & 276 & 61 & 127 & 28 & 36 & 8 & 10 & 2 & 449 \\
\hline Totals & 511 & 54 & 343 & 36 & 75 & 8 & 17 & 2 & 946 \\
\hline Analysis Unit 2: & & & & & & & & & \\
Feature 9 & 318 & 56 & 148 & 26 & 33 & 6 & 64 & 11 & 563 \\
Feature 16 & 458 & 61 & 194 & 26 & 39 & 5 & 63 & 8 & 754 \\
Feature 20 & 202 & 33 & 176 & 29 & 15 & 2 & 223 & 36 & 616 \\
\hline Totals & 978 & 51 & 518 & 27 & 87 & 5 & 350 & 18 & 1,933 \\
\hline Analysis Unit 3: & & & & & & & & & 9 \\
Feature 24 & 22 & 24 & 50 & 54 & 12 & 13 & 8 & 9 & 92 \\
East Block & 78 & 20 & 148 & 38 & 17 & 4 & 147 & 38 & 390 \\
\hline Total & 100 & 21 & 198 & 41 & 29 & 6 & 155 & 32 & 482 \\
\hline
\end{tabular}

* Only includes Quadrula houstonensis.

1 and 2, with a higher percentage of larger Amblema in the later unit but very similar size distributions of Quadrula (the sample from Analysis Unit 3 is too small for interpretation). A comparison of the composition of mussel shell features based on shell size and age initially was considered a means of addressing changing intensity of human predation on mussels, thereby providing an opening to explore the issue of dietary stress. One particular pattern sought was a decrease in shell size over time, which could suggest increased human predation. However, it is difficult to discern relationships between the sizes of the harvested shells at 41MM341 and particular cultural factors, and as Claassen (1999:113) notes, such expectations are probably naïve given the myriad natural factors, including spawning cycles and environmental stimuli, that can affect the size and age composition of a mussel bed.

An obvious difference in the distribution of features between the analysis units is that most of the pit hearths (Features 15, 39, and 48) and all of the processing pits (Features 2, 4, 42, 49a, $49 \mathrm{~b}$, and the five pits of Feature 50) are associated with Analysis Unit 1. Pit hearth Features 5 and 7, however, appear to relate to Analysis Unit 3. Feature 5 was located in Level 12 of test-

Table 8-5. Shell size distributions for Amblema plicata and Quadrula houstonensis by analysis unit

\begin{tabular}{|c|c|c|c|c|c|c|c|c|c|c|c|c|}
\hline \multirow[b]{3}{*}{ Shell Size $(\mathrm{mm})$} & \multicolumn{4}{|c|}{ Analysis Unit 1} & \multicolumn{4}{|c|}{ Analysis Unit 2} & \multicolumn{4}{|c|}{ Analysis Unit 3} \\
\hline & \multicolumn{2}{|c|}{ Amblema } & \multicolumn{2}{|c|}{ Quadrula } & \multicolumn{2}{|c|}{ Amblema } & \multicolumn{2}{|c|}{ Quadrula } & \multicolumn{2}{|c|}{ Amblema } & \multicolumn{2}{|c|}{ Quadrula } \\
\hline & \# & $\%$ & \# & $\%$ & \# & $\%$ & \# & $\%$ & \# & $\%$ & $\#$ & $\%$ \\
\hline $21-30$ & 1 & 1 & 18 & 5 & 6 & 2 & 31 & 10 & 0 & 0 & 2 & 22 \\
\hline $31-40$ & 33 & 33 & 141 & 39 & 196 & 80 & 116 & 36 & 1 & 100 & 7 & 78 \\
\hline $41-50$ & 24 & 24 & 22 & 6 & 32 & 13 & 14 & 4 & 0 & 0 & 0 & 0 \\
\hline $51-60$ & 33 & 33 & 0 & 0 & 8 & 3 & 0 & 0 & 0 & 0 & 0 & 0 \\
\hline $61-70$ & 9 & 9 & 181 & 50 & 2 & 1 & 161 & 50 & 0 & 0 & 0 & 0 \\
\hline Total & 100 & & 362 & & 244 & & 322 & & 1 & & 9 & \\
\hline
\end{tabular}


ing Block 1, and Feature 7 was located in Level 13 of a nonblock initial unit. Their position in the lower levels and a radiocarbon date placing Feature 7 between A.D. 640 and 760 are the reasons for associating them with Analysis Unit 3.

Pit hearths are small, shallow basins with burned rocks in the fill that may indicate use as cooking or baking pits. The presence of quantities of burned rocks and their shape and size make them appear to be smaller versions of the processing pits. And like the processing pits, oak was the wood of choice for use in these features. Feature 48 also produced carbonized wild onion bulb fragments, which are also common along with false garlic bulbs in the processing pits. Feature 7, a pit hearth associated with Analysis Unit 3, produced carbonized hickory nutshells. This slight difference may suggest that the function of the earlier pit hearths was closer to that of the ubiquitous surface hearths than of the later pit hearths and processing pits.

All of the processing pits were clustered in or adjacent to the South Block, $10 \mathrm{~m}$ or more from the Main Block. Two processing pits (Features 2 and 4) were identified in testing Block 2, and Feature 42 and the multiple pits of Features 49 and 50 were found in the South Block. The concentration of these features, which are interpreted as large cooking or baking pits, in Analysis Unit 1, along with the presence of the smaller pit hearths in the Main Block, indicates that an addition was made to the cooking technology represented by the surface hearths during the latter part of the occupation. This change may have been part of an overall intensification of use, which is also indicated by the distributions of some of the other remains. These distributions are discussed below.

Two burned rock concentrations (Features 14 and 18) are associated with Analysis Unit 1, and four (Features 13, 28, 36, and 45) are associated with Analysis Unit 2. These concentrations vary in size, density, and total rock weight. The two in Analysis Unit 1 are large and are adjacent to pit hearth Feature 15. Two of those in Analysis Unit 2 (Features 13 and 36) are also large; Feature 13 is near surface hearth Feature 8 , and Feature 36 is near surface hearth Feature 35. Features 28 and 45 are smaller and associated with shell lens Features 21a and 21b. The correspondence between some of the burned rock concentrations and hearth features, as well as the fact that scattered burned rocks were recovered from the shell lenses and from the cultural zone in general, suggests that the all hearth types probably included stones originally. The burned rock concentrations and scattered burned rocks may be displaced heating elements from these hearth features.

\section{Lithic Reduction Strategies}

The lithic reduction debris piles can be assigned to analysis units based on the locations of their most concentrated parts. Six piles are in Analysis Unit 1 (Piles 1, 2, 3, 4, 5, and 9), and four are in Analysis Unit 2 (Piles 6, 7, 8, and 10). No lithic reduction piles are associated with Analysis Unit 3. Hence, the debitage from Level 10 in all excavation units in the East Block was analyzed to provide a comparative sample from the earliest site occupation. Otherwise, the debitage analyzed consists of the complete recovery from Piles $1,3,6,7,8$, and 9. The analyzed specimens make up 28 percent of the debitage from Analysis Unit 1,34 percent of that from Analysis Unit 2, and 31 percent of the debitage from Analysis Unit 3. As discussed in Chapter 7, all of the piles reflect a mix of bifacial and core reduction, with Pile 1 in Analysis Unit 1 standing out because of the preponderance of core reduction debris. This distinction, though, translates into only small differences between the analysis units when all the analyzed debitage is looked at together (Table 8-6). Analysis Unit 1 has a slightly higher percentage of core preparation/reduction flakes than Analysis Unit 2 and almost the same percentage as Analysis Unit 3, while biface-reduction and biface-thinning flakes account for less of the Analysis Unit 1 debitage (17 percent) than that in Analysis Units 2 and 3 (20-22 percent). Overall, lithic reduction strategies do not seem to have changed much over time, which is interesting given that the analysis units encompass the change from dart point to arrow point production.

\section{Use Intensity}

Table 8-7 shows that, almost without exception, all classes of cultural materials increase in frequency or abundance from Analysis Unit 3 to 2 and again from Analysis Unit 2 to 1 . These increases cannot be explained fully by differences in the sizes of the excavations between 
Chapter 8: Analysis Units, Chronology, and Distributional Studies

Table 8-6. Flake type in the unmodified debitage by analysis unit

\begin{tabular}{l|c|c|c|c|c|c}
\hline \multirow{2}{*}{ Flake Type } & \multicolumn{2}{|c|}{ Analysis Unit 1 } & \multicolumn{2}{c|}{ Analysis Unit 2 } & \multicolumn{3}{c}{ Analysis Unit 3 } \\
\cline { 2 - 7 } & $\#$ & $\%$ & $\#$ & $\%$ & $\#$ & $\%$ \\
\hline Biface reduction & 593 & 9.7 & 574 & 12.2 & 85 & 8.9 \\
Biface resharpening & 375 & 6.1 & 245 & 5.2 & 59 & 6.2 \\
Biface thinning & 424 & 7.0 & 452 & 9.6 & 105 & 11.0 \\
Blade blank & 35 & 0.6 & 4 & 0.1 & 1 & 0.1 \\
Core preparation/reduction & 1,377 & 22.6 & 965 & 20.5 & 214 & 22.4 \\
Uniface manufacture/repair & 90 & 1.5 & 30 & 0.6 & 6 & 0.6 \\
Notching & 7 & 0.1 & 2 & 0.0 & 1 & 0.1 \\
Indeterminate & 3,197 & 52.4 & 2,427 & 51.6 & 483 & 50.6 \\
\hline Total & 6,098 & & 4,699 & & 954 & \\
\hline
\end{tabular}

Table 8-7. Summary of materials recovered by analysis unit

\begin{tabular}{l|c|c|c|c|c|c|c}
\hline \multirow{2}{*}{ Category } & \multicolumn{2}{|c|}{ Analysis Unit 1 } & \multicolumn{2}{c|}{ Analysis Unit 2 } & \multicolumn{2}{c|}{ Analysis Unit 3 } & \multicolumn{2}{c}{ Total } \\
\cline { 2 - 7 } & $\# /$ wt $(\mathrm{g})$ & $\%$ & $\# /$ wt $(\mathrm{g})$ & $\%$ & \#/wt $(\mathrm{g})$ & $\%$ & $\# / \mathrm{wt}(\mathrm{g})$ \\
\hline Formal chipped stone tools & 169 & 55.8 & 110 & 36.3 & 24 & 7.9 & 303 \\
Expedient tools & 288 & 61.4 & 143 & 30.5 & 38 & 8.1 & 469 \\
Cores & 90 & 53.6 & 60 & 35.7 & 18 & 10.7 & 168 \\
Unmodified debitage & 21,725 & 56.5 & 13,687 & 35.6 & 3,052 & 7.9 & 38,464 \\
Ground and battered stones & 15 & 55.6 & 9 & 33.3 & 3 & 11.1 & 27 \\
Burned rocks & $24,832.7$ & 44.2 & $27,893.3$ & 49.6 & $3,465.8$ & 6.2 & $56,191.8$ \\
Burned clay & $6,004.3$ & 62.9 & $3,454.6$ & 36.2 & 88.5 & 0.9 & $9,547.4$ \\
Mussel shells & $35,426.7$ & 43.2 & $37,547.4$ & 45.8 & $9,071.6$ & 11.1 & $82,045.7$ \\
Rabdotus shells & 7,174 & 55.9 & 5,059 & 39.4 & 609 & 4.7 & 12,842 \\
Animal bones & $1,762.5$ & 52.8 & $1,319.0$ & 39.5 & 259.4 & 7.8 & $3,340.9$ \\
Bone tools and modifed bones & 18 & 64.3 & 10 & 35.7 & 0 & 0.0 & 28 \\
Charred botanical remains & 188.4 & 49.6 & 181.5 & 47.7 & 10.3 & 2.7 & 380.2 \\
\hline
\end{tabular}

analysis units or the spans of time they represent. Instead, it is clear that the site was used with increasing intensity through time. The extent to which this was the case can be gauged by calculating a use-intensity index based on the number of pieces of unmodified debitage divided by the area excavated ( $170 \mathrm{~m}^{2}$ for Analysis Units 1 and 2 and $57 \mathrm{~m}^{2}$ for Analysis Unit 3) divided by occupation span for each analysis unit. Unmodified debitage is used here because of its ubiquity in all analysis units, because it is assumed that there is a positive correlation between the number of artifacts deposited on a site and the aggregate length of time the site was occupied, and because debitage is less likely to move from its locus of production compared to tools.
Of course, this measure of use intensity must be viewed as being rather gross given the difficulty of knowing just how much time each unit encompasses. A 200-year span is used here for each of the three units. For Analysis Unit 1, this corresponds to the ca. A.D. 1100-1300 interval discussed above where the analysis units are defined, acknowledging that the early end of this range is somewhat arbitrary. For Analysis Unit 2 , it refers to the period from about A.D. 900 to 1100. This ignores the earlier date from Feature 17, which would add another 100 years or so, because the dates suggest that most of this unit postdates A.D 900. The 200-year span for Analysis Unit 3 is more speculative. Radiocarbon dates suggest placement of this unit between A.D. 615 and 780. However, the dates are 
few in number and from relatively widely dispersed proveniences (i.e., two from the Main Block, one from the South Block, and one from testing Block 1 adjacent to the East Block). Because of this, the span is generalized to 200 years (i.e., ca. A.D. 600-800).

The resulting values are 0.64 for Analysis Unit 1, 0.40 for Analysis Unit 2, and 0.28 for Analysis Unit 3 and reflect a 43 percent increase in use intensity between the early and middle units and a 60 percent increase between the middle and late units. Interpreting these numbers is not easy, however, because differences in apparent use intensity could reflect several things, for example, changes in occupation duration, the frequency of reoccupation, site function, and group size. Accounting for the last of these could be problematical for 41MM341, since the excavations were restricted to the highway right of way. The site certainly extends west beyond the right of way, and it likely extends outside the right of way to the east as well. However, based on the assumption that group size is more-strongly correlated with site size than with artifact density in sites such as this (i.e., nonpermanent hunter-gatherer campsites), it seems likely that the use-intensity measure used here is not affected much by group size. The third variable listed above, site function, also can be held constant for this analysis. As discussed below, there is little evidence to indicate changes in the kinds of activities and site function, especially between Analysis Units 2 and 1. In fact, there is much more that unites these units than separates them, and they appear to represent a single span of time during which 41MM341 was used repeatedly for the same kinds of things.

Three measures are used to try to factor out the other two components of use intensity. The first-the ratio of unmodified debitage to formal chipped stone tools (minus preforms and early-stage and indeterminate bifaces, i.e., tools not yet available for use) - is based on the assumption that longer-term occupations tend to result in the deposition of numerous formal tools, while such tools are relatively infrequently discarded at short-term sites because tool uselives exceed the lengths of the occupations (Schiffer 1975). Ratios of expedient tools to formal chipped stone tools are also used to get at this variable. The third measure employed here is actually a set of indexes that deal with diversity (richness, Shannon's H', equitability J, and eveness) and is based on the assumption that longer-term occupations result in the deposition of relatively diverse assemblages because of the wide variety of activities performed (Rhode 1988:708).

Analysis Units 1 and 2 have very similar debitage to finished formal tool ratios-265 to 1 for Analysis Unit 1 and 254 to 1 for Analysis Unit 2-suggesting no differences in the duration of individual occupations. The value for Analysis Unit 3 is much lower, 161 to 1 . While this could be interpreted as indicating relatively long-lived occupations at the Late ArchaicLate Prehistoric transition, this would not be consistent with other indicators. Rather, the anomalous value for Analysis Unit 3 probably is due to the much smaller sample of finished tools $(\mathrm{n}=19)$ compared to Analysis Units 1 and $2(\mathrm{n}=82$ and 54, respectively). The ratios of expedient tools to all formal chipped stone tools vary some-1.7 to 1 for Analysis Unit 1, 1.3 to 1 for Analysis Unit 2, and 1.6 to 1 for Analysis Unit 3-but are similar enough to support the contention that occupation duration did not change, at least not much.

Richness is measured based simply on the numbers of tool classes present using the following 19 artifact categories: projectile points (arrows and darts combined); projectile point preforms (arrows and darts combined); knives; knife preforms; perforators; awls; gravers (including retouched gravers); adzes; wedges; gouges; chipped hammerstones (including hammerstones/choppers); choppers; retouched and use-modified scrapers; retouched spokeshaves; retouched denticulates; use-modified tools with sawing/cutting edges; battered hammerstones; ground stone abraders; and bone tools and modified bones. Early-stage and indeterminate bifaces are excluded because, while they reflect tool manufacture, they cannot be sorted reliably by the intended product. The Shannon index $\left(\mathrm{H}^{\prime}\right)$ is a function of both the number of categories of items present and the relative sizes of the categories (Pielou 1975:7-8). Thus, collections with numerous categories of equal size are considered to exhibit high diversity (high H'values), while those with few categories or uneven distributions among the categories are of low diversity (low H' values). A well-known problem with the use of the 
Shannon index in archeological situations stems from the fact that it often is positively correlated with sample size, and thus it can be difficult to compare assemblages of different sizes (Rhode 1988:708). The equitability $\mathrm{J}$ statistic helps compensate for this because it is calculated by dividing H' for a sample by the theoretical maximum $H^{\prime}$ for a sample of that size. Finally, eveness refers to how evenly a sample is distributed among categories, regardless of how many categories are represented.

All but 1 of the 19 tool categories are represented in Analysis Unit 2, and all but 2 are in Analysis Unit 1 . All 3 categories that are missing are infrequent overall, consisting of only 2 perforators, 1 wedge, and 7 chipped hammerstones, and thus their absence probably is not significant. Based on richness, Analysis Units 1 and 2 look comparable in terms of the ranges of activities represented, and hence occupation duration. Analysis Unit 3, with a richness value of 11, would appear to represent a narrower range of activities. However, it contains far fewer tools, and sample size probably explains its low value.

The Shannon index values for all analysis units are high, with Analysis Unit 2 being the highest (1.84) followed by Analysis Units 1 and 3 (1.68 and 1.49 , respectively). Recalculating these values without scrapers, which by far are most numerous in each assemblage and thus heavily influence the mathematics of the index, produces values for Analysis Units 1 and 2 that are almost identical (2.31 and 2.33), with the value for Analysis Unit 3 (1.92) still lagging behind. As above, the low value for Analysis Unit 3 is probably a function of sample size, and this is supported by the very similar equitability $\mathrm{J}$ values whether scrapers are included $(0.59,0.64$, and 0.62 for Analysis Units 1-3) or not (0.83, 0.82 , and 0.83 ). The evenness values also are similar, being highest both when scrapers are included $(0.32,0.35$, and 0.41$)$ and when they are excluded $(0.63,0.61$, and 0.68$)$. The comparable values for all of these measures suggest comparably broad ranges of activities, and this suggests that changes in occupation duration did not cause the differences in use intensity. Thus, the observed differences between the analysis units in this respect must represent increasingly frequent reoccupation of the site through time.

\section{Tool Assemblages and Ranges of Activities}

As noted, site function does not appear to have changed with succeeding occupations. This is reflected in the richness and diversity figures, and it is supported by the relative frequencies of the various formal chipped stone tool classes (Table 8-8). For example, projectile points (arrows and darts) make up nearly equal percentages of the collections from Analysis Units 1 and 2 (27.8 and 26.3 percent, respectively), suggesting that hunting-related activities were similarly important. They are more frequent in Analysis Unit 3 (37.5 percent), which could indicate that hunting was more important; the difference could also be a function of the much smaller sample size, though. If knives are added, the gap narrows (37.9, 37.2, and 41.7 percent), but the pattern remains the same.

The lithic reduction debris piles and the many arrow, dart, and knife preforms (see Table 8-8) indicate that chipped stone tool production was an important activity at the site, perhaps especially in Analysis Units 1 and 2 where the debris piles were common. The percentages of preforms and early-stage and indeterminate bifaces are comparable for Analysis Units 1 and 2 (51.5 and 50.9 percent) and much lower for Analysis Unit 3 (16.7 percent). This suggests that tool production was not as important during the earliest occupations. The fact that debitage is equally represented compared to all formal chipped stone tools in all units argues against this, however. Rather, it seems that sample size is the likely explanation for Analysis Unit 3 standing out.

Formal chipped stone tools other than projectile points, knives, preforms, and bifaces are few (see Table 8-8). Most, such as adzes, gouges, wedges, perforators, awls, and choppers, may have been associated with woodworking. Combined, these account for 9.5 and 8.2 percent of the formal chipped stone tools from Analysis Units 1 and 2, once again suggesting similar importance for these activities. They make up a higher percentage of the tools in Analysis Unit 3 (16.7 percent), although the significance of this difference is hard to gauge because of the smaller sample size. This also is the case for the high frequency of chipped stone hammerstones in this unit compared to the others, although it is worth noting that this type of hammer has 
Table 8-8. Formal chipped stone tools by analysis unit

\begin{tabular}{|c|c|c|c|c|c|c|c|}
\hline \multirow[b]{2}{*}{ Tool Category } & \multicolumn{2}{|c|}{ Analysis Unit 1} & \multicolumn{2}{|c|}{ Analysis Unit 2} & \multicolumn{2}{|c|}{ Analysis Unit 3} & \multirow[b]{2}{*}{ Total } \\
\hline & $\#$ & $\%$ & $\#$ & $\%$ & $\#$ & $\%$ & \\
\hline Arrow point & 45 & 26.6 & 25 & 22.7 & 3 & 12.5 & 73 \\
\hline Arrow preform & 38 & 22.5 & 21 & 19.1 & 1 & 4.2 & 60 \\
\hline Dart point & 2 & 1.2 & 4 & 3.6 & 6 & 25.0 & 12 \\
\hline Dart preform & 0 & 0.0 & 4 & 3.6 & 0 & 0.0 & 4 \\
\hline Knife & 17 & 10.1 & 12 & 10.9 & 1 & 4.2 & 30 \\
\hline Knife preform & 16 & 9.5 & 8 & 7.3 & 0 & 0.0 & 24 \\
\hline Perforator & 2 & 1.2 & 0 & 0.0 & 0 & 0.0 & 2 \\
\hline Awl & 1 & 0.6 & 1 & 0.9 & 0 & 0.0 & 2 \\
\hline Graver & 2 & 1.2 & 2 & 1.8 & 0 & 0.0 & 4 \\
\hline Adze & 6 & 3.6 & 1 & 0.9 & 0 & 0.0 & 7 \\
\hline Wedge & 0 & 0.0 & 1 & 0.9 & 1 & 4.2 & 2 \\
\hline Gouge & 6 & 3.6 & 4 & 3.6 & 0 & 0.0 & 10 \\
\hline Early-stage biface & 17 & 10.1 & 11 & 10.0 & 3 & 12.5 & 31 \\
\hline Indeterminate biface & 16 & 9.5 & 12 & 10.9 & 1 & 4.2 & 29 \\
\hline Hammerstone & 0 & 0.0 & 2 & 1.8 & 5 & 20.8 & 7 \\
\hline Chopper & 1 & 0.6 & 2 & 1.8 & 3 & 12.5 & 6 \\
\hline Total & 169 & & 110 & & 24 & & 303 \\
\hline
\end{tabular}

been found with Darl and Ensor dart points in Driftwood and Twin Sisters phase contexts in central Texas (Prewitt 1982:119-120).

Ground stone tools are also present in all three analysis units in low numbers (Table 8-9). However, bone tools and bone tool manufacturing debris, represented by equally few specimens, appear only in Analysis Units 1 and 2 (see Table 8-7). It can be suggested, however, that the abraders may have been used in bone tool manufacture or refurbishment. If so, the single abrader in Analysis Unit 3 may signal that bone tool manufacture occurred during the early occupation even though no actual tools or manufacturing debris were recovered. Once again, this probably is a function of sample size and the overall infrequency of modified bones. Hammerstones and abraders occur in nearly equal percentages in the three units, pointing to similarities in the activities represented.

Unlike the formal chipped stone tools possibly associated with woodworking, hammerstones, abraders, and bone tools, expedient tools occur in large enough numbers to suggest that they were employed in many common activities (Table 8-10). Expedient tools outnumber formal tools in all units, with the ratios being suffi- ciently close (Analysis Unit $1=1.7$, Analysis Unit $2=1.3$, Analysis Unit $3=1.6$ ) to indicate that the activities represented were of similar importance. Scraping tools are consistently most common, with the three categories reflecting such use accounting for $88.9,88.1$, and 89.5 percent of the modified edges. This is not surprising given the lack of formal scrapers in all analysis units.

\section{Subsistence}

The features and tools found indicate that hunting and collecting of subsistence resources and processing of those resources were important activities in all analysis units. The faunal remains tell us what some of those resources were. Freshwater mussels, land gastropods (Rabdotus), and vertebrate faunal remains are well represented in all analysis units (see Table 8-7). Vertebrates surely were more important to the diet than invertebrates, but both mussels and snails were harvested and consumed. In contrast to the animal bones and Rabdotus shells, which occur in similar percentages to formal chipped stone tools and unmodified debitage in all analysis units, mussel shells are relatively 
Chapter 8: Analysis Units, Chronology, and Distributional Studies

Table 8-9. Ground and battered stone tools by analysis unit

\begin{tabular}{l|c|c|c|c|c|c|c}
\hline \multirow{2}{*}{ Tool Type } & \multicolumn{2}{|c|}{ Analysis Unit 1 } & \multicolumn{2}{c|}{ Analysis Unit 2 } & Analysis Unit 3 & Total \\
\cline { 2 - 8 } & $\#$ & $\%$ & $\#$ & $\%$ & $\#$ & $\%$ & \\
\hline Hammerstones & 11 & 73.3 & 6 & 66.7 & 2 & 66.7 & 19 \\
Abraders & 4 & 26.7 & 3 & 33.3 & 1 & 33.3 & 8 \\
\hline Total & 15 & & 9 & & 3 & & 27 \\
\hline
\end{tabular}

Table 8-10. Expedient tool use by analysis unit

\begin{tabular}{l|c|c|c|c|c|c}
\hline \multirow{2}{*}{ Edge Type } & \multicolumn{2}{|c|}{ Analysis Unit 1 } & \multicolumn{2}{c|}{ Analysis Unit 2 } & \multicolumn{3}{|c}{ Analysis Unit 3 } \\
\cline { 2 - 7 } & $\#$ & $\%$ & $\#$ & $\%$ & $\#$ & $\%$ \\
\hline Retouched graver & 15 & 5.2 & 7 & 4.9 & 1 & 2.6 \\
Retouched scraper & 71 & 24.7 & 35 & 24.5 & 12 & 31.6 \\
Retouched spokeshave & 2 & 0.7 & 2 & 1.4 & 1 & 2.6 \\
Retouched denticulate & 5 & 1.7 & 2 & 1.4 & 0 & 0.0 \\
Use-modified sawing/cutting tool & 7 & 2.4 & 4 & 2.8 & 0 & 0.0 \\
Use-modified scraper & 174 & 60.4 & 79 & 55.2 & 20 & 52.6 \\
Use-modified scraper (two-sided) & 11 & 3.8 & 12 & 8.4 & 2 & 5.3 \\
Indeterminate & 3 & 1.0 & 2 & 1.4 & 2 & 5.3 \\
\hline Total & 288 & & 143 & & 38 & \\
\hline
\end{tabular}

abundant in Analysis Unit 2 and especially Analysis Unit 3 compared to Analysis Unit 1. This hints at a decrease in mussel use over time, although it is hard to gauge the dietary significance of such a change. Rabdotus shells are somewhat under-represented in Analysis Unit 3 , and this may indicate comparitively limited use of this invertebrate during the earliest occupations.

Analysis of the animal bones indicates that a wide array of animals were taken (Table 8-11). Terrestrial species predominate, although aquatic and avian species are present as well. Deer and deer-sized artiodactyls are well represented in all units but are especially common in Analysis Units 1 and 2, while fish and especially turtles are relatively frequent in Analysis Unit 3 (Table 8-12). Some of these differences become even stronger when the unidentified bones are factored out. Half or more of the identified bones in Analysis Units 1 and 2 (58 and 50 percent, respectively) are deer and large mammals, with just 29 percent of the bones from Analysis Unit 3 being in this category. Conversely, fish bones constitute 4 percent of the Analysis Unit 3 sample but less than 1 percent of the other samples, and turtle remains make up 46 percent of the specimens from Analysis Unit 3 and are consistently represented in Analysis Units 1 and 2 at 23 and 26 percent. These differences could indicate that the slough just north of the site still provided aquatic habitat during the early occupations of the site, and this would be supported by Nordt et al.'s (2003:86) interpretation that this slough and the larger one to the north began filling by about 1,300 years ago. Bird bones, though infrequent, also are relatively common in Analysis Unit 3. Micro, small, and medium-sized mammals, including opossum, rabbit, squirrel, cotton rat, raccoon, beaver, weasel, fox, dog, and coyote, are represented in similar percentages in Analysis Units 1 and 2 and are slightly more frequent in Analysis Unit 3.

The various species suggest consistent utilization of the Little River floodplain and environs and consistency in subsistence orientation through time, particularly throughout the primary occupation represented by Analysis Units 1 and 2 . The differences that are present between Analysis Unit 3 and the later ones may signal some change in hunting emphasis, but these changes appear to be ones of degree rather than kind. 
Data Recovery Excavations at the J. B. White Site

Table 8-11. Vertebrate faunal taxa by analysis unit

\begin{tabular}{|c|c|c|c|c|}
\hline Taxon & Common Name & $\begin{array}{c}\text { Analysis } \\
\text { Unit } 1\end{array}$ & $\begin{array}{c}\text { Analysis } \\
\text { Unit } 2\end{array}$ & $\begin{array}{c}\text { Analysis } \\
\text { Unit } 3\end{array}$ \\
\hline Vertebrata & Vertebrates & 1,507 & 1,595 & 188 \\
\hline Osteichthyes (Small) & Small bony fish & 1 & 2 & 0 \\
\hline Osteichthyes (Medium) & Medium bony fish & 4 & 0 & 7 \\
\hline Osteichthyes (Large) & Large bony fish & 1 & 0 & 0 \\
\hline Osteichthyes & Bony fish & 0 & 1 & 0 \\
\hline Lepisosteidae & Gars & 1 & 0 & 1 \\
\hline Aplodinotus grunniens & Freshwater drum & 0 & 5 & 2 \\
\hline Anura & Toads and frogs & 0 & 1 & 0 \\
\hline Testudinata & Turtles & 321 & 307 & 115 \\
\hline Kinosternidae & Mud and musk turtles & 4 & 2 & 5 \\
\hline Emydidae & Water and box turtles & 21 & 3 & 0 \\
\hline Chrysemys sensu lato & Painted turtles, cooters, sliders & 4 & 6 & 1 \\
\hline cf. Chrysemys sensu lato & Painted turtles, cooters, sliders & 2 & 0 & 0 \\
\hline Terrapene sp. & Box turtles & 4 & 3 & 0 \\
\hline Trionyx sp. & Softshell turtle & 1 & 46 & 9 \\
\hline Serpentes & Snakes & 0 & 14 & 2 \\
\hline Colubridae & Colubrid snakes & 5 & 32 & 0 \\
\hline Viperidae & Pitviper snakes & 0 & 1 & 0 \\
\hline Aves (Medium) & Crow-sized birds & 2 & 3 & 4 \\
\hline Aves (Large) & Duck/turkey-sized birds & 10 & 14 & 2 \\
\hline Meleagris gallapavo & Turkey & 1 & 3 & 0 \\
\hline Mammalia (Micro) & Shrew/mouse-sized mammals & 2 & 2 & 1 \\
\hline Mammalia (Micro/small) & Shrew/rabbit-sized mammals & 0 & 1 & 0 \\
\hline Mammalia (Small/medium) & Rabbit/canid-sized mammals & 69 & 61 & 11 \\
\hline Mammalia (Medium) & Canid-sized mammals & 0 & 1 & 0 \\
\hline Mammalia (Medium/large) & Canid/deer-sized mammals & 680 & 516 & 64 \\
\hline Mammalia & Mammals & 0 & 4 & 0 \\
\hline Didelphis virginiana & Virginia opossum & 9 & 50 & 15 \\
\hline Scalopus aquaticus & Eastern mole & 0 & 1 & 0 \\
\hline Leporidae & Rabbits and hares & 5 & 4 & 0 \\
\hline Lepus sp. & Jackrabbits & 8 & 4 & 0 \\
\hline Sylvilagus sp. & Cottontail rabbits & 77 & 68 & 18 \\
\hline Rodentia (Small) & Mouse-sized rodent & 1 & 7 & 5 \\
\hline Rodentia (Medium) & Rat-sized rodent & 11 & 3 & 0 \\
\hline Rodentia (Large) & Muskrat/beaver-sized rodent & 0 & 1 & 0 \\
\hline Sciuridae & Squirrels and chipmunks & 12 & 0 & 0 \\
\hline Sciurus sp. & Squirrels & 4 & 1 & 0 \\
\hline
\end{tabular}


Table 8-11, continued

\begin{tabular}{l|l|c|c|c}
\hline Taxon & Common Name & $\begin{array}{c}\text { Analysis } \\
\text { Unit 1 }\end{array}$ & $\begin{array}{c}\text { Analysis } \\
\text { Unit } 2\end{array}$ & $\begin{array}{c}\text { Analysis } \\
\text { Unit } 3\end{array}$ \\
\hline Geomys sp. & Pocket gophers & 4 & 6 & 0 \\
\hline Castor canadensis & Beaver & 4 & 1 & 0 \\
\hline Sigmodon sp. & Cotton rats & 29 & 12 & 4 \\
\hline Microtus sp. & Voles & 5 & 0 & 0 \\
\hline Carnivora & Carnivores & 0 & 3 & 0 \\
\hline Procyon lotor & Raccoon & 39 & 29 & 0 \\
\hline Mustelidae & Weasels and relatives & 2 & 5 & 0 \\
\hline Urocyon cinereoargenteus & Gray fox & 1 & 1 & 0 \\
\hline Canis sp. & Dogs & 3 & 1 & 0 \\
\hline Canis latrans & Coyote & 0 & 1 & 0 \\
\hline cf. Canis latrans & Coyote & 134 & 65 & 10 \\
\hline Artiodactyla (Medium) & Deer/pronghorn-sized ungulates & 38 & 45 & 3 \\
\hline Cervidae & Deer and relatives & 56 & 71 & 6 \\
\hline Odocoileus sp. & Deer & Deer & 2 & 0 \\
\hline cf. Odocoileus sp. & & 3,004 & 473 \\
\hline Total & & 1 & 084 \\
\hline
\end{tabular}

Table 8-12. Frequency of animal bones by faunal group and analysis unit

\begin{tabular}{l|c|c|c|c|c|c}
\hline \multirow{2}{*}{ Faunal Group } & \multicolumn{2}{|c|}{ Analysis Unit 1 } & \multicolumn{2}{c|}{ Analysis Unit 2 } & \multicolumn{2}{c}{ Analysis Unit 3 } \\
\cline { 2 - 7 } Fish & $\#$ & $\%$ & $\#$ & $\%$ & $\#$ & $\%$ \\
\hline Frogs & 7 & 0.2 & 8 & 0.3 & 10 & 2.1 \\
\hline Turtles & 0 & 0.0 & 1 & 0.0 & 0 & 0.0 \\
\hline Birds & 357 & 11.6 & 367 & 12.2 & 130 & 27.5 \\
\hline Snakes & 13 & 0.4 & 20 & 0.7 & 6 & 1.3 \\
\hline Deer/large mammals & 5 & 0.2 & 47 & 1.6 & 2 & 0.4 \\
\hline $\begin{array}{l}\text { Micro/small/medium } \\
\text { mammals }\end{array}$ & 909 & 29.5 & 699 & 23.3 & 83 & 17.5 \\
\hline Unidentified bones & 1,507 & 48.9 & 1,595 & 53.1 & 188 & 39.7 \\
\hline Total & 3,084 & & 3,004 & & 473 & \\
\hline
\end{tabular}

Faunal bone taphonomy also provides an indication of how animal resources were utilized at 41MM341. Most of the animal bones in each of the analysis units are broken, with spiral fractures accounting for 18 to 27 percent of each sample (Table 8-13). Spirally fractured bone has been associated with processing for marrow, and it appears that this was practiced more during the occupations that resulted in Analysis Units 1 and 2 than in the earliest occupations.
The fauna represented by the bones recovered would be expected in a riparian forest associated with the floodplain of the Little River. The floodplain setting of the site, coupled with its location near the boundary between the Blackland Prairie and the Oak Woodlands, means that a wide variety of plant resources would have been available for exploitation as well. Food remains are not abundant in the macrobotanical samples recovered, however. In 
Table 8-13. Animal bone fracturing by analysis unit

\begin{tabular}{|c|c|c|c|c|c|c|c|}
\hline \multirow[b]{2}{*}{ Fracture Type } & \multicolumn{2}{|c|}{ Analysis Unit 1} & \multicolumn{2}{|c|}{ Analysis Unit 2} & \multicolumn{2}{|c|}{ Analysis Unit 3} & \multirow[b]{2}{*}{ Total } \\
\hline & \# & $\%$ & \# & $\%$ & \# & $\%$ & \\
\hline Spirally fractured & 823 & 26.7 & 750 & 25.0 & 83 & 17.5 & 1,656 \\
\hline Angularly fractured & 2,191 & 71.0 & 2,165 & 72.1 & 370 & 78.2 & 4,726 \\
\hline Unbroken & 70 & 2.3 & 89 & 3.0 & 20 & 4.2 & 179 \\
\hline Total & 3,084 & & 3,004 & & 473 & & 6,561 \\
\hline
\end{tabular}

fact, the only such remains found are hardwood nuts (hickory and pecan nutshells and acorn nutmeats), bulbs (wild onion, false garlic, and unidentified), seeds, and minimal amounts of unidentified tubers (Table 8-14). All occur in such small quantities that it is hard to attach much significance to how they are distributed by analysis unit. Hardwood nuts apparently were eaten, but their low numbers in the samples indicate that nut harvesting and processing were only minor activities at 41MM341.

Bulbs and bulb fragments were recovered from more proveniences in the Main Block than were hardwood nuts, and they are also relatively well represented $(2.01 \mathrm{~g})$ in the processing pits of the South Block, which appear to be associated with Analysis Unit 1 but have not been added to Table 8-14. The greater ubiquity of the wild onion and false garlic bulbs suggests more than occasional use, and their presence in the features of the South Block indicates that they were involved in the processing activities that took place there. Charred wild onion and false garlic bulbs are known from a number of sites with earth ovens in the central Texas area (Mehalchick et al. 2004:224-232). Yet, their importance is still little understood. Fatty acid residues from both the processing pits and hearth features at 41MM341 suggest that animals were also cooked in these features, and thus use primarily for processing of plant foods, such as bulbs, is not indicated. Instead, it seems likely that wild onion and false garlic bulbs may have been used to flavor other foods being cooked.

Plant use also is indicated by the presence of small numbers of seeds of fruits such as

Table 8-14. Possible plant food remains in the analyzed macrobotanical samples by analysis unit

\begin{tabular}{l|c|c|c|c|c|c}
\hline \multirow{2}{*}{ Type } & \multicolumn{2}{|c|}{ Analysis Unit 1 } & \multicolumn{2}{c|}{ Analysis Unit 2 } & \multicolumn{2}{c}{ Analysis Unit 3 } \\
\cline { 2 - 7 } Hardwood Nuts & $\mathrm{wt}(\mathrm{g})$ & $\#$ & $\mathrm{wt}(\mathrm{g})$ & $\#$ & $\mathrm{wt}(\mathrm{g})$ & $\#$ \\
Acorn nutmeat & & & & & & \\
Hickory nutshell & 0.16 & 5 & 0.00 & 0 & 0.00 & 0 \\
Pecan nutshell & 1.78 & 39 & 2.33 & 86 & 0.07 & 8 \\
\hline Totals & 0.14 & 13 & 0.10 & 14 & 0.00 & 0 \\
\hline Bulbs & 2.08 & 57 & 2.43 & 100 & 0.07 & 8 \\
Wild onion & & & & & & \\
False garlic & 0.12 & 4 & 0.17 & 4 & 0.00 & 0 \\
Wild Onion/False Garlic? & 0.11 & 2 & 1.20 & 9 & 0.00 & 0 \\
Unidentified & 0.59 & 5 & 0.32 & 14 & 0.00 & 0 \\
\hline Totals & 0.43 & 29 & 0.61 & 44 & 0.00 & 0 \\
\hline Seeds & 1.25 & 40 & 2.30 & 71 & 0.00 & 0 \\
Prunus/unidentified fruit & 0.64 & 22 & 0.01 & 2 & 0.00 & 0 \\
Other & 0.88 & 71 & 1.81 & 84 & 0.10 & 6 \\
\hline Total & 1.52 & 93 & 1.82 & 86 & 1.10 & 6 \\
\hline Tubers & 0.00 & 0 & 0.21 & 2 & 0.00 & 0 \\
\hline
\end{tabular}


plum/cherry and plants such as hawthorn, knotweed, smartweed, mallow, marshelder, nightshade, poison ivy/oak/sumac, and grasses. The green leafy parts and fleshy fruits of many of these plants can be eaten and used medicinally. Seeds of knotweed, smartweed, and some forms of nightshade can also be used for their spicy quality (Tull 1999). Unidentified tubers are present in even smaller quantities and could represent food remains as well. Overall, the kinds of plants represented by the seeds and bulbs suggest use as condiments or for flavoring rather than as dietary staples. Plants used in this way would not require much effort in processing, and this may help explain the lack of processing tools such as grinding stones.

\section{Fuel Wood Use}

The analyzed macrobotanical samples contain many kinds of charred wood that likely represent materials used for fuel in the hearths and processing pits. Table 8-15 presents the data by identified fragment counts per analysis unit. Though there is some variation, there is substantial comparability between Analysis Units 1 and 2 in terms of the species represented and the numbers of species. Oaks are common in both, and hackberry/elm, boxelder/maple, and ash are moderately common. These species, as well as some that are less frequent such as cottonwood, pecan, and sweetgum, are consistent with the setting of the site today (i.e., on the Little River floodplain near the Blackland Prairie-Oak Woodlands boundary). Even the depauperate Analysis Unit 3 sample reflects this pattern to a degree, with its few fragments of oak and cottonwood. As noted in Appendix G, the presence of live oak may point to a slightly drier climate when the site was occupied than today. However, discrimination of this pattern to particular analysis units using tree species is not possible. Analysis Unit 2 does have twice as many identified fragments of live oak as Analysis Unit 1, but this difference, like the absence of live oak from Analysis Unit 3, may be a result of sample size or wood preferences. When the recovery from the processing pit features of the South Block, which appear to be associated with Analysis Unit 1 but are not included in Table 8-15, are taken into account, all oak counts for Analysis Unit 1 rise substantially with live oak at 40 fragments. This likely repre- sents the selection of oak to be used in the processing pits rather than environmental differences, though.

\section{PATTERNING IN HORIZONTAL DISTRIBUTIONS}

As discussed early in this chapter, 41MM341 has characteristics indicating that it has a high degree of integrity. The cultural deposits occurred as patchy lenses of artifacts and ecofacts associated with intact features in aggrading late Holocene alluvium. Among the features were concentrations of lithic artifacts clearly representing the debris from sets of discrete reduction episodes. Because the lenses are not widely separated within the alluvium and because the excavations were done in arbitrary $10-\mathrm{cm}$ levels, however, it has not been possible to segregate them into a neat series of sequential occupations. This is why the grosser analysis units were defined, lumping Levels 6 and 7 in the Main Block into Analysis Unit 1 and Levels 8 and 9 into Analysis Unit 2. Regardless of this limitation, remnant patterning in the horizontal distributions of some of the remains can be discerned. These patterns are examined here to see what they might say about how the site was used.

It was observed during both excavation and analysis that the lithic reduction debris piles often co-occurred with materials such as burned rocks, mussel shells, and animal bones, and that surface hearths were positioned adjacent to these material concentrations. The cooccurrence of food refuse, tools, tool manufacturing debris, and hearths in semidiscrete concentrations lends itself to an explanation akin to the workshop-habitation site formation model of Stevenson (1985) and Binford's (1978) Nunamuit hunting stand model. Both models address the organization of space within a site as a means of explaining group organization and site function within wider settlementsubsistence systems.

The first step in identifying potential activity loci within the Main Block was to plot the distributions of various classes of debris (burned clay, burned rocks, burned rock shatter, debitage, animal bones, mussel shells, and Rabdotus shells) relative to cultural features that the occupants of the site might have arranged their activities around. The surface and pit hearths 
Table 8-15. Tree species represented by wood charcoal by analysis unit

\begin{tabular}{|c|c|c|c|}
\hline & Analysis Unit 1 & Analysis Unit 2 & Analysis Unit 3 \\
\hline Live oak (Quercus L.) & 6 & 12 & 0 \\
\hline White oak (Quercus L.) & 48 & 58 & 0 \\
\hline Oak (Quercus L.) & 9 & 5 & 2 \\
\hline Sycamore (Platanus occidentalis L.) & 0 & 8 & 0 \\
\hline Sweetgum (Liquidambar styraciflua L.) & 2 & 13 & 0 \\
\hline Hackberry/elm family (Ulmaceae) & 16 & 11 & 0 \\
\hline Boxelder/Maple (Acer L.) & 10 & 9 & 0 \\
\hline Hackberry (Celtis L.) & 2 & 0 & 0 \\
\hline Ash (Fraxinus L.) & 11 & 24 & 0 \\
\hline Persimmon (Diospyros L.) & 0 & 2 & 0 \\
\hline Plum/cherry (Prunus L.) & 1 & 1 & 0 \\
\hline Hickory (Carya Nutt.) & 7 & 4 & 0 \\
\hline Pecan (Carya Nutt.) & 3 & 1 & 0 \\
\hline Hickory/pecan (Carya Nutt.) & 7 & 2 & 0 \\
\hline Holly/yaupon/haw (Ilex L.) & 8 & 1 & 0 \\
\hline Honeylocust (Gleditsia triacanthos L.) & 1 & 0 & 1 \\
\hline Hard elm (Ulmus L.) & 0 & 5 & 0 \\
\hline Slippery elm (Ulmus rubra Muhl.) & 1 & 2 & 0 \\
\hline American elm (Ulmus americana L.) & 8 & 0 & 0 \\
\hline Cottonwood (Populus L.) & 1 & 0 & 3 \\
\hline Diffuse porous & 5 & 7 & 3 \\
\hline Ring-porous & 4 & 8 & 2 \\
\hline Hardwood & 4 & 7 & 2 \\
\hline Diffuse porous III-3 & 0 & 8 & 0 \\
\hline Unidentifiable & 1 & 1 & 0 \\
\hline Total & 155 & 189 & 13 \\
\hline
\end{tabular}

are such features, since they appear to have been general purpose cooking or heating facilities. The distributions of the various debris classes were mapped based on isoplethic representations of the abundance (counts or weights) of each material type (Figures 8-7 through 8-10). This was done level by level within the Main Block (excluding Level 10, where the remains are too sparse to allow this), recognizing that the excavation levels do not represent tidy slices of time, because these are the smallest vertical increments available.

This distributional study began by gridding the raw counts or weights for the seven material classes (using the inverse distance method in Golden Software's Surfer program) and constructing contour maps for them for each level, keeping the contour intervals consistent from level to level. Then, for each material, a particular interval was selected to depict where the material is especially abundant. In most cases, the same interval was used for all levels, although in one (burned clay), intervals varied because of large variability in the abundance of that material. Interval selection was largely visual and subjective, but it is possible to examine how the intervals used relate to the underlying structure of the data by comparing them to summary descriptive statistics for the various categories. These summary measures were calculated on the amounts in Levels 6-9 of the Main Block, since these are the proveniences used in the analysis. Table 8-16 shows that all of the selected intervals are well above 


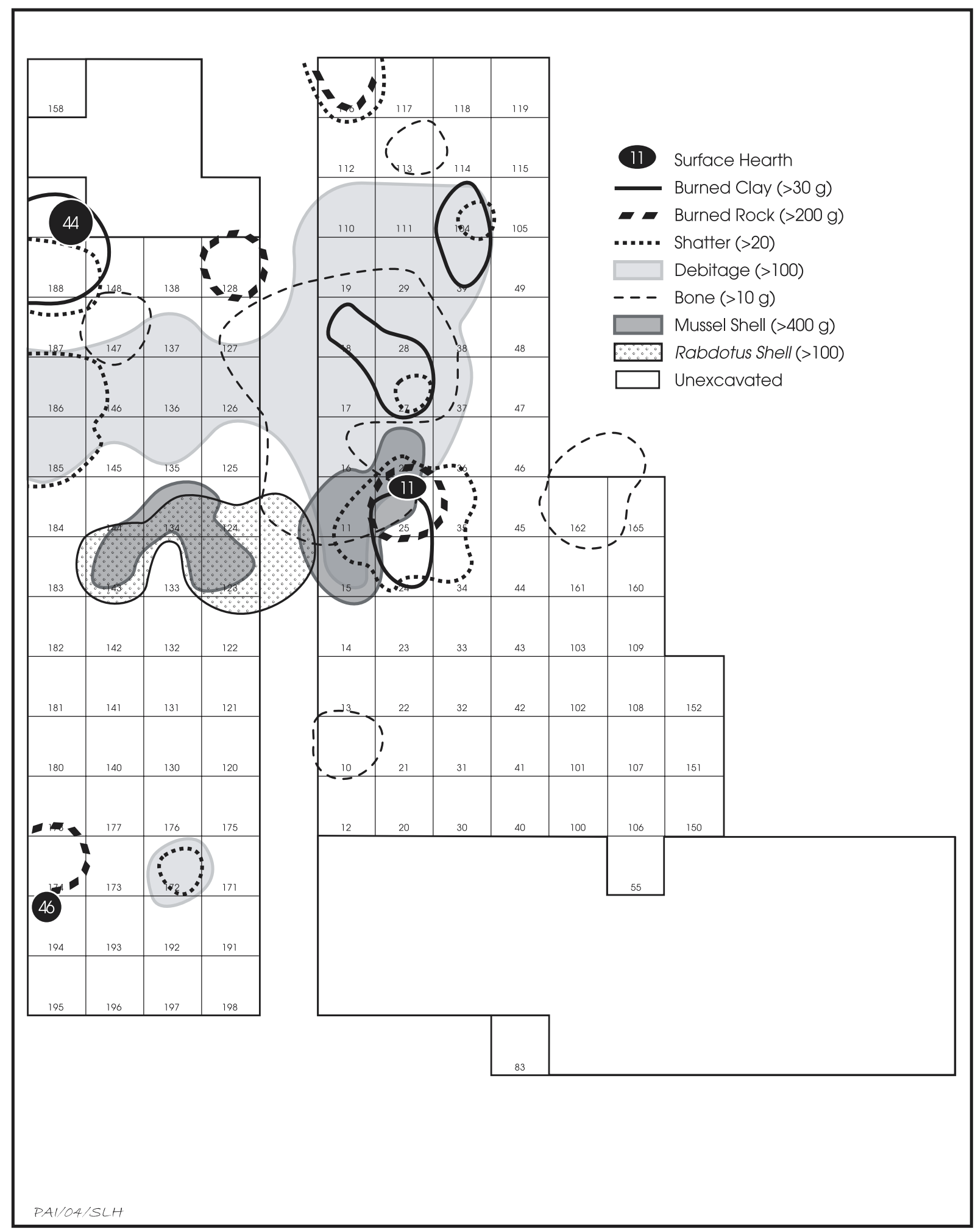

Figure 8-7. Material distributions and hearth locations for Level 6 of the Main Block. 


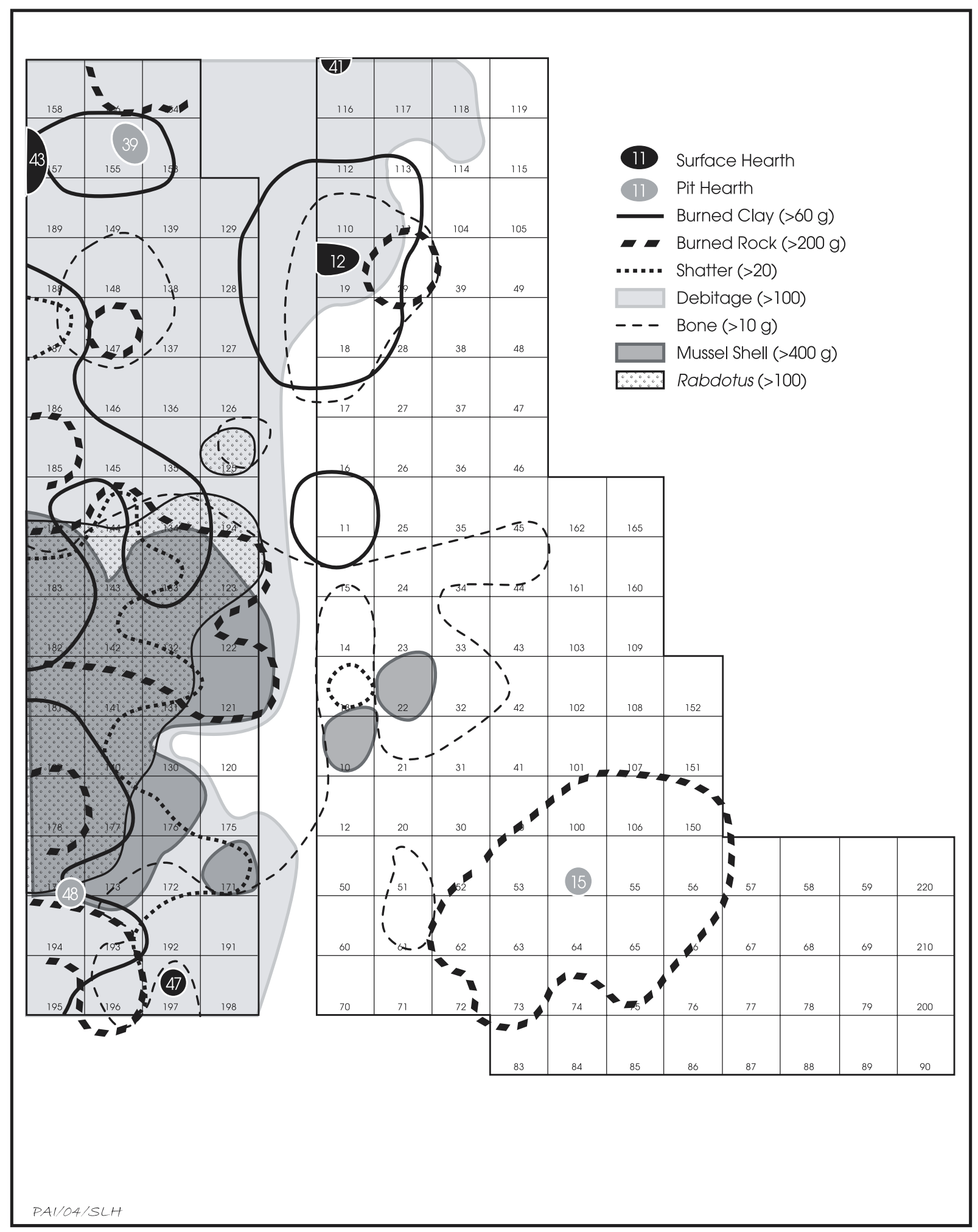

Figure 8-8. Material distributions and hearth locations for Level 7 of the Main Block. 


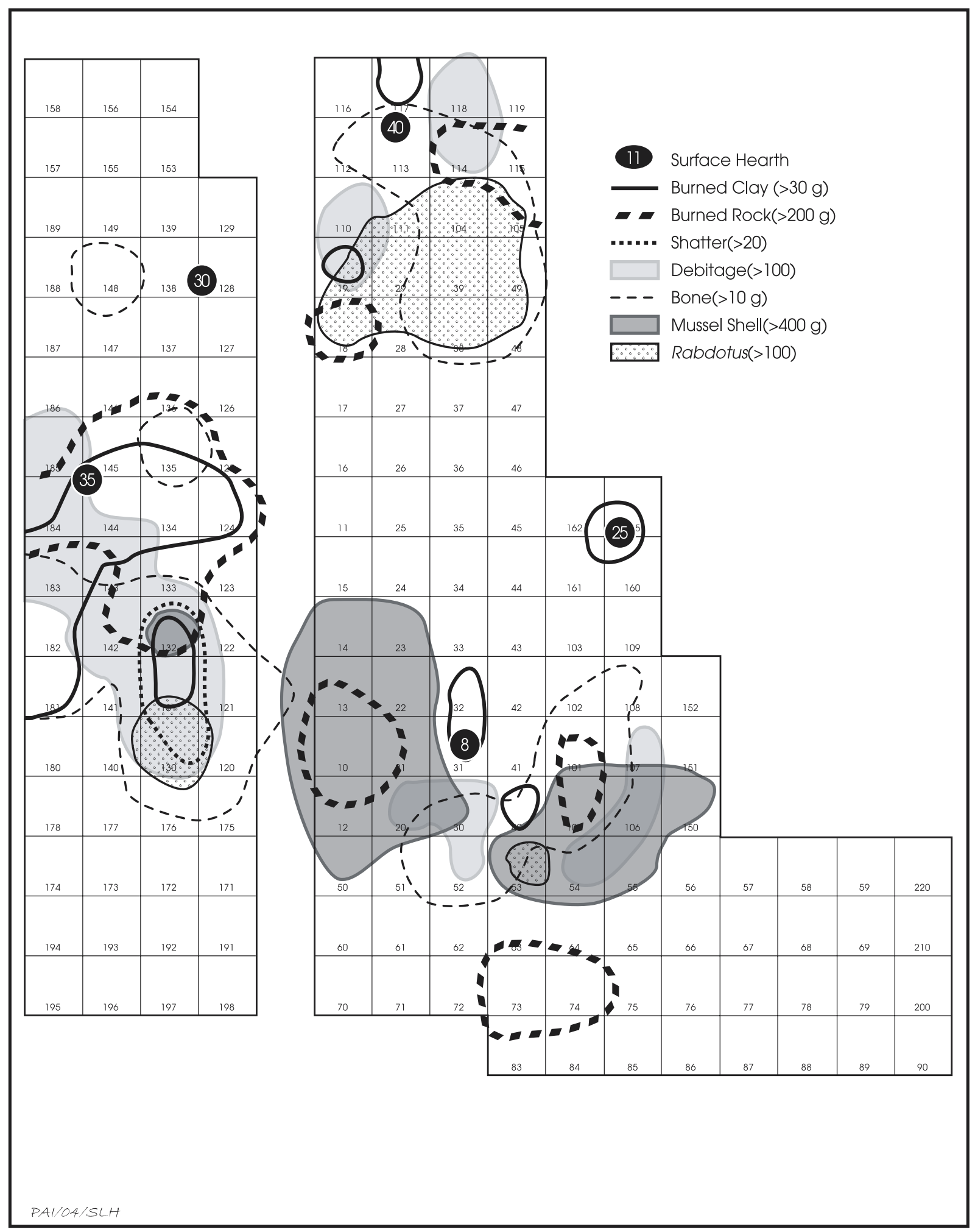

Figure 8-9. Material distributions and hearth locations for Level 8 of the Main Block. 


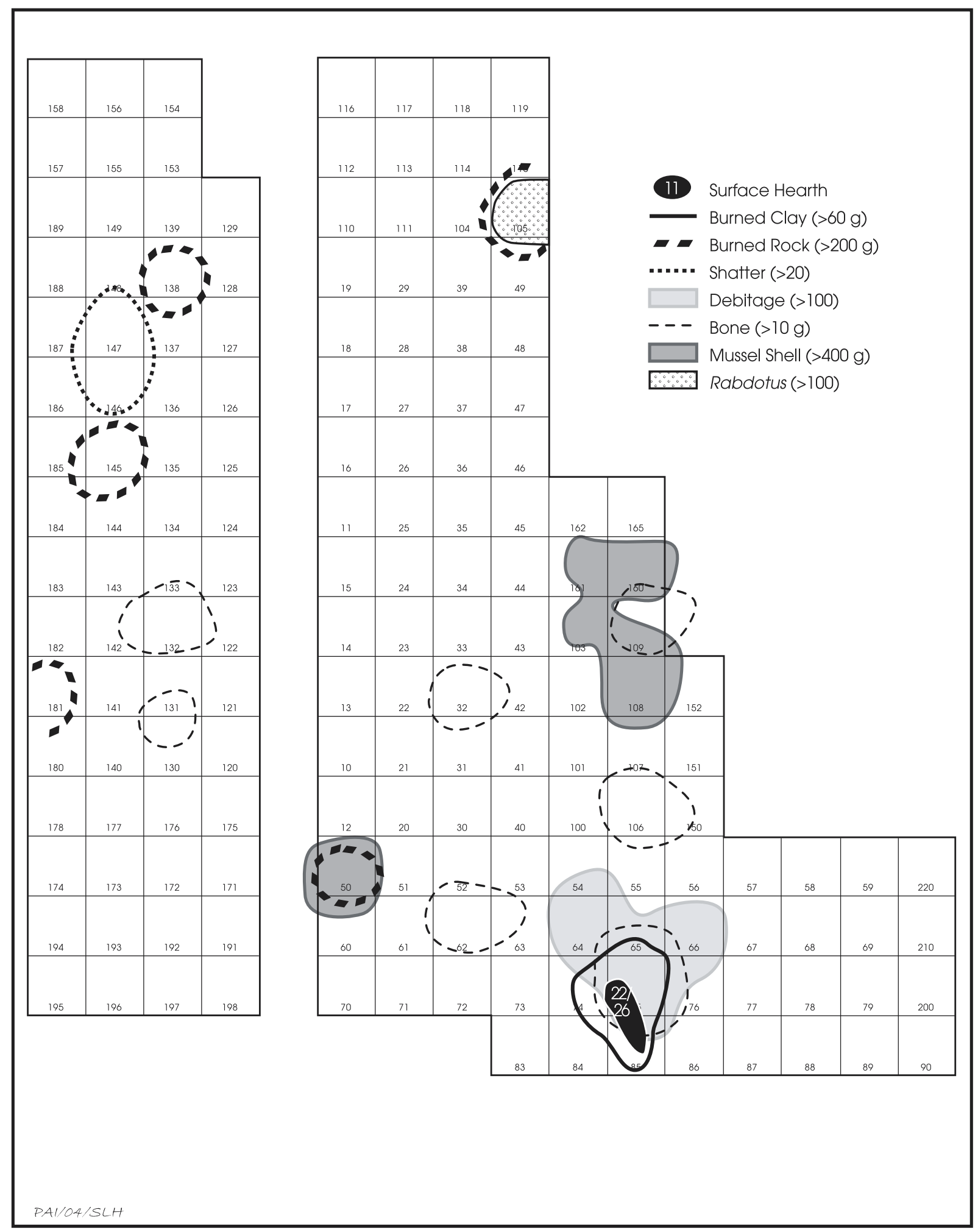

Figure 8-10. Material distributions and hearth locations for Level 9 of the Main Block. 
Chapter 8: Analysis Units, Chronology, and Distributional Studies

Table 8-16. Relationships between contour intervals used to show abundance of material classes in the Main Block distributional analysis and summary statistics for those classes

\begin{tabular}{l|c|c|c|c|c|c|c}
\hline & $\begin{array}{c}\text { Interval } \\
\text { (\# or wt) }\end{array}$ & $\begin{array}{c}\text { No. of } \\
\text { Levels }\end{array}$ & Minimum & Maximum & Median & Mean & $\begin{array}{c}\text { Mean }+1 \\
\text { Standard } \\
\text { Deviation }\end{array}$ \\
\hline Burned clay & 30 or 60 & 355 & 0.2 & 517.8 & 9.3 & 23.1 & 66.8 \\
Burned rocks & 200 & 264 & 0.2 & 2144.3 & 71.8 & 166.8 & 444.6 \\
Burned rock shatter & 20 & 308 & 1 & 358 & 5 & 10 & 34 \\
Debitage & & 580 & 1 & 706 & 26 & 59 & 138 \\
Mussel shells & 400 & 359 & 0.5 & 2150.5 & 28.1 & 141.4 & 466.2 \\
Rabdotus shells & & 275 & 1 & 1191 & 7 & 44 & 175 \\
Animal bones & 10 & 515 & 0.1 & 65.8 & 2.3 & 5.9 & 14.6 \\
\hline
\end{tabular}

both the median and mean values but within one standard deviation above the means. Hence, the contours of the various materials shown in Figures 8-7 though 8-10 effectively distinguish between areas where the materials are relatively abundant and areas where they are not.

\section{Material Distribution Patterns in the Main Block}

Similar materials and feature types were recovered from all levels in the Main Block, and distributional analysis suggests that there is a persistent pattern of materials and tools clustered around or adjacent to the hearth features. This pattern is clearest in Level 8 and then Level 6 , and examination of it starts there. Large quantities of overlapping materials complicate the picture in Level 7, while the opposite problem (i.e., limited quantities of materials) makes pattern identification difficult in Level 9. As noted above, materials are so sparse in Level 10 that it is not worth analyzing distributions.

Five surface hearths-Features 8, 25, 30, 35, and 40-were identified in Level 8. All were marked by burned clay, although it was abundant only in Feature 25. Features 8, 35, and 40 also contained ash, and the latter two of these also contained burned rocks. Features 8 and 25 are $4 \mathrm{~m}$ apart in the southeastern part of the block, and Features 30, 35, and 40 are $3-4 \mathrm{~m}$ apart in the northwestern part. The two groups of hearths are 7-8 $\mathrm{m}$ from one another. Figure 8-9 shows that Features 8,35 , and 40 are within or on the edges of concentrations of various materials, while Features 25 and 30 are not. Feature 25 is associated only with a concentration of burned clay. Feature 30 is not near con- centrations of any materials, except for a small concentration of animal bones. The fact that Features 25 and 30 are off by themselves suggests they had different use histories than the other hearths, or were used for different purposes, and it is interesting that they are in both the southeastern and northwestern feature groups. This configuration and the distances between hearths and between the groups hints at some consistency in the placement of cooking and heating facilities that would seem unlikely if the materials in Level 8 represented many occupations over a long span of time. Rather, this layout is what would be expected if the features were created during a single occupation, or perhaps multiple occupations that were separated by short intervals, such that the remains of the last occupation were still visible.

The concentrations of materials near Features 8,35 , and 40 are similar in some ways, but the differences between them suggest they are not fully equivalent to one another. For example, large concentrations of mussel shells pointing to processing of mussels are present only around Feature 8, where they were recorded as Features 9 and 16. A small concentration of shells is present $2 \mathrm{~m}$ southeast of Feature 35 , but it was not large or obvious enough to get a feature designation. Mussel shells are not abundant near Feature 40. Instead, Rabdotus shells are especially common there, with one large concentration south of the hearth recorded as Feature 17. As discussed in Appendix B, there is little doubt that these snails were procured for food. Much smaller snail concentrations are $1.5 \mathrm{~m}$ southeast of Feature 8 and 3.5 $\mathrm{m}$ southeast of Feature 35. Concentrations of animal bones cover extensive areas south and 
southeast of all three hearths and also represent discard of food debris. Within these are spirally fractured bones suggesting marrow extraction in Excavation Units 40 and 100 near Feature 8; Excavation Unit 113 near Feature 40; and Excavation Units 181, 182, and 183 near Feature 35.

One thing that the Feature 35 area has that the others do not is overlapping concentrations of burned clay, burned rocks, and burned rock shatter; this is in Excavation Units 130-132 ca. $2.5 \mathrm{~m}$ southeast of the hearth. Since burned rock shatter was almost nonexistent in the hearths, these burned materials probably do not represent hearth cleaning. Instead, they may represent a small heating or cooking feature that was not distinctive enough to be recognized and recorded as a feature during excavation. The Feature 35 area also has extensive, partly overlapping concentrations of burned rocks and burned clay east and south of the hearth that could represent materials removed from Feature 35 or perhaps reflect activities centered beyond the block to the west. Non-overlapping areas of concentrated burned rocks and burned clay occur around the other two hearths and also could indicate cleaning out of cooking features.

All three hearths are near concentrations of lithic reduction debris. Pile 7 is spread out mostly on the south side of Feature 8, with its locus in Excavation Unit 54 about $2 \mathrm{~m}$ southeast of the hearth. The locus of Pile 6 is in Excavation Unit 143 , ca. $1.5 \mathrm{~m}$ south-southeast of Feature 35; this pile is part of an extensive concentration of debitage that stretches southeast of the hearth and runs west to the edge of the block and probably beyond. Pile 10 is associated with Feature 40. As with the other two areas, the locus of this pile is ca. $2 \mathrm{~m}$ from the hearth, in this case to the south-southwest in Excavation Unit 110. Pile 10 lies south and east of the hearth and is expressed on Figure 8-9 as two high-density peaks. Based on the analyzed debitage from Piles 6 and 7, formal tool production and flake production for use as expedient tools appear to have generated the piles (see Chapter 6), and it is surmised that this is the case with Pile 10 as well.

These distributions of food remains and the debris from lithic tool production around hearths suggest that both workshop and living-related activities were performed in the same areas. Borrowing from Stevenson (1985:63), these dis- tributions appear to represent workshophabitation areas. As noted above, the remains in Level 8 may not be from a single occupation, but the concentrations can be interpreted as representing a series of occupations with similarly structured activities that likely occurred within a restricted time frame. The configuration of these workshop-habitation areas arcing around a space ca. $4-5 \mathrm{~m}$ in diameter where artifact densities are uniformly low could even suggest that they were placed relative to a shade tree or other fixed feature, or perhaps just to leave open space between them, although this interpretation obviously would require that all the hearth areas relate to a single occupation, and this cannot be proven. The central, empty area could even have contained a structure, although there is no positive indication of this, and the scarceness of all classes of cultural materials there argues otherwise. Structures almost certainly were built at 41MM341, but the available evidence does not tell us where they were or what they looked like.

The remains in Level 6 present a similar but perhaps less-complete picture (see Figure 8-7). Three surface hearths were identified in Level 6 as dense concentrations of ash (Features 11 and 46) or burned clay and ash (Feature 44), with Feature 46 also containing a moderate amount of burned rocks (see Table 6-2). Feature 11 is in the center of the block; Feature 44 is about $7 \mathrm{~m}$ away in the northwest corner; and Feature 46 is about $10 \mathrm{~m}$ southwest of Feature 11 in the southwest corner. Concentrations of burned materials encircle or are adjacent to all three hearths, and this likely is not a coincidence. The spatial relationships suggest that these materials were burned as a result of hearth use. Feature 11 is within and on the north edge of an area with high densities of burned rock shatter and burned clay, as well as burned rocks. Feature 44 coincides with an area with abundant burned rock shatter and burned clay; burned rocks are few, although a small concentration lies approximately $2 \mathrm{~m}$ to the east and could represent hearth clean-out. A separate concentration of burned rock shatter is $2 \mathrm{~m}$ south of Feature 44 and could be associated with this feature or unrecorded features beyond the boundaries of the excavation block. Feature 46 has burned rocks scattered to the north of it (as well as within it) but is not associated with abundant burned rock shatter or burned clay. A small 
concentration of shatter is present about $2 \mathrm{~m}$ east of it, though, and it is possible that associated burned materials could lie to the west beyond the edge of the excavations. Probably not associated with any of the recorded hearths is a concentration of burned rocks and burned rock shatter at the far north edge of the block. Considering the distances to the known hearths, these burned materials probably go with unrecorded features outside the block to the north.

Debitage, mussel shells, snail shells, and animal bones are concentrated around the surface hearths, and in the case of Feature 11 they overlap the hearth. As in Level 8, these material distributions likely represent primary discard locations associated with activities that took place around the hearths, and they provide indications of what those activities were.

Some of the debitage in Level 6 was analyzed as lithic reduction debris Piles 1 and 3 . That analysis indicates that cobble core reduction to generate flakes to be used as expedient tools and tool blanks and bifacial reduction to produce bifacial tools created these piles. The locus of Pile 1, which consists of 706 flakes and chunks, is in Excavation Unit 27 ca. $1 \mathrm{~m}$ north of Feature 11, and the locus of Pile 3 is in Excavation Unit 136 about $3 \mathrm{~m}$ southeast of Feature 44. These two piles are part of an extensive concentration of lithic debris that extends $5 \mathrm{~m}$ north of Feature 11 and in a 2-m-wide swath westward between Features 11 and 44 to the edge of the block and probably beyond. A much smaller concentration of lithic debris lies $2 \mathrm{~m}$ east of Feature 46. Whether it represents a knapping area or materials dumped there is unknown, although the fact that it coincides with a concentration of burned rock shatter, which probably did not result from the same kind of activity as the debitage, could suggest the latter.

Occurring within the main debitage concentration north of Feature 11 are two small concentrations of burned clay and burned rock shatter. As with the similar concentration in Level 8 (which also contained burned rocks), these could be heating or cooking features not recognized during excavation. Other activities that apparently overlapped discard of knapping debris included discard of food debris. This includes animal bones, which occur as a large concentration north and northwest of Feature 11. Though not reflected on Figure 8-7, within this bone concentration in Excavation Units 16, 17, 27 , and 29 are many spirally fractured bones. Their presence suggests that marrow extraction was another activity that was performed near this hearth. Several concentrations of bones are off by themselves-just north of the main debitage concentration, east of Feature 11, south of Feature 11, and southeast of Feature 44-and suggest activities segregated from the main locus of activities. The reasons for this are unclear, since the bones in these small concentrations do not stand out from the rest of the collection in terms of the taxa represented or kinds of breakage. Discard of food debris near Feature 11 also is represented by a concentration of mussel shells, recorded as Feature 10, south and west of Feature 11 and overlapping with the south end of lithic reduction debris Pile 1. Another concentration of mussel shells, this one with Rabdotus shells, lies to the west and does not overlap the main debitage concentration. This is the upper part of Feature 21a, however, which extends down into Level 7 and probably predates most of the materials in Level 6.

At a gross level, the materials in Level 6 appear to be structured like those in Level 8 and likely represent similar kinds of occupations. The picture is muddier, however, and this probably can be attributed to two factors. First, the block was less fortuitous in what it sampled in Level 6, catching fewer hearths and maybe a smaller part of the larger pattern than Level 8. Second, the site apparently was reoccupied more frequently in the latter part of its history than in the earlier part, making it harder to tease apart what goes with what. The fact that the upper part of shell lens Feature 21a shows up as a shell concentration west of Feature 11 in Level 6 is evidence of this, as are the distributions in Level 7 in general (see Figure 8-8).

Level 7 produced the largest recovery in almost every material category, and Figure 8-8 shows that most of those materials are concentrated on the west side of the Main Block. Some individual patterns on the periphery of the main concentration are not hard to interpret. For example, the burned rock concentration around pit hearth Feature 15 probably represents materials removed from the feature, and the burned clay and burned rock concentrations around or adjacent to Features 12, 39, and 43 likely are associated with use of those surface and pit hearths as well. However, most of the 
distributions overlap in a way that makes discerning patterns a hopeless task. The same kinds of things were going on at the site as before and after, but repeated reoccupation makes it impossible to look very closely at how those activities might have been arranged. Further complicating matters is the fact that so much of what went on at the site during the occupations represented by Level 7 apparently happened outside the Main Block in the unsampled area to the west. The western part of the block contains an extensive area with high densities of debitage (and including lithic reduction debris Piles 2, 4, 5, and 9) along with concentrations of every other class of debris, and all of these continue to the west beyond the block. Level 7 as exposed in the Main Block appears to be on the edge of an area that was occupied repeatedly and intensively.

Figure 8-10 shows that Level 9 presents a much simpler picture than the other levels. Interestingly, the pattern of materials arcing around a central vacant area seen in Level 8 appears with a few additions and substantially fewer materials in Level 9. This could suggest that Levels 8 and 9 crosscut a single occupational zone, especially where high densities of like materials overlie one another (or nearly so), and provide additional support for lumping the two levels for some analytical purpose. This could explain the concentrations of mussel shells and burned rocks in Excavation Unit 50; the animal bone concentrations in Excavation Units $62,106,131$, and 132; the burned rock concentration in Excavation Unit 145 and maybe the one in Excavation Unit 138 through association with hearth Feature 30 above; and the concentrations of burned rocks and Rabdotus shells in Excavation Unit 105. Materials in Level 9 that appear distinct from what is in Level 8 are restricted to the following: surface hearth Feature $22 / 26$, which co-occurs with abundant burned clay, animal bones, and debitage (lithic reduction debris Pile 8) at the south edge of the block; a concentration of mussel shells (recorded as Feature 20) and animal bones ca. 4-6 m north of the hearth; and a small concentration of animal bones 2 m west of the mussel shell concentration. The relationships between these are unclear. Since the two feature areas abut edges of the block, though, it may be that they go with additional occupational materials located east and south of the Main Block.

\section{Tool Distribution Patterns within the Main Block}

To look at how closely tools follow the workshop-habitation debris and to determine if certain kinds of tools were consistently recovered within or the beyond the debris scatters, tool frequencies were quantified by excavation unit for Levels 6 and 8, since these two levels have the clearest workshop-living area patterns. These distributions were then plotted against the overall extents of the main parts of the debris scatters, as construed from the distributions shown in Figures 8-8 and 8-10. Figure 8-11 shows these comparisons visually, and Table 8-17 summarizes the data by looking at the relative frequencies of the various tool classes within the main parts of the debris scatters and outside the main parts.

For both Levels 6 and 8, the overwhelming majority of the formal chipped stone, ground or battered stone, and bone tools (63 percent in Level 6 and 67 percent in Level 8) and expedient stone tools (81 and 79 percent) are within the main parts of the debris scatters (i.e., the areas where multiple classes of debris tend to be especially abundant). This indicates that most activities associated with tools occurred in close proximity to the areas marked by the hearths and surrounding debris scatters. The higher percentages for expedient tools probably is a function of the selection of flakes from the lithic reduction debris piles for immediate use followed by discard on the spot. Formal tools had more varied use histories, and thus their distributions are more varied. In Level 6, 37 percent of the formal tools and 19 percent of the expedient tools are outside the main part of the debris scatter; in Level 8, these figures are 33 and 21 percent. Most of these are within 1-2 $\mathrm{m}$ of the core areas, and thus they are still within the scatters, just not in their most concentrated parts. The single concentration of tools in Level 6 that is well-removed from the debris scatter is around Feature 46 in the southwest corner of the block; this concentration consists of one arrow point, two arrow point preforms, a hammerstone, and two expedient tools. In Level 8 , there is a concentration consisting of an arrow point preform, a knife, a gouge, a chopper, two early-stage bifaces, two indeterminate bifaces, and three expedient stone tools away from the debris scatters in the northwest part 


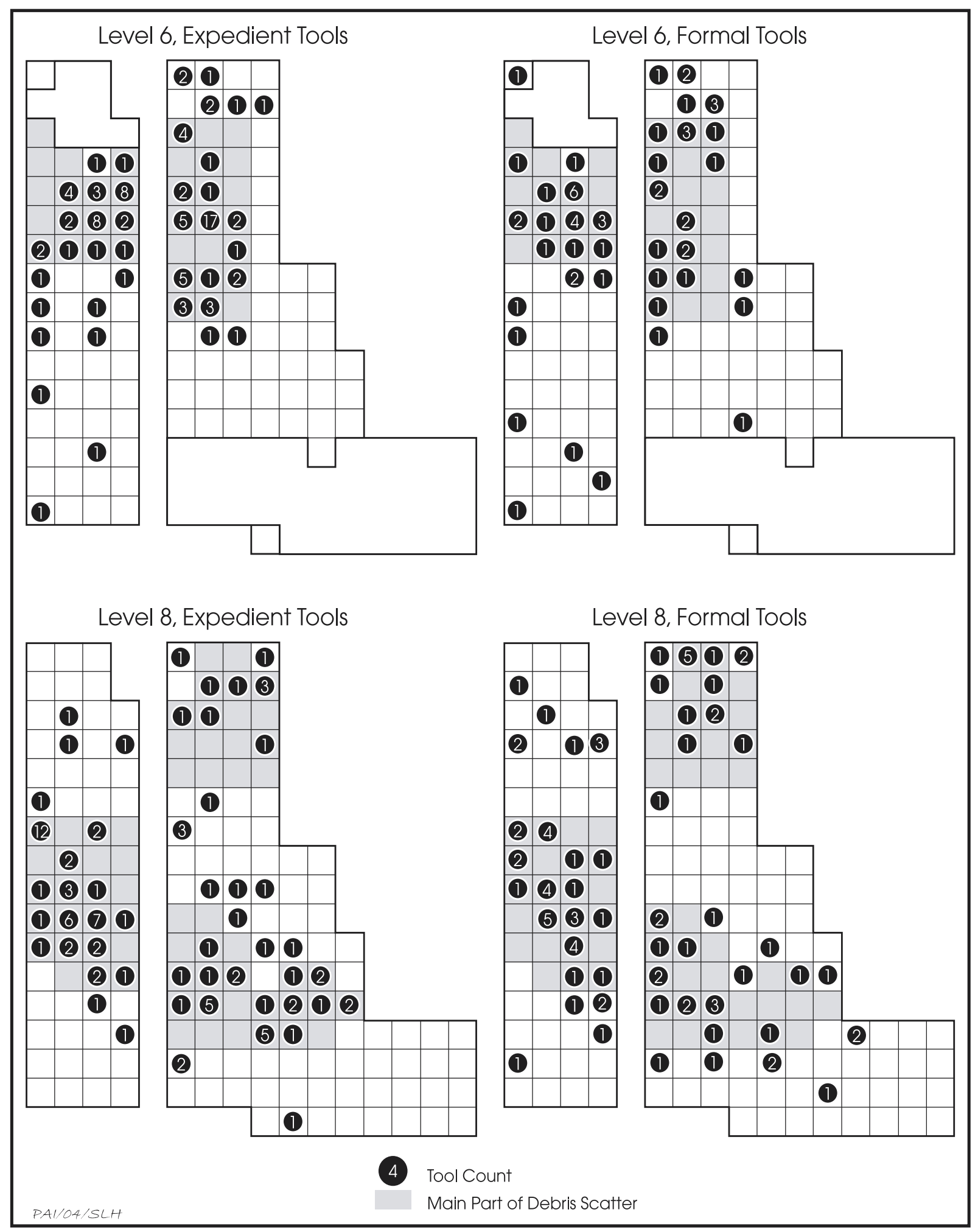

Figure 8-11. Distributions of tools relative to the main parts of the debris scatters in Levels 6 and 8 of the Main Block. 
Table 8-17. Distributions of various tool classes relative to the main parts of the debris scatters in the Main Block

\begin{tabular}{|c|c|c|c|c|c|c|c|c|c|c|c|c|}
\hline \multirow[b]{3}{*}{ Tool Category } & \multicolumn{4}{|c|}{ Level 6} & \multicolumn{4}{|c|}{ Level 8} & \multicolumn{4}{|c|}{ Total } \\
\hline & \multicolumn{2}{|c|}{ Inside } & \multicolumn{2}{|c|}{ Outside } & \multicolumn{2}{|c|}{ Inside } & \multicolumn{2}{|c|}{ Outside } & \multicolumn{2}{|c|}{ Inside } & \multicolumn{2}{|c|}{ Outside } \\
\hline & $\#$ & $\%$ & $\#$ & $\%$ & $\#$ & $\%$ & $\#$ & $\%$ & $\#$ & $\%$ & $\#$ & $\%$ \\
\hline \multicolumn{13}{|l|}{ FORMAL TOOLS } \\
\hline Arrow point & 13 & 86.7 & 2 & 13.3 & 11 & 73.3 & 4 & 26.7 & 24 & 80.0 & 6 & 20.0 \\
\hline $\begin{array}{l}\text { Arrow point } \\
\text { preform }\end{array}$ & 5 & 45.5 & 6 & 54.5 & 10 & 83.3 & 2 & 16.7 & 15 & 65.2 & 8 & 34.8 \\
\hline Dart point & 1 & 100.0 & 0 & 0.0 & 2 & 66.7 & 1 & 33.3 & 3 & 75.0 & 1 & 25.0 \\
\hline Dart point preform & 0 & - & 0 & - & 2 & 100.0 & 0 & 0.0 & 2 & 100.0 & 0 & 0.0 \\
\hline Knife & 5 & 83.3 & 1 & 16.7 & 5 & 50.0 & 5 & 50.0 & 10 & 62.5 & 6 & 37.5 \\
\hline Knife preform & 3 & 60.0 & 2 & 40.0 & 4 & 80.0 & 1 & 20.0 & 7 & 70.0 & 3 & 30.0 \\
\hline Perforator & 0 & 0.0 & 1 & 100.0 & 0 & & 0 & & 0 & 0.0 & 1 & 100.0 \\
\hline Adze & 0 & 0.0 & 1 & 100.0 & 1 & 100.0 & 0 & 0.0 & 1 & 50.0 & 1 & 50.0 \\
\hline Gouge & 1 & 50.0 & 1 & 50.0 & 2 & 66.7 & 1 & 33.3 & 3 & 60.0 & 2 & 40.0 \\
\hline Early-stage biface & 3 & 50.0 & 3 & 50.0 & 5 & 62.5 & 3 & 37.5 & 8 & 57.1 & 6 & 42.9 \\
\hline $\begin{array}{l}\text { Indeterminate } \\
\text { biface }\end{array}$ & 5 & 83.3 & 1 & 16.7 & 5 & 55.6 & 4 & 44.4 & 10 & 66.7 & 5 & 33.3 \\
\hline $\begin{array}{l}\text { Chipped } \\
\text { hammerstone }\end{array}$ & 0 & - & 0 & - & 1 & 100.0 & 0 & 0.0 & 1 & 100.0 & 0 & 0.0 \\
\hline Chopper & 0 & - & 0 & - & 0 & 0.0 & 1 & 100.0 & 0 & 0.0 & 1 & 100.0 \\
\hline $\begin{array}{l}\text { Battered } \\
\text { hammerstone }\end{array}$ & 1 & 33.3 & 2 & 66.7 & 3 & 60.0 & 2 & 40.0 & 4 & 50.0 & 4 & 50.0 \\
\hline Abrader & 1 & 50.0 & 1 & 50.0 & 1 & 33.3 & 2 & 66.7 & 2 & 40.0 & 3 & 60.0 \\
\hline $\begin{array}{l}\text { Bone tool/ } \\
\text { modified bone }\end{array}$ & 0 & 0.0 & 1 & 100.0 & 6 & 66.7 & 3 & 33.3 & 6 & 60.0 & 4 & 40.0 \\
\hline Subtotal & 38 & 63.3 & 22 & 36.7 & 58 & 66.7 & 29 & 33.3 & 96 & 65.3 & 51 & 34.7 \\
\hline \multicolumn{13}{|l|}{ EXPEDIENT TOOLS } \\
\hline & 80 & 80.8 & 19 & 19.2 & 78 & 78.8 & 21 & 21.2 & 158 & 79.8 & 40 & 20.2 \\
\hline
\end{tabular}

of the block. This concentration likely reflects activities associated with hearth Feature 30.

Looking at the individual types of formal tools (see Table 8-17), it is hard to see patterns suggesting that different kinds of tools were used or discarded in different places, in part because of the small sizes of many of the categories. One pattern may be worth noting, however. Specifically, arrow points and knives and their preforms combined occur more consistently within the cores of the debris scatters than do the other categories combined ( 71 vs. 59 percent). This is probably due to the fact that arrow points and knives were two of the main intended products that resulted in creation of the lithic reduction debris piles (with flakes for expedient use being the other), and when they broke during manufacture they were discarded immediately.

\section{The East Block}

The small size of the East Block $\left(12 \mathrm{~m}^{2}\right)$ makes distributional studies like that presented above meaningless, and so the distributions of the materials in Levels 10 and 11 are not presented here, even though these materials are included in Analysis Unit 3. Nonetheless, it is worth noting that these materials probably would have shown the same kinds of patterns as the Main Block if a larger area had been excavated, indicating similar kinds of occupations of this part of the site during the early period of site use. For example, the material distributions 
for Level 10 show overlapping concentrations of debitage and mussel shells in Excavation Units 318 and 319 on the south edge of the block and concentrations of debitage, mussel shells, burned rocks, and burned rock shatter in the northeastern corner of the block. These latter concentrations are likely a continuation of Feature 3 identified in testing Block 1. That feature originally was identified as a mussel shell lens with debitage (Mahoney and Tomka 2001:53). The presence of burned rocks and burned rock shatter in Excavation Units 311 and 312 suggests that the remnant of a hearth or other cooking or heating feature is also present in this area. Though only a small part of the pattern is visible in the block, the configuration of a hearth near a shell feature with a debitage concentration overlapping is reminiscent of the workshop-living areas proposed in the Main Block.

\section{The South Block}

In contrast to the East Block, the materials in the South Block bear no resemblance to those in the Main Block. The South Block was placed over a concentration of processing pit features, which are distinct from the features elsewhere on the site in terms of their larger size and greater intensity of burning. The highly fragmentary nature of the burned rocks, along with the fact that the processing pits intersect one another, suggest that this area was used repeatedly for the same purpose, apparently processing of both animal and plant foodstuffs. Based on their level of origin and the radiocarbon dates, these processing pits appear to be associated primarily, if not exclusively, with Analysis Unit 1. They represent a distinct kind of activity area that contrasts with those sampled by the Main Block, and the addition of these activities during the later occupations may relate to the increased intensity of use during that time. Given the small size of the South Block $\left(28 \mathrm{~m}^{2}\right)$, the sparse nature of the remains there, and the fact that much of this block is taken up by features, however, there is little to be learned from looking at the horizontal distributions of the archeological remains within the block.

One thing that is clear is that the activities associated with the processing pits were isolated from the activities that produced the workshophabitation areas in the Main Block. The initial units and the backhoe trenches indicate that the area between the South Block and the Main Block is relatively devoid of cultural materials in the levels of interest for this study. For example, Excavation Units 6 and 8 between the blocks produced a combined total of only 4 pieces of debitage in Levels 6 through 10. Excavation Unit 9 located closer to the southwest corner of the Main Block produced only 3 flakes from Levels 6 through 8; the 96 artifacts in Levels 9 and 10 probably indicates a patch of materials associated with the early site component (Analysis Unit 3). The lack of shell lenses or features in the northern end of Trench 3 also points to separation between the two parts of the site. The high frequencies of materials, especially in Level 7 , in the southwest corner of the Main Block likely continue for several meters south toward the South Block, but this set of overlapping debris scatters probably veers to the southwest beyond the stripped area and the project area boundary. In short, the evidence indicates a break of approximately $10 \mathrm{~m}$ between the activities associated with these two blocks. 



\section{SUMMARY OF INTERPRETATIONS AND PROJECT ASSESSMENT}

Many of the questions posed in the research design (Chapter 3 ) are addressed to one extent or another in Chapters 6-8. To ensure that they are addressed directly, though, this chapter summarizes the interpretations concerning 41MM341 under the five primary problem domains presented in the research design: environmental reconstruction, subsistence strategies, assemblage organization, intrasite patterning, and interregional interaction. Not surprisingly, some of the original questions changed, often becoming more complex, as research progressed, while others were found to be unanswerable using the analysis methods proposed. The strategy here is not to reiterate and try to answer the original questions oneby-one, but, instead, to convey what 41MM341 tells us about the prehistory of the area topically using the five problem domains. The interpretations presented here include some data not discussed in previous chapters, coupling it with data already discussed to address one overarching issue: how the site occupants made a living and how their physical and cultural environments affected this. Finally, this chapter closes with an assessment of the utility and value of some of the approaches and methods used in this data recovery project.

\section{ENVIRONMENTAL RECONSTRUCTION}

Three questions were posed in the research design that address how environmental conditions may have affected the behavior of the groups who occupied 41MM341. These questions concern environmental change on regional and local scales, the conditions at the time the site was occupied, and how those conditions affected group organization and subsistence orientations. Studies directed at determining climatic conditions at the time the site was occupied and change in those conditions through time include oxygen isotope analysis of shells of the mussel Amblema plicata and the land gastropod Rabdotus sp., analysis of diatoms preserved in burned clay from hearth features, and analysis of land gastropods collected from a column sample located away from the main activity areas at the site. The first three studies mentioned attempt to address regional conditions of temperature and rainfall through time, while the land gastropods drawn from the column sample provide a picture of microenvironmental conditions at the site.

Charting environmental patterns over a long period is necessary for understanding the effects of climate change on people. The analyses of materials from 41MM341 as they apply to climate are therefore complemented by investigations done previously using materials excavated from 41MM340, a Late Archaic site with occupations dating mostly from ca. 1400 to 400 B.C. This site is less than a half kilometer from 41MM341 within the floodplain of the Little River (Mahoney et al. 2003).

The uptake of the ${ }^{18} \mathrm{O}$ isotope in the shells of invertebrates is related to river water temperatures in the case of mussels and rainwater temperature for land gastropods and potentially can be used to track changes in ambient temperature (see Appendixes C and D). The results of analysis of oxygen isotopes in archeological materials can be interpreted using a modern baseline derived from the isotopic values from modern shell samples. Modern conditions were extrapolated for the Amblema plicata study using three shells collected by Texas Parks and 
Wildlife Department personnel from Belton Lake (Leon River) in Bell County, Texas. These three mussels were considered to have died recently (within a month or two of collection) because they had connective tissue or their inner and outer surfaces were not degraded (Robert G. Howells, personal communication 2003). These shells are considered representative of the modern climatic conditions of Milam County, as Bell and Milam Counties are adjacent and Belton Lake is within the Little River drainage. Presently, these two counties experience similar yearly rainfall totals and minimum and maximum temperatures (Carter et al. 1925; Huckabee et al. 1977). Two modern Rabdotus sp. shells were collected from near 41MM340 to provide data for the gastropod study (Tomka and Mauldin 2003a:103).

Analysis of oxygen isotope values for 12 mussel shells from 41MM341 and the 3 modern samples from Belton Lake suggest decreasing ambient temperature through the period of the site occupation (A.D. 600-1300), approximating modern conditions by the end of the occupation (see Appendix C). Examination of this pattern can be broadened by adding ${ }^{18} \mathrm{O}$ values from four samples of the mussel Quadrula houstonensis from 41MM340. The graphic representation of this comparison suggests that temperatures were generally warmer than the modern average when 41MM340 was occupied, although one sample (from Zone 5/6) points to a period with fluctuating, cooler temperatures (Figure 9-1). The values from $41 \mathrm{MM} 340$ are comparable to many of those from 41MM341, but they are notably higher than those from Analysis Unit 3. This suggests that temperatures increased between 400 B.C. and A.D. 600 and then began to decrease toward modern temperatures as the occupations associated with Analysis Unit 2 at 41MM341 began.

Analysis of oxygen isotopes in the Rabdotus sp. samples from 41MM341 and 41MM340 provided less-interpretable results than the freshwater mussel data, possibly because this species is not as sensitive to oxygen isotope uptake as some others (Claasen 1998:150). A plot of the sample values from 41MM341 shows a highly fluctuating pattern with what could be a general trend toward cooler, modern temperatures (see Appendix D), and the values from 41MM340 suggest fluctuating but, perhaps, generally warmer temperatures than the modern mean
(Tomka and Mauldin 2003a:103-105). Given the uncertainties of interpreting these data, however, it would be unwise to attach much meaning to these patterns.

The diatoms recovered from 41MM341 and $41 \mathrm{MM} 340$ could be suggestive of climate changes, although they also are hard to interpret. Diatoms were recovered from burned clay samples taken from seven surface hearths (see Appendix H). The numerous diatom species in these samples can be grouped based on whether they are aquatic species living only in water or aerophilic species that live in soil (although aerophilic diatoms must have water to reproduce, so they may not be exclusively associated with terrestrial environments). The relative frequencies of these two diatom groups may be useful for addressing climate based on the assumptions that the aquatic species were deposited within the site sediments by flooding and that fluctuations in their numbers through time could relate to changes in the frequency or duration of flood episodes and hence wet vs. dry conditions.

Of the three samples from hearths assigned to Analysis Unit 1, two (Samples 02 and 03) have very high percentages (91 and 95) of aquatic species, while the third (Sample 01) has a low percentage (16). The three Analysis Unit 2 samples show a similar split (82-83 percent aquatic species in Samples 04 and 05 and 8 percent in Sample 06), with overall lower percentages of aquatic species. The single sample from Analysis Unit 3 (Sample 07) has a moderate value of 34 percent. A single diatom sample from a hearth feature at 41MM340, recovered from Zone 2 during test excavations, has 76 percent aquatic diatoms (Mahoney and Tomka 2001:48). These data could be used to support the contention that the Little River floodplain was drier during the early occupations of 41MM341 than during the later ones there or the earlier ones at 41MM340, and this would parallel the temperature fluctuations suggested by the mussel shells. It is hard to feel confident that this was the case, though, because of the great variability in the percentages of aquatic species within both sets of samples from Analysis Units 1 and 2 , the low counts of diatoms in most samples (see Appendix H), and uncertainty about how the diatoms ended up in the hearth features. While it has been assumed that they were deposited there as a result of flooding, it is 


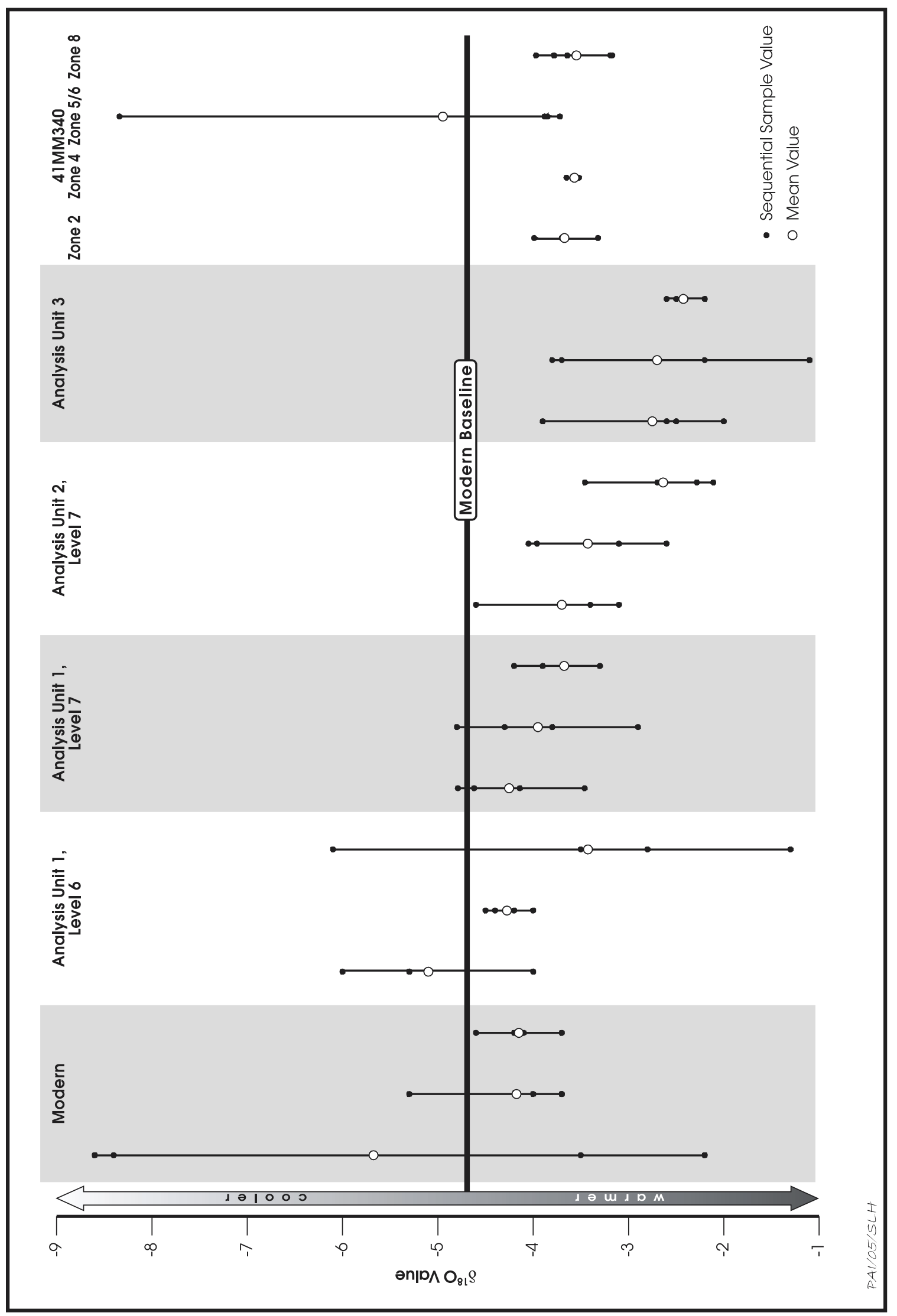

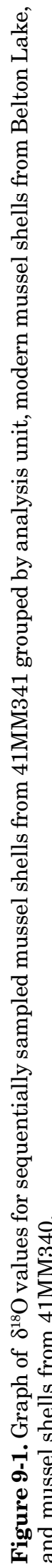


possible that they were brought to the site when mussels were harvested from the river. If that is the case, they are not good indicators of climatic conditions.

The arguments for climate change based on freshwater mussels and maybe diatoms are an attempt to gauge regional patterns based on how these organisms are affected by variability in rainfall and temperature. On a more-local level, the habitat preferences of the land gastropods can be informative as to the type of vegetative cover present during occupation of the site. Land gastropods recovered from a column sample at 4MM341 suggest that, for most of its history, the site was forested with open grassy areas nearby or that the forest cover was relatively open with a grassy understory (Table 9-1).

Changes in the percentages of gastropod species associated with particular habitat preferences can be graphed by level within the column sample to demonstrate the evolving habitat in the vicinity of 41MM341 (Figure 9-2). This graph shows overall stability in forest cover as forest or woodland snail percentages fluctuate between only 60 and 85 percent. There is, however, a notable decrease in forest or woodland species and corresponding increase in sparsely wooded/open species in Levels 10-12. This fluctuation indicates that during the initial period of occupation, the site area was relatively open. Forest and woodland species increase above Level 10, peaking in Level 6. Hence, it appears that forest cover increased in the later occupations of the site.

The results of these various studies suggest that, at the beginning of the occupation of $41 \mathrm{MM} 341$ at ca. A.D. 600 , climatic conditions were relatively warm and perhaps relatively dry, and that the forest or woodland canopy was relatively open. These conditions changed during the 700 years that the site was occupied to become cooler, maybe wetter, and more forested. Com-

Table 9-1. Land gastropod frequency in the column sample from $41 \mathrm{MM} 341$ by habitat association

\begin{tabular}{l|c|c}
\hline Habitat & Number & Percent \\
\hline Forest and wooded areas & 4,084 & 56.3 \\
Open grassy areas & 1,920 & 26.4 \\
Sparsely wooded areas & 624 & 11.6 \\
Other & 631 & 8.7 \\
\hline Total & 7,259 & \\
\hline
\end{tabular}

parison of these results with those of similar studies at $41 \mathrm{MM} 340$ suggest that, at some point after the occupation of $41 \mathrm{MM} 340$ and before the occupation of 41MM341 (i.e., between 400 B.C. and A.D. 600), environmental conditions significantly changed with a fluctuation to warmer and perhaps drier conditions. Interestingly, in his reanalysis of the pollen data from Weakly Bog in Leon County, Bousman (1998:207) points to a significant grass spike at ca. 1550 B.P. (A.D. 400) that he cautiously interprets as representing drier and warmer conditions. The timing of this Weakly Bog grass spike places it just before the Analysis Unit 3 occupation at $41 \mathrm{MM} 341$ and suggests that the changes discussed above were regional rather than local.

How these changing environmental conditions affected resource opportunities on the floodplain of the Little River and organization of the groups who lived in the area is difficult to address directly. However, using the environmental data presented here as a backdrop to the nature of the occupations associated with 41MM341 and 41MM340, the suggestion can be made that the warm, dry, and less-wooded conditions that appear to have occurred between occupation of the two sites and into the early occupation of 41MM341 may not have been favorable to the type of floodplain utilization represented at both sites. As discussed in Chapter 8, 41MM341 was used much less intensively during the Analysis Unit 3 occupations than during the later ones, with this difference apparently being a function of less-frequent reoccupation during the A.D. $600-800$ period.

To enable comparison with 41MM340, a useintensity index was calculated for Analytical Unit 2 at that site using the same formula used for 41MM341. Analytical Unit 2 at 41MM340 was mostly in stratigraphic Zone 2 representing the last occupations of the site (Mauldin et al. 2003:61-72). The use-intensity value for this unit can be calculated by dividing the 14,107 pieces of debitage by the area excavated $\left(56 \mathrm{~m}^{2}\right)$ divided by the 400 -year span represented (based on radiocarbon dates associated with Zone 2 [Mahoney and Tomka 2001:32]). The use-intensity index for Analytical Unit 2 is 0.62 , a value that is close to that for the latest analysis unit at 41MM341. This suggests that how the Little River floodplain was utilized by prehistoric groups shifted at a time when en- 


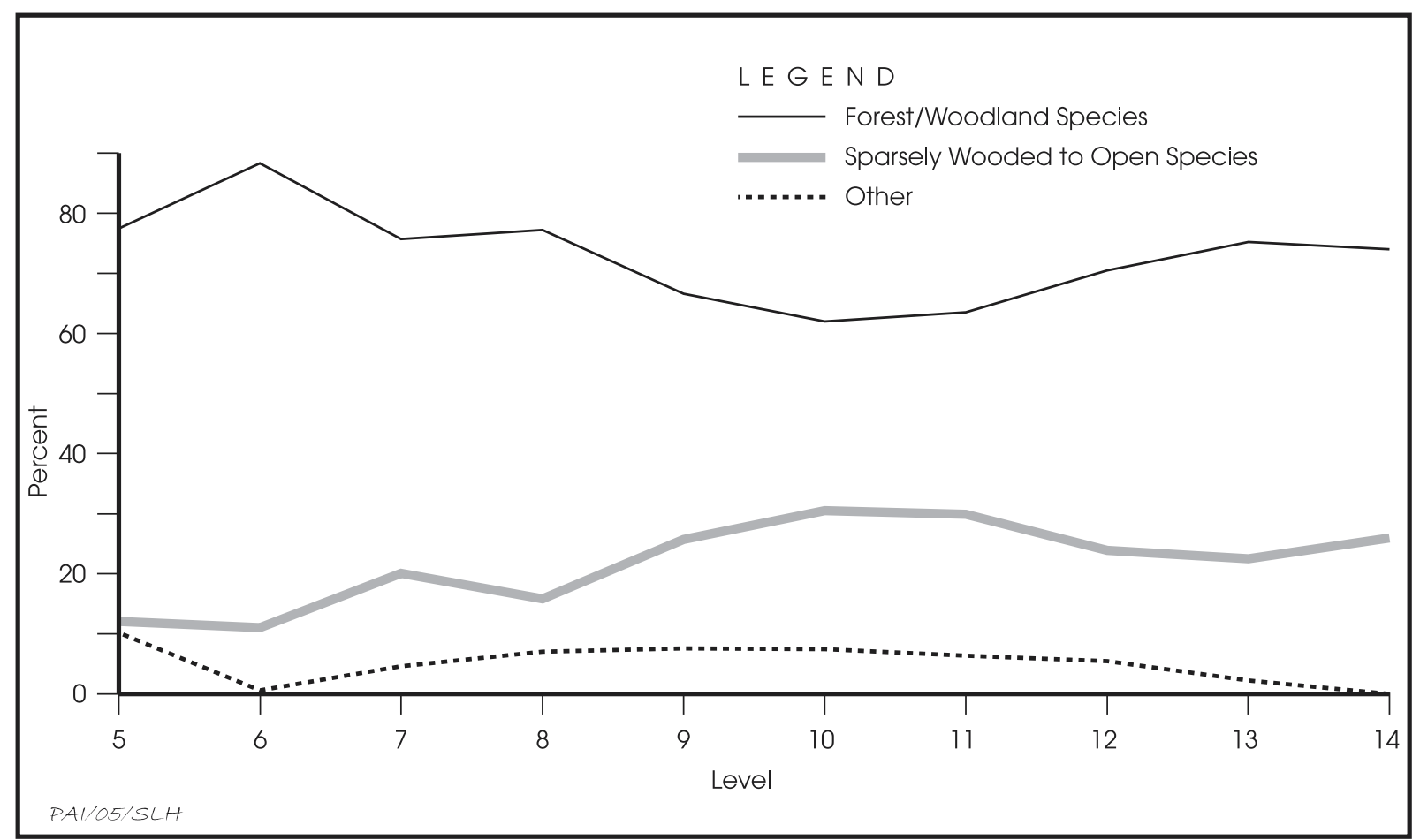

Figure 9-2. Graph of percentages of land gastropods by associated habitats by level in the column sample from $41 \mathrm{MM} 341$.

vironmental conditions also appear to have changed. The area appears to have been used intensively before 400 B.C. when cooler conditions prevailed. This was followed by a period of warmer, perhaps drier conditions and lessfrequent occupation of the floodplain at A.D. 600 800 and perhaps for some part of the preceding millennium. This may have culminated in a period of very limited floodplain occupation, explaining the ca. 100-year gap between Analysis Units 3 and 2. As occupation of 41MM341 resumed and intensified over the next 400 years, environmental conditions appear to have become cooler and maybe wetter again. How the groups who occupied 41MM341 utilized the resources available during such a period of climatic change is discussed further below as answers to research questions concerning subsistence are addressed.

\section{SUBSISTENCE}

Research questions posed in Chapter 3 about the subsistence practices of the occupants of 41MM341 addressed the kinds of botanical and faunal resources used and how those resources were distributed across the landscape.
This information is essential in determining the subsistence orientation of the people who used the site. Indications that certain kinds of resource utilization were a response to subsistence stress also factor into understanding that orientation, as does an understanding of when during the year the site was occupied. Lastly, questions about how environmental changes might have affected subsistence orientation are relevant.

The floral and faunal materials found at $41 \mathrm{MM} 341$ indicate some of the botanical resources and most of the vertebrate and invertebrate fauna that contributed to the subsistence base, with the species utilized not unexpected for a riparian locale situated at the boundary of the Blackland Prairie and Oak Woodlands. The botanical resources clearly illustrate utilization of all environmental zones encompassed by this boundary. The predominance of oak in the wood charcoal from Analysis Units 1 and 2 along with hackberry/elm, boxelder/maple, ash, sweetgum, and hickory/pecan indicate that both the upland and riparian woodlands were utilized for fuel. And, there is evidence in the other macrobotanical remains recovered to indicate the same for plants procured for food. 
Hardwood nut resources associated with oak, hickory, and pecan trees were used for food, but they were recovered in such small quantities that it appears they were not terribly important to the diet, at least not during the time of year when the site was occupied. While 210 nut fragments were identified in 50 flotation samples from features and 39 samples from 1/4-inch screening, all together these weigh only $6.7 \mathrm{~g}$ (see Appendix G). These quantities pale in comparison to the quantities of nuts found at sites such as McGuire's Garden in the oak woodlands of Freestone County, where excavations less extensive than those at 41MM341 produced $400 \mathrm{~g}$ of nutshells (Gadus et al. 2002:130). The contention that nut processing was not done much at 41MM341 is supported by the fact that only one pitted stone was recovered from the site, and it is a thin slab with a pit so small that it seems unlikely to have been used in nut processing (this specimen is from a lower level in one of the initial $1 \times 1-m$ units and thus is not assigned to an analysis unit, though it probably goes with occupations associated with Analysis Unit 3). The apparently limited importance of hardwood nuts is curious given that oak and hickory trees likely were abundant in the uplands surrounding the project area while pecan trees probably grew on the floodplain, and it may suggest that 41MM341 was occupied mostly in the spring or summer, although the long shelflife of hardwood nuts makes them poor candidates for indicators of seasonality.

Bulbs (wild onion and false garlic), while also infrequent, were recovered from more proveniences than nuts and are well represented in the processing pit features of the South Block. The importance of these plants to diet in terms of caloric contribution is debatable (i.e., they may have been used more for flavoring other foods), but their relatively ubiquitous occurrence suggests they were important to subsistence. Further, because wild onions and false garlic are indicative of open grassy environments and their usage at 41MM341 appears to have increased in Analysis Units 1 and 2 at a time when the area apparently was becoming increasingly forested, it appears that some effort may have been expended in procuring them at some distance from the site and transporting them back to 41MM341. In short, they appear to have been sought-after plants.

Other potential subsistence-related plants in the recovered assemblage are sparse indeed, consisting of small numbers of unidentified tubers and seeds of plum/cherry, hawthorn, knotweed, smartweed, mallow, marsh elder, nightshade, poison ivy/oak/sumac, and grasses. The dietary importance of these resources is hard to gauge, but their limited recovery suggests limited importance. One kind of resource that was not recovered is tropical cultigens such as maize and squash. Given the generally good preservation of organic materials, the absence of these kinds of resources provides convincing evidence that the people who lived at 41MM341 were not farmers or horticulturalists.

Terrestrial species dominate the vertebrate recovery in all analysis units with deer, deersized artiodactyls, and large mammals most common. In addition, turtles and small and medium-sized mammals such as rabbit, opossum, squirrel, and raccoon are variously represented, while fish, birds, and snakes are present in low numbers for all analysis units. Small to medium-sized animals appear to have been especially important in the early part of the occupation, as Analysis Unit 3 produced more of these animals in relation to deer/large mammals than the other units. This may signal a change toward greater emphasis on hunting deer late in the site occupation, though the difference probably was one of degree rather than kind.

Similar variability in usage can be seen in the invertebrate recovery. The main invertebrates utilized were the freshwater mussels Amblema plicata and Quadrula houstonensis and the land gastropod Rabdotus dealbatus dealbatus. Mussel consumption apparently decreased through time while consumption of Rabdotus increased, judging from changes in the abundance of mussel and snail shells relative to animal bones. Rabdotus is a snail associated with open grassy areas, and, as with the bulbs discussed above, its increased use at a time when the area was becoming more wooded suggests targeted procurement of this resource offsite and then transport back to 41MM341. This conclusion is supported by the snail's occurrence in features in adult form only and its near-absence from the analyzed column samples collected outside the main activity areas (see discussion of shell features in Chapter 6).

This overview suggests that certain resources were used more or less intensively during the many occupations of 41MM341 but that 
always a variety of resources from different environmental zones were exploited. The variety of resources used reflects a broad-based subsistence orientation, though with an emphasis on the hunting of deer. The persistence of this orientation throughout the occupation span is an indication that it was a successful means of adapting to the particular environmental circumstances found on the Little River floodplain.

A broad-based subsistence orientation can be interpreted as a response to dietary stress brought about by a lack of large concentrations of high-quality protein, such as that offered by bison herds or seasonal fish runs. Tomka and Mauldin (2003b:112-113) suggest that such stress may be represented in Analytical Unit 6 at $41 \mathrm{MM} 340$ by the apparent reliance on riverine resources (mussels and turtles) to supplement scarce bison. Such an interpretation is based on the assumption that more small packages of low-quality protein were needed to compensate for the lack of large-bodied animals. They further suggest that bone reduction patterns based on fragment weight and size between analytical units support this interpretation of dietary stress (Tomka and Mauldin 2003b:116-117), with highly fragmentary bones reflecting processing of the faunal resources to extract all available protein in the form of marrow or grease.

Such assumptions concerning dietary stress do not explain the subsistence data from 41MM341, however. For example, it could be postulated that the data from Analysis Unit 3 indicate dietary stress given that the frequency of deer/large mammals is low relative to small/ medium mammals, turtles, fish, and birds. This stress could have resulted partly from environmental conditions, as Analysis Unit 3 represents occupations that occurred during a period when the floodplain was relatively open and possibly not the best habitat for deer. However, other characteristics of the assemblage do not support this scenario.

For example, the percentage of intact bone is relatively high for Analysis Unit 3, and spirally fractured bone, a fracture type that can be associated with marrow extraction, is comparatively low. In general, highly reduced bone fragments that may be considered evidence of grease production were not observed by the faunal analyst for any of the analysis unit samples (see Appendix E). In fact, the analyst was impressed by the preservation of bones retaining grease at 41MM341. Also, if dietary stress was a factor during the occupations represented by Analysis Unit 3, then one would expect to see intensive use of small packages of readily available protein such as that provided by land gastropods, especially given that environmental conditions at that time favored the most-exploited snail, Rabdotus. But as noted above, Rabdotus snails apparently were utilized less during the Analysis Unit 3 occupations than they were later.

An understanding of how the occupations of 41MM341 were tied to the seasons of the year contributes to placement of the site in a wider settlement and subsistence system. Season-ofuse indicators include environmental characteristics of the site and certain floral and faunal species recovered. The main relevant environmental characteristic is the site's floodplain location. Historical statistics indicate that the Little River is prone to flooding in April and May and that those flood episodes are driven by rainfall (Mauldin and Mahoney 2003:6-12). These statistics may or may not be applicable to the earliest occupations of 41MM341 when climatic conditions may have differed from those of the present day, but they likely are relevant for the predominant occupations represented by Analysis Units 1 and 2. In general, it seems likely that the site would have been used mostly when the threat of flooding was low. About $0.7 \mathrm{~km}$ of floodplain separates the site from higher ground to the northwest, and this potential escape route is transected by one large slough that would have served as a flood chute during times of high water, as well as the smaller slough adjacent to the site. Reaching safety by going the other direction from the site would have been precluded by the river channel. Occupation mostly during seasons of low water also is suggested by the abundance of mussel shells and lithic materials obtained from the riverbed, since highwater conditions would have prevented collection of these resources.

Warm-season occupation is supported by the ubiquity of turtles in all analysis units and the high number of snakes in Analysis Unit 2, as these reptiles are most active during warmer periods. Also, the presence of seeds or fruits in all analysis units supports warm-season occupations, as does the presence of bulbs, which flower in the spring (Tull 1999:116) and would 
have been distinguishable then and in the summer from other grass-like forbs. As noted above, the scarceness of hardwood nuts also is consistent with warm-season occupations, although the fact that nuts can be stored easily means they may not be good indicators of seasonality. Regardless, the combined evidence points to occupation of $41 \mathrm{MM} 341$ during the summer months.

Utilization of the resource base provided by the Little River, the floodplain forests and grassy patches along the river, and the adjacent uplands did not change much during the occupation of 41MM341. This utilization represented a broad-based, probably seasonally differentiated subsistence strategy. Fitting this part of the puzzle into the larger picture of regional settlement and subsistence patterns is hampered by the scarceness of comparative data from excavated sites. One site that is relevant for comparative purposes is 41WM130 (hereafter referred to as Hoxie Bridge), based on its period of occupation (apparently ca. A.D. 2001200 judging from the diagnostic artifacts and three radiocarbon dates), the artifact assemblage (which includes Darl, Scallorn, and Alba points and Gahagan knives), the presence of large baking pit features, and its location within the Little River drainage just $40 \mathrm{~km}$ westsouthwest of 41MM341 (Bond 1978). This site was situated in Williamson County on a levee remnant along the San Gabriel River and is now inundated by Granger Lake. Another site useful for comparisons is the nearby Late Archaic site 41MM340. Because it contained older occupational remains, 41MM340 provides data from which to judge how subsistence patterns may have changed through time.

Though differences in preservation and recovery techniques affect these comparisons to some degree, macrobotanical evidence suggests that 41MM341, the Hoxie Bridge site, and 41MM340 are similar in terms of limited hardwood nut utilization. Recovered botanical remains from Hoxie Bridge are extremely sparse with only 26 charred fragments related to the prehistoric occupations (this could be due partly to the fact that limited flotation sampling was done, although some of the excavated sediments were water screened through fine-screen mesh and processed by flotation). Of these 26 fragments, 16 were identified as hickory nut, 1 as pecan, 4 as oak (presumably acorn), 1 as a grass seed, and 1 as possible Cucurbita (plant part unspecified) (Bond 1978:216-220). This nut recovery is even more meager than that from 41MM341, and like 41MM341 it did not produce pitted stones that could have been used in nut processing. In contrast, $41 \mathrm{MM} 340$ did yield two grinding stones, but no nutting stones (Mahoney et al. 2003:52), and a quantity of mostly hickory nut fragments $(\mathrm{n}=175,11.3 \mathrm{~g}$ ) that is comparable to that from 41MM341 (Dering 2003:225230). Apparently, nut processing was not a central subsistence activity at any of these sites.

No bulbs were identified within the limited botanical sample from Hoxie Bridge. Still, 45 large "fire pits" or baking pits similar to the large processing pits at 41MM341 were discovered at Hoxie Bridge indicating that food processing took place (Bond 1978:124-127). Though what was processed in the pits at Hoxie Bridge cannot be known, the apparent similarity in cooking technology between it and 41MM341 suggests similarities in the kinds of subsistence resources used, and this may have included bulbs. At 41MM340, burned rock concentrations and charcoal/burned clay features were identified, but no large processing pits were found (Mauldin and Tomka 2003:120-126). Whether this points to a difference in subsistence activities or is a function of something else, such as sampling, is unknown. However, a recent survey of known Texas sites both east and west of the Balconies Escarpment identified 7 sites with wild onion or false garlic remains and a total of 15 sites with some kind of charred geophyte, that is, bulbs, corms, tubers, rhizomes, or root fragments (Mehalchick et al. 2004:179-186). Most of these geophytes were associated with burned rock middens or baking pit features. Although radiocarbon dates from these sites suggest that geophyte utilization had a long temporal span, most dates demonstrate usage in the Late Archaic and Late Prehistoric periods. Clearly, food processing involving the use of bulbs as it occurred in association with processing pits at 41MM341 is related to a long-held practice for prehistoric groups in the region.

Based on the recovery from 41MM341, Hoxie Bridge, and 41MM340, invertebrates (whether freshwater mussels or land gastropods) were an important subsistence resource and remained consistently so from the Late Archaic into the Late Prehistoric. However, invertebrates appear to have been variously used, 
possibly depending on availability. For example, few freshwater mussel shells were recovered from the Hoxie Bridge site, though 7,199 Rabdotus shells were found. Most of these shells came from a horizontally extensive, $10-25-\mathrm{cm}$ thick midden zone (Bond 1978:208-216). The Rabdotus shells recovered from 41MM341 came from similar midden deposits that also contained many mussel shells. Site 41MM340 produced $262 \mathrm{~kg}$ of mussel shells and 5,145 Rabdotus shells. Thirty-four percent of the mussel shells and 73 percent of the Rabdotus shells came from Zone 8, the oldest dated zone at 14001260 B.C. (Tomka and Mauldin 2003a:96-102).

Substantial vertebrate faunal remains were recovered from all three sites: 41MM340 produced 10,844 bone fragments; Hoxie Bridge yielded 3,648 bone fragments, not including 482 armadillo bones and 30 unaccounted-for bones; and 41MM341 yielded 6,561 fragments. Because of apparent differences in preservation and fragmentation of the vertebrate samples, unidentified fragments were removed for intersite comparisons. Table 9-2 suggests that the consumption of large terrestrial mammals was a primary subsistence activity at all three sites, with deer and deer-sized mammals making up 50 percent or more of each sample. However, hunting of large mammals may have been relatively important during the occupations of Hoxie Bridge and 41MM340, as these sites have almost the same percentage (ca. 74 percent) of large animal bones when the categories of deer/ large mammal and bison/very large mammals are combined. The figure for $41 \mathrm{MM} 341$ is only 52 percent. Of the three sites, $41 \mathrm{MM} 341$ seems more tied to riverine resources, with 30 percent of the identified specimens being turtle, fish, and snake. Site 41MM340 is unusual for its high number of birds. One can wonder whether the percentage of birds in the sample from 41MM340, which is greater than that of small to medium-sized mammals, may reflect needs other than subsistence, such as production of crafts using feathers.

Subsistence data from 41MM341 suggest that certain resources were used more or less intensively during the various occupations of the site, but always a variety of resources from all nearby environmental zones were exploited. This broad-based subsistence orientation, though still with an emphasis on deer, endured throughout the history of occupation of the site. The evidence points to mostly warm-season occupations, possibly summer. This means, of course, that the people who created the site lived somewhere else for most of the year, but there is not enough comparative data to reconstruct the whole settlement and subsistence system. Data from the contemporaneous Hoxie Bridge site do indicate a somewhat different hunting orientation geared especially strongly toward large terrestrial mammals, though, and this may be a start toward such a reconstruction.

\section{ASSEMBLAGE ORGANIZATION}

Most of the artifacts recovered from 41MM341 are either chipped stone tools or the byproducts of stone tool manufacture. The assemblage is large, consisting of 313 formal tools, 494 expedient tools, 168 cores, and 39,872 pieces

Table 9-2. Identifiable vertebrate faunal remains from 41MM341, 41WM130, and $41 \mathrm{MM} 440$

\begin{tabular}{l|r|r|r|r|r|r}
\hline \multirow{2}{*}{ Faunal Group } & \multicolumn{2}{|c|}{$41 \mathrm{MM} 341$} & \multicolumn{2}{|c|}{$41 \mathrm{WM} 130$} & \multicolumn{2}{|c}{$41 \mathrm{MM} 340$} \\
\cline { 2 - 7 } Fish & No. & $\%$ & No. & $\%$ & No. & $\%$ \\
Frogs & 25 & 0.8 & 11 & 0.6 & 3 & $<0.1$ \\
Turtles & 1 & $<0.1$ & 2 & $<0.1$ & 0 & 0 \\
Birds & 854 & 26 & 33 & 1 & 180 & 4.4 \\
Snakes & 39 & 1.2 & 0 & 0 & 516 & 12.7 \\
Deer/large mammals & 54 & 1.6 & 53 & 1.7 & 4 & $<0.1$ \\
Bison/very large mammals & 1,691 & 52 & 2,246 & 74 & 2,705 & 66.2 \\
Micro/small/medium mammals & 607 & 18.5 & 640 & 21.2 & 343 & 8.4 \\
\hline Total & 3,271 & & 3,015 & & 4,071 & \\
\hline
\end{tabular}


of unmodified debitage. A unique aspect of this site is that concentrations of debitage appeared to have resulted from generally discrete sets of episodes of lithic tool manufacture and that materials associated with these lithic reduction debris piles could be linked to the tools recovered from the site. Given this, questions posed in the research design were directed toward defining the kinds of stone tool manufacture that occurred and explicating tool production strategies. Tool function was questioned as was how tools or groups of tools related to the extraction of resources. Answering questions of tool function and associated activities relates to the organization of the groups who utilized 41MM341. Specifically, was their organization based on immediate-return or delayed-return strategies or both?

That chipped stone tool manufacture was an important activity during all occupations of $41 \mathrm{MM} 341$ is evident. Chert cobbles were collected from gravel bars in the Little River and maybe from the Pleistocene terraces that flank the valley, brought back to the site, and reduced to create both formal and expedient tools. Most of the lithic reduction debris piles reflect a thorough mix of core reduction to produce usable flake tools or flake blanks, bifacial reduction, and bifacial-thinning reduction strategies. Only one of the debris piles shows a slant toward one strategy or another, with core reduction being especially well represented. Bifacial-resharpening flakes, likely associated with tool refurbishment, have a consistent but low presence. Other flake types associated with blade production, uniface manufacture/repair, and notching are extremely limited.

Many flakes removed from cores were used as expedient tools quite close to where they were struck. Expedient tools overwhelmingly were used for scraping, a fact that fits well with the lack of formal scraping tools. Arrow points, knives, and their preforms were the primary bifacial tools made on-site. Complete finished arrow points and knives, fragments of finished tools, and complete and fragmentary preforms were recovered from the lithic reduction piles, and often these could be related to specific identified cobbles. Break types and tool distributions indicate that arrow points and knives were fractured as a result of both manufacture and use, and some complete knives appear to have been discarded because they could no longer be resharpened without threat of breakage.

The arrow points and knives demonstrate the emphasis placed on the manufacture of hunting-related tools, which is not surprising given the high percentage of deer and large mammals in the faunal assemblage. These tools were part of a hunting and butchering tool kit that was associated mainly with the later occupations of the site. Formal scrapers to process hides are missing from this tool kit, but as noted above expedient flake tools probably were used for this task. Other activities that seem to have been important are wood working and bone tool manufacture. The consistent occurrence of adzes, wedges, gouges, gravers, perforators, and choppers suggests that they were important to the daily activities at the site, such as fashioning the wood or bone parts of hunting tools, including arrow or dart shafts, knife hafts, and bows. The bone tool fragments, bone tool manufacturing debris, and small sandstone abraders reflect multiple activities, with the antler tips and worked deer ulnas probably related to lithic tool manufacture and the needle and awl fragments related to manipulation of hides for clothing or other uses.

The tool assemblage from 41MM341 indicates that both immediate-return and delayedreturn strategies were employed by the groups who occupied 41MM341. The former is shown best by the high frequency of expedient tools found in the lithic reduction debris piles. As noted above, many flakes were struck from cores and used on the spot to meet immediate needs. The high overall ratio of expedient to formal chipped stone tools (1.5 to 1 ) reflects this, and the fact that the ratios for the three analysis units (1.7, 1.3, and 1.6 for Analysis Units 1, 2, and 3 , respectively) do not vary much suggests little diachronic change in this aspect of group organization. At the same time, however, delayed-return strategies seem to be represented by the manufacture of certain kinds of formal tools for the creation of a specific hunting and butchering tool kit and probably for trade. Demonstrating that some tools were traded away is difficult, but as noted later in this chapter, the Native Americans who lived in the Little River valley at this time were engaged in vigorous interregional interaction that involved movement of Alba arrow points and Gahagan bifaces eastward to the Caddoan area. These specific 
tool types were made at 41MM341 using local gravels, and while it is clear that many arrow points and bifaces were used and discarded there (based on evidence of reworking and break causes), there is no reason to think that others were not traded away. In fact, manufacture breaks are almost two-and-a-half times more frequent than use breaks in the total formal tool assemblage (134 vs. 57 ), and this is consistent with the idea of tool manufacture as a part of gearing-up activities in anticipation of future needs.

Comparative data for addressing this issue on an intersite basis are hard to come by. As noted above, comparison of the faunal materials from 41MM341, Hoxie Bridge, and 41MM340 indicates that, though 41MM341 and Hoxie Bridge were occupied during the same time period and produced similar tools and features, the latter is more similar to Late Archaic site $41 \mathrm{MM} 340$ in terms of an emphasis on the hunting of large game. These two sites also are more similar in their ratios of expedient to formal tools ( 0.7 to 1 for Hoxie Bridge, and 0.8 to 1 for 41MM340), which are low compared to that for 41MM341. This difference could be used to suggest that the occupations that created these sites were organized around a delayed-return strategy possibly directed toward large game hunting. From this perspective, Hoxie Bridge and 41MM341 would look like sites used for different purposes, and maybe at different times of the year, within a single system. They are obviously just miniscule parts of this system, though.

The hints in the tool assemblage that both immediate- and delayed-return strategies were used are not a surprise. Mixed strategies likely were the rule rather than the exception among mid-latitude hunter-gatherers. What is difficult is taking this small bit of interpretation and expanding on it (using all available evidence, not just lithic tools) to take an in-depth look at the organizational responses of the Native Americans who created 41MM341. Site 41MM341 looks very much like a generalpurpose campsite that was occupied by complete social groups long enough each time for a range of procurement, processing, and manufacturing activities to be performed and represented in the archeological record. As discussed above, this may have occurred most often in the summer months, and we can only speculate about what the sites might look like that were occupied at other times of the year. Without good, extensive comparative data, we are not able to go beyond speculation, nor does it make much sense to try to figure out the many ways in which the occupants of 41MM341 employed immediate- vs. delayed-return strategies and what this might indicate about collector- vs. forager-oriented systems. The lithic tools recovered provide some clues, but not answers.

\section{INTRASITE PATTERNING}

Questions posed in the research design relating to this topic were directed at the functions of different feature types and how the distributions of features and artifacts across the site could be used to define activity areas. Consistency or change in site function through time could then be discerned by comparing patterning between analysis units.

Seven feature types were defined at 41MM341, while the lithic reduction debris piles could be considered an eighth type. These seven feature types consist of surface hearths, pit hearths, processing pits, shell lenses, burned rock concentrations, possible postholes, and indeterminate features. The surface hearths, pit hearths, and processing pits appear to be related to food processing, and analysis of the botanical and faunal remains within them as well as fatty acid residues on burned rocks and burned clay nodules suggest that similar kinds of animal and plant resources were cooked in them. Hence, there is little to distinguish them functionally based on their organic contents. The shell lenses, burned rock concentrations, and lithic reduction debris piles, all of which overlap or occur adjacent to surface hearths, are different from the cooking features in that they are components of primary refuse scatters. Possible postholes and indeterminate features may be noncultural in origin and thus are of little interpretive value.

Grouping the features as either cooking related or primary refuse suggests a simple camp structure where a variety of debrisproducing activities were performed around and adjacent to the cooking features. There appears to have been continuity in this through time. For instance, surface hearths and shell lenses occur in all three analysis units with surface hearths most prevalent in Analysis Unit 2. Burned rock concentrations are also common in Analysis Unit 2, and they most likely resulted 
from the burning that occurred within the surface hearths. Pit hearths occur in Analysis Unit 3 and again in Analysis Unit 1. Those in Analysis Unit 1 may be smaller versions of the processing pits. The earlier pit hearths in Analysis Unit 3 may be more similar to surface hearths. The large processing pits are associated mostly or entirely with Analysis Unit 1. The processing pits were clustered in the South Block ca. $10 \mathrm{~m}$ from the activity areas identified in the Main Block. The presence of these large processing pit features suggests a change in cooking technology, or perhaps just intensity, late in the occupation of the site, possibly in connection with more-frequent reoccupation and increased overall intensity of use.

Patterning in the distributions of features, debris, tools, and other materials is clearest in Levels 6 and 8 in the Main Block. Patterns are obscured in Level 7 because of severe overprinting, and it is clear that the abundant materials in this level relate to activity areas that lie mostly to the west outside the Main Block. Patterns are hard to define in Level 9 because of few materials and features. In Level 8 of Analysis Unit 2, the configuration of five surface hearths forming an arc around a relatively empty space suggests a consistency of hearth placement that is suggestive of a single occupation or of multiple occupations happening in a short span of time. This arrangement is what would be expected if hearths were situated relative to a fixed feature such as a shade tree or around an open communal space, but the contemporaneity (or near contemporaneity) of the hearth features that would be required to determine this with certainty cannot be established. The concentrations of debitage, mussel shells, snail shells, animal bones, burned rocks, and burned clay surrounding these features vary enough to suggest some differences in the particular activities associated with particular hearths. Yet, overall the material distributions indicate that both workshop and living-related activities occurred together around the hearths. A similar conclusion can be drawn from the distributions in Level 6 of Analysis Unit 1, though the pattern appears less complete. Here, three hearths were defined, with two on the edges of the excavations suggesting that substantial parts of the activity loci extend to the north and west of the Main Block. Still, one hearth (Feature 11) occurs in the center of the block with a lithic reduction debris pile, mussel shells, snail shells, and animal bones concentrated around and overlapping the hearth.

For both Levels 6 and 8, tool distributions coincide with the main parts of the debris scatters indicating that most activities associated with tools were performed close to the hearths. Expedient tools are especially abundant in the main parts of the debris scatters, apparently as a result of the use and immediate discard of flakes selected from the lithic reduction debris piles. Most of the formal tools also occur with the debris scatters, but unlike the expedient tools they are not as often associated with the most-concentrated parts of the scatters. There is little evidence for different distributions of specific formal tool types, however, arrow points and knives and their preforms, like the expedient tools, are relatively concentrated in the hearts of the debris scatters, likely because they were discarded on the spot if broken during manufacture.

Thus, the archeological remains at 41M341 can be interpreted as a series of similarly structured workshop-habitation areas (Stevenson 1985:63) that were created over a ca. 700-year period. The kinds of activities associated with the workshop aspect of the pattern include the manufacture of mainly arrow points and knives, expedient tool manufacture, and the manufacture of wood and bone tools. Activities related more to habitation include expedient tool use, bone marrow extraction and consumption, the processing and consumption of vertebrate and invertebrate faunal resources, and the processing and consumption of botanical resources. There is little evidence in the materials themselves, their distributions, or measures of diversity calculated from them that the ranges of activities associated with this pattern changed over time (although small sample sizes hamper interpretation of Analysis Unit 3), and thus how the site functioned in regional settlement systems appears to have remained stable. The one change that can be documented is increased intensity of use in the later occupations. This appears to reflect more-frequent reoccupation rather than a change in site function, use by larger groups, or occupations of longer duration. Whether this increase in frequency of reoccupation reflects increasingly successful exploitation of the site environs because of changing environmental conditions as suggested 
earlier in this chapter, increasing population densities, or something else entirely (fortuitous reuse of this one spot on the landscape?) is hard to gauge. As for the other problem domains, comparative data from other sites are needed to determine this, and data on intrasite patterning are particularly lacking. Excavated sites like 41MM341 with preserved information of this kind are rare, and excavated ones that have this kind of information and that are relevant temporally and geographically (i.e., parts of the same settlement system as 41MM341) are nonexistent.

\section{INTERREGIONAL INTERACTION}

The questions posed in the research design under this topic relate mostly to lithic tool production and use and were prompted by one simple observation: 41MM341 yielded arrow points and bifaces that are essentially identical in workmanship and raw materials to artifacts that have been found in mortuary and nonburial contexts at the Caddo ceremonial center at the George C. Davis site in Cherokee County some $200 \mathrm{~km}$ to the northeast. Of course, this is not the only site in the middle Brazos River drainage that suggests interaction with the Caddo. The presence of Alba points and Caddo pottery at sites such as Chupik and Asa Warner (Turner 1997; Watt 1941, 1956) in the Waco area spurred Dee Ann Story (1990:364) to suggest that the archeology of the middle Brazos region exhibits a cultural complexity that cannot be explained by the Austin and Toyah phase constructs used for central Texas. She proposed that these remains could represent east Texas groups occupying the area year-round or seasonally or local groups interacting with east Texas Caddo groups through trade, marriage, or visitation.

Trade as a mechanism for this interregional interaction has received support recently from geochemical analyses of probable Caddo vessel ceramics recovered from 25 central Texas sites, including Chupik and Asa Warner, which have shown that these sherds were made from east Texas clays (Perttula et al. 2003:63). Trade was considered the likely mechanism as opposed to Caddoan groups settling in the area, since the latter should produce Caddo-style vessels made of local central Texas clays. Based on ceramic vessel styles and what is known of the ages of the sites from which the sherds came, Perttula et al. (2003:60) suggest that this trade occurred over a long period of time through the Late Prehistoric period and into the Historic period.

That Caddo ceramics were involved in a long history of interregional interaction is supported by early historic accounts of eastern groups such as the Hasinai Caddo coming west to the Balcones Escarpment to hunt bison (see Collins and Ricklis [1994:16-26] for a synopsis and discussion of historic accounts of native interaction). These same accounts also suggest that large congregations of different groups occurred at certain habitation sites along the escarpment. These historic congregations can be attributed to group displacement and the need for mutual defense, but Collins and Ricklis (1994:25) point out that these congregations were not uncommon and were readily established, suggesting a tradition of aggregation that had been in place prehistorically. Surely, such congregations of peoples presented opportunities for trade, and sites such as Chupik, which produced rare items like marine shell beads and a pendant in addition to numerous ceramics (Perttula et al. 2003:13), and Asa Warner, with its large collection of Caddo sherds, might have been places where such trade congregations occurred.

Coming from a different perspective on the movement of peoples and goods, Harry Shafer (2004) has proposed that groups who used such sites as Chupik and Asa Warner during the period from A.D. 1000 to 1300 were Caddo people who were local to the area and who served as the sustaining population for the ceremonial center at the George C. Davis site. ${ }^{1}$ This "Prairie Caddo" model is based, in part, on the apparently limited evidence of habitation sites

\footnotetext{
${ }^{1}$ Shafer presented an early version of this hypothesis in a paper delivered at the 2003 meetings of the Texas Archeological Society. Subsequently, TxDOT provided funding and substantive support for Shafer to flesh out his ideas in the form of a research module that could be posted online and serve as an impetus for further discussion. Preparation of this module was ongoing throughout the latter part of the 41MM341 analysis. Although there was communication between Shafer and Prewitt and Associates staff about the module and our interpretations of 41MM341, the two efforts were not truly integrated. Shafer's research module stands on its own, as does our assessment of its utility for helping interpret sites such as 41MM341.
} 
of the right age near the Davis site and the prevalence of an artifact assemblage that is seen as the material correlate for a Prairie Caddo social identity. This assemblage includes Caddo vessel ceramics similar to those found at the Davis site, Alba-Bonham arrow points, Gahagan knives, and bone needles and metapodial beamers representing the manufacture of fine deer-hide clothes. Items within this assemblage (except beamers) occur at the Davis site both in burial and nonburial contexts (Shafer 1973; Story 1972), and Shafer (2004) demonstrates that these items are common at sites along and just east of the Balcones Escarpment, although they do not always (or maybe even often) occur together.

Of these, Alba-Bonham points (Shafer's Bonham category would include the Perdiz points described in Chapter 7), Gahagan knives, and bone needles were found at 41MM341, while metapodial beamers were not. Only 4 small ceramic vessel sherds were recovered. None can be identified as representing Caddo ceramics, and in fact 1 sandy paste specimen is surely not from a Caddo vessel. Further, their associations are unclear. They could go with the sparse cultural materials in the uppermost deposits of the site that were stripped off before the block excavations began (13 sherds found in these upper deposits in testing were thought to relate to a Toyah phase occupation), or they could go with the occupations represented by Analysis Units 1 and 2. Even if the latter is true, though, it is clear that ceramic vessels played virtually no role in activities performed at the site.

How does this conclusion square with Shafer's hypothesis that 41MM341 and sites like it were occupied by Caddo Indians? Advocates of the applicability of the Prairie Caddo model probably would present two arguments to explain the absence (or near-absence) of pottery. First, maybe it is simply a function of sampling error. Maybe ceramic vessels were used more than the recovered remains indicate, but in different parts of the site not sampled during the data recovery excavations. And second, maybe it is due to site function, with ceramic vessels used less at floodplain sites such as 41MM341 than at more-substantially used base camps situated higher on the landscape. Neither explanation can be disproven, but there are effective counter-arguments.

Specifically, given the large size of the exca- vations $\left(219 \mathrm{~m}^{2}\right)$, sampling error seems to be a stretch. It is true that some unknown portion of the site outside the current project area remains unsampled, but to expect that ceramic sherds could have been deposited only in unsampled areas is unrealistic given the extent of the excavations and how many times the site must have been occupied over the ca. 400 years that Analysis Units 1 and 2 represent. The problem with the site function explanation is that 41MM341 does not look like a special-purpose or limited-function site. It is true that it is in a setting that would not have been conducive to year-round or multi-seasonal occupation, but the features and cultural materials found indicate a wide variety of activities associated with procurement, processing, maintenance, and gearing-up tasks. The site appears to have functioned as a general-purpose campsite where Native Americans brought subsistence resources and raw lithic materials collected nearby and from more-distant locations. Mussels and lithic cobbles came from the river, which was at or near its current position no closer than $0.4 \mathrm{~km}$ from the site, and some of the hardwood nuts and other subsistence resources probably came from upland areas farther away. The Native Americans processed these resources in various ways and consumed them, and then prepared for their next move in the seasonal round. If ceramic vessels were part of the material culture of these people, why would they not have needed them to perform some of these tasks? In this case, parsimony leads to the conclusion that pottery was not part of the material culture, removing one of the linchpins of the artifact assemblage that supposedly serves as the material correlate for a Prairie Caddo social identity.

It is hard to say much about the presence of bone pins and absence of metapodial beamers at 41MM341. Because they are perishable materials, they are apt to be the most-variably represented members of the proposed Prairie Caddo artifact assemblage and thus perhaps a relatively weak part of the argument. In contrast, Shafer's use of technological style to relate Alba-Bonham arrow points and Gahagan bifaces from sites in the middle Brazos drainage to those at the George C. Davis site is compelling. The importance of these items in the material culture of the people who created the Davis site is indisputable. In Mound C, clusters of Alba points, as if in quivers, were recovered 
from two elite burials associated with the third and fourth mound-building stages dating ca. A.D. 1100-1260 (Story 1972:13, 44-50). A cluster of Alba points, as if in a basket, and Gahagan knives were recovered from offerings set with a burial in the first stage of mound construction dated to ca. A.D. 860-1020 (Story 1972:13, 1522). Radiocarbon dates place these burials firmly within the same time frame as the occupations represented by Analysis Units 1 and 2 at 41MM341. The variety of stem and blade forms of the Alba points in those discrete contexts as grave offerings at the Davis site suggests that they may represent collections of arrows from multiple knappers, while the cherts from which they were made are nonlocal and probably mostly from central Texas (Shafer 1973:199209). Several of the Alba points found within those Mound $\mathrm{C}$ quivers are very close in style and workmanship to the Alba points recovered from 41MM341.

These similarities may not mean that points and knives that ended up as grave goods in burials of the Caddo elite at the Davis site actually were made at 41MM341. But there is no doubt that they were made in that vicinity, and probably by people who occupied 41MM341 at one time or another or by related groups. The people who lived at 41MM341 and westward to the Balcones Escarpment and probably eastward to the Brazos River (an east-west span of about 90 $\mathrm{km}$ ) had access to good raw materials, and they had the skills to produce finely crafted arrow points and knives. Many such tools were manufactured at 41MM341, and evidence of reworking and breakage patterns show that many were used and discarded there. As noted above, though, the high frequency of manufacture breaks relative to use breaks hints at the importance of gearing-up activities. Whether these activities were in response to anticipated hunting and butchering needs after seasonal abandonment of 41MM341, or in anticipation of having goods for future interactions with people who lived in east Texas, is not known. What does seem certain, though, is that somewhere people involved in the same cultural system that resulted in 41MM341 decided it was advantageous, or maybe unavoidably necessary, to manufacture lithic tools for transport to the Davis site.

The Prairie Caddo model would posit that this decision was made by Caddo people who needed something of value to offer, perhaps as tribute or in trade, when they traveled across the Brazos, Trinity, and Neches Rivers for feasting and other communal activities at the Davis site. As noted above, the lack of ceramics at 41MM341 and other characteristics of the site argue for a simpler explanation. Instead, based on the information from 41MM341 and the Hoxie Bridge site at Granger Lake (which, like 41MM341, yielded Darl, Scallorn, Alba, and a few Perdiz arrow points along with Gahagan bifaces and a small number of sherds, most of which appear not to represent Caddo vessels), it appears that the Little River valley and those of its tributaries were used in a consistent fashion from at least A.D. 600 to 1300 , with consistency farther back into Late Archaic times suggested by 41MM340. During the early part of this interval, these people used both Darl dart points and Scallorn arrow points. This was succeeded by a period where Scallorn points were the chief hunting implement. Alba arrow points were added to the repertoire, perhaps around A.D. 1100 , and may have been used along with Scallorn points for a time. Perdiz points (or Shafer's Bonham points) were added toward the end of the interval, by which time the Scallorn form probably had dropped out of favor. All three arrow point forms are similar technologically in terms of their blade treatments, and it appears that this whole sequence was part of a single tradition created by a single cultural group, or maybe a small number of related groups.

Coupled with the consistency in site use over time, this looks very much like a local development among hunter-gatherers who were welladapted to the Blackland Prairie and the ecotonal areas at its east and west margins. Among the resources that these people knew how to exploit were the local chert gravels. By A.D. 1100 or a century or two earlier, they were using these gravels to make not only tools for their own use but also as goods to be used during interactions with the Caddo. This production involved particular tools following specific technological styles, but the evidence for interaction involving lithics not manufactured to such specifications (and not focused so strongly on a single east Texas site) goes much farther back in time, suggesting that this pattern of connections between the eastern margin of central Texas and the eastern part of the state was a 
persistent one rooted in long-held traditions. This has been documented, for example, at the Jewett Mine in Freestone and Leon Counties, where a number of caches of bifacial and unifacial tool blanks of central Texas materials have been found, and where large quantities of debitage reflecting the staged reduction of central Texas cherts (including some identical to those found at 41MM341) have been identified in sites of various ages, including some dating to Late Archaic and even earlier times (Fields 1995:325). As noted above, ethnohistoric accounts indicate that substantial interaction between the two regions continued up to historic times, primarily in the form of Caddo groups traveling westward to hunt and trade. The reasons for this interaction may have changed over time, but the persistence of the pattern did not.

Contrary to what the Prairie Caddo model proposes, we think that the people who lived along the Little River in early to middle Late Prehistoric times were not ethnically Caddo peoples who provided support for the ceremonial center at the Davis site. Rather, we think they were a local group well adapted to their particular environs who interacted regularly with the east Texas Caddo, probably in simple face-to-face or maybe down-the-line trade relationships with limited dependencies and great group autonomy. The Prairie Caddo module implies the kinds of interaction that would create dependencies and reduce autonomy, with the social elite some $200 \mathrm{~km}$ away from 41MM341 attempting to exercise control over resources and possibly the organization of production associated with those resources. We see no evidence of this at $41 \mathrm{MM} 341$, although we acknowledge that the paucity of local comparative data makes it hard to tell for the region at large.

Michael Nassaney (1996:188-228) has explored similar questions in relation to stone tool production associated with the Toltec Mounds and the Plum Bayou culture (ca. A.D. 700-950) of central Arkansas. His investigations suggest that maintaining free access to particular resources and resisting specialization within the production process are means for minimizing dependencies. It can be argued that both of these pertain to 41MM341 and the surrounding area. Certainly, the sources of the lithic raw materials from which tools were made were widespread, occurring from the Balcones Escarpment east probably all the way to the Brazos River. Their locations within this broad area were generally predictable, but they changed as gravel bars moved and new stream channels were cut. These characteristics suggest that groups local to this part of the Blackland Prairie would have had constantly shifting knowledge about where lithic raw materials could have been procured, ensuring that they had access to them while discouraging any attempts by others to control access. Evidence from 41MM341 also indicates that the chipped stone tool production process was not specialized by segmentation (i.e., one specialist manufacturing preforms and another finishing the tools). The people who occupied 41MM341 made Alba points and Gahagan knives (i.e., the tools that were in demand by east Texas elites), but these tools were finished and used onsite. Manufacture and use of finished tools near the local lithic source suggests that the tools that were carried away from 41MM341 were likely finished as well and could have been used for hunting at a future time or as an asset for trade.

What did the groups occupying 41MM341 get in return for their well-made arrows and knives? This question is difficult to answer given that much of what could have been received, such as bear fat, salt, or bow wood, is perishable. One benefit of trade for the occupants of 41MM341, though, could have been the establishment and maintenance of cooperative alliances. Such alliances could have helped regulate competition among groups, and alliances often have been seen to coincide with evidence of violent death (Sassaman 1995:187). At the LoeveFox site about $45 \mathrm{~km}$ west-southwest of $41 \mathrm{MM} 341$, Scallorn points were found in the backs of several of the people buried in the Austin phase cemetery (Prewitt 1982:36, 42-43). These apparent violent deaths indicate that conflict and aggression were present within the 41MM341 region. Alliances aimed, in part, at modulating conflict in the middle Brazos drainage could, in fact, be reflected in the Alba arrow points in the elite burials at the Davis site. The arrows in these contexts appear to be from many different makers, and this, along with the fact that they were bundled together in quivers when they were included as grave offerings, may identify these elite individuals as the architects of alliances that extended far west of the Davis site. Such alliances could have been the organi- 
zational foundation that eventually enabled large congregations of people to come together for trade and other resource procurement activities such as bison hunting east of the Balcones Escarpment.

Dee Ann Story's (1990) suggestion that the presence of east Texas artifacts in central Texas sites points to something that cannot be explained by the Austin-Toyah phase sequence that characterizes the traditional view of the culture history of central Texas is on target. Harry Shafer proposes one model for understanding this complexity, and we advocate another. The former benefits from the fact that it is broad brushed and geographically expansive, and because it draws on data from many sites that are poorly known. It suffers for the same reasons. Because it is broad brushed, it uses limited data selectively. Because many of the sites are poorly known, many specifics about the occupations are vague or unknowable. The moretraditional model that we advocate based on the excavations at 41MM341 benefits chiefly from the fact that we know so much about that one site. To the extent that they are reflected in the archeological record and that we can deduce them from that record, the specifics about the nature of the occupations at 41MM341 are not vague. But it suffers from having so much data that must be tied up into a tidy interpretive package, and even more so from the paucity of comparative data from excavated sites nearby.

Clearly, 41MM341 as a workshop-habitation site is only a tiny part of a settlement system that existed within the valleys of the Little River and its tributaries, probably extending from the Brazos River to somewhere near the Balcones Escarpment. Hoxie Bridge on the San Gabriel River is the only excavated site that is a good candidate for being part of this system. Resolving the many unanswered questions about 41MM341, understanding that settlement system better, and evaluating competing ideas about the connections between this area and east Texas will require data from many more sites. As 41MM341 demonstrates, the better the data from these sites are, the more-confident and more-complete the interpretations will be.

A 1937 article entitled "Milam County, The Future Field for Archeologists" in the Central Texas Archeologist illustrates just how fragmentary the picture offered by 41MM341 is. The article, written by an avocational archeologist named J. B. White who had a collection of some 30,000 artifacts, extols the richness of the archeological record of the county, noting that

along the banks of these streams [Little River, San Gabriel River, Brushy Creek, and Sandy Creek] lie numerous villages....Indian villages dot the banks of Little River near Cameron. A chain of gravel hills feature the ancient bed of this stream which now throws its floods against the east bank. Down the valley of the river lie ancient lakes and around these depressions that once was the channel of the stream camps are found. In fact from Bell County on the west to Brazos on the east Little River remains our greatest Indian stream" (White 1937:44, 46).

Site $41 \mathrm{MM} 341$ is just one of the camps White noted adjacent to old channels of the Little River, and it is from him that the site gets its name. He goes on to describe two particularly rich sites, one of which he calls Hog Island:

Hog Island has thus far been the outstanding camp so far as numbers of flints taken. While my own collection has some 5,000 taken from this camp alone, other collectors have profited greatly by plundering its remains. From this camp in one afternoon I took 300 arrows, lances, and general blades and other implements. With each successive overflow the yield was rich....Just east of the Hog Island treasure lie the gravel banks and on a large hill now covered with farm houses, ancient shop sites can be seen where the artisan fashioned his blades and projectiles (White 1937:45).

The description in the article allows the location of the Hog Island site to be pinpointed. It lies just across the Little River from 41MM341, and the large hill with "ancient shop sites" is the one that State Highway 36 traverses before dropping into the Little River valley. Acknowledging that such general information makes temporal correlations tenuous, it is hard to imagine that these sites do not have early to middle Late Prehistoric components that are associated 
with 41MM341 and relate to the same cultural system. Understanding these sites, or others like them, would add immeasurably to understanding 41MM341.

\section{PROJECT ASSESSMENT}

As befits the amount of effort and the quantity of public dollars spent on the data recovery excavations at $41 \mathrm{MM} 341$, much has been learned through this project about how Native Americans used the Little River valley. Because of the amount of information gained, the project was a successful one, with that success resulting from collective efforts by TxDOT and Prewitt and Associates, starting with formulation of the research design, continuing through the excavations, and culminating in analysis of the data recovered and presentation of those data in this report. If we had this project to do over again, we would do most of it the same way. As in any archeological project, though, some things worked better than others. This final section offers a brief synopsis of which aspects of this project worked particularly well and which ones did not. This is done by focusing on a few large issues.

\section{Particularly Positive Points}

Starting data recovery by excavating scattered $1 \mathrm{x} 1-\mathrm{m}$ units and reopening old backhoe trenches allowed us to get a better handle on the isolability and locations of the site components so that the block excavations could focus on the most-productive parts of the site. This is why most of the excavations (the Main Block) were in a part of the site that had not been sampled, except with augering, during the 2000 test excavations.

Opening up horizontally extensive areas and taking a hard look at the distributions of the cultural remains across those areas proved integral in identifying the site as a seasonal camp at which both workshop and general habitation activities took place in a consistent way over time. This horizontally expansive approach allowed the nature of the occupations to be understood better than would have been the case with smaller excavations.

Infield tracking of the kinds and quantities of materials recovered provided immediate feedback that allowed the Main Block to expand fol- lowing the distribution of the cultural remains. This was especially important because of the patchy nature of the archeological deposits and the focus on exposing large areas of the site. While subsequent analysis showed that in some levels the Main Block actually sampled the edges of substantial cultural deposits located outside the project limits, in general the excavations progressed in a way that much was learned about the horizontal structure of the site.

Focusing the lithic analysis on the lithic reduction debris piles and tool production, use, and discard was critical to interpreting the nature of the occupations and how arrow points and knives made in sites along the Little River ended up at east Texas Caddoan sites such as George C. Davis. This is arguably the most-interesting research issue that $41 \mathrm{MM} 341$ contributes to, and the lithics had to be analyzed in a way that substantive information was obtained.

Fortuitously, analysis of 41MM341 happened concurrently with development by Harry Shafer of his Prairie Caddo model to explain the relationships between groups who occupied parts of the middle Brazos basin during the early and middle parts of the Late Prehistoric period and the Caddo of east Texas. Ultimately, we prefer an explanation other than that offered by the Prairie Caddo model, but Shafer's argument has its compelling points, and it provides a fruitful jumping-off point for discussion of this important research issue.

\section{Particularly Negative Points}

The original plan of work called for excavations that expanded around and connected the testing blocks. Even though this plan was changed to allow for excavation elsewhere (resulting in the Main Block), we still felt compelled to explore the areas around the two testing blocks. One of these, the South Block, provided important information, while the other, the East Block, did not. In retrospect, we should not have opened up the East Block. We knew what to expect there based on the testing data, with that part of the site having remains similar to those in the Main Block but harder to interpret because components were more compressed or mixed. The efforts spent on the East Block and the southeast corner of the Main Block, which was dug to help correlate the two blocks, could 
have been better spent expanding other parts of the Main Block.

During analysis, there was considerable hand-wringing over difficulties encountered in trying to address all the points raised in the research design. This probably was unavoidable to some extent. We felt that the research design needed to be comprehensive, and some parts were more robust and more doable than others. However, looking at things like forager vs. collector or delayed- vs. immediate-return models is bound to lead to frustration when one is dealing with data from a single site with limited comparative data that are spatially and temporally relevant. This is not an argument that data on such topics should not be collected and examined, but it is a caution against worrying too much about how to interpret those data.

The special studies resulted in information of variable usefulness. The ones that were least satisfying were analysis of carbon and oxygen isotopes in snail shells to examine paleoenvironments, sizing of mussel shells to look at issues such as procurement patterns and dietary stress, and analysis of diatoms for paleoenvironmental information. The first two of these probably were not worth doing, the first because of the complexity of the relationships between environmental conditions and the uptake of carbon and oxygen by snails and the second because of the limited baseline data on mussel ecology and the difficulty of formulating relevant archeological expectations. Diatom analysis, in contrast, appears to have some potential for providing useful paleoenvironmental information. In this case, though, interpretation is hampered by too few samples collected from too few contexts. More-ambitious sampling likely would have revealed whether the suggestive patterns noted in the analyzed samples reflect changes in paleoenvironments or something else entirely. 



\section{REFERENCES CITED}

Ahr, Steven W., and James T. Abbott

1999 Archeological Survey of the Proposed State Highway 36 Bridge Replacement over the Little River and Road Widening Between Travis Street in Cameron to US 77, Milam County. CSJ:0185-04-033 \& 034. Environmental Affairs Division, Texas Department of Transportation, Austin.

Bartram, Laurence E., Ellen M. Kroll, and Henry T. Bunn

1991 Variability in Camp Structure and Bone Food Refuse Patterning at Kua San Hunter-Gatherer Camps. In The Interpretation of Archaeological Spatial Patterning, edited by Ellen M Kroll and T. Douglas Price, pp. 77-148. Plenum Press, New York.

Bender, Barbara

1985 Emergent Tribal Formations in the American Midcontinent. American Antiquity 50:55-62.

Betancourt, Julio

1977 An Archeological Survey of a Proposed Lignite Mine Area, Shell Rockdale South Lease, Milam County, Texas. Office of the State Archeologist, Texas Historical Commission, Austin.

Binford, Lewis R.

1978 Dimensional Analysis of Behavior and Site Structure: Learning from an Eskimo Hunting Stand. American Antiquity 43(3):330-361.

1980 Willow Smoke and Dogs' Tails: HunterGatherer Settlement Systems and Archaeological Site Formation. American Antiquity 45(1):4-20. the Anthropological Archaeology 1:531.

Black, Stephen L.

2002 Research Module 2: Studying the Hearths of the Greater Edwards Plateau. Prepared for the Texas Department of Transportation as part of Pavo Real (41BX52) site report. Texas Archeological Research Laboratory, The University of Texas at Austin.

Black, Stephen L., Linda W. Ellis, Darrell G. Creel, and Glenn T. Goode

1997 Hot Rock Cooking on the Greater Edwards Plateau: Four Burned Rock Midden Sites in West Central Texas, Volumes 1 and 2. Studies in Archeology 22. Texas Archeological Research Laboratory, The University of Texas at Austin. Archeology Studies Program Report 2. Environmental Affairs Division, Texas Department of Transportation, Austin.

Blair, W. Frank

1950 The Biotic Provinces of Texas. The Texas Journal of Science 2(1):93-117.

Bond, Clell L.

1978 Three Archeological Sites at Hoxie Bridge, Williamson County, Texas. Report No. 43. Texas A\&M Research Foundation, College Station.

Bousman, C. Britt

1998 Paleoenvironmental Change in Central Texas: The Palynological Evidence. Plains Anthropologist 43(164):201219.

Bowman, Bradley F.

1985 Winnie's Mound (41BU17): A Study in the Prehistory of Burleson County, 
Texas. Bulletin of the Texas Archeological Society 56:39-74.

Braun, David P.

1986 Midwestern Hopewell Exchange and Supralocal Interaction. In Peer Polity Interaction and Sociopolitical Change, edited by C. Renfrew and J. Cherry, pp. 117-126. Cambridge University Press, Cambridge, England.

Brown, Kenneth M.

2002 Snails from the Quarter-inch and Eighthinch Screens. In The Smith Creek Bridge Site (41DW270), a Terrace Site in DeWitt County, Texas, by Dale Hudler, Keith Prilliman, and Thomas Gustavson. Studies in Archeology 35. Texas Archeological Research Laboratory, The University of Texas at Austin. Archeological Studies Program Report No. 17. Environmental Affairs Division, Texas Department of Transportation, Austin.

Brownlow, Russell K.

2003 Archeological Investigations at 41WM815, A Blackland Prairie Site, Williamson County, Texas. Studies in Archeology 36. Texas Archeological Research Laboratory, The University of Texas at Austin. Archeological Studies Program Report 23. Environmental Affairs Division, Texas Department of Transportation, Austin.

Camper, H. A.

1991 Pollen Analysis of the Patschke Bog. Master's thesis, Texas A\&M University, College Station.

Carlson, Shawn B., Christi Assad, Erwin Roemer, and David L. Carlson

1983 Archeological and Historical Investigations in Milam County. Archeology Surveys No. 1. Archeological Research Laboratory, Texas A\&M University, College Station.

Carter, W. T., M. W. Beck, E. H. Templin, and H. W. Hawker

1925 Soil Survey of Milam County, Texas. Soil Survey Report No. 25. U.S. Department of Agriculture, Bureau of Chemistry and Soils. U.S. Government Printing Office, Washington D.C.

Claassen, Cheryl

1998 Shells. Cambridge University Press, Cambridge.
Cobb, Charles R., and Michael S. Nassaney 1995 Interaction and Integration in the Late Woodland Southeast. In Native American Interactions: Multiscalar Analyses and Interpretations in the Eastern Woodlands, edited by Michael S. Nassaney and Kenneth E. Sassaman, pp. 205-228. The University of Tennessee Press, Knoxville.

Collins, Michael B.

1968 A Note on Broad Corner-Notched Projectile Points Used in Bison Hunting in Western Texas. The Bull Roarer 3(2):13-14. The U. T. Anthropological Society, Department of Anthropology, The University of Texas at Austin.

1995 Forty Years of Archeology in Central Texas. Bulletin of the Texas Archeological Society 66:361-400.

Collins, Michael B., and Robert A. Ricklis

1994 Cultural Background. In Archaic and Late Prehistoric Human Ecology in the Middle Onion Creek Valley, Hays County, Texas, by Robert A. Ricklis and Michael B. Collins. Studies in Archeology 19. Texas Archeological Research Laboratory, The University of Texas at Austin.

Crabtree, Don E.

1972 An Introduction to Flintworking. Occasional Papers of the Idaho Museum of Natural History Number 28. Pocatello.

Dering, J. Phillip

2003 Macrobotanical Analysis. In Data Recovery Excavations at 41MM340, a Late Archaic Site along Little River in Milam County, Texas, by Richard B. Mahoney, Steve A. Tomka, Raymond P. Mauldin, Harry J. Shafer, Lee C. Nordt, Russell D. Greaves, and Rebecca R. Galdeano, pp. 224-233. Archeological Studies Program Report No. 54. Environmental Affairs Division, Texas Department of Transportation, Austin. Archaeological Survey Report No. 340. Center for Archaeological Research, The University of Texas at San Antonio.

Diamond, David D., David H. Riskind, and Steve L. Orzell

1987 A Framework for Plant Community Classification and Conservation in Texas. The Texas Journal of Science 39(3):203-221.

Ellis, G.Lain, and James T. Abbott

1994 Movement of Chert within Fort Hood: Pre- 
liminary Observations and Hypotheses. In Archeological Investigations on 571 Prehistoric Sites at Fort Hood, Bell and Coryell Counties, Texas, edited by W. Nicholas Trierweiler, pp. 275-293. Archeological Resource Management Series, Research Report No. 31. United States Army, Fort Hood

Fields, Ross C.

1995 The Archeology of the Post Oak Savannah of East Central Texas. Bulletin of the Texas Archeological Society 66:301-330.

Fields, Ross C., and L. Wayne Klement

1995 Excavations at the Cottonwood Springs Site, Jewett Mine Project, Leon County, Texas. Reports of Investigations No. 102. Prewitt and Associates, Inc., Austin.

Fields, Ross C., L. Wayne Klement, C. Britt Bousman, Steve A. Tomka, Eloise F. Gadus, and Margaret A. Howard

1991 Excavations at the Bottoms, Rena Branch, and Moccasin Springs Sites, Jewett Mine Project, Freestone and Leon Counties, Texas. Reports of Investigations No. 82. Prewitt and Associates, Inc., Austin.

Fields, Ross C., Jennifer K. McWilliams, Corey J. Broehm, and Karl W. Kibler

2004 Interim Report on Test Excavations at 41BU51, Burleson County, Texas. Interim Report submitted to the Environmental Affairs Division, Texas Department of Transportation, by Prewitt and Associates, Inc., Austin.

Fullington, Richard W.

2001 Gastropod Analysis. In National Register Eligibility Testing of $41 M M 340$ and 41MM341, along Little River, Milam County, Texas, by Richard B. Mahoney and Steve A. Tomka, pp. 106-112. Archeological Studies Program Report No. 30. Environmental Affairs Division, Texas Department of Transportation, Austin. Archaeological Survey Report No. 303. Center for Archaeological Research, The University of Texas at San Antonio.

Gadus, E. Frances, Jennifer K. McWilliams, and Ross C. Fields

2002 Data Recovery Excavations at the McGuire's Garden Site (41FT425), Jewett Mine, Freestone County, Texas. Reports of Investigations No. 34. Prewitt and Associates, Inc., Austin.
Gilmore, Kathleen Kirk

1969 The San Xavier Missions: A Study in Historical Site Identification. Report Number 16. State Building Commission Archeological Program, Austin.

Gould, F. W.

1962 Texas Plants-A Checklist and Ecological Summary. The Agricultural and Mechanical College of Texas, Texas Agricultural Experiment Station, College Station.

Harrell, L. L.

1983 A Study of the Bone and Antler Tools from Hog Creek Reservoir, Bosque and Coryell Counties, Texas. Master's thesis, Department of Anthropology, The University of Texas at Austin.

Hayden, Brian

1986 Resource Models of Inter-Assemblage Variability. Lithic Technology 15(3):8289.

Headland, Tom, and Lawrence Reid

1989 Hunter-Gatherers and Their Neighbors from Prehistory to the Present. Current Anthropology 30:43-66.

Howells, Robert G.

2001 Freshwater Mussel Shells. In National Register Eligibility Testing of $41 M M 340$ and 41MM341, along Little River, Milam County, Texas, by Richard B. Mahoney and Steve A. Tomka, pp. 94-98. Archeological Studies Program Report No. 30. Environmental Affairs Division, Texas Department of Transportation, Austin. Archaeological Survey Report No. 303. Center for Archaeological Research, The University of Texas at San Antonio.

Huckabee, John W., Jr., David R. Thompson, Jim C. Wyrick, and E. G. Pavlat

1977 Soil Survey of Bell County, Texas. U.S. Department of Agriculture, Soil Conservation Service, in cooperation with the Texas Agriculture Experiment Station.

Huebner, Jeffery A.

1991 Late Prehistoric Bison Populations in Central and South Texas. Plains Anthropologist 36(137):343-358.

Ippolito, John E., and William Childs

1978 Archeological Investigations of Six Sites in the Proposed Milam Mine Area, Shell South Lease, Milam County, Texas. Report 
No. 45. Anthropology Research Laboratory, Texas A\&M University, College Station.

James, Stephen R.

1986 Cultural Resource Survey of Three Tracts of Land in the E Expansion of the Sandow Surface Mine, Milam County, Texas. Espey, Huston and Associates, Inc., Austin.

James, Steve, and David Moore

1987 Cultural Resource Investigations of Portions of the Sandow Surface Mine: Permit Renewal Area and E Extension Area, Milam County, Texas. Espey, Huston and Associates, Inc., Austin.

Jelks, Edward B.

1962 The Kyle Site: A Stratified Central Texas Aspect Site in Hill County, Texas. Archaeology Series No. 5. Department of Anthropology, The University of Texas at Austin.

Johnson, E. H.

1931 The Natural Regions of Texas. The University of Texas Bulletin No. 3113. Bureau of Business Research, Research Monograph No. 8. The University of Texas at Austin.

Johnson, Jay K.

1979 Archaic Biface Manufacture: Production Failures, A Chronicle of the Misbegotten. Lithic Technology 8(2):25-35.

1981 Further Biface Production Failures. Lithic Technology 10(2-3):26-28.

Johnson, LeRoy, Jr.

1994 The Life and Times of Toyah-Culture Folk As Seen from the Buckhollow Encampment, Site 41KM16, of Kimble County, Texas. Office of the State Archeologist Report 38. Texas Department of Transportation and Texas Historical Commission, Austin.

1995 Past Cultures and Climates at Jonas Terrace, 41ME29, Medina County, Texas. Office of the State Archeologist Report 40. Texas Department of Transportation and Texas Historical Commission, Austin.

1997 The Lion Creek Site (41BT105): Aboriginal Houses and Other Remains at a Prehistoric Rancheria in the Texas Hill Country (Burnet County). Archeology Studies Program Report 1. Environmental Affairs Division, Texas Department of Transportation, Austin. Office of the State
Archeologist Report 41. Texas Historical Commission, Austin.

2000 Life and Death as Seen at the Bessie Kruze Site (41WM13) on the Blackland Prairie of Williamson County, Texas. Archeology Studies Program Report 22. Environmental Affairs Division, Texas Department of Transportation, Austin.

Johnson, LeRoy, and Glenn T. Goode

1994 A New Try at Dating and Characterizing Holocene Climates, as Well as Archaeological Periods, on the Eastern Edwards Plateau. Bulletin of the Texas Archeological Society 65:1-51.

Jones, John G.

2001 Pollen and Phytolith Results. In National Register Eligibility Testing of 41MM340 and 41MM341, along Little River, Milam County, Texas, by Richard B. Mahoney and Steve A. Tomka, p. 104. Archeological Studies Program Report No. 30. Environmental Affairs Division, Texas Department of Transportation, Austin. Archaeological Survey Report No. 303. Center for Archaeological Research, The University of Texas at San Antonio.

Keller, John E., and Leonard LaVardera

1989 Final Report, Cultural Resources Investigations within the Sandow Mine Permit Renewal Area, Milam and Lee Counties, Texas. North American Consultants, Inc., Dallas.

Kibler, Karl W., and Ann M. Scott

2000 Archaic Hunters and Gatherers of the Balcones Canyonlands: Data Recovery Excavations at the Cibolo Crossing Site (41BX377), Camp Bullis Military Reservation, Bexar County, Texas. Reports of Investigations No. 126. Prewitt and Associates, Inc., Austin.

Kleinbach, Karl, Gemma Mehalchick, James T. Abbott, and J. Michael Quigg

1995 Other Analyses. In NRHP Significance Testing of 57 Prehistoric Archeological Sites on Fort Hood, Texas, Volume III, edited by James T. Abbott and W. Nicholas Treierweiler, pp. 765-842. Archeological Resource Management Series, Research Report No. 34. United States Army, Fort Hood.

Larson, Mary Lou, and Marcel Kornfeld

1997 Chipped Stone Nodules: Theory, Method, 
and Examples. Lithic Technology 22(1):418.

Lee, Richard B.

1992 Art, Science, or Politics? The Crisis in Hunter-Gatherer Studies. American Anthropologist 94:31-54.

Mahoney, Richard B., and Steve A. Tomka 2001 National Register Eligibility Testing of $41 M M 340$ and 41MM341, along Little River, Milam County, Texas. Archeological Studies Program Report No. 30. Environmental Affairs Division, Texas Department of Transportation, Austin. Archaeological Survey Report No. 303. Center for Archaeological Research, The University of Texas at San Antonio.

Mahoney, Richard B., Steve A. Tomka, and Raymond P. Mauldin

2003 Recovered Data. In Data Recovery Excavations at 41MM340, a Late Archaic Site along Little River in Milam County, Texas, by Richard B. Mahoney, Steve A. Tomka, Raymond P. Mauldin, Harry J. Shafer, Lee C. Nordt, Russell D. Greaves, and Rebecca R. Galdeano, pp. 43-59. Archeological Studies Program Report No. 54. Environmental Affairs Division, Texas Department of Transportation, Austin. Archaeological Survey Report No. 340. Center for Archaeological Research, The University of Texas at San Antonio.

Mahoney, Richard B., Steve A. Tomka, Raymond P. Mauldin, Harry J. Shafer, Lee C. Nordt, Russell D. Greaves, and Rebecca R. Galdeano

2003 Data Recovery Excavations at 41MM340, A Late Archaic Site along the Little River in Milam County, Texas. Archeological Studies Program Report No. 54. Environmental Affairs Division, Texas Department of Transportation, Austin. Archeological Survey Report No. 340. Center for Archaeological Research, The University of Texas at San Antonio.

Malainey, Mary E.

1997 The Reconstruction and Testing of Subsistence and Settlement Strategies for the Plains, Parkland, and Southern Boreal Forests. Ph.D. dissertation, University of Manitoba.

Malainey, M. E., R. Ptzybylski, and B. L. Sherriff 1999 Identifying the Former Contents of the Late Precontact Period Pottery Vessels from Western Canada Using Gas Chromatography. Journal of Archaeological Science 26:425-438.

Marquardt, William H.

1985 Complexity and Scale in the Study of Fisher-Gatherer-Hunters: An Example from the Eastern United States. In Prehistoric Hunter-Gatherers: The Emergence of Cultural Complexity, edited by T. D. Price and J.A. Brown, pp. 59-98. Academic Press, New York.

Mauldin, Raymond J., and Richard B. Mahoney 2003 Environmental Background. In Data Recovery Excavations at 41MM340, a Late Archaic Site along Little River in Milam County, Texas, by Richard B. Mahoney, Steve A. Tomka, Raymond P. Mauldin, Harry J. Shafer, Lee C. Nordt, Russell D. Greaves, and Rebecca R. Galdeano, pp. 519. Archeological Studies Program Report No. 54. Environmental Affairs Division, Texas Department of Transportation, Austin. Archaeological Survey Report No. 340. Center for Archaeological Research, The University of Texas at San Antonio.

Mauldin, Raymond J., and Steve A. Tomka

2003 Site Structural Issues. In Data Recovery Excavations at 41MM340, a Late Archaic Site along Little River in Milam County, Texas, by Richard B. Mahoney, Steve A. Tomka, Raymond P. Mauldin, Harry J. Shafer, Lee C. Nordt, Russell D. Greaves, and Rebecca R. Galdeano, pp. 119-131. Archeological Studies Program Report No. 54. Environmental Affairs Division, Texas Department of Transportation, Austin. Archaeological Survey Report No. 340. Center for Archaeological Research, The University of Texas at San Antonio.

Mauldin, Raymond J., Steve A. Tomka, and Richard B. Mahoney

2003 Defining Analytical Units at 41MM340. In Data Recovery Excavations at 41MM340, a Late Archaic Site along Little River in Milam County, Texas, by Richard B. Mahoney, Steve A. Tomka, Raymond P. Mauldin, Harry J. Shafer, Lee C. Nordt, Russell D. Greaves, and Rebecca R. Galdeano, pp. 61-74. Archeological Studies Program Report No. 54. Environmental Affairs Division, Texas Department of Transportation, Austin. Archaeological Survey Report No. 340. Center for Archaeological Research, The University of Texas at San Antonio. 
Mehalchick, Gemma, Douglas K. Boyd, Karl K. Kibler, and Christopher W. Ringstaff

2004 Shifting Sands and Geophytes: Geoarcheological Investigations at Paluxy Sites on Fort Hood, Texas. Draft Report. Archeological Resource Management Series, Research Report No. 48. United States Army, Fort Hood.

Mehalchick, Gemma, Karl Kleinbach, Douglas K. Boyd, and Karl W. Kibler

2000 Geoarcheological Investigations and $\mathrm{Na}$ tional Register Testing of 52 Prehistoric Archeological Sites on Fort Hood, Texas: The 1997 Season. Archeological Resource Management Series, Research Report No. 39. United States Army, Fort Hood.

Mehalchick, Gemma, Karl Kleinbach, Douglas K. Boyd, Steve A. Tomka, and Karl W. Kibler

1999 National Register Testing of 19 Prehistoric Archeological Sites at Fort Hood, Texas: The 1995 Season. Archeological Resource Management Series, Research Report No. 37. United States Army, Fort Hood.

Meissner, Barbara A.

2001 Vertebrate Faunal Remains. In National Register Eligibility Testing of $41 M M 340$ and 41MM341, along Little River, Milam County, Texas, by Richard B. Mahoney and Steve A. Tomka, pp. 90-91. Archeological Studies Program Report No. 30. Environmental Affairs Division, Texas Department of Transportation, Austin. Archaeological Survey Report No. 303. Center for Archaeological Research, The University of Texas at San Antonio.

Meissner, Barbara A., and Richard B. Mahoney 2003 Vertebrate Remains. In Data Recovery Excavations at 41MM340, a Late Archaic Site along the Little River in Milam County, Texas, by Richard B. Mahoney, Steve M. Tomka, Raymond P. Mauldin, Harry Shafer, Lee C. Nordt, Russell B. Greaves, and Rebecca R. Galdeano, pp. 198-206. Archeological Studies Program Report No. 54. Environmental Affairs Division, Texas Department of Transportation, Austin. Archeological Survey Report No. 340. Center for Archaeological Research, The University of Texas at San Antonio.

Moore, James A.

1983 The Trouble with Know-It-Alls: Information as a Social and Ecological Resource. In Archaeological Hammers and Theories, edited by J. A. Moore and A. S. Keene, pp. 173-191. Academic Press, New York.

Nassaney, Michael S.

1996 The Role of Chipped Stone in the Political Economy of Social Ranking. In Stone Tools, Theoretical Insights into Human Prehistory, edited by George H. Odell, pp. 181228. Plenum Press, New York.

Nordt, Lee C.

1995 Geoarchaeological Investigations of Henson Creek: A Low-Order Tributary in Central Texas. Geoarchaeology: An International Journal 10(3):205-221.

2001 Geoarchaelogy. In National Register Eligibility Testing of $41 M M 340$ and 41MM341, along Little River, Milam County, Texas, by Richard B. Mahoney and Steve A. Tomka, pp. 13-20. Archeological Studies Program Report No. 30. Environmental Affairs Division, Texas Department of Transportation, Austin. Archaeological Survey Report No. 303. Center for Archaeological Research, The University of Texas at San Antonio.

Nordt, Lee C., Russell D. Greaves, and Steve A. Tomka

2003 Floodplain Dynamics. In Data Recovery Excavations at 41MM34, A Late Archaic Site along Little River in Milam County, Texas, by Richard B. Mahoney, Steve A. Tomka, Raymond P. Mauldin, Harry J. Shafer, Lee C. Nordt, Russell D. Greaves, and Rebecca R Galdeano, pp. 75-94. Archeological Studies Program Report No. 54. Environmental Affairs Division, Texas Department of Transportation, Austin. Archaeological Survey Report No. 340. Center for Archaeologial Research, The University of Texas at San Antonio.

Odell, George H., and Frank Cowan

1986 Experiments with Spears and Arrows on Animal Targets. Journal of Field Archeology 13(2):195-212.

Parry, William J., and Robert L. Kelly

1987 Expedient Core Technology and Sedentism. In The Organization of Core Technology, edited by J. K. Johnson and C.A. Morrow, pp. 285-304. Westview Press, Boulder.

Pedersen, Jon, and Espen Waehle

1988 The Complexities of Residential Organization Among the Efe (Mbuti) and 
Bagombi (Baka): A Critical Review of the Notion of Flux in Hunter-Gatherer Societies. In Hunters and Gatherers: Volume 1, History, Evolution and Social Change, edited by T. Ingold, D. Riches, and J. Woodburn, pp. 75-90. Berg, New York.

Peregrine, Peter N.

1995 Networks of Power: The Mississippian World-System. In Native American Interactions, Multiscalar Analyses and Interpretations in the Eastern Woodlands, edited by M. S. Nassaney and K. E. Sassaman, pp. 247-265. The University of Tennessee Press, Knoxville.

Perttula, Timothy K.

1992 The Caddo Nation: Archaeological and Ethnohistoric Perspectives. University of Texas Press, Austin.

2001 Prehistoric Ceramic Sherds from 41MM341. In National Register Eligibility Testing of $41 M M 340$ and 41MM341, along Little River, Milam County, Texas, by Richard B. Mahoney and Steve A. Tomka, pp. 124-125. Archeological Studies Program Report No. 30. Environmental Affairs Division, Texas Department of Transportation, Austin. Archaeological Survey Report No. 303. Center for Archaeological Research, The University of Texas at San Antonio.

Perttula, Timothy K., Sergio A. Iruegas, and Hector Neff

2003 Caddoan Pottery in Central Texas: Geochemical Analyses of Ceramics from Fort Hood and Vicinity. Archeological Resource Management Series, Research Report No. 51. United States Army, Fort Hood.

Peterson, Fredrick A.

1965 The Erwin's Bridge Site at Somerville Reservoir, Burleson County, Texas. Texas Archeological Salvage Project, The University of Texas at Austin.

Pielou, E. C.

1975 Ecological Diversity. John Wiley \& Sons, Inc., New York.

Prewitt, Elton R.

1981 Cultural Chronology in Central Texas. Bulletin of the Texas Archeological Society 52:65-89.
Fox Site, Williamson County, Texas. Reprints in Archeology No. 1. Prewitt and Associates, Inc., Austin.

1985 From Circleville to Toyah: Comments on Central Texas Chronology. Bulletin of the Texas Archeological Society 54:201-238.

Rhode, David

1988 Measurement of Archaeological Diversity and Sample-Size Effect. American Antiquity 53(4):708-716.

Rick, John W.

1996 Projectile Points, Style, and Social Process in the Preceramic of Central Peru. In Stone Tools, Theoretical Insights into Human Prehistory, edited by G. H. Odell, pp. 245278. Plenum Press, New York.

Ricklis, Robert A.

2001 National Register Eligibility Testing at 41LE177, Alcoa Sandow Mine, Lee County, Texas: Archaeological, Geoarchaeological and Paleoenvironmental Assessment of an Upland Sandy Mantle Site. Coastal Archaeological Research, Inc., Corpus Christi.

Robinson, David G., and Solveig A. Turpin

1993 Hunter-Gatherer Mobility and Settlement in the Brazos Uplands: Archeology in the Calvert Mine, Robertson County, EastCentral Texas. Studies in Archeology 14. Texas Archeological Research Laboratory, The University of Texas at Austin.

Roemer, Erwin, Jr., and Shawn Bonath Carlson

1987 Excavations at 41BU16: State Highway 21 at the Brazos River, Burleson County, Texas. Contract Reports in Archaeology, Report Number 1. Highway Design Division, Texas State Department of Highways and Public Transportation, Austin.

Rogers, Robert

1993 Data Recovery of Three Prehistoric Sites at the Gibbons Creek Third Five-Year Mine Permit Area, Grimes County, Texas. Document No. 910529. Espey, Huston and Associates, Inc., Austin.

1995 Excavations at Sites 41GM166, 41GM281, and 41GM282 at the Gibbons Creek Lignite Mine, Grimes County, Texas. Document No. 940611. Espey, Huston and Associates, Inc., Austin.

1997 National Register Testing at Site 41LE120, 
Lee County, Texas. Document No. 970348. Espey, Huston and Associates, Inc., Austin.

1999 Excavations at the Walleye Creek Site (41LE57), Lee County, Texas. Document No. 981670. Espey, Huston and Associates, Inc., Austin.

Rogers, Robert, and Meg Cruse

1998 Cultural Resources Survey of the 429-acre $H$ Area Expansion at the Sandow Surface Mine, Lee, Milam, and Williamson Counties, Texas. Espey, Huston and Associates, Inc., Austin.

Rogers, Robert, and Steve Kotter

1995 Archaeological Investigations at the Chesser Site (41LE59), Lee County, Texas. Document No. 950209. Espey, Huston and Associates, Inc., Austin.

Rondeau, Michael F

1996 When is an Elko? In Stone Tools, Theoretical Insights into Human Prehistory, edited by G. H. Odell, pp. 229-244. Plenum Press, New York.

Root, Dolores

1983 Information Exchange and the Spatial Configuration of Egalitarian Societies. In Archaeological Hammers and Theories, edited by J. A. Moore and A. S. Keene, pp. 193-219. Academic Press, New York.

Rushmore, F. P., III, C. S. Flataker, and C. L. Bond 1980 Cultural Resources Survey: Selected Surface Mining Areas, Milam and Lee Counties, Texas. Report No. 9. Cultural Resources Laboratory, Texas A\&M University, College Station.

Rye, Danny, and Michael Sommer II

1980 Reconstructing Paleotemperature and Paleosalinity Regimes with Oxygen Isotopes. In Skeletal Growth of Aquatic Organisms, edited by D. Rhoads and R. Lutz, pp. 169-202. Plenum Press, New York.

Sassaman, Kenneth E.

1995 The Cultural Diversity of Interactions Among Mid-Holocene Societies of the American Southeast. In Native American Interactions, Multiscalar Analyses and Interpretations in the Eastern Woodlands, edited by M. S. Nassaney and K. E. Sassaman, pp. 174-204. The University of Tennessee Press, Knoxville.
Schiffer, Michael B.

1975 The Effects of Occupation Span on Site Content. In The Cache River Archaeological Project: An Experiment in Contract Archeology, assembled by Michael B. Schiffer and John H. House, pp. 265-269. Research Series No. 8. Publications in Archeology, Arkansas Archeological Survey, Fayetteville.

Shafer, Harry J.

1963 Test Excavations at the Youngsport Site: A Stratified Terrace Site in Bell County, Texas. Bulletin of the Texas Archeological Society 34:57-81.

1973 Lithic Technology at the George C. Davis Site Cherokee County, Texas. Ph.D. dissertation, Department of Anthropology, The University of Texas at Austin.

2004 People of the Prairie: A Possible Connection to the Davis Site Caddo. Draft research module prepared for the Environmental Affairs Division, Texas Department of Transportation, Austin.

Shafer, Harry J., Dee Ann Suhm, and J. Dan Scurlock

1964 An Investigation and Appraisal of the Archeological Resources of Belton Reservoir, Bell and Coryell Counties, Texas: 1962. Miscellaneous Papers No. 1. Texas Archeological Salvage Project, The University of Texas at Austin.

Sorrow, William M.

1966 The Pecan Springs Site, Bardwell Reservoir, Texas. Papers of the Texas Archeological Salvage Project No. 10. The University of Texas at Austin.

Stephenson, Robert L.

1970 Archeological Investigations in the Whitney Reservoir Area, Central Texas. Bulletin of the Texas Archeological Society 41:37-277.

Stevenson, Marc G.

1985 The Formation of Artifact Assemblages at Workshop/Habitation Sites: Models from Peace Point in Northern Alberta. American Antiquity 50(1):63-81.

Story, Dee Ann

1972 A Preliminary Report of the 1968, 1969, and 1970 Excavations at the George C. Davis Site, Cherokee County, Texas. The University of Texas at Austin. 
1985 Adaptive Strategies of Archaic Cultures of the West Gulf Coastal Plain. In Prehistoric Food Production in North America, edited by R. I. Ford, pp. 19-56. Anthropological Papers No. 75. Museum of Anthropology, University of Michigan, Ann Arbor.

1990 Cultural History of the Native Americans. In The Archeology and Bioarcheology of the Gulf Coastal Plain: Volume 1, by Dee Ann Story, Janice A. Guy, Barbara Burnett, Martha Doty Freeman, Jerome C. Rose, D. Gentry Steele, Ben W. Olive, and Karl J. Reinhard, pp. 163-365. Research Series No. 38. Arkansas Archeological Survey, Fayetteville.

Story, Dee Ann, and Harry J. Shafer

19651964 Excavations at Waco Reservoir, McLennan County, Texas: The Baylor and Britton Sites. Miscellaneous Papers No. 6. Texas Archeological Salvage Project, The University of Texas at Austin.

Suhm, Dee Ann

1955 Excavations at the Collins Site, Travis County. Bulletin of the Texas Archeological Society 26:7-54.

Suhm, Dee Ann, and Edward B. Jelks

1962 Handbook of Texas Archeology: Type Descriptions. Texas Archeological Society Special Publication 1 and Texas Memorial Museum Bulletin 4. Austin.

Thoms, Alston V., and Steven W. Ahr

1996 Archaeological Studies at Birch Creek Unit and Yegua Creek Fishing-Access Area, Lake Somerville State Park, Burleson County, Texas, Interim Report, September 1996. Center for Environmental Archaeology, Texas A\&M University, College Station.

Tomka, Steve A., and Raymond P. Mauldin

2003a Paleoenvironmental Reconstruction. In Data Recovery Excavations at 41MM340, a Late Archaic Site along Little River in Milam County, Texas, by Richard B. Mahoney, Steve A. Tomka, Raymond P. Mauldin, Harry J. Shafer, Lee C. Nordt, Russell D. Greaves, and Rebecca R. Galdeano, pp. 95-108. Archeological Studies Program Report No. 54. Environmental Affairs Division, Texas Department of Transportation, Austin. Archaeological Survey Report No. 340. Center for Archaeological Research, The University of Texas at San Antonio. 2003b Subsistence Strategies. In Data Recovery Excavations at 41MM340, a Late Archaic Site along Little River in Milam County, Texas, by Richard B. Mahoney, Steve A. Tomka, Raymond P. Mauldin, Harry J. Shafer, Lee C. Nordt, Russell D. Greaves, and Rebecca R. Galdeano, pp. 109-118. Archeological Studies Program Report No. 54. Environmental Affairs Division, Texas Department of Transportation, Austin. Archaeological Survey Report No. 340. Center for Archaeological Research, The University of Texas at San Antonio.

Tomka, Steve A., Gemma Mehalchick, Karl Kleinbach, and Douglas K. Boyd

1999 Methods of Investigations. In National Register Testing of 19 Prehistoric Archeological Sites at Fort Hood, Texas: The 1995 Season, by Gemma Mehalchick, Karl Kleinbach, Douglas K. Boyd, Steve A. Tomka, and Karl Kibler, pp. 2140. Archeological Resource Management Series, Research Report No. 37. United States Army, Fort Hood.

Tomka, Steve A., Harry J. Shafer, and Raymond P. Mauldin

2003 Lithic Technology at 41MM340. In Data Recovery Excavations at 41MM340, a Late Archaic Site along the Little River in Milam County, Texas, by Richard B. Mahoney, Steve A. Tomka, Raymond P. Mauldin, Harry J. Shafer, Lee C. Nordt, Russell D. Greaves, and Rebecca R. Galdeano, pp. 133-154. Archeological Studies Program Report No. 54. Environmental Affairs Division, Texas Department of Transportation, Austin. Archaeological Survey Report No. 340. Center for Archaeological Research, The University of Texas at San Antonio.

Toomey, Rickard S., III, Michael D. Blum, and Salvatore Valastro Jr.

1993 Late Quaternary Climates and Environments of the Edwards Plateau, Texas. Global and Planetary Change 7:299-320.

Trierweiler, W. Nicholas (editor)

1994 Archeological Investigations on 571 Sites at Fort Hood, Bell and Coryell Counties, Texas. Archeological Resource Management Series, Report No. 31. United States Army, Fort Hood.

Tull, Delena

1999 Edible and Useful Plants of Texas and 
the Southwest. University of Texas Press, Austin.

Turner, Ellen Sue, and Thomas R. Hester

1993 A Field Guide to Stone Artifacts of Texas Indians. Gulf Publishing Company, Houston.

Turner, Robert. L., Jr.

1997 Analysis of the Asa Warner (41ML46) Ceramics. In "The Asa Warner Site (41ML46), McLennan County, Texas," by Jodi F. Wright. Bulletin of the Texas Archeological Society 68:231-239.

Watt, Frank H.

1941 Preliminary Report on Potsherds from Chupek Site. Central Texas Archeological Society Newsletter. January, Part 2-IV.

1956 Archeological Materials from the Asa Warner Sites. Central Texas Archeologist 7:6-29.

Webb, Clarence H., and Monroe Dodd Jr.

1939 Further Excavations of the Gahagan Mound: Connections with a Florida Culture. Bulletin of the Texas Archeological and Paleontological Society 11:92-127.

Weed, Carol

1977 41MM106 Phase II Testing. Report No. 41. Anthropology Research Laboratory, Texas A\&M University, College Station.

Weed, Carol S., and John E. Ippolito

1977 An Archeological Survey of the Shell North Lease, Milam County, Texas. Report No. 40. Anthropology Research Laboratory, Texas A\&M University, College Station.

Weed, Carol, and F. Whittaker

1980 Excavations of 41MM116: The Tommy Swift Site on the Shell North Lease. Report No. 49. Anthropology Research Laboratory, Texas A\&M University, College Station.

White, J. B.

1937 Milam County, the Future Field for Archeologists. Central Texas Archeologist 3:4148.
Wiessner, Polly

1982 Beyond Willow Smoke and Dogs' Tails: A Comment on Binford's Analysis of HunterGatherer Settlement Systems. American Antiquity 47:171-177.

Wilmsen, Edwin

1989 Land Filled with Flies: Political Economy of the Kalahari. University of Chicago Press, Chicago.

Winsbourgh, Barbara

1995 Diatoms. In Late Quaternary Valley Fills and Paleoenvironments of the Southern High Plains, edited by V. Holiday, pp. 6783. Geological Society of America Memoir Number 186.

2001 Diatom Paleoenvironmental Analysis of Sediments. In National Register Eligibility Testing of $41 M M 340$ and 41MM341, along Little River, Milam County, Texas, by Richard B. Mahoney and Steve A. Tomka, pp. 114-117. Archeological Studies Program Report No. 30. Environmental Affairs Division, Texas Department of Transportation, Austin. Archaeological Survey Report No. 303. Center for Archaeological Research, The University of Texas at San Antonio.

Woodburn, James

1968 Stability and Flexibility in Hazda Residential Groupings. In Man the Hunter, edited by R. B. Lee and I. DeVore, pp. 103-110. Aldine, Chicago.

1982 Egalitarian Societies. Man 17:431-451.

1988 African Hunter-Gatherer Social Organization: Is it Best Understood as a Product of Encapsulation? In Hunters and Gatherers: Volume 1, History, Evolution and Social Change, edited by T. Ingold, D. Riches, and J. Woodburn, pp. 31-64. Berg, New York.

Yellen, John E.

1977 Archeological Approaches to the Present: Models for Reconstructing the Past. Academic Press, New York. 


\title{
APPENDIX A: Analysis of Mussel Shells from 41MM341
}

\author{
Karen M. Gardner
}





\section{INTRODUCTION}

Freshwater mussels shells from selected features and shell concentrations at 41MM341 were analyzed to provide information on the range and variety of species used. Only intact valves and umbo fragments were analyzed because body fragments are not suitable for identification and do not contribute to an accurate assessment of the assemblage. These mussel shell samples were collected from 7 of the 12 shell features identified in the Main Block and from Level 10 of the East Block. The parts of the features sampled were the parts with the densest shells and thus best-preserved parts of the shell concentrations; the analyzed samples constitute 40 to 67 percent of the total feature areas. The analyzed samples are from the following: Feature 9, Level 8 of Excavation Units 10, 13, 14, 20, and 22; Feature 10, Level 6 of Excavation Units 11, 123, and 134; Feature 16, Level 8 of Excavation Units 53, 54, 55, and 106; Feature 20, Level 9 of Excavation Units 108, 160, and 161; Feature 21a, Level 7 of Excavation Units 133, 142, 182, and 183; Feature 21b, Level 7 of Excavation Units 121, 140, 173, and 177; and Feature 24, Level 10 of Excavation Units 103,160 , and 161 . Though not designated a cultural feature, shells from Level 10 of 9 of the 12 East Block units were analyzed to provide a more-robust sample from the earlier site component. Most of the analyzed shell samples were recovered by $1 / 4$-inch water screening, although 9 of the samples were recovered from flotation. The flotation samples were taken from all or part of the feature within a particular unit and level. Materials from flotation samples were added to those from the water-screen recovery from that same unit and level, such that shells from the entire feature within the unit levels listed above were analyzed.

All shell was identified using comparative literature, including mussel identification guides and the Prewitt and Associates, Inc., comparative collection. Valves were identified to the species level, unless the condition of the shell made confident assessment of species questionable, at which point it was identified to just the genus level. A shell fragment was considered unidentified when the fragment was too small, too fragmentary, or too eroded for a definite identification. Intact valves were measured from anterior to posterior margins and grouped into size ranges, and umbo fragments, which includes valves not intact enough for a size measurement, were counted. Because valves were not identified to side (i.e., left or right), all counts indicate the number of individual valves rather than the number of individual animals present. Each shell was also examined for any evidence of intentional modification or indicators of heating and burning.

A total of 3,361 shells were analyzed, 2,828 of which were identified to the species level. Another 11 were identified to the genus level, with 522 being unidentified fragments. All of the species identified are freshwater mussels, members of the family Unionidae. As seen in Table A-1, two species dominate the collection, with Amblema plicata and Quadrula houstonensis representing 47 percent and almost 32 percent of the sample, respectively.

\section{SPECIES DESCRIPTIONS}

Amblema plicata, commonly known as threeridge, is the dominant species, making up 47.3 percent of the sample. It is a common species found throughout central and east Texas, ranging from the San Antonio and Guadalupe Rivers into other drainage basins to the north and east (Howells et al. 1996:34). This species is adaptable, having been found in a wide variety of locations from small streams to large rivers, as well as in lakes and reservoirs. Often found in 1 to $3 \mathrm{ft}$ of water, it favors a variety of substrates including mud, sand, clay, gravel, or combinations of these (Cummings and Mayer 1992:40; Howells et al. 1996:34; Parmalee and Bogan 1998:63).

Quadrula houstonensis, or smooth pimpleback, is the second-most-common species identified in the sample, making up 31.5 percent. This species is known to occur in the Colorado, Brazos, and San Jacinto drainage basins, with specimens documented in the central Texas region on the Brazos River (Howells et al. 1996:112). Quadrula houstonensis typically is found in substrates composed of mixed mud, sand, and fine gravel (Howells et al. 1996:113).

Quincuncina mitchelli, also known as false spike, is found in the Rio Grande, Guadalupe, Colorado, and Brazos River systems and makes up 2.0 percent of the sample. It is found in river environments and prefers a substrate of cobbles and mud (Howells et al. 1996:128). 


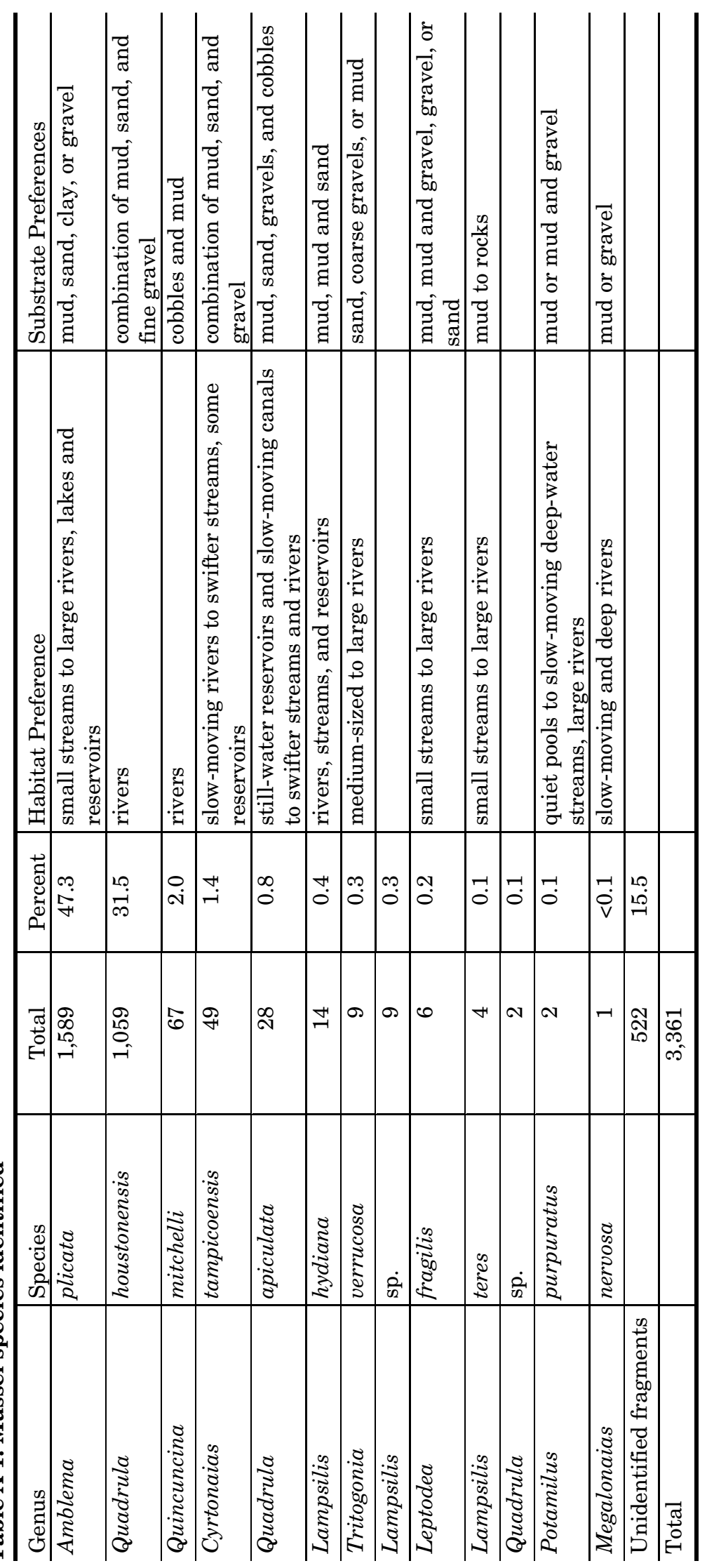


Cyrtonaias tampicoensis constitutes 1.5 percent of the analyzed sample. Also referred to as the Tampico pearlymussel, it has been documented in Texas in parts of the Trinity River system as well as the Rio Grande, Nueces, Frio, San Antonio, Guadalupe, and Brazos River systems (Howells et al. 1996:48). An adaptable species, it has been documented in slow rivers to swifter moving streams, as well as in some reservoirs. This species prefers substrates that are made up of a combination of mud, sand, and gravel, although it has occasionally been found on cobble or rock surfaces. It is rarely found on substrates of deep silt or shifting sands (Howells et al. 1996:49).

Quadrula apiculata, also known as southern mapleleaf, accounts for 0.8 percent of the sample. Common throughout Texas with the exception of west Texas and the Panhandle, this species is found in a variety of circumstances. It has been documented in still-water reservoirs, the slow-moving water of canals, and flowing waters of rivers and streams, usually on surfaces of mud or a combination of mud, sand, gravels, and cobbles. It is found at variable depths, ranging from less than $3 \mathrm{ft}$ up to $15 \mathrm{ft}$ or more (Howells et al. 1996:106; Parmalee and Bogan 1998:210).

Lampsilis hydiana, or Louisiana fatmucket, is found from the San Antonio River into other drainage systems to the north and east. It has also been documented in the Nueces River system (Howells et al. 1996:65). Making up only 0.4 percent of the analyzed sample, this species is found in rivers, streams, and reservoirs, typically with quiet or slow-moving waters. This species favors a mud bottom but also has been found on other surfaces such as mud and sand substrates (Cummings and Mayer 1992:150; Howells et al. 1996:66; Parmalee and Bogan 1998:134).

Tritogonia verrucosa, pistolgrip, makes up 0.3 percent of the collection and is documented as occurring in the Rio Grande, Guadalupe, Colorado, and Brazos River systems (Howells et al. 1996:127). Preferring substrates of sand, coarse gravels, or mud, it has been found living in medium-sized to large rivers at depths ranging from 1 to $20 \mathrm{ft}$ (Cummings and Mayer 1992:26; Howells et al. 1996:128; Parmalee and Bogan 1998:235)

Leptodea fragilis, also referred to as fragile papershell, makes up only 0.2 percent of the mussel shell sample. It ranges from the Colorado River basin into drainages to both the north and east and is typically found on mud, mud and gravel, gravel, and occasionally sandy substrates. An adaptable species, it has been documented in small streams and large rivers, clear and murky waters, shallow or deep waters, and still to swiftly moving waters (Cummings and Mayer 1992:120; Howells et al. 1996:75-76; Parmalee and Bogan 1998:149).

Lampsilis teres, or yellow sandshell, makes up 0.1 percent of the sample. This is a common Texas species and is found in all of the major river systems. It is also an adaptable mussel, having been documented in large and small streams and rivers and in slow- to fast-moving currents, at a variety of depths ranging up to $12-15 \mathrm{ft}$. This species is also found on many different bottom types from mud to rocks, although it appears to avoid deep and shifting sand substrates (Howells et al. 1996:69-70; Parmalee and Bogan 1998:138).

Potamilus purpuratus, or bleufer, constitutes only 0.1 percent of the analyzed shells. Found from the Gulf Coast drainages, including the Guadalupe River basin, into systems to the north and east, it has been documented throughout central and east Texas in both small and large streams and rivers (Howells et al. 1996:100; Parmalee and Bogan 1998:200). This species prefers quiet pools or deep-water streams with slow-moving waters, at depths of up to $3 \mathrm{ft}$. It favors stable substrates such as mud or mud and gravel (Howells et al. 1996:101; Parmalee and Bogan 1998:201).

Megalonaias nervosa is represented by only one specimen $(<0.1$ percent) and is often referred to as washboard. Found in all major river systems, it has been documented in central and east Texas and usually is found in large, slowmoving, deep rivers on substrates of mud or gravel (Howells et al. 1996:81). This is typically thought to be a large-river mussel, although it has been known to adapt to the conditions of some reservoirs, as well as occasionally to medium-sized rivers. It has been documented at depths of up to $50 \mathrm{ft}$ (Cummings and Mayer 1992:24; Howells et al. 1996:81; Parmalee and Bogan 1998:160).

Eleven specimens were identified only to the genus level, 9 of which are identified as Lampsilis sp., with the other 2 being Quadrula sp. Five hundred twenty-two specimens were not 
identified because they are poorly preserved or lack positive identifying characteristics.

\section{HABITAT PREFERENCES}

As described above and summarized in Table A-1, the freshwater species identified at 41MM341 are all found in Texas, and all are documented as occurring in the Brazos River drainage. Although there are some variations in the types of habitats and substrates preferred, all inhabit similar environments and have proven adaptable to living in a range of circumstances. They all also have been identified in archeological contexts in central Texas, including at $41 \mathrm{MM} 340$ not far from 41MM341 (Howells et al. 2003). The two most-common species, Amblema plicata and Quadrula houstonensis, have similar habitat and substrate preferences, allowing the possibility that they may have been collected or harvested from a common location. Given the similarities in habitat preferences of the identified species, it is reasonable to assume that there may have been a small number of favored collecting places that the inhabitants of 41MM341 used, although these spots likely changed over time as resources diminished at a location.

\section{DISTRIBUTION PATTERNS}

All of the mussels analyzed are from features in the Main Block and from one concentration in the East Block. As can be seen in Table A-2, the two most-common species, Amblema plicata and Quadrula houstonensis, and Quincuncina mitchelli occur in the East Block and in all of the features. Cyrtonaias tampicoensis and Quadrula apiculata occur in the East Block and all but one feature. Features $21 \mathrm{~b}$ and 24 show the greatest range of species represented, with each containing nine different species. Features 20 and $21 \mathrm{a}$ each contain eight species.

In the East Block, Quadrula houstonensis is the most numerous species, followed by Amblema plicata, with the other four species represented in this part of the site occurring in minimal quantities. Amblema plicata is most numerous in most of the features in the Main Block, followed closely by Quadrula houstonensis, but in Features 10 and 24 their order is reversed with Quadrula houstonensis occurring more frequently. Lampsilis hydiana, Megalonaias nervosa, Potamilus purpuratus, and Tritogonia verrucosa occur only in Features 20, 21a, 21b, and 24. Spatially, Features 20 and 24 are located near each other, as are Features $21 \mathrm{a}$ and $21 \mathrm{~b}$. Given the small quantities present of each of these four species, it is likely that they were collected inadvertently with other species. With the dominance of Amblema plicata and Quadrula houstonensis in the analyzed sample and the similarities in habitat preferences of all the species, it is difficult to say much about the presence or absence of the other represented mussels.

\section{MUSSEL SHELL SIZE AND AGE}

Determining growth rates and development patterns is difficult because the growth rates of individual mussels can vary widely and be influenced by a variety of factors. Different species may have different rates of growth, and external influences such as water temperature, water quality, and variable food sources all can have a marked effect on growth. Similarly, developing methods of determining the age of mussels is problematical because of the influences on growth as well as problems of interpretation. Various methods have been used, from counting growth-rest period annuli on the shell surface to examining the microscopic growth patterns of the internal shell structure, but all have been shown to have levels of subjective interpretation. It is therefore difficult to make anything other than generalizations about the age of any given mussel, tied to the assumption that the older the mussel, the larger the valve.

Table A-3 shows the size classes, in 5-mm increments, that were assigned for the 759 intact valves in the sample. An intact valve is one where the condition and preservation of the shell allows an accurate posterior to anterior margin measurement to be recorded. For the sample as a whole, 284 (37.4 percent) fall into the 36 40-mm class, closely followed by 232 (30.6 percent) in the 31-35-mm class. For the most-common species, Amblema plicata and Quadrula houstonensis, their greatest frequencies occur in these two size classes. Only Quadrula houstonensis is represented by sizes less than $26 \mathrm{~mm}$, and only Amblema plicata is represented by valves larger than $65 \mathrm{~mm}$. All of the remaining valves are clustered between 31 and $65 \mathrm{~mm}$, 
Table A-2. Mussel shells by block and feature

\begin{tabular}{|c|c|c|c|c|c|c|c|c|c|c|c|c|c|c|c|}
\hline $\begin{array}{l}\text { Block/ } \\
\text { Feature }\end{array}$ & 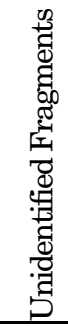 & 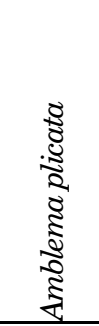 & 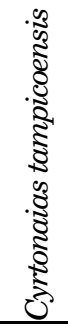 & 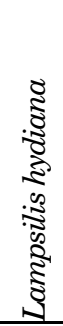 & 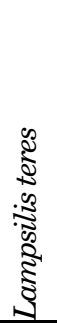 & 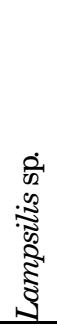 & 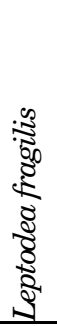 & 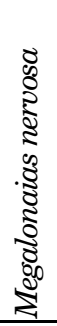 & 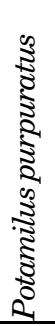 & 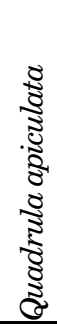 & 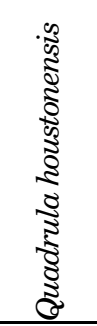 & 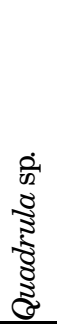 & 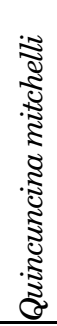 & 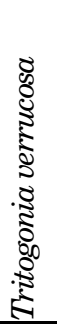 & Total \\
\hline $\begin{array}{l}\text { East } \\
\text { Block }\end{array}$ & 147 & 78 & 2 & & & 6 & & & & 4 & 148 & & 5 & & 390 \\
\hline 9 & 64 & 318 & 11 & & & & 1 & & & 8 & 148 & & 13 & & 563 \\
\hline 10 & 7 & 47 & 1 & & 2 & & & & & & 63 & 2 & 3 & & 125 \\
\hline 16 & 63 & 458 & 12 & & & & 3 & & & 6 & 194 & & 18 & & 754 \\
\hline 20 & 223 & 202 & & 4 & 2 & 2 & & & & 2 & 176 & & 4 & 1 & 616 \\
\hline $21 \mathrm{a}$ & & 188 & 4 & 4 & & & & & 1 & 5 & 153 & & 12 & 5 & 372 \\
\hline $21 \mathrm{~b}$ & 10 & 276 & 18 & 5 & & & 2 & & 1 & 1 & 127 & & 8 & 1 & 449 \\
\hline 24 & 8 & 22 & 1 & 1 & & 1 & & 1 & & 2 & 50 & & 4 & 2 & 92 \\
\hline Total & 522 & 1,589 & 49 & 14 & 4 & 9 & 6 & 1 & 2 & 28 & 1,059 & 2 & 67 & 9 & 3,361 \\
\hline
\end{tabular}

Table A-3. Mussel shell size classes

\begin{tabular}{|c|c|c|c|c|c|c|c|c|c|c|c|c|}
\hline Species & $21-25$ & $26-30$ & $31-35$ & $36-40$ & $41-45$ & $46-50$ & $51-55$ & $56-60$ & $61-65$ & $66-70$ & $71-75$ & Total \\
\hline $\begin{array}{l}\text { Amblema } \\
\text { plicata }\end{array}$ & & 7 & 95 & 135 & 28 & 28 & 18 & 23 & 8 & 3 & 2 & 347 \\
\hline $\begin{array}{l}\text { Quadrula } \\
\text { houstonensis }\end{array}$ & 6 & 45 & 133 & 131 & 28 & 8 & & & & & & 351 \\
\hline $\begin{array}{l}\text { Quincuncina } \\
\text { mitchelli }\end{array}$ & & & 2 & 10 & 5 & 4 & 1 & & & & & 22 \\
\hline $\begin{array}{l}\text { Cyrtonaias } \\
\text { tampicoensis }\end{array}$ & & & & 3 & 3 & 5 & 3 & 1 & & & & 15 \\
\hline $\begin{array}{l}\text { Quadrula } \\
\text { apiculata }\end{array}$ & & & 2 & 4 & 2 & & 3 & & & & & 11 \\
\hline $\begin{array}{l}\text { Lampsilis } \\
\text { hydiana }\end{array}$ & & & & & 1 & 3 & & 1 & 1 & & & 6 \\
\hline \multicolumn{13}{|l|}{ Lampsilis $\mathrm{sp}$. } \\
\hline $\begin{array}{l}\text { Tritogonia } \\
\text { verrucosa }\end{array}$ & & & & & & & 2 & 1 & & & & 3 \\
\hline $\begin{array}{l}\text { Leptodea } \\
\text { fragilis } \\
\end{array}$ & & & & 1 & & & 1 & & & & & 2 \\
\hline $\begin{array}{l}\text { Lampsilis } \\
\text { teres }\end{array}$ & & & & 1 & & & & & & & & 1 \\
\hline \multicolumn{13}{|l|}{$\begin{array}{l}\text { Potamilus } \\
\text { purpuratus }\end{array}$} \\
\hline Quadrula sp. & & & & & & 1 & & & & & & 1 \\
\hline \multicolumn{13}{|l|}{$\begin{array}{l}\text { Megalonaias } \\
\text { nervosa }\end{array}$} \\
\hline Total & 6 & 52 & 232 & 285 & 67 & 49 & 28 & 26 & 9 & 3 & 2 & 759 \\
\hline
\end{tabular}

Note: Measurements are in millimeters. 
with the greatest concentrations between 31 and $40 \mathrm{~mm}$. When quantified by feature and block, the same patterns hold. For the East Block and each of the features, as shown in Table A-4, most of the valves are within the 31-35- and 36-40mm groupings.

Given that 68 percent of the sample ranges in size between 31 and $40 \mathrm{~mm}$, it is apparent that the size distributions are not the result of general harvesting but rather selected exploitation. If general harvests had occurred, we would expect to see distributions that would more normally follow the life cycle of the mussel. It would be expected that the recovered shells would show a greater range of sizes, representing very young mussels with small shell sizes up to older, larger mussels. This is obviously not the case with the sample from the selected features and concentrations at 41MM341, where most of the shells fall into a narrow size range. This indicates that a specific range of shell size was intentionally targeted. Assumptions can be made as to why this specific size range was being exploited, from conservation of the resource by not taking the juvenile mussels to a preference for a certain size of mussel as food. Whatever the reason, the inhabitants of 41MM341 intentionally and deliberately selected mussels of a certain size for their use.

\section{MODIFICATION AND BURNING}

None of the analyzed shells show any indication of intentional modification, and less than 20 percent of the sample show any signs of burning or heating. The East Block has 105 speci- mens showing evidence of burning, and Features 20 and 16 have 329 and 107, respectively (Table A-5). The remaining features have small quantities, and Features 9 and 10 do not have any. In some cases, the preservation of the shells is poor enough that it is not possible to tell if the shells have been burned or if discoloration is part of the breakdown of the shells. Other than the unidentified fragments, most of the burned shells are either Amblema plicata or Quadrula houstonensis, consistent with their dominance in the overall sample.

\section{SUMMARY}

The 11 freshwater mussel species identified in the analyzed sample from 41MM341 are all representative examples of mussels from the central Texas region. Because they occupy similar habitats and favor similar substrates, it is not surprising to find these species in the features and concentrations selected for analysis. The dominance of Amblema plicata may be a function of two things: it is a common species in the region, and it has a thick and heavy shell that preserves well in the archeological record. Quadrula houstonensis also has a sturdier shell than some of the other species, increasing its chances of preservation and identification. Mussels such as Lampsilis teres and Leptodea fragilis have thin shells, which are easily destroyed. The small quantities of the other 9 species identified may represent their poor preservation at the site, their limited availability as a resource, or selective harvesting. 
Table A-4. Mussel shell size classes by feature and block

\begin{tabular}{|c|c|c|c|c|c|c|c|c|c|c|c|c|c|c|c|}
\hline Block/Feature & Size Class* & 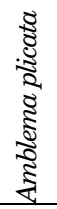 & 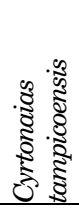 & 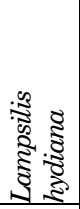 & 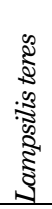 & 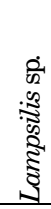 & 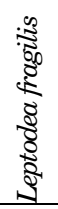 & 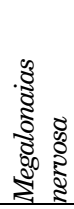 & 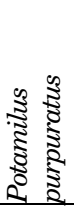 & 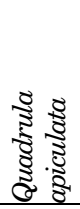 & 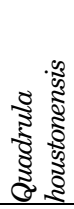 & 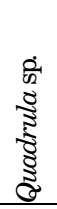 & 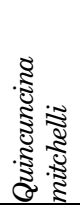 & 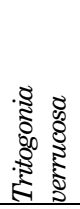 & Total \\
\hline East Block & $26-30$ & & & & & & & & & & 1 & & & & 1 \\
\hline East Block & $31-35$ & & & & & & & & & & 2 & & & & 2 \\
\hline East Block & $36-40$ & & & & & & & & & $?$ & & & & & 2 \\
\hline$\overline{\text { East Block }}$ & $41-45$ & & & & & & & & & 1 & & & & & 1 \\
\hline 9 & $26-30$ & 2 & & & & & & & & & 9 & & & & 11 \\
\hline 9 & $31-35$ & 35 & & & & & & & & & 24 & & & & 59 \\
\hline 9 & $36-40$ & 50 & 1 & & & & & & & & 24 & & 6 & & 81 \\
\hline 9 & $41-45$ & 7 & 1 & & & & & & & & 6 & & 2 & & 16 \\
\hline 9 & $46-50$ & 4 & 1 & & & & & & & & & & & & 5 \\
\hline 9 & $51-55$ & 2 & 2 & & & & & & & 1 & & & & & 5 \\
\hline 9 & $66-70$ & 1 & & & & & & & & & & & & & 1 \\
\hline 10 & $26-30$ & & & & & & & & & & 3 & & & & 3 \\
\hline 10 & $31-35$ & 3 & & & & & & & & & 12 & & & & 15 \\
\hline 10 & $36-40$ & 2 & & & 1 & & & & & & 9 & & & & 12 \\
\hline 10 & $41-45$ & 3 & & & & & & & & & 2 & & & & 5 \\
\hline 10 & $46-50$ & & & & & & & & & & 2 & 1 & 1 & & 4 \\
\hline 10 & $56-60$ & 1 & & & & & & & & & & & & & 1 \\
\hline 10 & $61-65$ & 1 & & & & & & & & & & & & & 1 \\
\hline 16 & $26-30$ & 4 & & & & & & & & & 18 & & & & 22 \\
\hline 16 & $31-35$ & 45 & & & & & & & & & 36 & & 1 & & 82 \\
\hline 16 & $36-40$ & 66 & 2 & & & & 1 & & & & 24 & & 4 & & 97 \\
\hline 16 & $41-45$ & 12 & 1 & & & & & & & 1 & 3 & & 1 & & 18 \\
\hline 16 & $46-50$ & 8 & 1 & & & & & & & & 4 & & & & 13 \\
\hline 16 & $51-55$ & 2 & & & & & & & & 2 & & & & & 4 \\
\hline$\overline{16}$ & $56-60$ & 4 & & & & & & & & & & & & & 4 \\
\hline 16 & $61-65$ & 1 & & & & & & & & & & & & & 1 \\
\hline 20 & $21-25$ & & & & & & & & & & 2 & & & & 2 \\
\hline 20 & $26-30$ & & & & & & & & & & 2 & & & & 2 \\
\hline 20 & $31-35$ & & & & & & & & & & 6 & & 1 & & 7 \\
\hline 20 & $36-40$ & & & & & & & & & & 2 & & & & 2 \\
\hline 20 & $41-45$ & 1 & & & & & & & & & 1 & & & & 2 \\
\hline 20 & $46-50$ & & & 1 & & & & & & & & & & & 1 \\
\hline 20 & $56-60$ & & & & & & & & & & & & & 1 & 1 \\
\hline 20 & $61-65$ & & & 1 & & & & & & & & & & & 1 \\
\hline
\end{tabular}


Data Recovery Excavations at the J. B. White Site

Table A-4, continued

\begin{tabular}{|c|c|c|c|c|c|c|c|c|c|c|c|c|c|c|c|}
\hline Block/Feature & Size Class* & 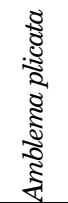 & 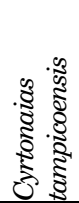 & 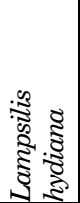 & 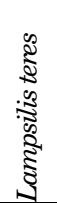 & 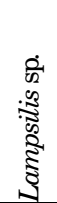 & 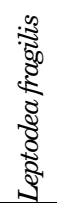 & 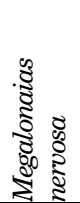 & 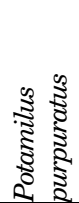 & 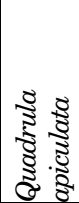 & 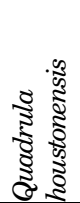 & 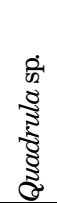 & 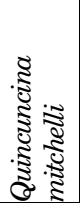 & 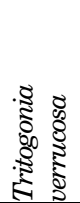 & Total \\
\hline $21 a$ & $21-25$ & & & & & & & & & & 2 & & & & 2 \\
\hline $21 \mathrm{a}$ & $26-30$ & 1 & & & & & & & & & 8 & & & & 9 \\
\hline $21 \mathrm{a}$ & $31-35$ & 4 & & & & & & & & 2 & 31 & & & & 37 \\
\hline $21 \mathrm{a}$ & $36-40$ & 8 & & & & & & & & 2 & 42 & & & & 52 \\
\hline $21 \mathrm{a}$ & $41-45$ & 2 & & 1 & & & & & & & 6 & & & & 9 \\
\hline $21 a$ & $46-50$ & 7 & & 1 & & & & & & & & & 1 & & 9 \\
\hline $21 \mathrm{a}$ & $51-55$ & 5 & 1 & & & & & & & & & & & 2 & 8 \\
\hline $21 \mathrm{a}$ & $56-60$ & 8 & & & & & & & & & & & & & 8 \\
\hline $21 \mathrm{a}$ & $61-65$ & 4 & & & & & & & & & & & & & 4 \\
\hline $21 \mathrm{a}$ & $71-75$ & 2 & & & & & & & & & & & & & 2 \\
\hline $21 b$ & $21-25$ & & & & & & & & & & 2 & & & & 2 \\
\hline $21 b$ & $26-30$ & & & & & & & & & & 3 & & & & 3 \\
\hline $21 b$ & $31-35$ & 7 & & & & & & & & & 22 & & & & 29 \\
\hline $21 \mathrm{~b}$ & $36-40$ & 9 & & & & & & & & & 25 & & & & 34 \\
\hline $21 \mathrm{~b}$ & $41-45$ & 3 & 1 & & & & & & & & 10 & & 2 & & 16 \\
\hline $21 b$ & $46-50$ & 9 & 3 & 1 & & & & & & & 2 & & 2 & & 17 \\
\hline $21 b$ & $51-55$ & 9 & & & & & 1 & & & & & & 1 & & 11 \\
\hline $21 \mathrm{~b}$ & $56-60$ & 10 & & 1 & & & & & & & & & & & 11 \\
\hline $21 \mathrm{~b}$ & $61-65$ & 2 & & & & & & & & & & & & & 2 \\
\hline $21 \mathrm{~b}$ & $66-70$ & 2 & & & & & & & & & & & & & 2 \\
\hline 24 & $26-30$ & & & & & & & & & & 1 & & & & 1 \\
\hline 24 & $31-35$ & 1 & & & & & & & & & & & & & 1 \\
\hline 24 & $36-40$ & & & & & & & & & & 5 & & & & 5 \\
\hline 24 & $56-60$ & & 1 & & & & & & & & & & & & 1 \\
\hline Total & & 347 & 15 & 6 & 1 & 0 & 2 & 0 & 0 & 11 & 351 & 1 & 22 & 3 & 759 \\
\hline
\end{tabular}

* Measurements are in millimeters. 
Table A-5. Burned mussel shells

\begin{tabular}{|c|c|c|c|}
\hline Block/Feature & Level & Species & Total \\
\hline East Block & 10 & Unidentified fragments & 32 \\
\hline East Block & 10 & Amblema plicata & 34 \\
\hline East Block & 10 & Lampsilis sp. & 5 \\
\hline East Block & 10 & Quadrula houstonensis & 34 \\
\hline 16 & 8 & Unidentified fragments & 15 \\
\hline 16 & 8 & Amblema plicata & 55 \\
\hline 16 & 8 & Quadrula houstonensis & 33 \\
\hline 16 & 9 & Unidentified fragments & 2 \\
\hline 16 & 9 & Amblema plicata & 2 \\
\hline 20 & 9 & Unidentified fragments & 88 \\
\hline 20 & 9 & Amblema plicata & 70 \\
\hline 20 & 9 & Quadrula houstonensis & 11 \\
\hline 20 & 9 & Tritogonia verrucosa & 1 \\
\hline 20 & 10 & Unidentified fragments & 44 \\
\hline 20 & 10 & Amblema plicata & 77 \\
\hline 20 & 10 & Lampsilis sp. & 1 \\
\hline 20 & 10 & Quadrula houstonensis & 37 \\
\hline $21 \mathrm{a}$ & 6 & Amblema plicata & 1 \\
\hline $21 \mathrm{a}$ & 6 & Quadrula houstonensis & 3 \\
\hline $21 \mathrm{a}$ & 7 & Amblema plicata & 2 \\
\hline $21 b$ & 7 & Unidentified fragments & 6 \\
\hline $21 b$ & 7 & Amblema plicata & 1 \\
\hline $21 b$ & 7 & Quadrula houstonensis & 3 \\
\hline 24 & 10 & Unidentified fragments & 4 \\
\hline 24 & 10 & Amblema plicata & 8 \\
\hline 24 & 10 & Quadrula houstonensis & 28 \\
\hline Total & & & 597 \\
\hline
\end{tabular}


Data Recovery Excavations at the J. B. White Site

\section{REFERENCES CITED}

Cummings, Kevin S., and Christine A. Mayer 1992 Field Guide to Freshwater Mussels of the Midwest. Manual 5. Illinois Natural History Survey, Champaign, Illinois.

Howells, Robert G., Raymond W. Neck, and Harold D. Murray

1996 Freshwater Mussels of Texas. Texas Parks and Wildlife Department. Austin, Texas.

Howells, Robert G., Jennifer Neel-Hartman, and Stacy A. Wagner

2003 Freshwater Mussel Shell from 41MM340. In Data Recovery Excavations at 41MM340, A Late Archaic Site along Little River in Milam County, Texas, by
Richard B. Mahoney, Steve A. Tomka, Raymond P. Mauldin, Harry J. Shafer, Lee C. Nordt, Russell D. Greaves, and Rebecca R. Galdeano, pp. 88-101. Archeological Studies Program Report No. 54. Environmental Affairs Division, Texas Department of Transportation, Austin. Archaeological Survey Report No. 340, Center for Archaeological Research, The University of Texas at San Antonio.

Parmalee, Paul W., and Arthur E. Bogan

1998 The Freshwater Mussels of Tennessee. The University of Tennessee Press. Knoxville. 


\title{
APPENDIX B: Analysis of Gastropod Shells from 41MM341
}

\author{
Karen M. Gardner
}





\section{INTRODUCTION}

Gastropods from selected proveniences at 41MM341 were analyzed to provide information on possible paleoenvironmental conditions. Gastropods were analyzed from a column taken from the south wall of Excavation Unit 9. This column was outside the excavation blocks in an area with sparse cultural materials thereby presenting a sample of gastropods that may approximate normal populations. Each $10-\mathrm{cm}$ level in the column, correlating to levels used in the block excavations, was collected as upper and lower halves, labeled A and B; because so many minute and microscopic gastropods were recovered, only the B parts were analyzed. Also analyzed were gastropods from selected proveniences in seven of the shell features in the Main Block. These gastropods were collected from processed flotation samples, both heavy and light fractions. Gastropods were analyzed using a digital microscope (60x) and a Triplet $21-\mathrm{mm}$ hand lens (10x). Gastropods were identified by comparing them to published literature and references, as well as the Prewitt and Associates, Inc., comparative collection.

A total of 7,259 gastropods were identified from these samples, representing 8 families with 12 species identified (Table B-1). Two additional groups were identified to the genus level. The condition and preservation of the gastropods were good, allowing the maximum opportunity for identification, although the fragmentary condition of 249 of the gastropods did not allow for their identification. Rabdotus shells were collected by $1 / 4$-inch water-screen recovery for most feature proveniences, as this land snail was considered a possible food resource. The information on bulk Rabdotus recovery from the features is presented in Chapter 6. While the bulk Rabdotus totals include the Rabdotus recovery from the flotation samples, the bulk recovery is not reflected in the analysis presented here.

\section{SPECIES DESCRIPTIONS}

Strobilops texasiana (Pilsbry and Ferriss) is the most common gastropod, representing 36.6 percent of the analyzed sample. A member of the Strobilopsidae family, it is found throughout eastern Texas in areas of deciduous forest and woodlands, preferring moist environments of leaf litter, fallen logs, loose bark, and other forest-floor debris (Fullington and Pratt 1974:26; Leonard 1959:167). It also has been found along the margins of lakes and streams (Allen and Cheatum 1961:294, 307).

Rabdotus dealbatus dealbatus (Say) is the next most-abundant gastropod in the sample, representing 23.2 percent of those analyzed. Belonging to the Bulimulidae family, this is a common Texas species, typically found in semiarid and open grassy areas such as the tall grass prairies, although it has been recorded in sparsely wooded areas as well. It can be found under rocks and logs and other objects that provide cover (Allen and Cheatum 1961:294, 301; Fullington and Pratt 1974:16). This species is known for its ability to climb tall grasses and shrubs and for its habit of burrowing into the soil during hibernation (Fullington and Pratt 1974:16; Leonard 1959:104).

Gastrocopta contracta (Say) belongs to the family Pupillidae and is found widely throughout Texas. Constituting 8.3 percent of the analyzed sample, this species is found in wooded areas and near the margins of woodland pools and streams. It typically prefers a moist environment with leaf litter and fallen trees (Allen and Cheatum 1961:294, 303; Cheatum and Fullington 1973:11, 13).

Helicodiscus parallelus (Say) makes up 6.7 percent of the sample. A member of the Endodontidae family, this species is found throughout Texas, most commonly in wooded areas in shady or humid areas with leaf litter and fallen trees (Cheatum and Fullington 1971a:9; Leonard 1959:132).

Hawaiia minuscula (Binney), a member of the Zonitidae family, represents 4.5 percent of the analyzed sample. A common Texas species, it prefers a habitat made up of leaf litter and fallen trees in wooded areas, although it has also been found under rocks and stones and in clumps of grass in grassland areas (Allen and Cheatum 1961: 294, 303; Leonard 1959:120).

Helicina orbiculata tropica (Say) represents 3.9 percent of the sample and belongs to the family Helicindae. Found throughout much of Texas, this species is most common in sparsely wooded areas, but also may be found in open grassy areas (Allen and Cheatum 1961:295, 309; Fullington and Pratt 1974:9).

$$
\text { Anguispira alternata (Say), another }
$$


Data Recovery Excavations at the J. B. White Site

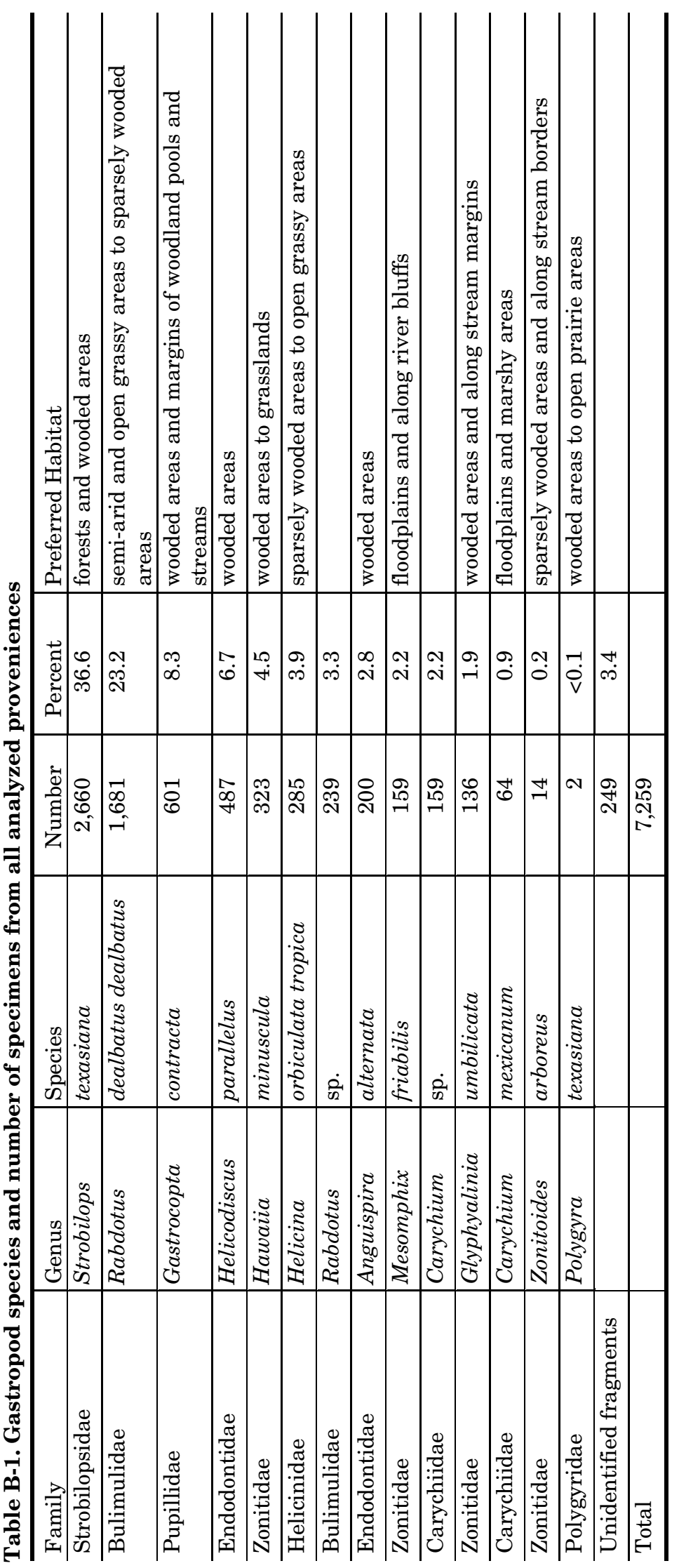


member of the Endodontidae family, is documented in east Texas as well as parts of central Texas (Cheatum and Fullington 1971a:8). This species, which constitutes 2.8 percent of the analyzed gastropods, is considered a woodland inhabitant with a preference for moist leaf litter and fallen trees, although it has also been found living in upland areas (Allen and Cheatum 1961:294, 307; Leonard 1959:130).

Mesomphix friabilis (Binney) has been documented in central and east Texas and is a member of the family Zonitidae. It is most commonly found on floodplains and along river bluffs and appears to prefer habitats where it can burrow into moist leaf litter (Leonard 1959:115; Malof n.d.).

Glyphyalinia umbilicata, historically known as Retinella indenta, is also a member of the family Zonitidae and makes up 1.9 percent of the analyzed sample. This species is found in wooded areas and along stream margins, although on occasion it has been documented in upland and open grassland areas. It is typically found in leaf litter, in rotting logs, and among other forest debris (Allen and Cheatum 1961:294, 303; Leonard 1959:114).

Carychium mexicanum (Pilsbry), a member of the family Carychiidae, makes up less than 1 percent of the sample. It is found ranging through the Gulf Coastal plain and extending up stream valleys into the Edwards Plateau (Fullington and Pratt 1974:9-10). It is typically found in leaf litter around old logs and other vegetation, usually on floodplains and marshy areas (Fullington and Pratt 1974:10; Leonard 1959:194).

Zonitoides arboreus (Say) belongs to the family Zonitidae and is represented in the sample in a limited amount ( 0.2 percent). Found throughout Texas, it most typically is encountered in sparsely wooded areas, but has also been found along the borders of streams (Allen and Cheatum 1961:294, 303; Cheatum and Fullington 1971a:9). It is found most commonly under rocks and fallen trees and in and around the loose bark of decaying trees (Leonard 1959:122).

Polygyra texasiana (Moricand) is represented by only two specimens. It is found throughout Texas. Belonging to the family Polygyridae, it is found in a range of habitats, including woodlands, the margins of streams and rivers, and areas of open prairie (Allen and Cheatum 1961:295, 310; Cheatum and Fullington 1971b:10-12).

Two groups of immature gastropods were classified only to the genus level. Of the 398 immature specimens, 239 are Rabdotus sp., family Bulimulidae, and 159 are Carychium sp., of the family Carychiidae. The remaining specimens in the gastropod sample are too fragmentary to be positively identified and make up 3.4 percent of the total sample.

\section{HABITAT PREFERENCES}

As can be seen in the species descriptions, and as summarized in Table B-1, although there is some variety in the habitat preferences of the different species, they fall into four main groupings:

- Primarily wooded and forested areas Strobilops texasiana Helicodiscus parallelus Anguispira alternata

- Sparsely wooded areas to grasslands and prairies

Rabdotus dealbatus dealbatus

Hawaiia miniscula

Helicina orbiculata tropica

Polygyra texasiana

- Wooded areas to stream and river margins Gastrocopta contracta Glyphyalinia umbilicata

Zonitoides arboreus

- Floodplains to marshy areas

Mesomphix friabilis

Carychium mexicanum

It is important to keep in mind that these are general habitat preference groupings because most of the species will inhabit a variety of locations, given the right conditions. As a group, they prefer locations where there is some type of floor covering-whether leaf litter, forest debris, or grass cover-and some degree of moisture present. They are often found near, under, or attached to fallen trees, rocks, plants, and anything else that presents an attachable surface.

Site 41MM341 is located in a floodplain setting along the Little River and sits along the 
margin of both the Blackland Prairie and the Oak Woodlands. These two regions include all of the areas that are favored by the identified gastropod species, from grasslands to sparsely wooded areas in floodplains on the Blackland Prairie to wooded areas and forests and grass understory of the Oak Woodlands (Mauldin and Mahoney 2003:5). The environmental conditions and physical environments present would have provided ideal habitat for the variety of gastropods that have been identified.

\section{DISTRIBUTION PATTERNS}

As can be seen in Table B-2, Strobilops texasiana is by far the dominant species in the column sample, accounting for more than 53 percent. Rabdotus dealbatus dealbatus, the secondmost-common species in the analyzed sample as a whole, represents less than 1 percent of the gastropods in the column sample, with only 6 specimens represented. Twenty immature specimens identified as Rabdotus sp. are also present and are found concentrated in the lower levels of the column sample. The greatest concentrations of Carychium mexicanum are found in the upper two levels and are missing from the lower levels, with the exception of a small number of specimens close to the bottom of the column. Mesomphix friabilis, by contrast, is present in only the lower levels of the column and in only small quantities. Overall, the greatest concentrations of gastropods, with the greatest number of species represented, occurs in Levels 7B-13B. There does not appear to be any specific concentration throughout the levels that can be tied to any environmental condition, because all of the species occupy a range of habitats. Interestingly, the two species found in a floodplain to marshy habitat occur, for the most part, in distinct sections of the column rather than being found together.

The gastropods found in the Main Block present a different pattern, as seen in Table B-3. Although Rabdotus dealbatus dealbatus and Rabdotus sp. together made up less than 1 percent of the column sample, in the block excavation they consitute almost 55 percent of the sample. By far, the greatest concentration of gastropods and largest range of species are found in Level 8. Gastropod concentrations are fairly consistent in the other levels, with the exception of Level 9, which shows a drastic reduction in the number of gastropods.

Because the gastropods analyzed were from selected proveniences, it is possible that the variability in occurrence may reflect sampling bias more than any environmental indicator or exploitation factor. However, it is still possible to see the ranges and relative frequencies of the different species in different levels across the site. In the column and Main Block samples, the greatest quantity and the greatest variety occur in Level 8 (160-170 cm below surface) and Level 8B (165-170 cm below surface).

When looking at the gastropods that came from selected features, as shown in Table B-4, similar patterns are observed. Strobilops texasiana and Rabdotus dealbatus dealbatus remain the most-common species, although they appear in the greatest concentrations in different features. Features 9, 21b, and 24 each contain primarily Strobilops texasiana, but Feature 17 contains mostly Rabdotus dealbatus dealbatus. Both are dominant species in Feature $21 \mathrm{a}$, and only Feature 16 has a different species, Gastrocopta contracta, that is most common, although even in this feature it is only slightly more numerous than Strobilops texasiana. When looking at habitat preferences and environmental indicators, once again the gastropods represented show a range of habitat preferences, without any clear delineators based on habitat. Only Feature 29 contains species that prefer the same habitat of a sparsely wooded area to grasslands and prairies; given the extremely small number of specimens from Feature 29 however, this cannot be viewed as a viable indicator. Rather, as demonstrated in the other analyses of the patterns of the gastropods, it appears that conditions were general enough and variable enough to provide a range of habitats that satisfied each of the different gastropod species.

Since Feature 17 is unusual in that is composed primarily of Rabdotus dealbatus dealbatus and Rabdotus sp. shells, the length of each snail was measured from base to apex for grouping into size classes. The intent was to see if it could be determined if the Rabdotus concentration was a natural occurrence or if it was cultural. If the concentration was natural, it would be expected that there would be a range of sizes, including both adult and immature 
Appendix B: Analysis of Gastropod Shells

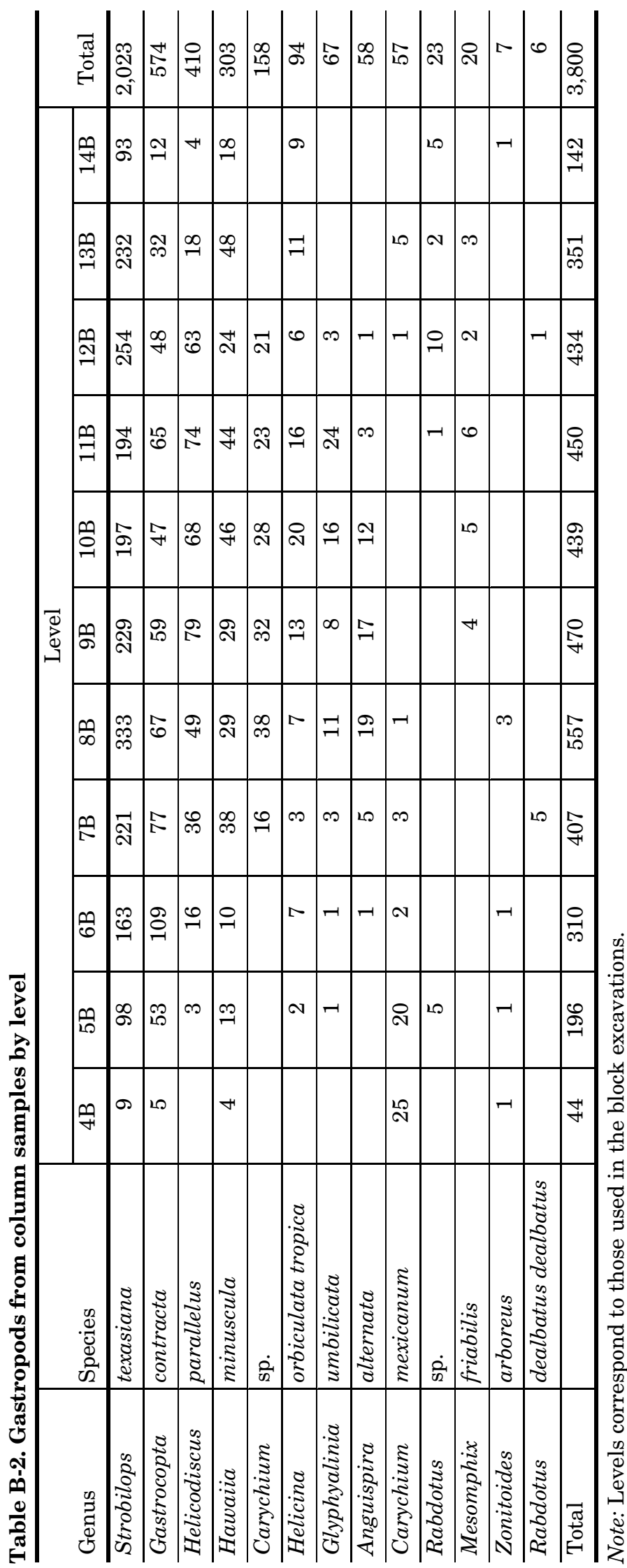


Table B-3. Gastropods from selected shell features in the Main Block by level

\begin{tabular}{|c|c|c|c|c|c|c|}
\hline \multirow[b]{2}{*}{ Genus } & \multirow[b]{2}{*}{ Species } & \multicolumn{4}{|c|}{ Level } & \multirow[b]{2}{*}{ Total } \\
\hline & & 6 & 7 & 8 & 10 & \\
\hline Rabdotus & dealbatus dealbatus & 84 & 256 & 1,333 & 2 & 1,675 \\
\hline Strobilops & texasiana & 56 & 119 & 246 & 216 & 637 \\
\hline Rabdotus & sp. & 17 & 67 & 130 & 2 & 216 \\
\hline Helicina & orbiculata tropica & 6 & 17 & 158 & 10 & 191 \\
\hline Anguispira & alternata & 11 & 33 & 97 & 1 & 142 \\
\hline Mesomphix & friabilis & 3 & 17 & 118 & 1 & 139 \\
\hline Helicodiscus & parallelus & 6 & 22 & 23 & 26 & 77 \\
\hline Glyphyalinia & umbilicata & 8 & 15 & 44 & 2 & 69 \\
\hline Gastrocopta & contracta & 1 & & 24 & 2 & 27 \\
\hline Hawaiia & minuscula & 1 & 4 & 6 & 9 & 20 \\
\hline Carychium & mexicanum & & & & 7 & 7 \\
\hline Zonitoides & arboreus & 2 & & 5 & & 7 \\
\hline Polygyra & texasiana & 1 & & 1 & & 2 \\
\hline Carychium & sp. & & 1 & & & 1 \\
\hline $\begin{array}{l}\text { Unidentified } \\
\text { fragments }\end{array}$ & & & & 249 & & 249 \\
\hline Total & & 196 & 551 & 2,434 & 278 & 3,459 \\
\hline
\end{tabular}

gastropods, reflecting the natural life cycle and community of the gastropod. If the concentration contained mainly larger, adult Rabdotus, the inference could be made that the feature represents the intentional selection of the gastropod as a food source. As can be seen in Table B-5, most of the Rabdotus shells from Feature 17 range between 16 and $30 \mathrm{~mm}$, with by far the greatest quantity being in the 21-25-mm size class. Given this distribution, it is likely that Feature 17 represents an intentional collection or harvest of Rabdotus, with selection focusing on the larger mature snails.

\section{SUMMARY}

At 41MM341, a range of gastropods was recovered. All of the species identified are known to inhabit the region, and the environment provides the range of habitats preferred by each of the species. Based on the analysis of selected features, it appears that there was intentional exploitation of at least one of the species, Rabdotus dealbatus dealbatus. 
Table B-4. Gastropods from selected features

\begin{tabular}{|c|c|c|c|c|c|}
\hline Feature & Level & Family & Genus & Species & Total \\
\hline 9 & 8 & Strobilopsidae & Strobilops & texasiana & 143 \\
\hline 9 & 8 & Helicinidae & Helicina & orbiculata tropica & 93 \\
\hline 9 & 8 & Endodontidae & Anguispira & alternata & 53 \\
\hline 9 & 8 & Zonitidae & Glyphyalinia & umbilicata & 19 \\
\hline 9 & 8 & Bulimulidae & Rabdotus & dealbatus dealbatus & 18 \\
\hline 9 & 8 & Endodontidae & Helicodiscus & parallelus & 14 \\
\hline 9 & 8 & Zonitidae & Mesomphix & friabilis & 13 \\
\hline 9 & 8 & Zonitidae & Zonitoides & arboreus & 5 \\
\hline 9 & 8 & Zonitidae & Hawaiia & minuscula & 3 \\
\hline 9 & 8 & Pupillidae & Gastrocopta & contracta & 2 \\
\hline 9 & 8 & Polygyridae & Polygyra & texasiana & 1 \\
\hline 9 & 8 & Unidentified fragments & & & 10 \\
\hline Subtotal & & & & & 374 \\
\hline 16 & 8 & Pupillidae & Gastrocopta & contracta & 20 \\
\hline 16 & 8 & Strobilopsidae & Strobilops & texasiana & 16 \\
\hline 16 & 8 & Helicinidae & Helicina & orbiculata tropica & 6 \\
\hline 16 & 8 & Endodontidae & Anguispira & alternata & 5 \\
\hline 16 & 8 & Zonitidae & Glyphyalinia & umbilicata & 2 \\
\hline 16 & 8 & Endodontidae & Helicodiscus & parallelus & 1 \\
\hline Subtotal & & & & & 50 \\
\hline 17 & 8 & Bulimulidae & Rabdotus & dealbatus dealbatus & 1,315 \\
\hline 17 & 8 & Bulimulidae & Rabdotus & sp. & 130 \\
\hline 17 & 8 & Zonitidae & Mesomphix & friabilis & 105 \\
\hline 17 & 8 & Strobilopsidae & Strobilops & texasiana & 87 \\
\hline 17 & 8 & Helicinidae & Helicina & orbiculata tropica & 59 \\
\hline 17 & 8 & Endodontidae & Anguispira & alternata & 39 \\
\hline 17 & 8 & Zonitidae & Glyphyalinia & umbilicata & 23 \\
\hline 17 & 8 & Endodontidae & Helicodiscus & parallelus & 8 \\
\hline 17 & 8 & Zonitidae & Hawaiia & minuscula & 3 \\
\hline 17 & 8 & Pupillidae & Gastrocopta & contracta & 2 \\
\hline 17 & 8 & Unidentified fragments & & & 239 \\
\hline Subtotal & & & & & 2,010 \\
\hline $21 \mathrm{a}$ & 6 & Bulimulidae & Rabdotus & dealbatus dealbatus & 84 \\
\hline $21 \mathrm{a}$ & 6 & Strobilopsidae & Strobilops & texasiana & 56 \\
\hline $21 \mathrm{a}$ & 6 & Bulimulidae & Rabdotus & sp. & 17 \\
\hline $21 a$ & 6 & Endodontidae & Anguispira & alternata & 11 \\
\hline $21 \mathrm{a}$ & 6 & Zonitidae & Glyphyalinia & umbilicata & 8 \\
\hline $21 a$ & 6 & Helicinidae & Helicina & orbiculata tropica & 6 \\
\hline $21 \mathrm{a}$ & 6 & Endodontidae & Helicodiscus & parallelus & 6 \\
\hline $21 \mathrm{a}$ & 6 & Zonitidae & Mesomphix & friabilis & 3 \\
\hline $21 \mathrm{a}$ & 6 & Zonitidae & Zonitoides & arboreus & 2 \\
\hline $21 \mathrm{a}$ & 6 & Polygyridae & Polygyra & texasiana & 1 \\
\hline $21 \mathrm{a}$ & 6 & Pupillidae & Gastrocopta & contracta & 1 \\
\hline $21 \mathrm{a}$ & 6 & Zonitidae & Hawaiia & minuscula & 1 \\
\hline $21 \mathrm{a}$ & 7 & Bulimulidae & Rabdotus & dealbatus dealbatus & 232 \\
\hline $21 \mathrm{a}$ & 7 & Bulimulidae & Rabdotus & sp. & 64 \\
\hline $21 \mathrm{a}$ & 7 & Zonitidae & Mesomphix & friabilis & 10 \\
\hline $21 \mathrm{a}$ & 7 & Endodontidae & Anguispira & alternata & 4 \\
\hline $21 \mathrm{a}$ & 7 & Zonitidae & Glyphyalinia & umbilicata & 1 \\
\hline Subtotal & & & & & 507 \\
\hline
\end{tabular}


Table B-4, continued

\begin{tabular}{|c|c|c|c|c|c|}
\hline Feature & Level & Family & Genus & Species & Total \\
\hline $21 b$ & 7 & Strobilopsidae & Strobilops & texasiana & 119 \\
\hline $21 b$ & 7 & Endodontidae & Anguispira & alternata & 29 \\
\hline $21 b$ & 7 & Bulimulidae & Rabdotus & dealbatus dealbatus & 24 \\
\hline $21 b$ & 7 & Endodontidae & Helicodiscus & parallelus & 22 \\
\hline $21 b$ & 7 & Helicinidae & Helicina & orbiculata tropica & 17 \\
\hline $21 b$ & 7 & Zonitidae & Glyphyalinia & umbilicata & 14 \\
\hline $21 b$ & 7 & Zonitidae & Mesomphix & friabilis & 7 \\
\hline $21 b$ & 7 & Zonitidae & Hawaiia & minuscula & 4 \\
\hline $21 b$ & 7 & Bulimulidae & Rabdotus & sp. & 3 \\
\hline $21 b$ & 7 & Carychiidae & Carychium & sp. & 1 \\
\hline Subtotal & & & & & 240 \\
\hline 24 & 10 & Strobilopsidae & Strobilops & texasiana & 216 \\
\hline 24 & 10 & Endodontidae & Helicodiscus & parallelus & 26 \\
\hline 24 & 10 & Zonitidae & Hawaiia & minuscula & 9 \\
\hline 24 & 10 & Helicinidae & Helicina & orbiculata tropica & 9 \\
\hline 24 & 10 & Carychiidae & Carychium & mexicanum & 7 \\
\hline 24 & 10 & Pupillidae & Gastrocopta & contracta & 2 \\
\hline 24 & 10 & Bulimulidae & Rabdotus & sp. & 2 \\
\hline 24 & 10 & Zonitidae & Glyphyalinia & umbilicata & 2 \\
\hline 24 & 10 & Zonitidae & Mesomphix & friabilis & 1 \\
\hline 24 & 10 & Endodontidae & Anguispira & alternata & 1 \\
\hline Subtotal & & & & & 275 \\
\hline 29 & 10 & Bulimulidae & Rabdotus & dealbatus dealbatus & 2 \\
\hline 29 & 10 & Helicinidae & Helicina & orbiculata tropica & 1 \\
\hline Subtotal & & & & & 3 \\
\hline \multicolumn{5}{|l|}{ Total } & 3,459 \\
\hline
\end{tabular}

Table B-5. Rabdotus dealbatus dealbatus and Rabdotus sp. from Feature 17 by size class

\begin{tabular}{l|l|c|c|c|c|c|c|c|c|c}
\hline Genus & Species & Fragmentary & $<10$ & $<5$ & $10-15$ & $16-20$ & $21-25$ & $26-30$ & $31-35$ & Total \\
\hline Rabdotus & $\begin{array}{l}\text { dealbatus } \\
\text { dealbatus }\end{array}$ & 84 & 1 & & 5 & 200 & 814 & 210 & 1 & 1,315 \\
\hline Rabdotus & sp. & 115 & 2 & 13 & & & & & & 130 \\
\hline Total & & 199 & 3 & 13 & 5 & 200 & 814 & 210 & 1 & 1,445 \\
\hline
\end{tabular}

Note: Measurements are in millimeters. 


\section{REFERENCES CITED}

Allen, D. C., and E. P. Cheatum

1961 Ecological Implications of Fresh-Water and Land Gastropods in Texas Archeological Studies. Bulletin of the Texas Archeological Society 31:291-316.

Cheatum, E. P., and R. W. Fullington

1971a Bulletin 1: The Aquatic and Land Mollusca of Texas. Supplement: Keys to the Families of the Recent Land and Fresh-Water Snails of Texas. The Dallas Natural Science Association and the Dallas Museum of Natural History. Dallas, Texas.

1971b Bulletin 1: The Aquatic and Land Mollusca of Texas. Part One: The Recent and Pleistocene Members of the Gastropod Family Polygyridae in Texas. The Dallas Natural Science Association and the Dallas Museum of Natural History. Dallas, Texas.

1973 Bulletin 1: The Aquatic and Land Mollusca of Texas. Part Two: The Recent and Pleistocene Members of the Pupillidae and Urocoptidae (Gastropoda) in Texas. The Dallas Natural Science Association and the Dallas Museum of Natural History. Dallas, Texas.

Fullington, Richard W., and William Lloyd Pratt Jr. 1974 Bulletin 1: The Aquatic and Land Mollusca of Texas. Part Three: The Helicinidae, Carychiidae, Achatinidae, Bradybaenidae,
Bulimulidae, Cionellidae, Haplotrematidae, Helicidae, Oreohelicidae, Spiraxidae, Streptaxidae, Strobilopsidae, Thysanophoridae, Valloniidae (Gastropoda) in Texas. The Dallas Natural Science Association and the Dallas Museum of Natural History. Dallas, Texas.

Leonard, A. Byron

1959 Handbook of Gastropods in Kansas. Miscellaneous Publication No. 20. University of Kansas Museum of Natural History. Topeka, Kansas.

Malof, Andrew F.

n.d. Texas Snails in Archaeological Contexts. Available from http:/www.dirtbrothers.org/ editorial/malof.htm [Accessed on April 15, 2004].

Mauldin, Raymond P., and Richard B. Mahoney 2003 Environmental Background. In Data Recovery Excavations at 41MM340, A Late Archaic Site along Little River in Milam County, Texas, by Richard B. Mahoney, Steve A. Tomka, Raymond P. Mauldin, Harry J. Shafer, Lee C. Nordt, Russell D. Greaves, and Rebecca R. Galdeano. Archaeological Studies Program Report No. 54. Environmental Affairs Division, Texas Department of Transportation, Austin. Archaeological Survey Report No. 340. Center for Archaeological Research, The University of Texas at San Antonio. 



\title{
APPENDIX C: Stable Carbon and Oxygen Isotope Analysis of Mussel Shells from 41MM341
}

\author{
E. Frances Gadus \\ Prewitt and Associates, Inc. \\ and \\ Robert H. Tykot \\ University of South Florida
}





\section{INTRODUCTION AND METHODS}

Analysis of stable carbon and oxygen isotopes in shells is now commonly used to assess environmental seasonality (for an overview, see Claassen 1998; see Davis 2001, Deith 1986, Mannino 2003, and Mueller-Lupp et al. 2004 for some specific examples of applications). The measurement of oxygen isotopes in particular is used to obtain water temperature data that can be related to ambient temperature and thus estimate the season of death in the outermost layers of shells. Carbon isotope values in shells mainly reflect geological carbonate contributions to the water, and the $\mathrm{C}_{3}$ photosynthetic pathway of phytoplankton, while varying significantly between freshwater (lakes and rivers) and saltwater environments. While some studies go back to the 1950s, modern automated instrumentation provides more precise results, but with limitations (see Bailey et al. 1983; Shackleton 1973).

Two approaches were taken to sampling of the selected Amblema plicata (threeridge mussel) shells in this study. First, duplicate samples were taken of the outer edge layers of 19 shells. The duplicate sampling was done to test the reliability of sampling the last growth increment and thereby assess the applicability of Amblema plicata to season of death reconstruction. Second, four sequential samples starting at the outer edge of the shell and moving inward for approximately $3 \mathrm{~mm}$ were taken from another 16 individual shells. Sequential sampling was done to mitigate single-sample variability and to address climatic variation through time.

The shells were sampled by the Laboratory for Archaeological Science at the University of South Florida. All shells were cut in half to provide a clear flat interior surface that could be easily sampled. The shells were then cleaned in an ultrasonic distilled/deionized water bath, and a $0.75-\mathrm{mm}$ drill bit was used to sample the shells, with the immediate surface powder discarded to avoid any contamination. At most, a few milligrams were collected in each drilling, and only $1 \mathrm{mg}$ was actually analyzed on the mass spectrometer.

Samples were analyzed using a Finnigan MAT DeltaPlus XL stable isotope ratio mass spectrometer equipped with a Kiel III individual acid bath carbonate system, which eliminates the need both for off-line production of $\mathrm{CO}_{2}$ by reaction of the sample with 100 percent pure phosphoric acid in a vacuum-sealed glass tube, and the cryogenic purification of the resulting gas sample. After the sample is converted to $\mathrm{CO}_{2}$, the gaseous sample is then ionized and the different masses $(44,45,46)$ collected in separate Faraday cups. Mass 46 is mostly a result of a single ${ }^{18} \mathrm{O}$, so its measurement allows for a formulaic determination of how much of the mass 45 signal is from ${ }^{17} \mathrm{O}$ and therefore how much is from ${ }^{13} \mathrm{C}$. Mass 44 represents the dominant ${ }^{12} \mathrm{C}$ and ${ }^{16} \mathrm{O}$ isotopes.

Accuracy and precision are controlled by the use of reference gases against which samples are measured, coupled with the analysis of several solid standard samples at the beginning of each run and then after every six or seven archeological samples. The analytical precision for stable isotope ratio mass spectrometry is typically $\pm 0.1 \%$ for $\delta^{13} \mathrm{C}$ and $\pm 0.2 \%$ for $\delta^{18} \mathrm{O}$.

The archeological shells in this study were recovered from 41MM341 on the Little River floodplain in Milam County, Texas. Three analysis units were defined at this site spanning a 700-year period. Multiple shell features associated with each of the analysis units were sampled for this study. Shell Features 10, 21a, and $21 \mathrm{~b}$ were in Analysis Unit 1 (ca. A.D. 11001300); Features 9, 16, and 20 were in Analysis Unit 2 (ca. A.D. 800-1100); and Feature 29 along with shells from Excavation Unit 315, Level 10, were in Analysis Unit 3 (ca. A.D. 600-800). The shells were recovered from multiple proveniences within generally the most horizontally discrete parts of the features. The shell features sampled ranged in maximum dimension from 0.8 to $6.0 \mathrm{~m}$ and were 5 to $15 \mathrm{~cm}$ thick. They appear to have resulted from discrete occupations of the site. The number of shells selected from each feature provenience ranged from one to four with an average of three. This low number is directly related to the numbers of shells with intact outer edges. Shells selected for duplicate isotope sampling came from Features 9, $16,20,21 \mathrm{a}$, and $21 \mathrm{~b}$; these features were large enough to provide many intact shells. Shells sequentially sampled came from Features 9,10 , 21b, and 29, as well as Excavation Unit 315, Level 10. In addition, sequential samples were taken from three modern Amblema plicata shells with a known season of death (Robert G. Howells of the Texas Parks and Wildlife Department provided the modern shells). These 
Data Recovery Excavations at the J. B. White Site

Table C-1. Results of stable carbon and oxygen isotope analysis of mussel shells

\begin{tabular}{|c|c|c|c|c|c|}
\hline USF Lab No. & Feature & Provenience & Sample & $\delta^{13} \mathrm{C}$ & $\delta^{18} \mathrm{O}$ \\
\hline \multicolumn{6}{|c|}{ Duplicate Samples: } \\
\hline 7311 & 9 & EU 14, Level 8 & Shell 1, Sample 1 & -7.5 & -3.7 \\
\hline 7312 & & & Shell 1, Sample 2 & -7.6 & -3.4 \\
\hline 7313 & 9 & EU 14, Level 8 & Shell 2, Sample 1 & -7.5 & -3.6 \\
\hline 7314 & & & Shell 2, Sample 2 & -7.4 & -3.5 \\
\hline 7315 & 9 & EU 14, Level 8 & Shell 3, Sample 1 & -7.6 & -4.4 \\
\hline 7316 & & & Shell 3, Sample 2 & -6.5 & -3.8 \\
\hline 7291 & 9 & EU 50, Level 8 & Shell 1, Sample 1 & -8.8 & -3.8 \\
\hline 7292 & & & Shell 1, Sample 2 & -8.3 & -3.7 \\
\hline 7293 & 9 & EU 50, Level 8 & Shell 2, Sample 1 & -6.6 & -2.8 \\
\hline 7294 & & & Shell 2, Sample 2 & -6.7 & -3.3 \\
\hline 7307 & 9 & EU 50, Level 9 & Shell 1, Sample 1 & -7.8 & -4.5 \\
\hline 7308 & & & Shell 1, Sample 2 & -8.5 & -4.8 \\
\hline 7309 & 9 & EU 50, Level 9 & Shell 2, Sample 1 & -7.1 & -3.8 \\
\hline 7310 & & & Shell 2, Sample 2 & & \\
\hline 7279 & 16 & EU 53, Level 8 & Shell 1, Sample 1 & -9.0 & -4.8 \\
\hline 7280 & & & Shell 1, Sample 2 & -7.0 & -3.5 \\
\hline 7277 & 16 & EU 53, Level 8 & Shell 2, Sample 1 & -9.9 & -4.1 \\
\hline 7278 & & & Shell 2, Sample 2 & -10.0 & -4.5 \\
\hline 7281 & 16 & EU 53, Level 8 & Shell 3, Sample 1 & -6.4 & -2.0 \\
\hline 7282 & & & Shell 3, Sample 2 & -7.4 & -3.6 \\
\hline 7289 & 20 & EU 108, Level 9 & Shell 1, Sample 1 & -5.6 & -2.9 \\
\hline 7290 & & & Shell 1, Sample 2 & -5.6 & -2.9 \\
\hline 7269 & $21 \mathrm{a}$ & EU 43, Level 6 & Shell 1, Sample 1 & -6.9 & -4.6 \\
\hline 7270 & & & Shell 1, Sample 2 & -6.6 & -4.0 \\
\hline 7271 & $21 \mathrm{a}$ & EU 43, Level 6 & Shell 2, Sample 1 & -7.5 & -5.0 \\
\hline 7272 & & & Shell 2, Sample 2 & -8.1 & -5.0 \\
\hline 7283 & $21 \mathrm{a}$ & EU 123, Level 6 & Shell 1, Sample 1 & -7.1 & -5.2 \\
\hline 7284 & & & Shell 1, Sample 2 & -7.9 & -6.1 \\
\hline 7285 & $21 \mathrm{a}$ & EU 123, Level 6 & Shell 2, Sample 1 & -6.4 & -4.1 \\
\hline 7286 & & & Shell 2, Sample 2 & -6.4 & -4.2 \\
\hline 7287 & $21 \mathrm{a}$ & EU 123, Level 6 & Shell 3, Sample 1 & -7.3 & -4.9 \\
\hline 7288 & & & Shell 3, Sample 2 & -6.7 & -4.1 \\
\hline 7241 & $21 \mathrm{~b}$ & EU 131, Level 7 & Shell 1, Sample 1 & -7.2 & -5.5 \\
\hline 7242 & & & Shell 1, Sample 2 & -7.5 & -2.0 \\
\hline 7239 & $21 \mathrm{~b}$ & EU 131, Level 7 & Shell 2, Sample 1 & -8.5 & -2.5 \\
\hline 7240 & & & Shell 2, Sample 2 & -7.2 & -6.2 \\
\hline 7243 & $21 b$ & EU 131, Level 7 & Shell 3, Sample 1 & -6.5 & -4.2 \\
\hline 7244 & & & Shell 3, Sample 2 & -6.3 & -4.0 \\
\hline \multicolumn{6}{|c|}{ Sequential Samples: } \\
\hline 7295 & 9 & EU 13, Level 8 & Shell 1, Sample A & -7.8 & -2.3 \\
\hline 7296 & & & Shell 1, Sample B & -6.0 & -3.5 \\
\hline 7297 & & & Shell 1, Sample C & -5.1 & -2.1 \\
\hline 7298 & & & Shell 1, Sample D & -4.8 & -2.7 \\
\hline 7299 & 9 & EU 13, Level 8 & Shell 2, Sample A & -6.7 & -4.0 \\
\hline 7300 & & & Shell 2, Sample B & -6.3 & -4.0 \\
\hline 7301 & & & Shell 2, Sample C & -5.6 & -2.6 \\
\hline 7302 & & & Shell 2, Sample D & -6.0 & -3.1 \\
\hline 7303 & 9 & EU 13, Level 8 & Shell 3, Sample A & -7.8 & -4.6 \\
\hline 7304 & & & Shell 3, Sample B & -4.5 & -3.1 \\
\hline
\end{tabular}


Appendix C: Carbon and Oxygen Isotope Analysis of Mussel Shells

Table C-1, continued

\begin{tabular}{|c|c|c|c|c|c|}
\hline USF Lab No. & Feature & Provenience & Sample & $\delta^{13} \mathrm{C}$ & $\delta^{18} \mathrm{O}$ \\
\hline 7305 & & & Shell 3, Sample C & -6.4 & -3.4 \\
\hline 7306 & & & Shell 3, Sample D & -6.2 & -3.7 \\
\hline 7257 & 10 & EU 11, Level 6 & Shell 1, Sample A & -6.5 & -4.5 \\
\hline 7258 & & & Shell 1, Sample B & -5.7 & -4.4 \\
\hline 7259 & & & Shell 1, Sample C & -5.6 & -4.0 \\
\hline 7260 & & & Shell 1, Sample D & -4.8 & -4.2 \\
\hline 7261 & 10 & EU 11, Level 6 & Shell 2, Sample A & -6.1 & -3.5 \\
\hline 7262 & & & Shell 2, Sample B & -6.5 & -1.3 \\
\hline 7263 & & & Shell 2, Sample C & -6.0 & -6.1 \\
\hline 7264 & & & Shell 2, Sample D & -8.6 & -2.8 \\
\hline 7265 & 10 & EU 11, Level 6 & Shell 3, Sample A & -5.9 & -4.0 \\
\hline 7266 & & & Shell 3, Sample B & -5.7 & -5.3 \\
\hline 7267 & & & Shell 3, Sample C & -6.2 & -6.0 \\
\hline 7268 & & & Shell 3, Sample D & -4.8 & -5.1 \\
\hline 7245 & $21 b$ & EU 177, Level 7 & Shell 1, Sample A & -6.9 & -2.9 \\
\hline 7246 & & & Shell 1, Sample B & -7.9 & -4.8 \\
\hline 7247 & & & Shell 1, Sample C & -5.6 & -3.8 \\
\hline 7248 & & & Shell 1, Sample D & -5.9 & -4.3 \\
\hline 7249 & $21 b$ & EU 177, Level 7 & Shell 2, Sample A & -8.3 & -3.3 \\
\hline 7250 & & & Shell 2, Sample B & -7.7 & -3.3 \\
\hline 7251 & & & Shell 2, Sample C & -6.2 & -4.2 \\
\hline 7252 & & & Shell 2, Sample D & -7.6 & -3.9 \\
\hline 7253 & $21 b$ & EU 177, Level 7 & Shell 3, Sample A & -7.3 & -4.8 \\
\hline 7254 & & & Shell 3, Sample B & -7.0 & -4.6 \\
\hline 7255 & & & Shell 3, Sample C & -7.1 & -3.5 \\
\hline 7256 & & & Shell 3, Sample D & -7.8 & -4.1 \\
\hline 7231 & 29 & EU 151, Level 10 & Shell 1, Sample A & -4.8 & -3.8 \\
\hline 7232 & & & Shell 1, Sample B & -4.6 & -1.1 \\
\hline 7233 & & & Shell 1, Sample C & -5.7 & -2.2 \\
\hline 7234 & & & Shell 1, Sample D & -5.0 & -3.7 \\
\hline 7235 & 29 & EU 151, Level 10 & Shell 2, Sample A & -5.7 & -2.6 \\
\hline 7236 & & & Shell 2, Sample B & -5.4 & -3.9 \\
\hline 7237 & & & Shell 2, Sample C & -6.5 & -2.0 \\
\hline 7238 & & & Shell 2, Sample D & -7.2 & -2.5 \\
\hline 7227 & 29 & EU 151, Level 10 & Shell 3, Sample A & -5.3 & -2.2 \\
\hline 7228 & & & Shell 3, Sample B & -6.2 & -2.5 \\
\hline 7229 & & & Shell 3, Sample C & -5.7 & -2.4 \\
\hline 7230 & & & Shell 3, Sample D & -7.5 & -2.6 \\
\hline 7273 & & EU 315, Level 10 & Shell 1, Sample A & -5.8 & -3.8 \\
\hline 7274 & & & Shell 1, Sample B & -5.1 & -4.1 \\
\hline 7275 & & & Shell 1, Sample C & -5.5 & -3.5 \\
\hline 7276 & & & Shell 1, Sample D & -10.3 & -5.0 \\
\hline 7212 & & Modern sample & Shell 1, Sample A & 1.7 & -2.2 \\
\hline 7213 & & & Shell 1, Sample B & -7.0 & -8.6 \\
\hline 7214 & & & Shell 1, Sample C & -4.7 & -3.5 \\
\hline 7215 & & & Shell 1, Sample D & -9.1 & -8.4 \\
\hline 7219 & & Modern sample & Shell 2, Sample A & -6.3 & -4.2 \\
\hline 7220 & & & Shell 2, Sample B & -5.6 & -3.7 \\
\hline 7221 & & & Shell 2, Sample C & -3.9 & -4.6 \\
\hline 7222 & & & Shell 2, Sample D & -4.3 & -4.1 \\
\hline 7223 & & Modern sample & Shell 3, Sample A & -5.9 & -5.3 \\
\hline
\end{tabular}


Data Recovery Excavations at the J. B. White Site

Table C-1, continued

\begin{tabular}{c|l|l|l|c|c}
\hline USF Lab No. & Feature & Provenience & Sample & $\delta^{13} \mathrm{C}$ & $\delta^{18} \mathrm{O}$ \\
\hline 7224 & & & Shell 3, Sample B & -4.5 & -4.0 \\
\hline 7225 & & & Shell 3, Sample C & -5.3 & -3.7 \\
\hline 7226 & & & Shell 3, Sample D & -5.6 & -3.7 \\
\hline
\end{tabular}

Note: No values for USF Lab No. 7310 because mass spectrometer failed.

modern samples came from the Leon River (Belton Lake) in Bell County, Texas. The Leon River merges with the Lampasas River to become the Little River approximately $54 \mathrm{~km}$ westnorthwest of the project area. As such, the modern shells are from the same drainage and same region as the archeological shells. Modern samples were not drawn from the Little River at or near the project area because living mussel beds are not known to exist within this part of the river.

\section{RESULTS}

The results of the isotopic analysis for this study are presented in Table C-1. Values for both ${ }^{13} \mathrm{C}$ and ${ }^{18} \mathrm{O}$ were generated and are presented, though ${ }^{13} \mathrm{C}$ values are not pertinent to this study and hence are not discussed further. Values for ${ }^{18} \mathrm{O}$ that are relatively negative are considered to represent cooler water and thereby cooler ambient temperatures, while less-negative values indicate warmer temperatures.

To the authors' knowledge, no isotope study directed at seasonal or climatic variation has used the freshwater mussel Amblema plicata. The mussel was selected for this study due to its ubiquity in all analysis units at 41MM341 and its robustness, such that many complete shells (shells with the important last growth layer intact) were recovered. Still, this study raises questions as to the appropriateness of this species for such a study. Shackleton (1973:133134) discusses what makes a species useful for seasonality analysis. Most problematic for this study is Shackleton's caution to use a fast-growing species for isotopic studies of seasonal variation. Discrete shell increments in a fast-growing mollusk may represent only a few weeks of growth, and thus the analyst can be confident of what is being sampled. Slow-growing species, on the other hand, may compress years of growth into the very edge of the shell, making it difficult to sample the true final growth increment needed to establish season of death. Amblema plicata is considered a relatively slow-growing mollusk (Howells et al. 1996:8). As such, its appropriateness for season of death studies must be evaluated. Duplicate sampling of the outer edges of a selection of shells was done to try to determine whether the last growth increment could be consistently identified. This duplicate sampling thus provides some assessment of the utility of this species for studying season of death.

The results of the duplicate sampling suggest that the final growth increment on Amblema plicata cannot be consistently identified and sampled. Of the 18 shells so sampled (excluding the second shell from Feature 9, EU 50, Level 9, which does not have paired values because of problems with the mass spectrometer), half have paired $\delta^{18} \mathrm{O}$ values where the second one differs by more than 10 percent from the first; in 4 cases, the difference exceeds 25 percent. Only two sets of samples have identical values. This variation suggests that Amblema plicata is not appropriate for seasonality studies, or at best should be used with extreme caution.

In contrast, the sequentially sampled shells generated isotope data that appear to be useful for looking at climatic variations through time. Sequential samples where taken from the edges of 16 shells. These consist of 6 shells from Analysis Unit 1, Features 10 and 21b; 3 shells from Analysis Unit 2, Feature 9; 3 shells from Analysis Unit 3, Feature 29; and 3 modern shells (1 additional shell from EU 315, Level 10, was sampled, but its values are not used here because the context and age of this shell are less certain than the other samples). The four $\delta^{18} \mathrm{O}$ values provide data for the last few years of growth of each shell. Figure C-1 presents the raw values from each shell and the mean for each set of four values by analysis unit. These are set against a baseline derived from the mean for all values generated by the modern shells. While some sets of values have large ranges making interpretation difficult, the sample 
Appendix C: Carbon and Oxygen Isotope Analysis of Mussel Shells

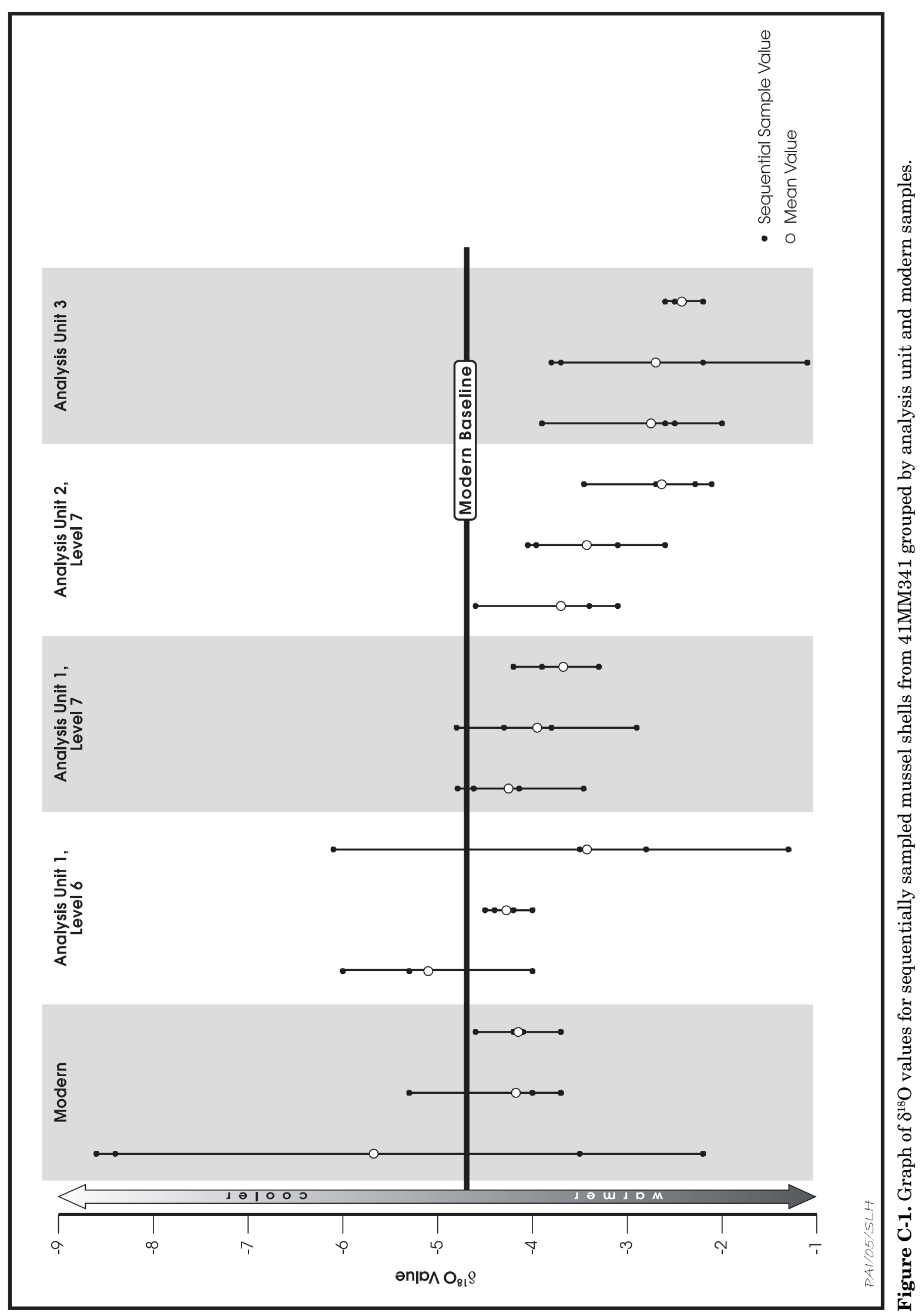


means point to an overall decrease in water temperature and, by extrapolation, ambient tem- perature from Analysis Unit 3 (ca. A.D. 600-800) to modern times.

\section{REFERENCES CITED}

Bailey, G. N., M. R. Deith, and N. J. Shackleton 1983 Oxygen Isotope Analysis and Seasonality Determinations: Limits and Potential of a New Technique. American Antiquity 48(2):390-398.

Claassen, C. 1998 Shells. Cambridge University Press.

Davis, L. G.

2001 A Late Pleistocene to Holocene Record of Precipitation Reflected in Margaritifera falcata Shell $\delta^{18} \mathrm{O}$ from Three Archaeological Sites in the Lower Salmon River Canyon, Idaho. Journal of Archaeological Science 28(3):291-303.

Deith, M. R.

1986 Subsistence Strategies at a Mesolithic Camp Site: Evidence from Stable Isotope Analyses of Shells. Journal of Archaeological Science 13(1):61-78.

Howells, Robert G., Raymond W. Neck, and Harold D. Murray
1996 Freshwater Mussels of Texas. Texas Parks and Wildlife Department, Inland Fisheries Division, Austin.

Mannino, M. A.

2003 Sampling Shells for Seasonality: Oxygen Isotope Analysis on Shell Carbonates of the Inter-tidal Gastropod Monodonta lineata (da Costa) from Populations Across Its Modern Range and from a Mesolithic Site in Southern Britain. Journal of Archaeological Science 30(6):667679.

Mueller-Lupp, T., H. A. Bauch, and H. Erlenkeuser 2004 Holocene Hydrographical Changes of the Eastern Laptev Sea (Siberian Arctic) Recorded in $\delta^{18} \mathrm{O}$ Profiles of Bivalve Shells. Quaternary Research 61(1):32-41.

Shackleton, N. J.

1973 Oxygen Isotope Analysis as a Means of Determining Season of Occupation of Prehistoric Midden Sites. Archaeometry 15(1):133-141. 


\section{APPENDIX D: Stable Carbon and Oxygen Isotopic Variability in Snail Shells from 41MM340 and 41MM341}

Raymond Mauldin, Ph.D.

Center for Archaeological Research

The University of Texas at San Antonio 



\section{INTRODUCTION}

As a component of the investigation of paleoenvironmental parameters at 41MM340, the Center for Archaeological Research at The University of Texas at San Antonio (CAR) conducted an isotopic analysis of shell carbonates from 38 samples of snail in the genus Rabdotus. Eighteen of these samples taken from 41MM341 were provided by Prewitt and Associates, Inc. These samples were from Features 17, 20, and 21a. All three features are well dated, spanning a period of roughly 600 years from about 680 B.P. to 1280 B.P. CAR, working at nearby $41 \mathrm{MM} 340$, had previously conducted isotopic analysis of 30 samples of Rabdotus, 28 of which came from a single unit (N49/E15) that spanned a period of roughly 700 years from 2350 B.P. back to 3050 B.P. (Mauldin 2003; Tomka and Mauldin 2003:103-105). Two additional modern samples, collected from the site in summer 2003, were also analyzed in that earlier study at 41MM340. As a component of the current investigations, 20 additional Rabdotus samples from unit N49/E15 at 41MM340 were analyzed. The combination of these various data sets provide isotopic information on 68 samples that date back to roughly 3000 B.P. This report summarizes these results.

Isotopic ratios of stable carbon $\left({ }^{13} \mathrm{C} /{ }^{12} \mathrm{C}\right)$ and oxygen $\left({ }^{18} \mathrm{O} /{ }^{16} \mathrm{O}\right)$ of carbonates in land snail shells have been used by a variety of investigators to explore paleoenvironmental variation in climate and vegetation (e.g., Abell and Plug 2000; Goodfriend 1991, 1999; Goodfriend and Ellis 2000). While the use of both isotopic ratios for paleoenviromental research presents complex interpretive problems (see Claassen 1998; Goodfriend and Ellis 2002), snail shells do contain signatures of past climates.

The carbon isotopic composition of snail organic mater is primarily a function of snail diet (see Goodfriend 1988) and, therefore, reflects the photosynthetic pathways $\left(\mathrm{CAM}, \mathrm{C}_{4}, \mathrm{C}_{3}\right.$ ) of the vegetation consumed. Carbonate in snail shell is, unfortunately, more complex. While probably a function to some degree of the different mixes of plant photosynthetic pathways consumed over the life of a snail, as well as variation in atmospheric $\mathrm{CO}_{2}$ that is exchanged between the body and shell of the snail, snail shell also incorporates ingested carbonates such as limestone. In limestone-rich settings, this can have a signifi- cant impact on the isotopic signature (see Ellis et al. 1996; Goodfriend et al. 1999). Recent studies of modern Rabdotus in Texas by Goodfriend and Ellis (2002) suggest that variation in vegetation density may also have a significant impact. They suggest that in dense vegetation areas, local plant respiration and decomposition may alter the atmospheric $\mathrm{CO}_{2}$ at the ground surface, resulting in a depleted ${ }^{13} \mathrm{C}$ signature relative to the atmosphere. Their study concludes that much of the variation in stable carbon values in shell reflects local conditions, primarily local vegetation density (Goodfriend and Ellis 2002:1992-1994).

The oxygen isotopic composition of carbonates in land snail shell is a function of the oxygen signatures of rainwater. In addition, there appears to be a strong correlation between ${ }^{18} \mathrm{O}$ values in water and temperature (e.g., Coplan and Kendall 2000; GNIP 2001). Several researchers have been successful in monitoring aspects of paleo-temperature or changes in rainfall seasonality by monitoring changes in ${ }^{18} \mathrm{O}$ values in shell (e.g., Abell and Hoelzmann 2000; Goodfriend 1991). Although the relationship is complex (see Claassen 1998; Goodfriend and Ellis 2002), it is generally the case that decreasing ambient temperatures result in decreasing water temperatures and a depletion of ${ }^{18} \mathrm{O}$. Therefore, the more negative the ${ }^{18} \mathrm{O}$ values the cooler the water and ambient temperatures, and the less negative the ${ }^{18} \mathrm{O}$ values the warmer the water and ambient temperatures. One of several complications of this link between temperature and ${ }^{18} \mathrm{O}$ patterns is related to differences in the source of rainfall, as well as seasonal patterns of evaporation and precipitation (see Goodfriend and Ellis 2002:1994-1996). Water vapor traveling greater distances will be depleted in ${ }^{18} \mathrm{O}$. In the context of the current site locations, storms originating in the Gulf of Mexico should have more positive values relative to storms originating in the Pacific.

\section{SAMPLE PROCESSING AND ANALYSIS}

As noted previously, 68 snail shells of the genus Rabdotus were analyzed for this study, including 30 samples presented and discussed previously in association with work at 41MM340 (Mauldin 2003; Tomka and Mauldin 2003). All samples were processed at CAR. A given snail 
shell was cleaned with water and broken to gain access to the shell interior. All interior sediments were removed, and the shell fragments were again washed with water. Fragments were then dried and pulverized using a ceramic mortar and pestle. The resulting carbonate powder was then placed in a plastic vial.

Analysis of the carbonate powder was conducted by Dr. Ethan Grossman, Department of Geology at Texas A\&M University. The results of the analysis are presented in Table D-1. Based on multiple runs of selected samples, Dr. Grossman reports that the precision on standards for the $\delta^{18} \mathrm{O}$ is approximately $\pm 0.07 \%$, while the $\delta^{13} \mathrm{C}$ precision is approximately $\pm 0.04 \%$. Note that the number of runs for a given sample is listed to the far right of the table. To arrive at the isotopic values presented in the table, the multiple runs on the same sample were averaged. Table D-2 presents summary statistics for the samples.

\section{DISCUSSION}

Figure D-1 presents a box plot (see Chambers et al. 1983; Tukey 1977) of the ${ }^{18} \mathrm{O}$ isotopic values of snail shell carbonates by approximate age. The upper and lower quartiles of the distribution form the box in the figure, so that 50 percent of the cases are within the box. The median value is identified as the line in the box. Upper and lower adjacent values, which are defined as \pm 1.5 times the interquartile range (upper quartile-lower quartile), form the length of the solid lines extending from the box. Outliers are identified as falling above or below the adjacent values (see Tukey 1977). Note that a single outlier, a sample from 41MM341, Feature 20, Level 9 (Sample Q in Table D-1), is not shown in the plot. To the degree that the snail ${ }^{18} \mathrm{O}$ readings are indicative of temperature differences, the pattern in the median values suggests a gradual, consistent warming trend from 3050 B.P. that culminates at around 2550 B.P. Temperatures then oscillate through the remainder of the sequence. There is also considerable variability reflected in several of the earlier periods, especially at around 2550 B.P., 2700 B.P., and before 2900 B.P. Reduced variability is reflected at 2800 B.P., as well as at 2400 B.P. (see Table D-2). If the range in values is any indication, then mean annual temperatures or the source of rainfall may have fluctuated more widely during the early portions of sequence.

Figure D-2 presents a similar plot of the ${ }^{13} \mathrm{C}$ isotopic values for snail shell. Recall that variations in ${ }^{13} \mathrm{C}$ values probably reflect, in part, both local vegetation density and vegetation composition, with less-negative values indicating a more-open habitat or a vegetation community dominated more by $\mathrm{C}_{4}$ or CAM plants, and lower ${ }^{13} \mathrm{C}$ values indicative of denser vegetation or a community dominated more by $\mathrm{C}_{3}$ plants. The most striking aspect of the figure is the extreme difference between the two modern samples, which are tightly clustered with a value of -12.8 , and all prehistoric samples, which have an average value of -9.7. These two modern samples were collected from a dense vegetation area on a terrace of the Little River, in a vegetation setting dominated by $\mathrm{C}_{3}$ vegetation. Focusing on the prehistoric patterns, there is a consistent decrease in ${ }^{13} \mathrm{C}$ median values at $41 \mathrm{MM} 340$ from roughly 2925 B.P. to roughly 2450 B.P. In fact, with the exception of a slight increase associated with the 2400 B.P. date, the sequence shows values (see Table D-2) suggestive of an increased $\mathrm{C}_{3}$ vegetation component or increased vegetation density. The 18 samples from 41MM341, taken from three dated contexts, have essentially identical median values. While they are different from the terminal pattern at $41 \mathrm{MM} 340$, this difference may simply reflect differences in vegetation density at a local scale between these two sites.

When considered together, then, these two data sets suggest that between roughly 3000 B.P. and 2500 B.P. conditions at $41 \mathrm{MM} 340$ and 41MM341 may have been gradually warming relative to modern temperatures, though considerable variation in temperatures or rainfall patterns are indicated. This may have resulted in vegetation change, specifically an increase in the density of plants, and possibly an increase in the percentage of $\mathrm{C}_{3}$ plants, in the immediate environment. After about 2500 B.P., the oxygen data suggest a fluctuating pattern in temperatures or rainfall, with decreased variability. However, given the interpretive complications posed by both the oxygen and carbon isotopic analysis of snail shell, conclusions are tentative at best. 
Appendix D: Carbon and Oxygen Isotopic Variability in Snail Shells

Table D-1. Carbon and oxygen isotopic values on snail shell carbonates, Little River

\begin{tabular}{|c|c|c|c|c|c|}
\hline Sample Code & Site & ${ }^{13} \mathrm{C} /{ }^{12} \mathrm{C}$ & ${ }^{18} \mathrm{O} / /^{16} \mathrm{O}$ & Date (B.P.) & No. of Runs \\
\hline $00-00-0-0-\mathrm{A}$ & Modern-Little River & -12.728 & -1.279 & 0 & 1 \\
\hline $00-00-0-0-B$ & Modern-Little River & -12.897 & -1.724 & 0 & 1 \\
\hline 341-EU183-F21A-L6/7-G & 41MM341 & -9.271 & -1.488 & 685 & 1 \\
\hline 341-EU183-F21A-L6/7-H & 41MM341 & -8.722 & -1.303 & 685 & 1 \\
\hline 341-EU183-F21A-L6/7-I & $41 \mathrm{MM} 341$ & -8.589 & -1.935 & 685 & 1 \\
\hline 341-EU183-F21A-L6/7-J & 41MM341 & -8.405 & -1.833 & 685 & 3 \\
\hline 341-EU183-F21A-L6/7-K & $41 \mathrm{MM} 341$ & -9.740 & -1.557 & 685 & 1 \\
\hline 341-EU183-F21A-L6/7-L & $41 \mathrm{MM} 341$ & -9.669 & -1.389 & 685 & 1 \\
\hline 341-EU29-F17-L8-A & 41MM341 & -8.966 & -1.021 & 1110 & 1 \\
\hline 341-EU29-F17-L8-B & $41 \mathrm{MM} 341$ & -8.170 & -1.035 & 1110 & 1 \\
\hline 341-EU29-F17-L8-C & 41MM341 & -9.082 & -1.250 & 1110 & 2 \\
\hline 341-EU29-F17-L8-D & 41MM341 & -9.041 & -1.045 & 1110 & 1 \\
\hline 341-EU29-F17-L8-E & 41MM341 & -8.988 & -1.466 & 1110 & 1 \\
\hline 341-EU29-F17-L8-F & 41MM341 & -8.520 & -1.410 & 1110 & 3 \\
\hline 341-EU108-F20/L9-M & 41MM341 & -9.337 & -0.606 & 1280 & 1 \\
\hline 341-EU108-F20/-L9-N & $41 \mathrm{MM} 341$ & -9.590 & -1.620 & 1280 & 5 \\
\hline 341-EU108-F20-L9-O & 41MM341 & -7.770 & -1.785 & 1280 & 2 \\
\hline 341-EU108-F20-L9-P & 41MM341 & -7.608 & -1.519 & 1280 & 1 \\
\hline 341-EU108-F20-L9-Q & $41 \mathrm{MM} 341$ & -9.962 & -3.589 & 1280 & 1 \\
\hline 341-EU108-F20-L9-R & 41MM341 & -8.645 & -1.260 & 1280 & 2 \\
\hline $340-49-15-2-1-\mathrm{C}$ & 41MM340 & -9.810 & -1.228 & 2350 & 1 \\
\hline 340-49-15-2-1-E & $41 \mathrm{MM} 340$ & -9.550 & -1.305 & 2350 & 2 \\
\hline $340-49-15-2-1-\mathrm{F}$ & 41MM340 & -10.174 & -0.281 & 2350 & 1 \\
\hline 340-49-15-2-2-A & 41MM340 & -9.913 & -1.562 & 2400 & 1 \\
\hline 340-49-15-2-2-B & $41 \mathrm{MM} 340$ & -9.324 & -1.331 & 2400 & 1 \\
\hline 340-49-15-2-2-D & 41MM340 & -9.513 & -1.253 & 2400 & 1 \\
\hline $340-49-15-2-2-\mathrm{G}$ & $41 \mathrm{MM} 340$ & -8.971 & -1.420 & 2400 & 1 \\
\hline 340-49-15-3B-1-A & 41MM340 & -9.565 & -1.730 & 2450 & 2 \\
\hline 340-49-15-3B-1-B & $41 \mathrm{MM} 340$ & -9.720 & -1.620 & 2450 & 1 \\
\hline 340-49-15-3B-1-D & $41 \mathrm{MM} 340$ & -10.112 & -1.256 & 2450 & 1 \\
\hline 340-49-15-3B-1-F & 41MM340 & -9.693 & -1.283 & 2450 & 1 \\
\hline 340-49-15-3B-1-G & 41MM340 & -9.440 & -0.650 & 2450 & 3 \\
\hline 340-49-15-3B-2-C & $41 \mathrm{MM} 340$ & -10.218 & -1.633 & 2450 & 1 \\
\hline 340-49-15-3B-2-E & 41MM340 & -9.185 & -1.503 & 2450 & 1 \\
\hline 340-49-15-3C-1-A & 41MM340 & -9.637 & -1.463 & 2500 & 1 \\
\hline 340-49-15-3C-1-B & $41 \mathrm{MM} 340$ & -10.551 & -1.186 & 2500 & 1 \\
\hline 340-49-15-3C-1-C & 41MM340 & -8.770 & -1.183 & 2500 & 1 \\
\hline 340-49-15-3C-1-D & $41 \mathrm{MM} 340$ & -9.451 & -1.169 & 2500 & 1 \\
\hline $340-49-15-3 \mathrm{C}-1-\mathrm{E}$ & 41MM340 & -9.896 & -1.828 & 2500 & 1 \\
\hline 340-49-15-4-1-A & $41 \mathrm{MM} 340$ & -9.403 & -0.749 & 2550 & 1 \\
\hline 340-49-15-4-1-B & $41 \mathrm{MM} 340$ & -9.425 & -1.549 & 2550 & 1 \\
\hline 340-49-15-4-1-C & 41MM340 & -10.024 & -0.276 & 2550 & 1 \\
\hline 340-49-15-4-1-D & 41MM340 & -10.048 & -1.176 & 2550 & 1 \\
\hline $\begin{array}{l}340-49-15-4-1-\mathrm{E} \\
\end{array}$ & $41 \mathrm{MM} 340$ & -9.060 & -2.450 & 2550 & 2 \\
\hline $340-49-15-4-3-\mathrm{F}$ & 41MM340 & -8.971 & -1.901 & 2650 & 1 \\
\hline $340-49-15-4-3-G$ & $41 \mathrm{MM} 340$ & -9.165 & -0.735 & 2650 & 2 \\
\hline 340-49-15-4-3-H & $41 \mathrm{MM} 340$ & -9.695 & -0.866 & 2650 & 1 \\
\hline 340-49-15--4-3-I & 41MM340 & -9.275 & -1.460 & 2650 & 1 \\
\hline
\end{tabular}


Data Recovery Excavations at the J. B. White Site

Table D-1, continued

\begin{tabular}{l|c|c|c|c|c}
\hline Sample Code & Site & ${ }^{13} \mathrm{C} /{ }^{12} \mathrm{C}$ & ${ }^{18} \mathrm{O} /{ }^{16} \mathrm{O}$ & Date (в.P.) & No. of Runs \\
\hline $340-49-15-5-1-\mathrm{A}$ & $41 \mathrm{MM} 340$ & -9.130 & -0.803 & 2700 & 3 \\
\hline $340-49-15-5-1-\mathrm{B}$ & $41 \mathrm{MM} 340$ & -8.955 & -0.645 & 2700 & 1 \\
\hline $340-49-15-5-1-\mathrm{C}$ & $41 \mathrm{MM} 340$ & -7.495 & -2.430 & 2700 & 2 \\
\hline $340-49-15-5-1-\mathrm{D}$ & $41 \mathrm{MM} 340$ & -9.501 & -2.334 & 2700 & 1 \\
\hline $340-49-15-5-1-\mathrm{E}$ & $41 \mathrm{MM} 340$ & -10.304 & -1.232 & 2700 & 1 \\
\hline $340-49-15-6-1-\mathrm{A}$ & $41 \mathrm{MM} 340$ & -8.585 & -1.240 & 2800 & 1 \\
\hline $340-49-15-6-1-\mathrm{B}$ & $41 \mathrm{MM} 340$ & -9.250 & -1.359 & 2800 & 1 \\
\hline $340-49-15-6-1-\mathrm{C}$ & $41 \mathrm{MM} 340$ & -9.363 & -1.238 & 2800 & 1 \\
\hline $340-49-15-6-1-\mathrm{D}$ & $41 \mathrm{MM} 340$ & -7.935 & -0.720 & 2800 & 2 \\
\hline $340-49-15-6-1-\mathrm{E}$ & $41 \mathrm{MM} 340$ & -6.941 & -1.276 & 2800 & 1 \\
\hline $340-49-15-6-1-\mathrm{F}$ & $41 \mathrm{MM} 340$ & -8.390 & -1.940 & 2800 & 1 \\
\hline $340-49-15-7-1-\mathrm{A}$ & $41 \mathrm{MM} 340$ & -6.739 & -1.007 & 2925 & 1 \\
\hline $340-49-15-7-1-\mathrm{B}$ & $41 \mathrm{MM} 340$ & -8.151 & -1.657 & 2925 & 1 \\
\hline $340-49-15-7-1-\mathrm{C}$ & $41 \mathrm{MM} 340$ & -9.558 & -0.529 & 2925 & 1 \\
\hline $340-49-15-7-1-\mathrm{D}$ & $41 \mathrm{MM} 340$ & -8.325 & -1.728 & 2925 & 1 \\
\hline $340-49-15-8-1-\mathrm{A}$ & $41 \mathrm{MM} 340$ & -9.628 & -1.892 & 3050 & 1 \\
\hline $340-49-15-8-1-\mathrm{B}$ & $41 \mathrm{MM} 340$ & -9.609 & -0.871 & 3050 & 1 \\
\hline $340-49-15-8-1-\mathrm{C}$ & $41 \mathrm{MM} 340$ & -8.240 & -0.780 & 3050 & 2 \\
\hline $340-49-15-8-1-\mathrm{D}$ & $41 \mathrm{MM} 340$ & -9.071 & -1.442 & 3050 & 1 \\
\hline $340-49-15-8-1-\mathrm{E}$ & $41 \mathrm{MM} 340$ & -8.439 & -2.056 & 3050 & 1 \\
\hline
\end{tabular}

Table D-2. Summary statistics for carbon and oxygen readings in Table D-1

\begin{tabular}{c|c|c|c|c|c|c|c|c|c}
\hline $\begin{array}{c}\text { No.of } \\
\text { Samples }\end{array}$ & $\begin{array}{c}\text { Estimated } \\
\text { Date (B.P.) }\end{array}$ & $\begin{array}{c}\text { Mean } \\
{ }^{13} \mathrm{C}\end{array}$ & $\begin{array}{c}\text { Median } \\
{ }^{13} \mathrm{C}\end{array}$ & $\begin{array}{c}\text { Std. Dev. } \\
{ }^{13} \mathrm{C}\end{array}$ & $\begin{array}{c}\text { Coefficient } \\
\text { of Variation } \\
{ }^{13} \mathrm{C}\end{array}$ & $\begin{array}{c}\text { Mean } \\
{ }^{18} \mathrm{O}\end{array}$ & $\begin{array}{c}\text { Median } \\
{ }^{18} \mathrm{O}\end{array}$ & $\begin{array}{c}\text { Std. Dev. } \\
{ }^{18} \mathrm{O}\end{array}$ & $\begin{array}{c}\text { Coefficient } \\
\text { of Variation } \\
{ }^{18} \mathrm{O}\end{array}$ \\
\hline 6 & 0 & -12.81 & -12.81 & 0.120 & 0.009 & -1.50 & -1.50 & 0.314 & 0.209 \\
\hline 6 & 685 & -9.07 & -8.99 & 0.573 & 0.064 & -1.58 & -1.52 & 0.250 & 0.158 \\
\hline 6 & 1110 & -8.79 & -8.98 & 0.367 & 0.041 & -1.20 & -1.15 & 0.200 & 0.167 \\
\hline 3 & 1280 & -8.82 & -8.99 & 0.976 & 0.109 & -1.73 & -1.57 & 1.000 & 0.578 \\
\hline 4 & 2350 & -9.84 & -9.81 & 0.313 & 0.032 & -0.94 & -1.23 & 0.570 & 0.608 \\
\hline 7 & 2400 & -9.43 & -9.42 & 0.393 & 0.042 & -1.39 & -1.38 & 0.132 & 0.095 \\
\hline 5 & 2500 & -9.70 & -9.69 & 0.363 & 0.037 & -1.38 & -1.50 & 0.369 & 0.267 \\
\hline 5 & 2550 & -9.66 & -9.64 & 0.649 & 0.067 & -1.37 & -1.19 & 0.286 & 0.209 \\
\hline 4 & 2650 & -9.28 & -9.43 & 0.431 & 0.046 & -1.24 & -1.18 & 0.827 & 0.667 \\
\hline 5 & 2700 & -9.08 & -9.13 & 0.306 & 0.033 & -1.24 & -1.16 & 0.541 & 0.436 \\
\hline 6 & 2800 & -8.41 & -8.49 & 0.898 & 0.106 & -1.30 & -1.26 & 0.389 & 0.299 \\
\hline 4 & 2925 & -8.19 & -8.24 & 1.154 & 0.140 & -1.23 & -1.33 & 0.569 & 0.463 \\
\hline 2 & 3050 & -9.00 & -9.07 & 0.645 & 0.071 & -1.41 & -1.44 & 0.578 & 0.410 \\
\hline
\end{tabular}


Appendix D: Carbon and Oxygen Isotopic Variability in Snail Shells

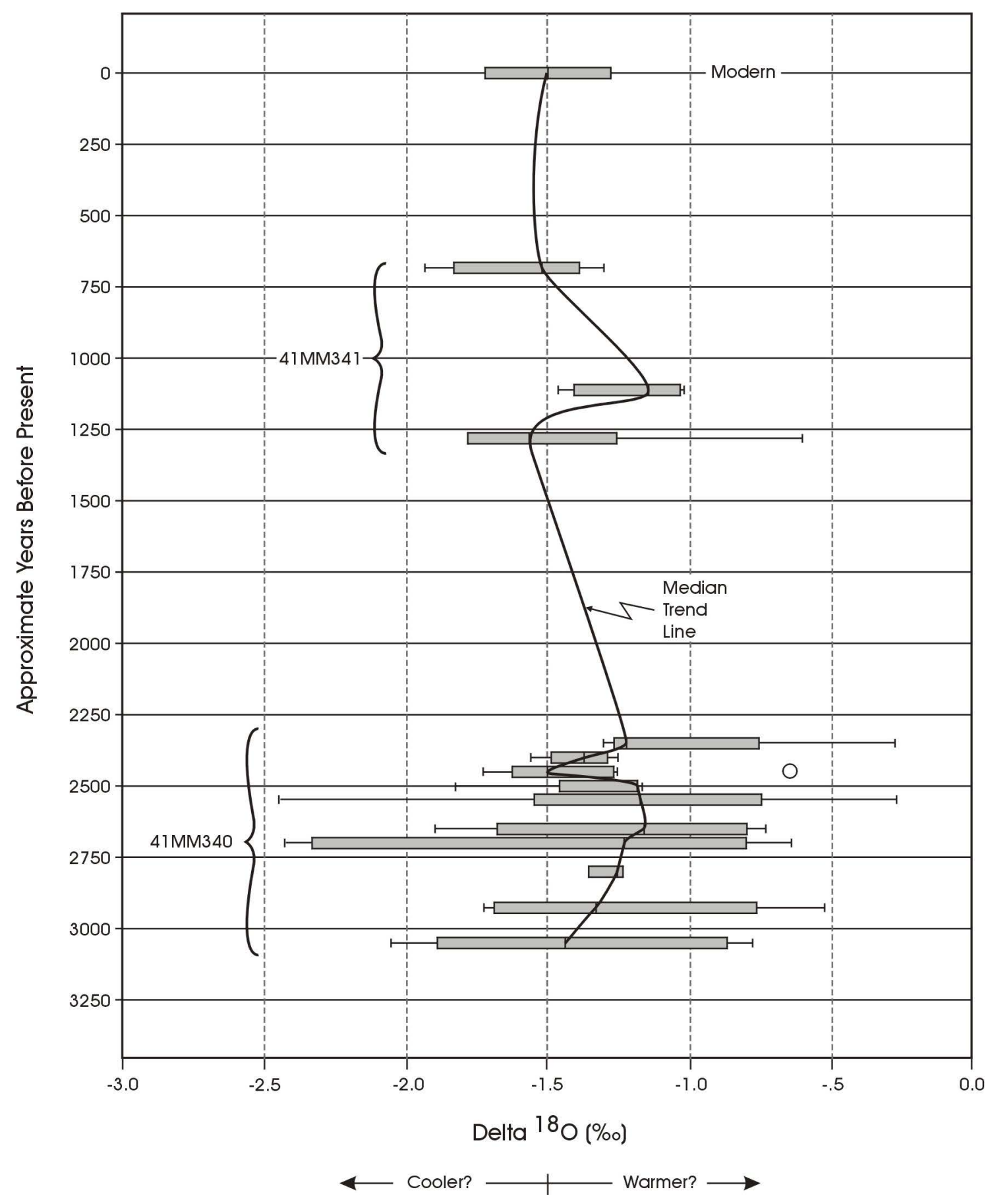

Figure D-1. Box plot of ${ }^{18} \mathrm{O}$ isotopic values of snail shell carbonates by approximate age for 41MM340 and 41MM341. 
Data Recovery Excavations at the J. B. White Site

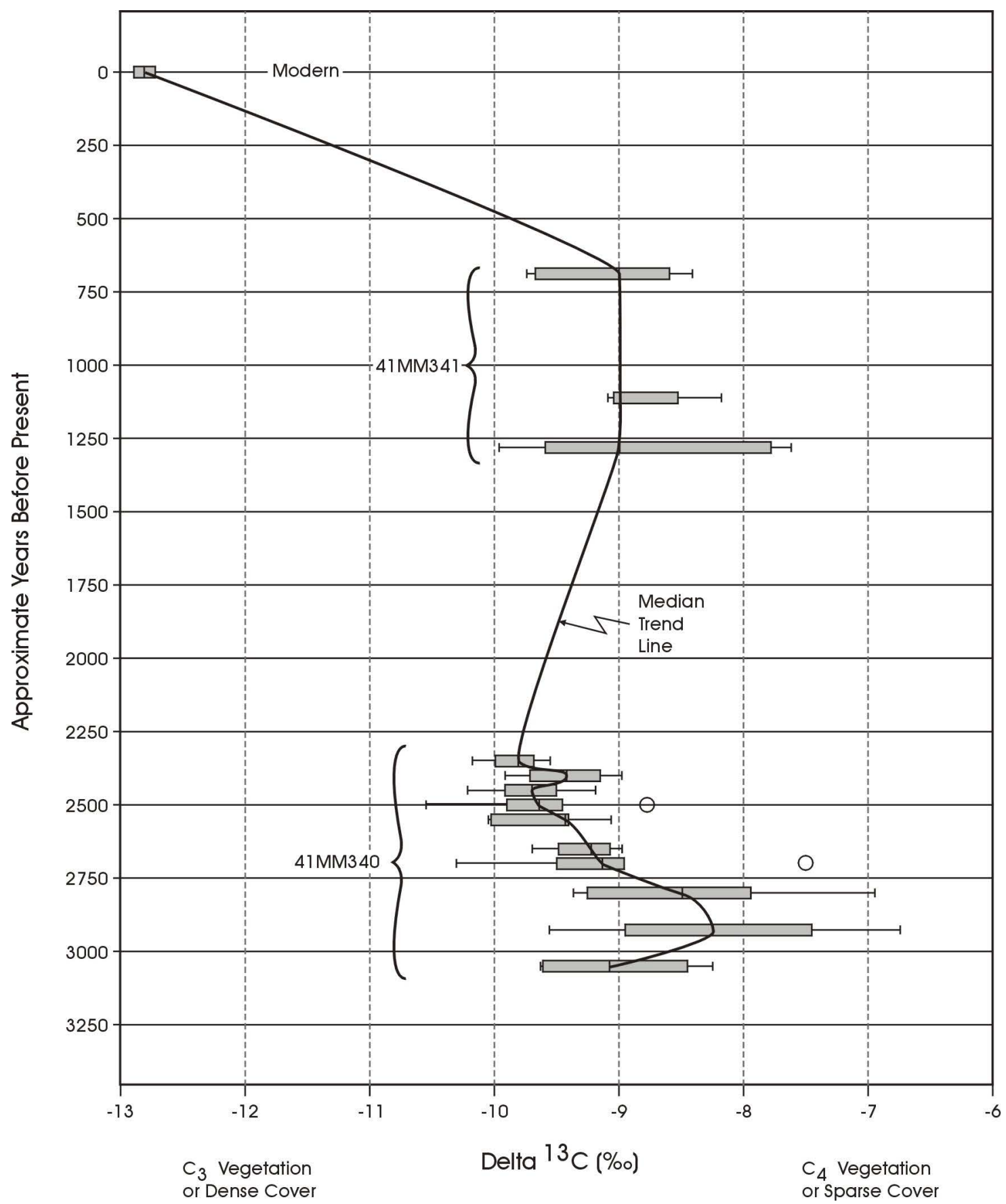

Figure D-2. Box plot of ${ }^{13} \mathrm{C}$ isotopic values of snail shell carbonates by approximate age for 41MM340 and $41 \mathrm{MM} 341$. 
Appendix D: Carbon and Oxygen Isotopic Variability in Snail Shells

\section{REFERENCES CITED}

Abell, P. I., and P. Hoelzmann

2000 Holocene Paleoclimates in Northwestern Sudan: Stable Isotope Studies on Mollusks. Global and Planetary Change 26:1-12.

Abell, P. I., and I. Plug

2000 The Pleistocene/Holocene Transition in South Africa: Evidence of the Younger Dryas Event. Global and Planetary Change 26:173-179.

Chambers, J. M., W. S. Cleveland, B. Kleiner, and P. A. Tukey

1984 Graphical Methods for Data Analysis. Duxbury Press, Boston.

Claassen, C.

1998 Shells. Cambridge Manuals in Archaeology. Cambridge University Press, Cambridge, United Kingdom.

Coplan, T. B., and C. Kendall

2000 Stable Hydrogen and Oxygen Isotope Ratios for Selected Sites of the U.S. Geological Survey's NASQAN and Benchmark Surface-water Networks. Report 00160. U.S. Geological Survey. Reston, Virginia.

Ellis, G. L., G. Goodfriend, J. Abbott, P. Hare, and D. W. von Endt

1996 Assessment of Integrity and Geochronology of Archaeological Sites Using Amino Acid Racemization in Land Snail Shells: Examples from Central Texas. Geoarchaeology 11:189-213.

GNIP (Global Network of Isotopes in Precipitation)

2001 IAEA/WHO GNIP Database. Available from http:/isohis.iaea.org.

Goodfriend, G.

1988 Mid-Holocene Rainfall in the Negev Desert from ${ }^{13} \mathrm{C}$ of Land Snail Shell Organic Matter. Nature 333:757-760.

1991 Holocene Trends in ${ }^{18} \mathrm{O}$ in Land Snail Shells from the Negev Desert and their Implications for Changes in Rainfall Source Areas. Quaternary Research 35:417-426.

1999 Terrestrial Stable Isotope Records of Late Quaternary Paleoclimates in the Eastern Mediterranean Region. Quaternary Science Review 18:501-513.
Goodfriend, G., and G. L. Ellis

2000 Stable Carbon Isotopic Record of Middle to Late Holocene Climate Changes from Land Snail Shells at Hinds Cave, Texas. In "Holocene Environmental Change on the Great Plains of North America," edited by S. Wolfe, G. Goodfriend, and R. Baker. Quaternary International $67: 47-60$

2002 Stable carbon and oxygen variations in modern Rabdotus land snail shells in the southern Great Plains, USA, and their relation to environment. Geochemica et Cosmochemica Acta 66:1987-2002.

Goodfriend, G., G. L. Ellis, and L. J. Toolin

1999 Radiocarbon age anomalies in land snail shells from Texas: Ontogenetic, individual, and geographic patterns of variation. Radiocarbon 41:149-156.

Mauldin, R. P.

$2003{ }^{18} \mathrm{O}$ and ${ }^{13} \mathrm{C}$ Isotopes. In Data Recovery Excavations at 41MM340, A Late Archaic Site along Little River in Milam County, Texas, by R. B. Mahoney, S. A. Tomka, R. P. Mauldin, H. J. Shafer, L. C. Nordt, R. D. Greaves, and R. R. Galdeano, pp. 275-277. Archeological Studies Program Report No. 54, Environmental Affairs Division, Texas Department of Transportation, Austin. Archaeological Survey Report No. 340. Center for Archaeological Research, The University of Texas at San Antonio.

Tomka, S. A., and R. P. Mauldin

2003 Paleoenvironmental Reconstruction. In Data Recovery Excavations at 41MM340, A Late Archaic Site along Little River in Milam County, Texas, by R. B. Mahoney, S. A. Tomka, R. P. Mauldin, H. J. Shafer, L. C. Nordt, R. D. Greaves, and R. R. Galdeano, pp. 95-108. Archeological Studies Program Report No. 54. Environmental Affairs Division, Texas Department of Transportation, Austin. Archaeological Survey Report No. 340. Center for Archaeological Research, The University of Texas at San Antonio.

Tukey, J. W.

1977 Exploratory Data Analysis. AddisonWesley, Reading, Massachusetts. 



\title{
APPENDIX E: Analysis of the Vertebrate Remains from 41MM341
}

\author{
Brian S. Shaffer, Ph.D. \\ Curatorial Assistant \\ Dallas Museum of Natural History
}





\section{INTRODUCTION}

Vertebrate remains recovered from 41MM341 were analyzed to assess the taxa represented in the recovered assemblage, cultural modification, and noncultural taphonomic impacts on the sample. Additionally, environmental factors were considered, including habitat use and exploitation of the available vertebrates as represented by the specimens recovered. The sample analyzed consists of 6,961 bone and tooth specimens recovered during data recovery excavations.

\section{METHODS}

Specimens were analyzed using the comparative collection at the University of North Texas, Institute of Applied Sciences, Zooarchaeology Laboratory. Identifications were made based on visual comparison with these specimens. Identifications that were equivocal were either taken to the next higher level (e.g., from genus to family level) or were given "cf." as a prefix to indicate that the specimen compared favorably with the taxon but the identification was equivocal.

Attributes were recorded using a vertebrate faunal analysis coding system (Shaffer and Baker 1992) and were entered into a computer for tabulation. Attributes recorded included taxon, element, portion of element, siding, age criteria, aging, weathering, breakage, impact point, burning, gnawing, chemical dissolution, and presence of bone grease; a comments field recorded additional information such as notation of medical disorders or descriptions of cut marks. No medical disorders were observed.

The remains were tabulated using two methods (Table E-1). The number of identified specimens (NISP), or simple specimen count, was tabulated for each category of identification. Based on the NISP, 2,002 (29 percent) of the specimens were identified to the level of order or below. The minimum number of individuals (MNI) was computed as a single aggregate for the site based on element, portion of element, and aging criteria for each unique taxonomic group, usually at the genus level. In some cases, categories were combined for this estimate. For example, all "cf." categories were combined with their respective positively identified counterparts. Specimens identified as Artiodactyla were combined with those identified as Odocoileus sp. (deer), since no other deer-sized artiodactyls such as pronghorn were identified in the assemblage and the representation was almost identical for the MNI. An MNI of six was determined based on replication of right petrosals identified as Artiodactyla, although an MNI of five was made based on distal fibulas that could be identified as deer. Aging was also taken into account but was based on age categories (e.g., juvenile, subadult, and adult). The MNI calculations were not increased with the addition of age categories, however. Broader categories such as Osteichthyes (fish) or Mammalia (mammals) were not tabulated by MNI.

Taphonomic information was recorded for each specimen including both natural and cultural processes. Weathering was recorded as light or marked depending on the amount of damage to the bone's exterior resulting from exposure. Specimens with little or no significant surface damage were recorded as having light weathering. Those with fine-line cracking and exfoliation were the specimens in the worst condition and were recorded as having marked weathering.

A second surface impact that is sometimes associated with weathering is chemical etching and dissolution. Osseus and dental elements can be impacted by ground $\mathrm{pH}$, roots, and ingestion by animals such as carnivores and raptors. Light amounts of etching were noted when the etching did not impact much of the surface of the specimen, but was prominent enough to be readily spotted during analysis. Marked chemical etching was recorded when a significant portion of the specimen's surface was deteriorated or when it precluded identification through the destruction of landmarks. The only positive form of chemical dissolution observed was root etching, and the patterns of rootlets were observed on several specimens.

Breakage was recorded as unbroken, angularly fractured, or spirally fractured. Angular fractures are produced in bones that usually do not spirally fracture (e.g., fish bone, cranial elements, or turtle shell) or when bone has lost its collagen (Johnson 1985). Spiral fractures are most common in long bones but can occur in other thick-walled cortical bone. Often, spiral fractures are produced as a result of intentional breakage of the bone for the removal of marrow or for processing into grease (e.g., Johnson 1985; 
Table E-1. Number of identified specimens (NISP) and minimum number of individuals (MNI) by faunal taxon and common name

\begin{tabular}{|c|c|c|c|}
\hline Taxon & Common Name & NISP & MNI \\
\hline Vertebrata & Vertebrates & 3,458 & \\
\hline Osteichthyes (Small) & Small bony fish & 4 & \\
\hline Osteichthyes (Medium) & Medium bony fish & 11 & \\
\hline Osteichthyes (Large) & Large bony fish & 1 & \\
\hline Osteichthyes & Bony fish & 3 & \\
\hline Lepisosteidae & Gars & 31 & 1 \\
\hline Aplodinotus grunniens & Freshwater drum & 7 & 6 \\
\hline Anura & Toads and frogs & 1 & 1 \\
\hline Testudinata & Turtles & 823 & \\
\hline Kinosternidae & Mud and musk turtles & 12 & 1 \\
\hline Emydidae & Water and box turtles & 26 & \\
\hline Chrysemys sensu lato & Painted turtles, cooters, sliders & 13 & 3 \\
\hline cf. Chrysemys sensu lato & Painted turtles, cooters, sliders & 2 & \\
\hline Terrapene sp. & Box turtles & 7 & 1 \\
\hline Trionyx sp. & Softshell turtle & 58 & 1 \\
\hline Serpentes & Snakes & 16 & \\
\hline Colubridae & Colubrid snakes & 39 & 2 \\
\hline Viperidae & Pitviper snakes & 1 & 1 \\
\hline Aves (Medium) & Crow-sized birds & 9 & \\
\hline Aves (Large) & Duck/turkey-sized birds & 27 & \\
\hline Meleagris gallopavo & Turkey & 4 & 1 \\
\hline Mammalia (Micro) & Shrew/mouse-sized mammals & 9 & \\
\hline Mammalia (Micro/small) & Shrew/rabbit-sized mammals & 1 & \\
\hline Mammalia (Small/medium) & Rabbit/canid-sized mammals & 154 & \\
\hline Mammalia (Medium) & Canid-sized mammals & 1 & \\
\hline Mammalia (Medium/large) & Canid/deer-sized mammals & 1,313 & \\
\hline Mammalia & Mammals & 4 & \\
\hline Didelphis virginiana & Virginia opossum & 75 & 4 \\
\hline Scalopus aquaticus & Eastern mole & 1 & 1 \\
\hline Leporidae & Rabbits and hares & 9 & \\
\hline Lepus sp. & Jackrabbits & 12 & 1 \\
\hline Sylvilagus sp. & Cottontail rabbits & 174 & 10 \\
\hline Rodentia (Small) & Mouse-sized rodent & 17 & \\
\hline Rodentia (Medium) & Rat-sized rodent & 16 & \\
\hline Rodentia (Large) & Muskrat/beaver-sized rodent & 1 & \\
\hline Sciuridae & Squirrels and chipmunks & 12 & \\
\hline Sciurus sp. & Squirrels & 6 & 3 \\
\hline Geomys sp. & Pocket gophers & 11 & 1 \\
\hline Castor canadensis & Beaver & 5 & 1 \\
\hline Sigmodon sp. & Cotton rats & 50 & 7 \\
\hline Microtus sp. & Voles & 5 & 1 \\
\hline Carnivora & Carnivores & 3 & \\
\hline Procyon lotor & Raccoon & 68 & 5 \\
\hline Mustelidae & Weasels and relatives & 7 & 1 \\
\hline Urocyon cinereoargenteus & Gray fox & 1 & 1 \\
\hline Canis sp. & Dogs & 2 & \\
\hline Canis latrans & Coyotes & 6 & 1 \\
\hline
\end{tabular}


Appendix E: Analysis of Vertebrate Remains

Table E-1, continued

\begin{tabular}{l|l|c|c}
\hline Taxon & Common Name & NISP & MNI \\
\hline cf. Canis latrans & Coyote & 1 & \\
\hline Artiodactyla (Medium) & Deer/pronghorn-sized ungulates & 219 & \\
\hline Cervidae & Deer and relatives & 85 & \\
\hline Odocoileus sp. & Deer & 137 & 6 \\
\hline cf. Odocoileus sp. & Deer & 3 & \\
\hline Total & & 6,961 & 61 \\
\hline
\end{tabular}

Lintz 1976:87-88). This intentional breakage often is produced by percussion, resulting in impact marks on the bone (Johnson 1985).

Burning was noted as charred; burned brown or black; or calcined, burned white. Charring results in incomplete combustion of the bone, whereas calcination is a more-complete burning of the bone. Both forms were observed in the assemblage. Of particular interest is the presence of turtle shell that exhibits pronounced charring on the exterior surfaces but not on the interior. This is discussed in more detail below.

Two types of gnawing were noted in the assemblage. Rodent gnawing was evidenced by the parallel grooved gnaw marks typically produced by rodent incisors. Carnivore gnawing was evidenced by tooth puncture damage through the bone walls. When observed, rodent gnawing usually was not extensive and would consist of just a few marks. There were a few specimens, however, where the gnawing was quite extensive and resulted in enough destruction of the bone to preclude more-specific identification.

Cut marks were recorded as per their number and location. Any marks deemed equivocal were not recorded as cut marks. All of the cut marks observed appear to have been made with stone tools as evidenced by multiple grooves produced in the apex of each cut.

For the purpose of this paper, topics are discussed in two manners. First, gross observations are made at the site level of resolution. This is followed by more-refined observations on the data that pertain to specific issues and then to discussions of the data by feature and nonfeature contexts.

\section{TAXONOMIC OBSERVATIONS}

\section{General Assemblage}

Animal taxa exploited came from both terrestrial and aquatic habitats, although terres- trial taxa were more important economically. The assemblage is dominated by various turtle taxa, predominantly aquatic varieties such as softshells and sliders (see Table E-1). Of course, turtle shells are highly identifiable, even when fragmented into small pieces. Their pronounced representation in the recorded assemblage is partially due to their ease of identification. In fact, only six individuals could be specifically tallied. There were just as many drum (fish) individuals identified based on otoliths, but only seven otoliths recovered. In contrast to turtles, otoliths are also readily identifiable but much smaller and more durables occur in low frequencies in fish, usually one per side. So while turtle remains have a much greater NISP, the MNI is the same as the less well-represented drum.

Turtle remains include both water turtles and box turtles. Turtles represent a fairly easily obtained resource, especially if procured on land where their slowness makes them readily available for pick up. The presence of turtles indicates that the site was occupied during warmer months when turtles would be active, although in Texas, the author has observed aquatic turtles active during every month of the year, even in warm periods in the winter months. This indicates that turtles are not so much a good indicator of seasonality as they are of warmer weather. Like their terrestrial counterparts, aquatic turtles (i.e., sliders) can be readily gathered when on land. In water, aquatic turtles can be procured via methods such as netting and clubbing, especially when some form of floating bait is used to bring the turtles to the surface.

The only specific artiodactyl identified is deer, and most of the artiodactyl assemblage is represented by specimens of pronghorn/deersized animals. The only exception is antler fragments identified as Cervidae. Aside from deer, elk (Cervus canadensis) also produce antlers and were present in Texas prehistorically (see Shaffer et al. 1995). Given the great variability 
in antler dimensions and formation, it was not possible to distinguish deer from elk based on the fragmentary specimens available. Therefore, identification could only be made to the family level, Cervidae.

Artiodactyls represent the second-mostcommonly identified taxonomic group represented by the NISP but tallied just six individuals based on the MNI. Of the taxa recovered, deer and deer-sized artiodactyl remains represent the single largest animal resource represented and no doubt were exploited for their meat, marrow, and grease, as well as use of skeletal elements as tools. Exploitation of the bone as a food resource is discussed below.

A variety of other taxa occur with a lower NISP than turtles and artiodactyls, but like drum, are well represented and sometimes better represented in the MNI. The mammals show a variety of exploited taxa such as raccoon, cotton rat, cottontail rabbit, and opossum. Cottontail rabbit remains have the highest MNI for the site with 10 individuals, followed by cotton rat with 7 . Many of these smaller mammals are represented largely by dental elements including teeth, mandibles, and maxillae. The limited postcranial representation may be due to recovery methods, visibility in the field, processing by the site inhabitants, and lack of identifiability of smaller fragmentary remains as compared to dental elements.

Other taxa occur in much lower numbers and usually do not show any signs of definitive human modification; some show none. Fish are represented by vertebrae and various cranial elements. For example, unidentified fish are represented by cranial and vertebral elements. Gar are represented by vertebrae and scales. Aside from turtles, the only other reptiles recovered were 56 snake vertebrae representing at least 1 poisonous and 2 nonpoisonous individuals. For Amphibia, only 1 specimen was identified as an anuran (frog or toad). Bird remains are low in frequency as well. Forty specimens were recovered, of which 9 are from medium-sized birds, 27 are from large birds, and 4 are from turkey. Infrequent mammals include a mole, several rodents, mustelids, and canids.

\section{Area Assemblages}

Table E-2 provides the breakdown of taxa from nonfeature contexts as a single aggregate along with taxa identified in Features 6-17. Tables E-3, E-4, and E-5 provide breakdowns for the other features. The nonfeature tallies follow the overall site pattern of taxonomic representation, in large part because most of the assemblage is from nonfeature contexts.

It was hoped that, for the lower-frequency taxa, that some assessment of their significance could be found by examining their proportions in the total assemblage, nonfeature assemblage, and assemblage of all features combined (Table E-6). Taxa occurring in low frequencies and without definite cultural modification are problematic for interpretation. Should they occur in relatively higher proportions in the combined feature assemblage (summed counts for all features), then their importance within the assemblage might need to be evaluated further. This perspective was taken because, aside from their presence in the assemblage, the lower-frequency taxa lack diagnostic culturally induced modification, and this leaves little that can be said about them. In general, though, the breakdown of the feature assemblage compared to those of the total assemblage and the nonfeature assemblage shows no apparent variation that provides insights as to why taxa are or are not present in the whole assemblage or in features. For example, the proportions of cottontail remains for the entire site, nonfeature contexts, and features are nearly equal. In the cases where taxa are more common in the feature assemblage, it is because of extremely low frequencies.

In looking at the composition differences among the site, nonfeature, and feature assemblages, the general pattern that emerges is that the greater diversities of taxa come with the higher NISP counts. The five largest featuresFeatures 9, 10, 17, 21a, and 21b-all show a similar pattern. In the two largest Features, 21a and $21 \mathrm{~b}$, taxa represented include turtles, rodents, cottontails, raccoons, and artiodactyls (see Table E-3). The same holds true for Feature 9 and, to a lesser extent, Features 10 and 17 (see Table E-2).

The rest of the features with lower specimen counts show no specific patterns of taxa representation. It is true, though, that those taxa with higher frequencies are most commonly represented in the features. While not all higher-frequency taxa are present in all features, when taxa are identified in lowerfrequency features, they tend to be the taxa 


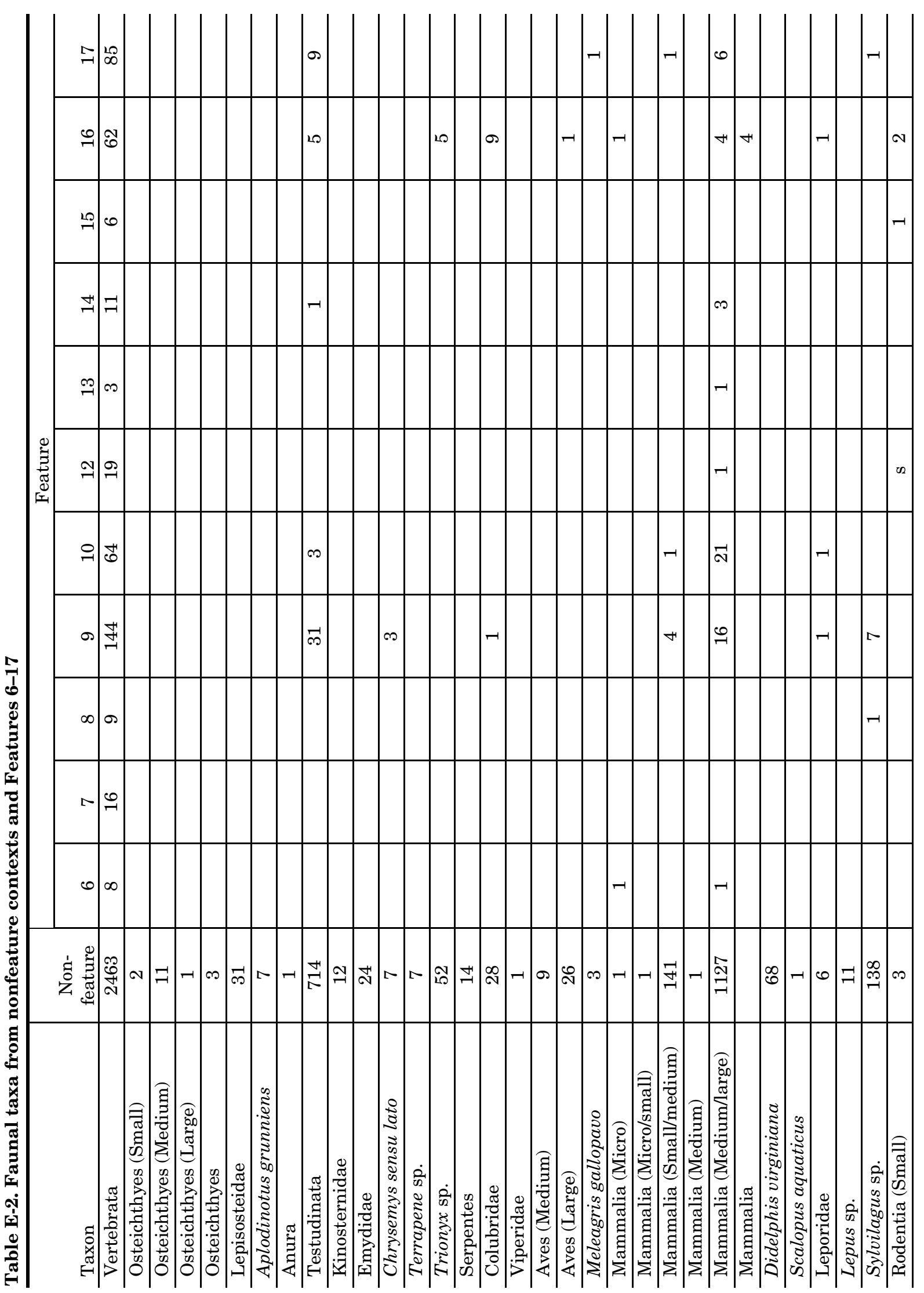


Data Recovery Excavations at the J. B. White Site

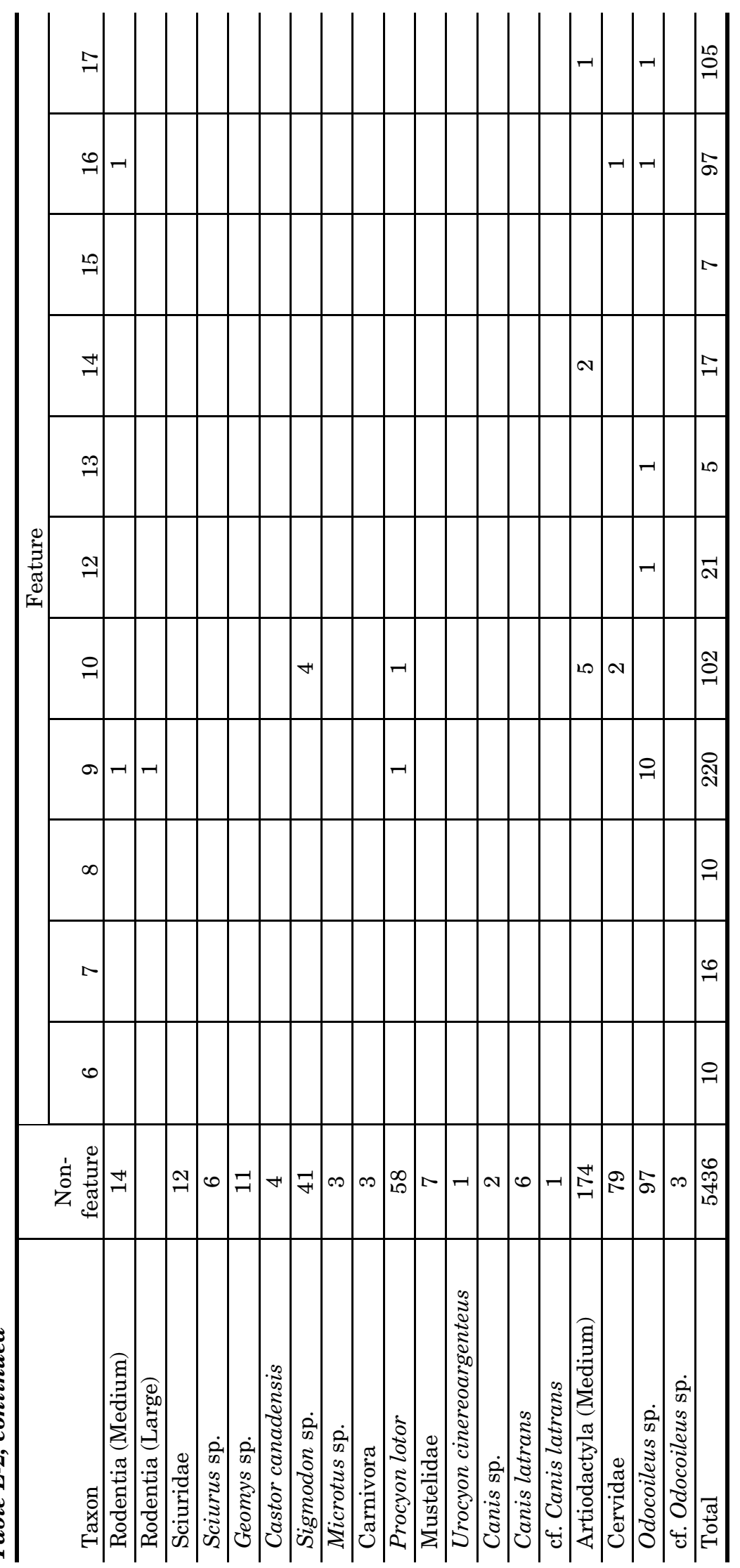



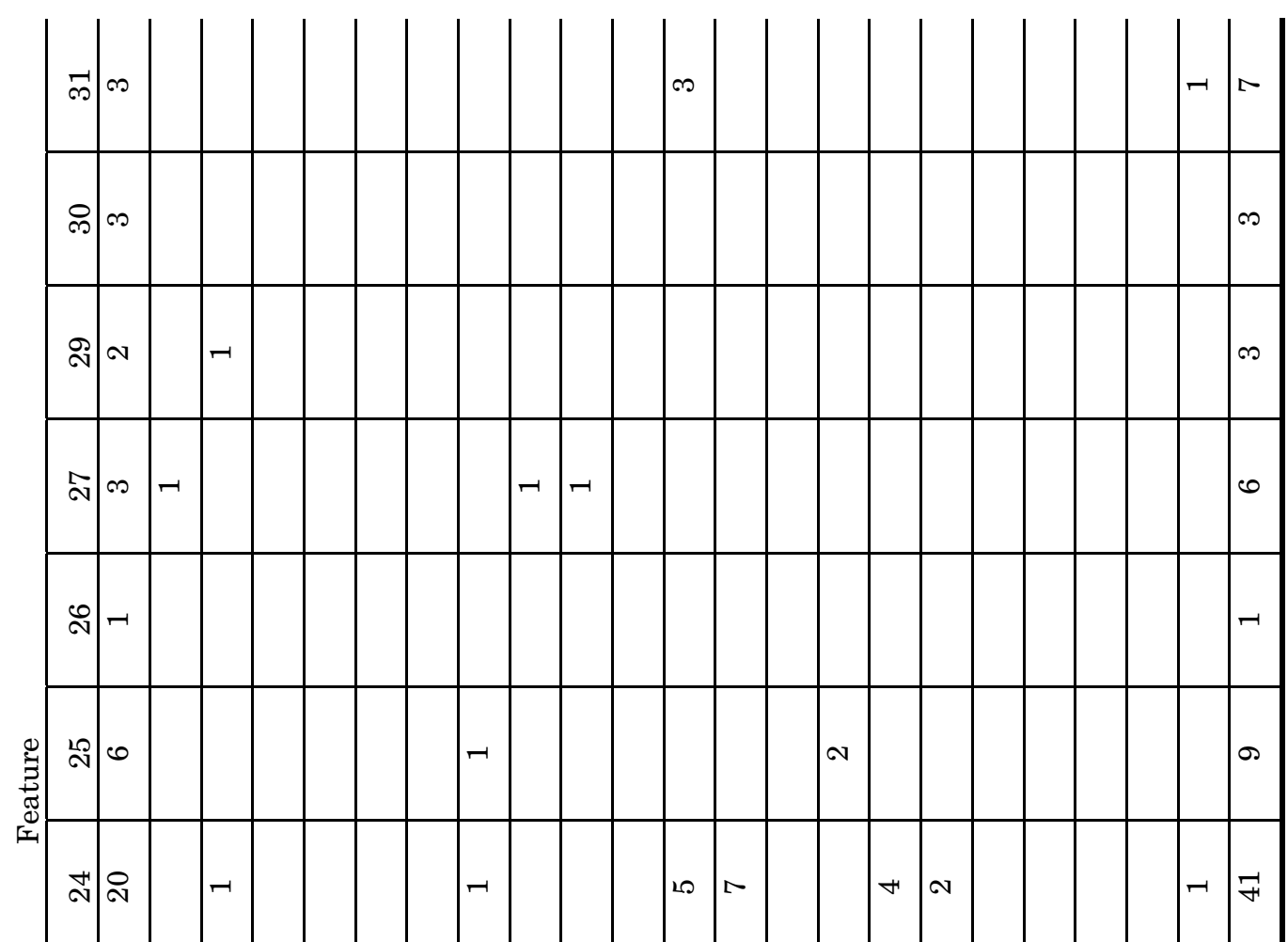

ลิ ก

N

ㅇำ

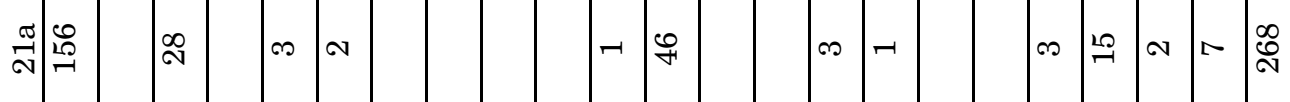

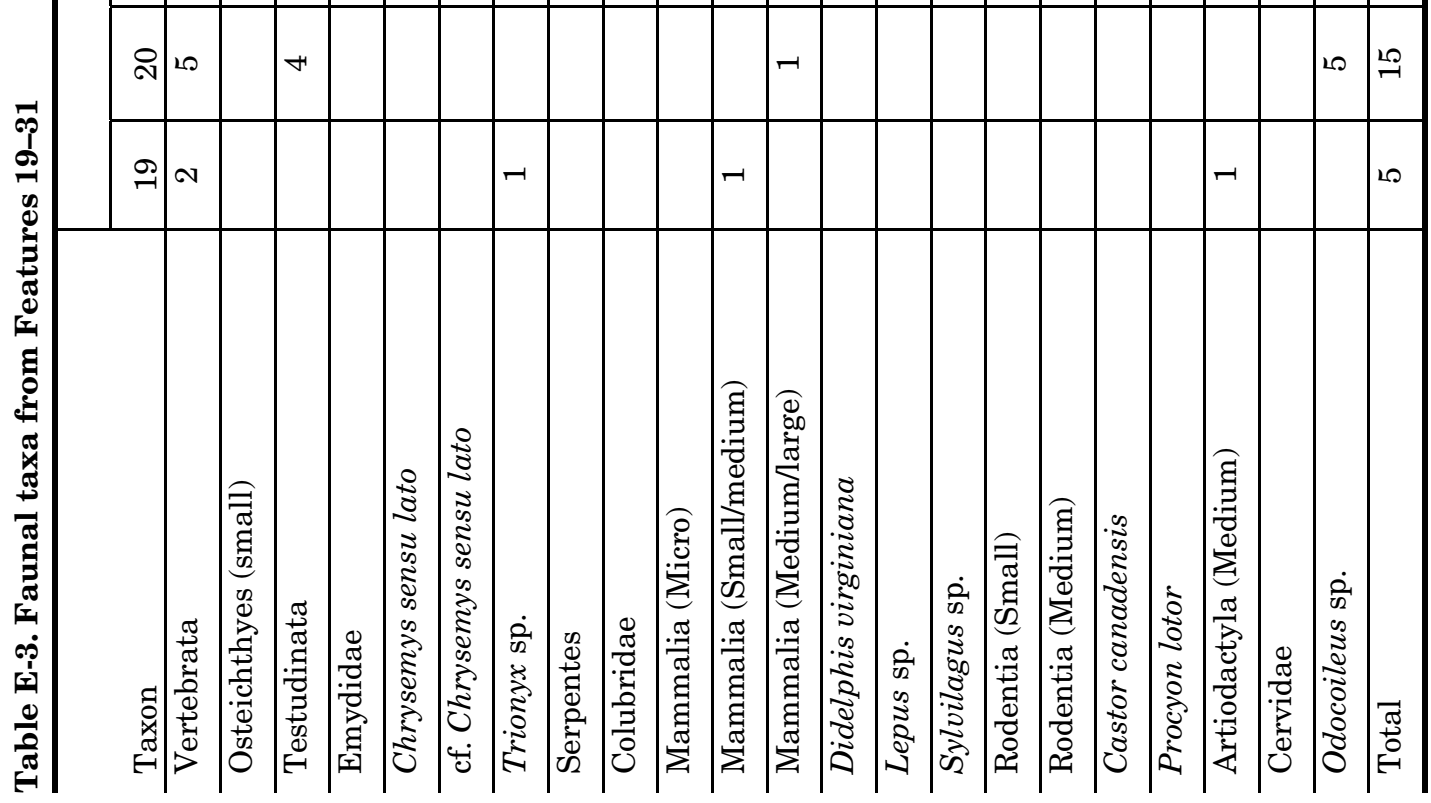


Data Recovery Excavations at the J. B. White Site

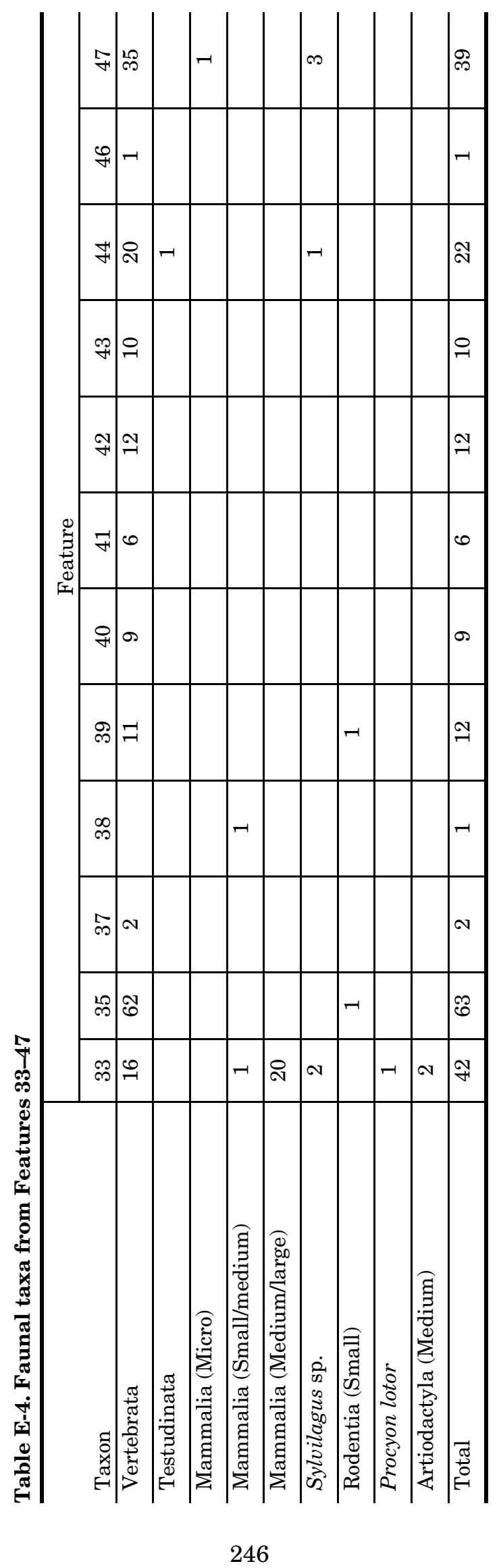


Appendix E: Analysis of Vertebrate Remains

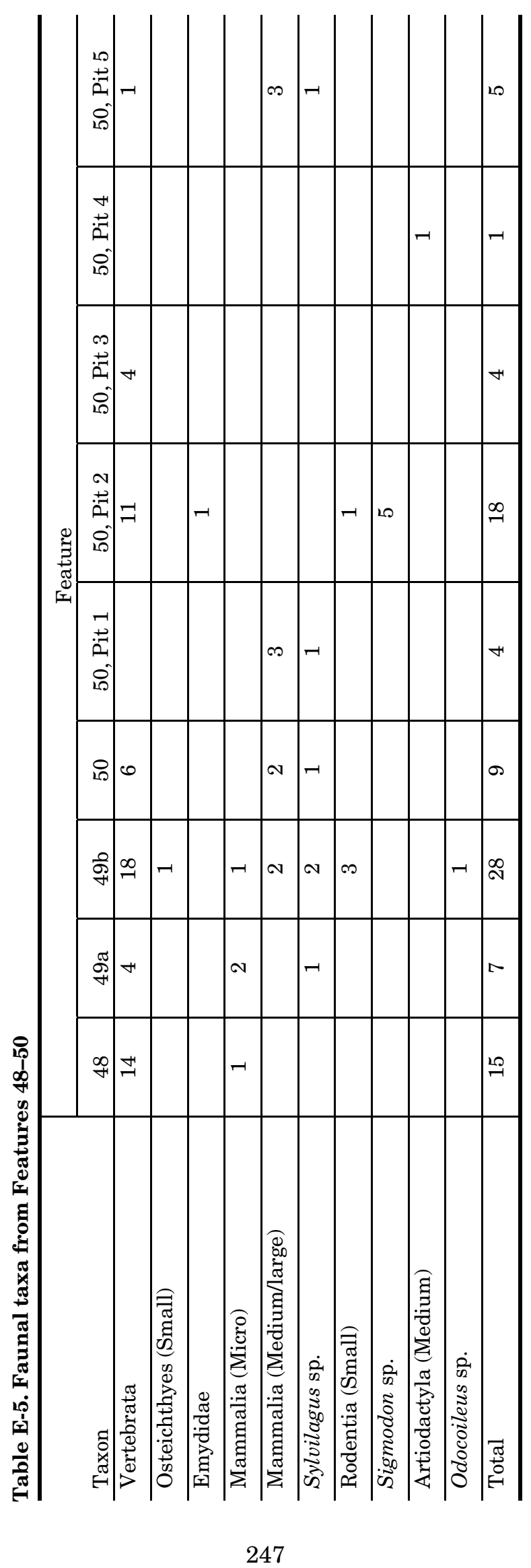


Data Recovery Excavations at the J. B. White Site

Table E-6. Portions of faunal taxa by site, nonfeature, and feature assemblages

\begin{tabular}{|c|c|c|c|}
\hline Taxon & Site & Nonfeature & Feature \\
\hline Vertebrata & 49.7 & 45.0 & 65.2 \\
\hline Osteichthyes (Small) & 0.06 & 0.04 & 0.10 \\
\hline Osteichthyes (Medium) & 0.16 & 0.20 & \\
\hline Osteichthyes (Large) & 0.01 & 0.02 & \\
\hline Osteichthyes & 0.04 & 0.06 & \\
\hline Lepisosteidae & 0.45 & 0.57 & \\
\hline Aplodinotus grunniens & 0.10 & 0.13 & \\
\hline Anura & 0.01 & 0.02 & \\
\hline Testudinata & 11.8 & 13.0 & 7.1 \\
\hline Kinosternidae & 0.17 & 0.22 & \\
\hline Emydidae & 0.37 & 0.44 & 0.10 \\
\hline Chrysemys sensu lato & 0.19 & 0.13 & 0.40 \\
\hline cf. Chrysemys sensu lato & 0.03 & & 0.10 \\
\hline Terrapene sp. & 0.10 & 0.13 & \\
\hline Trionyx sp. & 0.83 & 0.96 & 0.40 \\
\hline Serpentes & 0.23 & 0.26 & 0.10 \\
\hline Colubridae & 0.56 & 0.52 & 0.70 \\
\hline Viperidae & 0.01 & 0.02 & \\
\hline Aves (Medium) & 0.13 & 0.17 & \\
\hline Aves (Large) & 0.39 & 0.48 & 0.10 \\
\hline Meleagris gallopavo & 0.06 & 0.06 & 0.10 \\
\hline Mammalia (Micro) & 0.13 & 0.02 & 0.50 \\
\hline Mammalia (Micro/small) & 0.01 & 0.02 & \\
\hline Mammalia (Small/medium) & 2.21 & 2.60 & 0.90 \\
\hline Mammalia (Medium) & 0.01 & 0.02 & \\
\hline Mammalia (Medium/large) & 18.9 & 21.0 & 12.2 \\
\hline Mammalia & 0.06 & & 0.30 \\
\hline Didelphis virginiana & 1.1 & 1.30 & 0.50 \\
\hline Scalopus aquaticus & 0.01 & 0.02 & \\
\hline Leporidae & 0.13 & 0.11 & 0.20 \\
\hline Lepus sp. & 0.17 & 0.20 & 0.10 \\
\hline Sylvilagus sp. & 2.5 & 2.5 & 2.4 \\
\hline Rodentia (Small) & 0.24 & 0.06 & 0.90 \\
\hline Rodentia (Medium) & 0.23 & 0.26 & 0.10 \\
\hline Rodentia (Large) & 0.01 & & 0.10 \\
\hline Sciuridae & 0.17 & 0.22 & \\
\hline Sciurus sp. & 0.09 & 0.11 & \\
\hline Geomys sp. & 0.16 & 0.20 & \\
\hline Castor canadensis & 0.07 & 0.07 & 0.10 \\
\hline Sigmodon sp. & 0.72 & 0.75 & 0.60 \\
\hline Microtus sp. & 0.07 & 0.06 & 0.10 \\
\hline Carnivora & 0.04 & 0.06 & \\
\hline Procyon lotor & 0.98 & 1.1 & 0.70 \\
\hline Mustelidae & 0.10 & 0.13 & \\
\hline Urocyon cinereoargenteus & 0.01 & 0.02 & \\
\hline Canis sp. & 0.03 & 0.04 & \\
\hline
\end{tabular}


Table E-6, continued

\begin{tabular}{|c|c|c|c|}
\hline Taxon & Site & Nonfeature & Feature \\
\hline Canis latrans & 0.09 & 0.11 & \\
\hline cf. Canis latrans & 0.01 & 0.02 & \\
\hline Artiodactyla (Medium) & 3.2 & 3.2 & 3.0 \\
\hline Cervidae & 1.2 & 1.5 & 0.50 \\
\hline Odocoileus sp. & 2.0 & 1.8 & 2.6 \\
\hline cf. Odocoileus sp. & 0.04 & 0.06 & \\
\hline NISP Total & 6,961 & 5,436 & 1,525 \\
\hline
\end{tabular}

Note: Frequencies are taken to two decimal places if less than one.

that occur in higher frequencies at the site.

What does the representation of taxa across the features represent? None of the features appear to be any sort of specialized processing areas for particular taxa. The five largest features reflect generalized taxa use or discard that potentially could be associated with normal food consumption activities. For the rest of the features, data are not sufficient to suggest particular human behaviors relevant to the taxa recovered.

\section{TAPHONOMIC OBSERVATIONS}

\section{General Assemblage}

With the exception of breakage, the assemblage is in fairly good taphonomic condition, and many specimens have preserved exceptionally well. Table E-7 represents the taphonomic data by provenience.

Most of the assemblage exhibits light weathering with 1.2 percent of the assemblage exhibiting signs of marked weathering. Additional degradation via chemical etching was noted but is not prevalent. Just 1.5 percent of the assemblage was recorded with light etching and another 1.3 percent with marked etching. Other natural impacts come in the form of gnawing, which is even less common. Rodent gnawing was identified on less than 1 percent of the specimens, and carnivore gnawing was observed on just one specimen.

Two forms of taphonomic insult are often associated with or considered indicative of human impacts. These are breakage and burning. Spiral breakage is associated with the breaking of cortical bone while still fresh or containing bone grease (collagen). When bone has lost its grease, the fracture pattern tends to be more angular. While spiral fractures may be associated with human activity, they can occur via various non-human processes such as trauma to a living animal, gnawing by a carnivore, and even trampling in some cases. With just one carnivore gnaw mark identified, carnivores do not appear to have contributed appreciably to the spiral fracturing of bone. No signs of trampling were identified in the assemblage, although if present they may have been too subtle to identify.

At a gross level, 24.8 percent of the assemblage was identified with spiral fractures. In looking at spiral fractures by feature, some features do have higher percentages of spirally fractured bone than the site average. However, spiral fracturing is no more common in the features as a group than in nonfeature contexts.

As noted, the spiral fracturing of bone often is associated with processing for marrow or grease (e.g., Binford 1978:158; DeMarcay 1986; Lintz 1976:87-88; Vehik 1977:172; Zierhut 1967:33-36), especially when accompanied by impact fractures that would indicate intentional human breakage of the bones, since impact fractures usually do not occur naturally (Johnson 1985:192). While some of the bones may have been spirally fractured as a result of carcass processing, such high amounts of spirally fractured bones would not be expected unless it was being processed for marrow or grease.

Using impact fractures as an indicator of intentional human bone breakage, 33 specimens were identified with impact fractures. Of these, 21 were observed with single impacts. Nine specimens have two impacts. Three specimens have three impacts present. Of those with impact fractures, 1 specimen is of indeterminate taxon, 14 are from medium-sized to large mammals, 16 are from deer-sized artiodactyls, and 2 are from deer. With the exception of the 
Data Recovery Excavations at the J. B. White Site

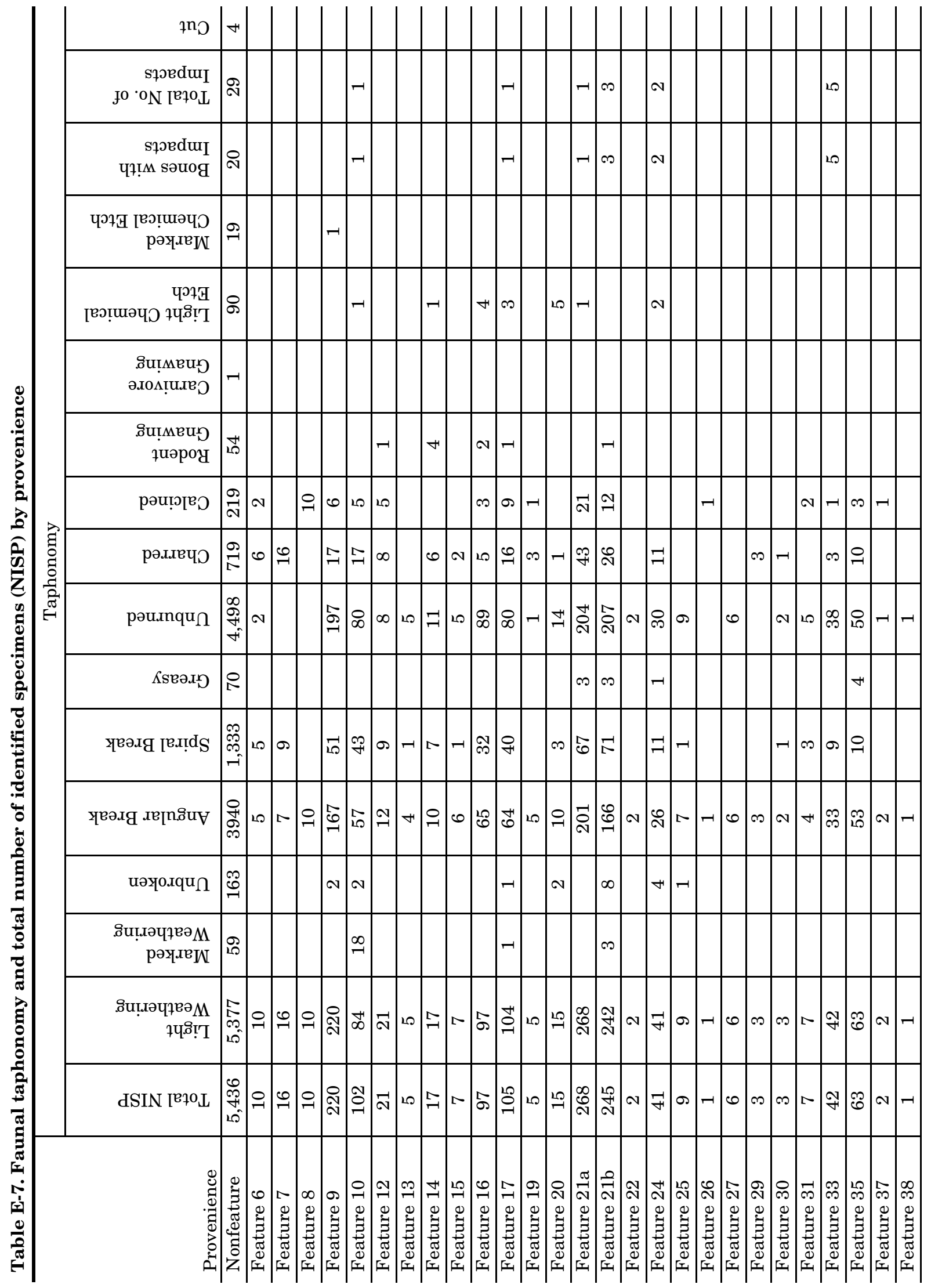




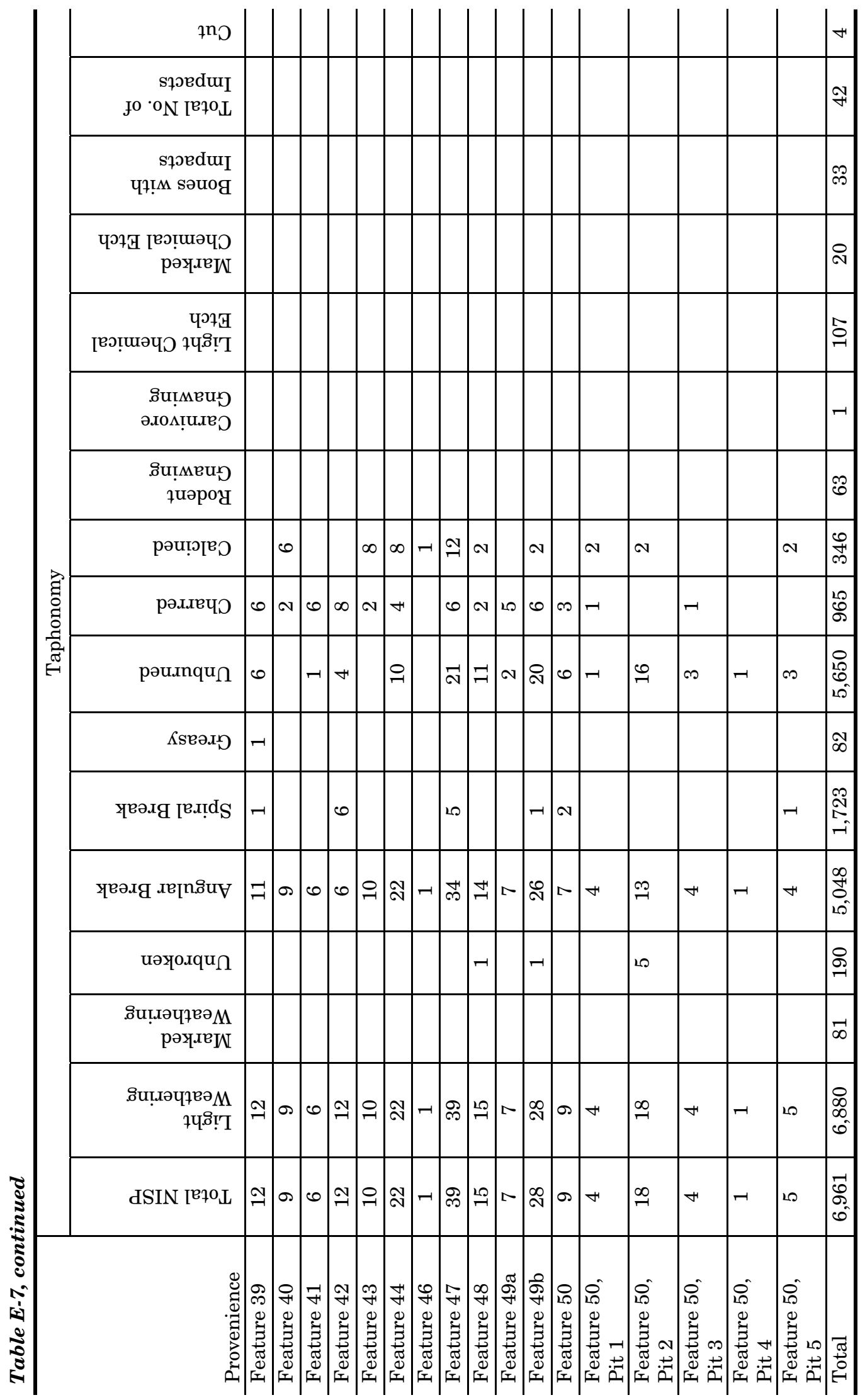


specimen of indeterminate taxon, the rest appear to be from deer or canid/deer-sized taxa. Of interest, however, is the same number of specimens identified specifically as deer and medium-sized artiodactyl. The specifically identified elements with impact fractures are all long bone specimens with larger marrow cavities that allow easy access to the marrow once the bone is opened. This is in contrast to specimens such as the pelvis that contain goodly amounts of marrow. In these instances, the marrow is not contained primarily in a single large cavity, but trapped within countless pockets of trabecular bone. Identified specimens with impact fractures include four femur, four radius, three humerus, three metacarpal, two metatarsal, and two tibia sections.

Marrow retrieval can be performed by simply breaking open the bone to expose the marrow. Grease manufacture, however, has been identified based on the presence of concentrations of small, spirally fractured bone chips (Lintz 1976:87-88). According to Lintz (1976), the bones are broken into small pieces and boiled for grease manufacture. The smaller the fragments, the more relative surface area of the bone and hence the more grease that can be extracted from the bone. Once the process is completed and the grease removed from the water, the bone is poured out, which results in concentrations of spirally fractured bone (Lintz 1976:87-88). No such concentrations were noted in the assemblage. This, combined with the fact that much of the spirally fractured bone consists of larger specimens, indicates that marrow extraction and probably not grease processing is the primary activity represented.

The collagen (bone grease) in recovered specimens is also of interest. Of the specimens that are still greasy, most were identified first on the basis of appearance and then by feel. Most of the specimens actually retain a slight reflective sheen and slight waxy or oily feel. The largest amount $(n=45)$ are medium- to large mammals, followed by specimens identified as Vertebrata $(n=24)$, artiodactyl $(n=10)$, cotton rat $(\mathrm{n}=2)$, and large bird $(\mathrm{n}=1)$.

The presence of greasy bone does not appear to be correlated with features with higher or lower numbers of spirally fractured bone or bones with impacts. It might be expected that, if grease was being processed, locations with higher frequencies of spirally fractured bone and impacts would be areas where bone was most processed and, hence, the chance for recovery of greasy bone lessened. This is not borne out by the sample. Instead, the presence of greasy bone does not appear to reflect a particular pattern relative to features.

Relative to excavation units, however, there are potential patterns. Eighty-two greasy bone specimens were recovered in a total of 33 excavation units, including some with features. In looking at units with greasy bone, there is a gradient in the number of specimens present. In 17 of the excavation units where greasy bone was recovered, only 1 specimen was identified per unit. In 9 more, 2 specimens were identified per unit. Three were present in 1 excavation unit, 4 in another. Five were present in 2 units. In 3 other units, however, the numbers were much higher. Eight were recovered from Unit 23, 9 from Unit 17, and 13 from Unit 18. The reason for the concentrations of greasy bone in these units is not clear from the faunal assemblage itself.

Within features, bones still containing grease are infrequent. Greasy bones were identified in just five features (Features 21a, 21b, 24,33 , and 39) and account for just 12 specimens. The first four features were identified as shell lenses and the last as a pit hearth. No connection between greasy bone preservation and feature type was discerned.

In reference to the previously noted marrow and grease processing, one aspect seemed unusual: of the greasy bone recovered, two medium-sized to large mammal specimens also exhibit impact points. One specimen from Feature 33 has two impact points, and one specimen from Excavation Unit 193 has one impact. In an assemblage where impact points and greasy bones account for such small percentages of the overall assemblage, it is surprising to find two that exhibit both. While the low frequencies are far from conclusive, the presence of greasy bone with impact points would seem to indicate that marrow was being harvested (hence the reason for breaking open the bone), but that grease was not being rendered or was not necessary to be rendered from all available material. Of course, a final possibility is that the greasy bone with impacts was simply lost or missed in the bone reduction process. This seems unlikely given the amount of greasy bone recovered at the site. Surprisingly, the 82 
specimens constitute 1.2 percent of the total site assemblage, more than the author has previously encountered in any other assemblage by count and by percentage.

Another 72.5 percent of the assemblage contains angular fractures. Angular fractures occur in specimens not capable of spiral breakage or in specimens that can spirally fracture but that have lost their collagen at the time of breakage. Collagen loss can be the result of grease processing, weathering, burning, and chemical insults that leach the collagen from the bone. Some specimens, however, even after losing collagen, were unbroken (2.7 percent).

Burning is present in only 18.8 percent of the assemblage. Of the two types of burning noted, 13.9 percent are charred and 4.9 percent are calcined. In most cases, burned bone is not indicative of cooking activities, as flesh-covered bone has little bone surface that might be in contact with open flame. There are exceptions to this, however. In some animals that are roasted, bones covered with minimal amounts of flesh may show signs of burning. These would include parts such as feet, joints of the knee or elbow, etc., located just under the skin and not otherwise covered with much soft tissue (Szuter 1991). In some taxa, there is more exposed material than in others. For example, gar-like other fish-may be cooked with the scales left on. The scales of the gar will often survive direct exposure to flame and will actually show different burns between the exterior and interior surfaces of the scales, the exterior showing the greatest signs of exposure to heat (Shaffer 1995:E-31 and E-34). Interior and exterior surfaces of gar scales are readily identifiable, making it possible to determine that the exterior surfaces were the surfaces showing direct exposure to fire.

Bony specimens with burning on areas covered in muscle or organs would probably not have been burned as the result of cooking activities. They may have been burned as a source of fuel for fire, as part of trash disposal, or as unintentional burning where a fire is constructed over shallowly covered or buried bone, but not as part of food preparation. Most of the burned bone in the 41MM341 assemblage was likely burned for these reasons. No cooking burn patterns were identified on mammals or gar, although the turtle remains do show a unique pattern of burning similar to the gar example noted above. Of the 126 burned turtle shell specimens, 28 were recorded with mostly exterior burning and another 5 simply denoted with just one side burned (no determination made as to interior or exterior). In these cases, one side shows charring of the surface (none calcined) while the other side only showed a tan or browned darkening of the surface. All of these differentially burned shell fragments are from nonfeature areas of the site (Excavation Units $35,38126,171,187,188,306$, and 320). While it would be possible for the turtle shell fragments to be burned on just one side simply due to very limited exposure to flame, it is not common, as the shell is not thick and burning tends to include both sides unless one side is somehow protected. As with mammals and gar noted above, one way in which this might happen is due to one side being covered in flesh. As such, it may be that the turtles were procured and then prepared in their shells, possibly cooked like a baked potato in the coals of a fire (as done with rodents [e.g., Beals 1934:349; Steward 1934:255]) or over an open flame. The exterior of their shells would show charring, but the same pattern would not be present on the interior. It might also be possible that turtle shells were used as cooking containers for heating water or cooking foods other than the original turtle's flesh.

\section{Area Assemblages}

As with the taxonomic representation, there is a correlation between frequencies and representation. Taphonomic traits in the highest frequencies are most likely to be represented in any one feature, and features with the greatest frequencies are likely to have the greatest number of taphonomic traits represented.

For the features with the greatest counts (Features 9, 10,17, 21a, and 21b) that were identified in the taxonomic section as showing generalized taxonomic use with most of the typical food taxa, it would be expected that these features might show the greatest amounts of food processing in the way of spirally fractured bone and impact points. This turns out to be only partially correct. In looking at Table E-7, Feature 9 has 23 percent spirally fractured bone and no impacts. Feature 10 has 42 percent and one impact point. Feature 17 has 38 percent and one impact point: Feature 21a has 25 percent and 
one impact point. And Feature $21 \mathrm{~b}$ has 30 percent and three impact points. Especially with the impact points, these areas show food preparation activity in the manner of intentional bone breakage. With that said, two other features have bones with impacts but much lower overall frequencies of bone. Feature 24 has 27 percent spiral breakage and two bones with impacts. Feature 33 has 21 percent spiral breakage and five bones with impacts-the largest feature concentration. All of these features were identified as shell lenses.

Cut marks would have been very useful in helping to identify feature use as well. However, only four specimens were recovered with cut marks, and none are from feature areas. Two of the four are artiodactyl remains, and the other two are medium-sized to large mammal specimens.

\section{ARTIODACTYL ELEMENT REPRESENTATION}

Given that deer and deer-sized artiodactyls represent the most common larger animals present in the assemblage and, hence, represent a major source of food and raw materials, it was decided to more closely examine artiodactyls in the assemblage. In looking at Table E-8, it is apparent that there is a disparity of elements represented. Missing are the vertebrae (including sacrum and caudal vertebrae), sternae, and ribs. These elements could have been broken beyond taxonomic identification and therefore would simply have been identified as medium/ large mammal. However, just 63 rib fragments were identified in this category, and they likely include some smaller animals as well, such as the canids. No cervical, 2 thoracic, 1 lumbar, and 1 caudal were the only vertebral elements identified from this general-sized category.

So where are the missing elements? It might be suggested that differential field butchering resulted in the transport of only select portions of the carcasses back to the site. If so, then more scapulae should have been present, as the forequarter contains a large amount of readily removable meat that would include the scapula and humerus. As noted, humeri occur in a higher frequency than scapulae. This seems to parallel the representation of femora and pelvis fragments as well.

If select portions of the carcass were not re-
Table E-8. Number of identified specimens (NISP) for deer, deer-sized artiodactyl, and cervid elements

\begin{tabular}{l|c}
\hline Element & NISP \\
\hline Cranium & 25 \\
\hline Mandible & 12 \\
\hline Permanent tooth & 38 \\
\hline Deciduous tooth & 13 \\
\hline Tooth & 28 \\
\hline Scapula & 3 \\
\hline Humerus & 15 \\
\hline Radius & 13 \\
\hline Ulna & 10 \\
\hline Pelvis & 4 \\
\hline Femur & 15 \\
\hline Patella & 2 \\
\hline Tibia & 19 \\
\hline Distal fibula & 8 \\
\hline Metapodial & 31 \\
\hline Fused 3rd \& 4th metacarpal & 15 \\
\hline Fused 3rd \& 4th metatarsal & 32 \\
\hline Proximal phalange & 19 \\
\hline Middle phalange & 15 \\
\hline Distal phalange & 7 \\
\hline Dist. phalange of paradigit & 3 \\
\hline Carpal & 1 \\
\hline Fourth carpal bone & 2 \\
\hline Radial carpal bone & 2 \\
\hline Intermediate carpal bone & 1 \\
\hline Accessory carpal bone & 1 \\
\hline First tarsal & 1 \\
\hline Fused second \& third tarsal & 3 \\
\hline Astragalus & 3 \\
\hline Calcaneus & 5 \\
\hline Fused central/fourth tarsal & 2 \\
\hline Proximal sesamoid & 1 \\
\hline Proximal axial sesamoid & 3 \\
\hline Proximal abaxial sesamoid & 4 \\
\hline Long bone & 2 \\
\hline Antler & 844 \\
\hline Total & \\
\hline & \\
\hline
\end{tabular}

turned to the site because of transporting issues, then field butchering seems to have been rather select in the removal of body elements, rather than limb elements. While possible, the reasoning for this specific selection is not clear from the remains alone. Given that taphonomy does not appear to be the reason for the missing elements, the only other reasonable explanation is 
that site sampling-possibly in conjunction with some sort of differential discard of said elements-resulted in these elements not being represented in the analyzed sample.

\section{COMPARISON WITH 41MM340}

Site 41MM340 was selected for comparison with $41 \mathrm{MM} 341$ as it represents a local site that predates 41MM341 and might be useful for comparisons to look at change through time in faunal composition. While a comparison of the taxonomic representation is fairly straightforward, comparison of interpretations is not. Because interpretations are subjective, they may reflect as much about the perspectives of the interpreters as the actual data.

In looking at the data presented by Meissner and Mahoney (2003) and further interpreted by Tomka and Mauldin (2003), it is apparent that the vertebrate assemblage from 41MM340 does not differ strikingly from that from 41MM341, with the exception of the presence of bison and bison-sized elements that were not recovered from 41MM341. This information is presented in Table E-9. Both sites are dominated by unidentifiable remains. At 41MM340, they were identified as Mammalia, and at 41MM341, they were recorded as Vertebrata. In either case, the specimens were too small or unidentifiable for further comment. Aside from these unidentifiable remains, both collections are composed of large amounts of medium-large mammalian taxa, most of which appear to be from deer and deer-sized artiodactyls, although only deer were identified in this size of artiodactyl at each site. Beyond these differences, 41MM340 has substantially more avian resources, while 41MM341 has a much greater amount of aquatic and smaller mammal resources.

Do these differences represent substantial differences in Late Archaic and Late Prehistoric diet strategies, environmental utilization, changes through time, or seasonality? Do such differences reflect different levels of subsistence stress to the human occupants at the sites? This is where differences in perspective will influence interpretation, and limited samples greatly influence the comparison.

From Tomka and Mauldin (2003:116):

In general, an increase in diet breadth suggests that a greater number of spe- cies have to be included in the diet to meet protein needs. Conversely, a narrow diet indicates that much of the necessary protein requirements are being met through the exploitation of a few, higher-ranked species. Broad diets tend to include a variety of very small to small body sized species while narrow diets tend to be dominated by medium to large and very large body sized species. Finally, a broadening of the diet may be indicative of some degree of subsistence stress.

This quote forms an interesting basis for interpreting the 41MM341 sample and comparing that sample with the one from 41MM340. If the stated parameters are taken at face value, on diversity alone it is difficult to tell at which site the occupants were most stressed. The sites show differences in diversity by the types of taxa represented. Based on animal size indicators, both show a large amount of larger mammal remains, especially those from deer-sized animals including deer. But 41MM340 has 1 bison, 2 bovid, and 312 very large mammal elements, which would give the impression that maybe the occupants at 41MM340 were less stressed, since the bison and bison-sized mammalian remains outrank whatever was present at 41MM341. If so, in looking at the relative percentages of medium to larger mammals from both sites, including specimens identified to a general category or to the more-specific family, genus, or species, then each site is composed of about the same frequency of larger taxa. So then, maybe the sites are fairly comparable if the Tomka and Mauldin (2003) parameters are followed.

However, the premise for their evaluation is unfounded. They assumed that all of the taxa represented in the assemblage are there specifically to meet protein needs, and larger and higher-ranked animals have the composition to provide more protein. This would therefore allow for a narrower diet breadth, thereby making unnecessary the procurement of other smaller or lower-ranked animals. This further assumes that, as the diet diversifies, there must be increased subsistence stress because the protein needs are not being met. However, this fails to take into consideration factors such as environment, seasonality, food taboos, food preferences, size of the human population, makeup of 
Table E-9. Comparison of vertebrate faunal remains (NISP) from 41MM341 and 41MM340

\begin{tabular}{|c|c|c|}
\hline Taxon & 41MM341 & $41 \mathrm{MM} 340$ \\
\hline Vertebrata & 3,458 & 4 \\
\hline Osteichthyes (Small) & 4 & \\
\hline Osteichthyes (Medium) & 11 & \\
\hline Osteichthyes (Large) & 1 & \\
\hline Osteichthyes & 3 & 3 \\
\hline Lepisosteidae & 31 & \\
\hline Aplodinotus grunniens & 7 & \\
\hline Anura & 1 & \\
\hline Testudinata & 823 & 109 \\
\hline Kinosternidae & 12 & \\
\hline Emydidae & 26 & 6 \\
\hline Chrysemys sensu lato & 13 & \\
\hline cf. Chrysemys sensu lato & 2 & \\
\hline Terrapene sp. & 7 & \\
\hline Trionyx sp. & 58 & 64 \\
\hline Trachemys sp. & & 1 \\
\hline Serpentes & 16 & \\
\hline Colubridae & 39 & 1 \\
\hline Viperidae & 1 & 3 \\
\hline Aves (Medium) & 9 & 12 \\
\hline Aves (Large) & 27 & 179 \\
\hline Aves (Very Large) & & 5 \\
\hline Aves & & 311 \\
\hline Anas sp. & & 2 \\
\hline Buteo sp. & & 2 \\
\hline Anatidae & & 1 \\
\hline Ardeidae & & 1 \\
\hline Phasianidae & & 1 \\
\hline Strigoformes & & 1 \\
\hline Meleagris gallopavo & 4 & 1 \\
\hline Mammalia (Micro) & 9 & 2 \\
\hline Mammalia (Micro/small) & 1 & 126 \\
\hline Mammalia (Small/medium) & 154 & \\
\hline Mammalia (Medium/large) & 1,314 & 2,334 \\
\hline Mammalia (Very Large) & & 317 \\
\hline Mammalia & 4 & 6,769 \\
\hline Didelphis virginiana & 75 & 3 \\
\hline Scalopus aquaticus & 1 & \\
\hline Leporidae & 9 & \\
\hline Lepus sp. & 12 & 67 \\
\hline Sylvilagus sp. & 174 & 74 \\
\hline Rodentia & 34 & 10 \\
\hline Sciuridae & 12 & \\
\hline Sciurus sp. & 6 & \\
\hline Geomys sp. & 11 & \\
\hline
\end{tabular}


Table E-9, continued

\begin{tabular}{l|c|c}
\hline Taxon & 41MM341 & 41MM340 \\
\hline Castor canadensis & 5 & 17 \\
\hline Sigmodon sp. & 50 & 2 \\
\hline Microtus sp. & 5 & \\
\hline Carnivora & 3 & 3 \\
\hline Concepatus mesoleucus & & 5 \\
\hline Mephitis mephitis & & 1 \\
\hline Procyon lotor & 68 & 3 \\
\hline Mustelidae & 7 & \\
\hline Urocyon cinereoargenteus & 1 & 1 \\
\hline Canis sp. & 2 & 29 \\
\hline Canis latrans & 6 & \\
\hline cf. Canis latrans & 1 & \\
\hline Artiodactyla (Medium) & 219 & 220 \\
\hline Cervidae & 85 & \\
\hline Odocoileus sp. & 137 & 151 \\
\hline cf. Odocoileus sp. & 3 & \\
\hline Bovinae & & 2 \\
\hline Bison bison & 6,961 & 10,844 \\
\hline Total & &
\end{tabular}

the human population (males, females [pregnant, nursing, not pregnant], youngsters, etc.), site type, protein requirements, fat requirements, hide requirements, brain requirements, bone tool resource requirements, and other animal product requirements. Tomka and Mauldin (2003:112) do note that some of the differences in taxa represented might be due to seasonal availability of resources, but they go on to say that their data lack the temporal resolution to further investigate the idea. Also not considered were the actual costs of resource procurement inclusive of aspects such as energy expenditure and danger to those procuring the resources. For example, the risk cost of trapping/clubbing/ shooting a rabbit are nearly nil compared to the risk cost of procuring a bison. Slow game such as turtles (especially when caught on land) or mollusks are also extremely low risks. So, to suggest that these smaller and lower-ranked game are indicative of food stress is fairly naïve, as the cost of procuring these resources is so low. Also not included in the evaluation is the reward potential beyond protein, such as status within the society.

Given this premise by Tomka and Mauldin (2003), a site represented by a broad range of taxa, and especially including so-called lowerranked resources such as turtles and smaller mammals, would indicate subsistence stress as compared to a single bison-kill site where protein needs were being met by a single large, high-ranked animal. Just because a site is dominated by more taxa does not indicate that protein needs are or are not being sufficiently met. In fact, the greater diversity of taxa may actually reflect a healthier diet where a greater variety of animal resources provided a broader spectrum for the human body. Protein and other animal-based nutrition needs can be met by multiples of small taxa without necessarily indicating subsistence stress.

Another aspect to consider is the amount of bone processing that went on at the two sites. Little mention is made regarding bone breakage (intentional or otherwise) beyond saying that the bone at $41 \mathrm{MM} 340$ was heavily processed. Tomka and Mauldin (2003:117) divided a sample from one unit into those specimens with "recent, excavation-related breaks" and old breaks. With the excavation-related breaks removed from consideration, the remaining specimens were measured and found to be small. This finding was the basis for saying the sample was heavily processed, but the reason for such extensive processing could not be ascertained. It was, therefore, suggested that "maximum processing [of bone] would have been the norm 
when meat protein was in short supply." This one unit sample consisted of just 195 specimens, 1.8 percent of the total assemblage of 10,734 specimens.

The above description by Tomka and Mauldin (2003:117) does not appear to be representative of how the overall sample was described by Meissner and Mahoney (2003:198). While they also did not quantify breakage type, they did note that only 7.2 percent of the sample could be identified to the taxonomic level of order because of the amount of breakage in the sample, some of which was broken during recovery, but "the majority of the bone had already been reduced to small pieces while it was still fresh." Just what percentage of that majority was actually spirally fractured bone was not presented, and not all of it could have been spirally fractured unless the sample was unique, as no such type of sample has been reported to date. Occupational processes such as burning and postdepositional processes (chemical leaching, ground compaction, etc.) will produce nonfresh (angular) breaks that must have impacted the 41MM340 assemblage. Furthermore, probably not all the specimens recovered were broken, and some simply were incapable of spiral fracturing (e.g., turtle shell, teeth, etc.).

Without assessing the differences between spiral and angular fracturing of bone, attributing extensive processing of the bone to human activity and tying this to protein shortage is unfounded. Knowing just how much of the 41MM340 sample was unbroken, angularly broken, and spirally broken, and how much showed impact points might have provided additional insights for comparisons with 41MM341. Assessment of the bone processing cannot be evaluated without presenting breakage types and frequencies.

\section{SUMMARY}

The vertebrate sample recovered from $41 \mathrm{MM} 341$ represents an assemblage that is fairly well preserved with the exception of frag- mentation. Occupational and postoccupational processes did negatively impact the assemblage, but they also served to preserve the assemblage in a beneficial manner as evidenced by the amount of material that still contains bone grease.

The assemblage is not unusual for a huntergatherer assemblage and is dominated by terrestrial taxa, predominantly by specimens of larger terrestrial taxa such a deer and deer-sized artiodactyl. This does not negate the contribution of smaller taxa, however, which occurred in considerable frequency throughout the site as a diversified group of animals. This diversity included both terrestrial and aquatic taxa. This is what would be expected for a group of people who simply utilized the many resources locally available to them during occupation.

It was hoped that the taxonomic and taphonomic composition of the samples from the features would shed light on specific human activities at those features. No patterns were noted in the feature assemblages that could be separated from the nonfeature assemblage. In part, this was because the faunal complement of many of the features was low.

Two unique observations were made tied directly to the taphonomic information. The first was the differential burning of turtle shells, with the exteriors showing more pronounced burning than the interiors. The likely reason for this burn pattern is that the shells were used as cooking containers, either directly with the turtle inside the shell or possibly after the turtle had been removed from the shell.

The second observation pertained to spiral breakage, impact fractures, and greasy bone. Site 41MM341 preserved an unusual amount of greasy bone. Combining the three categories together, it appears that marrow may have been harvested from many long bones, the long bones being broken open intentionally as evidenced by the impact points. The presence of grease in 1.2 percent of the assemblage seems to indicate that grease was not being rendered from the bones. 
Appendix E: Analysis of Vertebrate Remains

\section{REFERENCES CITED}

Beals, Ralph L.

1934 Ethnology of the Nisenan. University of California Publications in American Archaeology and Ethnography 31:335-414.

Binford, Lewis D.

1978 Nunamiut Ethnoarchaeology. Academic Press, New York.

DeMarcay, Gary B.

1986 Vertebrate Fauna from Landergin Mesa: An Antelope Creek Period Village Site. Master's thesis. Department of Anthropology, Texas A\&M University, College Station, Texas.

Johnson, Eileen

1985 Current Developments in Bone Technology. In Advances in Archaeological Method and Theory, Volume 8, edited by M. B. Schiffer, pp. 157-235. Academic Press, New York.

Lintz, Christopher R.

1976 The McGrath Site of the Panhandle Aspect. Oklahoma Anthropological Society Bulletin 25:1-110.

Meissner, Barbara A., and Richard B. Mahoney 2003 Vertebrate Remains. In Data Recovery Excavations at 41MM340, A Late Archaic Site along Little River in Milam County, Texas, by Richard B. Mahoney, Steve A. Tomka, Raymond P. Mauldin, Harry J. Shafer, Lee C. Nordt, Russell D. Greaves, and Rebecca R. Galdeano, pp. 198-206. Archeological Studies Program Report No. 54. Environmental Affairs Division, Texas Department of Transportation, Austin. Archaeological Survey Report No. 340. Center for Archaeological Research, The University of Texas at San Antonio.

Shaffer, Brian S.

1995 Faunal Analysis of the Vertebrate Remains from $41 \mathrm{CH} 70,41 \mathrm{CH} 252,41 \mathrm{CH} 357$, and 41LB4, Wallisville Lake Project, Southeast Texas. In Archeological Test Excavations at Four Shell Midden Sites in the Wallisville Lake Project Area, Chambers and Liberty Counties, Texas, edited by H. Blaine Ensor, pp E-1-E-37. Wallisville Lake Project Technical Series, Reports of
Investigations No. 2. Geo-Marine, Inc., Plano, Texas.

Shaffer, B. S., and B. W. Baker

1992 A Vertebrate Faunal Analysis Coding System: With North American Taxonomy and dBase Support Programs and Procedures (Version 3.3), Museum of Anthropology Technical Report 23. University of Michigan, Ann Arbor.

Shaffer, Brian S., Bonnie C. Yates, and Barry W. Baker 1995 An Additional Record of Native American Elk (Cervus elaphus) from North Texas. Texas Journal of Science 47(2):159 160.

Steward, J. H.

1934 Ethnography of Owens Valley Paiute. University of California Publications in American Archaeology and Ethnography 33:233350 .

Szuter, Christine R.

1991 Hunting by Prehistoric Horticulturalists in the American Southwest. Garland Publishing, New York.

Tomka, Steve A., and Raymond P. Mauldin

2003 Subsistence Strategies. In Data Recovery Excavations at 41MM340, A Late Archaic Site along Little River in Milam County, Texas, by Richard B. Mahoney, Steve A. Tomka, Raymond P.. Mauldin, Harry J. Shafer, Lee C. Nordt, Russell D. Greaves, and Rebecca R. Galdeano, pp. 109-118. Archeological Studies Program Report No. 54. Environmental Affairs Division, Texas Department of Transportation, Austin. Archaeological Survey Report No. 340. Center for Archaeological Research, The University of Texas at San Antonio.

Vehik, Susan C.

1977 Bone Fragment and Bone Grease Manufacturing: A Review of the Archaeological Use and Potential. Plains Anthropologist 22:169-182.

Zierhut, N. W.

1967 Bone Breaking Activities of the Calling Lake Creek. Alberta Anthropologist 1:3336 . 



\section{APPENDIX F: Analysis of the Fatty Acid Compositions of Archeological Residues from 41MM341}

M. E. Malainey, Ph.D.

Winnipeg, Manitoba (Canada) 



\section{INTRODUCTION}

Samples from 41MM341, Milam County, Texas, consisting of 30 rocks and 2 pieces of burned clay were submitted for analysis of the fatty acid compositions and archeological residues. Where indicated, subsamples were taken from the top surfaces of burned rocks. Exterior surfaces were ground to remove any contaminants. Samples were powdered, and absorbed lipid residues were extracted with organic solvents. Fatty acid components of the lipid extracts were analyzed using gas chromatography (GC). Residues were identified using criteria developed from the decomposition patterns of experimental residues. The first section of this report outlines the development of the identification criteria. The second section presents analytical procedures and results.

\section{FATTY ACIDS AND DEVELOPMENT OF THE IDENTIFICATION CRITERIA}

\section{Introduction and Previous Research}

Fatty acids are the major constituents of fats and oils (lipids) and occur in nature as triglycerides, consisting of three fatty acids attached to a glycerol molecule by ester-linkages. The shorthand convention for designating fatty acids, Cx:ywz, contains three components. The " $\mathrm{Cx}$ " refers to a fatty acid with a carbon chain length of " $x$ " number of atoms. The " $y$ " represents the number of double bonds or points of unsaturation, and the "wz" indicates the location of the most distal double bond on the carbon chain (i.e., closest to the methyl end). Thus, the fatty acid expressed as C18:1w9, refers to a mono-unsaturated isomer with a chain length of 18 carbon atoms with a single double bond located 9 carbons from the methyl end of the chain. Similarly, the shorthand designation C16:0 refers to a saturated fatty acid with a chain length of 16 carbons.

Their insolubility in water and relative abundance compared to other classes of lipids, such as sterols and waxes, make fatty acids suitable for residue analysis. Since employed by Condamin et al. (1976), GC has been used extensively to analyze the fatty acid component of absorbed archeological residues. The composi- tion of uncooked plants and animals provides important baseline information, however, it is impossible to directly compare modern uncooked plants and animals with highly degraded archeological residues. Unsaturated fatty acids, which are found widely in fish and plants, decompose more readily than saturated fatty acids, sterols, or waxes. In the course of decomposition, simple addition reactions might occur at points of unsaturation (Solomons 1980), or peroxidation might lead to the formation of a variety of volatile and nonvolatile products that continue to degrade (Frankel 1991). Peroxidation occurs most readily in fatty acids with more than one point of unsaturation.

Attempts have been made to identify archeological residues using criteria that discriminate uncooked foods (Loy 1994; Marchbanks 1989; Skibo 1992). Marchbanks's (1989) percent of saturated fatty acids (\%S) criteria has been applied to residues from a variety of materials including pottery, stone tools, and burned rocks (Collins et al. 1990; Marchbanks 1989; Marchbanks and Quigg 1990). Skibo (1992:89) instead used two ratios of fatty acids, C18:0/ C16:0 and C18:1/C16:0. Skibo reported that it was possible to link the uncooked foods with residues extracted from modern cooking pots actively used to prepare one type of food (1992); however, the ratios could not identify food mixtures. The utility of these ratios did not extend to residues extracted from archeological potsherds because the ratios of the major fatty acids in the residue changed with decomposition (Skibo 1992:97). Loy (1994) proposed the use of a Saturation Index (SI), determined by the ratio: $\mathrm{SI}=1-[(\mathrm{C} 18: 1+\mathrm{C} 18: 2) /$ C12:0+C14:0+C16:0+C18:0)]. Loy (1994) admitted, however, that poorly understood decompositional changes to the original suite of fatty acids make it difficult to develop criteria for distinguishing animal and plant fatty acid profiles in archeological residues.

The major drawback of the distinguishing ratios proposed by Marchbanks (1989), Skibo (1992), and Loy (1994) is that they have never been empirically tested. The proposed ratios are based on criteria that discriminate food classes on the basis of their original fatty acid composition. The resistance of these criteria to the effects of decompositional changes has not been demonstrated. Rather, Skibo (1992) found his fatty acid ratio criteria could not be used to 
identify highly decomposed archeological samples.

To identify a fatty acid ratio unaffected by degradation processes, Patrick et al. (1985) simulated the long-term decomposition of one sample and monitored the resulting changes. An experimental cooking seal residue was prepared and degraded to identify a stable fatty acid ratio. Patrick et al. (1985) found that the ratio of two C18:1 isomers-oleic and vaccenic — did not change with decomposition; this fatty acid ratio was then used to identify an archeological vessel residue as seal. While the fatty acid composition of uncooked foods must be known, Patrick et al. (1985) showed that the effects of cooking and decomposition over long periods of time on the fatty acids must also be understood.

\section{Development of the Identification Criteria}

As the first stage in developing the identification criteria used herein, GC was used to determine the fatty acid compositions of more than 130 uncooked native food plants and animals from western Canada (Malainey 1997; Malainey et al. 1999a). When the fatty acid compositions of modern food plants and animals were subjected to cluster and principal component analyses, the resultant groupings generally corresponded to divisions that exist in nature (Table F-1). Clear differences in the fatty acid compositions of large mammal fat, large herbivore meat, fish, plant roots, greens, and berries/ seeds/nuts were detected, but it was difficult to distinguish between the fatty acid composition of meat from medium-sized mammals and the fatty acid composition of berries/seeds/nuts.

Samples in Cluster A, the large mammal and fish cluster, had elevated levels of C16:0 and C18:1 (see Table F-1). Divisions within this cluster stemmed from the very high level of C18:1 isomers in fat, high levels of C18:0 in large herbivore meat, and high levels of very-long-chain unsaturated fatty acids (VLCU) in fish. Differences in the fatty acid compositions of plant roots, greens, and berries/seeds/nuts reflect the amounts of $\mathrm{C} 18: 2$ and $\mathrm{C} 18: 3 \mathrm{w} 3$ present. The berry, seed, and nut samples and the mixed samples, which may include small mammal meat, appearing in Cluster B had very high levels of C18:2, ranging from 36 to 64 percent (see Table F-1). Samples in Subclusters V, VI, and
VII had levels of C18:1 isomers from 29 to 51 percent, as well. Plant roots, plant greens, and some berries appear in Cluster C. All Cluster C samples had moderately high levels of C18:2; except for the berries in Subcluster XII, levels of C16:0 are also elevated. High levels of C18:3w3 and very-long-chain saturated fatty acids (VLCS) also are common.

Secondly, the effects of cooking and degradation over time on fatty acid compositions were examined. Originally, 19 modern residues of plants and animals from the plains, parklands, and forests of western Canada were prepared by cooking samples of meats, fish, and plants (alone or combined) in replica vessels over an open fire (Malainey 1997; Malainey et al. 1999b). After four days at room temperature, the vessels were broken and a set of sherds analyzed to determine changes after a short decomposition period. A second set of sherds remained at room temperature for 80 days and were then placed in an oven at $75^{\circ} \mathrm{C}$ for 30 days to simulate the processes of long-term decomposition. The relative percentages were calculated on the basis of the 10 fatty acids (C12:0, C14:0, C15:0, C16:0, C16:1, C17:0, C18:0, C18:1w9, C18:1w11, and $\mathrm{C} 18: 2$ ) that regularly appeared in Precontact period vessel residues from western Canada. A method for identifying the archeological residues was developed by observing changes in fatty acid composition of the experimental cooking residues (Table F-2).

It was determined that levels of mediumchain fatty acids (C12:0, C14:0, and C15:0), $\mathrm{C} 18: 0$, and C18:1 isomers could be used to distinguish degraded experimental cooking residues (Malainey 1997; Malainey et al. 1999b). These fatty acids are suitable for the identification criteria because saturated fatty acids are stable and the mono-unsaturated fatty acid degrades very slowly, as compared to polyunsaturated fatty acids (deMan 1992). Higher levels of medium-chain fatty acids, combined with low levels of C18:0 and C18:1 isomers, were detected in the decomposed experimental residues of plants, such as roots, greens, and most berries. High levels of C18:0 indicated the presence of large herbivores. Moderate levels of C18:1 isomers, with low levels of C18:0, indicated the presence of either fish or foods similar in composition to corn. High levels of C18:1 isomers with low levels of C18:0 were found in residues of beaver or foods of similar fatty acid 


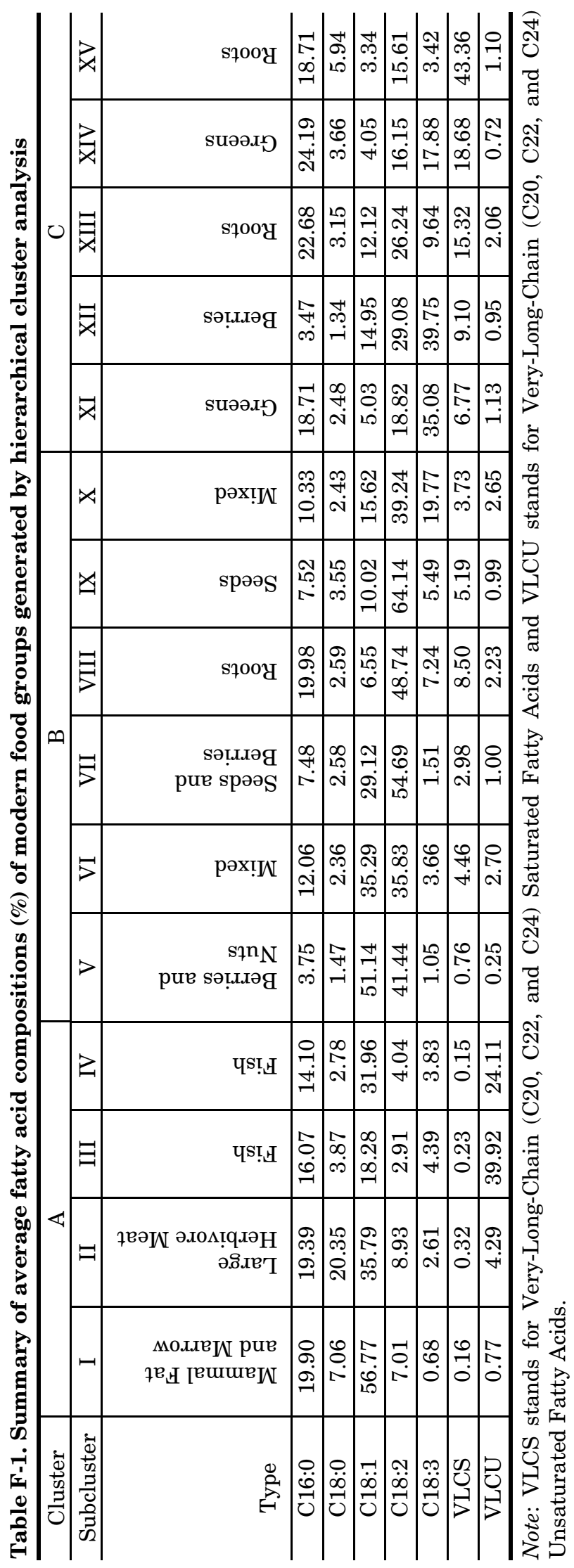


Table F-2. Criteria for the identification of archeological residues

\begin{tabular}{l|c|c|c}
\hline Identification & $\begin{array}{c}\text { Medium } \\
\text { Chain }\end{array}$ & C18:0 & C18:1 isomers \\
\hline Large herbivore & $\leq 15 \%$ & $\geq 27.5 \%$ & $\leq 15 \%$ \\
\hline $\begin{array}{l}\text { Large herbivore with } \\
\text { plant or bone marrow }\end{array}$ & low & $\geq 25 \%$ & $15 \% \leq X \leq 25 \%$ \\
\hline $\begin{array}{l}\text { Plant with large } \\
\text { herbivore }\end{array}$ & $\geq 15 \%$ & $\geq 25 \%$ & no data \\
\hline Beaver & low & Low & $\geq 25 \%$ \\
\hline Fish or corn & low & $\leq 25 \%$ & $15 \% \leq X \leq 27.5 \%$ \\
\hline Fish or corn with plant & $\geq 15 \%$ & $\leq 25 \%$ & $15 \% \leq X \leq 27.5 \%$ \\
\hline Plant (except corn) & $\geq 10 \%$ & $\leq 27.5 \%$ & $\leq 15 \%$ \\
\hline
\end{tabular}

Note: Criteria based on patterns of decomposition of experimental cooking residues prepared in pottery vessels.

composition. The criteria for identifying six types of residues were established experimentally; the seventh type, plant with large herbivore, was inferred (see Table F-2). These criteria were applied to residues extracted from more than 200 pottery cooking vessels from 18 western Canadian sites (Malainey 1997; Malainey et al. 1999c; Malainey, Przybylski et al. 2001). The identifications were consistent with the evidence from faunal and tool assemblages for each site.

Work to understand the decomposition patterns of various foods and food combinations has continued (Malainey et al. 2000a, 2000b, 2000c; Malainey, Malisza et al. 2001; Quigg et al. 2001). The collection of modern foods has expanded to include plants from the Southern Plains. The fatty acid compositions of mesquite beans (Prosopis glandulosa), Texas ebony seeds (Pithecellobium ebano Berlandier), tasajillo berry (Opuntia leptocaulis), prickly pear fruit and pads (Opuntia engelmannii), Spanish dagger pods (Yucca treculeana), cooked sotol (Dasylirion wheeler), agave (Agave lechuguilla), cholla (Opuntia imbricata), piñon (Pinus edulis), and Texas mountain laurel (or mescal) seed (Sophora secundiflora) have been determined. Experimental residues of many of these plants, alone or in combination with deer meat, have been prepared by boiling foods in clay cylinders or using sandstone for either stone boiling (Quigg et al. 2000) or as a griddle. To accelerate the processes of oxidative degradation that naturally occur at a slow rate with the passage of time, the rock or clay tile containing the experimental residue was placed in an oven at $75^{\circ} \mathrm{C}$. After either 30 or 68 days, residues were ex- tracted and analyzed using GC. The results of these decomposition studies enabled refinement of the identification criteria.

\section{Methodology}

Descriptions of the 32 samples from 41MM341 are presented in Table F-3. Possible contaminants were removed by grinding exterior surfaces with a Dremel® tool fitted with a silicon carbide bit. Immediately thereafter, the sample was crushed with a hammer mortar and pestle and the powder transferred to an Erlenmeyer flask. Lipids were extracted using a variation of the method developed by Folch et al. (1957). The powdered sample was mixed with a 2:1 mixture, by volume, of chloroform and methanol $(2 \times 30 \mathrm{~mL})$ using ultrasonication $(2 \times 10$ $\min )$. Solids were removed by filtering the solvent mixture into a separatory funnel. The lipid/ solvent filtrate was washed with $16 \mathrm{~mL}$ of double-distilled water. Once separation into two phases was complete, the lower chloroform-lipid phase was transferred to a round-bottom flask and the chloroform removed by rotary evaporation. Any remaining water was removed by evaporation with benzene $(1.5 \mathrm{~mL}) ; 1.5 \mathrm{~mL}$ of chloroform-methanol $(2: 1, \mathrm{v} / \mathrm{v})$ was used to transfer the dry total lipid extract to a screw-top glass vial with a Teflon®-lined cap. The sample was flushed with nitrogen and stored in a $-20^{\circ} \mathrm{C}$ freezer.

A $450 \mathrm{~mL}$ sample of the total lipid extract solution was placed in a screw-top test tube and dried in a heating block under nitrogen. Fatty acid methyl esters (FAMES) were prepared by treating the dry lipid with $6 \mathrm{~mL}$ of $0.5 \mathrm{~N}$ anhydrous hydrochloric acid in methanol $\left(68^{\circ} \mathrm{C}\right.$; $60 \mathrm{~min}$ ). Fatty acids that occur in the sample as di- or triglycerides are detached from the glycerol molecule and converted to methyl esters. After cooling to room temperature, $4 \mathrm{~mL}$ of double-distilled water was added. FAMES were recovered with petroleum ether $(3 \mathrm{~mL})$ and transferred to a vial. The solvent was removed by heat under a gentle stream of nitrogen; the FAMES were dissolved in $75 \mu \mathrm{L}$ of iso-octane and then transferred to a GC vial with a conical glass insert. 
Table F-3. List of samples analyzed for organic residues

\begin{tabular}{|c|c|c|c|}
\hline Lab No. & Feature & Material Type & $\begin{array}{l}\text { Sample } \\
\text { Size (g) }\end{array}$ \\
\hline 3PAI 1 & 7 & limestone & 63.392 \\
\hline 3PAI 2 & 7 & limestone & 62.328 \\
\hline 3PAI 3 & 12 & burned clay & 58.294 \\
\hline 3PAI 4 & 14 & limestone & 65.817 \\
\hline 3 PAI 5 & 14 & limestone & 44.996 \\
\hline 3PAI 6 & 18 & quartzite & 47.839 \\
\hline 3PAI 7 & 18 & limestone & 26.757 \\
\hline 3PAI 8 & 18 & limestone & 59.361 \\
\hline 3PAI 9 & 25 & burned clay & 68.604 \\
\hline 3PAI 10 & 35 & sandstone & 40.621 \\
\hline 3PAI 11 & 36 & limestone & 67.442 \\
\hline 3PAI 12 & 36 & sandstone & 61.047 \\
\hline 3PAI 13 & 36 & quartzite & 49.436 \\
\hline 3PAI 14 & 39 & sandstone & 37.326 \\
\hline 3PAI 15 & 39 & limestone & 50.333 \\
\hline 3PAI 16 & 39 & limestone & 36.351 \\
\hline 3PAI 17 & 42 & limestone & 43.570 \\
\hline 3PAI 18 & 42 & limestone & 50.467 \\
\hline 3PAI 19 & 42 & limestone & 49.978 \\
\hline 3PAI 20 & 46 & sandstone & 43.417 \\
\hline 3PAI 21 & 48 & limestone & 44.512 \\
\hline 3PAI 22 & 50, Pit 1 & limestone & 45.277 \\
\hline 3PAI 23 & 50, Pit 1 & quartzite & 48.673 \\
\hline 3PAI 24 & 50, Pit 1 & limestone & 40.308 \\
\hline 3PAI 25 & 50, Pit 5 & limestone & 49.563 \\
\hline $3 \mathrm{PAI} 26$ & 50, Pit 4 & limestone & 52.134 \\
\hline 3PAI 27 & 50, Pit 4 & limestone & 46.984 \\
\hline 3PAI 28 & 50, Pit 4 & limestone & 52.377 \\
\hline 3PAI 29 & 50, Pit 5 & limestone & 46.716 \\
\hline 3PAI 30 & 50, Pit 3 & limestone & 48.084 \\
\hline 3PAI 31 & 50, Pit 3 & limestone & 49.968 \\
\hline 3PAI 32 & 50 , Pit 3 & quartzite & 55.579 \\
\hline
\end{tabular}

this step was unnecessary for the analysis of archeological residues, previously the solventlipid mixture was not washed. This step was recently adopted to remove impurities so that clearer chromatograms could be obtained in the region where very-long-chain fatty acids (C20:0, C20:1, C22:0, and C24:0) occur. It was anticipated that the detection and accurate assessment of these fatty acids could be instrumental in separating residues of animal origin from those of plants (Malainey et al. 2000a, 2000b, 2000c; Malainey, Malisza et al. 2001).

To identify the residue, the relative percentage composition was determined first with respect to all fatty acids present in the sample (including very-longchain fatty acids) and secondly with respect to the 10 fatty acids utilized in the development of the identification criteria (C12:0, C14:0, C15:0, C16:0, C16:1, C17:0, C18:0, C18:1w9, C18:1w11, and C18:2). The second step is necessary for the application of the identification criteria presented in Table F-2.

It should be noted that the identifications given do not necessarily mean that these particular foods were actually prepared, since different foods of similar

Solvents and chemicals were checked for purity by running a sample blank. The entire lipid extraction and methyl esterification process was performed, and FAMES were dissolved in $75 \mathrm{~mL}$ of iso-octane. Traces of contamination were subtracted from sample chromatograms. The relative percentage composition was calculated by dividing the integrated peak area of each fatty acid by the total area of fatty acids present in the sample.

The step in the extraction procedure where the chloroform, methanol, and lipid mixture is washed with water is standard procedure for the extraction of lipids from modern samples. Following Evershed et al. (1990), who reported that fatty acid composition and lipid content would produce similar residues. It is possible to say, however, that the material of origin for the residue was similar in composition to the food(s) indicated.

The GC analysis was performed on a Hewlett-Packard 5890 gas chromatograph fitted with a flame ionization detector connected to a personal computer. Samples were separated using a DB-23 fused silica capillary column ( $30.0 \mathrm{~m}$ x $0.25 \mathrm{~mm}$ I.D.; J\&W Scientific, Folsom, California). An autosampler injected a $3 \mathrm{~mL}$ sample using a split injection system with the ratio set at 1:20. Hydrogen was used as the carrier gas at a linear velocity of approximately 
$40 \mathrm{~cm} /$ second. Column temperature was programmed from $155^{\circ}$ to $215^{\circ} \mathrm{C}$ at $2^{\circ} \mathrm{C}$ per minute. The lower temperature was held for 2 minutes; the upper temperature was held for 10 minutes. Chromatogram peaks were integrated using ChromPerfect $\circledR_{\text {software and identified through }}$ comparisons with several external qualitative standards (NuCheck Prep, Elysian, Minnesota). Using this procedure, fatty acids are detectable to the nanogram $\left(1 \times 10^{-9} \mathrm{~g}\right)$ level.

\section{RESULTS OF ARCHEOLOGICAL DATA ANALYSIS}

The fatty acid compositions of residues extracted from 26 samples are presented in Table F-4. The term "Area" represents the area under the chromatographic peak of a given fatty acid, as calculated by the ChromPerfect@ software minus the solvent blank. The term "Rel\%" represents the relative percentage of the fatty acid with respect to the total fatty acids in the sample. Hydroxide or peroxide degradation products can interfere with the integration of the $\mathrm{C} 22: 0$ and $\mathrm{C} 22: 1$ peaks; these fatty acids were excluded from the analysis.

Insufficient fatty acids were recovered from residues 3PAI 11, 3PAI 19, 3PAI 22, 3PAI 25, 3PAI 31, and 3PAI 32 to attempt identification; the latter two were almost completely devoid of lipids. All of these were extracted from limestone, except 3PAI 32, which was from quartzite. Of the remaining 26, recoveries from 6 samples (3PAI 15, 3PAI 23, 3PAI 26, and 3PAI 28-30) were relatively low.

Eleven residues appear to result from the preparation of foods with medium fat content, such as mesquite or corn. These residues have elevated levels of C18:1 isomers and relatively lower levels of C18:0. Fish produces similar residues, but given the elevated levels of mediumchain and very-long-chain saturated or mono-unsaturated fatty acids present, plant origins are probable for most. Six residues (3PAI 7, 3PAI 13, 3PAI 16, 3PAI 17, 3PAI 24, and 3PAI 28 ) are very similar in composition and may have the same origin. Residue 3PAI 10 is slightly different from the 6 in that its level of C16:0 is higher. The level of 18:0 in residue 3PAI 8 is extremely low. Residues 3PAI 4 and 3PAI 21, and to a lesser extent 3PAI 6, appear to contain elevated levels of C20:1 and C24:1. Given the variability in composition, it is possible that three or four different foods produced the residues described above.

One residue, 3PAI 2, may result from the combination of a medium-fat-content food with a low-fat-content food. A low-fat-content food would account for the elevated levels of mediumand very-long-chain saturated fatty acids in this residue. Low-fat-content foods include plant greens, roots, and certain berries.

Eight residues are consistent with the preparation of large herbivores. In the Great Plains, bison and deer are the most likely sources of residues of this composition; however, javelina and the seeds of certain cacti are known to produce similar residues. Residues 3PAI 15, 3PAI 23, 3PAI 29, and 3PAI 30 may have resulted from the preparation of fairly lean meat, whereas the fat content in residues 3PAI 14, 3PAI 26, and 3PAI 27 is higher. Residue 3PAI 18 has somewhat elevated levels of very-longchain fatty acids, possibly due to the presence of plants.

Three residues-3PAI 1, 3PAI 3, and 3PAI 20-are typical of foods of moderate-high fat content. These residues have relatively high levels of C18:1 isomers and relatively low levels of C18:0. Examples of such foods include Texas ebony seeds and the fatty meat of medium-sized mammals such as beaver. Residues 3PAI 1 and 3PAI 3 have elevated levels of very-long-chain saturated fatty acids, suggesting they could be of plant origin. The origin of 3PAI 20 is less certain.

The composition of 3PAI 12 is characterized by a high level of C18:1 isomers, almost 42 percent. This value is somewhat higher than one would expect in residues from foods of moderate-high fat content, such as Texas ebony and beaver meat; however, it is slightly lower than would be produced by a veryhigh-fat content food, such as piñon. Possible candidates for these residues include pure mammal fat (other than from large herbivores) or locally available seeds and nuts with high fat content. Alternatively, a combination of foods with moderate-high fat and very high fat content could also produce similar residues. The compositions of the two remaining residues (3PAI 5, 3PAI 9) fall on the border between foods with medium and moderate-high fat content. 


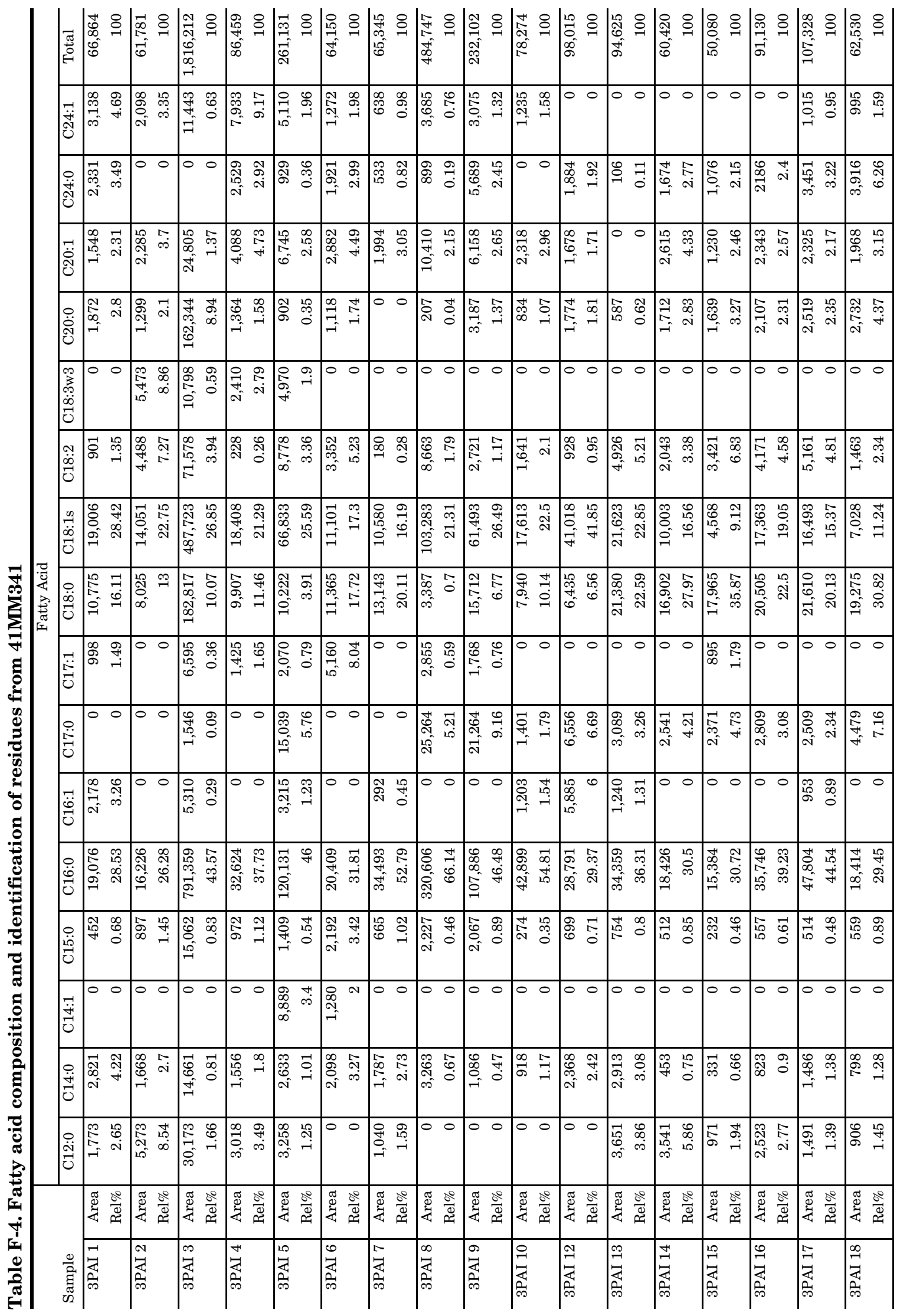




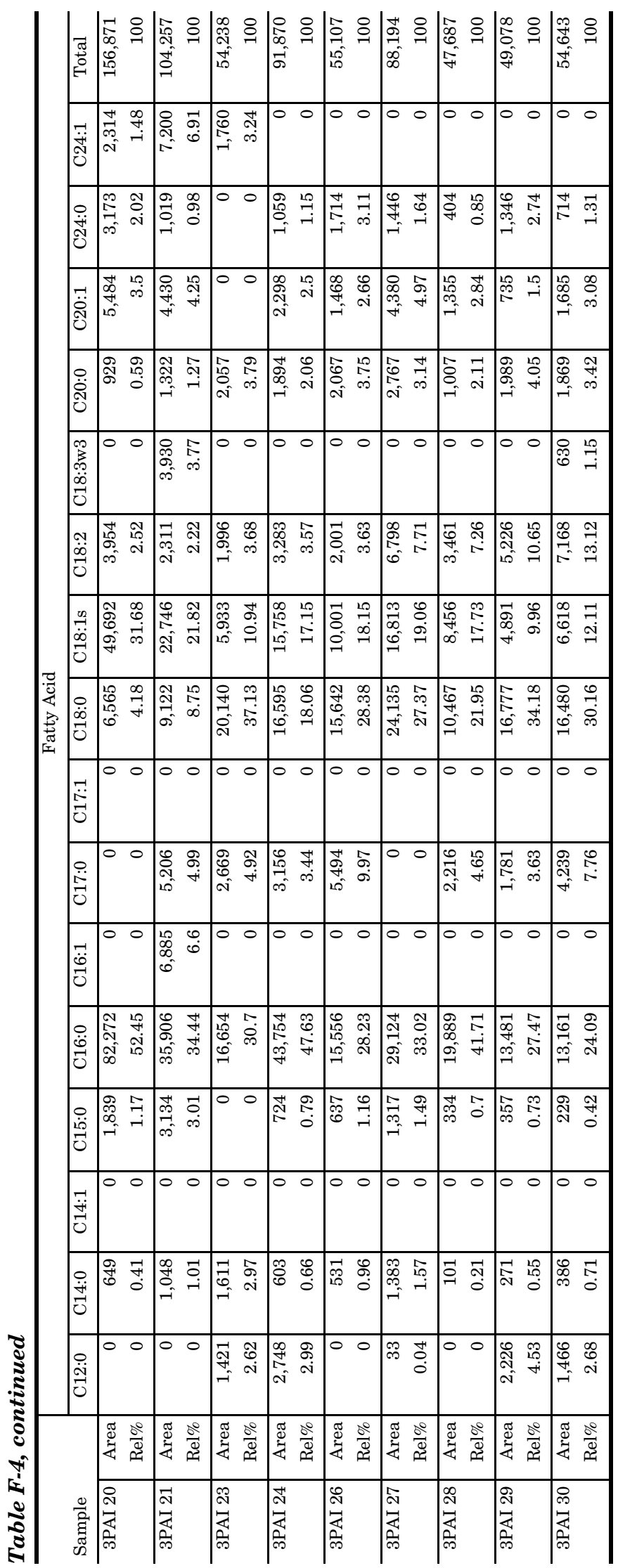




\section{REFERENCES CITED}

Collins, M. B., B. Ellis, and C. Dodt-Ellis

1990 Excavations at the Camp Pearl Wheat Site (41KR243): An Early Archaic Campsite on Town Creek, Kerr County, Texas. Studies in Archeology 6. Texas Archeological Research Laboratory, The University of Texas at Austin.

Condamin, J., F. Formenti, M. O. Metais, M. Michel, and P. Blond

1976 The Application of Gas Chromatography to the Tracing of Oil in Ancient Amphorae. Archaeometry 18(2):195-201.

deMan, J. M.

1992 Chemical and Physical Properties of Fatty Acids. In Fatty Acids in Foods and their Health Implications, edited by C. K. Chow, pp. 17-39. Marcel Dekker, New York.

Evershed, R. P., C. Heron, and L. J. Goad

1990 Analysis of Organic Residues of Archaeological Origin by High Temperature Gas Chromatography and Gas Chromatography-Mass Spectroscopy. Analyst 115:1339-1342.

Folch, J., M. Lees, and G. H. Sloane-Stanley

1957 A Simple Method for the Isolation and Purification of Lipid Extracts from Brain Tissue. Journal of Biological Chemistry 191:833.

Frankel, E. N.

1991 Recent Advances in Lipid Oxidation. Journal of the Science of Food and Agriculture 54:465-511.

Loy, T.

1994 Residue Analysis of Artifacts and Burned Rock from the Mustang Branch and Barton Sites (41HY209 and 41HY202). In Archaic and Late Prehistoric $\mathrm{Hu}$ man Ecology in the Middle Onion Creek Valley, Hays County, Texas, Volume 2: Topical Studies, by R. A. Ricklis and M. B. Collins, pp. 607-627. Studies in Archeology 19. Texas Archeological Research Laboratory, The University of Texas at Austin.

Malainey, M. E.

1997 The Reconstruction and Testing of Subsistence and Settlement Strategies for the Plains, Parkland and Southern Boreal Forest. Ph.D. dissertation.
Department of Anthropology, University of Manitoba.

Malainey, M. E., K. L. Malisza, R. Przybylski, and G. Monks

2001 The Key to Identifying Archaeological Fatty Acid Residues. Paper presented at the 34th Annual Meeting of the Canadian Archaeological Association, Banff, Alberta.

Malainey, M. E., R. Przybylski, and B. L. Sherriff

1999a The Fatty Acid Composition of Native Food Plants and Animals of Western Canada. Journal of Archaeological Science 26:8394.

1999b The Effects of Thermal and Oxidative Decomposition on the Fatty Acid Composition of Food Plants and Animals of Western Canada: Implications for the Identification of Archaeological Vessel Residues. Journal of Archaeological Science 26:95-103.

1999c Identifying the Former Contents of Late Precontact Period Pottery Vessels from Western Canada Using Gas Chromatography. Journal of Archaeological Science 26(4):425-438.

2001 One Person's Food: How and Why Fish Avoidance May Affect the Settlement and Subsistence Patterns of Hunter-Gatherers. American Antiquity 66(1):141-161.

Malainey, M. E., R. Przybylski, and G. Monks

2000a The Identification of Archaeological Residues Using Gas Chromatography and Applications to Archaeological Problems in Canada, United States and Africa. Paper presented at the 11th Annual Workshops in Archaeometry, State University of New York at Buffalo.

2000b Refining and Testing the Criteria for Identifying Archaeological Lipid Residues Using Gas Chromatography. Paper presented at the 33rd Annual Meeting of the Canadian Archaeological Association, Ottawa.

2000c Developing a General Method for Identifying Archaeological Lipid Residues on the Basis of Fatty Acid Composition. Paper presented at the Joint Midwest 
Archaeological \& Plains Anthropological Conference, Minneapolis, Minnesota.

Marchbanks, M. L.

1989 Lipid Analysis in Archaeology: An Initial Study of Ceramics and Subsistence at the George C. Davis Site. Master's thesis. The University of Texas at Austin.

Marchbanks, M. L., and J. M. Quigg

1990 Organic Residue and Phytolith Analysis. In Phase II Investigations at Prehistoric and Rock Art Sites, Justiceburg Reservoir, Garza and Kent Counties, Texas, Volume II, by D. K. Boyd, J. T. Abbott, W. A. Bryan, C. M. Garvey, S. A. Tomka, and R. C. Fields, pp. 496-519. Reports of Investigations No. 71. Prewitt and Associates, Inc., Austin.

Patrick, M., A. J. de Konig, and A. B. Smith 1985 Gas Liquid Chromatographic Analysis of Fatty Acids in Food Residues from Ceramics Found in the Southwestern Cape, South Africa. Archaeometry 27(2):231-236.
Quigg, J. M., C. Lintz, S. Smith, and S. Wilcox 2000 The Lino Site: A Stratified Late Archaic Campsite in a Terrace of the San Idelfonzo Creek, Webb County, Southern Texas. Technical Report No. 23765. TRC Mariah Associates Inc., Austin. Archeological Studies Program Report 20. Texas Department of Transportation, Environmental Affairs Division, Austin.

Quigg, J. M., M. E. Malainey, R. Przybylski, and G. Monks

2001 No Bones About it: Using Lipid Analysis of Burned Rock and Groundstone Residues to Examine Late Archaic Subsistence Practices in South Texas. Plains Anthropologist 46(177):283-303.

Skibo, J. M.

1992 Pottery Function: A Use-Alteration Perspective. Plenum Press, New York.

Solomons, T. W. G.

1980 Organic Chemistry. John Wiley \& Sons, Toronto. 


\section{APPENDIX G: Analysis of Macrobotanical Remains from 41MM341}

Leslie L. Bush, Ph.D.

Austin, Texas 



\section{INTRODUCTION}

Site 41MM341 is on the floodplain of the Little River near Cameron, Texas. The site was discovered by a cultural resources survey team in the late $1990 \mathrm{~s}$, and testing was conducted by the Center for Archaeological Research of The University of Texas at San Antonio (Mahoney and Tomka 2001). The macrobotanical remains reported here were taken during data recovery excavations conducted in summer and fall 2002 by Prewitt and Associates, Inc. Most of the botanical analysis focuses on distinguishing behavioral differences relating to differences in feature type, but some possible temporal differences are considered as well.

\section{SITE SETTING}

Many authors have divided Texas into vegetational regions, noting that different combinations of ecological factors (soil, topography, climate, etc.) give rise to different combinations of plants that interact in predictable ways (e.g., Diamond et al. 1987; Gould 1962; Johnson 1931; Tharp 1939; Turner 1959). These plant communities may be in different stages of succession, climax, or even disclimax at any given time, and their boundaries may not always be well defined. The nature of plant communities has long been contested among researchers, with some experts holding - on the one extreme-that plant communities are discrete entities analogous to individual organisms (e.g., Whittaker 1953) and - on the other extreme- that they represent continua and have no actual boundaries in space or time (e.g., Gleason 1939). Still other critics point out, correctly, that descriptions of vegetation regions reduce or obscure significant local variation and overlook rare plant types (see Gehlbach 1975 in Diamond et al. 1987). Nonetheless, the vegetation region concept has considerable value in many fields. Not least, it explains the differences in vegetation noticed even by casual observers. In archeology, vegetation regions can help construct null hypotheses for expected vegetation near a particular site when combined with data on past climate.

Site 41MM341 lies near the modern boundary between two vegetation regions: the Blackland Prairie and Post Oak Savannah. Palynologists have analyzed cores from several bogs in the region, including Boriack and
Patschke (Lee County), South Soefje and Hershop (Gonzales County), Gause (Milam County), and Franklin (Robertson County). Many early pollen studies focused on contrasting Pleistocene and Holocene floras and determining the distribution of boreal species in Texas during post-Pleistocene times (Graham and Heimsch 1960; Larson et al. 1972; Potzger and Tharp 1947, 1954). Later studies, however, specifically comment on variation in vegetation during the last few millennia (Bousman and Brown 1998). Bousman's work with the Weakly Bog (Leon County) data indicates that conditions during the period from roughly 700 to 1250 B.P. may have been drier than modern ones (Bousman 1998:Figure 7). He notes, however, that due to averaging effects and the poor representation of juniper, "it is more likely that most of the Late Holocene samples do represent woodlands" (Bousman 1998:212). It is possible that the boundary between the Blackland Prairie and the Post Oak Savannah (or their ecological ancestors) may have been slightly farther east during Late Prehistoric times, but these two vegetation regions currently intergrade across a broad band of east-central Texas. The presence of the modern vegetational boundary near $41 \mathrm{MM} 341$ and the suggestion that the Late Prehistoric vegetation consisted of woodlands does suggest a broadly ecotonal location for the site. The three vegetational areas to which inhabitants of 41MM341 would have had ready access are as follows:

Blackland Prairie: The topography of this true prairie region ranges from gently rolling to nearly level with elevations of 300 to $800 \mathrm{ft}$ above sea level. Rainfall on the eastern edge averages more than 40 inches per year, but the land near $41 \mathrm{MM} 341$ sees closer to 35 inches (Thomas 1962:10). The fertile soils are mostly under cultivation today, but little bluestem was the climax dominant in the pre-settlement past. Other important grasses were big bluestem, Indiangrass, switchgrass, sideoats grama, hairy grama, tall dropseed, silver bluestem, and Texas wintergrass. Post oak (Quercus stellata) and blackjack oak (Q. marilandica) occur on the lighter-textured soils of the area, and mesquite is common under 
conditions of heavy grazing, as are other plants that may not have been particularly important in the past (Thomas 1962:10).

Post Oak Savannah: As its name suggests, this vegetative region has affinities to both deciduous forests and grasslands (Thomas 1962:9). Understory vegetation is typically tall grass, and there may have been fewer trees in the past than is the case today. Topography is gently rolling to hilly, with elevations ranging from 300 to $800 \mathrm{ft}$ above sea level. Rainfall averages 3545 inches, with highest monthly rainfalls occurring in May or June. Soils in the uplands are acid sandy loams or sands. Bottomland soils are also acid and range from sandy loams to clays. Climax grasses include little bluestem, Indiangrass, switchgrass, purpletop, silver bluestem, Texas wintergrass, and various woodoats. Overstory is primarily post oak, a member of the white oak group, and blackjack oak, a red oak. Many other brush and weedy species are common in the plant communities of this area (Thomas 1962:9).

Riparian Forest: In addition to the Blackland Prairie and Post Oak Savannah, the Little River and its floodplain would have offered a third, separate ecological zone for exploitation by prehistoric people. Rivers and riparian forests provide uniform habitats in which similar plant communities may be found, even when the river valley cuts across very different upland ecological zones (Lee 1945). Not surprisingly, plants of riparian zones tend to tolerate flooding and other disturbances better than their upland counterparts. As in rainforests, a great many species may share the canopy in a floodplain forest, and "dominance is absent or poorly defined" (Lee 1945:163). Trees adjacent to the river channel near 41MM341 today include cottonwood, willow, box elder, elm, and pecan. All of these taxa were identified in wood charcoal samples from the site.

\section{METHODS}

The flotation samples from which some of the botanical remains analyzed here came were processed by personnel from Prewitt and Associates in a Flote-Tech flotation machine with bottom mesh openings of $1.0 \mathrm{~mm}$ (Dausman 1989; Hunter and Gassner 1998; Rossen 1999). Samples were soaked in a solution of water and baking soda prior to flotation. Because separation of botanical materials by flotation was imperfect, charcoal was removed by hand from the resulting heavy fractions. Three heavy fractions from three feature types were examined by the author after charcoal had been removed. Although little carbonized material was visible to the naked eye in these heavy fractions, microscopic examination produced some macrobotanical remains. Thus, macrobotanical remains from 41MM341 may be somewhat underreported here, especially heavier plant types such as nutshell and wood charcoal. It is worth noting, however, that no new taxa were recovered from any of the heavy fraction samples. That is, microscopic examination of each heavy fraction produced only plant types that had already been recovered from light fractions and hand picking of that flotation sample.

Samples analyzed and reported here consist of 50 flotation samples from cultural features and 39 1/4-inch-screen samples. Of the latter, 17 are from parts of cultural features where the fill was screened and not collected for flotation. The other 22 1/4-inch-screen samples represent contexts in which carbonized remains other than wood charcoal were observed by excavation or laboratory crews. Macrobotanical remains recovered by screening are reported separately from those recovered by flotation. All nonfeature samples submitted to the author did indeed contain carbonized botanical remains other than wood charcoal. The 50 flotation samples reported here represent 37 features (with the five pits that make up Feature 50 counted separately) and total 1,123.7 liters of fill.

Botanical samples were sorted in the author's laboratory in Austin. Each flotation sample was weighed on an electronic balance with a sensitivity of $0.01 \mathrm{~g}$ before being sizesorted through a stack of geologic screens with mesh openings of $2.00,1.40$, and $0.71 \mathrm{~mm}$. 
Materials in the $>2-\mathrm{mm}$ size fraction were completely sorted, and all charred botanical remains were counted, weighed, recorded, and labeled. For samples in which more than 100 wood charcoal fragments were present, counts were estimated from the weight of a random sample of 50 fragments. Materials other than charred botanical remains in the $>2-\mathrm{mm}$ size fraction were weighed, recorded, and labeled but not counted.

All materials in the $>2$-mm size fraction (other than bones and charred plants) are referred to as "contamination." At 41MM341, these usually consist of rootlets, gastropods, uncharred hackberry seeds, unidentifiable bone fragments, and chert. Materials that fell through the 2-mm mesh, referred to as "residue," were examined under a stereoscopic microscope at 7-45x magnification for charred botanical remains other than nutshell, wood charcoal, and bulb fragments. All plant materials removed from the residue were counted, weighed, and labeled. The presence of uncharred taxa in the residue also was recorded on laboratory forms, but these materials were not usually removed from the residue.

For each excavation context reported here, wood charcoal fragments were selected at random from those larger than $2 \mathrm{~mm}$, with large and small fragments chosen alternately. Fragments were snapped to reveal a transverse section and examined under a stereoscopic microscope at 28-180x magnification. When necessary, tangential or radial sections were examined for ray seriation, presence of spiral thickenings, types and sizes of intervessel pitting, and other minute characteristics that can only be seen at higher magnifications (Hoadley 1990).

Botanical materials were identified to the lowest possible taxonomic level by comparing them to materials in the author's comparative collection and through the use of standard reference works (e.g., Davis 1993; Hoadley 1990; Martin and Barkley 1961; Panshin and de Zeeuw 1980). In some cases, botanical remains could be identified to the level of species through positive identification (e.g., Ulmus rubra) or elimination of other members of the genus (e.g., Platanus occidentalis, Carya illinoinensis). Most commonly, botanical materials were identified to the level of genus, but sometimes only family identification was possible.

\section{RESULTS}

The results of the botanical analysis are presented in Tables G-1-G-5. Table G-1 provides data on the presence/absence of uncarbonized plant remains other than rootlets. This table also includes weight and count data for hackberry (Celtis) seeds, the most common uncarbonized plant part on the site. Table G-2 shows counts and weights of carbonized remains recovered by flotation from feature contexts. Table G-3 provides count and weight data for macrobotanical remains recovered from the $1 / 4$-inch-screen samples. Table G-4 presents the results of wood charcoal identification from flotation contexts. Table G-5 shows wood charcoal identified from screened contexts.

\section{Uncarbonized Plant Remains}

Uncarbonized seeds are a common occurrence on most archeological sites, but they usually represent seeds of modern plants that have made their way into the soil either through their own dispersal mechanisms or by faunalturbation, floralturbation, or argilliturbation (Bryant 1985:51-52; Miksicek 1987:231-232). In all except the driest areas of North America, uncarbonized plant material from open-air sites can be assumed to be of modern origin unless compelling evidence suggests otherwise (Lopinot and Brussell 1982; Miksicek 1987:231). Site 41MM341 has offered no such evidence, and only carbonized plant remains are believed to be ancient. Further, as shown in Table G-1, uncarbonized taxa at the site consist of typical modern field or range weeds, indicating that they represent seed rain of modern origin. Often, quantities of uncarbonized plant remains on archeological sites decrease rapidly with depth, a characteristic signature of seed rain in most situations. At 41MM341, however, no such trend is discernible. In fact, the number of hackberry seeds per liter of floated sediment increases from Level 6 (0.001) to Level 7 (0.002) and especially Level 8 (0.006), before decreasing in Level 9 (0.002), Level 10 (0.001), and Level 11 (0.002). This finding, however, probably does not reflect a cultural origin for the uncarbonized remains. Rather, it reflects the shallow nature of the site, where only half a meter separates Level 6 from Level 11, the shallowest and deepest levels considered here. The presence of 
Data Recovery Excavations at the J. B. White Site

\begin{tabular}{|c|c|c|c|c|c|c|c|c|c|c|c|c|c|c|c|c|c|c|c|c|c|c|c|c|}
\hline 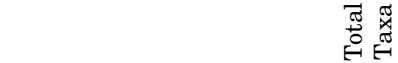 & จ & $\neg$ & $\infty$ & $\infty$ & $\curvearrowright$ & ง & $\infty$ & 4 & 0 & N & 0 & 6 & $\sim$ & $\infty$ & $\curvearrowright$ & $\infty$ & $\infty$ & $\infty$ & + & ง & $\bullet$ & & $\infty$ & \\
\hline 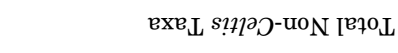 & -1 & - & a & ค & 6 & - & $\infty$ & $\infty$ & 20 & -1 & 10 & 0 & $\sim$ & ๙ & 0 & N & + & + & $\infty$ & -1 & 2 & & -1 - & \\
\hline 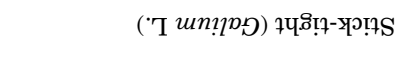 & & & & & & & & & & & & & & & & & & & & & & & & \\
\hline 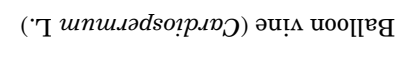 & & & & & & & & & & & & & & & $\rtimes$ & & & & & & & & & \\
\hline 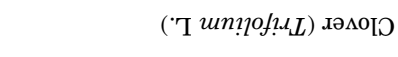 & & & & & $\rtimes$ & & & & & & & & & & & & & & & & & & & \\
\hline (әвәэвив [о S) әрвчรұч.8̊!N & & & & & & & & & & & & & & & & & & & & & & & & \\
\hline 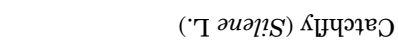 & & & & & & & & & & & & & & & & & & & & & & & & \\
\hline ) ('T s??! & & & & & & & & & & & & & & & & & & & & & & & & \\
\hline 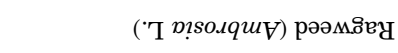 & & & & & & & & & & & & & & & & & & & & & & & & \\
\hline 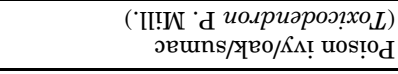 & & & & & & & & & & & & & & & & & & & & & & & & \\
\hline (ләчұо) рәу!̨иәрти & & & & $\rtimes$ & & & & & & & & & & & & & & & & & & & & \\
\hline ('Т иояо. & & & & & & & & & & & 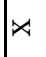 & & & & & & & & & & 18 & 4 & & \\
\hline 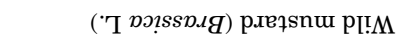 & & & & & & & & & $x$ & & & $\bowtie$ & & & & & & & & & & & & \\
\hline 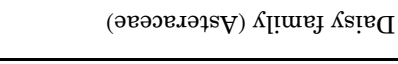 & & & & & & & & & & & $x$ & & & & & & & & & & p & 4 & & \\
\hline 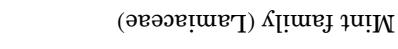 & & & $x$ & & & & ง & & 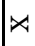 & & & ๙ & & & & & & & & & 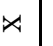 & & & \\
\hline 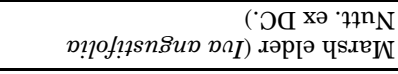 & & & & & & & $\rtimes$ & $x$ & $x$ & & & & & & & & & & & & $x$ & & & \\
\hline ('Т $\operatorname{s!}]^{p x_{O}}$ ) [ə.xовроом & & & & & $\rtimes$ & & $\rtimes$ & $x$ & & & & & & & $\rtimes$ & & & $\rtimes$ & & & & & & \\
\hline ('T ипџродоиәчО) s.әұдеnb s,quет & & & & & & & $\rtimes$ & & & & & & & & $x$ & & $\bowtie$ & & & & & & $x$ & \\
\hline (әвәэво & & & & & $\rtimes$ & & & & & & & $\bowtie$ & & & & & & & & & $x$ & & & \\
\hline ('Т виочәәю) १!quәН & $x$ & $x$ & & & $x$ & & $\rtimes$ & $x$ & & 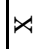 & & & & & & & $\rtimes$ & $x$ & & & & & & \\
\hline 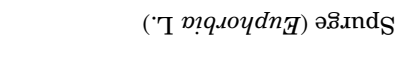 & & & & $\rtimes$ & $\rtimes$ & & $\rtimes$ & & & & $\rtimes$ & & $x$ & $\rtimes$ & $x$ & $\rtimes$ & $\rtimes$ & $x$ & $\rtimes$ & & $x$ & & & \\
\hline 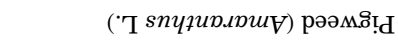 & & & & & $\rtimes$ & & $\rtimes$ & & $x$ & & $\rtimes$ & $\bowtie$ & & & $\rtimes$ & & $\rtimes$ & $x$ & $\rtimes$ & & & & & \\
\hline 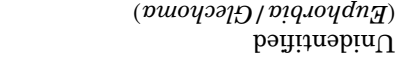 & & & $x$ & & & $x$ & & & $\nexists$ & & $\bowtie$ & $\bowtie$ & $\bowtie$ & $\bowtie$ & $x$ & $x$ & & & $x$ & $x$ & $x$ & 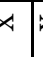 & \begin{tabular}{l|l}
$x$ & $x$ \\
\end{tabular} & \\
\hline 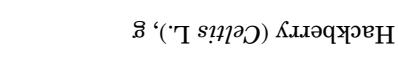 & : & & $\stackrel{0}{0}$ & & חָ & 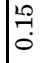 & & & 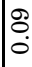 & \&ุ & ?ר. & & & \begin{tabular}{|l|l|} 
\\
0 \\
0 \\
0
\end{tabular} & & : & $\begin{array}{ll}m \\
0 \\
0\end{array}$ & \begin{tabular}{|l|l|} 
& \\
0 & \\
0
\end{tabular} & \begin{tabular}{|l|} 
\\
0 \\
0 \\
0
\end{tabular} & i: & $\begin{array}{ll}\text { th } \\
0 \\
0\end{array}$ & & 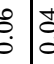 & \\
\hline 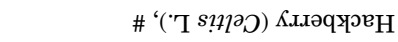 & ค & & - & $\rtimes$ & os & $\infty$ & & $\not x$ & H & 웅 & $\infty$ & & & -7 & $\bowtie$ & 0 & - & 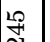 & $\omega$ & م & a & & $m \mid \sigma$ & \\
\hline 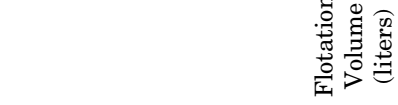 & $\stackrel{\circ}{\circ}$ & $\stackrel{\circ}{\stackrel{\leftrightarrow}{\mathrm{I}}}$ & 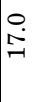 & 这 & 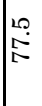 & $\stackrel{\dot{0}}{\circ}$ & 迥 & $\dot{0}$ & 童 & $\dot{0}$ & 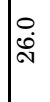 & $\mid$ & 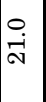 & 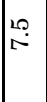 & 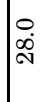 & $\mid \begin{array}{l}0 \\
\stackrel{\sim}{N} \\
\text { in }\end{array}$ & 造 & $\begin{array}{l}\dot{0} \\
\dot{\leftrightarrow}\end{array}$ & 造 & : & $\underset{\substack{\infty \\
\stackrel{\infty}{\infty}}}{0}$ & ف요. & \begin{tabular}{c}
0 \\
\hdashline \\
6
\end{tabular} & \\
\hline 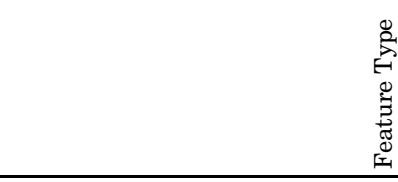 & 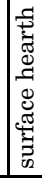 & 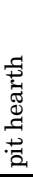 & 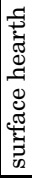 & 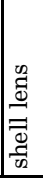 & 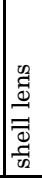 & 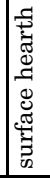 & a & 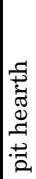 & 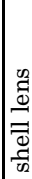 & 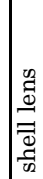 & 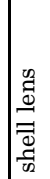 & 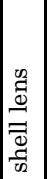 & 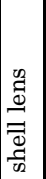 & 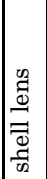 & 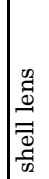 & 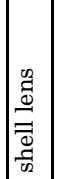 & 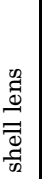 & $\mid$ & 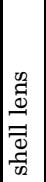 & 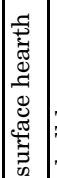 & 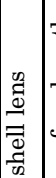 & 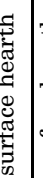 & 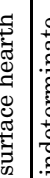 & \\
\hline 总 & 0 & 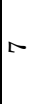 & $\infty$ & o & os & $\approx$ & $\exists$ & 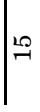 & $\stackrel{0}{1}$ & 气 & $\cong$ & จ & คิ & సี & $\stackrel{\pi}{\text { ล }}$ & $\frac{\pi}{\sim}$ & $\frac{\pi}{2}$ & $\vec{A}$ & जे & 迹 & N & & 80 & \\
\hline
\end{tabular}




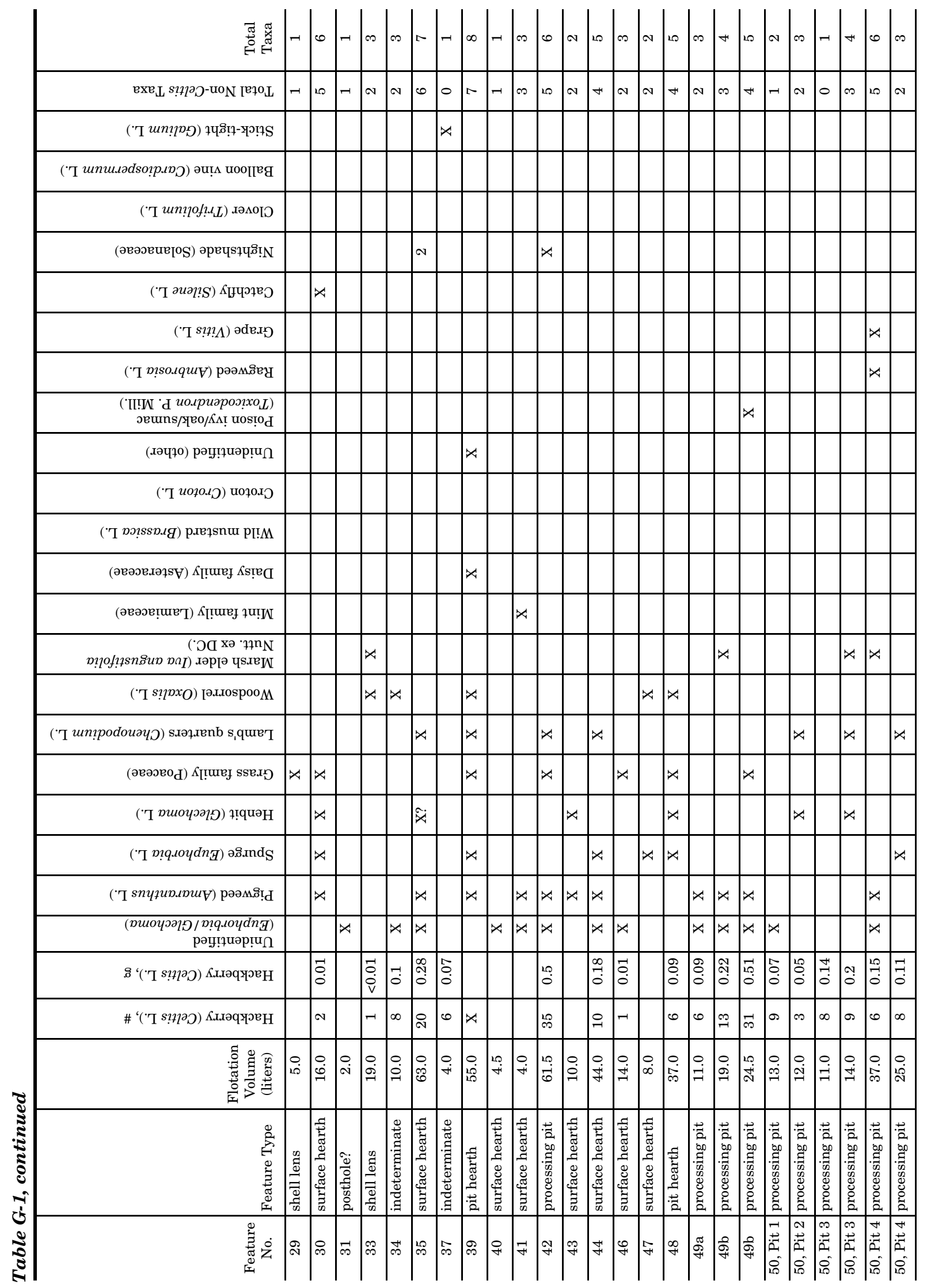


Data Recovery Excavations at the J. B. White Site

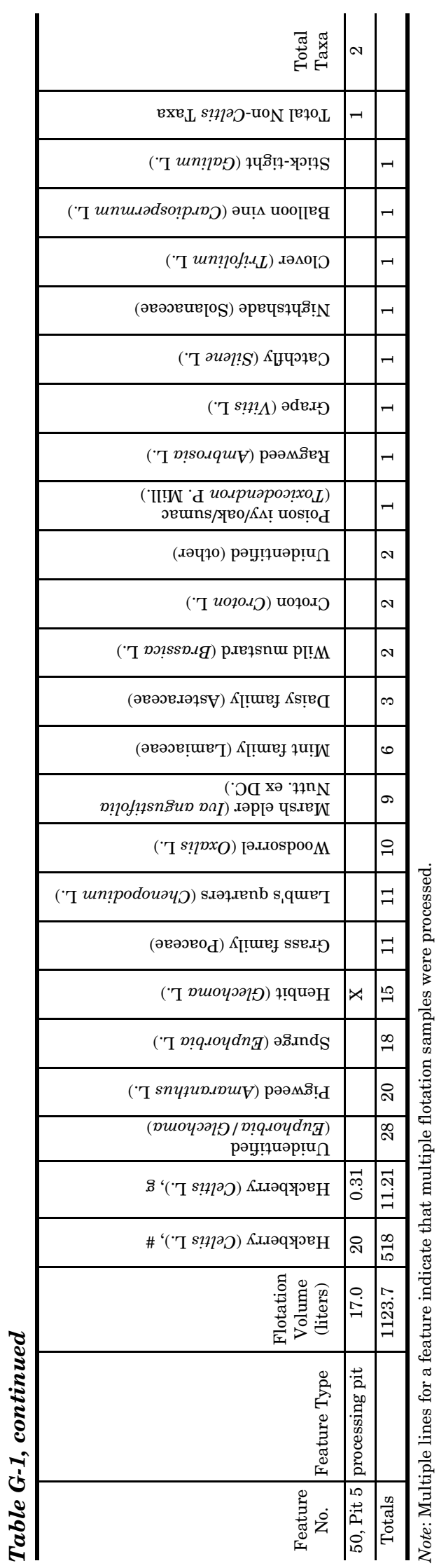


Appendix G: Analysis of Macrobotanical Remains

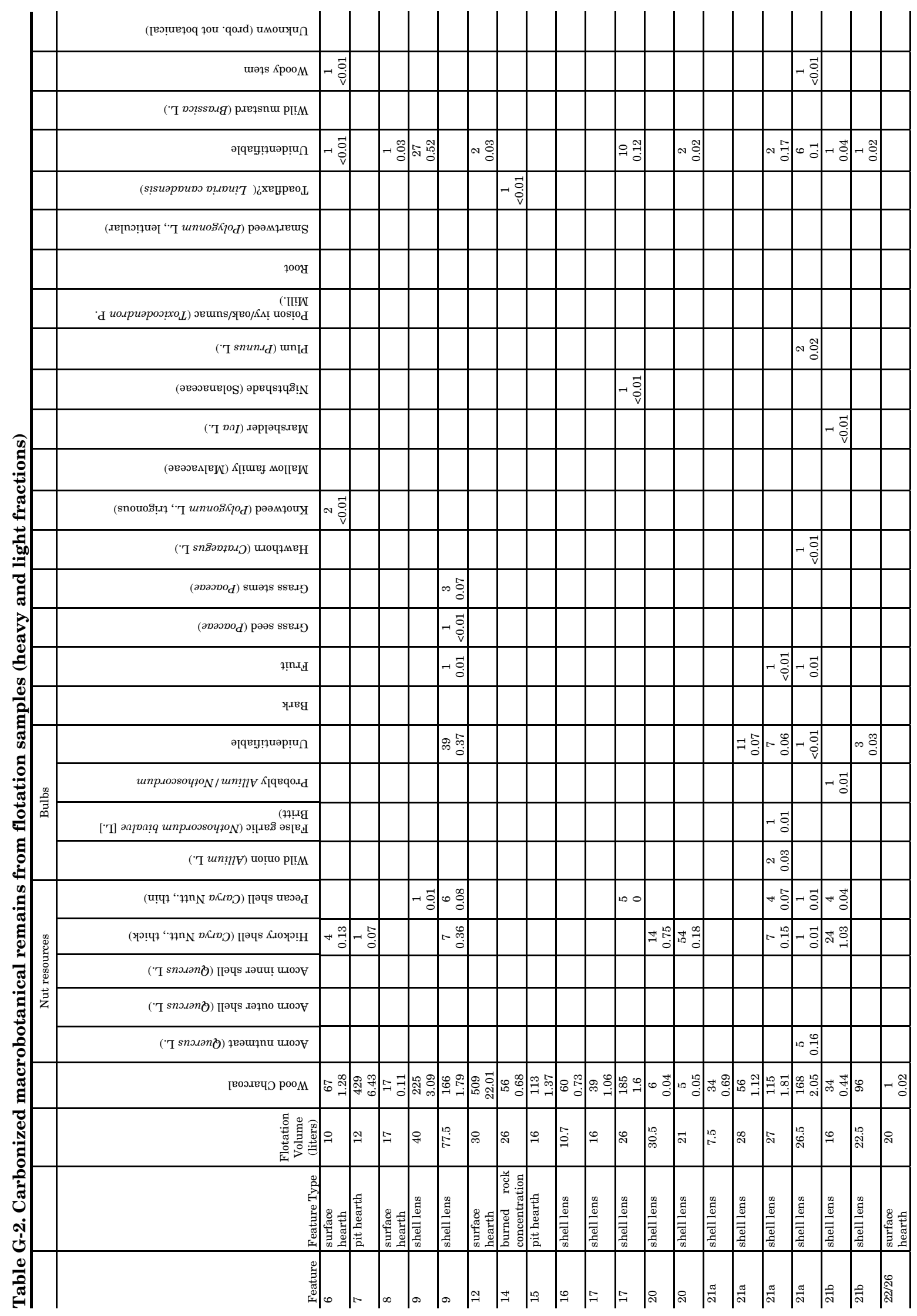


Data Recovery Excavations at the J. B. White Site

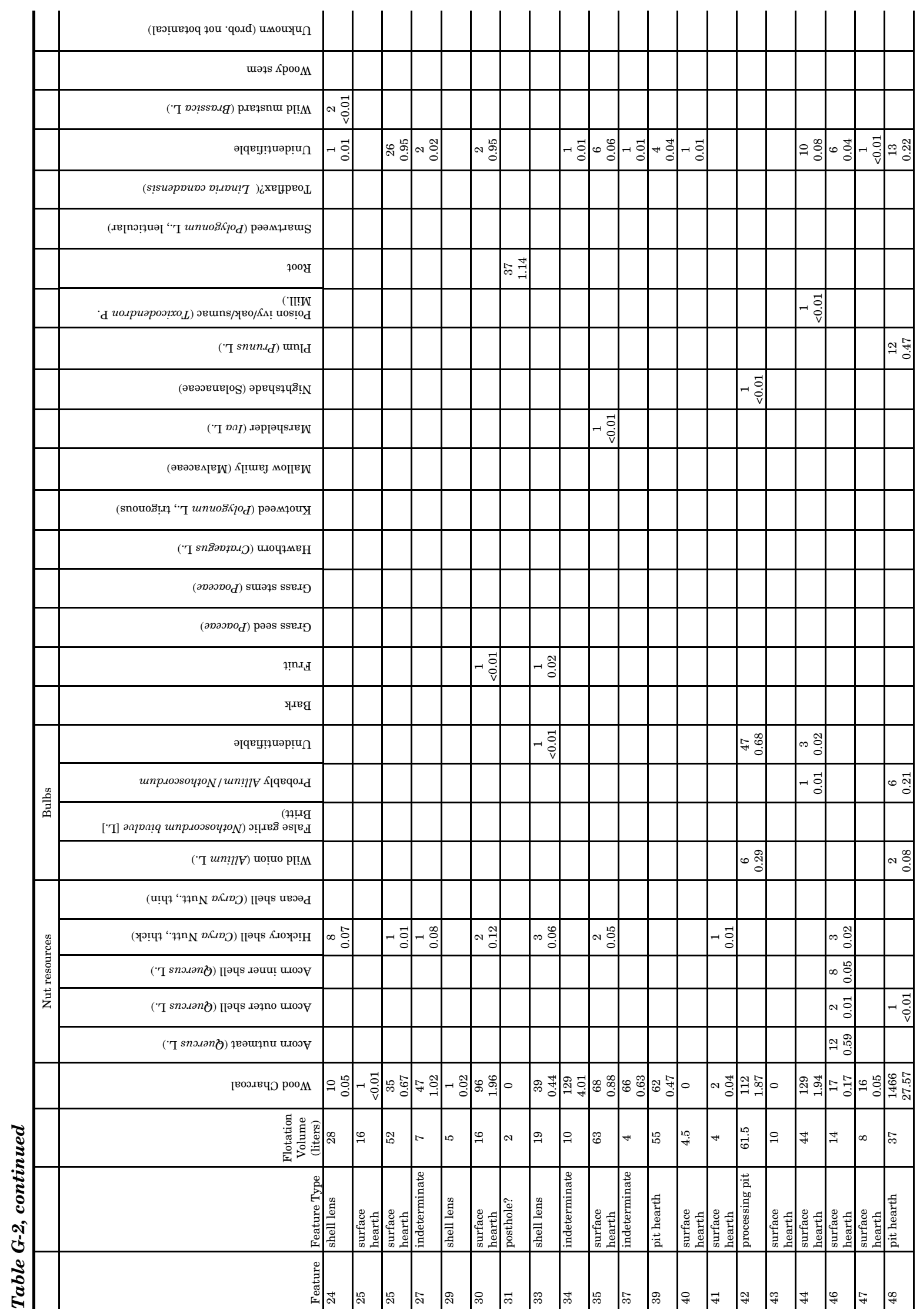


Appendix G: Analysis of Macrobotanical Remains

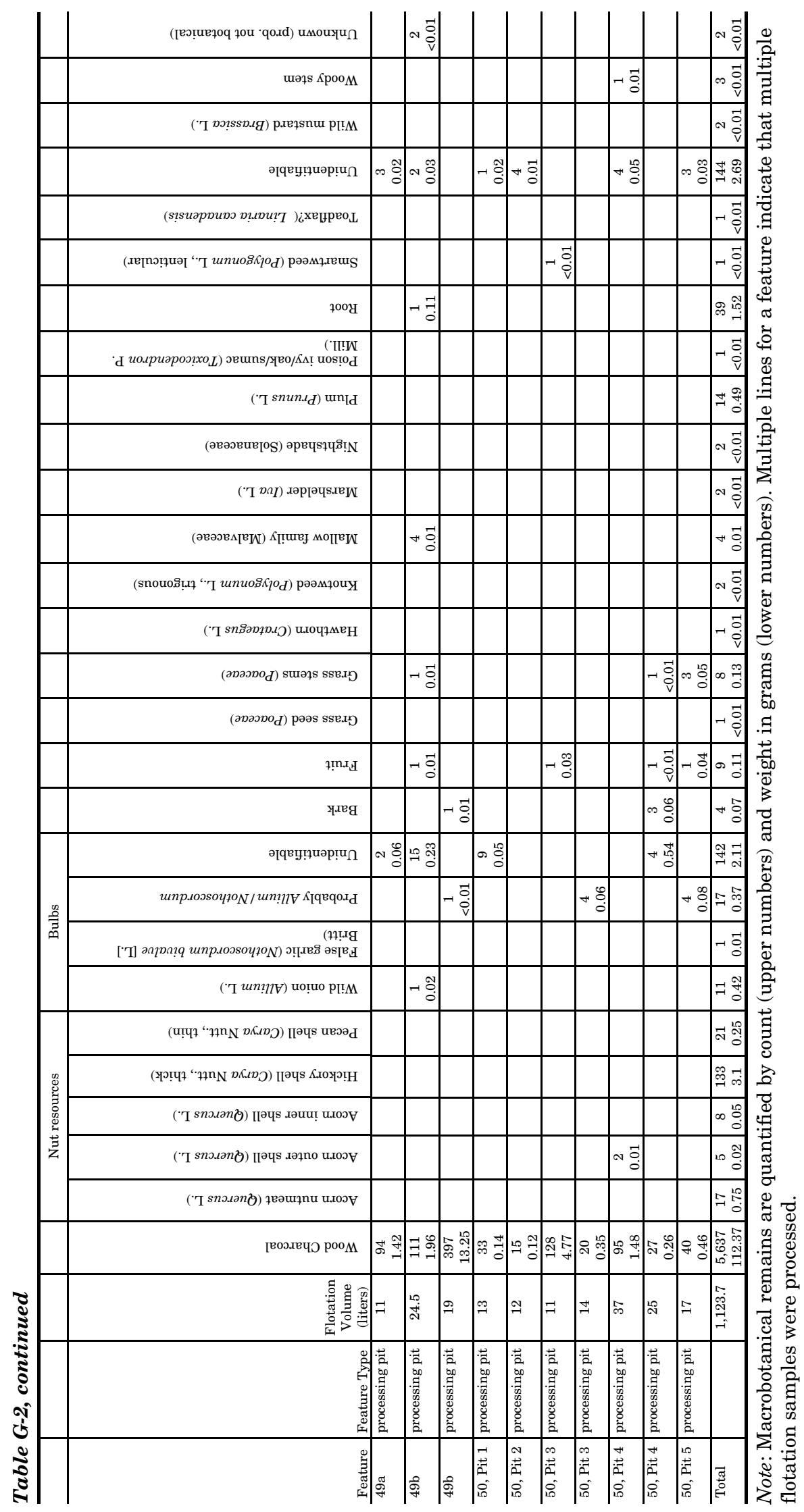


Data Recovery Excavations at the J. B. White Site

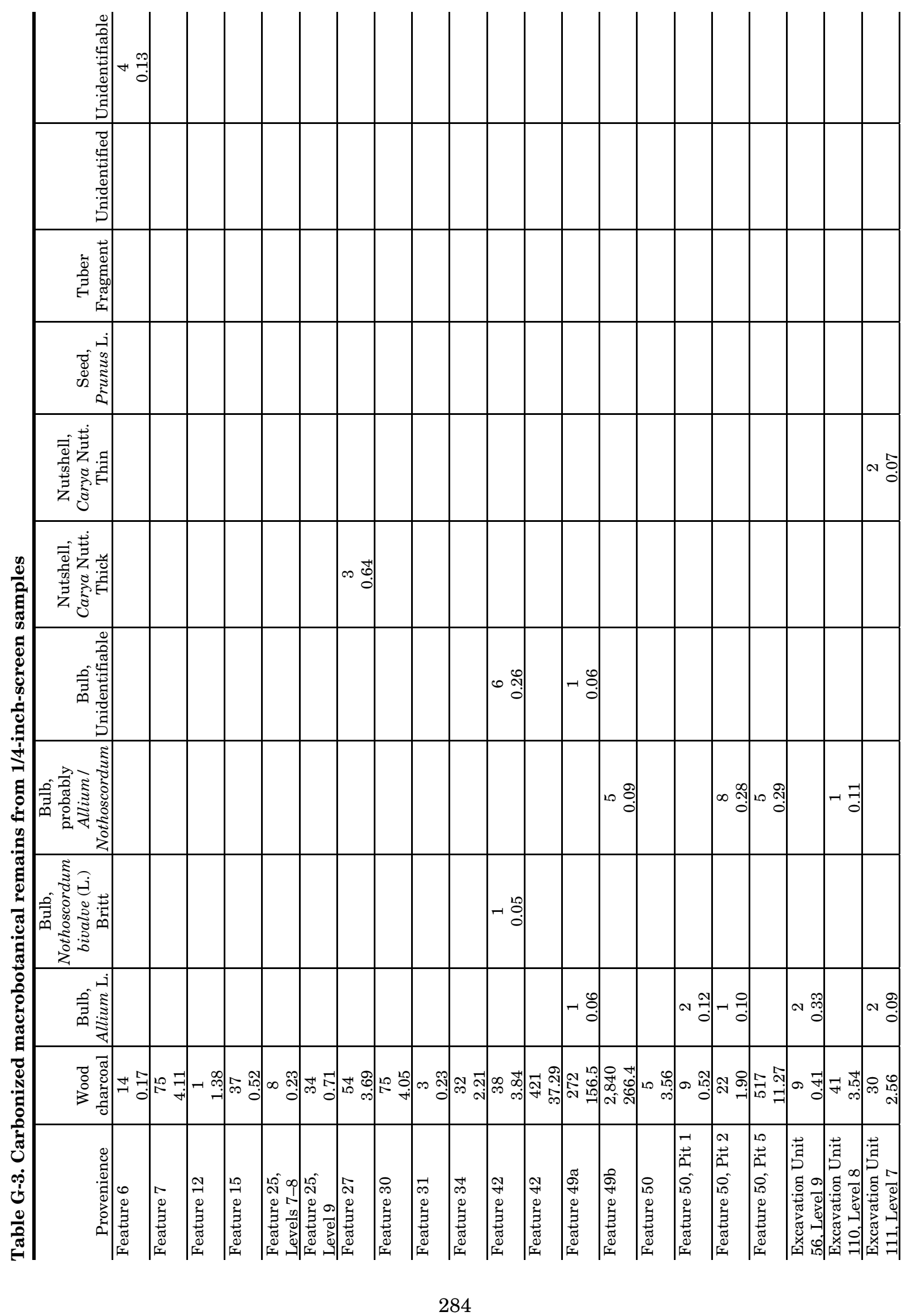


Appendix G: Analysis of Macrobotanical Remains

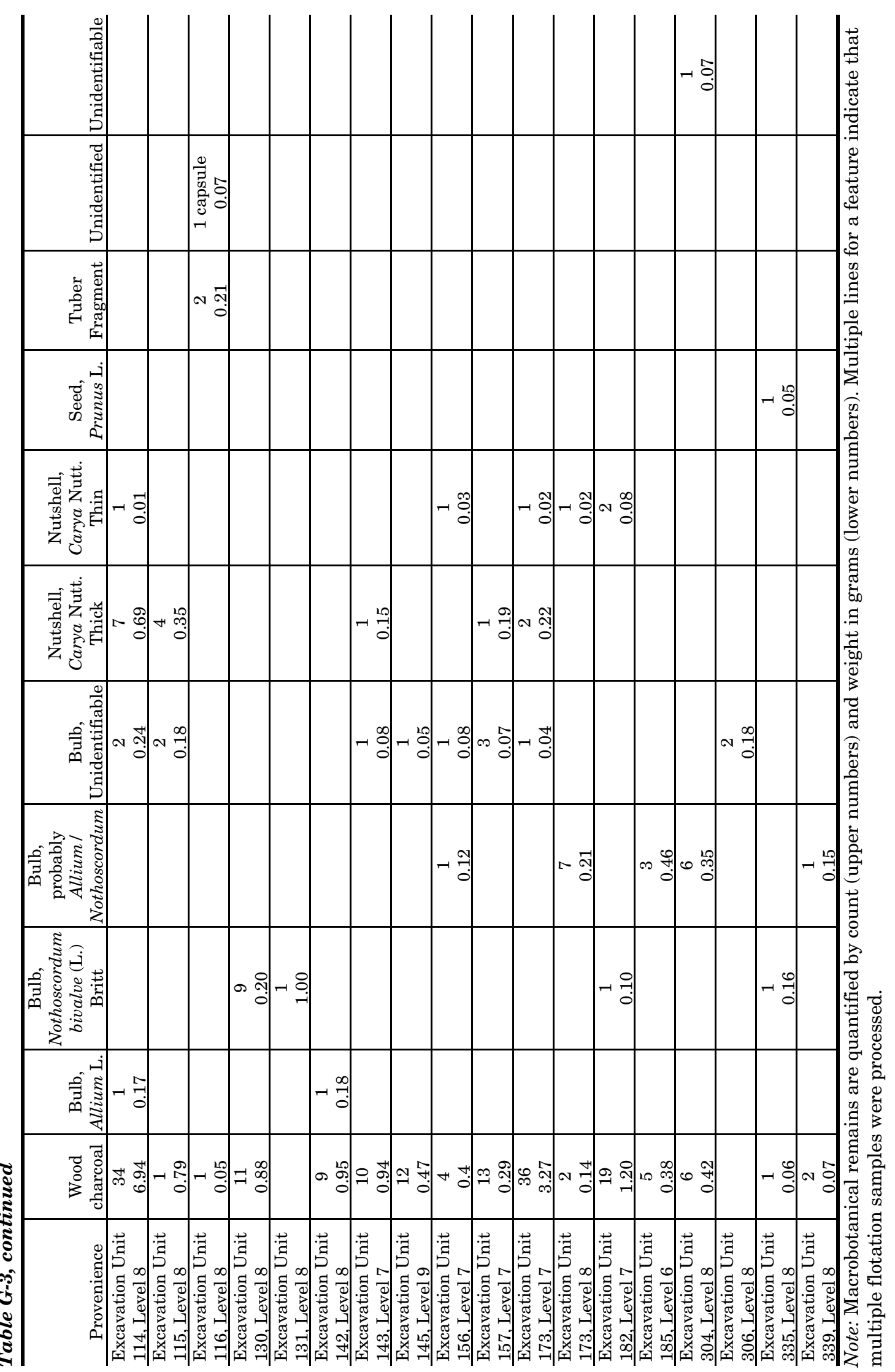


Data Recovery Excavations at the J. B. White Site

\begin{tabular}{|c|c|c|c|c|c|c|c|c|c|c|c|c|c|c|c|c|c|}
\hline 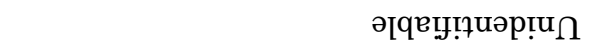 & & & & & & & & & & & -1 & & & & & | & \\
\hline \&-III snолоd әsпэџ! & & & & & & & & s & & ๑ & $\infty-$ & & & & & & \\
\hline роомрлен & & & & & a & & & ล & & & & ค & & & & -1 & \\
\hline snoxod-.̊и!̣प & & 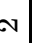 & & -1 & & - & & & $\infty$ & & 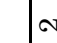 & & & & -1 & - & \\
\hline snoxod әsnנJ!̣ & & & & -1 & & a & & -1 & & & & & & -1 & & $\nabla$ & \\
\hline 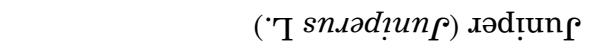 & & & & & & & & & & & & & & & & & \\
\hline ('T X!̣ $\left.{ }^{e} \mathrm{~S}\right)$ MOII!M & & & & & & & & & & & & & & & & & \\
\hline ('[Чn] & & & & & & & & & & & & & & & & & \\
\hline ('Т sпшй) шіә рлен & & & & & & & & & & & & & & & & & \\
\hline ('T snindod) роомиоұ7o & & & & & & & & & & & & & & & & & \\
\hline 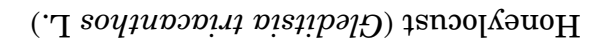 & & & & & & & & & & & & & & & & & \\
\hline 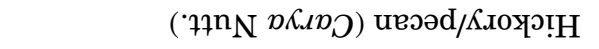 & & & & & & & & & & & & & $\infty$ & & -1 & & \\
\hline$\left({ }^{\prime} 7 n_{N}\right.$ pК. & & & & & & & & -1 & & & & & & & -1 & $\sigma$ & \\
\hline 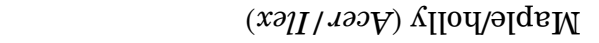 & & & & & & -1 & & & & & & & & & & & \\
\hline 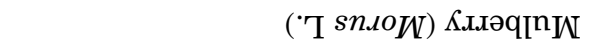 & & & $\sim$ & & & & & & & & & & & & & & \\
\hline 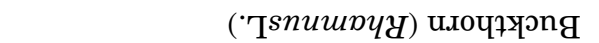 & & & & & -1 & & & & & & & & & & & & \\
\hline 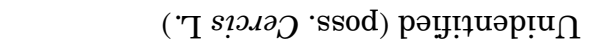 & & & & & & & & & & & & & & & & & \\
\hline$\left({ }^{\prime} \mathrm{T}\right.$ snun.ıd) К..хәчว/un Id & & & & & & & & & & & & & & & & - & \\
\hline ('T souरdso?G) uouw!s.ıəd & & & & & * & & & & & & * & & & & & & \\
\hline$\left({ }^{\prime} \mathrm{T}\right.$ snu?xp. & & & & & m & & o & 10 & $\infty$ & $\sim$ & & $\infty$ & -1 & & N) & -1 & - \\
\hline 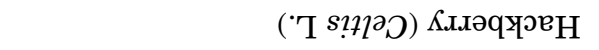 & & & & & & & & & & & & & & & & & \\
\hline 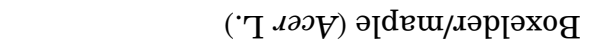 & os & & & & مـ & $\mid$ a & & $\mid \mathrm{N}$ & & - & & $\infty$ & ค & -1 & & م & \\
\hline 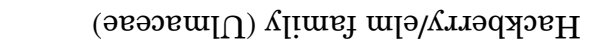 & & & & $\infty$ & & & & & & & & -1 & & مـ & & & \\
\hline 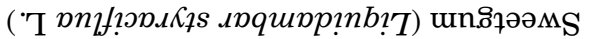 & & 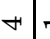 & -1 & N & & & & N & a & m & & & & & -1. & -1 & \\
\hline ('Т s!lрұиар!әэо sпирұрld) әлошеэ $\kappa_{\mathrm{S}}$ & & & $\infty$ & $\infty$ & & & & & & & & & & & & & \\
\hline 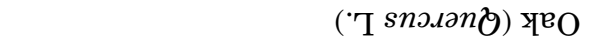 & & & & H & & & & & & & & & & & & H & \\
\hline ('Т snэ.љnð) уео рәч & & & & & & & & & & & & & & & & & \\
\hline ('Т snљљәпð) צво әұ!ЧМ & -1 & o & & 0 . & o & a & - & 10 & a & -1 & ง & & 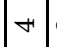 & $\infty:$ & $\exists=$ & 70 & \\
\hline 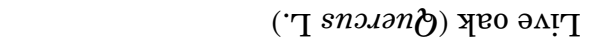 & & 0 & & 인. & & & & & & & & & & & & $\theta$ & + \\
\hline 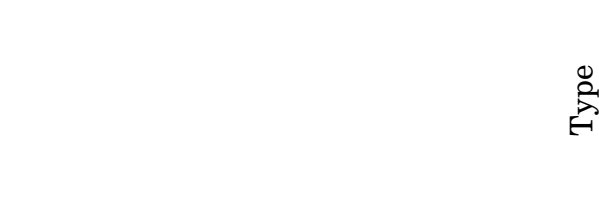 & 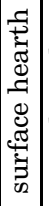 & 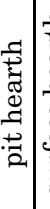 & 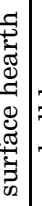 & 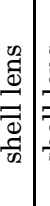 & 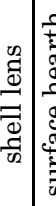 & 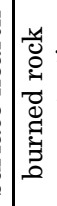 & 窝: & 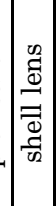 & 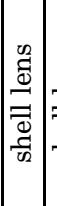 & 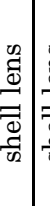 & 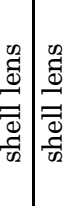 & 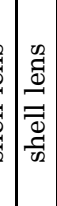 & 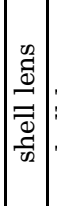 & 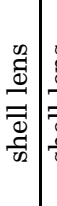 & 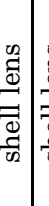 & 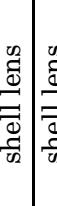 & 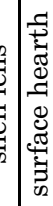 \\
\hline 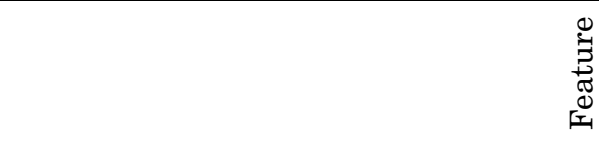 & 0 & $\ltimes$ & $\infty$ & の & $\infty$ & ت્ & 10 & $\stackrel{0}{-1}$ & $\bumpeq$ & $\therefore \lesssim$ & ৫) & $\frac{\pi}{\sim}$ & $\frac{\pi}{\sim}$ & $\vec{\pi}$ & $\frac{\pi}{\pi}$ & $\overrightarrow{\mathrm{a}}$ & 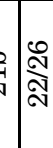 \\
\hline
\end{tabular}




\begin{tabular}{|c|c|c|c|c|c|c|c|c|c|c|c|c|c|c|c|c|c|c|c|}
\hline әчфеџ!ฺนәрти & & & & & & & & & & & ๙ & & & & & & & & \\
\hline \&-III snoxod әsnנџ! & & & & & & & & & & & & & -1 & & & & & & \\
\hline роомрлен & จ & & & & - & & & & $7 \mathrm{~T}$ & $\infty$ & -1 & & -1 & & $c$ & & & & \\
\hline snoxod-sిu!y & 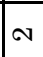 & -1 & & ๙ & & & $\neg$ & -1 & & & N & & & & 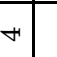 & & & & \\
\hline snoxod әsnנङ! & $\infty$ & & ๑ & & & & & & 10 & & $\infty$ & & & & & & -4 & & \\
\hline (`T snıəd!̣un $\rho)$ xəd!̣un $\rho$ & & & & & & & & & & & & & & & & & & & \\
\hline ('T X!! $\left.{ }^{e} \mathrm{~S}\right)$ MOII!M & & & & & & & & & & & & & & & & & & & \\
\hline ('IYn]N & & & & & & & & & & & & & & & & & & & \\
\hline ('Т sпшиһ) шгә рлен & & & & & 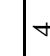 & 4 & & & & & & & & & & & - & & \\
\hline 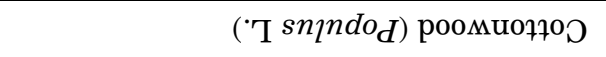 & & & & & $b$ & & & & & & & & & & & & & & \\
\hline 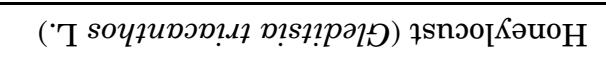 & -1 & & H & & & & & & & & & & & & & & & & \\
\hline 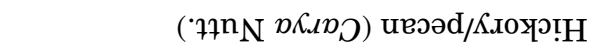 & & & & & & & & & & & & & & & 。 & $\mathrm{N}$ & & & \\
\hline$\left({ }^{\prime} 7 n_{N}\right.$ bК. & & & & $\infty$ & & & & & & & & & & & H & & & & \\
\hline 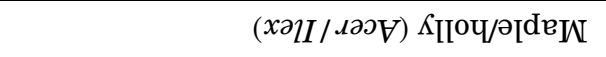 & & & & & & & & & & & & & & & 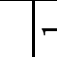 & -1 & $\sigma$ & & \\
\hline 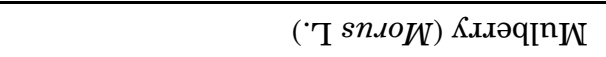 & & & & & & & & & & & & & & & & & & & \\
\hline 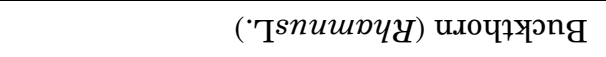 & & & & & & & & & & & & & & & & & & & \\
\hline ('T s!̣ıวग 'ssod) pәџ!̨uәр!̣u & & & & & & & & & & & & & & & & & & & \\
\hline 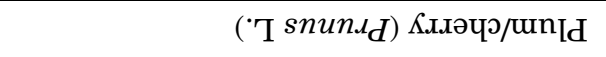 & & & 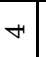 & & & & & & & & -1 & & & & & & & & \\
\hline 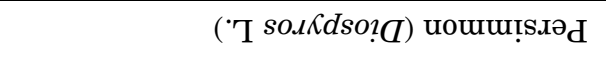 & & & & & & & & & $\neg$ & & $r$ & & & & & & & & \\
\hline 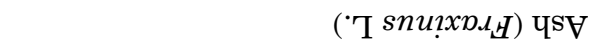 & & & & & & & a & & & & 6 & & -1 & & & & & & \\
\hline 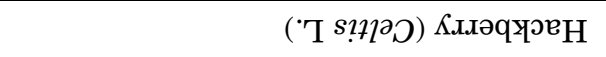 & & & & & & & & & & & & & & & & & & & \\
\hline 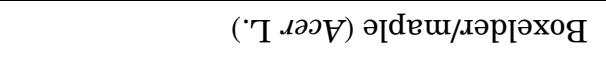 & & & & & & & N & & & & & & & & & & & & $\sim$ \\
\hline 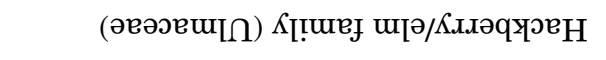 & & & & & 2 & & $\neg$ & & & & & -1 & & & -7 & & & & \\
\hline 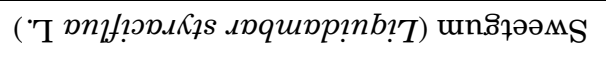 & & & & & & & & & & & & & & & & & & & \\
\hline ('T s!?рұиар!ээо snирұрld) әлошеэ $\mathrm{S}_{\mathrm{S}}$ & & & & & & & & & & & & & & & & & & & \\
\hline 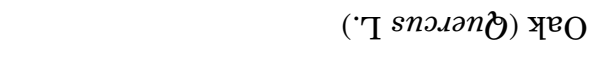 & ง & & & & & & & & & & & & & & -1 & & & & \\
\hline ('Т sпэләпð) чео рәч & & & & & & & & & & & & & & & & & & & $\sim \sim$ \\
\hline (`Т sпэ.љпð) чео әұ!ЧМ & & & & & - & & $\infty$ & 이 & $\infty$ & $\triangle$ & 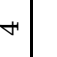 & & $\sim$ & & - & -1 & & & \\
\hline 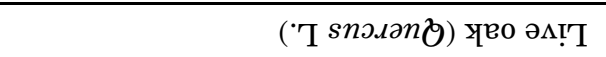 & & & & & & & $\neg$ & & & & & & & & & & & & 0 \\
\hline$\sum_{F}^{\circ}$ & 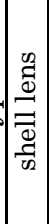 & 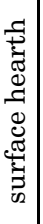 & 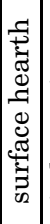 & 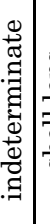 & 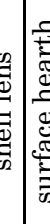 & 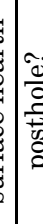 & 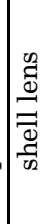 & 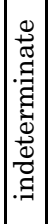 & 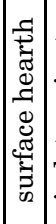 & 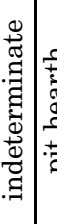 & 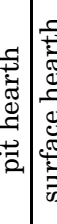 & 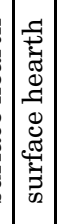 & 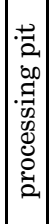 & 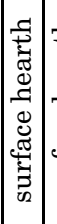 & 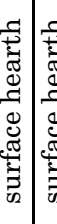 & 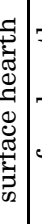 & $\begin{array}{l}z \\
z \\
z \\
z \\
z \\
z \\
z \\
z \\
z \\
z \\
z\end{array}$ & & 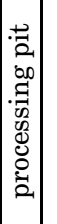 \\
\hline 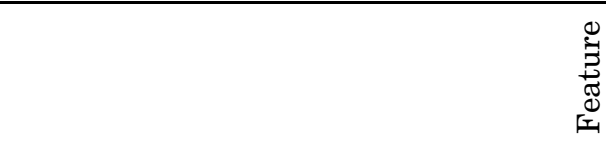 & カ & & $\stackrel{2}{\circ}$ & $\widehat{ล}$ & হ) & $b$ & 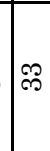 & 品 & $\infty$ & 命 & s) & $F$ & พ & F্子 & 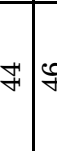 & \& & & & क्ष \\
\hline
\end{tabular}


Data Recovery Excavations at the J. B. White Site

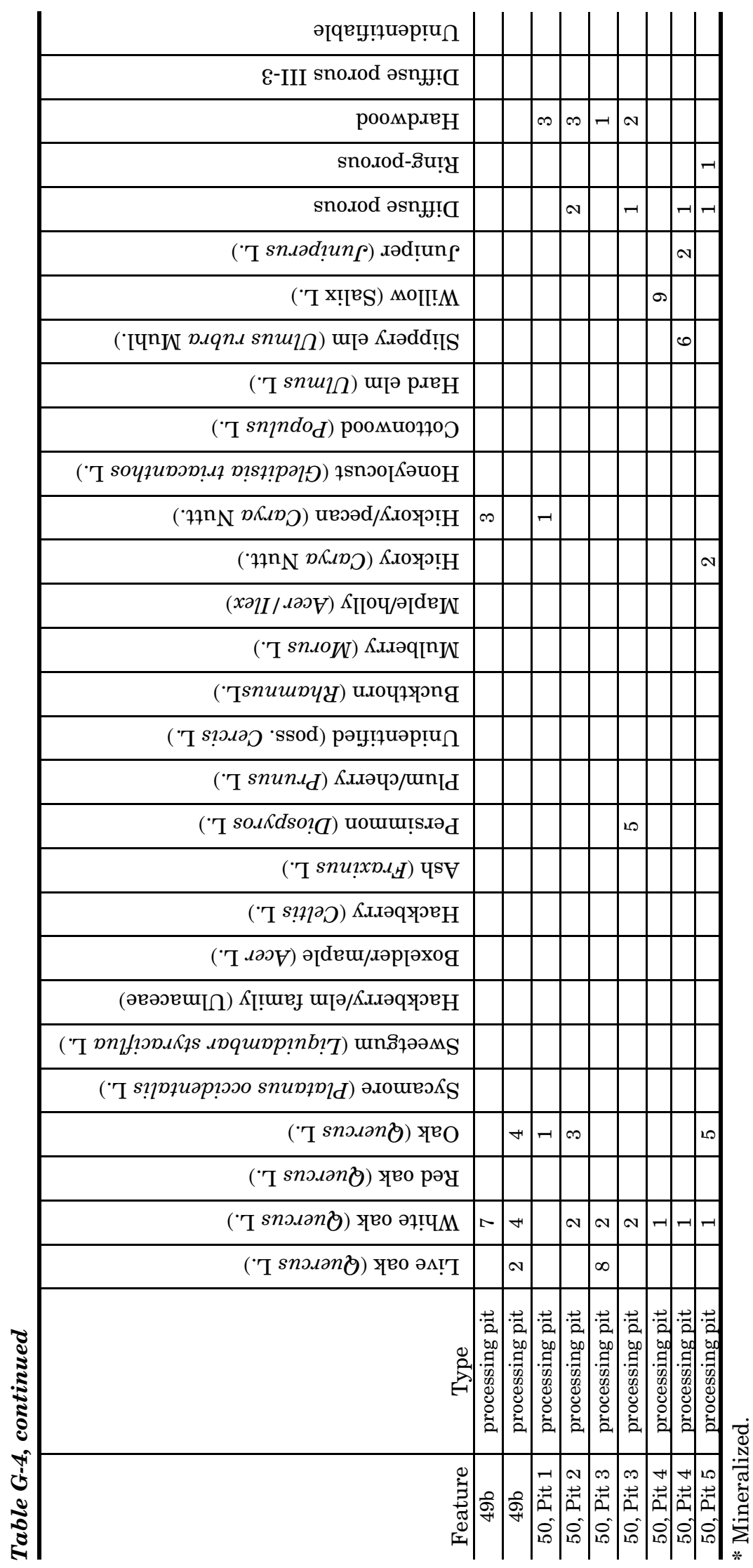




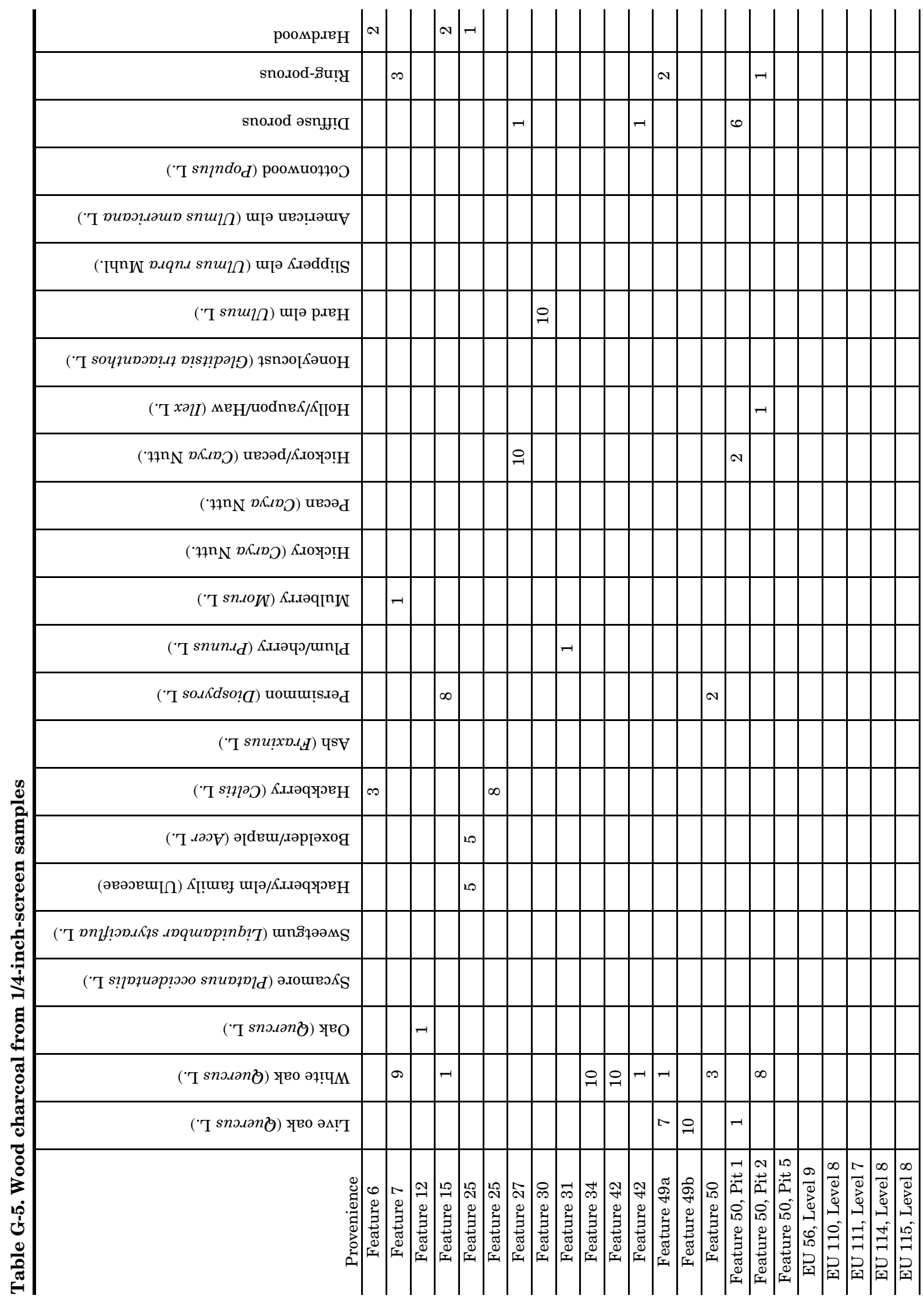


Data Recovery Excavations at the J. B. White Site

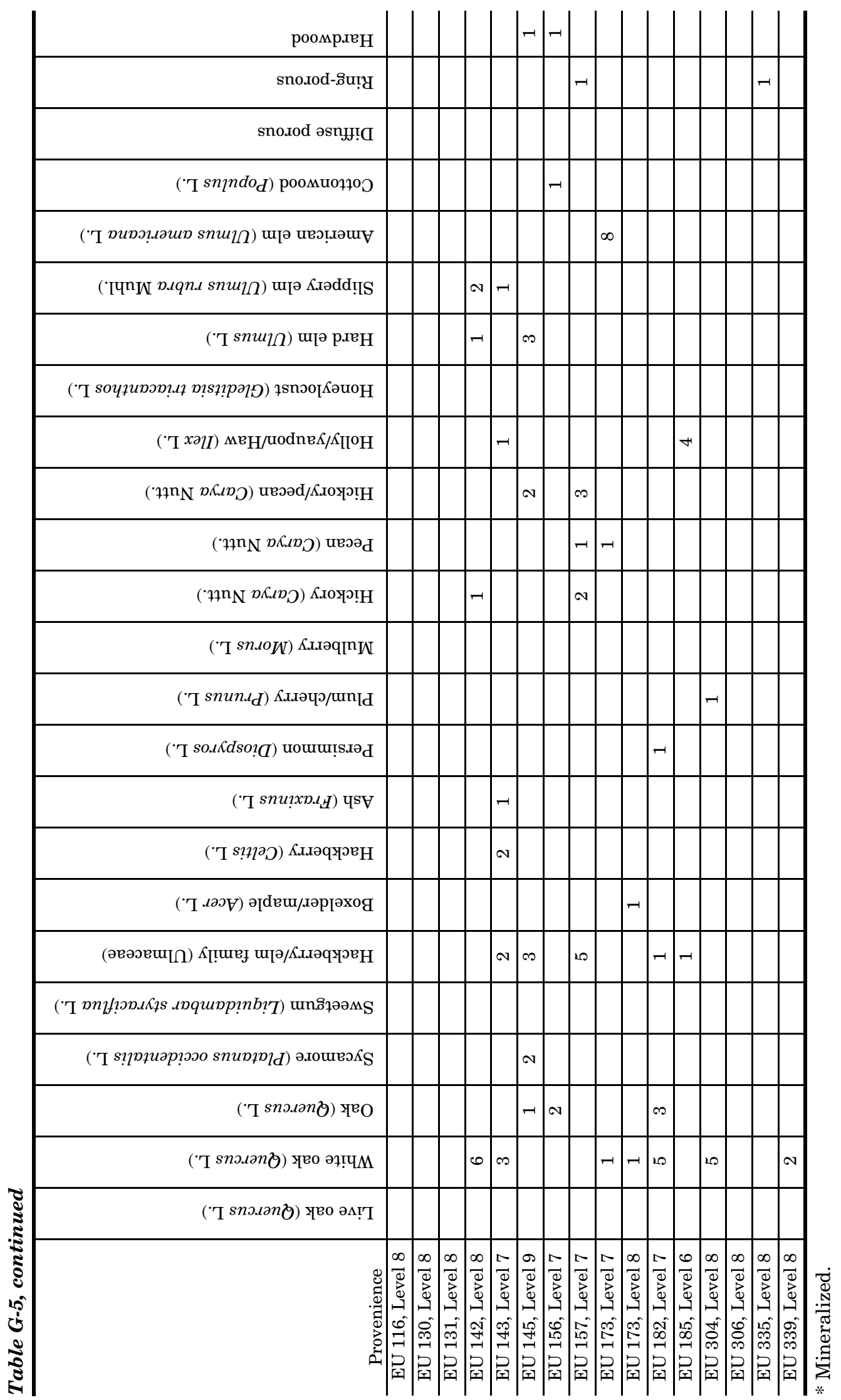


hackberry seeds also could reflect the fact that large areas of the site were opened and exposed to modern seed rain during the course of the investigations. It is possible that some carbonized plant remains at 41MM341 represent charcoal generated in natural fires or charcoal that washed onto the site during episodes of alluviation. Taxa such as wild mustard and poison ivy that occur in both carbonized and uncarbonized forms must be treated with particular care in analysis. However, the relatively large quantities of carbonized plant remains, in association with other artifacts, indicate that most of the carbonized flora is indeed associated with the Late Prehistoric occupation of the site.

\section{Carbonized Plant Remains}

\section{Wood Charcoal}

The most-common carbonized plant type found in the samples from 41MM341 is wood charcoal. Although it is possible that some of this wood was originally used for tools or construction, the contexts and the carbonized state indicate that combustion was an importantand probably the only-use for much of this wood. A total of 10,340 wood charcoal fragments weighing $634.71 \mathrm{~g}$ was recovered from the botanical samples. Of these, 772 were snapped for identification, resulting in identification of 642 fragments to at least the family level. Approximately half of the identifiable fragments (308 or 48 percent) are oak. Of the 277 oak fragments that could be assigned to a subgenus, 218 (79 percent) are white oak, with live oak represented by 57 fragments ( 21 percent) and red oak by only 2 specimens. As noted above, both white and red oak are typically present in the modern Blackland Prairie and Post Oak Savannah vegetational zones. That live oak is also a significant presence bolsters pollen evidence indicating that the area may have been somewhat drier when the site was occupied.

Many of the other woods identified appear to represent constituents of the floodplain forest near the Little River. These include sycamore, boxelder, cottonwood, elms, pecan, and possibly sweetgum. Although sweetgum is most commonly associated with the Piney Woods vegetational zone in Texas and is most ubiquitous in the Lower Mississippi Valley, the University of Texas at Austin herbarium collections include a specimen of sweetgum from Lee County (Herbarium Ref: D. S. Correll \#32171). Wood charcoal fragments matching the anatomical characteristics of sweetgum are therefore reported here as sweetgum. Three other wood taxa (pecan, hickory, and plum/cherry) are notable because they indicate exploitation of the same plants for food and fuel by the site inhabitants.

Table G-6 shows that different contexts exhibit differences in wood charcoal composition. The processing pits of the South Block are strongly associated with oak. The identifiable oak types found in these features are divided between white oak $(\mathrm{n}=47)$ and live oak $(n=26)$, and the only two specimens of red oak identified from the site are from this area (Feature 49a). A variety of other woods also were represented in processing pit features, including the site's only softwood (Juniperus), found in Feature 50, Pit 4. The relatively high percentage of live oak in these features and the presence of juniper suggest that the woods used in processing pits generally represent exploitation of more-xeric environmental zones than those represented in, for example, the surface hearth features.

Surface hearths, in general, contain less charcoal than other feature types, and two samples (Features 40 and 43) contain no wood whatsoever. Although the relatively small sample sizes make conclusions tentative, these features are most strongly associated with woods of the hackberry/elm family. These woods predominate in Feature 30, and are present in 6 of the 11 hearths that contain wood charcoal. Elm accounts for most of the wood charcoal in Feature 30, persimmon in Feature 12, boxelder in Feature 6, and hickory in Feature 44. Only Feature 25 contained a large number of identifiable specimens from a range of woods. Members of the hackberry/elm family were sufficiently abundant in hearth features that this feature type contains approximately twothirds (39 of 59) of the hackberry or elm specimens identified on the site. The elm, boxelder, cottonwood, and sycamore trees represented in these features suggest exploitation of the floodplain for wood resources. Feature 12, with its persimmon specimens, is an exception here. Pit hearths contain a variety of wood charcoal, mostly oaks and other hardwoods. The mostnumerous wood charcoal types in these features 
Table G-6. Wood charcoal by feature type

\begin{tabular}{l|c|c|c|c|c|c|c}
\hline & $\begin{array}{c}\text { Burned Rock } \\
\text { Concentration } \\
(\mathrm{n}=5)\end{array}$ & $\begin{array}{c}\text { Surface } \\
\text { Hearth } \\
(\mathrm{n}=95)\end{array}$ & $\begin{array}{c}\text { Pit Hearth } \\
(\mathrm{n}=70)\end{array}$ & $\begin{array}{c}\text { Processing } \\
\text { Pit } \\
(\mathrm{n}=128)\end{array}$ & $\begin{array}{c}\text { Shell Lens } \\
(\mathrm{n}=166)\end{array}$ & $\begin{array}{c}\text { Indeterminate } \\
(\mathrm{n}=45)\end{array}$ & $\begin{array}{c}\text { Posthole } \\
(\mathrm{n}=1)\end{array}$ \\
\hline Oak & 2 & 8 & 30 & 88 & 87 & 27 & 0 \\
\hline Hackberry/elm & 0 & 39 & 1 & 9 & 10 & 0 & 0 \\
\hline Acer/Ilex & 3 & 16 & 9 & 3 & 18 & 0 & 0 \\
\hline Hickory/pecan & 0 & 6 & 0 & 8 & 8 & 18 & 0 \\
\hline $\begin{array}{l}\text { Other } \\
\text { hardwood }\end{array}$ & 0 & 26 & 30 & 18 & 43 & 0 & 1 \\
\hline Softwood & 0 & 0 & 0 & 2 & 0 & 0 & 0 \\
\hline Note: Inc
\end{tabular}

Note: Includes both flotation and 1/4-inch-screen recovery.

include oak (mostly white oak), ash, and persimmon. One of the four pit hearths (Feature 48) contained only specimens that may be either boxelder or yaupon, and another (Feature 7) contained six specimens of sweetgum.

Like processing pits, shell lenses are dominated by oak, but to a lesser extent. The oak in these features is predominantly white oak, and well-represented woods other than oak include ash, boxelder, and members of the elm/hackberry family.

The lone sample from a burned rock concentration that was analyzed contained too few identifiable fragments for discussion $(n=5)$. In two of the three indeterminate features (Features 34 and 37 ), only white oak was identified, while the other indeterminate feature (Feature 27 ) yielded only hickory or hickory/pecan woods.

Two samples from a possible posthole (Feature 31 ) were analyzed, one recovered by flotation and one by screening. Only the screen sample contained identifiable wood tissue, in the form of a single plum or cherry specimen. The other tissue fragments from this feature contain a great deal of pith and appear to be root fragments. It is hypothesized that the wood charcoal contents of Feature 31 represent portions of the burned root of a plum or cherry tree. Whether the feature stain originated with the tree or whether the tree exploited the fertile soil of an existing archeological feature cannot be determined from the macrobotanical contents alone.

The finding that different feature types exhibit different wood charcoal assemblages at 41MM341 is particularly interesting. Archeological studies have tended to examine wood charcoal with the site as the unit of analysis, using the results to reconstruct local ecology under the "firewood indifference hypothesis"
(Asch and Asch 1986). Alternatively, analysis of wood charcoal has focused on construction practices or craft technology, examining woods from particular craft items or structures (e.g., Simon 2003). Careful selection of particular woods for particular purposes is well known in the Euro-American tradition (Reynolds and Pierson 1942:6-8), and ethnohistorical sources indicate that Native Americans were well aware of the burning properties of different woods and exploited them accordingly. For instance, traditional Kawaiisu (Shoshone) Indians prefer Douglas oak (Quercus douglasii) for roasting yucca bulbs (Zigmond 1981:57). Similarly, Melvin Gilmore notes that Chippewas use black ash (Fraxinus nigra Marsh) "when a quiet fire is desired, for in burning this species does not crackle and shoot sparks as some others do" (Gilmore 1933:139). Results from 41MM341 indicate that significant information about aboriginal wood selection in prehistoric times can be gleaned from archeological studies of wood charcoal with respect to feature type.

\section{Nut Resources}

A total of 210 fragments $(6.71 \mathrm{~g}$ ) of nutmeat or nutshells were recovered from 41MM341. All nutshells recovered by screening are either hickory $(\mathrm{n}=18, \mathrm{~g}=2.31)$ or pecan $(\mathrm{n}=8$, $\mathrm{g}=0.23$ ). One hundred eighty-four fragments weighing $4.17 \mathrm{~g}$ were recovered by flotation processing. Thirty of these $(0.80 \mathrm{~g})$ are from acorns (25 fragments and $0.65 \mathrm{~g}$ of which are from hearth Feature 46), and the remainder represent pecans or other hickories. The bulk of these pecan and hickory nutshells $(\mathrm{n}=144, \mathrm{~g}=3.02)$ were recovered from shell lenses. Nearly half of the shell lens total by count comes from 
Feature 20, where 68 hickory shell fragments $(0.93 \mathrm{~g})$ were recovered.

Although their absolute numbers are not particularly impressive, the acorn and, especially, hickory remains indicate a potentially important food resource for the inhabitants of 41MM341. Data from modern vegetational studies, pollen analysis, and the wood charcoal identification reported here all indicate that hickory and pecan trees (and oak trees) would have been available near the site, with pecan specifically along the Little River.

Both technically and popularly, pecan is usually construed as a type of hickory. The botanical genus Carya constitutes both pecans and hickories, but some authorities note difficulty in distinguishing between species in the genus, especially since members of different species often hybridize (Simpson 1999:77). Botanists usually distinguish pecans from true hickories by the presence of parenchyma bands in the earlywood (USDA-FS 2002). These pecan trees usually-but not always-produce thin-shelled nuts, the criterion widely used by archeologists to distinguish pecan nuts from those of hickory. The thin nutshell at 41MM341 probably represents C. illinoinensis, a pecan hickory that is the only thin-shelled nut producer commonly found in the area today. Carya texana, another pecan hickory, is also present but produces thickshelled nuts (Cox and Leslie 1988; USDA-NRCS 2002).

Hickory and pecan nutmeats are high in fat and contain more protein than most plant foods, with a 100 -g portion of hickory nutmeats having $64 \mathrm{~g}$ of fat (nearly $72 \mathrm{~g}$ for pecans), about 13 $\mathrm{g}$ of protein (9 $\mathrm{g}$ for pecans), and 657 calories (691 calories for pecans) (USDA-ARS 2003). Hall (Hall 2000:109-110) points out that these nutrients, particularly the linolenic fatty acids, may have been critical to hunter-gatherers who relied on lean meat for a portion of the year.

In Texas, ripe hickories and pecans are available from mid-October through mid-January, with heaviest production occurring in November and December (Hall 2000:109). The nuts may be stored for many months without any special preparation, however, so their presence at an archeological site does not indicate a particular season of use. Talalay and colleagues (Talalay et al. 1984) have shown that the oil and nutmeats of thick-shelled hickories are most efficiently extracted by crushing and boiling the nuts. Although no such studies have been conducted specifically for thin-shelled hickories, Hall (2000:109) suggests that pecans also "are amenable to this technique." Fritz and colleagues (Fritz et al. 2001) have documented a preparation of hickory nuts ("nut soup") among modern Cherokee people and suggest techniques for recognizing this kind of nut preparation in the archeological record. Unfortunately, the small quantities of nutshells recovered from 41MM341 and the current lack of comparative data do not lend themselves to any firm conclusion about the processing technique used here. The efficiency of nut soup preparation makes it an appealing hypothesis for nut preparation reflected in the archeological record. On the other hand, hand-shelling of pecans is more efficient than for thick-shelled hickories, and the oily nut soup or prepared soup balls might have spoiled relatively quickly in the warm Texas weather.

\section{Bulbs}

A total of 251 bulbs or bulb fragments weighing $8.90 \mathrm{~g}$ were recovered from 41MM341. Of these, 171 fragments weighing $2.91 \mathrm{~g}$ were recovered by flotation. Bulb identification was accomplished by the author, guided by helpful suggestions generously offered by botanist Phil Dering. Exfoliation of layers exhibited by the specimens at $41 \mathrm{MM} 341$ indicates that they are all true bulbs. A bulb is "a short underground stem covered by enlarged and fleshy leaf bases containing stored food" (Raven et al. 1992:740). Bulb identification hinges on examination of scale cells, which are easily obscured by erosion or dirt and therefore best visible in newly exposed sections of the bulb. Bulb size and shape are largely determined by bulb age and conditions of growth. Conditions of carbonization can also greatly affect these attributes. Bulb size and shape are therefore less reliable attributes, although the shape of the root attachment and the roots themselves, if present, can be helpful. Only a small number of bulbs or bulb fragments exhibited characteristics sufficient for identification at 41MM341. All but 2 of these are members of the genus Allium (wild onion/ garlic). The remaining 2 appear to be the similar (but scentless) plant Nothoscordum bivalve (false garlic). Another 35 fragments are consistent with an identification of either Allium or 
Nothoscordum-but so are many other bulbs. The remainder of the bulb fragments, which constitute most of the bulb assemblage, are unidentifiable.

Ethnographically, wild onions were widely used in North America for food, especially as a relish or flavoring (Gilmore 1991:19; Moerman 1998:56-59). They also have medicinal uses (Densmore 1974:286; Moerman 1998:56-59). The large numbers of bulbs found at 41MM341 and their association with other food remains (i.e., animal bones) in the processing pits argue that culinary use of wild onions was the primary use of this plant at the site.

With their high water content, bulbs are nutritionally more similar to leaves and roots than to other, more densely nutritious, underground organs such tubers. As shown in Table G-7, a 100-g portion of modern onions (about two-thirds cup, chopped) yields only 42 calories, $10 \mathrm{~g}$ carbohydrates, less than $1 \mathrm{~g}$ of protein, and virtually no fat. A 100 -g portion of scallions (bulbs and tops, about a cup, chopped) yields about 32 calories, $7 \mathrm{~g}$ of carbohydrates, almost $2 \mathrm{~g}$ of protein, and no fat. A $100 \mathrm{-g}$ portion of sweet potato, in contrast, yields 76 calories, most of which come from the $17.61 \mathrm{~g}$ of carbohydrates present. For their minimal caloric yield, however, onions contain respectable quantities of minerals and vitamins, especially potassium, calcium, vitamin $\mathrm{C}$, and folate (all nutritional data are from USDA-ARS 2003).

\section{Other Plant Remains}

Other than nut parts and bulbs, the remains of several potential economic plants were identified at 41MM341. Of these, most are pit fragments from fruits of the genus Prunus, which in Texas includes plums, cherries, and peachbush. All fragments large enough for more-precise identification appear to be plums, probably Prunus angustifolia. The edible flesh of this relatively large fruit can be eaten fresh, or it can be dried and stored for future consumption. Plum and cherry plants also have many medicinal uses, but these relate more to the bark than to the fruits (Moerman 1998). Fifteen pit fragments weighing $0.54 \mathrm{~g}$ were recovered, with 12 fragments $(0.47 \mathrm{~g})$ coming from Feature 48 , a pit hearth. Eight small, unidentifiable fruits were recovered, as were 4 seeds from plants of the mallow family.

Other potential food plants present in very small quantities include marsh elder, wild mustard, smartweed, nightshade, and hawthorn. The grass stems $(n=8)$ may represent fuel remains, accidental burning, or use of grass stems in basketry or other crafts. The lone poison ivy/oak/ sumac seed may represent medicinal use of this plant, which has few other known uses (Moerman 1998:564-565). It is also possible, but unlikely, that the specimen represents disposal of a nuisance plant. Unlike other such plants, poison ivy is not wisely disposed of in campfires, since its combustion produces smoke that can affect those allergic to the plant.

\section{Discussion}

The macrobotanical assemblage at 41MM341 suggests an environment similar to, but perhaps slightly drier than, that found in the ecological zones defined in the region today. Pollen data from the area and the presence of live oak in the wood charcoal samples indicate that the immediate environment was perhaps somewhat drier than present-but there is no particular reason to believe that the plants at 41MM341 represent the immediate site area exclusively. The current (and probably past) location of the site near the boundary between

Table G-7. Nutrient composition of some domesticated bulbs, roots, and tubers

\begin{tabular}{l|c|c|c|c|c|c|c}
\hline & Onion & $\begin{array}{c}\text { Scallion } \\
\text { (green and } \\
\text { white parts) }\end{array}$ & $\begin{array}{c}\text { Lettuce } \\
\text { (iceberg) }\end{array}$ & Spinach & Carrot & $\begin{array}{c}\text { Sweet } \\
\text { potato }\end{array}$ & Russet potato \\
\hline Kcal & 42 & 32 & 10 & 23 & 41 & 76 & 79 \\
\hline Water (g) & 88.54 & 89.83 & 96.26 & 91.4 & 88.29 & 79.78 & 78.58 \\
\hline Carbohydrates (g) & 10.11 & 7.34 & 2.09 & 3.63 & 9.58 & 17.61 & 18.07 \\
\hline Protein (g) & 0.92 & 1.83 & 0.81 & 2.86 & 0.93 & 1.57 & 2.14 \\
\hline Fat (g) & 0.08 & 0.19 & 0.11 & 0.39 & 0.24 & 0.05 & 0.08 \\
\hline
\end{tabular}

Note: Data from USDA-ARS 2003. All measurements are taken from 100-g portions of raw vegetables. 
two vegetational zones (Blackland Prairie and Post Oak Savannah) means that a large variety of resources were within plausible range for the site inhabitants. Certainly no plants are present that would most likely have originated outside central or eastern Texas. Understanding of the past environment near 41MM341 is hindered by botanical remains that can be identified only to genus rather than species, and the necessarily imprecise understanding from the pollen record of what the ecological setting of the immediate site area was like when the site was occupied.

In terms of subsistence strategies, when the macrobotanical remains are considered in isolation from other aspects of the subsistence base at 41MM341, elements of both foraging and collecting strategies seem to be present. Foragers move residentially in response to an economic base where resources are scattered, occur in small quantities, or are unreliable. Collectors move logistically from a more-fixed residence, exploiting rich resources that occur reliably at specific times in large quantities. Nut resources at 41MM341 could point toward a collector strategy: they are rich and occur reliably and in large quantities in the fall (though some years are better than others), and the trees that will bear them may be noted at any time of year. Such knowledge may be gathered and stored years in advance of the need for nuts because nutbearing trees are long-lived and resistant to many disasters. Bulbs, however, could point toward a foraging strategy, having relatively low nutritional value and sporadic occurrence (or at least they do not occur in patches that are large relative to human nutritional needs). Bulbs may be fairly reliable, however. Bulb fragments $(\mathrm{n}=251)$ and nut resources $(\mathrm{n}=210)$ are present in similar quantities at 41MM341, but nutshells are far more likely to be preserved through carbonization than bulbs. In isolation, the macrobotanical remains cannot suggest whether a collector or forager strategy was more typical of the inhabitants of site 41MM341. Because the bulbs were most likely a condiment for another food element used at the site (or possibly a curative element), and because the scarcity of ground stones suggests the nut processing was relatively unimportant, the question of foraging versus collecting is perhaps best evaluated using lines of evidence other than macrobotanical remains.

\section{SUMMARY}

The most common food plants identified at 41MM341 are nut resources (hickory, pecan, and acorn) and bulbs (wild onion/garlic), but a few other plants are also represented, most notably plums. Both the wood charcoal assemblage and the herbaceous plants recovered indicate an ecological situation close to-but not necessarily identical to- the modern one. Both upland and riparian zones were exploited by the site inhabitants. Perhaps the most interesting find from the macrobotanical assemblage is that different feature types are associated with different wood charcoal assemblages, suggesting that future studies of this association at other sites may yield important information about aboriginal use of wood. 


\section{REFERENCES CITED}

Asch, Nancy B., and David L. Asch

1986 Woodland Period Archeobotany of the Napoleon Hollow Site. In Woodland Period Occupations of the Napoleon Hollow Site in the Lower Illinois Valley, edited by M. D. Wiant and C. R. McGimsey, pp. 427-512. Research Series, Volume 6. Center for American Archeology, Kampsville Archeological Center, Kampsville, Illinois.

Bousman, C. Britt

1998 Paleoenvironmental Change in Central Texas: The Palynological Evidence. Plains Anthropologist 43(164):201-219.

Bousman, C. Britt, and David O. Brown

1998 Setting the Stage: Previous Paleoclimatic Research in Texas and Surrounding Areas. Plains Anthropologist 43(164):105-110.

Bryant, John A.

1985 Seed Physiology. The Institute of Biology's Studies in Biology No. 165. Edward Arnold, Ltd., London.

Cox, Paul W., and Patty Leslie

1988 Texas Trees: A Friendly Guide. Corona Publishing Company, San Antonio.

Dausman, Raymond J.

1989 Multimodal flotation. Wisconsin Archaeologist 70(3):362-366.

Davis, Linda W.

1993 Weed Seeds of the Great Plains: A Handbook for Identification. University Press of Kansas, Lawrence.

Densmore, Frances

1974 How Indians Use Wild Plants For Food, Medicine, and Crafts. Dover Publications, Mineola, New York.

Diamond, David D., David H. Riskind, and Steve L. Orzell

1987 A Framework for Plant Community Classification and Conservation in Texas. The Texas Journal of Science 39(3):203-221.

Fritz, Gayle J., Virginia Drywater Whitekiller, and James W. McIntosh

2001 Ethnobotany of Ku-Nu-Che: Cherokee Hickory Nut Soup. Journal of Ethnobiology 21(2):1-27.

Gilmore, Melvin R.
1933 Some Chippewa Uses of Plants. Papers of the Michigan Academy of Science, Arts and Letters 17:119-143.

1991 Uses of Plants by the Indians of the Missouri River Region. Originally published 1919. University of Nebraska Press, Lincoln and London.

Gleason, H. A.

1939 The Individualistic Concept of the Plant Association. American Midland Naturalist 21(1):92-110.

Gould, Frank W.

1962 Texas Plants: A Checklist and Ecological Summary. The Agricultural and Mechanical College of Texas, Texas Agricultural Experiment Station, College Station, Texas.

Graham, Alan, and Charles Heimsch

1960 Pollen Studies of Some Texas Peat Deposits. Ecology 41(4):751-763.

Hall, Grant D.

2000 Pecan Food Potential in Prehistoric North America. Economic Botany 54(1):103-112.

Hoadley, R. Bruce

1990 Identifying Wood: Accurate Results with Simple Tools. The Taunton Press, Newtown, Connecticut.

Hunter, Andrea A., and B. R. Gassner

1998 Evaluation of the Flote-Tech Machine-Assisted Flotation System. American Antiquity 63(1):127-132.

Johnson, Elmer H.

1931 The Natural Regions of Texas. The University of Texas Bulletin No. 3113. Research Monograph No. 8. Bureau of Business Research, The University of Texas at Austin.

Larson, Donald A., Vaughn M. Bryant, and Tom S. Patty

1972 Pollen Analysis of a Central Texas Bog. American Midland Naturalist 88(2):358-367.

Lee, Mordie B.

1945 An Ecological Study of the Floodplain Forest along the White River System of Indiana. Butler University Botanical Studies 7:155-175. 
Lopinot, Neal H., and David Eric Brussell

1982 Assessing Uncarbonized Seeds from Open-air Sites in Mesic Environments: An Example from Southern Illinois. Journal of Archaeological Science 9:95108.

Mahoney, Richard B., and Steve A. Tomka

2001 National Register Eligibility Testing of 41MM340 and 41MM341, along Little River, Milam County, Texas. Archaeological Survey Report No. 303. Center for Archaeological Research, The University of Texas at San Antonio.

Martin, A. C., and W. D. Barkley

1961 Seed Identification Manual. University of California Press, Berkeley.

Miksicek, Charles H.

1987 Formation Processes of the Archaeo-botanical Record. In Advances in Archaeological Method and Theory, Vol. 10, edited by Michael B. Schiffer, pp. 211-247. Academic Press, Inc.

Moerman, Daniel E.

1998 Native American Ethnobotany. Timber Press, Portland, Oregon.

Panshin, A. J., and Carol de Zeeuw

1980 Textbook of Wood Technology: Structure, Identification, Properties, and Uses of the Commercial Woods of the United States and Canada. Fourth Edition. McGraw-Hill Book Company, New York.

Potzger, J. E., and B. C. Tharp

1947 Pollen Profile from a Texas Bog. Ecology 28(3):274-280.

1954 Pollen Study of Two Bogs in Texas. Ecology 35(4):462-466.

Raven, Peter H., Ray F. Evert, and Susan E. Eichhorn 1992 Biology of Plants. Fifth Edition. Worth Publishers, New York.

Reynolds, R. V., and Albert H. Pierson

1942 Fuel Wood Used in the United States 1630-1930. United States Department of Agriculture Circular 641 (February 1942):19.

Rossen, Jack

1999 The Flote-Tech Flotation Machine: Messiah or Mixed Blessing? American Antiquity 64(2):370-372.
Simon, Mary L.

2003 Building Social Boundaries: Mississippian Period Red Cedar Use in the American Bottom. Paper presented at the 68th Annual Meeting of the Society for American Archaeology. Milwaukee, Wisconsin.

Simpson, Benny J.

1999 A Field Guide to Texas Trees. Gulf Publishing Field Guide Series. Lone Star Books, Laham, Massachusetts.

Talalay, Laurie, Donald R. Keller, and Patrick J. Munson

1984 Hickory Nuts, Walnuts, Butternuts, and Hazelnuts: Observations and Experiments Relevant to Their Aboriginal Exploitation in Eastern North America. In Experiments and Observations on Aboriginal Wild Plant Food Utilization in Eastern North America, edited by Patrick J. Munson, pp. 338-359. Volume VI, Number 2. Indiana Historical Society, Indianapolis.

Tharp, Benjamin Carroll

1939 The Vegetation of Texas. Texas Academy Publications in Natural History, Nontechnical series. The Anson Jones Press, Houston.

Thomas, Gerald W.

1962 Texas Plants: An Ecological Summary. In Texas Plants: A Checklist and Ecological Summary, edited by Frank W. Gould, pp. 5-14. The Agricultural and Mechanical College of Texas, Texas Agricultural Experiment Station, College Station.

Turner, Billie L.

1959 The Legumes of Texas. University of Texas Press, Austin.

\section{USDA-ARS}

2003 USDA Nutrient Database for Standard Reference, Nutrient Data Laboratory Home Page. Release 15. 2003. United States Department of Agriculture, Agricultural Research Service.

USDA-FS

2002 Technology Transfer Fact Sheet, Vol. 2003.

United States Department of Agriculture, Forest Service, Center for Wood Anatomy Research.

U. S. Department of Agriculture, NRCS

2002 The PLANTS Database. Version 3.5. 2003. 
Data Recovery Excavations at the J. B. White Site

United States Department of Agriculture, Natural Resources Conservation Service.

Whittaker, R. H.

1953 A Consideration of Climax Theory:
The Climax as Population and Pattern. Ecological Monographs 23(1):41-78.

Zigmond, Maurice L.

1981 Kawaiisu Ethnobotany. University of Utah Press, Salt Lake City. 


\section{APPENDIX H: Diatom Paleoecology of Burned Clay Samples from 41MM341}

Barbara M. Winsborough, Ph.D.

Winsborough Consulting

Leander, Texas 



\section{INTRODUCTION}

In this study, burned clay material from radiocarbon-dated prehistoric surface hearths was analyzed for diatom content. The purpose was to investigate the possibility of using diatoms associated with site $41 \mathrm{MM} 341$ to identify relatively wet or dry periods. These hearths consist of thin patches of burned clay, ash, and charcoal within the soil matrix. The burned clay samples were chosen for analysis because they are time sensitive and could allow comparisons of diatoms deposited by floodwaters within each analysis unit. The material is the result of fires constructed directly on the surface with little or no preparation of the underlying soils.

The site is on the floodplain of the Little River about $2 \mathrm{~km}$ southeast of Cameron in Milam County, Texas. Broad floodplain deposits, including indistinct low terrace deposits composed of calcareous clay and silt, quartz sand, and siliceous gravel flank the river. The surface geology of the basin consists of Upper and Lower Cretaceous clays, shales, marls, chalks, limestones, dolomites, and cherts (Barnes 1974). The Little River is a tributary of the Brazos River in the lower Brazos basin.

Diatoms are unicellular, eukaryotic, pigmented, photosynthetic algae distinguished by the possession of a silica cell wall. Diatoms can be found living in a wide variety of natural and man-made terrestrial and aquatic habitats, including seeps, wet walls, dry and damp soil, caves, springs, streams, ponds, lakes, marshes, lagoons, estuaries, bogs, swamps, fens, ditches, canals, temporary pools, travertine accumulations, water and sewage treatment facilities, cooling towers, and hatcheries; on ice and snow; on turtles, whales, other mammals, invertebrates, and fish; and in estuaries, bays, oceans, and seas. Most are cosmopolitan-found in many parts of the world under similar environmental conditions.

Many diatom species have predictable environmental requirements and pollution tolerances, and a large and growing body of information exists on the range of ecological tolerance of many common taxa. Diatoms have short life spans and a capacity for rapid regeneration, and they can be readily identified to species. After death, the organic components of the diatom cell decompose but the silica cell wall is often intactly preserved to accumulate in the sediments. Since diatoms are sensitive indicators of water chemistry, habitat, and substrate (and are often found in large numbers in sedimentary deposits), they are well-suited for use in studies of short-term environmental variability, as well as for more-extensive investigations of long-term paleoenvironmental reconstruction.

\section{METHODS}

Sequential numbers were assigned to the samples during processing at Winsborough Consulting.

Sample 1: Feature 11, Excavation Unit 25, Level 6. Sample recovered from water screening pedestal with shell and burned material; no date, but the feature was surrounded by shell lens Feature 10, which produced two calibrated one-sigma radiocarbon date ranges of A.D. 1040 1180 and A.D. 1010-1160.

Sample 2: Feature 43, Excavation Unit 157, Level 7. Sample recovered from flotation fill at 152-157 cm below datum; no date.

Sample 3: Feature 47, Excavation Unit 197, Level 7. Sample recovered from flotation of feature fill at $152-158 \mathrm{~cm}$ below datum; dated to A.D. $1020-1160$.

Sample 4: Feature 8, Excavation Unit 31, Level 8. Sample recovered from flotation of feature fill; no date.

Sample 5: Feature 40, Excavation Unit 113/ 117, Level 8. Sample recovered from flotation of feature fill at 160-162 cm below datum; dated to A.D. $895-1000$.

Sample 6: Feature 22/26, Excavation Unit 85, Level 9. Sample collected from flotation of feature fill at $170-180 \mathrm{~cm}$ below datum; dated to A.D. $700-1030$.

Sample 7: Feature 6, Excavation Unit 7, Level 11. Sample recovered from flotation of feature fill at $187-200 \mathrm{~cm}$ below datum; no date, but Feature 7 (located $10 \mathrm{~cm}$ below) produced a one-sigma date range of A.D. 640-760.

Samples were cleaned of organic materials and soluble minerals in preparation for microscopic analysis by first boiling in hydrogen peroxide and then nitric acid. The oxidized, decalcified material was rinsed repeatedly until a $\mathrm{pH}$ of about 6-7 was reached. A few drops of the cleaned material was air-dried onto glass coverslips and mounted on glass slides using HYRAX@, a synthetic resin with a high index of refraction developed to aid in resolving the 
details of diatom cell wall morphology. Two slides of each sample were prepared and scanned, and the results of the two slides were combined. Slides were scanned at $1500 \mathrm{x}$ magnification, and all diatoms present were counted from each slide until 500 cells were recorded or the entire slide was scanned.

\section{RESULTS}

Diatoms were recovered from all of the samples submitted for analysis. The diatoms were diluted by sediment, and some of the samples contained more diatoms than others. The data from each of the samples are summarized in Table $\mathrm{H}-1$, along with an indication of whether (in central Texas) the taxon is typically found in a submerged aquatic habitat or an aerial habitat.s

A total of 435 diatom cells was recorded from the seven samples. These counts represent 35 different taxa. The most abundant species were Denticula kuetzingii Grunow, Hantzschia abundans Lange-Bertalot, Luticola mutica (Kützing) D. G. Mann, Synedra ulna Ehrenberg, and Cymbella neocistula Krammer. These common species are important in that they provide the basic paleoenvironmental information about a site. It can be reasonably presumed that diatoms that are abundant in an assemblage are growing well within their environmental limitations. The rare taxa are also important because they provide supplemental information on the range of water quality conditions.

\section{DISCUSSION}

The samples were small and yet they contained well-preserved diatoms. In a mature stream environment without recent disturbance, a diatom population would include the community of algae drifting with the current; attached to submerged plants, animals, and wood; and living in the microbial mat or film coating the sediment, sand, or stone surfaces. Substantial kinds and numbers of diatom cells were to be expected in the cleaned material. A stream in this part of Texas can support as many as 40 60 diatom species at any one time, depending on size, depth, nutrient concentration, and substrate diversity. Many more species are added when seasonality and succession are taken into account. An aerial habitat typically contains a third or fewer species, depending on how damp and diverse the substrate and environment are. In an overbank or similar habitat, the samples include sediment particles, aquatic algae from the river itself, diatoms transported from associated tributaries throughout the catchment basin, and soil algae washed into the water.

The density of diatoms in an overbank deposit is substantially reduced by dilution with suspended sediments in the floodwater. Some diatom species are firmly attached to their substrate and others are motile or less firmly attached, adding a bias to the kinds of species most likely to be dislodged and transported in a flood. If the area flooded remained under water for more than a few days, the diatoms that were still alive would have a chance to reproduce, thereby increasing the numbers of diatom cells on the surface of the resultant deposit. Additionally, soil diatoms already at the site have the opportunity to bloom while the area is wet.

Sample 3, was the most diatomaceous by far, with 259 diatoms found on the slides (see Table $\mathrm{H}-1$ ). This sample contains diatoms that represent the wettest conditions of any of the samples. About 12 percent of the population are aerophilic diatoms found typically in aerophilic habitats such as soils, muds, and moss (Achnanthes coarctata [Brébisson] Grunow, Cymbella neocistula Krammer, Hantzschia abundans Lange-Bertalot, Luticola goeppertiana [Bleisch] D. G. Mann, L. mutica [Kützing] D. G. Mann, and Pinnularia appendiculata [Agardh] Cleve); the remainder are typically aquatic. The diatoms are a mixture of shallow-water, benthic, attached forms found typically along the margins of ponds or attached to stones, sediment, and vegetation in small to medium-sized streams. One facultatively planktonic diatom found only in this sample (Cyclotella meneghiniana) blooms during flood conditions when water is turbid. It can drift up into the photic zone and thrive at a time when the sun is blocked from reaching the benthic diatoms. The diatoms in this sample prefer circumneutral to definitely alkaline, moderate- to high-conductivity water. Many of them, such as Pseudostaurosira brevistriata (Grunow) Williams \& Round, Cocconeis placentula Ehrenberg, Gomphonema parvulum Kützing, and Synedra ulna Ehrenberg, are opportunists; and in central Texas they are known to be early colonizers of newly created habitats. Others (Denticula elegans Kützing, D. kuetzingii 
Table H-1. Diatom abundance in burned clay samples from 41MM341

\begin{tabular}{|c|c|c|c|c|c|c|c|c|c|}
\hline \multirow[b]{2}{*}{ Diatom Name } & \multirow[b]{2}{*}{ Type* } & \multicolumn{7}{|c|}{ Sample No. } & \multirow[b]{2}{*}{ Total } \\
\hline & & 01 & 02 & 03 & 04 & 05 & 06 & 07 & \\
\hline Achnanthes coarctata (Brébisson) Grunow & $\mathrm{A}$ & & & 1 & & & & & 1 \\
\hline Achnanthidium minutissimum Kützing & $\mathrm{W}$ & & 1 & & & & & & 1 \\
\hline $\begin{array}{l}\text { Amphora coffeaeformis (C. A. Agardh) } \\
\text { Kützing }\end{array}$ & $\mathrm{W}$ & & 1 & & & & & & 1 \\
\hline Amphora ovalis (Kützing) Kützing & $\mathrm{W}$ & & & 9 & & & & & 9 \\
\hline Amphora veneta Kützing & $\mathrm{W}$ & & & 7 & & & & & 7 \\
\hline Brachysira vitrea (Grunow) Ross & $\mathrm{W}$ & & 2 & & & & & & 2 \\
\hline Cocconeis placentula Ehrenberg & $\mathrm{W}$ & & & 11 & & & & 1 & 12 \\
\hline Cyclotella meneghiniana Kützing & $\mathrm{W}$ & & & 2 & & & & & 2 \\
\hline Cymbella neocistula Krammer & $\mathrm{W}$ & & 10 & 16 & & & 1 & & 27 \\
\hline Cymbella delicatula Kützing & $\mathrm{W}$ & & 2 & & & & & & 2 \\
\hline Denticula elegans Kützing & $\mathrm{W}$ & & 1 & 17 & & & & & 18 \\
\hline Denticula küetzingii Grunow & $\mathrm{W}$ & 2 & 7 & 132 & 4 & 2 & & 8 & 155 \\
\hline Diadesmis contenta (Grunow) D. G. Mann & $\mathrm{A}$ & & & & & & 2 & & 2 \\
\hline Encyonema silesiacum (Bleisch) D. G. Mann & $\mathrm{W}$ & & 2 & & & & & & 2 \\
\hline Epithemia adnata (Kützing) Brébisson & $\mathrm{W}$ & & & & & 2 & & & 2 \\
\hline Epithemia argus (Ehrenberg) Kützing & $\mathrm{W}$ & 1 & & 1 & & & & & 2 \\
\hline Epithemia turgida (Ehrenberg) Kützing & $\mathrm{W}$ & & & & & 1 & 2 & 1 & 4 \\
\hline $\begin{array}{l}\text { Gomphonema angustatum (Kützing) } \\
\text { Rabenhorst }\end{array}$ & $\mathrm{W}$ & & & & & 1 & 2 & & 3 \\
\hline Gomphonema parvulum Kützing & $\mathrm{W}$ & & & 6 & & & & & 6 \\
\hline Hantzschia abundans Lange-Bertalot & $\mathrm{A}$ & & 2 & 2 & 2 & 2 & 28 & 8 & 44 \\
\hline Luticola goeppertiana (Bleisch) D. G. Mann & $\mathrm{A}$ & & & 4 & & & 10 & 3 & 17 \\
\hline Luticola mutica (Kützing) D. G. Mann & $\mathrm{A}$ & 16 & 1 & 4 & 1 & & 16 & 2 & 40 \\
\hline Mastogloia elliptica Agardh & $\mathrm{W}$ & & & 2 & 2 & & & & 4 \\
\hline Mastogloia smithii Thwaites & $\mathrm{W}$ & & 1 & & & & & & 1 \\
\hline Navicuila brasiliana (Cleve) Cleve & $\mathrm{W}$ & & & 1 & & & & & 1 \\
\hline Navicula libonensis Schoeman & $\mathrm{W}$ & & & & 1 & & & & 1 \\
\hline Navicuila veneta Kützing & $\mathrm{W}$ & & & & & & & 1 & 1 \\
\hline Nitzschia palea (Kützing) W. Smith & $\mathrm{W}$ & & & & 3 & & & & 3 \\
\hline Orthoseira roeseana (Rabenhorst) O'Meara & $\mathrm{A}$ & & & & & & & 8 & 8 \\
\hline Pinnularia appendiculata (Agardh) Cleve & $\mathrm{A}$ & & & 2 & & & & & 2 \\
\hline Pinnularia viridis (Nitzsch) Ehrenberg & $\mathrm{W}$ & & & & & 1 & & & 1 \\
\hline $\begin{array}{l}\text { Pseudostaurosira brevistriata (Grunow) } \\
\text { Williams \& Round }\end{array}$ & $\mathrm{W}$ & & & 16 & & & & & 16 \\
\hline $\begin{array}{l}\text { Reimeria sinuata (Gregory) Kociolek \& } \\
\text { Stoermer }\end{array}$ & $\mathrm{W}$ & & 5 & & & & & & 5 \\
\hline Rhopalodia gibba (Ehrenberg) O. Müller & $\mathrm{W}$ & & & 3 & & & & & 3 \\
\hline Synedra ulna Ehrenberg & $\mathrm{W}$ & & & 23 & 4 & 3 & & & 30 \\
\hline Number of taxa & & 3 & 12 & 19 & 7 & 7 & 7 & 8 & 35 \\
\hline Total cells counted & & 19 & 35 & 259 & 17 & 12 & 61 & 32 & 435 \\
\hline
\end{tabular}

* A = aerophil; $\mathrm{W}=$ aquatic 
Grunow, Epithemia argus [Ehrenberg] Kützing, and Rhopalodia gibba [Ehrenberg] O. Müller) are particularly well equipped to withstand drastic changes in osmotic pressure such as would be found in a frequently drying pool. Cymbella neocistula is reported from dried-out lakes. Overall, this assemblage is characteristic of a very shallow or even temporary pool or depression.

The diatom assemblage in the clay nodules is one with a broad tolerance for temperature and salinity variations. Algae in shallow, benthic habitats-especially habitats that dry out periodically-are more exposed to the local extremes of temperature, adjusting to their preferred temperature range by their individual seasonality. They must tolerate salinity variations, as well, if they are exposed to precipitating salt crusts. Another characteristic of the diatoms found in the nodules is that they are opportunistic species that bloom when new or disturbed habitats are available.

The diatoms in Sample 3 may represent a pond, slough, or temporary habitat near or where they were collected. Rather than being associated with a flood deposit, the diatoms could have been collected in a vessel and carried from a nearby water source along with water used for domestic purposes, and then they accumulated on the ground surface as the water was used. That does not explain why only one sample was so much richer in diatoms than the others, unless, during the time when the clay from Sample 3 was accumulating, there was a local topographic depression where water accumulated and evaporated.

The remaining samples contained substantially fewer diatoms relative to Sample 3, but all the hardened clay samples examined during this study were remarkably similar in the kinds of diatoms that were found. The differences among the diatom assemblages from the other samples are in the proportions of aquatic to aerophilic diatoms. Sample 6 was the next-densest sample with 61 diatom cells. In contrast to Sample 3, these diatoms are almost all aerial species that would be associated typically with a moist soil and not a submerged habitat. Sample 1 contained almost all aerial species; Samples 2, 4, and 5 are depauperate versions of Sample 3; and Samples 6 and 7 are dominated by soil diatoms but contain a few aquatic species as well.
Modern materials and burned clay nodules from 41MM340 were analyzed previously (in 2000) for Steve Tomka at the Center for Archaeological Research, The University of Texas at San Antonio (Table H-2). An additional modern sample collected in September 2004 from the Little River at the town of Little River, in Milam County, provides data on the diatom composition of the river shortly after a long and intense rain on the watershed, when there was evidence of overbank flooding in Milam County. The river at the time was about $8 \mathrm{~m}$ wide, of an unknown depth, very turbid, a medium brown color, and flowing very swiftly. The autecology of the modern diatom species is included in Table $\mathrm{H}-3$ with the ecological information about the taxa found in the present and previous clay nodule studies. The ecological variability in the published records for the various taxa reflect the range of tolerance of individual diatom species and suggests that there is a complex of physical and chemical interactions that influence each diatom's ability to thrive.

The modern collections provide the beginning of a general reference for the kinds of diatoms that are to be found in the Little River today. Ideally, a modern database for establishing transfer functions applicable to paleoenvironmental reconstruction would include detailed samples collected frequently over at least a few annual cycles, along with relevant water chemistry and physical data. This diatom database would be at least similar to what was present in the Little River for the last few thousand years. One major ecological difference is that there are several man-made lakes in the upper part of the watershed that allow for the development of diatom phytoplankton species (such as Bacillaria paxilifer [O. F. Müller] Hendey and Cyclotella spp. that may not have been there before the tributaries of the Little River were impounded. Before construction of the lakes, the water flowing through the watershed had a shorter retention time.

The modern samples contained a greater diversity of diatom species than the nodule samples, with 69 taxa in the three modern samples analyzed (see Table H-2). In comparison, there were 35 taxa in the present clay nodule study and 27 species in the previous study of clay nodules from 41MM340. The modern diatoms, however, represent essentially the same general water chemistry profile as is reflected 
Table H-2. Diatom abundance in modern samples collected in the vicinity of 41MM341 and in fired clay nodules previously analyzed from nearby $41 \mathrm{MM340}$

\begin{tabular}{|c|c|c|c|c|c|c|}
\hline \multirow[b]{3}{*}{ Diatom Name } & \multicolumn{6}{|c|}{ Sample No. } \\
\hline & \multicolumn{3}{|c|}{ Modern } & \multicolumn{3}{|c|}{ 41MM340 } \\
\hline & 1 & 2 & 3 & 9 & 11 & 12 \\
\hline Achnanthes clevei Grunow & & 2 & & & & \\
\hline Achnanthidium minutissimum Kützing & & 14 & & & & \\
\hline Amphora montana Krasske & & 8 & & & & \\
\hline Amphora ovalis (Kützing) Kützing & 15 & 3 & 3 & 1 & & \\
\hline Amphora pediculus (Kützing) Grunow & 6 & 10 & & & & \\
\hline Amphora veneta Kützing & & 1 & & & & \\
\hline Bacillaria paxilifer (paradoxa) (O. F. Muller) Hendey & & 9 & & & & \\
\hline Caloneis bacillum (Grunow) Cleve & & & & 22 & & \\
\hline Cocconeis pediculus Ehrenberg & 6 & & & & & \\
\hline Cocconeis placentula Ehrenberg & 258 & 28 & & & & \\
\hline Craticula cuspidata (Kützing) Mann & & 25 & 476 & 1 & & \\
\hline Cyclotella atomus Hustedt & & 2 & & & & \\
\hline Cyclotella ocellata Pantocsek & & 1 & & & & \\
\hline Cymatopleura solea (Brébisson) W. Smith & & 2 & & & & \\
\hline Cymbella affinis Kützing & 12 & & & & & \\
\hline Cymbella mexicana (Ehrenberg) Cleve & 2 & & & & & \\
\hline Diadesmis confervacea (Grunow) D. G. Mann & 1 & 17 & & & & \\
\hline Diadesmis gallica W. Smith & & & 3 & 2 & & \\
\hline Diatoma vulgare Bory & & 23 & & & & \\
\hline Diploneis parma Cleve & & 7 & & & & \\
\hline Encyonema silesiacum (Bleisch) D. G. Mann & 10 & 7 & & 1 & & \\
\hline Eolimna (Navicula) minima (Grunow) Lange-Bertalot & & 6 & & 6 & & \\
\hline Epithemia adnata (Kützing) Brébisson & & & & 4 & & \\
\hline Epithemia turgida (Ehrenberg) Kützing & & & & 4 & & \\
\hline Fragilaria capucina Desmazières & 2 & & & & & \\
\hline Gomphonema angustum Agardh & 44 & 6 & & & & \\
\hline Gomphonema clavatum Ehrenberg & 4 & 4 & & & & \\
\hline $\begin{array}{l}\text { Gomphonema grovei var lingulatum (Hustedt) Lange- } \\
\text { Bertalot }\end{array}$ & 2 & & & & & \\
\hline Gomphonema parvulum Kützing & 20 & 13 & & 19 & & \\
\hline Gyrosigma scalproides (Rabenhorst) Cleve & 3 & 2 & 4 & & & \\
\hline Hantzschia abundans (amphioxys) Lange-Bertalot & & & 2 & 82 & 1 & 2 \\
\hline $\begin{array}{l}\text { Hippodonta capitata (Ehrenberg) Lange-Bertalot, } \\
\text { Metzeltin \& Witkowski }\end{array}$ & & 10 & & & & \\
\hline $\begin{array}{l}\text { Hippodonta hungarica (Grunow) Lange-Bertalot, } \\
\text { Metzeltin \& Witkowski }\end{array}$ & & 2 & & & & \\
\hline Luticola mutica (Kützing) D. G. Mann & & 3 & 1 & 30 & 2 & \\
\hline Melosira varians Agardh & & 18 & & & & \\
\hline Meridion circulare (Greville) Agardh & & & & 2 & & \\
\hline Navicula cryptocephala Kützing & & 3 & & 11 & & \\
\hline Navicula cryptotenella Lange-Bertalot & & 7 & & 29 & & \\
\hline Navicula lenzii Hustedt & & 1 & & & & \\
\hline Navicula menisculus Schumann & & 6 & & & & \\
\hline Navicula rhynchotella (rhynchocephala) Lange-Bertalot & 1 & 8 & & 6 & & \\
\hline Navicula salinarum Grunow & & 6 & & & & \\
\hline Navicula sanctaecrucis Østrup & & 21 & & & & \\
\hline Navicula subminuscula Manguin & & 9 & & & & \\
\hline Navicula symmetrica Patrick & & 1 & & 2 & & \\
\hline Navicula texana Patrick & & 12 & & 5 & & \\
\hline
\end{tabular}


Table H-2, continued

\begin{tabular}{|c|c|c|c|c|c|c|}
\hline \multirow[b]{3}{*}{ Diatom Name } & \multicolumn{6}{|c|}{ Sample No. } \\
\hline & \multicolumn{3}{|c|}{ Modern } & \multicolumn{3}{|c|}{ 41MM340 } \\
\hline & 1 & 2 & 3 & 9 & 11 & 12 \\
\hline Navicula tripunctata (O. F. Müller) Bory & 25 & 25 & & 7 & & \\
\hline Navicula viridula var. rostellata (Kützing) Cleve & & 7 & & & & \\
\hline Nitzschia acuminata (William Smith) Grunow & & 3 & 1 & & & \\
\hline Nitzschia amphibia Grunow & 5 & 24 & 3 & 58 & & \\
\hline Nitzschia angustata (William Smith) Grunow & & & 6 & & & \\
\hline Nitzschia compressa (Bailey) Boyer & & 2 & & & & \\
\hline Nitzschia constricta (Kützing) Ralfs & & 5 & & & & \\
\hline Nitzschia dissipata (Kützing) Grunow & & 16 & & 2 & & \\
\hline Nitzschia frustulum (Kützing) Grunow & & 1 & & 4 & & \\
\hline Nitzschia inconspicua Grunow & & 15 & & 4 & & \\
\hline Nitzschia levidensis var. salinarum (W. Smith) Grunow & & 2 & & & & \\
\hline Nitzschia linearis (Agardh) William Smith & 1 & 11 & & & & \\
\hline Nitzschia palea (Kützing) William Smith & & 10 & & 111 & & \\
\hline Nitzschia solita Hustedt & & 2 & & & & \\
\hline Pinnularia cf. viridis (Nitzsch) Ehrenberg & & & & & 2 & \\
\hline $\begin{array}{l}\text { Plagiotropis lepidoptera var. proboscidea (Cleve) } \\
\text { Reimer }\end{array}$ & & 1 & 1 & & & \\
\hline Pleurosigma salinarum Grunow & & 1 & & & & \\
\hline Pleurosira laevis (Ehrenberg) Compère & 6 & & & & & \\
\hline $\begin{array}{l}\text { Pseudostaurosira brevistriata (Grunow) Williams \& } \\
\text { Round }\end{array}$ & & 1 & & & & \\
\hline Reimeria sinuata (Gregory) Kociolek \& Lange-Bertalot & 62 & 15 & & & & \\
\hline $\begin{array}{l}\text { Rhoicosphena abbreviata (C. A. Agardh) Krammer \& } \\
\text { Lange-Bertalot }\end{array}$ & 5 & 2 & & & & \\
\hline Rhopalodia brebissonii Krammer & & 4 & & 52 & & \\
\hline Rhopalodia gibba (Ehrenberg) O. Müller & & & & 35 & & \\
\hline Sellaphora (Nav.) pupula (Kützing) Mereschkowsky & & 4 & & & & \\
\hline Staurosira construens Ehrenberg & & 17 & & & & \\
\hline Surirella brebissonii Krammer \& Lange-Bertalot & & 7 & & & & \\
\hline Surirella minuta Brébisson & & 5 & & & & \\
\hline Surirella ovalis Brébisson & & 5 & & & & \\
\hline Synedra (Fragilaria) ulna (Nitzsch) Ehrenberg & 6 & 18 & & & 1 & \\
\hline Terpsinoë americana (Bailey) Ralfs & 4 & & & & & \\
\hline Totals & 500 & 500 & 500 & 500 & 6 & 2 \\
\hline
\end{tabular}

1. Plankton sample collected from the Little River at Little River, Milam Co., September 2004.

2. Bottom sludge sample from Little River at SH 77 crossing, collected February 2000.

3 . Top $1 \mathrm{~cm}$ of soil from modern slough located $60 \mathrm{~m}$ south of 41MM340, collected February 2000.

9. Fired clay nodules from 41MM340, Lot 99, Block 3, Unit A, Zone 3-1, 70-80 cm.

11. Fired clay nodules from 41MM340, Lot 185, Block 3, Unit A, Zone 4-3, 94-104 cm.

12. Fired clay nodules from 41MM340, Lot 229, Block 3, Unit A, Zone 6-1, 124-134 cm. 
Table H-3. Published autecological characteristics of ancient diatoms preserved in burned clay nodules from 41MM340 and 41MM341 and modern diatoms collected from nearby Little River

\begin{tabular}{|c|c|}
\hline Diatom Name & Description \\
\hline $\begin{array}{l}\text { Achnanthidium } \\
\text { (Achnanthes) clevei } \\
\text { (Grunow) Czarnecki }\end{array}$ & $\begin{array}{l}\text { alkaliphil (15); in fringing waters of hot pool (50); periphytic, oligohalobous, } \\
\text { alkaliphilous, in eutrophic waters, limnophilous, commonly reported from } \\
\text { lakes and rivers (10) }\end{array}$ \\
\hline $\begin{array}{l}\text { Achnanthes coarctata } \\
\text { (Brébisson) Grunow }\end{array}$ & $\begin{array}{l}\text { soil, rocks, moss, thatched roofs, flowing and standing water, swampy } \\
\text { stream banks, dry walls, calcareous cliffs }(27)\end{array}$ \\
\hline $\begin{array}{l}\text { Achnanthidium } \\
\text { minutissimum Kützing }\end{array}$ & $\begin{array}{l}\text { brackish-fresh to freshwater, often a primary colonizer of disturbed } \\
\text { habitats and characteristic of running water (8); periphytic, oligohalobous- } \\
\text { indifferent, alkaliphilous, oligosaprobic; requires well-aerated (i.e., well- } \\
\text { oxygenated) environments best developed in running water but also found } \\
\text { in the plankton and periphyton of lakes (10); prefers epiphytic habitats in } \\
\text { well-aerated waters, abundant in weakly acidic to weakly alkaline water } \\
\text { (14); optimum salinity } 0.9 \mathrm{~g} / \mathrm{l}(30) \text {; indifferent to organic pollution (40); } \\
\text { eurysaprobic (47); pH near } 7 \text { (48); attached, oligohalobous (49); salt- } \\
\text { indifferent, pH-indifferent, current-indifferent, attached (5); epipelic (55) }\end{array}$ \\
\hline $\begin{array}{l}\text { Amphora coffeaeformis (C. } \\
\text { A. Agardh) Kützing }\end{array}$ & 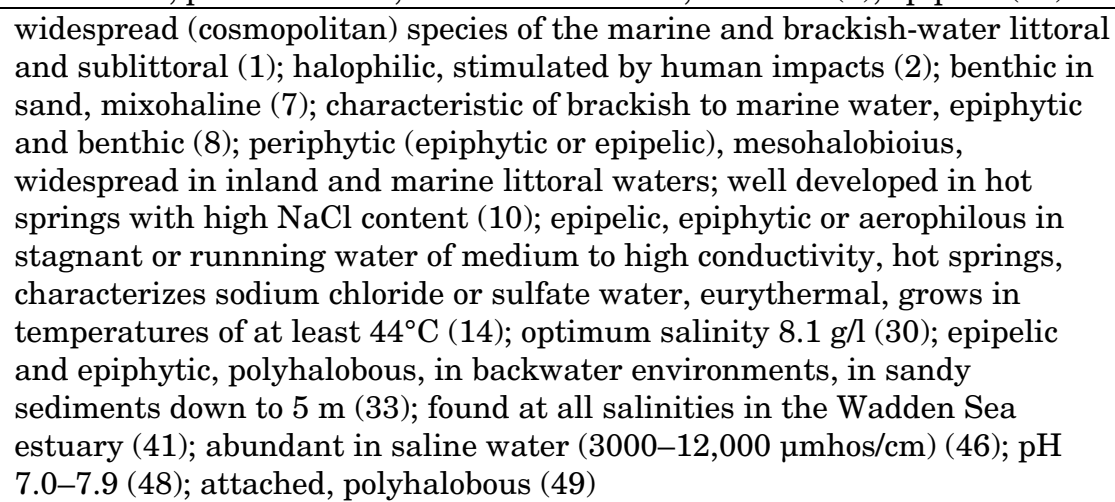 \\
\hline $\begin{array}{l}\text { Amphora montana } \\
\text { Krasske }\end{array}$ & $\begin{array}{l}\text { fresh, slightly brackish, or inland salty water (16); aerophilous, never } \\
\text { abundant, in oxbow lakes, abandoned quarries or rivers with a moderately } \\
\text { high conductivity and probably with a fluctuating water level, pH } \\
\text { circumneutral to alkaline (52) }\end{array}$ \\
\hline $\begin{array}{l}\text { Amphora ovalis (Kützing) } \\
\text { Kützing }\end{array}$ & $\begin{array}{l}\text { periphytic, calciphilous, alkaliphilous (16); standing and flowing water, soil, } \\
\text { wet rocks, fresh and brackish water (4) }\end{array}$ \\
\hline $\begin{array}{l}\text { Amphora pediculus } \\
\text { Ehrenberg }\end{array}$ & $\begin{array}{l}\text { commonly found as an epiphyte in well-aerated, shallow water or in the } \\
\text { current, mostly on filamentous algae or large diatoms, oligohalobe- } \\
\text { indifferent, alkaliphil, not often reported in large numbers (16); on sand } \\
(55)\end{array}$ \\
\hline Amphora veneta Kützing & $\begin{array}{l}\text { frequent and abundant as a cosmopolitan in eutrophic waters (3); brackish- } \\
\text { fresh, epontic (characteristic of the mixolimnia of meromictic lakes) and } \\
\text { benthic (8); periphytic (epipelic or epiphytic), oligohalobous-indifferent } \\
\text { (possibly halophilous), alkaliphilous; tolerates high pollution, at the limit } \\
\text { between alpha-mesosaprobous and polysaprobous (10); in lake periphyton, } \\
\text { slowly running rivers and springs as an epiphyte or an epiphytic form (14); } \\
\text { optimum salinity } 1.4 \mathrm{~g} / \mathrm{l}(30) \text {; characteristic of hyposaline water with a } \\
\text { salinity optimum of } 6.7 \% \text { and a tolerance range of } 1.5-29.0 \% \text { in Antarctic } \\
\text { lakes, also in freshwater lakes (32); epipelic and epilithic (43); benthic, } \\
\text { oligohalobous (49) }\end{array}$ \\
\hline $\begin{array}{l}\text { Bacillaria paxilifer }(\mathrm{O} . \mathrm{F} \text {. } \\
\text { Müller) Hendey }\end{array}$ & brackish and electrolyte-rich inland waters (1); mesohalobous (22) \\
\hline $\begin{array}{l}\text { Brachysira vitrea (Grunow) } \\
\text { Ross }\end{array}$ & $\begin{array}{l}\text { cosmopolitan in littoral zone of oligosaprobic and oligotrophic, chalk- } \\
\text { bearing water (4); adapted to a wide range of ecological conditions but } \\
\text { seems to prefer alkaline water (15) }\end{array}$ \\
\hline $\begin{array}{l}\text { Caloneis bacillum } \\
\text { (Grunow) Cleve }\end{array}$ & $\begin{array}{l}\text { soft, hard or slightly brackish water, often in standing alkaline water (15); } \\
\text { brackish (1); in lakes and rivers of moderately high to high conductivities, }\end{array}$ \\
\hline
\end{tabular}


Table H-3, continued

\begin{tabular}{|c|c|}
\hline Diatom Name & Description \\
\hline & not in oligo-or dystrophic waters, often in well-aerated habitats (52) \\
\hline $\begin{array}{l}\text { Cocconoeis pediculus } \\
\text { Ehrenberg }\end{array}$ & $\begin{array}{l}\text { widespread eurytopous, epiphytic, not often abundant, resistant to organic } \\
\text { pollution, alkaliphil, salt-indifferent (15); epiphytic, oligohalobous- } \\
\text { indifferent to halophilous, alkaliphilous, current-indifferent, beta- } \\
\text { mesosaprobic (10) }\end{array}$ \\
\hline $\begin{array}{l}\text { Cocconeis placentula } \\
\text { Ehrenberg }\end{array}$ & $\begin{array}{l}\text { cosmopolitan, fresh-brackish, epontic, often a primary colonizer of disturbed } \\
\text { habitats, used as an indicator of a change from brackish to fresher water } \\
\text { (8); periphytic (epiphytic, epilithic, and epipsammic), oligohalobous- } \\
\text { indifferent, alkaliphilous, calciphilous, can tolerate moderately polluted } \\
\text { waters (10); optimum salinity } 0.2 \mathrm{~g} / \mathrm{l}(30) \text {; brackish/freshwater epiphyte, } \\
\text { oligohalobous-indifferent, alkaliphilous, eutrophic, temperate (31); found at } \\
\text { all salinities in the Wadden Sea estuary (41); inhibited by high light } \\
\text { intensities, found under a wide temperature range, circumneutral to } \\
\text { slightly alkaline water (44); eurysaprobic (47); pH 8.0-8.6 (48); attached, } \\
\text { oligohalobous (49); salt-indifferent, alkaliphilous, current-indifferent, } \\
\text { attached, eutrophic (5) }\end{array}$ \\
\hline $\begin{array}{l}\text { Craticula cuspidata } \\
\text { (Kützing) Mann }\end{array}$ & $\begin{array}{l}\text { periphytic in lakes and ponds, oligohalobous-indifferent, alkaliphilous, } \\
\text { eutrophic, beta-mesosaprobic; thermal springs with high conductivities } \\
\text { (10); pH optimum } 8.3-8.6 \text {, survives up to } 50^{\circ} \mathrm{C}(14) \text {; optimum salinity } 1.7 \mathrm{~g} / \mathrm{l} \\
\text { (30); epipelic and epilithic (43); saprophilous (47); benthic, oligohalobous } \\
\text { (48); indifferent to salts, alkaliphilous, current-indifferent (5) }\end{array}$ \\
\hline Cyclotella atomus Hustedt & $\begin{array}{l}\text { a cosmopolitan nannoplankter, possibly also in water with high } \\
\text { electrolytes, abundant along the Norwegian coast in a mixture of fresh and } \\
\text { marine water (29); planktonic, halophilous (10) }\end{array}$ \\
\hline $\begin{array}{l}\text { Cyclotella meneghiniana } \\
\text { Kützing }\end{array}$ & $\begin{array}{l}\text { tychoplanktonic or periphytic, halophilous, alkaliphilous, alpha- } \\
\text { mesosaprobic; in oligo-mesohaline waters of various chemistry; tolerates } \\
\text { high temperatures (10); littoral or planktonic, swamps, thermal springs, } \\
\text { wells, lakes, abundant at pH of } 7 \text { to above } 8 \text {, favors medium high to high } \\
\text { mineral content, grows optimally in nitrogen-rich waters (14); abundant in } \\
\text { the littoral zone (30); brackish/freshwater plankton, oligohalobous and } \\
\text { halophilous, alkaliphilous, eutrophic, temperate (31); abundant in fresh and } \\
\text { saline water ( } 3000-12,000 \mu \text { mhos/cm) (46); eurysaprobic (47); pH near } 8.6 \\
\text { (48); planktonic, oligohalobous (49); halophilous, alkaliphilous, current- } \\
\text { indifferent, eutrophic (5) }\end{array}$ \\
\hline $\begin{array}{l}\text { Cyclotella ocellata } \\
\text { Pantocsek }\end{array}$ & $\begin{array}{l}\text { lakes and rivers (54); cosmopolitan, in the littoral of freshwater lakes but } \\
\text { also in flowing waters (29); planktonic, periphytic (epipelic), oligohalobous- } \\
\text { indifferent, alkaliphilous to pH-indifferent; in highly concentrated alkaline } \\
\text { waters, prefers oligotrophic waters (10) }\end{array}$ \\
\hline $\begin{array}{l}\text { Cymatopleura solea } \\
\text { (Brébisson) W. Smith }\end{array}$ & $\begin{array}{l}\text { cosmopolitan, in littoral, epipelic and epiphytic as well as planktonic in } \\
\text { pelagic in eutrophic water with moderate to high electrolytes (9); periphytic } \\
\text { (epipelic or epiphytic), oligohalobous-indifferent, oligosaprobic to } \\
\text { mesosaprobic prefers eutrophic waters (10) }\end{array}$ \\
\hline Cymbella affinis Kützing & $\begin{array}{l}\text { epilithic and epiphytic in stagnant and running waters, in swamps and } \\
\text { ponds of high to very high conductivity, pH alkaline, benthic and periphytic } \\
\text { (52); periphytic (epiphytic or epilithic), oligohalobous-indifferent, } \\
\text { alkaliphilous, oligosaprobic to beta-mesosaprobic, current-indifferent (10) }\end{array}$ \\
\hline $\begin{array}{l}\text { Cymbella mexicana } \\
\text { (Ehrenberg) Cleve }\end{array}$ & $\begin{array}{l}\text { abundant in some fossil samples, recently widely distributed in North } \\
\text { America (18); most often reported from hard water, alkaliphil (16) }\end{array}$ \\
\hline $\begin{array}{l}\text { Cymbella neocistula } \\
\text { (cistula) Krammer }\end{array}$ & $\begin{array}{l}\text { in flowing waters, cosmopolitan, most frequently reported from } \\
\text { circumneutral to slightly alkaline, mesotrophic waters with average to high } \\
\text { electrolytes, in dried-out lakes, epiphytic and epilithic, found from the } \\
\text { arctic to subtropics, very abundant in temperate regions (18); periphytic, } \\
\text { oligohalobous-indifferent, alkaliphilous, oligosaprobic (10) }\end{array}$ \\
\hline $\begin{array}{l}\text { Cymbella delicatula } \\
\text { Kützing }\end{array}$ & $\begin{array}{l}\text { periphtic, in Europe occurs abundantly in oligotrophic, calcium-rich } \\
\text { freshwaters (10) }\end{array}$ \\
\hline Denticula elegans Kützing & periphytic, mesohalobious, alkaliphilous, often found in warm water, also \\
\hline
\end{tabular}


Appendix H: Diatom Paleoecology

Table H-3, continued

\begin{tabular}{|c|c|}
\hline Diatom Name & Description \\
\hline & reported as oligohalobous-indifferent, occasionally aerophilous (10) \\
\hline $\begin{array}{l}\text { Denticula küetzingii } \\
\text { Grunow }\end{array}$ & $\begin{array}{l}\text { widespread and often abundant in water with moderate to high electrolytes } \\
\text { (9); epiphytic, epipelic, or planktonic, in rivers, springs, lakes, } \\
\text { oligohalobous, alkaliphilous, in fresh or slightly brackish, alkaline water, } \\
\text { pH optimum } 8.2-8.5 \text { (14) }\end{array}$ \\
\hline $\begin{array}{l}\text { Diadesmis (Navicula) } \\
\text { confervacea (Grunow) D. G. } \\
\text { Mann }\end{array}$ & $\begin{array}{l}\text { periphytic or aerophilous in shallow water, oligohalobous-indifferent, } \\
\text { alkaliphilous, beta-mesosaprobic; epiphytic and epipelic, cosmopolitan (10); } \\
\text { epiphytic or epipelic in lakes, can grow in water with high mineral content } \\
\text { (14); epipelic and epilithic (43); saprophilous (47); alkaliphilous (5) }\end{array}$ \\
\hline $\begin{array}{l}\text { Diadesmis contenta } \\
\text { (Grunow) D. G. Mann }\end{array}$ & $\begin{array}{l}\text { low light, peat bogs, cliffs, cave walls, mud in pools and streams, } \\
\text { aerophilous in extremely dry habitats, moss, stone fences, standstone cliffs; } \\
\text { oligohalobous, alkaliphilous, subaerial, oxygen-rich water (14) }\end{array}$ \\
\hline $\begin{array}{l}\text { Diadesmis gallica W. } \\
\text { Smith }\end{array}$ & $\begin{array}{l}\text { colonial, in aerophilous habitats and in lakes, oligohalobous and } \mathrm{pH}- \\
\text { indifferent (14) }\end{array}$ \\
\hline Diatoma vulgare Bory & epilithic, epiphytic, common in spring, streams and rivers (53) \\
\hline Diploneis parma Cleve & cool-water form (4) \\
\hline $\begin{array}{l}\text { Encyonema silesiacum } \\
\text { (Bleisch) D. G. Mann }\end{array}$ & $\begin{array}{l}\text { characteristic of fresh to brackish waters, epontic and benthic (8); } \\
\text { periphytic, oligohalobous-indifferent, pH-indifferent, oligosaprobic to beta- } \\
\text { mesosaprobic; widespread mainly in temperate regions (10); attached, } \\
\text { oligohalobous (49); abundant in boreal and alpine regions (17) }\end{array}$ \\
\hline $\begin{array}{l}\text { Eolima (Navicula) minima } \\
\text { (Grunow) Lange-Bertalot }\end{array}$ & $\begin{array}{l}\text { tolerant of a wide range from oligotrophic to eutrophic waters without } \\
\text { discernible preference (2); occurred in lake periphyton, rivers, and peat- } \\
\text { bogs, as a benthic, epiphytic or aerophilous form, oligohalobous and } \\
\text { alkaliphilous (14); brackish/freshwater, aerophilous, oligohalobous- } \\
\text { indifferent, alkaliphilous, meso-eutrophic, temperate (31); indifferent to } \\
\text { organic pollution (40); epipelic and epilithic (43); saprophilous (47) }\end{array}$ \\
\hline $\begin{array}{l}\text { Epithemia adnata } \\
\text { (Kützing) Brébisson }\end{array}$ & $\begin{array}{l}\text { highest vitality in stronger mesotrophic to eutrophic waters (2); } \\
\text { characteristic of fresh to brackish waters, epontic (8); epiphytic, } \\
\text { oligohalobous-indifferent, alkalipilous, saproxenous to beta-mesosaprobic, } \\
\text { brackish coastal waters (10); usually regarded as alkaliphilous or } \\
\text { alkalibiontic, prefers slightly to moderately alkaline waters, also found in } \\
\text { low conductivity, low to medium-low alkalinity waters (14); optimum } \\
\text { salinity } 0.5 \mathrm{~g} / \mathrm{l}(30) \text {; freshwater epiphyte, oligohalobous-indifferent, } \\
\text { alkalibiontic, meso-oligotrophic, temperate (31); epipelic and epilithic (43); } \\
\text { attached, oligohalobous (49) }\end{array}$ \\
\hline $\begin{array}{l}\text { Epithemia argus } \\
\text { (Ehrenberg) Kützing }\end{array}$ & $\begin{array}{l}\text { prefers water with moderate to fairly high amounts of calcium carbonate, in } \\
\text { streams, lakes, and ponds (16); also reported from calcium sulfide- and } \\
\text { sodium bicarbonate-rich water (14); one of the most tolerant diatoms to the } \\
\text { osmotic stress of drying conditions (36); epipelic and epilithic (43); pH 8.6- } \\
10.9 \text { (48); attached, oligohalobous (49) }\end{array}$ \\
\hline $\begin{array}{l}\text { Epithemia turgida } \\
\text { (Ehrenberg) Kützing }\end{array}$ & $\begin{array}{l}\text { epiphytic, oligohalobous-indifferent, alkaliphilous (10); optimum salinity } \\
0.4 \mathrm{~g} / \mathrm{l}(30) \text {; freshwater epiphyte, oligohalobous-indifferent, alkalibiontic, } \\
\text { meso-eutrophic, temperate (31); epiphytic, oligohalobous-indifferent (33); } \\
\text { attached, oligohalobous (49); alkalibiont (50); on stromatolites in very } \\
\text { shallow, warm water (51) }\end{array}$ \\
\hline $\begin{array}{l}\text { Fragilaria capucina } \\
\text { Desmazières }\end{array}$ & $\begin{array}{l}\text { prefers slightly alkaline water, indifferent to small amounts of sodium } \\
\text { chloride (15); optimum salinity } 0.3 \mathrm{~g} / \mathrm{l}(30) \text {; eurysaprobic }(47)\end{array}$ \\
\hline $\begin{array}{l}\text { Gomphonema angustatum } \\
\text { (Kützing) Rabenhorst }\end{array}$ & $\begin{array}{l}\text { characteristic of fresh-brackish waters (8); alkaliphilous, } \mathrm{pH} \text { optimum } \\
\text { between } 7.5 \text { and } 7.7 \text {, typically in circumneutral to slightly alkaline, } \\
\text { oligotrophic to somewhat mesotrophic freshwater (14); optimum salinity } 0.2 \\
\mathrm{~g} / 1(30) \text {; freshwater epiphyte, oligohalobous-indifferent, alkaliphilous, meso- } \\
\text { eutrophic, temperate water (31); epiphytic, oligohalobous-indifferent (33); } \\
\text { eurysaprobic (47) }\end{array}$ \\
\hline $\begin{array}{l}\text { Gomphonema angustum } \\
\text { Agardh }\end{array}$ & $\begin{array}{l}\text { indifferent to } \mathrm{pH} \text {, in oligotrophic waters with varying electrolyte contents } \\
(52)\end{array}$ \\
\hline Gomphonema clavatum & al conditions from low to high electrolyte \\
\hline
\end{tabular}


Table H-3, continued

\begin{tabular}{|c|c|}
\hline Diatom Name & Description \\
\hline Ehrenberg & contents (52) \\
\hline $\begin{array}{l}\text { Gomphonema grovei var. } \\
\text { lingulatum (Hustedt) } \\
\text { Lange-Bertalot }\end{array}$ & $\begin{array}{l}\text { freshwater, widely distributed (16); abundant in meso- to eutrophic water } \\
\text { (4) }\end{array}$ \\
\hline $\begin{array}{l}\text { Gomphonema parvulum } \\
\text { Kützing }\end{array}$ & $\begin{array}{l}\text { tolerant of a wide range from oligotrophic to eutrophic waters without } \\
\text { discernible preference (2); cosmopolitan in fresh-brackish waters (8); } \\
\text { periphytic, oligohalobous-indifferent, pH-indifferent, rheophilous, alpha- } \\
\text { mesosaprobic, when abundant may be regarded as a pollution indicator } \\
\text { (10); tolerates variations in osmotic pressure and pH, prefers low mineral } \\
\text { content water (14); damp pond margin leaf litter (23); optimum salinity } 0.2 \\
\text { g/l (30); freshwater epiphyte, oligohalobous-indifferent, pH-indifferent, } \\
\text { meso-eutrophic, temperate (31); epipelic and epilithic (43); eurysaprobic } \\
\text { (47); attached, oligohalobous (49); salt-indifferent, pH-indifferent, } \\
\text { rheophilous, attached (5); epipelic (55) }\end{array}$ \\
\hline $\begin{array}{l}\text { Gyrpsigma scalproides } \\
\text { (Rabenhorst) Cleve }\end{array}$ & $\begin{array}{l}\text { in freshwater of moderate to higher electrolyte content, in stagnant and } \\
\text { running waters of medium to high conductivity (52) }\end{array}$ \\
\hline $\begin{array}{l}\text { Hantzschia abundans } \\
\text { Lange-Bertalot }\end{array}$ & $\begin{array}{l}\text { aerophil (2); sand, brackish water (7); fresh-brackish waters, epontic, in } \\
\text { exposed zones of the littoral (8); periphytic, oligohalobous-indifferent, } \\
\text { alkaliphilous, mesosaprobic, sometimes reported as an aerophil (10); } \\
\text { eurytopic, eurythermal, tolerates a wide range of chemical conditions (14); } \\
\text { damp pond margin leaf litter (23); becomes frequent only upon rewetting } \\
\text { after drought (24); brackish/freshwater, aerophilous, oligohalobous- } \\
\text { indifferent, pH-indifferent, eutrophic, temperate (31); epipelic and } \\
\text { aerophilic, oligohalobous-indifferent, peat, coastal shallows, salt meadows } \\
\text { (33); littoral, ubiquitouis, estuarine, brackish water, saprophilous, pH } \\
\text { range 5.5-9.4 (42); epipelic and epilithic (43); eurysaprobic (47); benthic, } \\
\text { oligohalobous (49); salt-indifferent, alkaliphilous, current-indifferent, } \\
\text { benthic, subaerial (5) }\end{array}$ \\
\hline $\begin{array}{l}\text { Hippodonta (Navicula) } \\
\text { capitata (Ehrenberg) } \\
\text { Lange-Bertalot, Metzeltin, } \\
\text { \& Witkowski }\end{array}$ & $\begin{array}{l}\text { tolerates a wide variety of water chemistry (15); ponds, lakes, streams (22); } \\
\text { epipelon of springs and flowing water (53) }\end{array}$ \\
\hline $\begin{array}{l}\text { Hippodonta hungarica } \\
\text { (Grunow) Lange-Bertalot, } \\
\text { Metzeltin, \& Witkowski }\end{array}$ & $\begin{array}{l}\text { seems to tolerate a wide variety of water conditions, in the littoral of lakes } \\
\text { (15); springs and flowing water, epipelon, soils (53) }\end{array}$ \\
\hline $\begin{array}{l}\text { Luticola goeppertiana } \\
\text { (Bleisch) D. G. Mann }\end{array}$ & $\begin{array}{l}\text { periphytic in moderately high mineral content but not brackish, tolerates } \\
\text { high levels of pollution, also aerophilous (10); listed as a synonym for } L \text {. } \\
\text { mutica by Kellogg \& Kellogg, 2002; saprophilous (40); saprophilous (47); on } \\
\text { subaerial mosses in a peat bog, sometimes in extremely polluted water (14) }\end{array}$ \\
\hline $\begin{array}{l}\text { Luticola mutica (Kützing) } \\
\text { D. G. Mann }\end{array}$ & $\begin{array}{l}\text { tolerant of a wide range from oligotrophic to eutrophic waters without } \\
\text { discernible preference (2); benthic and periphytic in brackish-freshwaters, } \\
\text { common in estuaries (8); periphytic to tychoplanktonic in springs and } \\
\text { streams, sometimes aerophilous in soils and crusts, oligohalobous- } \\
\text { indifferent to halophilous, alkaliphilous to pH-indifferent (10); found in a } \\
\text { variety of biotopes including rivers, swamps, hot springs, and peat bogs, } \\
\text { epiphytic or aerophilous, prefers waters of rather high conductivity or } \\
\text { subaerial habitats such as peat bogs or hot springs (14); optimum salinity } 0 \\
\text { g/l (30); found in both fresh and saline lakes (32); aerophilous, } \\
\text { oligohalobous-indifferent, common in coastal peat, on sandy beaches and } \\
\text { subaerial habitats, optimal water depth } 0.3 \text { m, range } \pm 0.9 \text { m (33); } \\
\text { saprophilous (40); saprophilous (47); salt-indifferent, alkaliphilous, current- } \\
\text { indifferent, subaerial (5) }\end{array}$ \\
\hline $\begin{array}{l}\text { Mastogloia elliptica } \\
\text { Agardh }\end{array}$ & $\begin{array}{l}\text { common in brackish waters, in saline inland waters, and in the littoral of } \\
\text { freshwater lakes with high conductivity (1); characteristic of brackish } \\
\text { waters, epontic and benthic (8); periphytic, halophilous-mesohalobious in } \\
\text { coastal and continental environments; reported from a NaCl-type thermal }\end{array}$ \\
\hline
\end{tabular}


Table H-3, continued

\begin{tabular}{|c|c|}
\hline Diatom Name & Description \\
\hline & $\begin{array}{l}\text { spring and from alkaline waters (10); usually in sodium chloride waters, } \\
\text { calciphilous, circumneutral-alkaline } \mathrm{pH}(14) \text {; epipelic, mesohalobous, in salt } \\
\text { marshes and lagoons, on sandy shores (33); saline water (14,000-20,000 } \\
\text { pmhos/cm) (46); benthic, mesohalobous (49) }\end{array}$ \\
\hline $\begin{array}{l}\text { Mastogloia smithii } \\
\text { Thwaites }\end{array}$ & water with moderate to high electrolytes and brackish water (4) \\
\hline Melosira varians Agardh & ponds, soil (22); epiphytic, epilithic, in rivers (53) \\
\hline $\begin{array}{l}\text { Meridion circulare } \\
\text { (Greville) Agardh }\end{array}$ & $\begin{array}{l}\text { characteristic of fresh-brackish waters (8); epiphytic (14); planktonic, } \\
\text { oligohalobous-indifferent, alkaliphilous, mesotrophic, cold (31); epiphytic, } \\
\text { oligohalobous-indifferent (33); epiphytic (55) }\end{array}$ \\
\hline $\begin{array}{l}\text { Navicuila brasiliana } \\
\text { (Cleve) Cleve }\end{array}$ & freshwater, warm regions (4) \\
\hline $\begin{array}{l}\text { Navicula libonensis } \\
\text { Schoeman }\end{array}$ & $\begin{array}{l}\text { probably cosmopolitan, scattered in electrolyte rich, eutrophic waters with } \\
\text { up to critical levels of pollution (1); eutrophic (2); optimum salinity } 1.2(30)\end{array}$ \\
\hline $\begin{array}{l}\text { Navicula sanctaecrucis } \\
\text { Østrup }\end{array}$ & slightly brackish water or water with high mineral content (15) \\
\hline Navicuila veneta Kützing & $\begin{array}{l}\text { oligohalobous (salt-indifferent), prefers brackish water or freshwater of } \\
\text { high dissolved salt content (TDS) (15); cosmopolitan, in electrolyte-rich to } \\
\text { brackish water, particularly when heavily polluted, pollution tolerant (6) }\end{array}$ \\
\hline $\begin{array}{l}\text { Nitzschia acuminata (W. } \\
\text { Smith) Grunow }\end{array}$ & $\begin{array}{l}\text { Cosmopolitan, abundant in suitable regions along the seacoast, in the } \\
\text { Baltic Sea, penetrating brackish water }(9)\end{array}$ \\
\hline $\begin{array}{l}\text { Nitzschia angustata }(\mathrm{W} . \\
\text { Smith) Grunow }\end{array}$ & $\begin{array}{l}\text { cosmopolitan, abundant where it occurs, abundant in many kinds of waters, } \\
\text { its center of distribution is in waters with moderate to high electrolytes, up } \\
\text { to beta-mesosaprobic water (9) }\end{array}$ \\
\hline $\begin{array}{l}\text { Nitzschia compressa } \\
\text { (Bailey) Boyer }\end{array}$ & $\begin{array}{l}\text { cosmopolitan in the littoral of somewhat electrolyte-rich lakes (9); } \\
\text { periphytic, mesohalobious, common in marine coastal waters, hot springs, } \\
\text { euryhaline, eurythermal (10) }\end{array}$ \\
\hline $\begin{array}{l}\text { Nitzschia palea (Kützing) } \\
\text { W. Smith }\end{array}$ & $\begin{array}{l}\text { highest vitality in stronger mesotrophic to eutrophic waters }(2) \text {; planktonic } \\
\text { and benthic in freshwater, abundant in marine sand bottoms ( } 7) \text {; fresh- } \\
\text { brackish water, epontic and benthic (8); cosmopolitan, periphytic or } \\
\text { tychoplanktonic, oligohalobous-indifferent, pH-indifferent to alkaliphilous, } \\
\text { inhabits eutrophic waters, alpha-mesosaprobic to polysaprobic; good } \\
\text { indicator of pollution when abundant in a population of low diversity (10); } \\
\text { damp pond margin leaf litter (23); optimum salinity } 0.7 \mathrm{~g} / \mathrm{l}(30) \text {; freshwater } \\
\text { epiphyte, oligohalobous-indifferent, pH-indifferent, eutrophic, temperate } \\
\text { (31); saprophilous (40); epipelic and epilithic (43); saprophilous (47); pH } \\
7.0-7.9 \text { (48); epipelic (55) }\end{array}$ \\
\hline $\begin{array}{l}\text { Orthoseira roeseana } \\
\text { (Rabenhorst) O’Meara }\end{array}$ & $\begin{array}{l}\text { subaerial, alkaliphilous, salt tolerant, sandstone cliffs, mosses, wet rocks, } \\
\text { dry moss, drought resistant, aerobiontic (29) }\end{array}$ \\
\hline $\begin{array}{l}\text { Pinnularia appendiculata } \\
\text { (Agardh) Cleve }\end{array}$ & $\begin{array}{l}\text { cosmopolitan, characteristic of freshwater, acidophilous (8); periphytic, } \\
\text { oligohalobous-halophobous, pH-indifferent; cosmopolitan, widely } \\
\text { distributed in the periphyton of freshwaters but sometimes aerophilous } \\
\text { (10); cosmopolitan, occurring in masses where found; prefers mineralized } \\
\text { waters, salt-rich inland waters, salines, soda lakes (13); epipelic (43); pH } \\
5.0-6.9 \text { (48) }\end{array}$ \\
\hline $\begin{array}{l}\text { Pinnularia viridis } \\
\text { (Nitzsch) Ehrenberg }\end{array}$ & $\begin{array}{l}\text { found in water with higher mineral content than many of the species of } \\
\text { Pinnularia, seems to prefer circumneutral water (15); oligohalobous- } \\
\text { indifferent, pH-indifferent (14) }\end{array}$ \\
\hline $\begin{array}{l}\text { Plagiotropis lepidoptera } \\
\text { var. proboscidea (Cleve) } \\
\text { Reimer }\end{array}$ & alkaline freshwater streams and lakes, low chloride freshwaters (16) \\
\hline $\begin{array}{l}\text { Pseudostaurosira } \\
\text { brevistriata (Grunow) } \\
\text { Williams \& Round }\end{array}$ & $\begin{array}{l}\text { periphytic or planktonic in shallow lakes, ponds, rivers or swamps; } \\
\text { oligohalobous-indifferent, alkaliphilous, oligosaprobic, inhabits eutrophic } \\
\text { waters (10); common in dilute, circumneutral to slightly alkaline water of } \\
\text { different chemical types, well developed in running water, could be an } \\
\text { indicator of oxygen-rich water (14); optimum salinity } 0.2 \mathrm{~g} / \mathrm{l}(30) \text {; }\end{array}$ \\
\hline
\end{tabular}


Table H-3, continued

\begin{tabular}{|c|c|}
\hline Diatom Name & Description \\
\hline & $\begin{array}{l}\text { brackish/freshwater tychoplankton, oligohalobous-indifferent, } \\
\text { alkaliphilous, meso-oligotrophic, temperate ( } 31) \text {; benthic and } \\
\text { tychoplanktonic, oligohalobous-indifferent, optimal water depth } 6.4 \mathrm{~m} \text {, } \\
\text { range } \pm 0.8 \mathrm{~m}, \text { has a distribution similar to F. pinnata and } F \text {. construens } \\
\text { (33); eurysaprobic (47); salt-indifferent, alkaliphilous, current-indifferent } \\
\text { (50) }\end{array}$ \\
\hline $\begin{array}{l}\text { Reimeria sinuata (Gregory) } \\
\text { Kociolek \& Stoermer }\end{array}$ & $\begin{array}{l}\text { freshwater, associated with stone surfaces particularly in rivers }(20) \text {, seems } \\
\text { to be } \mathrm{pH} \text {-indifferent, oligohalobe (16); littoral in southern Chile }(22)\end{array}$ \\
\hline $\begin{array}{l}\text { Rhopalodia gibba } \\
\text { (Ehrenberg) O. Müller }\end{array}$ & $\begin{array}{l}\text { cosmopolitan, characteristic of brackish-fresh to fresh-brackish water, } \\
\text { epontic (8); epiphytic in swamps, lakes, and rivers, oligohalobous, } \\
\text { alkaliphilous to alkalibiontic (14); optimum salinity } 0.7 \mathrm{~g} / \mathrm{l}(30) ; \\
\text { brackish/freshwater epiphyte, oligohalobous-indifferent, alkalibiontic, } \\
\text { eutrophic, temperate (31); epipelic and epilithic (43); abundant in saline } \\
\text { water (3000-12,000 } \mathrm{mh} \text { mos/cm) (46); attached, oligohalobous (49) }\end{array}$ \\
\hline $\begin{array}{l}\text { Synedra (Fragilaria) ulna } \\
\text { (Nitzsch) Ehrenberg }\end{array}$ & $\begin{array}{l}\text { cosmopolitan, fresh to fresh-brackish water (8); epiphytic and planktonic, } \\
\text { alkaliphilous, oligohalobous-indifferent, eutrophic, eurythermal, favors } \\
\text { freshwater environments with rather low alkalinity and conductivity (14); } \\
\text { optimum salinity } 0.4 \mathrm{~g} / \mathrm{l}(30) \text {; freshwater epiphyte, oligohalobous- } \\
\text { indifferent, pH-indifferent, meso-eutrophic, temperate (31) }\end{array}$ \\
\hline
\end{tabular}

1. Witkowski, A., H. Lange-Bertalot, \& D. Metzeltin, 2000. Diatom Flora of Marine Coasts I. A. R. Gantner Verlag K. G., 925 pp.

2. Lange-Bertalot, H. \& S. I. Genkal, 1999. Diatoms from Siberia, 1. Islands in the Arctic Ocean (YugorskyShar Strait). Iconographia Diatomologica 6:1-271.

3. Lange-Bertalot, H., P. Cavacini, N. Tagliaventi \& S. Alfinito, 2003. Diatoms of Sardinia. A.R.G.Gantner Verlag K. G., 438 pp.

4. Krammer, K. \& H. Lange-Bertalot, 1986. Susswasserflora von Mitteleuropa Bd 2, Bacillariophyceae, Teil 1, Naviculaceae. In: H. Ettl, H. Gerloff, H Heynig, D. Mollenhauer (Hrg.), Gustav Fischer Stuttgart, New York, $876 \mathrm{pp}$.

5. Haworth, E. Y., 1977. The Sediments of Lake George (Uganda) v. the Diatom Assemblages in Relation to the Ecological History. Arch. Hydrobiologia 80(2):200-215.

6. Lange-Bertalot, H., 2001. Diatoms of Europe, Vol. 2, Navicula sensu stricto, 10 Genera Separated from Navicula sensu lato, Frustulia. A.R.G. Gantner Verlag K. G., 526 pp.

7. Garcia-Baptista, M., 1993. Psammic Algae from Praia Azul, Brazil. Bibliotheca Phycologica Band 94, J. Cramer, Berlin, 167 pp.

8. Hodgson, D, W. Vyverman \& P. Tyler, 1997. Diatoms of Meromictic Lakes Adjacent to the Gordon River, and of the Gordon River Estuary in Southwest Tasmania. Bibliotheca Diatomologica Band 35, J. Cramer, Berlin, 173 pp.

9. Krammer, K. \& H. Lange-Bertalot, 1988. Susswasserflora von Mitteleuropa, Bd 2, Bacillariophyceae, Teil 2, Epithemiaceae, Bacillariaceae, Suirellaceae. In: H. Ettl, H. Gerloff, H. Heynig, D. Mollenhauer (Hrg.), Gustav Fischer Stuttgart, New York, 596 pp.

10. Ehrlich, A., 1995. Atlas of the Inland-water Diatom Flora of Israel. The Geological Survey of Israel, The Israel Academy of Sciences and Humanities, Jerusalem, 166 pp.

13. Krammer, K., 2000. Diatoms of Europe Vol. 1, the Genus Pinnularia. A.R.G. Gantner Verlag K. G., 703 pp.

14. Gasse, F., 1986. East African Diatoms, Taxonomy, Ecological Distribution. Bibliotheca Diatomologica 11, 


\section{Table H-3, continued}

J. Cramer, Berlin, 201 pp.

15. Patrick, R. \& C. W. Reimer, 1966. The Diatoms of the United States Exclusive of Alaska and Hawaii, Vol. 1. Monograph of the Academy of Natural Sciences of Philadelphia, 688 pp.

16. Patrick, R. \& C. W. Reimer, 1975. The Diatoms of the United States Exclusive of Alaska and Hawaii, Vol. 2, Part 1, Monograph of the Academy of Natural Sciences of Philadelphia, No. 13, 688 pp.

17. Krammer, K., 1997. Die cymbelloiden Diatomeen, Eine Monographie der weltweit bekannen Taxa, Vol. 1, Allgemeines und Encyonema Part. J. Cramer, Berlin, 382 pp.

18. Krammer, K., 2002. Diatoms of Europe Vol. 3, Cymbella. A.R.G. Gantner Verlag, K. G., 584 pp.

20. Round, F. E., R. M. Crawford \& D. G. Mann, 1990. The Diatoms, Biology \& Morphology of the Genera. Cambridge University Press, Cambridge, 747 pp.

22. Kellogg, T. B. \& D. E. Kellogg, 2002. Non-Marine and Littoral Diatoms from Antarctic and Subarctic Regions. A.R.G. Gantner Verlag K. G., 795 pp.

23. Evans, J. H., 1960. Further Investigations of the Algae of Pond Margins. Hydrobiologia 15:384-394.

24. Evans, J. H., 1958. The Survival of Freshwater Algae During Dry Periods. J. Ecology 46:149-168.

27. Krammer, K. \& H. Lange-Bertalot, 1991. Susswassweflora von Mitteleuropa Bd 2, Bacillariophyceae, Teil 4, Achnanthaceae. In: H. Ettl, H. Gerloff, H. Heynig, D. Mollenhauer (Hrg.), Gustav Fischer Stuttgart, New York, $437 \mathrm{pp}$.

29. Krammer, K. \& H. Lange-Bertalot, 1991. Susswasserflora von Mitteleuropa Bd 2, Bacillariophyceae, Teil 3, Centrales, Fragilaceae, Eunotiaceae. In: H. Ettl, H. Gerloff, H Heynig, D. Mollenhauer (Hrg.), Gustav Fischer Stuttgart, New York, 576 pp.

30. Cumming, B. F. \& J. P. Smol, 1993. Development of Diatom-based Salinity Models for Paleoclimatic Research from Lakes in British Columbia (Canada). Hydrobiologia 269/270:179-196.

31. Vos, P. C. \& H. de Wolf, 1993. Diatoms as a Tool for Reconstructing Sedimentary Environments in Coastal Wetlands; Methodological Aspects. Hydrobiologia 269/270:285-296.

32. Roberts, D. \& A. McMinn, 1999. Diatoms of the Saline Lakes of the Vestfold Hills, Antarctica. Biblioteca Diatomologica 44:1-81.

33. Campeau, S., R. Pienitz, A. Héquette, 1999. Diatoms from the Beaufort Sea Coast, Southern Arctic Ocean (Canada), Modern Analogues for Reconstructing Late Quaternary Environments and Relative Sea Levels. Bibliotheca Diatomologica 42:1-244.

36. Robinson, M., 2004. A Late Glacial and Holocene Diatom Record from Clettnadal, Shetland Islands, Northern Scotland. Journal of Paleolimnology 31:295-319.

40. Watanabe, T. \& K. Asai, 2004. Dominant Taxa in Epilithic Diatom Assemblages and Their Ecological Properties. In: M. Poulin, ed. Seventeenth International Diatom Symposium, 2002, Biopress Limited, Bristol:423-432.

41. Admiraal, W., 1984. The Ecology of Estuarine Sediment-inhabiting Diatoms. In: Round, F., and D. J. Chapman eds., Progress in Phycological Research 3, Biopress Ltd., Bristol:269-322.

42. Larson, D. D., 1974. Paleoecological Investigations of Diatoms in a Core from Kerguelen Islands, Southeast Indian Ocean. Institute of Polar Studies Report 50, The Ohio State University Research Foundadtion, Columbus, Ohio:1-61. 


\section{Table H-3, continued}

43. Czarnecki, David B., 1979. Epipelic and Epilithic Diatom Assemblages in Montezuma Well National Momument, Arizona. J. Phycol. 15:346-352.

44. Maulood, B. K. \& G. C. Hinton, 1979. Tychoplanktonic Diatoms from a Stenothermal Spring in Iraqi Kurdistan. Br. Phycol. J. 14:175-183.

46. Fritz, S. C. \& Battarbee, R. W., 1988. Sedimentary Diatom Assemblages in Freshwater and Saline Lakes of the Northern Great Plains, North America: Preliminary Results. In: Round, F. E. ed., Proceedings of the 9th International Diatom Symposium, Biopress Ltd., Bristol 265-271.

47. Watanabe, T., K. Asai \& A. Houki, 1988. Numerical Water Quality Monitoring of Organic Pollution Using Diatom Assemblages. In: Round, F. (ed.) Proceedings of the 9th International Diatom Symposium, Biopress Ltd., Bristol and Koelts Scientific Books, Koenigstein 123-141.

48. Gasse, F. \& F. Tekaia, 1983. Transfer functions for Estimating Paleoecological Conditions (pH) from East African Diatoms. Hydrobiologia 103:85-90.

49. Zalat, A., 2003. Paleoecological and Environmental History of Lake Mariut, Egypt, by Means of Diatoms. Diatom Research 18(1):161-184.

50. Cassie, V., 1989. A contribution to the Study of New Zealand Diatoms. Bibliotheca Diatomologica Vol. 17, J. Krammer, Berlin, 266 pp.

51. Winsborough, B. M. \& Jms. Seeler, 1986. The Relationship of Diatom Epiflora to the Growth of Limnic Stromatolites and Microbial Mats. In: Ricard, M. (ed.) Proceedings of the 8th International Diatom Symposium, Paris, Aug. 27-Sept. 1, 1984, Koenigstein, Koeltz, 781 pp.

52. Vyverman, W., 1991. Diatoms from Papua New Guinea. Bibliotheca Diatomologica Vol. 22, J. Cramer, Berlin, $223 \mathrm{pp}$.

53. Round, F. E., 1981. The Ecology of the Algae. Cambridge University Press, Cambridge, 653 pp.

54. Håkansson, H., 1993. Morphological and taxonomic problems in Four Cyclotella Species (Bacillariophyceae). Diatom Research 8(2):309-316.

55. Haworth, E. Y., 1984. Stratigraphic Changes in Algal Remains (Diatoms and Chrysophytes) in the Recent Sediments of Blelham Tarn, English Lake District. In: Haworth, E. Y. \& J. Lund (eds.) Lake Sediments and Environmental History. University of Minnesota Press, Minneapolis, 165-190. 
in the archeological samples except that there are more aerophilic diatoms in the latter. This is to be expected as the soil diatoms already present in the overbank sediments would have had the opportunity to grow while the ground was wet. The modern diatom assemblage is characteristic of what is found typically in hardwater, carbonate-rich, moderate- to highconductivity, circumneutral to alkaline and possibly seasonal or saline stream, lake, and aerophilic habitats in central Texas. Many of the species tolerate or prefer water with an elevated salinity, and this probably reflects the contribution of chloride salts in water coming from the upper part of the basin and the increase in salts due to evaporation. There are no acidic taxa that might suggest a change in water $\mathrm{pH}$ over time.

\section{REFERENCES}

(See Table H-3 for Ecology References)

Barnes, V. E.

1974 Geologic Atlas of Texas, Austin Sheet. Bureau of Economic Geology, The University of Texas at Austin. 

APPENDIX I: Metric Data for Stone Tools 



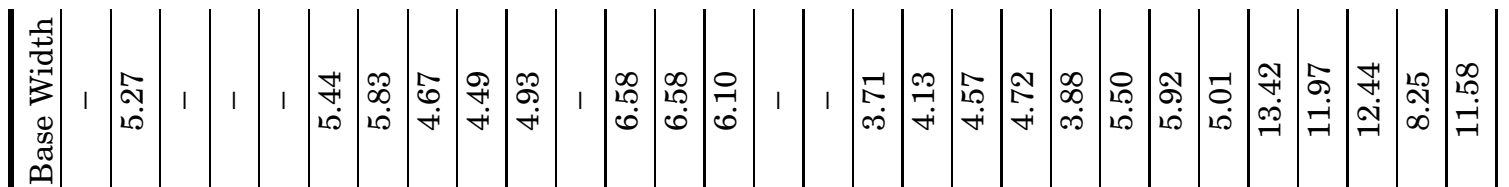

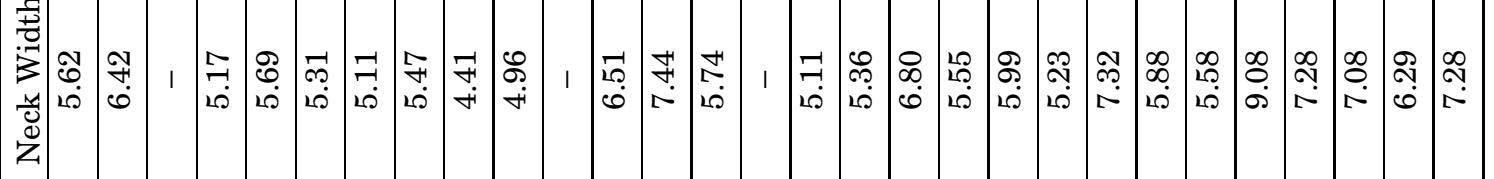

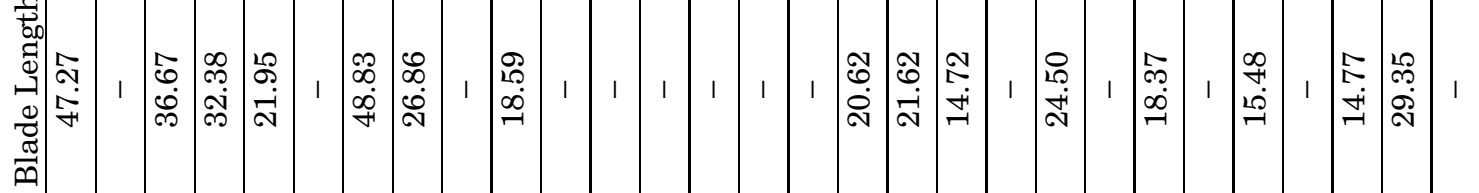

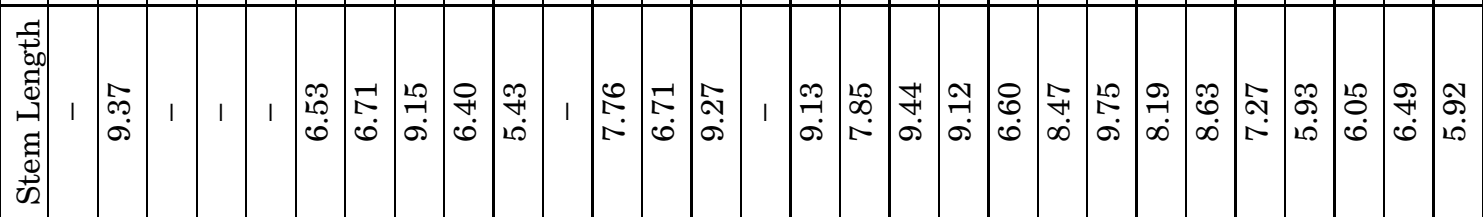

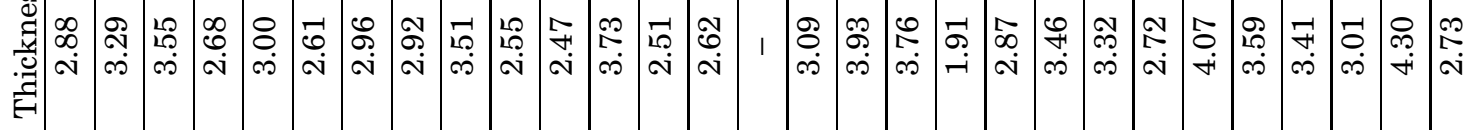

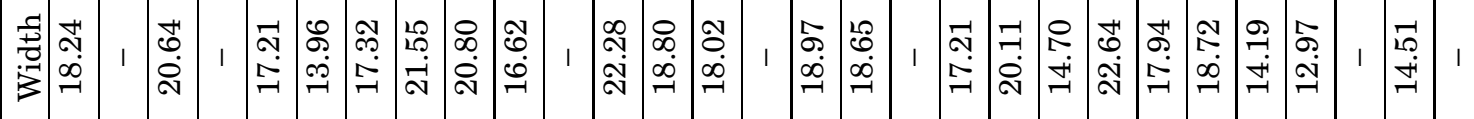

\begin{tabular}{|c|c|c|c|c|c|c|c|c|c|c|c|c|c|c|c|c|c|c|c|c|c|c|c|c|c|c|c|c|}
\hline & 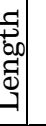 & & 1 & 1 & 1 & 1 & I & $\mid \begin{array}{l}4 \\
10 \\
10 \\
10 \\
10\end{array}$ & $\mid \begin{array}{l}\overrightarrow{0} \\
\dot{0} \\
\dot{\infty}\end{array}$ & 1 & 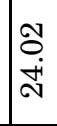 & 1 & 1 & 1 & 1 & 1 & 1 & 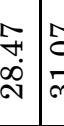 & 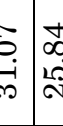 & ذ. & 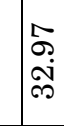 & 1 & $\mid \begin{array}{l}0 \\
20 \\
\dot{0} \\
\stackrel{0}{N}\end{array}$ & 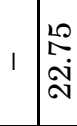 & 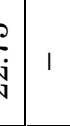 & $\begin{array}{l}\infty \\
\infty \\
\dot{\mathcal{N}} \\
\dot{\mathcal{N}}\end{array}$ & 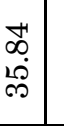 & 1 \\
\hline & $\begin{array}{l}0 \\
0 \\
0 \\
0 \\
0 \\
0 \\
0 \\
0 \\
\vdots \\
0 \\
0\end{array}$ & 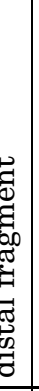 & 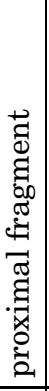 & 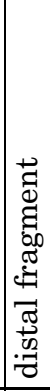 & 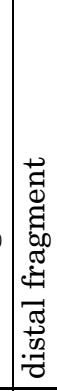 & 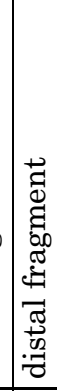 & 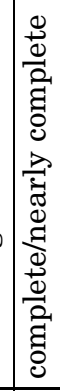 & 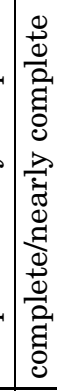 & 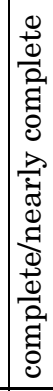 & 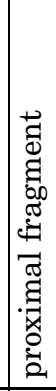 & 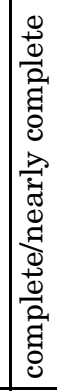 & 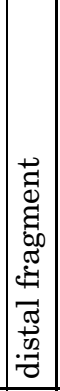 & 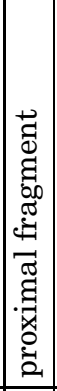 & 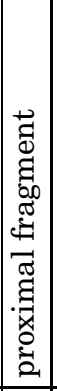 & 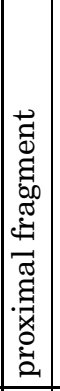 & 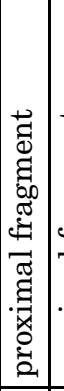 & 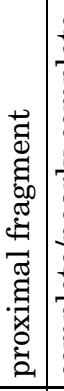 & 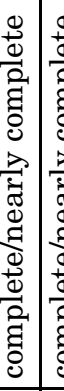 & 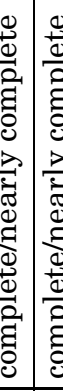 & 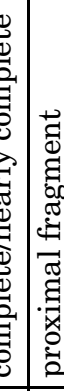 & 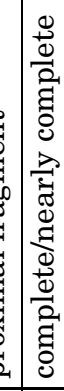 & 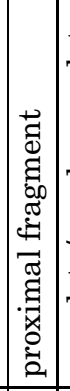 & 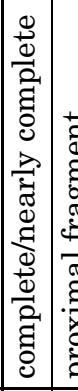 & 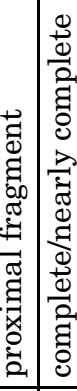 & 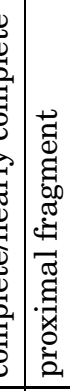 & 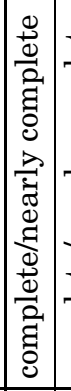 & 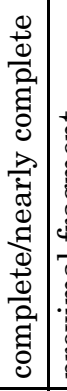 & 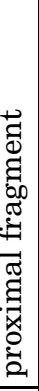 \\
\hline & | & & & 으 & & & & $\frac{\pi}{\Delta}$ & $\stackrel{\sigma}{\Delta}$ & & & & & & & 尔 & & & & & $\vec{N}$ & & & & & & $\stackrel{9}{\rightarrow}$ & \\
\hline & 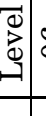 & ๑ & 8 & 18 & 8 & 5 & $\infty$ & 5 & $\%$ & $\infty$ & $\%$ & 5 & $\infty$ & 동 & 5 & 5 & 5 & 5 & 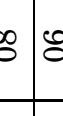 & 8 & 35 & 동 & 5 & $50^{\infty}$ & : & 8 & 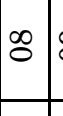 & 8 \\
\hline & tiv & & $\stackrel{\bullet}{\stackrel{v}{*}}$ & $\stackrel{\bullet}{\circ}$ & $\stackrel{F}{+}$ & م & ঙิ & $\stackrel{\Re}{\mathfrak{G}}$ & $\stackrel{\text { Iึ }}{\text { ำ }}$ & $\vec{m}$ & 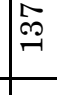 & $\vec{F}$ & $\underset{\mathscr{I}}{\sim}$ & - & $\mid \begin{array}{l}\mathscr{0} \\
\infty \\
-1\end{array}$ & 옴 & $\stackrel{\infty}{\stackrel{一}{\sim}}$ & + & $+\infty$ & 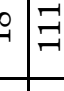 & $\stackrel{\mathscr{N}}{\sim}$ & $\stackrel{\infty}{\infty}$ & $\mathscr{\sim}$ & ऽ્ & $\hbar \hat{\sim}$ & 尔 & F & L̊ \\
\hline & & & $\stackrel{\pi}{\approx}$ & ש6 & $\stackrel{\pi}{\frac{\pi}{4}}$ & & 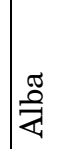 & 疍 & 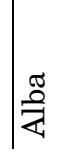 & $\stackrel{\pi}{\frac{\pi}{4}}$ & 胥 & $\frac{\pi}{0}$ & & $\mid$ & $\left|\begin{array}{c}\pi \\
\stackrel{\bar{\psi}}{4}\end{array}\right|$ & 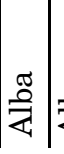 & $\stackrel{\widetilde{\pi}}{\stackrel{4}{4}}$ & 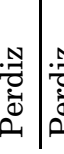 & $\begin{array}{ll}0 \\
0 \\
0\end{array}$ & 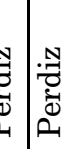 & 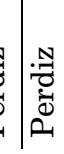 & $\mid$ & 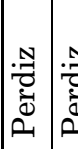 & 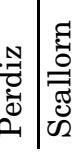 & 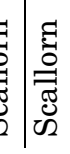 & 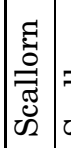 & 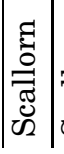 & 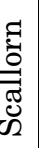 \\
\hline
\end{tabular}




\begin{tabular}{|c|c|c|c|c|c|c|c|c|c|c|c|c|c|c|c|c|c|c|c|c|c|c|c|c|c|}
\hline 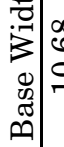 & $\begin{array}{lll}0 \\
\dot{b} \\
\dot{4} & 0 \\
& \\
\end{array}$ & 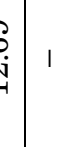 & 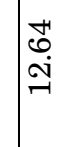 & $\mid \begin{array}{l}+ \\
\stackrel{2}{0} \\
0\end{array}$ & 1 & 1 & 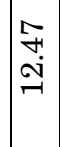 & 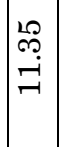 & $\begin{array}{l}\infty \\
\infty \\
\infty \\
\infty\end{array}$ & 1 & 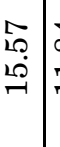 & 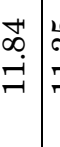 & 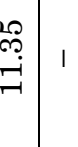 & 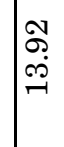 & $\left|\begin{array}{c}\stackrel{g}{H} \\
\stackrel{\mathfrak{I}}{-}\end{array}\right|$ & $1 \mid \begin{array}{l}\nabla \\
\sigma\end{array}$ & 1 & 1 & \begin{tabular}{l|l}
1 & 1
\end{tabular} & \begin{tabular}{l|l}
1 & 1
\end{tabular} & 1 & 1 & I & & \\
\hline 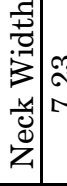 & 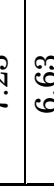 & \begin{tabular}{l|l}
$:$ \\
$\dot{0}$ \\
\end{tabular} & $\mid \begin{array}{l}\text { f } \\
0\end{array}$ & $\mid \begin{array}{l}\mathcal{N} \\
\infty \\
\dot{0}\end{array}$ & 芦 & \begin{tabular}{|l|}
1 \\
10 \\
10 \\
10
\end{tabular} & 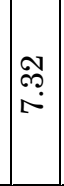 & \begin{tabular}{|l}
$\vec{A}$ \\
$\oplus$ \\
$\oplus$
\end{tabular} & $\mid \begin{array}{c}\infty \\
0 \\
0 \\
0\end{array}$ & $\begin{array}{l}\mathscr{\ell} \\
\dot{0} \\
0\end{array}$ & \begin{tabular}{l}
$\infty$ \\
\multirow{2}{*}{} \\
$\vdots$
\end{tabular} \mid & $\begin{array}{l}\stackrel{2}{D} \\
\dot{0}\end{array}$ & 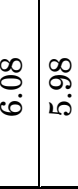 & $\mid \begin{array}{l}\mathbb{N} \\
20\end{array}$ & $\left|\begin{array}{l}\infty \\
\infty \\
20\end{array}\right|$ & \begin{tabular}{l|l}
$\infty$ & 1 \\
0 & 1 \\
0 & 1
\end{tabular} & 1 & 1 & \begin{tabular}{l|l}
1 & 1
\end{tabular} & 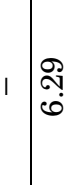 & 1 & 1 & I & & \\
\hline 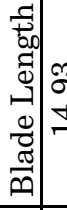 & & I & 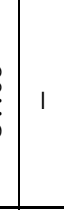 & 1 & 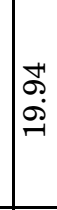 & $\begin{array}{l}\stackrel{8}{ } \\
\infty \\
\infty \\
\stackrel{0}{*}\end{array}$ & $\mid \begin{array}{l}\qquad \\
\stackrel{\Xi}{*} \\
\stackrel{+}{*}\end{array}$ & 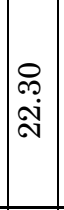 & 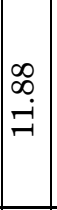 & 1 & 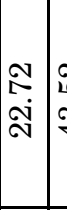 & 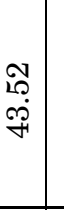 & \begin{tabular}{l|l}
1 & 1
\end{tabular} & 1 & 1 & 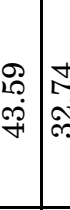 & 1 & 1 & \begin{tabular}{l|l}
1 & 1
\end{tabular} & । 1 尽 & 1 & 1 & I & I & \\
\hline 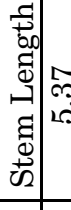 & 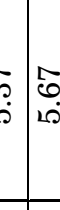 & \begin{tabular}{l|l} 
\\
$\dot{0}$ & $\stackrel{0}{0}$
\end{tabular} & $\mid \begin{array}{l}0 \\
-1 \\
\infty\end{array}$ & $\mid \begin{array}{l}\infty \\
10 \\
10 \\
10\end{array}$ & $\mid \begin{array}{l}\mathcal{N} \\
\infty \\
\dot{\alpha} \\
\dot{0}\end{array}$ & $\mid \begin{array}{l}\qquad \\
\stackrel{6}{*} \\
+\end{array}$ & $\left|\begin{array}{l}\mathscr{0} \\
\dot{0} \\
\dot{\Omega}\end{array}\right|$ & $\mid \begin{array}{l}\mathscr{0} \\
\dot{0} \\
\dot{0} \\
10\end{array}$ & $\mid \begin{array}{l}\approx \\
0 \\
\dot{0}\end{array}$ & هit & \begin{tabular}{|c|}
$\infty$ \\
0 \\
0 \\
0
\end{tabular} & $\begin{array}{l}\overrightarrow{5} \\
\text { के }\end{array}$ & \begin{tabular}{l|l}
1 & 1
\end{tabular} & $\mid \begin{array}{l}0 \\
0 \\
0\end{array}$ & 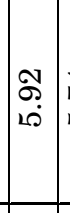 & 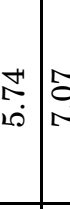 & 1 & 1 & \begin{tabular}{l|l}
1 & 1
\end{tabular} & \begin{tabular}{l|l}
1 & 1
\end{tabular} & 1 & 1 & I & & \\
\hline
\end{tabular}

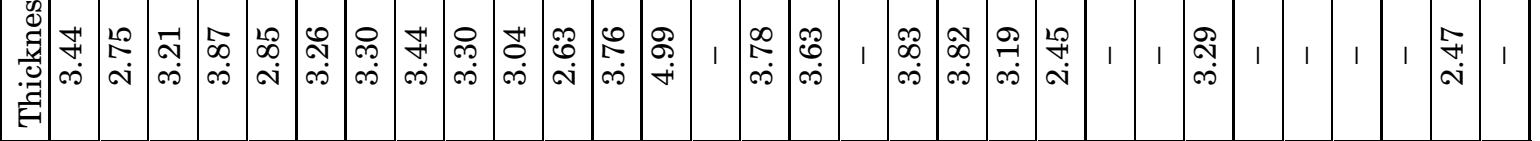

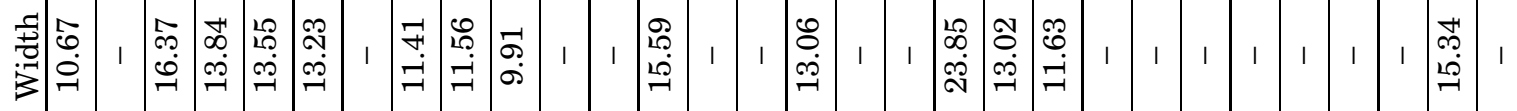

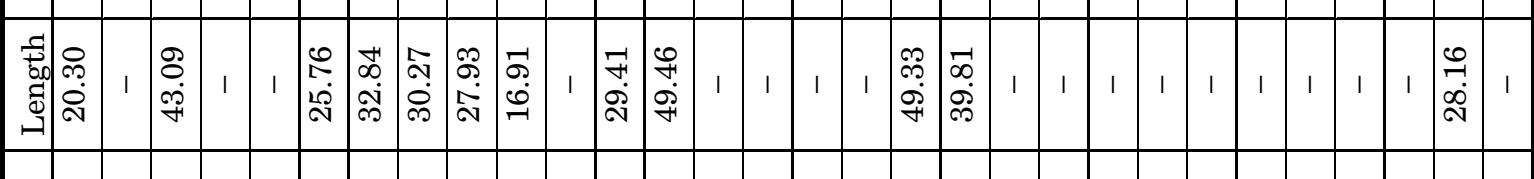

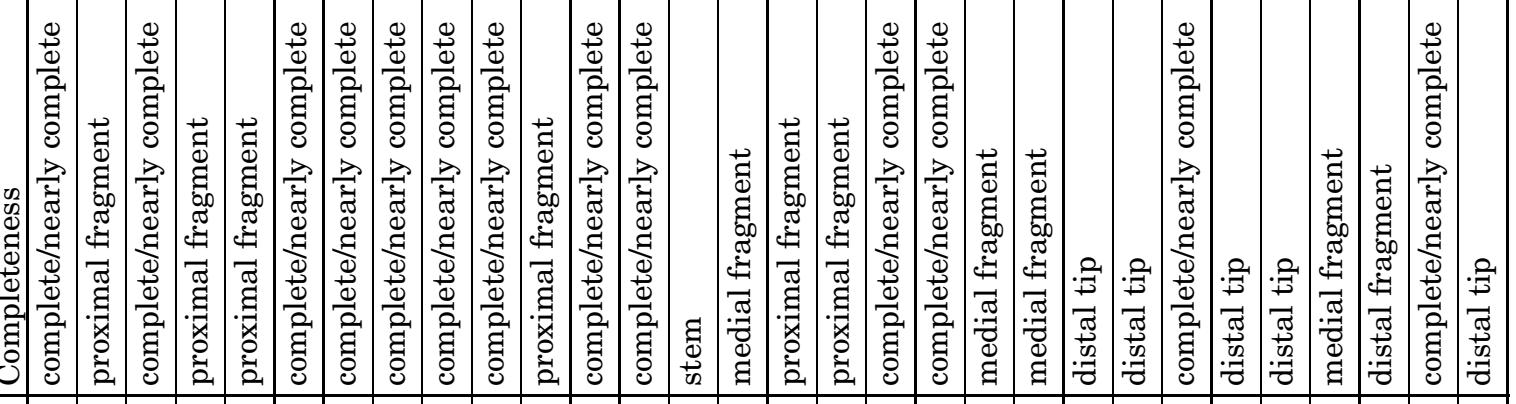

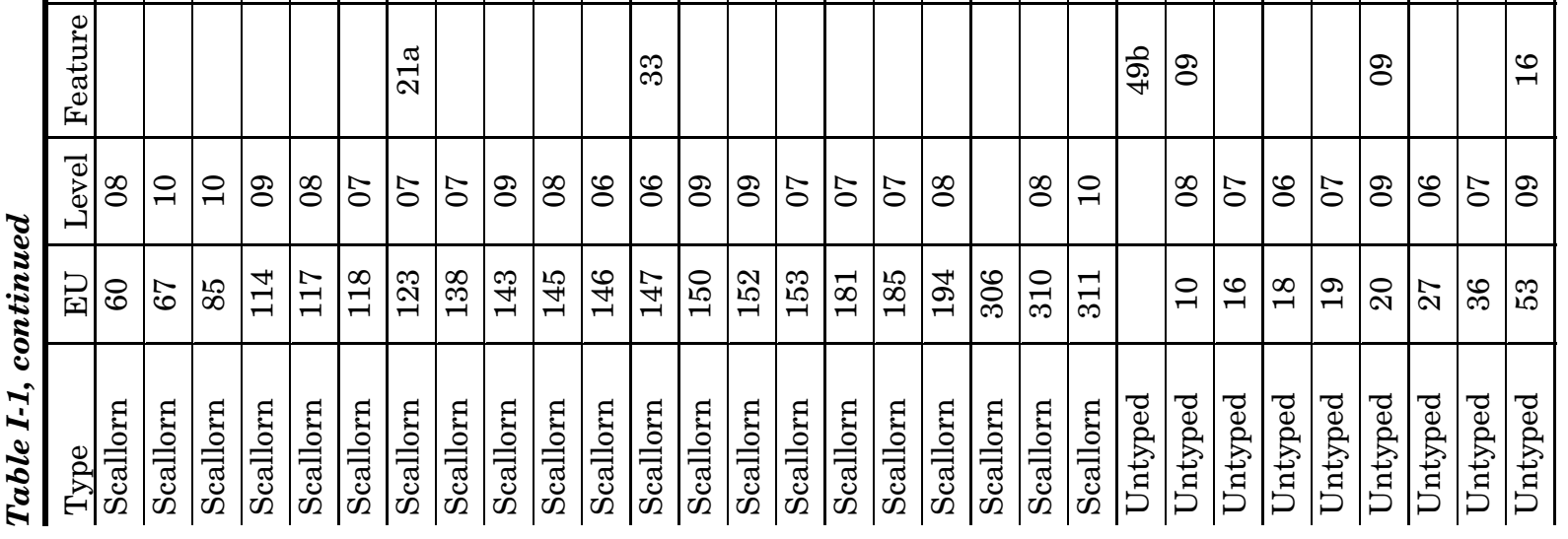


Appendix I: Metric Data for Stone Tools

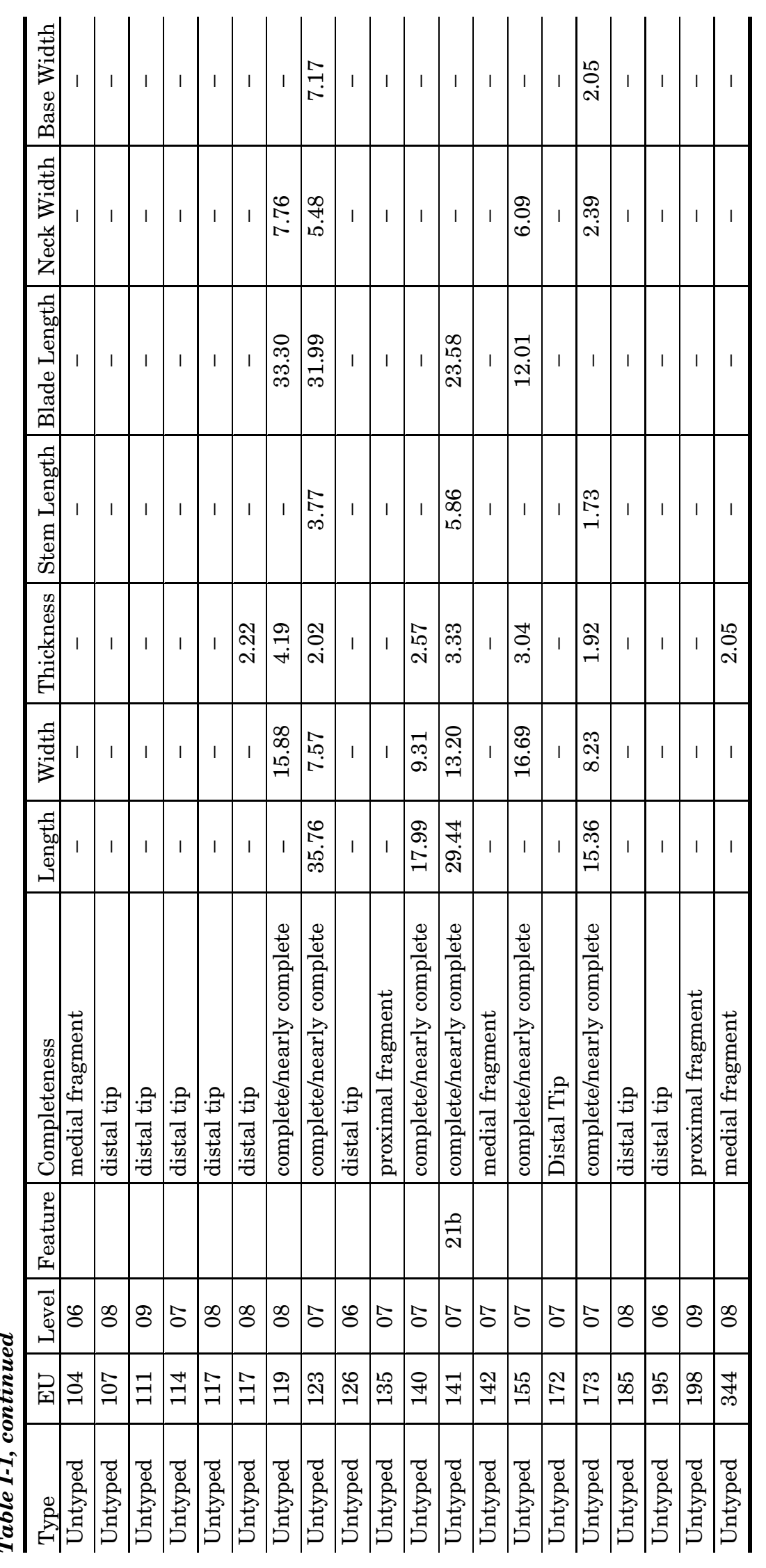


Data Recovery Excavations at the J. B. White Site

Table I-2. Arrow point preform metric data (in mm)

\begin{tabular}{|c|c|c|c|c|c|c|c|}
\hline Tool Type & EU & Level & Feature & Stem Edge/Base Shape & Length & Width & Thickness \\
\hline Arrow Preform & 13 & 07 & & Straight/Convex & - & 27.90 & 3.76 \\
\hline Arrow Preform & 16 & 07 & & - & - & 21.09 & 3.97 \\
\hline Arrow Preform & 16 & 07 & & Straight/Convex & - & 23.86 & 7.18 \\
\hline Arrow Preform & 20 & 08 & 09 & - & - & 21.46 & 4.47 \\
\hline Arrow Preform & 22 & 08 & 09 & Contracting/Rounded & - & 22.44 & 4.79 \\
\hline Arrow Preform & 27 & 06 & & - & - & - & - \\
\hline Arrow Preform & 29 & 07 & & - & - & - & 4.19 \\
\hline Arrow Preform & 30 & 08 & & Contracting/Rounded & - & 25.90 & 4.59 \\
\hline Arrow Preform & 33 & 08 & & Contracting/Rounded & - & 16.66 & 4.60 \\
\hline Arrow Preform & 52 & 08 & 09 & Straight/Straight & 53.25 & 19.08 & 4.53 \\
\hline Arrow Preform & 54 & 08 & 16 & - & - & - & - \\
\hline Arrow Preform & 54 & 09 & 16 & Contracting/Rounded & 56.30 & 26.52 & 5.98 \\
\hline Arrow Preform & 60 & 09 & & Straight/Straight & - & 26.63 & 4.21 \\
\hline Arrow Preform & 66 & 09 & & Straight/Convex & - & 18.18 & 4.44 \\
\hline Arrow Preform & 66 & 09 & & Contracting/Rounded & 45.45 & 25.35 & 6.05 \\
\hline Arrow Preform & 75 & 09 & & - & - & - & 4.37 \\
\hline Arrow Preform & 76 & 09 & & - & - & - & - \\
\hline Arrow Preform & 116 & 06 & & - & - & - & 2.57 \\
\hline Arrow Preform & 117 & 07 & & - & - & - & 3.33 \\
\hline Arrow Preform & 117 & 07 & & Straight/Convex & 33.45 & 22.60 & 6.13 \\
\hline Arrow Preform & 117 & 09 & & Flaring/Convex & 43.67 & 14.64 & 4.10 \\
\hline Arrow Preform & 118 & 07 & & Straight/Convex & 35.59 & 21.25 & 4.75 \\
\hline Arrow Preform & 121 & 07 & $21 \mathrm{~b}$ & Contracting/Rounded & - & 25.16 & 4.69 \\
\hline Arrow Preform & 125 & 07 & & - & - & - & 3.50 \\
\hline Arrow Preform & 126 & 06 & & Contracting/Rounded & - & 24.57 & 3.54 \\
\hline Arrow Preform & 126 & 06 & & - & - & - & - \\
\hline Arrow Preform & 131 & 08 & & - & - & - & 2.43 \\
\hline Arrow Preform & 134 & 06 & & Contracting/Rounded & - & 25.84 & 4.07 \\
\hline Arrow Preform & 135 & 06 & & Flaring/Convex & 43.17 & 22.95 & 3.56 \\
\hline Arrow Preform & 137 & 06 & & Contracting/Rounded & 28.73 & 19.84 & 4.35 \\
\hline Arrow Preform & 137 & 07 & & Flaring/Convex & - & 13.44 & 2.96 \\
\hline Arrow Preform & 138 & 06 & & - & - & - & - \\
\hline Arrow Preform & 138 & 07 & & Straight/Convex & 49.55 & 24.75 & 4.61 \\
\hline Arrow Preform & 138 & 08 & & Flaring/Convex & - & 12.79 & 2.89 \\
\hline Arrow Preform & 141 & 07 & & - & 32.26 & 22.55 & 6.96 \\
\hline Arrow Preform & 142 & 08 & & Flaring/Convex & 39.97 & 21.92 & 3.59 \\
\hline Arrow Preform & 143 & 07 & & Flaring/Convex & - & 23.63 & 3.72 \\
\hline Arrow Preform & 145 & 08 & & Contracting/Straight & - & 20.85 & 4.48 \\
\hline Arrow Preform & 147 & 07 & & - & - & - & 3.05 \\
\hline Arrow Preform & 148 & 07 & & Straight/Convex & 55.44 & 20.63 & 4.51 \\
\hline Arrow Preform & 148 & 07 & & - & - & - & - \\
\hline Arrow Preform & 149 & 07 & & Contracting/Rounded & 39.83 & 21.92 & 4.40 \\
\hline
\end{tabular}


Appendix I: Metric Data for Stone Tools

Table I-2, continued

\begin{tabular}{l|c|c|c|l|c|c|c}
\hline Tool Type & EU & Level & Feature & Stem Edge/Base Shape & Length & Width & Thickness \\
\hline Arrow Preform & 153 & 09 & & Contracting/Straight & 58.82 & 18.52 & 5.28 \\
\hline Arrow Preform & 161 & 07 & & - & - & - & 2.60 \\
\hline Arrow Preform & 171 & 07 & & - & - & - & 3.17 \\
\hline Arrow Preform & 171 & 07 & & - & - & 23.00 & 3.33 \\
\hline Arrow Preform & 172 & 06 & & - & - & - & 3.75 \\
\hline Arrow Preform & 174 & 07 & & Flaring/Convex & - & - & - \\
\hline Arrow Preform & 174 & 07 & & Flaring/Convex & 36.98 & 22.56 & 3.34 \\
\hline Arrow Preform & 177 & 07 & & Contracting/Rounded & - & - & 4.91 \\
\hline Arrow Preform & 183 & 06 & & Flaring/Convex & 35.80 & 21.03 & 4.83 \\
\hline Arrow Preform & 183 & 08 & & Straight/Convex & - & 17.57 & 3.63 \\
\hline Arrow Preform & 185 & 08 & & Straight/Convex & - & 18.92 & 5.03 \\
\hline Arrow Preform & 185 & 09 & & - & - & - & 2.76 \\
\hline Arrow Preform & 188 & 07 & & Flaring/Convex & 28.10 & 21.10 & 4.02 \\
\hline Arrow Preform & 188 & 07 & & Straight/Convex & - & 20.22 & 3.64 \\
\hline Arrow Preform & 188 & 07 & & Flaring/Convex & - & 19.71 & 4.48 \\
\hline Arrow Preform & 191 & 06 & & Contracting/Rounded & - & 30.59 & 5.53 \\
\hline Arrow Preform & 198 & 07 & & - & - & - & 2.70 \\
\hline Arrow Preform & 311 & 10 & & Contracting/Straight & - & 20.79 & 5.20 \\
\hline
\end{tabular}


Data Recovery Excavations at the J. B. White Site

\begin{tabular}{|c|c|c|c|c|c|c|c|c|c|c|c|c|c|c|c|c|c|c|}
\hline & & & & & 1 & $\begin{array}{l}\mathscr{\rho} \\
\stackrel{2}{9} \\
\stackrel{9}{9}\end{array}$ & 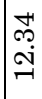 & 1 & 1 & 1 & 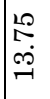 & 1 & 1 & 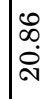 & & 1 & 1 & |l \\
\hline $\begin{array}{l}\infty \\
\infty \\
c\end{array}$ & & & & $\begin{array}{l}\text { 엄 } \\
\text { İ }\end{array}$ & 1 & פִ & $\begin{array}{l}\stackrel{\Im}{\Im} \\
\stackrel{\leftrightarrow}{\rightarrow}\end{array}$ & 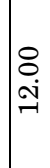 & 1 & 1 & $\underset{\sim}{\stackrel{\Omega}{二}}$ & $\begin{array}{l}\mathcal{O} \\
\dot{0} \\
\\
-1\end{array}$ & $\mid$ & 1 & 1 & 1 & 1 & 1 \\
\hline & 8 & & I & 1 & 1 & 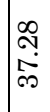 & 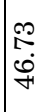 & 1 & 1 & 1 & 1 & 1 & 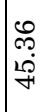 & 1 & 1 & 1 & 1 & 1 \\
\hline & 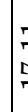 & & & ְִ & 1 & $\begin{array}{l}\text { N } \\
\stackrel{0}{\circ}\end{array}$ & $\stackrel{\infty}{\stackrel{-}{\rightleftarrows}}$ & 1 & 1 & 1 & 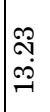 & $\begin{array}{l}\infty \\
\infty \\
\dot{\infty}\end{array}$ & $\vec{b}_{\infty}^{-1}$ & 1 & 1 & 1 & 1 & 1 \\
\hline $\mathscr{\sigma}$ & 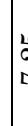 & & 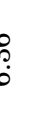 & 울. & $\mid \begin{array}{l}8 \\
\dot{0}\end{array}$ & $\begin{array}{l}\stackrel{9}{7} \\
\dot{0}\end{array}$ & \begin{tabular}{|l}
$\overrightarrow{5}$ \\
$\dot{0}$
\end{tabular} & 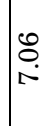 & $\mid \begin{array}{l}50 \\
100 \\
100\end{array}$ & $\mid \begin{array}{l}\mathscr{\theta} \\
\dot{+}\end{array}$ & $\stackrel{-}{-1}$ & 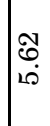 & ஓं & $\begin{array}{l}\hat{s} \\
0 \\
0 \\
0\end{array}$ & 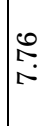 & 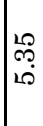 & 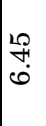 & 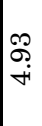 \\
\hline & & & & 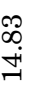 & 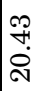 & $\begin{array}{l}\infty \\
\infty \\
\stackrel{\sim}{\infty} \\
\stackrel{\infty}{0}\end{array}$ & $\begin{array}{l}\stackrel{0}{0} \\
\stackrel{\text { वे }}{2}\end{array}$ & 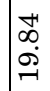 & I & 1 & 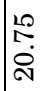 & $\begin{array}{l}\infty \\
\stackrel{\infty}{0} \\
\dot{\sim}\end{array}$ & $\mid \begin{array}{l}\Delta \\
0 \\
\stackrel{0}{0} \\
\text { an }\end{array}$ & 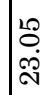 & 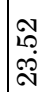 & 1 & $\mid \begin{array}{l}\infty \\
\infty \\
\infty \\
\infty \\
\infty \\
\end{array}$ & 1 \\
\hline$\left[\begin{array}{l}\alpha \\
\infty \\
\infty\end{array}\right.$ & $\vdots$ & & I & 1 & 1 & $\begin{array}{l}20 \\
0 \\
\infty \\
\infty \\
\infty\end{array}$ & 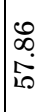 & I & 1 & 1 & 1 & 1 & 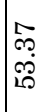 & \begin{tabular}{|l}
100 \\
100 \\
0 \\
0 \\
0
\end{tabular} & 1 & 1 & 1 & 1 \\
\hline 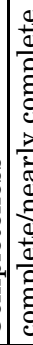 & & & 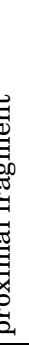 & 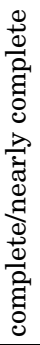 & 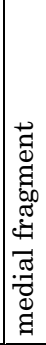 & 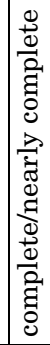 & 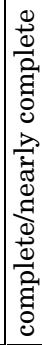 & 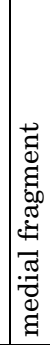 & 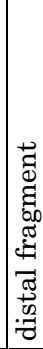 & 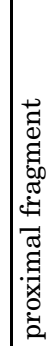 & 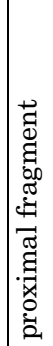 & 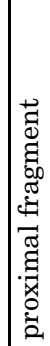 & 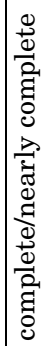 & 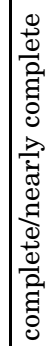 & 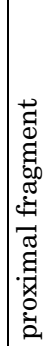 & 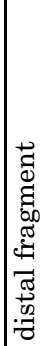 & 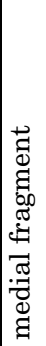 & 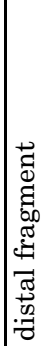 \\
\hline & & & 8 & & & 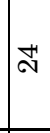 & & त्न & & & & & & & & & & \\
\hline & & & $B$ & \& & $\infty_{0}^{\infty}$ & 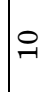 & $\stackrel{ }{-}$ & 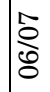 & $\infty^{\infty}$ & 8 & 응 & $\stackrel{9}{\circ}$ & $\exists$ & $\mathcal{F}$ & $\infty$ & $\stackrel{\infty}{\circ}$ & 8 & 8 \\
\hline & & & 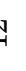 & $\stackrel{m}{\rightarrow}$ & 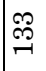 & $\overrightarrow{\underline{B}}$ & $\overrightarrow{0}$ & $\underset{\sim}{\mathbb{N}}$ & 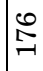 & $\mid \begin{array}{l}\infty \\
-\infty\end{array}$ & 严 & $\frac{\infty}{\infty}$ & 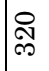 & $\infty$ & $\underset{-}{\stackrel{H}{ }}$ & $\stackrel{\text { ঞ }}{\sharp}$ & 落 & 崩 \\
\hline & & & E & $\begin{array}{l}\mathbb{8} \\
\end{array}$ & 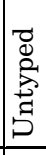 & 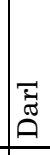 & 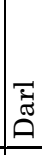 & 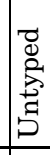 & 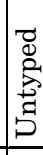 & 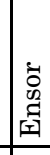 & \begin{tabular}{|l}
$\overline{\tilde{\sigma}}$ \\
$\stackrel{\text { I. }}{ }$
\end{tabular} & \begin{tabular}{|l}
$\overrightarrow{\tilde{\tilde{\sigma}}}$ \\
$\stackrel{\Omega}{\mid}$
\end{tabular} & 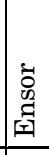 & 1 & 1 & 1 & 1 & 1 \\
\hline & & & 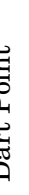 & D. & 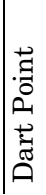 & 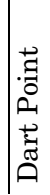 & 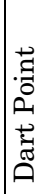 & 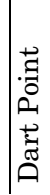 & 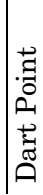 & 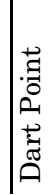 & 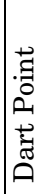 & 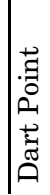 & 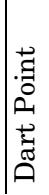 & 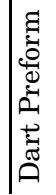 & 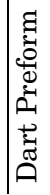 & 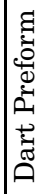 & 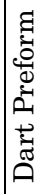 & 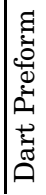 \\
\hline
\end{tabular}


Table I-4. Knife metric data (in mm)

\begin{tabular}{|c|c|c|c|c|c|c|c|c|}
\hline Tool Type & EU & Level & Feature & Completeness & Length & Width & Thickness & $\begin{array}{c}\text { Base } \\
\text { Width }\end{array}$ \\
\hline Knife & 3 & 13 & & medial fragment & - & - & 5.16 & - \\
\hline Knife & 11 & 10 & & proximal fragment & - & - & 7.21 & - \\
\hline Knife & 41 & 08 & 16 & proximal fragment & - & 26.06 & 3.86 & - \\
\hline Knife & 77 & 09 & & complete/nearly complete & 78.56 & 21.31 & 6.10 & 31.54 \\
\hline Knife & 102 & 08 & & distal fragment & - & 24.50 & 3.84 & - \\
\hline Knife & 105 & 07 & & medial fragment & - & - & 6.60 & - \\
\hline Knife & 105 & 07 & & medial fragment & - & - & 6.42 & - \\
\hline Knife & 112 & 07 & & proximal fragment & - & - & 5.70 & 29.94 \\
\hline Knife & 118 & 07 & & medial fragment & - & - & 4.66 & - \\
\hline Knife & 118 & 07 & & medial fragment & - & - & 2.89 & - \\
\hline Knife & 119 & 08 & & complete/nearly complete & 95.84 & 36.73 & 6.18 & 30.04 \\
\hline Knife & 128 & 08 & & medial fragment & - & - & 4.67 & - \\
\hline Knife & 131 & 08 & & distal fragment & - & - & 3.67 & - \\
\hline Knife & 131 & 08 & & proximal fragment & - & 32.35 & 8.35 & - \\
\hline Knife & 134 & 06 & $21 \mathrm{a}$ & medial fragment & - & 24.27 & 6.95 & - \\
\hline Knife & 136 & 06 & & proximal fragment & - & 0.00 & 4.26 & - \\
\hline Knife & 137 & 06 & & proximal fragment & - & - & 3.78 & - \\
\hline Knife & 137 & 06 & & complete/nearly complete & 103.57 & 27.01 & 5.44 & 26.69 \\
\hline Knife & 141 & 07 & & complete/nearly complete & 55.68 & 29.30 & 7.08 & - \\
\hline Knife & 145 & 06 & & distal tip & - & - & 3.01 & - \\
\hline Knife & 145 & 07 & & proximal fragment & - & 27.08 & 5.38 & 25.15 \\
\hline Knife & 145 & 08 & & medial fragment & - & 25.90 & 3.52 & - \\
\hline Knife & 157 & 07 & & distal fragment & - & - & 4.85 & - \\
\hline Knife & 171 & 07 & $21 b$ & distal fragment & - & - & 4.76 & - \\
\hline Knife & 175 & 08 & & distal fragment & - & - & 4.25 & - \\
\hline Knife & 184 & 08 & & complete/nearly complete & 82.47 & 21.52 & 4.60 & 25.98 \\
\hline Knife & 184 & 08 & & longitudinal & - & - & 4.86 & - \\
\hline Knife & 188 & 06 & & proximal fragment & - & 34.81 & 5.83 & 42.24 \\
\hline Knife & 195 & 07 & & proximal fragment & - & - & 3.57 & - \\
\hline Knife & 196 & 07 & & proximal fragment & - & - & 5.30 & 29.46 \\
\hline Knife & 220 & 09 & & distal fragment & - & - & 4.08 & - \\
\hline
\end{tabular}


Data Recovery Excavations at the J. B. White Site

Table I-5. Knife preform metric data (in $\mathbf{~ m m}$ )

\begin{tabular}{|c|c|c|c|c|c|c|c|c|}
\hline Tool Type & EU & Level & Feature & Completeness & Length & Width & Thickness & $\begin{array}{l}\text { Base } \\
\text { Width }\end{array}$ \\
\hline Knife Preform & 16 & 06 & & proximal fragment & - & - & 5.02 & 31.28 \\
\hline Knife Preform & 30 & 09 & & distal fragment & - & - & 4.95 & - \\
\hline Knife Preform & 75 & 09 & & proximal fragment & - & - & - & - \\
\hline Knife Preform & 76 & 08 & & complete/nearly complete & 91.09 & 31.27 & 5.12 & 29.48 \\
\hline Knife Preform & 111 & 08 & 17 & proximal fragment & - & 37.25 & 8.17 & 34.87 \\
\hline Knife Preform & 113 & 06 & & distal fragment & - & - & 5.77 & - \\
\hline Knife Preform & 118 & 07 & & medial fragment & - & - & 5.30 & - \\
\hline Knife Preform & 121 & 07 & & proximal fragment & - & - & 4.46 & - \\
\hline Knife Preform & 123 & 07 & $21 \mathrm{a}$ & proximal fragment & - & 30.72 & 5.25 & 26.10 \\
\hline Knife Preform & 136 & 06 & & distal fragment & - & - & 5.16 & - \\
\hline Knife Preform & 136 & 07 & & complete/nearly complete & 107.15 & 38.61 & 13.71 & 44.19 \\
\hline Knife Preform & 137 & 06 & 33 & proximal fragment & - & - & 6.40 & - \\
\hline Knife Preform & 142 & 08 & & distal fragment & - & - & 5.35 & - \\
\hline Knife Preform & 143 & 07 & $21 \mathrm{a}$ & distal fragment & - & - & 5.85 & - \\
\hline Knife Preform & 143 & 08 & & medial fragment & - & 49.14 & 5.42 & - \\
\hline Knife Preform & 143 & 08 & & distal fragment & - & - & 4.82 & - \\
\hline Knife Preform & 158 & 06 & & distal fragment & - & - & 6.35 & - \\
\hline Knife Preform & 171 & 07 & $21 b$ & distal fragment & - & - & 4.12 & - \\
\hline Knife Preform & 171 & 07 & & distal fragment & - & - & 7.95 & - \\
\hline Knife Preform & 180 & 09 & & proximal fragment & - & 44.82 & 8.66 & - \\
\hline Knife Preform & 183 & $06 / 07$ & $21 \mathrm{a}$ & distal fragment & - & - & 7.50 & - \\
\hline Knife Preform & 191 & 07 & & proximal fragment & - & 42.99 & 9.45 & - \\
\hline Knife Preform & 196 & 07 & & medial fragment & - & - & 10.73 & - \\
\hline Knife Preform & 198 & 07 & & distal fragment & - & 39.42 & 10.81 & - \\
\hline
\end{tabular}


Table I-6. Other formal chipped stone tool metric data (in mm)

\begin{tabular}{|c|c|c|c|c|c|c|}
\hline Tool Type & EU & Level & Feature & Length & Width & Thickness \\
\hline Adze & & & & - & 43.62 & 8.46 \\
\hline Adze & 38 & 07 & & 41.10 & 46.40 & 11.90 \\
\hline Adze & 45 & 06 & & 43.20 & 48.70 & 12.40 \\
\hline Adze & 131 & 07 & $21 b$ & 43.80 & 39.80 & 15.60 \\
\hline Adze & 134 & 08 & & 64.50 & 57.80 & 17.60 \\
\hline Adze & 136 & 07 & & - & - & 7.52 \\
\hline$\overline{\text { Adze }}$ & 157 & 07 & & 56.50 & 40.70 & 13.70 \\
\hline Adze & 196 & 07 & & 49.20 & 36.10 & 12.90 \\
\hline Awl & 20 & 09 & 09 & 64.70 & 46.70 & 19.50 \\
\hline Awl & 141 & 07 & $21 b$ & - & - & 11.60 \\
\hline Chopper & 59 & 10 & & 107.00 & 56.80 & 19.60 \\
\hline Chopper & 101 & 10 & & 61.70 & 54.80 & 43.10 \\
\hline Chopper & 153 & 09 & & 76.40 & 67.40 & 30.90 \\
\hline Chopper & 188 & 08 & & 65.30 & 63.70 & 28.70 \\
\hline Chopper & 195 & 07 & & 85.00 & 67.30 & 26.50 \\
\hline Chopper & 320 & 11 & & 79.80 & 58.20 & 33.60 \\
\hline Early-Stage Biface & 11 & 06 & 10 & 52.70 & 33.10 & 7.80 \\
\hline Early-Stage Biface & 12 & 08 & 09 & - & 28.68 & 5.49 \\
\hline Early-Stage Biface & 14 & 06 & & 103.40 & 69.00 & 19.60 \\
\hline Early-Stage Biface & 15 & 06 & 10 & - & - & 6.88 \\
\hline Early-Stage Biface & 39 & 06 & & - & - & 12.20 \\
\hline Early-Stage Biface & 50 & 09 & 09 & - & - & 10.03 \\
\hline Early-Stage Biface & 54 & 07 & 14 & - & 46.88 & 14.50 \\
\hline Early-Stage Biface & 60 & 09 & & 60.30 & 35.20 & 13.20 \\
\hline Early-Stage Biface & 63 & 09 & 16 & - & 44.90 & 17.90 \\
\hline Early-Stage Biface & 104 & 08 & & - & - & 5.47 \\
\hline Early-Stage Biface & 114 & 07 & & - & - & 6.82 \\
\hline Early-Stage Biface & 114 & 08 & & - & - & 5.86 \\
\hline Early-Stage Biface & 116 & 07 & & - & 30.86 & 8.73 \\
\hline Early-Stage Biface & 117 & 06 & & - & - & 7.29 \\
\hline Early-Stage Biface & 117 & 06 & & - & - & 6.83 \\
\hline Early-Stage Biface & 122 & 08 & & - & - & 5.43 \\
\hline Early-Stage Biface & 124 & 08 & & - & - & 7.40 \\
\hline Early-Stage Biface & 128 & 08 & & 41.71 & 37.18 & 12.65 \\
\hline Early-Stage Biface & 128 & 10 & & - & - & 15.95 \\
\hline Early-Stage Biface & 144 & 07 & & 59.30 & 27.40 & 13.10 \\
\hline Early-Stage Biface & 148 & 07 & & 49.60 & 29.10 & 10.30 \\
\hline Early-Stage Biface & 155 & 07 & & - & 52.90 & 24.10 \\
\hline Early-Stage Biface & 173 & 07 & $21 b$ & 45.50 & 28.40 & 8.20 \\
\hline Early-Stage Biface & 175 & 08 & & - & - & 5.66 \\
\hline Early-Stage Biface & 188 & 08 & & - & 50.40 & 14.30 \\
\hline Early-Stage Biface & 189 & 07 & 44 & 38.40 & 25.90 & 9.10 \\
\hline
\end{tabular}


Data Recovery Excavations at the J. B. White Site

Table I-6, continued

\begin{tabular}{|c|c|c|c|c|c|c|}
\hline Tool Type & EU & Level & Feature & Length & Width & Thickness \\
\hline Early-Stage Biface & 193 & 07 & & - & 24.06 & 8.04 \\
\hline Early-Stage Biface & 194 & 07 & & - & 30.67 & 5.68 \\
\hline Early-Stage Biface & 195 & 07 & & 48.96 & 37.98 & 11.32 \\
\hline Early-Stage Biface & 310 & 10 & & - & 61.80 & 16.10 \\
\hline Early-Stage Biface & 312 & 10 & & - & - & - \\
\hline Gouge & 27 & 07 & & 59.90 & 40.00 & 22.50 \\
\hline Gouge & 70 & 07 & & 53.10 & 41.30 & 28.50 \\
\hline Gouge & 114 & 06 & & 63.50 & 50.60 & 27.20 \\
\hline Gouge & 115 & 09 & & 57.70 & 41.00 & 27.50 \\
\hline Gouge & 117 & 08 & & 51.30 & 32.70 & 16.10 \\
\hline Gouge & 117 & 08 & & 40.10 & 29.00 & 18.10 \\
\hline Gouge & 122 & 07 & $21 b$ & 30.80 & 51.30 & 28.50 \\
\hline Gouge & 128 & 08 & & 54.50 & 40.20 & 22.70 \\
\hline Gouge & 177 & 07 & $21 b$ & 70.70 & 34.50 & 32.80 \\
\hline Gouge & 186 & 06 & & 59.20 & 40.50 & 18.50 \\
\hline Graver & 19 & 07 & & 42.50 & 37.40 & 18.30 \\
\hline Graver & 142 & 07 & & 46.50 & 40.60 & 16.60 \\
\hline Graver & 152 & 09 & & 54.90 & 48.00 & 25.00 \\
\hline Graver & 153 & 09 & & 57.20 & 48.50 & 16.40 \\
\hline Hammerstone & 29 & 08 & 17 & 53.60 & 47.70 & 40.10 \\
\hline Hammerstone & 151 & 10 & & 63.20 & 52.20 & 54.00 \\
\hline Hammerstone & 161 & 10 & 24 & 65.20 & 62.40 & 48.50 \\
\hline Hammerstone/Chopper & 107 & 10 & 24 & 84.90 & 84.50 & 56.80 \\
\hline Hammerstone/Chopper & 139 & 09 & & 70.90 & 58.40 & 32.70 \\
\hline Hammerstone/Chopper & 161 & 10 & 24 & 97.10 & 67.50 & 40.40 \\
\hline Hammerstone/Chopper & 316 & 11 & & 82.30 & 54.30 & 45.00 \\
\hline Indeterminate Biface & 19 & 07 & & - & - & 3.44 \\
\hline Indeterminate Biface & 20 & 08 & & - & - & 8.27 \\
\hline Indeterminate Biface & 25 & 06 & 10 & 80.30 & 36.60 & 13.70 \\
\hline Indeterminate Biface & 29 & 07 & & - & - & 4.11 \\
\hline Indeterminate Biface & 30 & 08 & 09 & - & - & 3.38 \\
\hline Indeterminate Biface & 64 & 08 & 15 & - & - & 9.95 \\
\hline Indeterminate Biface & 76 & 09 & & 38.60 & 24.90 & 10.10 \\
\hline Indeterminate Biface & 85 & 09 & & - & - & 5.18 \\
\hline Indeterminate Biface & 101 & 10 & & - & - & 4.57 \\
\hline Indeterminate Biface & 110 & 06 & & - & - & 3.19 \\
\hline Indeterminate Biface & 114 & 06 & & 82.70 & 53.30 & 23.00 \\
\hline Indeterminate Biface & 117 & 07 & & - & - & 4.16 \\
\hline Indeterminate Biface & 118 & 08 & & - & - & 1.53 \\
\hline Indeterminate Biface & 130 & 08 & & - & - & 2.33 \\
\hline Indeterminate Biface & 136 & 06 & & - & - & 4.63 \\
\hline Indeterminate Biface & 136 & 06 & & 59.00 & 49.40 & 17.20 \\
\hline Indeterminate Biface & 137 & 06 & & - & - & 8.52 \\
\hline
\end{tabular}


Appendix I: Metric Data for Stone Tools

Table I-6, continued

\begin{tabular}{|c|c|c|c|c|c|c|}
\hline Tool Type & $\mathrm{EU}$ & Level & Feature & Length & Width & Thickness \\
\hline Indeterminate Biface & 145 & 08 & & - & 28.79 & 9.21 \\
\hline Indeterminate Biface & 148 & 07 & & - & - & 5.09 \\
\hline Indeterminate Biface & 149 & 08 & & 55.30 & 24.30 & 12.30 \\
\hline Indeterminate Biface & 157 & 08 & & - & - & 4.94 \\
\hline Indeterminate Biface & 171 & 07 & & - & - & - \\
\hline Indeterminate Biface & 171 & 08 & & - & - & 4.83 \\
\hline Indeterminate Biface & 174 & $06 / 07$ & $21 b$ & - & - & - \\
\hline Indeterminate Biface & 181 & 07 & & - & 18.96 & 3.33 \\
\hline Indeterminate Biface & 183 & $06 / 07$ & $21 \mathrm{a}$ & - & - & 5.05 \\
\hline Indeterminate Biface & 184 & 09 & & - & - & 4.88 \\
\hline Indeterminate Biface & 192 & 07 & & - & - & 4.90 \\
\hline Indeterminate Biface & 197 & 07 & & - & - & - \\
\hline Perforator & 141 & 07 & & 53.16 & 30.78 & 9.52 \\
\hline Perforator & 182 & 06 & & - & 22.66 & 6.05 \\
\hline Wedge & 152 & 10 & 24 & 60.20 & 53.30 & 19.90 \\
\hline Wedge & 160 & 09 & 20 & 69.90 & 45.70 & 23.10 \\
\hline
\end{tabular}



APPENDIX J: Radiocarbon Dates 



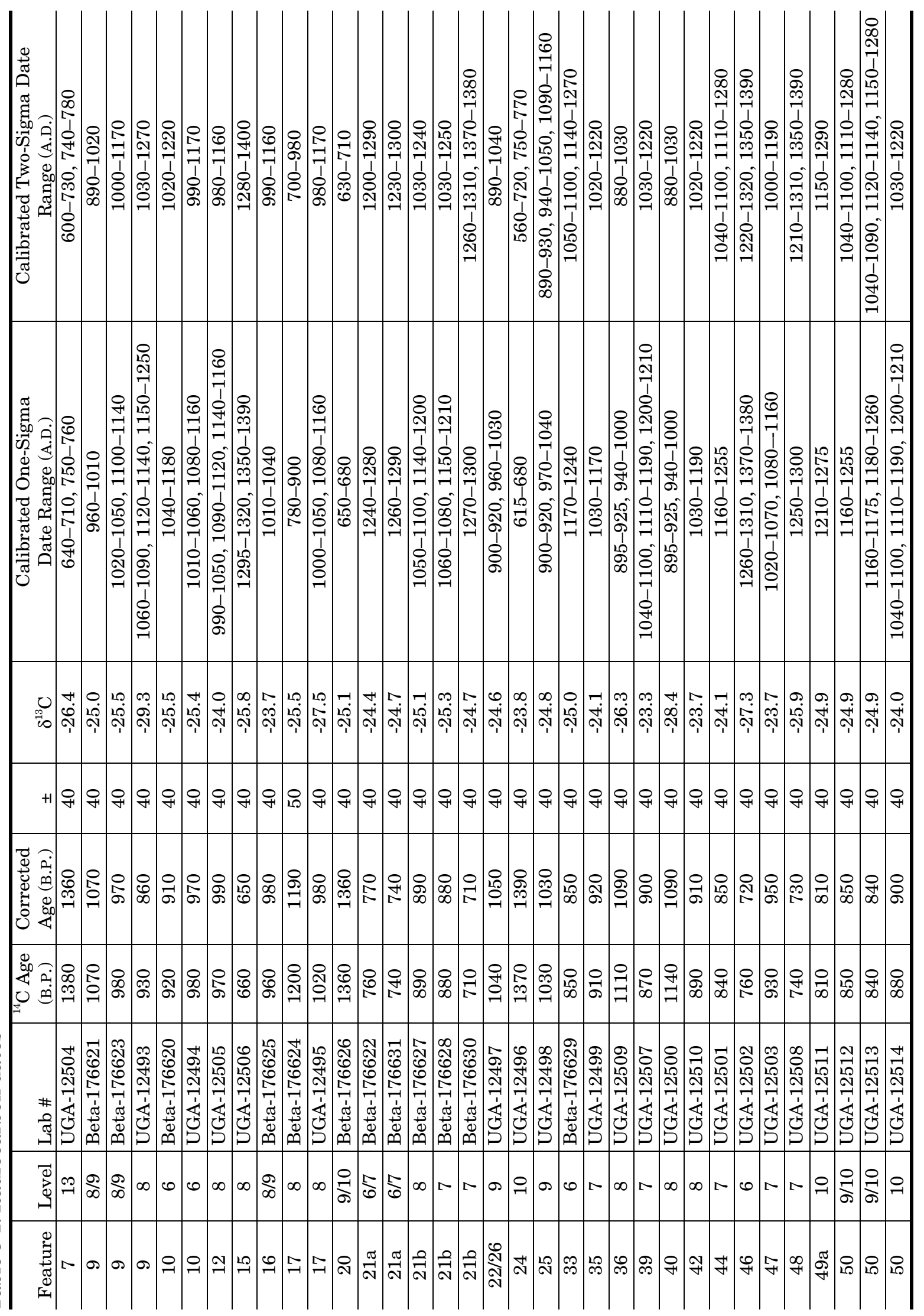




